


\section{Economic Outlook \\ for Southeast Asia, China \\ and India \\ 2020}

RETHINKING EDUCATION FOR THE DIGITAL ERA

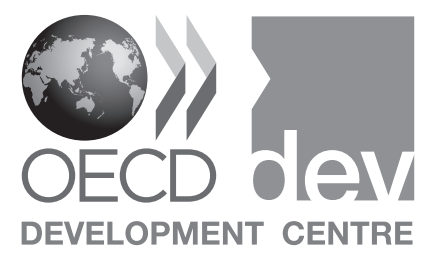


This work is published under the responsibility of the Secretary-General of the OECD. The opinions expressed and arguments employed herein do not necessarily reflect the official views of the member countries of the OECD or its Development Centre.

This document, as well as any data and map included herein, are without prejudice to the status of or sovereignty over any territory, to the delimitation of international frontiers and boundaries and to the name of any territory, city or area.

The statistical data for Israel are supplied by and under the responsibility of the relevant Israeli authorities. The use of such data by the OECD is without prejudice to the status of the Golan Heights, East Jerusalem and Israeli settlements in the West Bank under the terms of international law.

\section{Please cite this publication as:}

OECD (2019), Economic Outlook for Southeast Asia, China and India 2020: Rethinking Education for the Digital Era, OECD Publishing, Paris, https://doi.org/10.1787/1ba6cde0-en.

ISBN 978-92-64-46660-9 (print)

ISBN 978-92-64-78838-1 (pdf)

Economic Outlook for Southeast Asia, China and India

ISSN 2310-1105 (print)

ISSN 2310-1113 (online)

Photo credits: Cover design by Elisa Lopez (OECD Development Centre) on the basis of images from @ Lemberg Vector studio/Shutterstock.com. 


\section{Foreword}

The Economic Outlook for Southeast Asia, China and India is a biannual publication on Asia's regional economic growth, development and regional integration processes. It focuses on the economic conditions of the Association of Southeast Asian Nations (ASEAN) member countries (Brunei Darussalam, Cambodia, Indonesia, Lao PDR, Malaysia, Myanmar, the Philippines, Singapore, Thailand and Viet Nam) and two large economies in the region, China and India.

Beginning with the first release of the Update of the Outlook in 2018, following the Special Supplements of the 2016 and 2017 editions, the Outlook has become a biannual publication to ensure that the projections, data and analysis remain current and useful. The first issue of the report will be released in the fall and its update released the following spring. This publication evolved from the Southeast Asian Economic Outlook.

The Outlook was initially proposed at an informal reflection group on Southeast Asia in 2008 as a follow-up of the Council Meeting at Ministerial level (MCM) in 2007 and was accepted by ministers/senior officials from ASEAN countries at the occasion of the 2nd OECD-Southeast Asia Regional Forum in Bangkok in 2009. The Outlook project was officially launched in 2010 and each edition is regularly presented at the occasion of the ASEAN/ East Asia Summit. It was included in the OECD's Southeast Asia Regional Programme (SEARP) at the Steering Group Meeting in Jakarta, Indonesia in March 2015, with its role of providing a horizontal view of activities, identifying emerging trends in the region and providing a backbone for the different streams of the Programme confirmed at the 2015 MCM. The Outlook serves as a strategic foresight and policy dialogue tool for the SEARP. The Outlook Consultation Group (OCG) was established in 2014 with OECD Delegations, Asian embassies in Paris.

This edition of the Outlook is comprised of three main parts: a regional economic monitor, a thematic focus specific to each year's report, and structural policy country notes. The 2020 edition of the Outlook focuses on the policy challenges for Emerging Asian countries in upgrading education for the digital era. Digitalisation and new technologies are developing rapidly, affecting businesses and the labour market. The digital era presents a huge opportunity while at the same time bringing significant risks. Education systems will therefore need to adapt to meet this new demand. Policy options to be considered in upgrading education for the digital era could include providing sufficient ICT infrastructure to schools and increasing access to ICT tools, improving ICT skills of teachers, and adapting curricula to include ICT. Closing the gender digital divide is also critical, while the role of TVET and lifelong learning will need to be enhanced as paths to digital inclusion.

The OECD Development Centre is committed to working alongside governments of developing and emerging economies and regional actors to identify key areas of intervention in order to address these challenges. The Centre enjoys the full membership of three Southeast Asian countries, namely Indonesia, Thailand and Viet Nam, as well as India and China. This project has also benefited from the generous support of other Emerging Asian countries.

The OECD is committed to supporting Asian countries in their efforts to promote economic and social well-being through rigorous analysis, peer learning and the sharing of best practices. 



\section{Acknowledgements}

The 2020 edition of the Economic Outlook for Southeast Asia, China and India: Rethinking education for the digital era was prepared by the Asia Desk of the OECD Development Centre. The publication benefited from discussions with the ASEAN Secretariat. The team was led by Kensuke Tanaka, Head of the Asia Desk and valuable guidance was provided by Mario Pezzini, Director of the OECD Development Centre.

This volume was drafted by a core team composed of Kensuke Tanaka, Prasiwi Ibrahim, Ryan Jacildo, Sybrand Brekelmans, Jingjing Xia, and Rahmalia Devita. Le Huong Linh provided significant inputs. Sonja Marki provided useful administrative support for this project. Elizabeth Nash, Delphine Grandrieux, Studio Pykha, Aida Buendia and Elisa Lopez Roldan turned the manuscript into the publication.

The Outlook 2020 benefited from discussions with OECD Delegations at two Outlook Consultation Group (OCG) meetings in February and September 2019 in Paris, led by co-chairs of this consultation group, Ambassador Nguyen Thiep and Christoph Graf, together with Ambassador Manuel Escudero. The Outlook also benefited from discussion with experts in the region at the $7^{\text {th }}$ Asian Regional Roundtable on Macroeconomic and Structural Policies, jointly organised by the ASEAN+3 Macroeconomic Research Office (AMRO), the Asian Development Bank (ADB), the Asian Development Bank Institute (ADBI), ERIA and the OECD Development Centre, in Jakarta on 18-19 June 2019. The authors are grateful to Toshinori Doi, Director of AMRO, Naoyuki Yoshino, Dean of the ADBI, Hidetoshi Nishimura, President of ERIA, as well as Izuru Kobayashi, Chul Ju Kim, Anita Prakash, Abdul Abiad, Rana Hasan, Aladdin Rillo, Nella Hendriyetty, Donny Hutabarat, Yumiko Murakami, Atsushi Higuchi, Yuri Belfali, Habibah Abdul Rahim, and Totok Suprayitno. The Outlook was also presented at the occasion of the ASEAN/East Asia Summit in Bangkok, Thailand in November 2019.

Support from OECD delegations and embassies of Asian countries in Paris, in particular, Ambassador Hyoung Kwon Ko, Chargée d'affaires Seong-ho Lee, Ambassador Hiroshi Oe, Ambassador Sarun Charoensuwan, Ambassador Kyaw Zeya, Ambassador Zainal Mantaha, Thanh Thao Nguyen, Thi Van Anh Nguyen, Nguyen Tan Van, Hye Won Kim, Yoonrae Park, Sasilada Kusump, Sherwin Loh, Philip Pierros, Rudjimin, Lydia Safitri, Karina Ratnamurti, Hans Siriban, Hazel Imperial, Taro Fujii, Satoshi Watarai, Satoshi Nishijima, Premanand Jothy, Syed Nizamuddin Sayed Khassim, Houmphanh Soukprasith, Sisouphanh Keobandavong, Zaidah Shahminan, Mang Hau Thang, Phe Grace Mee, Bonira Chan, Liwnapha Chanthavone, Sisavanh Phimsavanh, Litthiphone Silileuxay, Sakthavy Xaobouddavong, Chanphanith Chhay, Sonisa Eat, Chhavy Sovann, Bin Zhang, Bo Chen, and Sining Zhao, is gratefully acknowledged. Equally, contributions from the European Commission are gratefully acknowledged.

Last but not least, the OECD Development Centre would like to acknowledge gratefully the financial support received from the governments of Japan, Korea and Switzerland, and the European Union. 



\section{Table of contents}

Acronyms and abbreviations

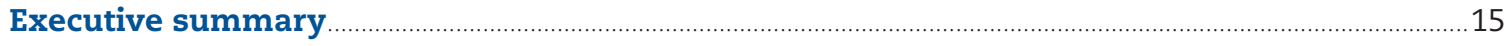

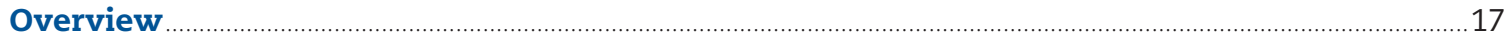

Chapter 1. Macroeconomic assessment and economic outlook …………….............................................. 35

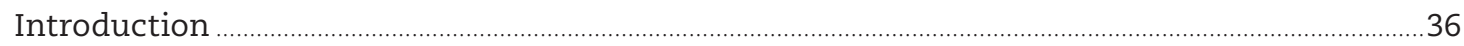

Overview and main findings ....................................................................................................................

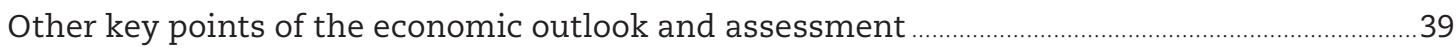

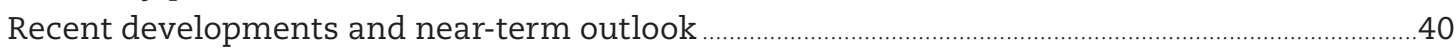

Risks persist for Emerging Asia's exports amid global trade instability …………………................56

Export weakness is accompanied by falling investment as manufacturing struggles ................59

Current account balances are under stress but remain largely stable ...................................................60

Headline inflation remains subdued but food prices are rising in some countries .......................62

Central banks take strong steps to prop up growth and investment sentiment ...........................66

Enhancing the effectiveness of monetary policy in Emerging Asia ……...................................70

The flattening of the Phillips curve in Southeast Asia

Governments favour gradual and contained fiscal expansion …………………………………...73

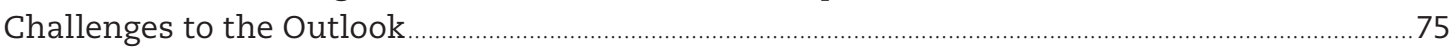

Assessing the economic impact of natural disasters: Local data change the picture ……..........79

New approaches to disaster risk management are needed, including at the local level..............79

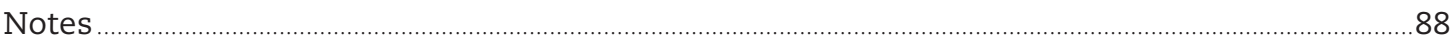

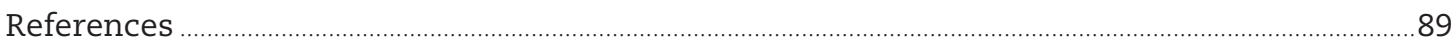

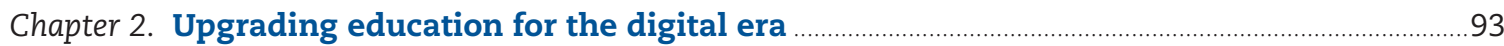

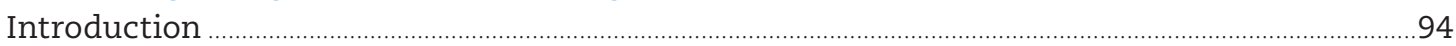

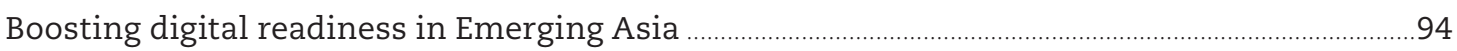

Vocational and lifelong learning as paths to digital inclusion ............................................ 121

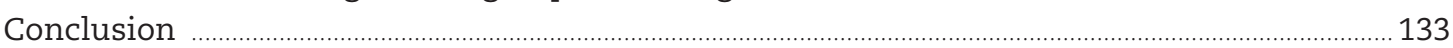

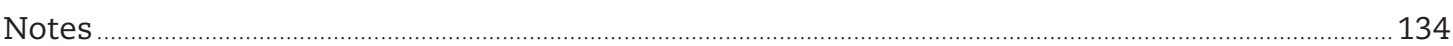

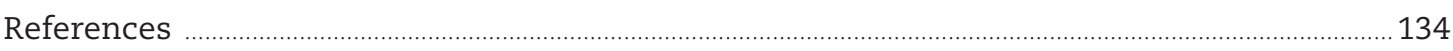

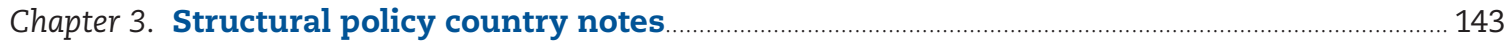

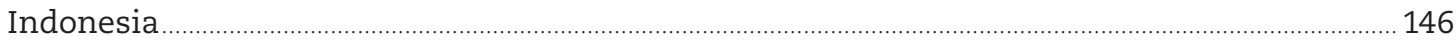

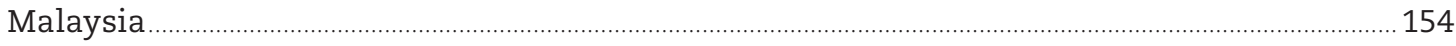

Philippines

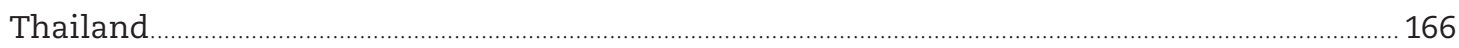

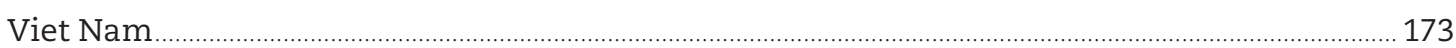

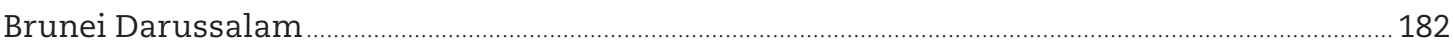

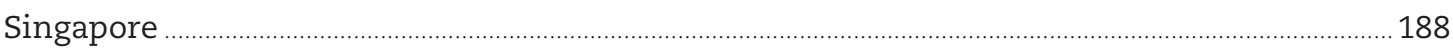

Cambodia .

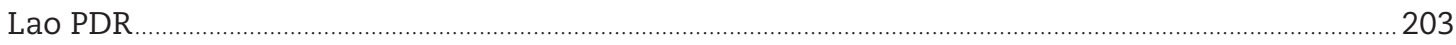

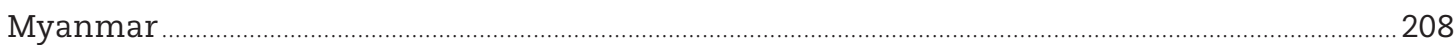

China

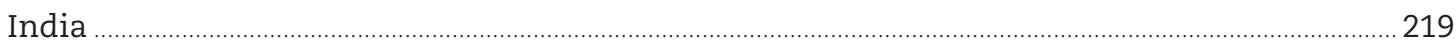

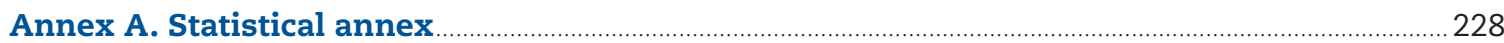


Figures

1. Real GDP growth in Southeast Asia, China and India ............................................................... 18

2. Growth in goods imports of China and United States by partner, 2017-19 ….........................20

3. Real growth in selected GDP components in Indonesia, Malaysia,Philippines,

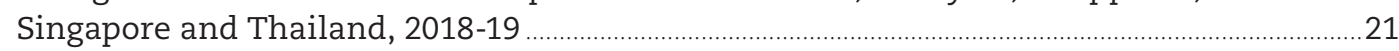

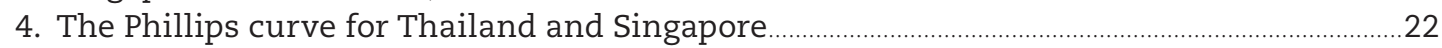

5. Target inflation band and actual inflation in Thailand and Indonesia ......................................22

6. Current and future skills demand and supply in three Emerging

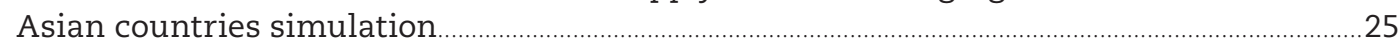

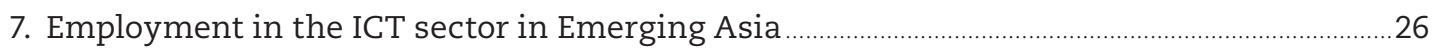

8. Change in adult learning participation rates in Emerging Asia since 2009............................29

9. Countries collecting information by type of outcome in Emerging Asia ..................................30

1.1 Real GDP growth in Southeast Asia, China and India ...........................................................

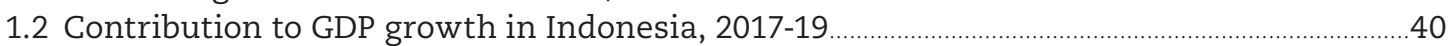

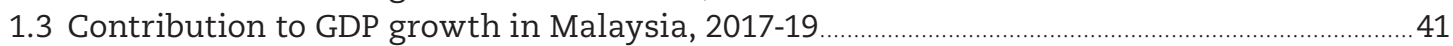

1.4 Consumer confidence indices in Indonesia, Malaysia, the Philippines and Thailand, 2017-19.

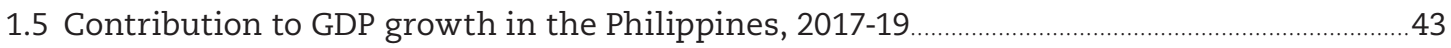

1.6 Contribution to GDP growth in Thailand, 2017-19 ….......................................................................4 44

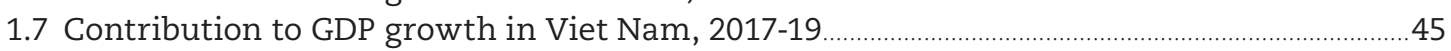

1.8 Insured losses from natural disasters in Asian countries, 2012-18 ……................................46

1.9 Contribution to GDP growth in Brunei Darussalam, 2017-19...................................................47

1.10 Contribution to GDP and total demand growth in Singapore, 2017-19 ….....................................48

1.11 Business expectations and leading indicator indices in Singapore, 2017-19...........................49

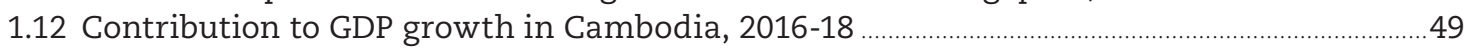

1.13 Contribution to GDP growth in Lao PDR, 2016-18

1.14 Contribution to GDP growth in Myanmar, 2016-18 ....................................................................51

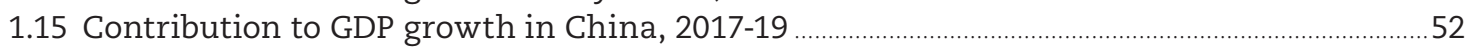

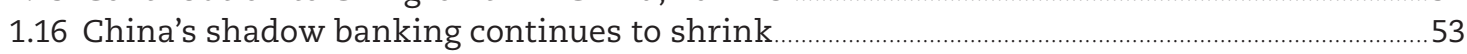

1.17 Purchasing managers' and confidence indices in China, 2017-19.....................................54

1.18 Contribution to GDP growth in India, 2017-19

1.19 Purchasing managers' and confidence indices in India, 2017-19 ……...............................55

1.20 Growth in goods exports of Emerging Asia, 2017-19 ……………………………………….........56

1.21 Growth in goods imports of China and the United States by partner, 2017-19 …....................58

1.22 Private consumption, exports and fixed investment real growth ............................................60

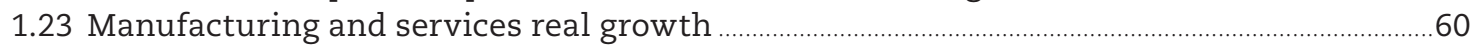

1.24 Current account balance and net exports of Emerging Asia, 2017-19 …................................61

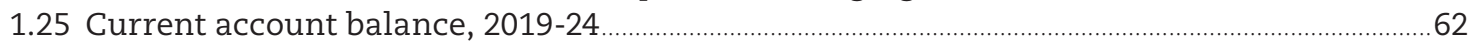

1.26 Foreign direct investment in Emerging Asia, 2017-19..........................................................................62

1.27 Headline, core and food inflation in Emerging Asia, 2017-19 .........................................63

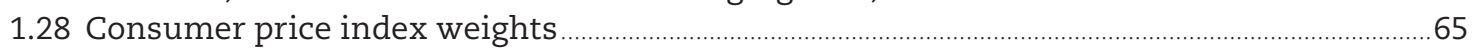

1.29 Monetary policy actions in selected Emerging Asian economies in 2019 ..................................66

1.30 Benchmark bond yield and term differentials ................................................................................67

1.31 Portfolio and other investment liability inflows in Emerging Asia 2017-19 …....................67

1.32 Nominal effective exchange rate in selected Emerging Asian economies, 2019..................68

1.33 Returns on benchmark equity indices in Emerging Asia, 2018-19 ..........................................69

1.34 Growth in house price indices of selected Emerging Asian economies, 2018-19...................69

1.35 Headline inflation in Indonesia, Malaysia, Philippines, Singapore and Thailand ………......70

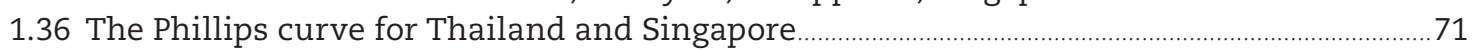

1.37 Target inflation band and actual inflation in Thailand ....................................................

1.38 Target inflation band and actual inflation in Indonesia and the Philippines...........................73

1.39 Recorded occurrences of natural disasters in Emerging Asia, 1950-2018 ....................................76 
1.40 Occurrence of tsunamis in Emerging Asia in the last 50 years

1.41 Three-year average growth rates of selected variables after a natural disaster, based on principal component analysis (PCA) approach ................................................... 79

1.42 Annual new internal displacement associated with disasters, 2013-18 average .................84

2.1 Current and future skills demand and supply in three Emerging

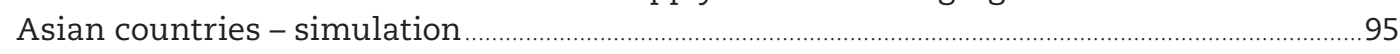

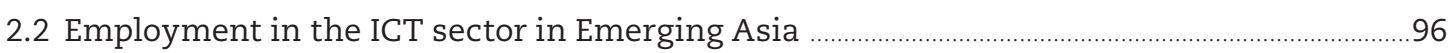

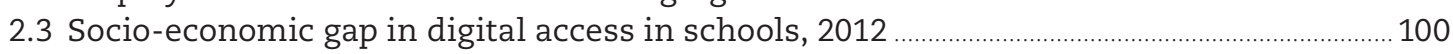

2.4 PISA 2015 performance and ICT use at school

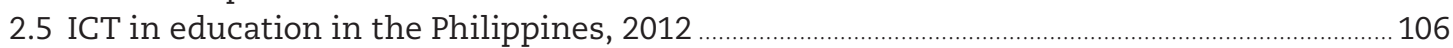

2.6 Vocational teachers with satisfactory computer skills in Viet Nam, $2017 \ldots \ldots \ldots \ldots \ldots \ldots \ldots \ldots \ldots \ldots . . . . . . . . .110$

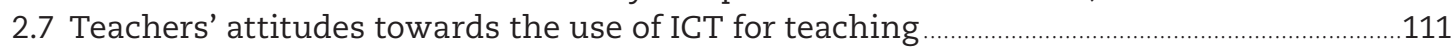

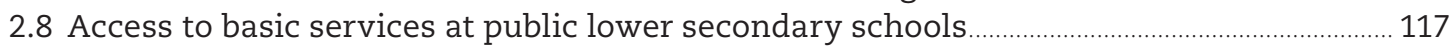

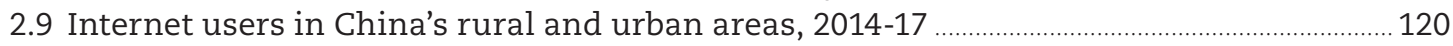

2.10 ICT usage indicators in selected Emerging Asian countries, 2017 .............................................. 120

2.11 Share of secondary students enrolled in vocational programmes, 2016 ……………............... 122

2.12 The education system in Finland ……........................................................................................ 124

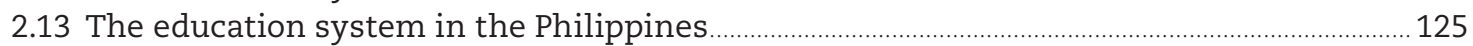

2.14 Change in adult learning participation rates in Emerging Asia since 2009........................... 131

2.15 Countries collecting information by type of outcome in Emerging Asia .................................. 132

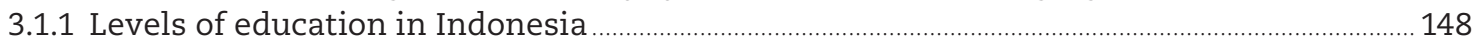

3.1.2 Main weaknesses of SMKs as perceived by employees in Indonesia ......................................... 150

3.1.3 SMK teachers' level of education in Indonesia .............................................................................. 151

3.2.1 Proportion of enterprises per 1000 people in Malaysia ................................................................ 155

3.3.1 Participation of non-high school graduates in the Philippine labour force, 2012-18 161

3.4.1 The main sources of income for elderly people in Thailand, 2007 and 2017.......................... 168

3.4.2 Average sources of income for older people for OECD countries,

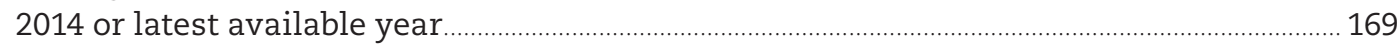

3.6.1 Share of workforce with tertiary education as highest educational

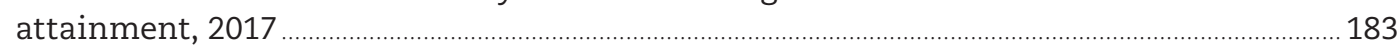

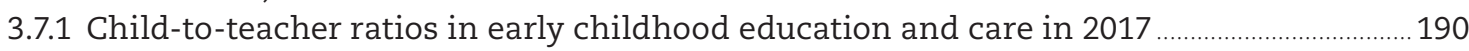

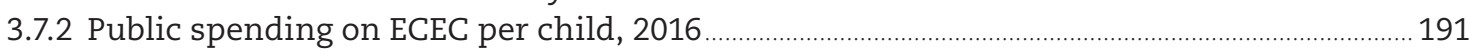

3.8.1 Labour force distribution in Cambodia by education level, 2010-16 …….......................... 200

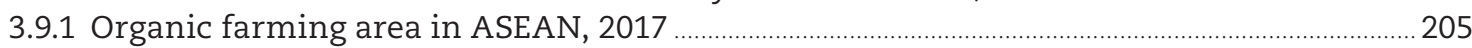

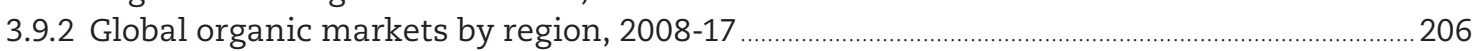

3.11.1 Contribution to growth 2000-18: A key role for investment in China …………............... 215

3.11.2 China's current account balance, saving rate and investment rate, 1997-2018 ................... 216

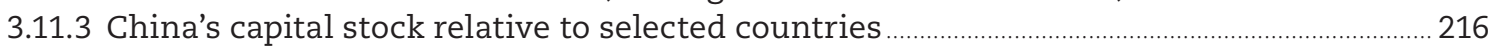

\section{Tables}

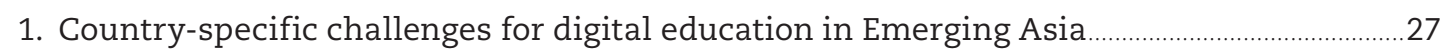

2. Structural policy challenges in Emerging Asian countries .................................................... 31

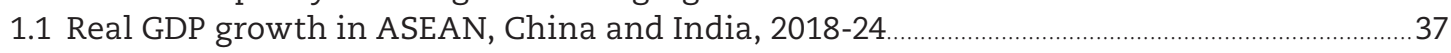

1.2 Quarterly real GDP growth in ASEAN, China and India, 2018-19 ...........................................40

1.3 Tariff measures and reprieves, United States and China, 2018-19 ….......................................57

1.4 Economic benefits of coral reefs

1.5 Conventional vs. smart approaches to disaster risk management …..................................85

2.1 Country-specific challenges for digital education in Emerging Asia …….........................99

2.2 Key figures on ICT and education sectors in Indonesia $\ldots \ldots \ldots \ldots$

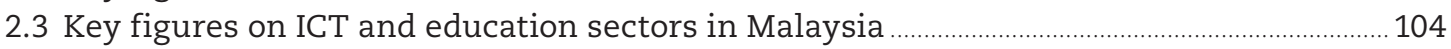

2.4 Key figures on ICT and education sectors in the Philippines .................................................... 105 
2.5 Key figures on ICT and education sectors in Thailand …...................................................... 107

2.6 Key figures on ICT and education sectors in Viet Nam …........................................................... 110

2.7 Key figures on ICT and education sectors in Brunei Darussalam ......................................... 112

2.8 Key figures on ICT and education sectors in Singapore ........................................................... 113

2.9 Key figures on ICT and education sectors in Cambodia …........................................................ 115

2.10 Key figures on ICT and education sectors in Lao PDR …........................................................... 115

2.11 Key figures on ICT and education sectors in Myanmar .......................................................... 116

2.12 Key figures on ICT and education sectors in China ……........................................................... 119

2.13 Key figures on ICT and education sectors in India ................................................................ 121

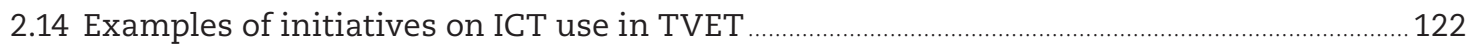

2.15 Purposes and sources of the Informatisation Promotion Fund .................................................. 130

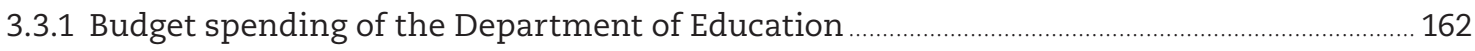

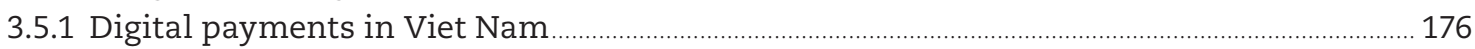

3.5.2 ICT development index for Viet Nam and selected Asian countries..................................... 178

3.12.1 Mechanisms employed to manage the flow of road traffic ..........................................................22 221

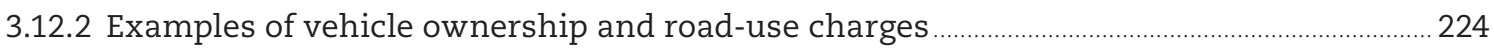

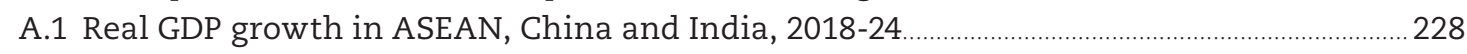

A.2 Current account balances of ASEAN, China and India, 2019-24 ...........................................228

A.3 General government fiscal balances of ASEAN, China and India, 2019-24 ........................229

\section{Boxes}

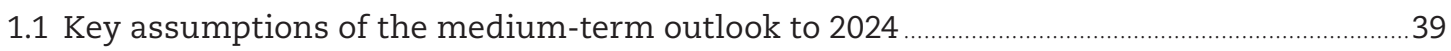

1.2 Strengthening the disaster risk insurance market in ASEAN ……..........................................45

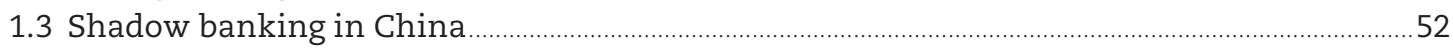

1.4 Recent developments in the US-China trade tensions …............................................................57

1.5 Consumer price index composition in Emerging Asia ....................................................................64

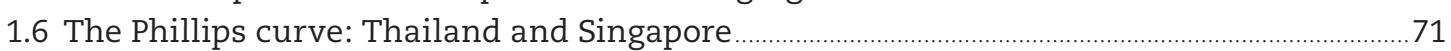

1.7 The case for installing tsunami detection buoys ..................................................................................77

1.8 The economic benefits of coral reefs in reducing natural disaster risks ...............................78

1.9 Recent reforms to disaster risk management frameworks at the national level ...................80

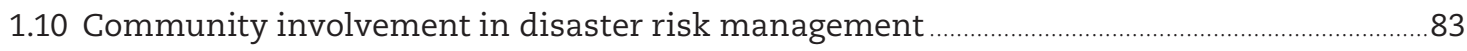

1.11 The effect of natural disasters on internal migration ……...............................................................83

1.12 Early warning steps in the Hyogo Framework for Action 2005-15 ........................................85

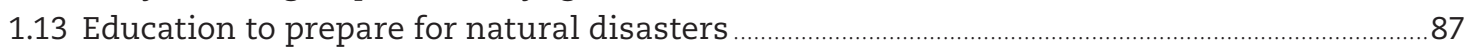

2.1 Teaching digital skills to rural women in Thailand ............................................................................98

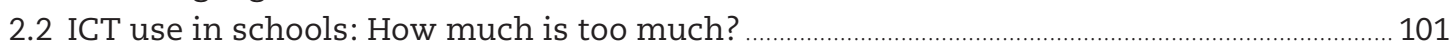

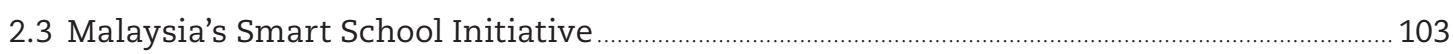

2.4 Perspective on teachers' digital skills from OECD economies .................................................. 108

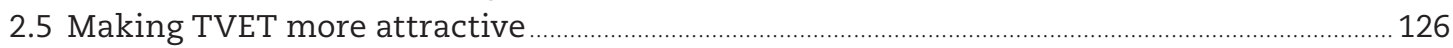

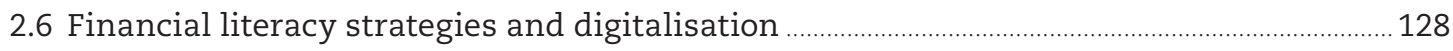

2.7 The Estonian digital education framework ................................................................................. 129

2.8 Korea's ICT human resource development policy …............................................................... 130

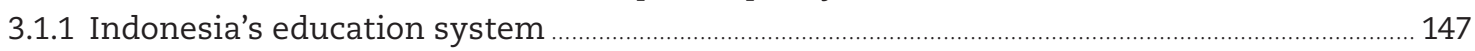

3.1.2 Harmonising certification system and improving non-formal institutions ....................... 149

3.2.1 Human capital and innovation programmes for SMEs in Malaysia ..................................... 155

3.4.1 KiwiSaver's strategies for boosting people's propensity to save …........................................ 170

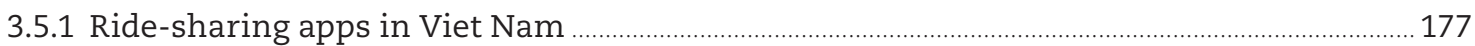

3.8.1 Recent programmes to develop human capital in Cambodia ................................................200 


\title{
Acronyms and abbreviations
}

\author{
AADMER ASEAN Agreement on Disaster Management and Emergency Response \\ ACARA Australian Curriculum Assessment and Reporting Authority \\ ADB Asian Development Bank \\ ADBI Asian Development Bank Institute \\ AEC ASEAN Economic Community \\ AI Artificial Intelligence \\ AICTE All India Council for Technical Education \\ AMRO ASEAN+3 Macroeconomic Research Office \\ APEC Asia-Pacific Economic Co-operation \\ APSEMO Albay Public Safety and Emergency Management Office \\ ASEAN Association of Southeast Asian Nations \\ ASEAN+3 ASEAN-10 countries plus China, Japan and South Korea \\ ASEAN+6 ASEAN+3 countries plus Australia, India and New Zealand \\ ASEAN-5 Indonesia, Malaysia, the Philippines, Thailand and Viet Nam \\ ASEAN-6 Brunei Darussalam, Indonesia, Malaysia, Philippines, Singapore, Thailand \\ ASEM Asia-Europe Meeting \\ BLK Balai Latihan Kerja \\ BMTC Bangalore Metropolitan Transport Corporation \\ BMRCL Bangalore Metro Rail Corporation Limited \\ BND Brunei dollars \\ BOP Balance of Payments \\ BRIC Brazil, Russia, India and China \\ CAICT China Academy of Information and Communications Technology \\ CBRD Capacity Building, Research and Development \\ CCA Climate Change Adaptation \\ CCCPC Central Committee of the Communist Party of China \\ CICT Commission on Information and Communication Technology \\ CIPG Centre for Innovation Policy and Governance \\ CLM Cambodia, Lao PDR, Myanmar \\ CLMV Cambodia, Lao PDR, Myanmar and Viet Nam \\ CNNIC China Internet Network Information Center \\ CPI Consumer Price Index \\ CRED Centre for Research on the Epidemiology of Disasters \\ DBM Department of Budget and Management \\ DOP Department for Older Persons \\ DRFI Disaster Risk Financing and Insurance \\ DRM Disaster Risk Management \\ DRR Disaster Risk Reduction \\ DRRM Disaster Risk Reduction and Management \\ EAS East Asia Summit \\ ECDA Early Childhood Development Agency \\ ECEC Early-Childhood Education and Care \\ EHIS Estonian Education Information System \\ ERIA Economic Research Institute for ASEAN and East Asia \\ EU European Union \\ FAO Food and Agriculture Organization \\ FDI Foreign Direct Investment \\ GDP Gross Domestic Product
}




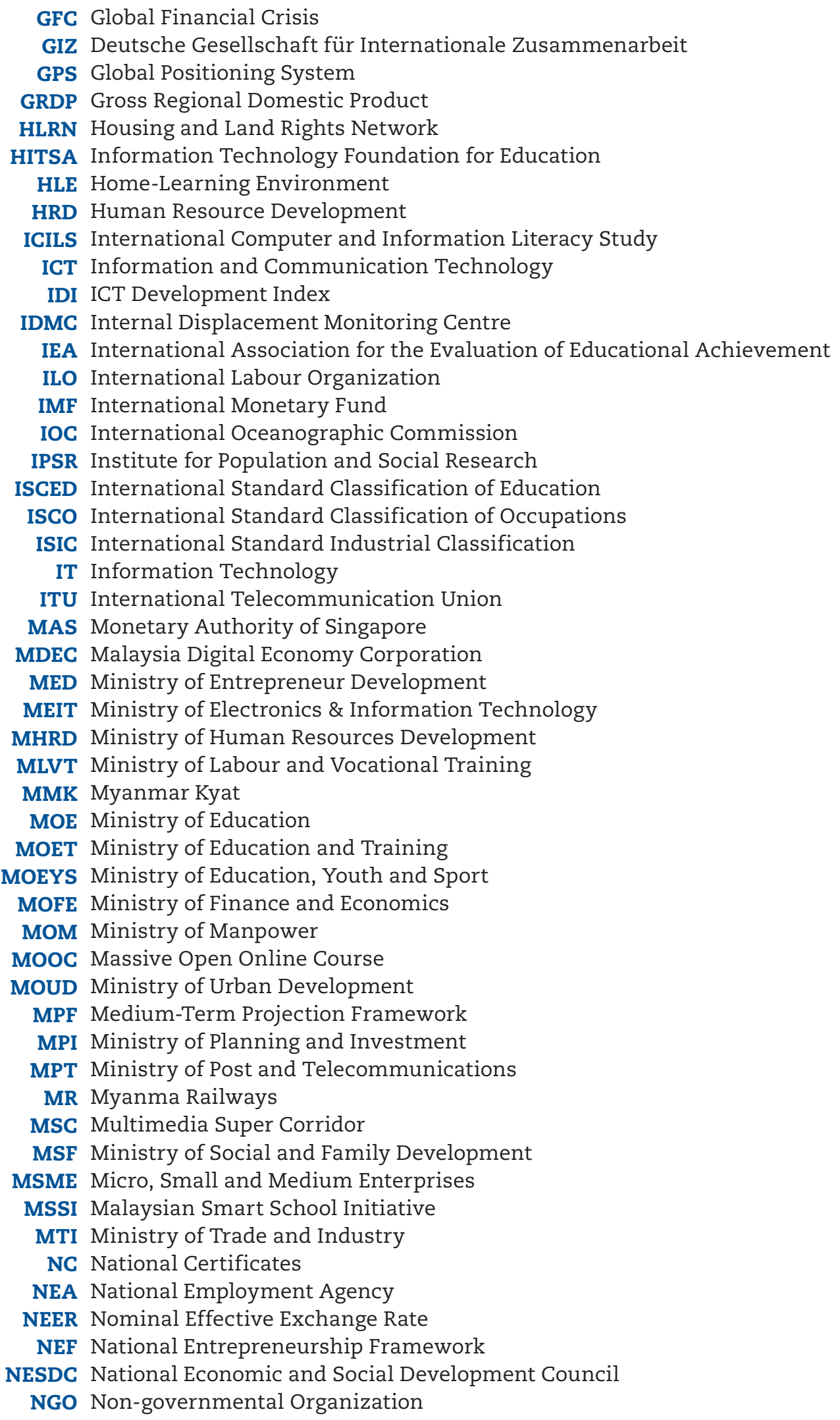


NIVET National Institute for Vocational Education and Training

NOS National Occupational Skills

NSO National Statistical Office

OECD Organisation for Economic Co-operation and Development

PIAAC Programme for the International Assessment of Adult Competencies

PISA Programme for International Student Assessment

PMI Purchasing Managers' Index

PPP Public-Private Partnership

PSA Philippine Statistics Authority

PSTRE Problem Solving in Technology Rich Environments

QR Quick Response

RGC Royal Government of Cambodia

R\&D Research and Development

RRR Reserve Requirement Ratio

SEAMEO Southeast Asian Ministers of Education Organization

SEZ Special Economic Zone

SGD Singapore Dollar

SME Small and Medium-sized Enterprises

SMK Sekolah Menengah Kejuruan

SOE State-owned Enterprise

SSQS Smart School Qualification Standards

STEM Science, Technology, Engineering and Mathematics

TALIS Teaching and Learning International Survey

TDRI Thailand Development Research Institute

TGRI Thai Gerontology Research and Development Institute

THB Thai baht

TVET Technical and Vocational Education and Training

UIL UNESCO Institute for Lifelong Learning

UIS UNESCO Institute for Statistics

UMTA Unified Metropolitan Transport Authority

UN United Nations

UNCTAD United Nations Conference on Trade and Development

UNESCAP United Nations Economic and Social Commission for Asia and the Pacific

UNESCO United Nations Educational, Scientific and Cultural Organization

UNHCR United Nations High Commissioner for Refugees

UNISDR United Nations Secretariat of the International Strategy for Disaster Reduction

UN-OHRLLS United Nations Office of the High Representative for the Least Developed Countries, Landlocked Developing Countries and Small Island Developing States

USD US dollars

UTF Urban Transport Fund

VND Vietnamese Dong

WBTC West Bengal Transport Corporation

WEF World Economic Forum

WHO World Health Organization

WMO World Meteorological Organization

WTO World Trade Organization 



\section{Executive summary}

At a time of global uncertainty over trade, geopolitics and the climate, economic growth in Emerging Asia is forecast to moderate in the near-term. Growth in the region is expected to remain buoyant over the medium term though less impressive than the previous years. The OECD's Economic Outlook for Southeast Asia, China and India 2020 presents the growth picture for the region over the next five years. This year's Outlook also focuses on a challenge for Emerging Asia: boosting economic prospects by upgrading education to take advantage of the new opportunities offered by the digital era. In the Country Notes, it discusses structural policy changes needed in the region's 12 economies across a range of areas.

\section{Economic outlook to 2024}

Emerging Asia is expected to grow at a slower pace than projected in the July 2019 Outlook Update. The current medium-term forecast for the region as a whole predicts gross domestic product (GDP) growth of $5.7 \%$ in $2020-24$, down from $6.7 \%$ in $2013-17$. In Southeast Asia, growth is projected to reach $4.9 \%$ during the period, compared to $5.0 \%$ in 2013-17. China's anticipated growth will taper further, to $5.6 \%$, as structural reform continues, while India's expected growth, at $6.6 \%$, will also be more modest in the medium term as the banking sector regains its footing.

Emerging Asia's growth is anchored by the resilience of private consumption, as in the past. The region's exports were affected by the broadening economic weakness in advanced economies, compounded by the US-China trade tensions and uncertainties over Brexit. Policy signals are still mixed and risks remain high, even for countries where export growth is stabilising. Some countries in the region may benefit from trade diversion and deflection as a result of the trade tensions in the near term.

As exports cave in to trade tensions, real fixed investment growth is pulling back and cautiousness in business sentiment rises. Nonetheless, current account positions remain solid amid the trade uncertainties. The region's lacklustre export earnings have been offset by a pullback in import payments. Volatility in financial flows has been contained, as has movement in exchange rates and equity prices. Overall, the fiscal stance of many Emerging Asian economies is favouring contained expansion in the near term.

Against a backdrop of benign inflationary pressures, monetary authorities are easing liquidity conditions to lift consumer and investment sentiment. Enhancing the effectiveness of monetary policy in a changing economic environment is a challenge in this context. The flattening of the Phillips curve, which indicates a weakening linkage between inflation and the labour market, merits consideration. In view of the current environmental and climate risks, strengthening local government participation and capacity in disaster resilience initiatives is another challenge facing the region, given its exposure to natural disasters.

\section{Upgrading education for the digital era}

Digitalisation is bringing important developments for businesses and the workforce, but these changes present risks as well as opportunities. New industries requiring advanced and specialised digital skills are arising. New technologies are restructuring the workplace, requiring employees to upskill and reskill as automation causes jobs to disappear and digitalisation creates new forms of work. For Emerging Asian countries to be internationally 
competitive in the digital era, they need to upgrade their education systems to provide the necessary skills in information and communications technology (ICT).

Specific challenges need to be addressed by countries in the region to ensure that the labour force is equipped with digital skills. Cambodia, Lao PDR and Myanmar need to address a lack of ICT infrastructure and increase access to ICT tools. In countries where infrastructure is relatively better, including Thailand, Brunei Darussalam and Singapore, teachers' digital skills need more attention. Countries like Malaysia and China need to resolve a mismatch between demand for skills and supply of talent. Women in Emerging Asia continue to face challenges due to a gender digital divide. In the Asia-Pacific region, the estimated gender gap in Internet use was 17\% in 2017, compared to $7.9 \%$ in Europe. In order to boost the participation of women in the modern economy, the region's countries need to develop strategies for increasing the digital skills of girls and women and improving their access to ICT.

Alternative paths to education can provide digital skills while taking inclusion into account, and these also need upgrading in Emerging Asia. Technical and vocational education and training (TVET) has great potential in the digital era, but it suffers from an image problem in the region. TVET can be made more attractive by offering flexible programmes, encouraging private-sector involvement and publicising its benefits to students and their parents. Another alternative path is lifelong learning, which can also provide the opportunity to acquire new digital skills. However, effective policy on adult education requires an extensive information base of good quality. Better data collection and monitoring are essential.

\section{Key structural policy challenges}

The Country Notes highlight key structural policy challenges in Emerging Asian countries. In order to improve prospects for inclusive and sustainable growth, structural reforms are necessary. This edition of the Outlook discusses policy areas including education, small and medium-sized businesses, social safety nets, digital trade, startup ecosystems, agriculture, infrastructure, investment and urban transportation. The Country Notes cover the ASEAN economies - Brunei Darussalam, Cambodia, Indonesia, Lao PDR, Malaysia, Myanmar, the Philippines, Singapore, Thailand and Viet Nam - as well as China and India. 


\section{Overview}

\section{Chapter 1: Macroeconomic assessments and economic outlook for Emerging Asia}

Emerging Asian economies - Southeast Asia, China and India - experienced further moderation of growth midway through 2019. Overall, Emerging Asia's GDP growth in 2019 and 2020 is expected to come in at a slower pace than the rates projected in the Outlook Update in July 2019 (OECD, 2019a). In the medium term, the region's performance from 2020-24 is also anticipated to be less impressive than from 2013-17. The resilience of private consumption anchored the growth momentum, as in the past. However, exports continued to reel from trade tension headwinds accompanied by a softening of fixed investment.

Moving forward, and beyond tariff-related uncertainties, the grimmer growth picture in advanced economies is dampening external prospects despite historically low interest rates. Monetary tools have been used within and outside the region to spur economic growth, while some countries in the region are also considering other stimulus measures. The challenge for Emerging Asian economies is to reinforce the effectiveness of these policies. Strengthening local government involvement in disaster resilience initiatives to address environmental and climate risks is also vital.

\section{Overview and main findings: The economic outlook for 2024}

Gross domestic product (GDP) growth in Emerging Asia is forecast to come in at $5.7 \%$ on average in 2020-24 (Figure 1), based on the OECD Development Centre's Medium-term Projection Framework 2020. Trade tensions between the United States and China are continuing, and the broadening economic weakness in advanced economies adds substantial uncertainty to export prospects. Stability in the labour market, and in certain cases inflows of income from overseas workers, will sustain domestic consumption. Realisation of infrastructure projects that are already in the pipeline should provide more lift to domestic demand. Given this backdrop, Emerging Asia's expected growth over the next five years will be weaker than the 2013-17 pace of 6.7\%. Southeast Asia is estimated to grow by $4.9 \%$ during the period, down from the average rate of $5.0 \%$ in $2013-17$. China's growth will taper further as structural reform continues. India is also anticipated to grow relatively more modestly in 2020-24 than in 2013-17 while the banking sector regains its footing. 
Figure 1. Real GDP growth in Southeast Asia, China and India

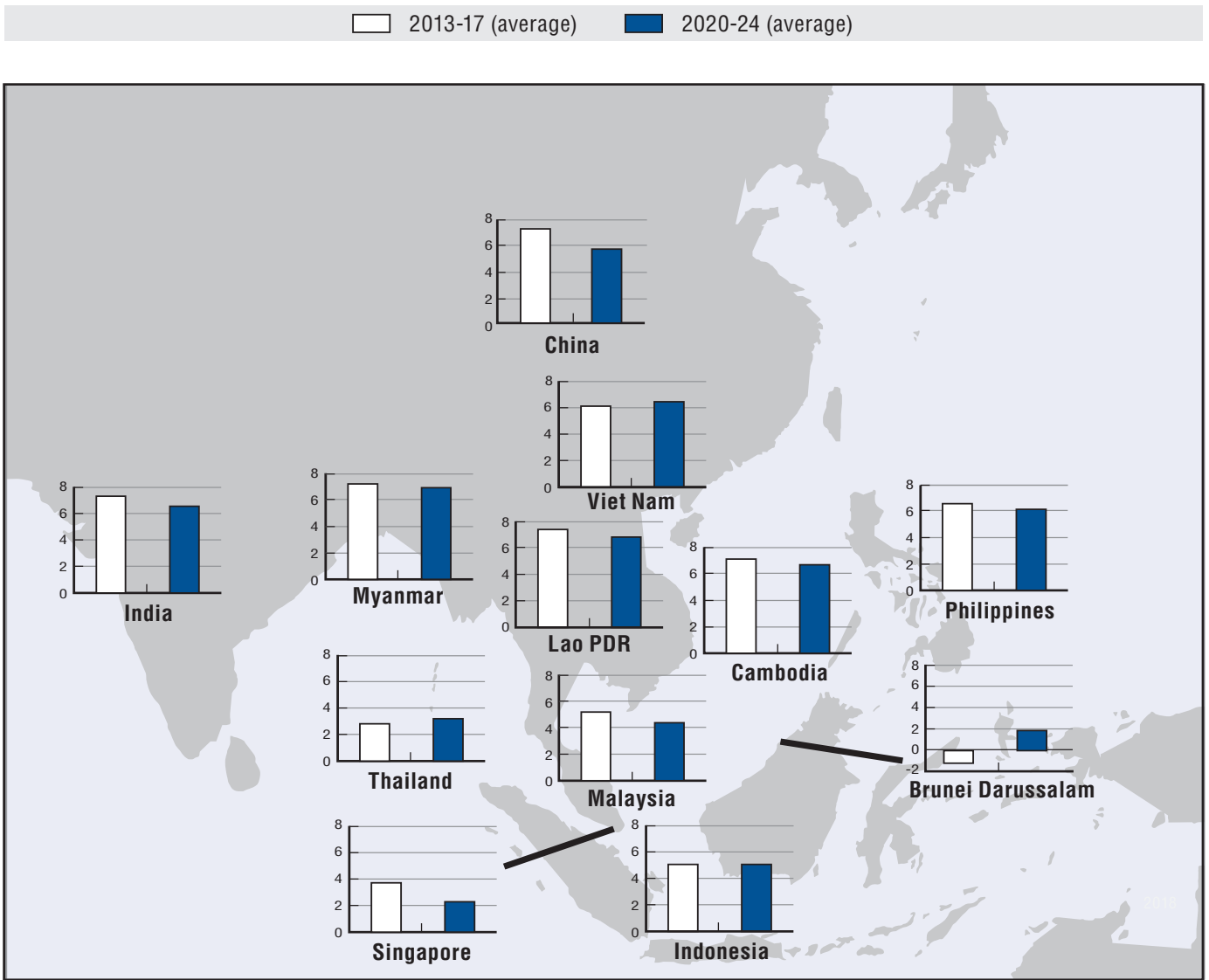

Source: OECD Development Centre, Medium-term Projection Framework (MPF-2020).

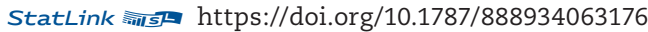

\section{ASEAN-5}

- Indonesia's GDP growth in the medium term is forecast to reach $5.1 \%$, in line with the 2013-17 average. A steady decline in the unemployment rate is fuelling consumption prospects, while the expansion of special economic zones (SEZs) bodes well for investment. Improving efficiency in tax administration and infrastructure spending are among the key challenges.

- Medium-term economic growth in Malaysia is estimated to settle at $4.4 \%$, lower than the 2013-17 average of 5.2\%. Labour market stability should continue to fuel private consumption, although real-wage growth is slowing. The country's push to improve digital infrastructure and broaden the economy's technology base are positive, although further policy actions are needed to increase the ease of starting a business and to strengthen tax mobilisation.

- GDP growth in the Philippines is projected to come in at $6.2 \%$ in $2020-24$, below the 2013-17 average of 6.6\%. Labour market conditions are working in favour of consumption, but a thorough examination of the declining labour force participation rate is needed to deepen the market. Infrastructure implementation delays remain a challenge.

- In Thailand, medium-term economic growth is estimated at 3.2\%, higher than the average growth rate of $2.8 \%$ in 2013-17. An improvement in the country's business climate metrics is encouraging for capital formation, labour market prospects and 
private consumption. Facilitating an enabling environment for the growing fintech services field is a key challenge in the coming years.

- Viet Nam's economy is forecast to grow by about $6.5 \%$ in the medium term, surpassing the average rate of expansion of 6.2\% in 2013-17. The vibrant investment climate bodes well for the country's privatisation and foreign investment strategies. Recently signed free-trade agreements should buttress the export sector amid external headwinds. Keeping rural areas in step with developments in urban centres is a key challenge.

\section{Brunei Darussalam and Singapore}

- Brunei Darussalam's medium-term growth is forecast to reach $1.9 \%$, in a reversal of the negative growth of $-1.2 \%$ recorded from 2013-17. A steady improvement in business-climate metrics should buttress efforts to increase private-sector activity and bolster the labour market, while the country's big-ticket projects should help to improve economic efficiency. Strengthening the central bank's capacity to administer monetary policy is a crucial challenge as the country deepens its capital markets.

- Singapore's economy is forecast to grow by 2.3\% in 2020-24, below the 2013-17 average of $3.7 \%$. Trade will likely dominate the growth story in the next few years. The start-up ecosystem is showing considerable promise, though it requires targeted support. Addressing participation barriers in lifelong learning programmes is another challenge.

\section{Cambodia, Lao PDR and Myanmar}

- Cambodia's average GDP growth in 2020-24 is estimated to come in at $6.7 \%$, slower than the 2013-17 rate of 7.1\%. Fixed investment will remain a key growth anchor as infrastructure development continues. Corporate bond issuances in local currency are helpful for capital market development and facilitate the use of the riel, which is essential for monetary policy efficacy. Continued progress in addressing deficiencies in capital flow regulations is vital.

- The economy of Lao PDR is projected to grow by $6.8 \%$ in 2020-24, a milder expansion than the $7.4 \%$ seen in 2013-17. Infrastructure projects and energy exports are expected to provide much of the growth steam. However, limited improvement in the ease of doing business could hold back the development of other sectors. Coming up with a sound framework to deal with environmental hazards is another challenge for broadening the sources of economic growth.

- Myanmar's GDP is forecast to grow by $6.9 \%$ in the medium term, slightly softer than the 2013-17 average of 7.2\%. Fixed investment backed by foreign direct investment (FDI) is set to propel economic activity. Exports should gain from a planned expansion of SEZ operations. Nonetheless, the business climate could be improved. Stability and sufficiency of power supply is one issue. As for education (including digital literacy), access and quality, though improving, remain a challenge.

\section{China and India}

- China's GDP growth will continue to slow, at 5.6\% in the medium term from its 2013-17 average of 7.1\%. Growth started to slow a few years ago as the economy is rebalancing from investment-led to consumption-led growth. Investment slows on the back of excess capacity in some manufacturing industries, while consumption is not picking up in a lack of structural reforms to reduce precautionary savings. Nevertheless, consumption remains robust against the backdrop of steadily rising incomes. Ageing pressures are increasing, even though the population is still 
growing, but the working age population has been falling for several years already. Productivity-boosting structural reforms, including dismantling administrative monopolies and further opening up the economy would lift the growth potential.

- GDP growth in India in 2020-24 is forecast to reach about 6.6\%, lower than its 2013-17 average of $7.4 \%$. While reliance on consumption will continue, the large informal labour share indicates that there is room to strengthen the consumption base. Sustaining efforts to prop up the health of the banking sector is a vital challenge, while bridging the disparity in urban and rural infrastructure is important for spreading investment and economic opportunities while addressing urbanisation.

\section{Other key points and challenges}

\section{Navigating increasingly restrictive trade policies}

Countries in the region need to pay careful attention to several challenges. One is navigating the ongoing trade tensions between the United States and China at a time when real sectors in advanced economies are weakening. The broadening economic weakness in advanced economies affects export prospects. The policy signals are still quite mixed and the risk remains high even for countries where export growth is stabilising. The contraction in China's exports may have eased but there are no indications of a strong rebound. Weak sentiment is more palpable on the import side due to the combined effects of the trade war and structural transformation.

Interesting contrasts can be observed by zeroing in on the recent trade performance of ASEAN and India on the one hand with China and the United States on the other. In general, growth in US imports from Emerging Asia, excluding China, has been sturdier (Figure 2), with hints of trade rerouting through the smaller economies. The larger ASEAN economies and India show susceptibility to the trade frictions in the China and US markets, although the depth of impact on imports differs between the two markets.

Figure 2. Growth in goods imports of China and United States by partner, 2017-19

3-month moving average, year-on-year, percentage
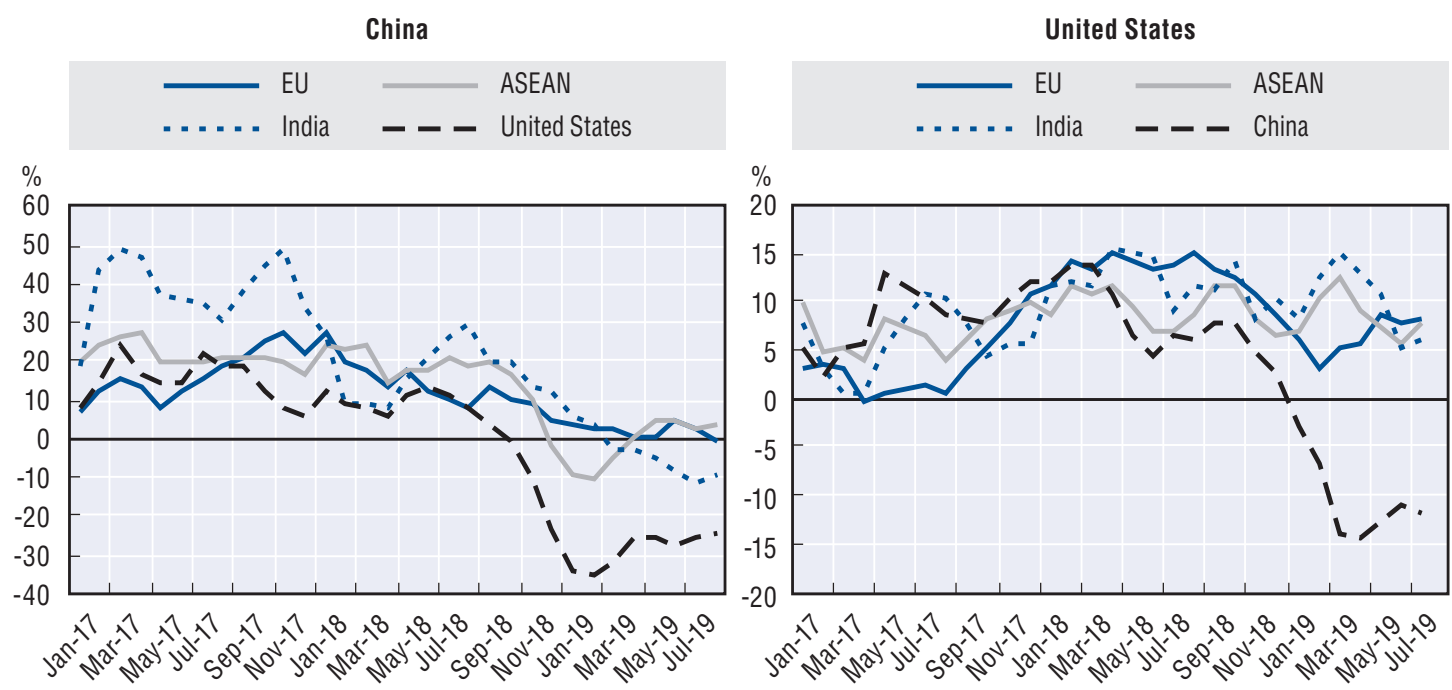

Note: The EU grouping is based on the definitions of the national source and may not necessarily be the same in China and the United States.

Source: OECD Development Centre calculations based on data from CEIC and national sources.

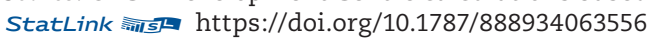


As exports cave in to trade tensions, real growth in fixed investment is pulling back in a number of Emerging Asian economies, leaving private consumption to do the heavy lifting to support economic activity (Figure 3). Business sentiment further signals growing cautiousness in a number of economies. Production data show that offshore marketdependent manufacturing sectors are feeling external pressures quite strongly relative to services sectors, which tend to have a bigger domestic driver component.

Figure 3. Real growth in selected GDP components in Indonesia, Malaysia, Philippines, Singapore and Thailand, 2018-19

Year-on-year percentage change

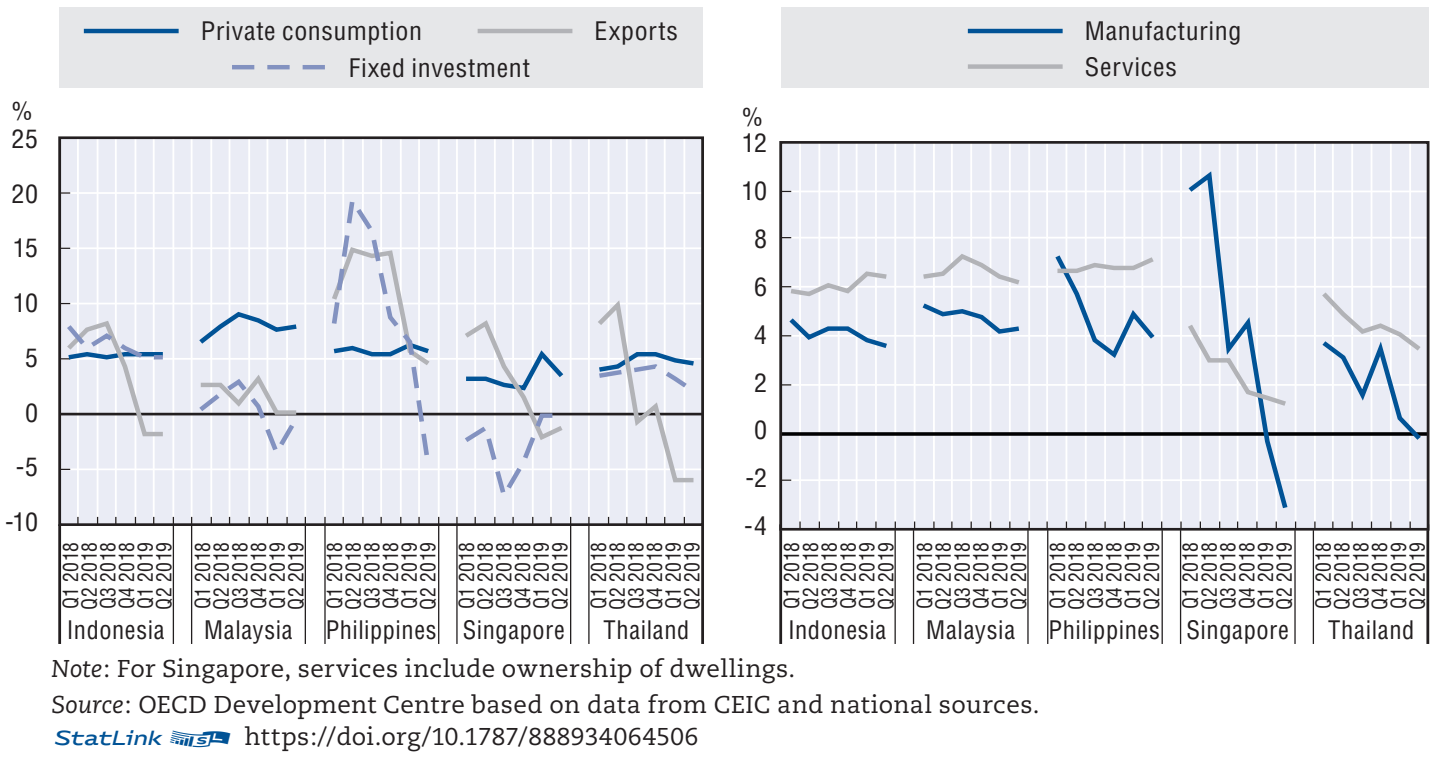

Meanwhile, current account positions remain solid amid trade uncertainties. The region's lacklustre export earnings were offset by a pullback in import payments. Volatility in financial flows has been contained, as has the movement in exchange rate and equity prices.

\section{Enhancing the impact of monetary policy in a changing economic landscape}

Against a backdrop of benign inflationary pressures, monetary authorities are easing liquidity conditions to lift consumer and investment sentiment. Enhancing the effectiveness of monetary policy is a challenge in this environment. One of the changes is the weakening of the relationship between inflation and the output gap or unemployment. In this context, the Phillips curve - the inverse relationship between unemployment or output gap and inflation - is attracting increasing attention. The idea of the Phillips curve is that when unused economic capacity, or economic slack, is reduced, prices are expected to rise through wage adjustments and consumer demand. Indeed, the shape of the curve in advanced economies has posed policy questions, as inflation has generally stayed weak despite the recovery of the labour market, supported by monetary interventions. Recently the Phillips curve has been flattening in advanced economies such as the euro area and the United States, as well as in Emerging Asia, though the extent differs. Possible explanations for the flattening of Phillips curves include domestic wage rigidities, structural changes, technological shifts, global competitive pressures and changing expectations of inflationary pressures. 
In Southeast Asia, inflation has declined in general from previous decades, in line with the global picture (Figure 4). Similar to advanced economies, the gradual flattening of the Phillips curve in ASEAN countries like Thailand and Singapore can also be observed. Nonetheless, the economic environment in these two countries is different.

In general, the flattening of the Phillips curve in Southeast Asia is argued to be associated more with the increasing role of global factors, including the "global output gap", than with the domestic factors seen in the euro area and the United States. Inflation expectations are also gaining importance in determining price trends and they are considered to be well anchored thanks to policy regimes such as inflation targeting in many Southeast Asian countries (Figure 5).

Figure 4. The Phillips curve for Thailand and Singapore
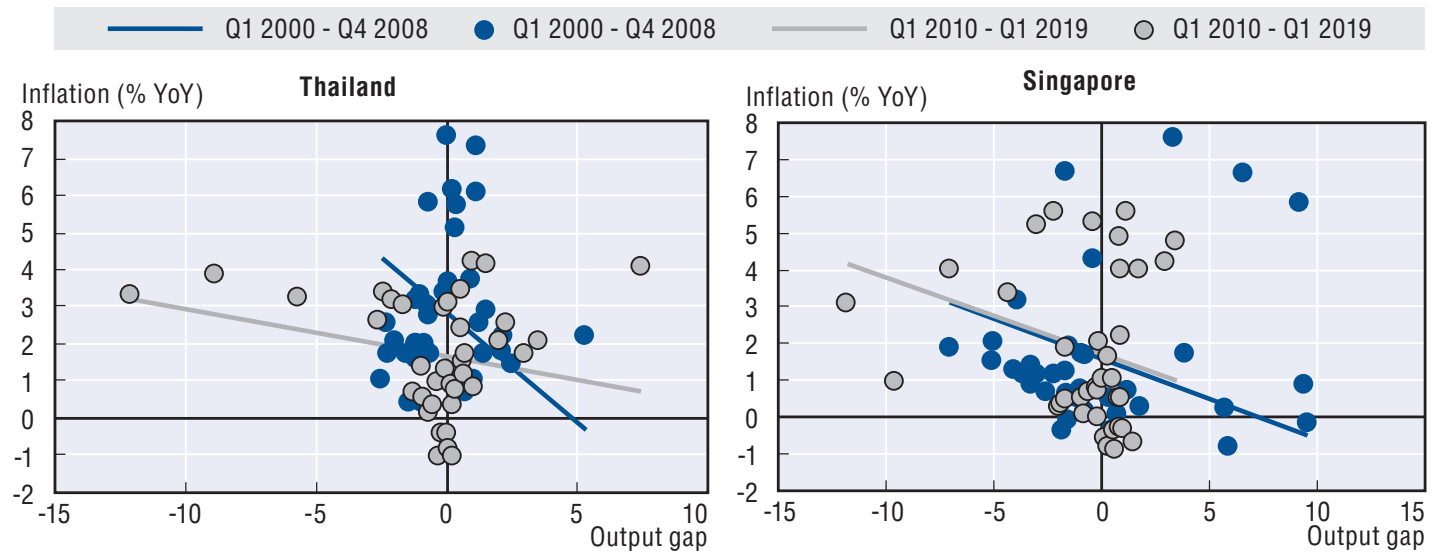

Note: The sample was split in two, from Q1 2000 to Q4 2008, and from Q1 2010 to Q1 2019; the estimation therefore does not include the global financial crisis.

Source: OECD Development Centre based on data from CEIC and national sources.

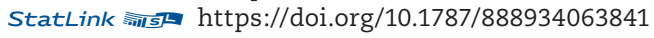

Figure 5. Target inflation band and actual inflation in Thailand and Indonesia Percentage

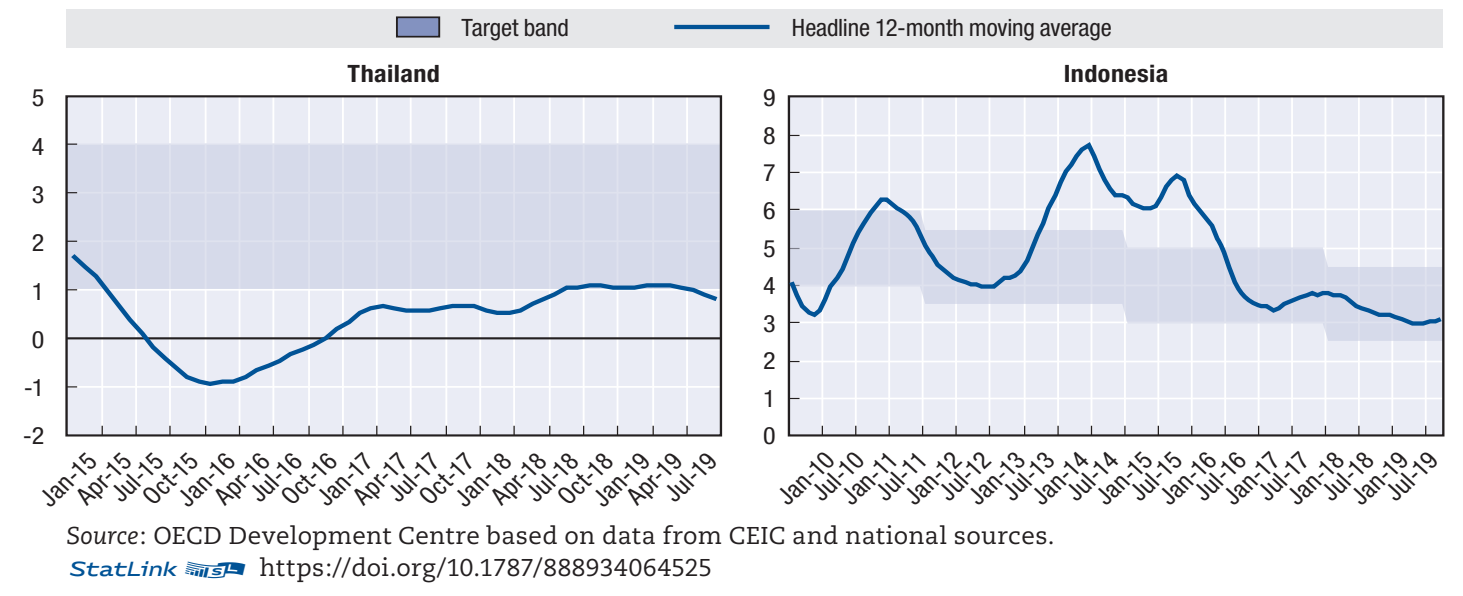

On the fiscal front, the stance of many Emerging Asian economies is favouring contained expansion in the near-term overall. The potential impact of the trade tensions on public revenue in the near term is hard to pin down given the lack of clear direction in the ongoing negotiations. 


\section{Strengthening the capacity of local governments to deal with natural disasters}

Strengthening local government participation and capacity in disaster resilience initiatives is another challenge facing the region given the current environmental and climate risks. Emerging Asia is relatively exposed to the risk of natural disasters, which can lead to heavy loss of life and which carry enormous opportunity costs, interrupt normal life and disproportionately affect lower-income citizens. The impact of natural disasters also tends to linger in the areas directly affected and cannot be captured fully by economic performance data.

Disaster resilience initiatives have been launched in Emerging Asia at the national and international levels. However, the integration of disaster risk reduction and climate change adaptation (CCA) with urban development ultimately needs to be driven at subnational levels. An example of a local-level approach that was instrumental in mitigating the impact of a disaster can be seen in the Thai city of Nonthaburi, which preventively mapped and identified at-risk areas along the Chao Phraya River before disaster struck.

A similar local-level example was the establishment in the Philippines in 1995 of the Albay Public Safety and Emergency Management Office, the country's first permanent disaster management office. Its goal was to integrate disaster risk reduction into the local government's development plans. This has enabled local government units in Albay province to develop hazard maps, area- and hazard-specific plans, community-based early warning systems and well-tested rescue and evacuation protocols.

Restricted institutional capacity can limit the disaster risk management strategies of local governments. Cities often lack personnel and a well-resourced department or division dedicated to disaster management. The tendency of governments to transfer personnel is another factor. Since disasters may occur years or decades apart, the valuable know-how and experience of city personnel who responded to past disasters is seldom properly documented and transmitted to their successors. Community involvement at all stages of disaster planning can help overcome some of these challenges.

There is also a need to raise the policy focus on several preventive measures: flood-riskintegrated water resources management; construction of disaster-resilient multipurpose evacuation and community centres; mangrove afforestation to protect shorelines from storms and floods; and hydroponics projects that could generate incomes during normal times and maintain food security when disaster occurs. Tsunamis are of particular concern in the region and could become more damaging in future due to increased urbanisation along coastlines. Tsunami early warning systems are therefore of increasing importance in at-risk areas, although their deployment and maintenance are costly. Protecting coral reefs is another way for local authorities to reduce natural disaster risks.

Policy makers should also consider how natural disasters influence internal migration. Natural disasters result in the displacement of people in the affected areas during preemptive operations and post-disaster relocation. An estimate of roughly 13 million people were displaced by environmental calamities in Asia in 2018, with China and the Philippines accounting for about 7.6 million. Population movements of such magnitude, which could ultimately lead to forced migration, necessitate strategic planning that puts a premium on constant needs assessment and engagement with affected communities. Such planning can make guidelines more responsive to ground-level conditions.

Other prominent challenges in the region include the uncertainties surrounding Brexit and its aftermath, and the influence on global oil prices of the volatile geopolitical situation in the oil-producing countries. 


\section{Chapter 2. Upgrading education for the digital era}

Digitalisation is bringing important developments for businesses and the workforce. New technologies, such as robotics, artificial intelligence and advances in information and computer technology (ICT), are changing the way societies interact, produce and create. These developments present a huge opportunity to improve human welfare and well-being through increased productivity. Yet the changes also carry significant risks. Automation of jobs can obligate affected workers to acquire new skills for jobs that are still in demand. New technologies can also change non-automated jobs, necessitating upskilling and reskilling of employees, and digitalisation can create new types of jobs that require new skill sets.

As success in the digital era requires new sets of skills, education systems need to adapt. They notably need to provide the tools necessary for people to keep up with digitalisation and succeed under the new circumstances. Emerging Asian countries must address certain challenges to ensure that their education systems are ready to provide the right ICT skills to all citizens. This means providing sufficient ICT infrastructure to schools; training teachers to boost their digital skills and learn how to incorporate ICT in the classroom; and adapting curricula to include ICT - not for its own sake, but rather to support teaching at all levels. Closing the gender digital divide is also crucial, while technical and vocational education and training (TVET) and lifelong learning need to be enhanced as paths to digital inclusion.

\section{Digital readiness needs to be enhanced in Emerging Asia}

For countries to be internationally competitive in the digital era, a skilled labour force is needed. Emerging Asian countries are in the process of closing the gap between demand for skills and supply of skilled personnel. For example, Cambodia, Indonesia and Thailand are currently experiencing a shortage of skilled labour to varying degrees (Figure 6). The trends show that skills mismatch in both skilled and unskilled labour is likely to decrease in 2021, but a shortage of skilled labour will remain high in many countries. In general, the lack of skilled labour is a key challenge in the region. 
Figure 6. Current and future skills demand and supply in three Emerging Asian countries - simulation

Cambodia

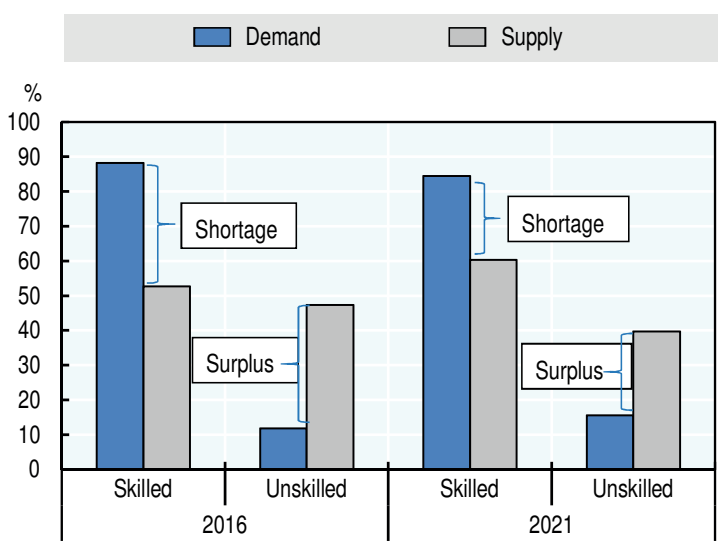

Indonesia
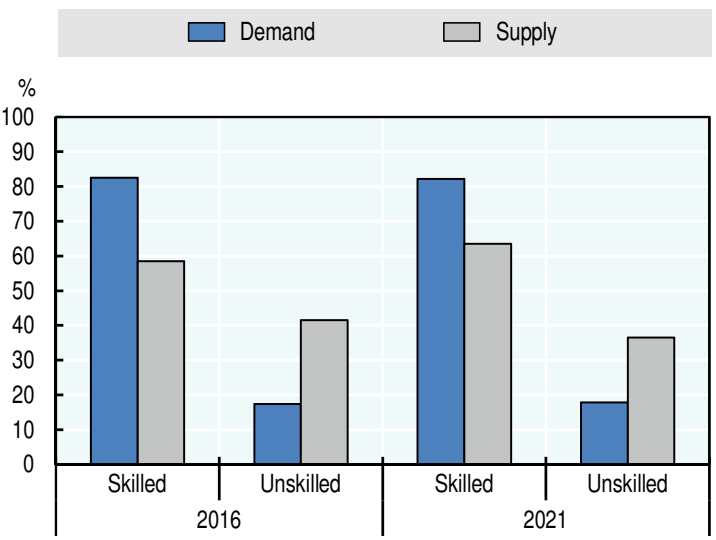

Thailand

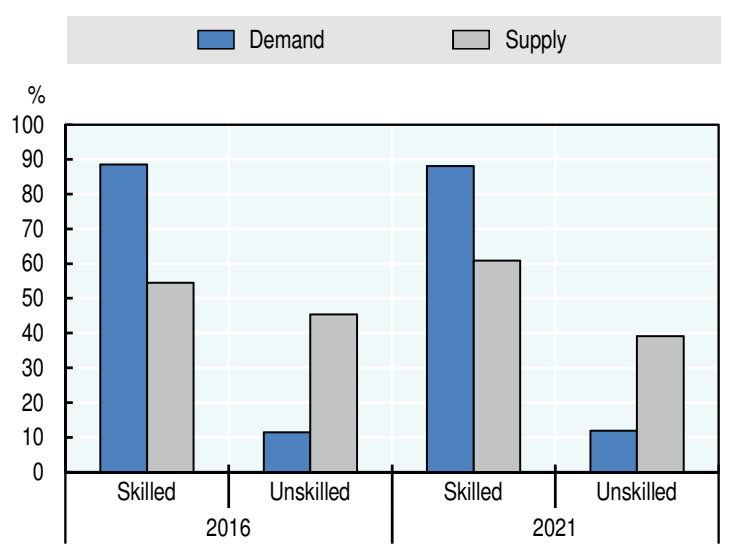

Note: Skilled refers to all occupations above ISCO-08 level 1 and levels of education above ISCED 1997 level 1, while unskilled refers to all occupations of ISCO-08 level 1 and levels of education ISCED 1997 level 1. Forward-looking data points are based on linear projections. Skill levels on the demand side were obtained by mapping ISCO-08 occupational categories from the Labour Force Surveys into ISCO-08 skill levels according to ILO (2012), merging levels 2, 3 and 4 as "skilled". Demand for skills refers to the occupational structure of employment. Skills levels on the supply side were obtained from the educational attainment variable in the Labour Force Surveys and mapped to ISCO-08 skill levels based on ILO (2012). The supply-side structure of skills was then compared with demandside data to determine mismatches.

Source: OECD Development Centre calculations based on ILO and national sources data.

StatLink 角ISt https://doi.org/10.1787/888934063974

\section{Rising demand for specialised ICT skills in Emerging Asia}

The demand for ICT skills is increasing, both in OECD countries and in Emerging Asia. As digitalisation changes the tasks associated with various occupations, new industries requiring advanced and specialised ICT skills are arising. All Emerging Asian countries have workers employed in the new ICT services sector (Figure 7). As for reaping the benefits of this growing sector, differences can be observed across the region. The sector represents a large share of employment in Singapore and is strong in the Philippines, while greater numbers are participating in Brunei Darussalam, Indonesia and Cambodia. According to the latest available data, however, the ICT services sector has stagnated in Thailand and Viet Nam in recent years. In China, based on a broader definition that includes more than purely ICT-related sectors (due to data constraints), the sector has grown steadily in the last years. 
Figure 7. Employment in the ICT sector in Emerging Asia

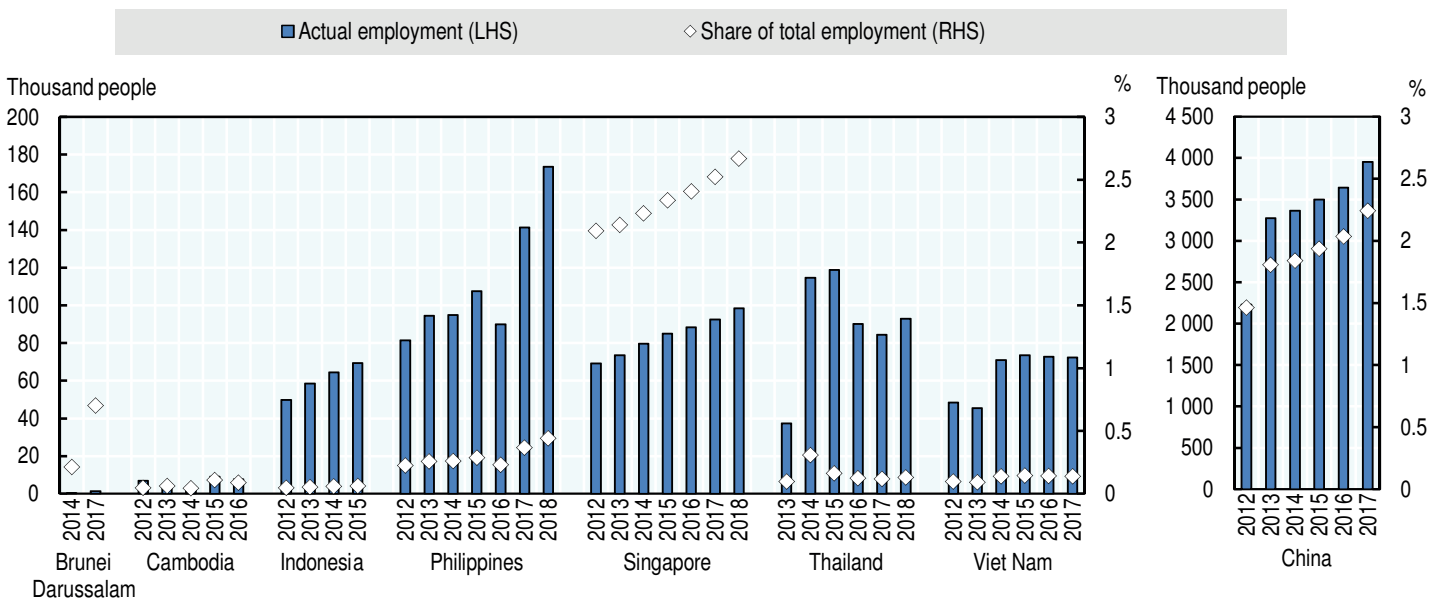

Note: Employment for Southeast Asian countries refers to ISIC rev. 4 Section J., division 62 (Computer programming, consultancy and related activities) and division 63 (Information service activities), and data come from ILO. For Cambodia, there is no division 62 data available for 2012, 2013 and 2014 and no division 63 data for 2016. Employment for China refers to Information Transmission, Computer Service and Software sectors classified by the National Bureau of Statistics in China, which is also the source of data.

Source: OECD Development Centre calculations based on ILO and CEIC data.

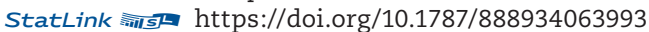

\section{Enhancing the curriculum and updating teachers' skills}

In light of digitalisation's job-market implications, many countries are taking advantage of ICT to retool the delivery of education and strengthen the resilience of the workforce. Retooling education for the digital era involves two key facets: the curriculum and the quality of teachers, especially in the context of Emerging Asia. The curriculum plays a pivotal role in programmes to incorporate ICT into education. Facilitating a seamless transition for students from one level to another and from school to the job market is another key consideration. Factors affecting curriculum-based outcomes include the availability, sufficiency and quality of materials and academic facilities and, importantly, the quality of teachers. As regards the quality of teachers, the rigorousness of tertiary training for aspiring educators and the responsiveness of professional training programmes that help them adapt to developments are two of the key concerns.

\section{Addressing Emerging Asia's gender digital divide}

Women in Emerging Asia continue to face challenges due to their limited access to ICT. In the Asia-Pacific region, the estimated gender gap in Internet use was $17 \%$ in 2017. In other words, the proportion of women using the Internet was $17 \%$ lower than the proportion of men. By comparison, the Internet-use gender gap in Europe stood at $7.9 \%$ in the same year. Improving ICT access for women and increasing their digital skills would boost their participation in the modern economy. Yet a gender gap also persists in terms of employment of ICT specialists. This is partly due to the low proportion of female students in ICT-related training and studies, including in the TVET sector. Strategies to increase the participation of girls and young women in ICT studies are therefore also needed in the region.

\section{Addressing country-specific challenges}

While digitalisation brings common challenges in Emerging Asia, each country's government also needs to focus on specific challenges (Table 1). Indonesia would need 
to address the uneven access to technology at schools across the country, while Malaysia needs to bridge the skills mismatch between ICT graduates and industry demands. Providing ICT infrastructure to schools and training for teachers are the main challenges in the Philippines. Teachers' readiness for digital education requires more attention in Thailand, while Viet Nam will need to strengthen TVET for digital skills training. The benefit of advanced ICT infrastructure in schools can be further maximised in Brunei Darussalam by improving teachers' capacity in using digital technologies, while Singapore needs to foster teachers' and school leaders' belief in the value-added impact of ICT use in the classroom. Improving ICT infrastructure and electricity supplies is critical in Cambodia. Lao PDR is also facing challenges in ICT infrastructure, particularly in the high cost and low speed of Internet. Limited access to ICT infrastructure and equipment is also one of the main challenges in Myanmar. China would need to bridge the gap between demand and supply of digital talent, while improving digital literacy and increasing access to digital devices are critical in India.

As a general trend, some countries including Cambodia, Lao PDR and Myanmar, need to address a lack of ICT infrastructure and to increase access to ICT tools. In countries where infrastructure is relatively better, such as Thailand, Brunei Darussalam and Singapore, teaching capacity and teachers' digital skills need more attention. A mismatch between demand for skills and supply of talent is another major issue in countries including Malaysia and China.

\section{Table 1. Country-specific challenges for digital education in Emerging Asia}

\begin{tabular}{ll}
\hline \multicolumn{1}{c}{ Country } & \multicolumn{1}{c}{ Digital education challenges } \\
\hline ASEAN-5 & \\
\hline Indonesia & Ensuring access to technology at schools across the country \\
Malaysia & Bridging the gap between ICT graduates and industry demands \\
Philippines & Providing schools with more ICT infrastructure and trained teachers \\
Thailand & Improving teachers' readiness for digital education \\
Viet Nam & Strengthening vocational education to meet demand for digital skills \\
\hline Brunei Darussalam and Singapore & \\
\hline Brunei Darussalam & Fostering teachers' capacity for ICT use in classrooms \\
Singapore & Strengthening teachers' belief in ICT use in the classroom \\
\hline CLM & \\
\hline Cambodia & Improving ICT infrastructure and power supplies for better access \\
Lao PDR & Increasing access to ICT tools for both teachers and students \\
Myanmar & Providing quality ICT to all schools \\
\hline China and India & \\
\hline China & Bridging the digital talent gap between demand and supply \\
India & Raising digital literacy through broader access to digital devices \\
\hline
\end{tabular}

\section{Vocational education and lifelong learning in the digital era}

As alternative paths of education, TVET and lifelong learning have the potential to provide digital skills while at the same time taking inclusion into account. However, certain challenges need to be addressed: enhancing the image and attractiveness of TVET; encouraging private-sector involvement; improving monitoring of lifelong learning programmes; and broadening publicity campaigns to boost participation.

TVET focuses on preparing students for work, with education and training programmes that are designed for, and typically lead to, a particular job or type of job. TVET usually begins at upper secondary level (ISCED 3), and typically continues at the post-secondary 
level, although in some countries it starts as early as lower secondary level (ISCED 2). Digitalisation involves science, technology and engineering as well as ICT skills, and vocational education is playing a role in these areas.

Attracting students to vocational schools remains one of the biggest challenges. Vocational education is often overshadowed by the increasing emphasis on general education and preparing students for university studies, and TVET is often seen as having a low status. This is the case in Emerging Asia. In many countries in the region, vocational education is viewed as second-class, with a lower status than general education, holding no prestige and as a choice for students who are less qualified academically.

Indeed, in most Emerging Asian countries, enrolment is generally much lower in vocational schools than in general education. In some countries, almost $100 \%$ of secondary school students are enrolled in general education institutions. In contrast, students in some OECD countries participate almost equally in general and vocational secondary education. In these countries, TVET has a better image and is seen more as a choice than a last resort. It is perceived as offering high-quality programmes to prepare people for the world of work by developing the skills required to get a job.

\section{Enhancing the image of TVET in Emerging Asia}

Most countries in Emerging Asia have recognised that enhancing the image and attractiveness of TVET is crucial. However, despite initiatives to improve the image of vocational education, further efforts are needed. One possibility is to promote pathways for TVET students to move onto a university track. TVET programmes can be designed to prepare students not only for the job market but also for continuing to a higher level of education. Furthermore, a balance is needed between occupation-specific, practical skills and broader education, including core academic competencies and theoretical knowledge. To achieve this, efforts are needed by all stakeholders. Governments should formulate policy that supports the acceptance of TVET students by universities. At the same time, universities need to embrace TVET not only by accepting TVET students, but also by contributing to the development of TVET programmes.

In some OECD countries, education systems are more flexible, offering different paths at various levels to avoid dead ends. In Emerging Asia, some countries already allow TVET students to move on to general education, although usually not directly after graduating from secondary level but rather after completing a post-secondary non-tertiary level. For TVET to be attractive, it should provide flexible programmes rather than focusing only on occupation-specific skills. One possible approach is to offer students the option of combining studies from different TVET programmes, for example robotic technology with mechanical and software engineering. Promotional campaigns and publicity about the benefits of TVET can help enhance the image of vocational education among students and their parents.

However, the rapid pace of digitalisation is already affecting the labour market and the skills it requires, while improving the image of TVET will take time. To meet this challenge, the digital skills provided by vocational schools should complement those provided by general education, and vice versa.

\section{Maximising the role of the private sector in TVET}

The private sector can play a key role in helping TVET to adapt to an evolving labour market in the digital era. It can provide a clearer view of the changes occurring amid rapid digitalisation and can offer information on the skills needed by industry. To ensure that TVET prepares its students to be ready for work, companies and other key stakeholders must be encouraged to co-operate and become more engaged in TVET planning and 
processes, including curriculum design, training and mentoring. In some OECD countries, the private sector plays a significant role. In Germany, for example, stakeholders including the government, employers and trade unions take part in decision making, with influence on the form and content of TVET. In Germany's dual system of vocational education, students spend part of their time in school and the rest as employees in companies. This allows a smooth transition of students to the labour market and fosters partnership with employers. This system should be integrated into all vocational programmes while also being systematic, quality assured, assessed and credit bearing.

\section{Recognising the importance of lifelong learning in the digital era}

Lifelong learning involves efforts to skill, upskill and reskill people across the social spectrum. As such, it is one of the key aspects of the human capital development agenda in Emerging Asia. It can help the working population adapt to changing labour market conditions and can assist people with limited education in improving their social condition. Lifelong learning is also associated with initiatives that encourage older people to stay economically active. Collaborators in lifelong learning initiatives can include traditional educational institutions, portals for open online courses, open high schools and universities, and community-based learning groups, as well as technical and vocational schools.

\section{Using monitoring and publicity to boost participation in lifelong learning}

Globally, there have been improvements in key pillars of adult education and lifelong learning, including targeting of policy, governance, consultation and financing. In terms of financing, schemes can vary, taking the form of public-private partnerships or government grants and subsidies. However, substantial gaps remain in areas such as monitoring and participation. Figure 8 shows that six Emerging Asian economies indicated an increase in adult learning participation among residents of rural areas and workers in low-skilled jobs between 2009 and 2015, while one indicated a deterioration. The other five countries either had no information or failed to answer. Worryingly, the number of countries noting improved participation for other target groups is lower, and the number that did not provide any information is higher, especially regarding migrants and adults seeking recognition for prior learning.

Figure 8. Change in adult learning participation rates in Emerging Asia since 2009

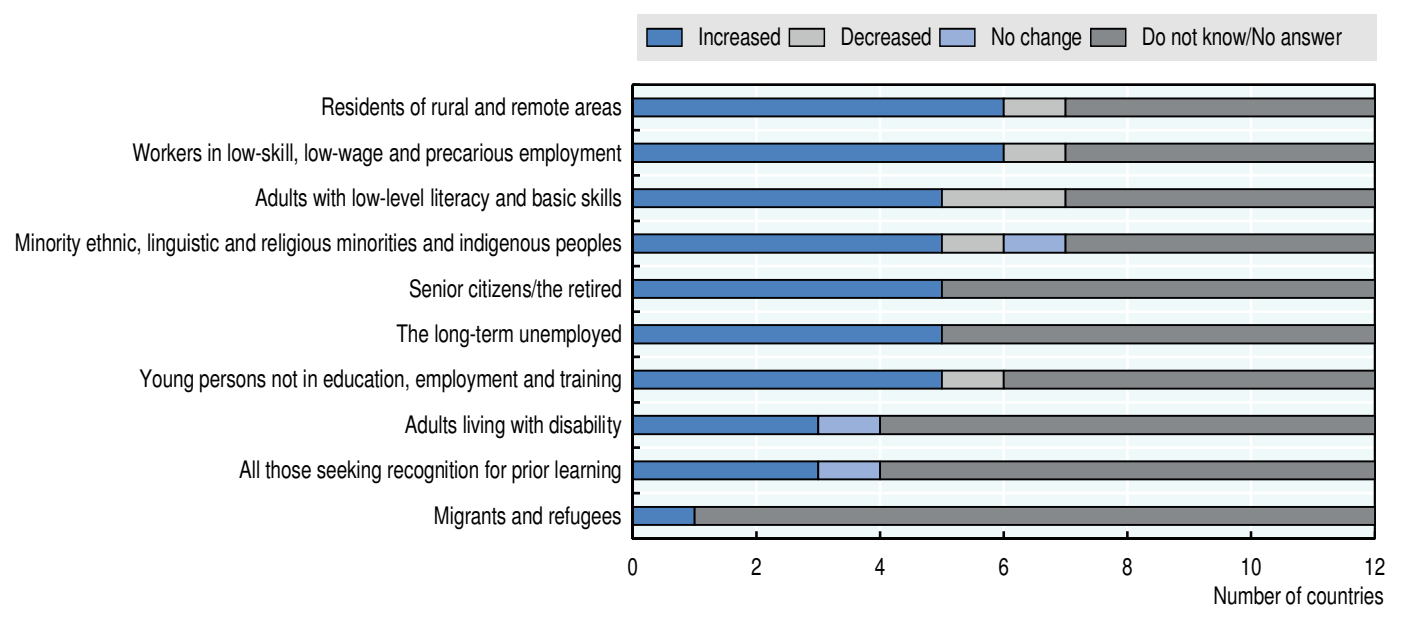

Note: GRALE 3 survey results were published in 2016 benchmarking on the GRALE 1 survey results published in 2009. Source: OECD Development Centre calculations based on UIL (2016c), GRALE 3 (database).

StatLink Ainst https://doi.org/10.1787/888934064183 
The lack of information on participation in adult learning programmes suggests that systematic data collection is absent in the region. Indeed, only seven Emerging Asian countries monitor adult learning certificates, and just six monitor labour market outcomes (Figure 9). The number that monitor completion rates and social outcomes is even lower.

\section{Figure 9. Countries collecting information by type of outcome in Emerging Asia}

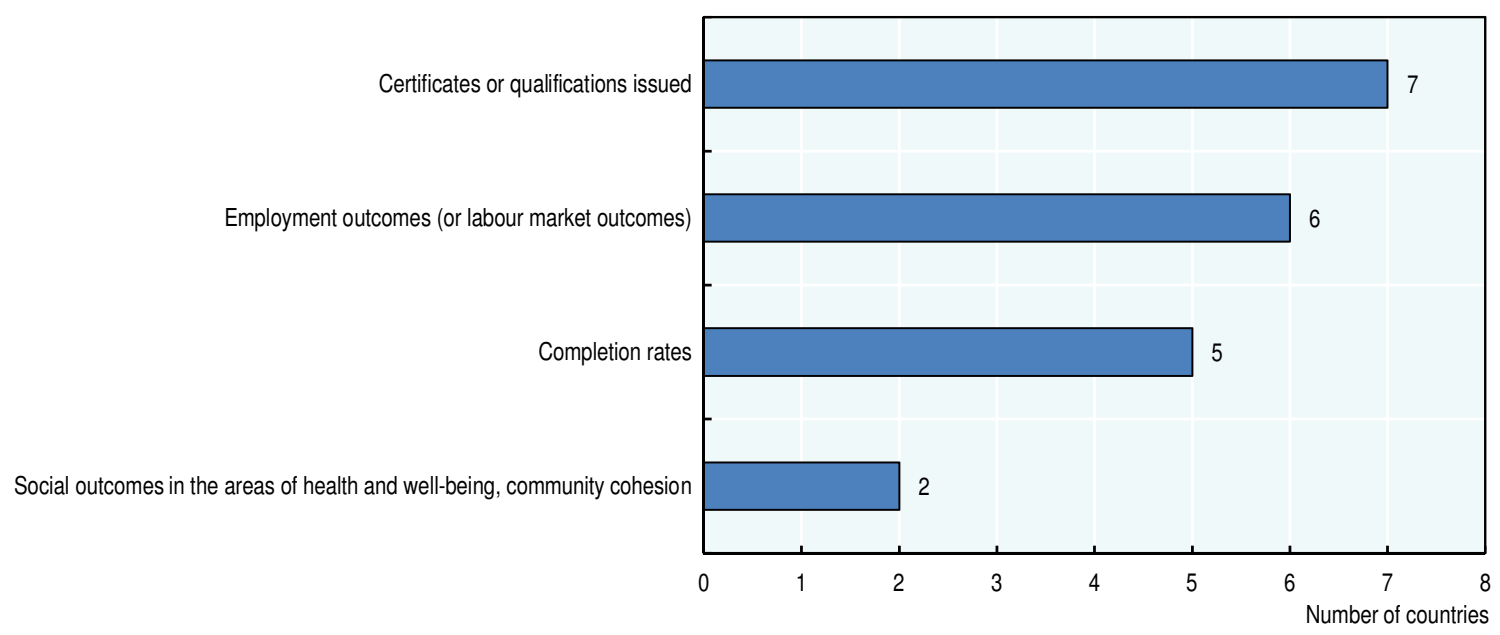

Note: GRALE 3 survey results were published in 2016 benchmarking on the GRALE 1 survey results published in 2009.

Source: OECD Development Centre calculations based on UIL (2016c), GRALE 3 (database).

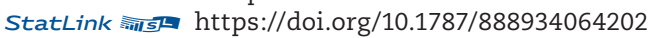

Formulating effective ways forward in policy on adult learning requires an extensive information base of good quality. Better data collection and monitoring is therefore needed. This applies to the extent of participation at the very least, preferably with the addition of data on outcomes and implementation. The labour force survey is one instrument that can be exploited to gather data on this policy area with regularity.

To enhance participation, adult learning campaigns can be publicised through mass, social and other media. In many countries in the region, programme delivery is still fragmented. Countries need a clear national plan on how to get various stakeholders involved and on how to connect the different learning channels, including community learning centres. Anchoring the expectations of potential participants is also crucial for the credibility of adult learning programmes. Participation can be constrained by perceptions that the programmes offer limited value, as well as by cultural sensitivities and lack of awareness.

\section{Scaling up open learning in Emerging Asia}

Digitalisation can facilitate lifelong learning in the region through massive open online courses (MOOCs), open educational resources and online open university courses. It is encouraging that the use of such open and distance learning is increasing in Asia, since these platforms not only widen the scope of training, but make access to learning materials more flexible. There are also promising initiatives to make the most of mobile phones and mobile Internet penetration to promote learning opportunities through applications.

However, capitalising on these developments requires an enabling environment. Digital literacy is still uneven across and within countries in the region. Raising digital know-how should go beyond the working age or midstream population to reach older 
people and young children. With this in mind, an effective national programme for promoting digital learning tools requires a thorough understanding of the learning preferences of people of different age groups and different socio-economic backgrounds. In addition, deeper private-sector engagement can help scale up the use of MOOCs. Private firms can be a valuable source of insight concerning course content, as well as a source of capital. They can also make learning platforms more sustainable by taking maintenance and the updating of materials into account. The integrity of MOOC modules must be reaffirmed regularly. This can be done via a system that validates their quality following a standardised set of parameters. Finally, collaboration among institutions can yield significant synergy gains. Strengthening interscholastic ties can help to broaden the network, while incorporating community learning centres into the network can bolster awareness, especially in rural areas.

In terms of financing, schemes can vary, taking the form of public-private partnerships or government grants and subsidies. Earmarking income from certain industries for ICT training of target sectors is also being practised.

\section{Chapter 3. Structural policy country notes}

The Outlook's country notes highlight key structural policy challenges in Emerging Asia (Table 2).

Table 2. Structural policy challenges in Emerging Asian countries

\begin{tabular}{|c|c|c|}
\hline Country & Topic & Focus \\
\hline \multicolumn{3}{|l|}{ ASEAN-5 } \\
\hline Indonesia & Education & Reforming technical and vocational education and training \\
\hline Malaysia & SMEs & Developing the entrepreneurship of SMEs \\
\hline Philippines & Education & Enhancing the outcomes of a new basic education framework \\
\hline Thailand & Social safety net & Improving the social safety net to help elderly people \\
\hline Viet Nam & Digital trade & Developing the digital economy to enhance trade \\
\hline \multicolumn{3}{|c|}{ Brunei Darussalam and Singapore } \\
\hline Brunei Darussalam & Start-up eco-system & Developing an economic environment that spurs start-ups \\
\hline Singapore & Education & Boosting investment and parental involvement in pre-schools \\
\hline \multicolumn{3}{|l|}{ CLM } \\
\hline Cambodia & SMES & Improving training for MSMEs to achieve inclusive growth \\
\hline Lao PDR & Agriculture & Promoting export-oriented organic agriculture \\
\hline Myanmar & Infrastructure & Unleashing the potential of the railways \\
\hline \multicolumn{3}{|l|}{ China and India } \\
\hline China & Investment & Allocating investment more efficiently \\
\hline India & Urban transportation & Strengthening smart land transportation \\
\hline
\end{tabular}

\section{ASEAN-5}

\section{Indonesia}

Education: TVET is an important part of Indonesia's Industry 4.0 strategy. Vocational education still faces many challenges, however, including a skills mismatch and negative perceptions among the general public. The government began a revitalisation process 
in 2016 and overhauled curricula to improve the skills of TVET graduates and increase employability through closer connection with industry. Further efforts are needed to promote public-private partnerships in the TVET sector, address a shortage of qualified vocational teachers, strengthen interagency co-ordination, and harmonise the national skills certification system.

\section{Malaysia}

SMEs: Malaysia has made significant strides in improving its domestic business climate for small and medium-sized enterprises. Government initiatives that support SMEs include programmes to develop human capital, foster innovation, facilitate digitalisation and nurture technology-oriented start-ups. Malaysia could improve the effectiveness of its SME policies by strengthening monitoring and evaluation, leveraging entrepreneurship programmes to encourage informal enterprises to enter the formal sector, setting policy targets in terms of firm-level competitiveness and growth contribution, and building a comprehensive firm-level database.

\section{Philippines}

Education: The Philippines has rolled out a new K-12 basic education framework aimed at aligning education duration with international practice, tackling congestion in core course curricula and increasing the employability of high school graduates. Despite some positive outcomes, resource-related issues such as budgetary constraints, poor resource management and uneven teaching quality continue to pose a challenge for state-funded education. To address the challenge, the government should adopt a more transparent and responsive approach to resource management, improve efficiency in policy implementation and strengthen private-sector participation for additional funding. The involvement of multiple stakeholders in programme appraisal would also be valuable, as would strengthening collaboration between schools and local government.

\section{Thailand}

Social safety net: Changes in Thailand's demography have resulted in an ageing population. With increasing numbers of senior citizens relying on the government's allowance for the elderly, the authorities may need to improve their capacity to provide income security. Increasing the budget allocation for the elderly and improving management of the social security fund are important. The government should also encourage saving for retirement by offering incentives, carrying out targeted communication and education campaigns, and improving registration procedures.

\section{Viet Nam}

Digital trade: There is broad consensus that digital trade can bring significant benefits to Viet Nam's economy, both through domestic trade and digital exports. In order to facilitate the development of digital trade, the government is paying particular attention to promoting electronic payment, expanding ICT infrastructure and ensuring network security. Challenges include insufficient high-quality human resources with digital knowledge, lack of trust among customers of online businesses and the limited capacity of logistics services. In order to further promote digital trade, the government needs to address these challenges and also eliminate barriers affecting the competitiveness of the country's digital exports. 


\section{Brunei Darussalam and Singapore}

\section{Brunei Darussalam}

Start-up eco-system: Brunei Darussalam already has several competitive advantages for developing a start-up friendly ecosystem, including a highly educated Englishspeaking population, access to the vast ASEAN market, abundance of financial resources and an existing embryonic start-up ecosystem to build upon. The government could further support innovative start-ups by financing special centres at universities to foster entrepreneurship among students, provide business guidance and raise awareness about intellectual property rights. The government could also enhance equity financing for start-ups through support for venture capital, either by assuming the role of venture capital investor or by providing support for private venture-capital firms.

\section{Singapore}

Education: The pre-school education system in Singapore has two major shortfalls: insufficient teachers and a lack of parental involvement. Increasing public spending on pre-school education offers a clear way to reduce the child-to-teacher ratio without affecting accessibility. In addition, the government could strengthen the home learning environment by supporting parents of young children through Early Childhood Education and Care (ECEC). It could, for example, provide parenting instructions through ECEC centres and create a constructive and supportive relationship between parents and teachers. In addition, further efforts are needed to encourage young parents to participate in parental engagement activities.

\section{CLM}

\section{Cambodia}

SMEs: Micro, small and medium-sized enterprises (MSMEs) form the backbone of Cambodia's economy and account for more than half of national employment and GDP. However, the lack of qualified human resources is a pressing issue due to the limited size of the skilled labour force and competition for talent from larger corporations with better employee welfare. Better training and education, such as a high-quality TVET system, could help to address this challenge. To reap the benefits of vocational training for MSMEs, policy makers need to foster a positive image of TVET, address a mismatch between training and market demands, and improve the quality of vocational education through closer collaboration with the private sector and other stakeholders.

\section{Lao PDR}

Agriculture: Development of export-oriented organic agriculture could energise the stagnant growth of the agriculture and forestry sectors in Lao PDR. Although organic agriculture development is at an early stage in the country, with relatively little available farmland and a limited domestic market, there is vast potential for expansion. Most farmers rely on subsistence agriculture, which is convertible to organic methods at relatively little extra cost. The organic agriculture sector could benefit from tapping into regional and international markets that are more mature. However, the country first needs to improve the quality of its organic products, develop recognisable organic brands, enhance co-ordination among stakeholders, establish national regulations on organic agriculture and trade, and boost marketing efforts via ICT technologies. 


\section{Myanmar}

Infrastructure: The railway sector in Myanmar has been in decline in terms of both passenger transport and freight traffic. To revive the sector, the government needs to shift the focus of its investment policy to improving the operational performance of critical railway assets. The railway sector needs to achieve an adequate ratio of cost coverage and become self-sustaining. Potential policy measures include building efficient and consistent pricing systems, improving railway services, modernising equipment for efficient handling of freight, introducing container train services and intermodal facilities, and renovating and upgrading existing locomotives.

\section{China and India}

\section{China}

Investment: Investment has been the main driver of China's robust growth for many years. Following the global financial crisis, the Chinese economy started to rebalance away from investment and towards consumption. At present, against a backdrop of slowing investment, China needs to place greater emphasis on the efficiency of investment projects and let the market play a greater role in the allocation of resources and pricing of the factors of production. This could be done, for example, by removing implicit guarantees to public entities and ending bailouts. The government should also ensure greater transparency in the investment process and with procurement contracts, as well as rigorous feasibility studies before and after investing in projects.

\section{India}

Urban transportation: Cities in India have adopted smart technologies to deliver better urban transport services in response to long-standing issues of congestion, pollution and transport inefficiency. In order to encourage more people to use mass transport, the absorptive capacity and quality of public transportation need to be addressed comprehensively. Attracting talent is another concern for the development of intelligent transport systems. To address the fragmented nature of urban-transport management, unified metropolitan transport authorities and urban-transport funds can play a critical role. It is also important to make full use of innovations in technology, strengthen the management of road transport infrastructure and involve the private sector in transport management. 


\section{Chapter 1}

\section{Macroeconomic assessment and economic outlook}

Emerging Asian economies - Southeast Asia, China and India experienced further moderation of economic growth midway through 2019. The resilience of private consumption anchored the growth push, as in the past. However, exports continued to reel from trade tension headwinds accompanied by a softening of fixed investment. Moving forward, beyond tariff-related uncertainties, the grimmer growth picture in advanced economies is dampening external prospects despite historic low interest rates. Monetary tools have been used within and outside the region to ease economic frictions. The challenge for Emerging Asian economies is to reinforce the effectiveness of these policies. Strengthening local government involvement in disaster resilience initiatives to address environmental and climate risks is also vital. 


\section{Introduction}

Emerging Asian economies - Southeast Asia, China and India - experienced further moderation of economic growth midway through 2019. The resilience of private consumption anchored the growth push, as in the past. However, exports continued to reel from trade tension headwinds accompanied by a softening of fixed investment. Moving forward, beyond tariff-related uncertainties, the grimmer growth picture in advanced economies is dampening external prospects despite historic low interest rates.

Monetary tools have been used within and outside the region to spur economic growth. The challenge for Emerging Asian economies is to reinforce the effectiveness of these policies, while some of them are also considering other stimulus measures. Strengthening local government involvement in disaster resilience initiatives to address environmental and climate risks is also vital. Overall, Emerging Asia's GDP growth in 2019 and 2020 is expected to come in at a slower pace than the rates projected in the Outlook Update in July 2019 (OECD, 2019a). In the medium term, the region's performance from 2020-24 is also anticipated to be less impressive than from 2013-17 (Figure 1.1).

Figure 1.1. Real GDP growth in Southeast Asia, China and India

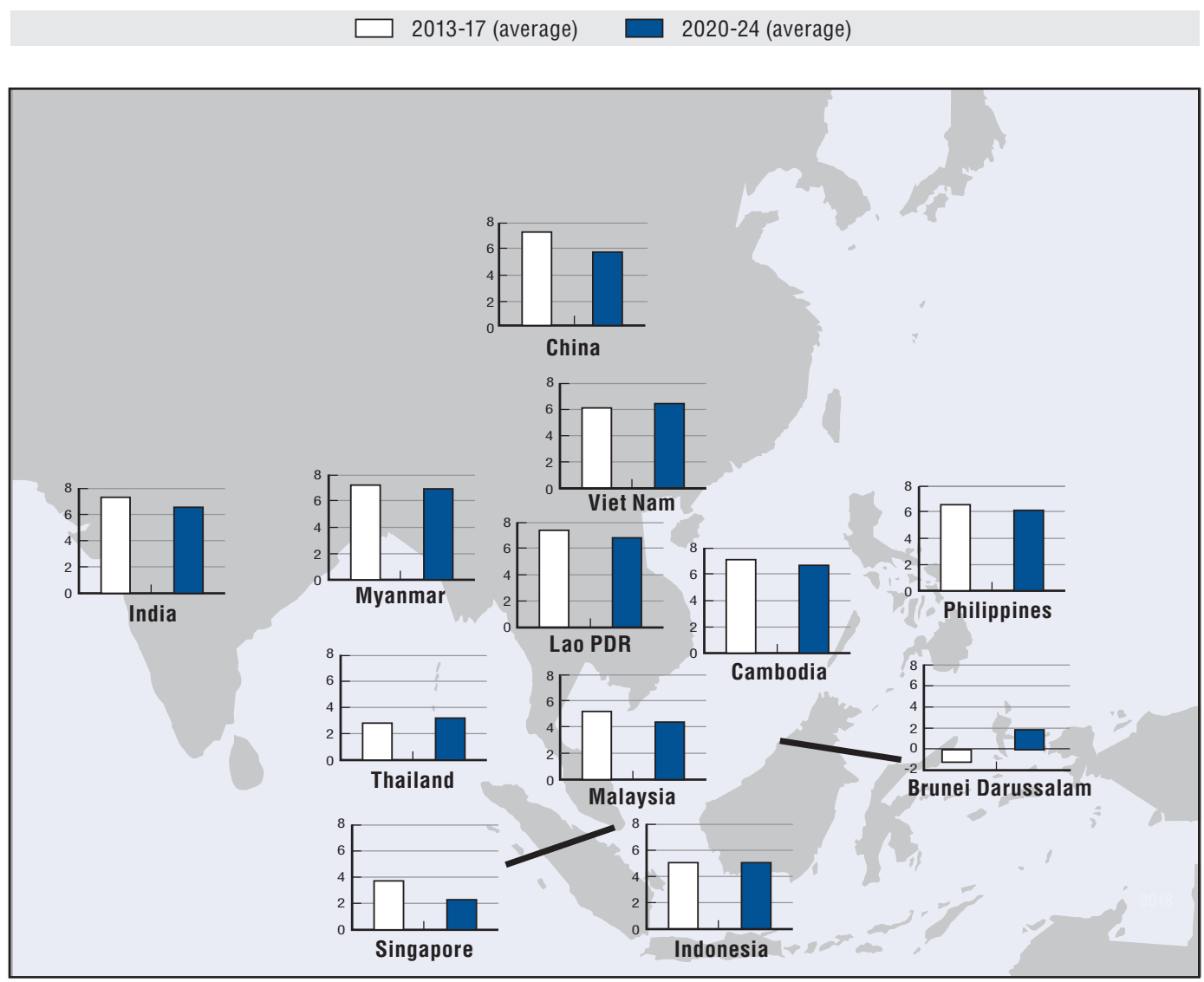

Source: OECD Development Centre, Medium-term Projection Framework (MPF-2020).

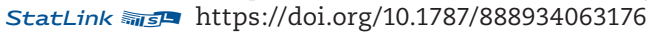

\section{Overview and main findings}

Gross domestic product (GDP) growth in Emerging Asia is forecast to come in at $5.7 \%$ on average in 2020-24 (Table 1.1), based on the OECD Development Centre's Medium-term Projection Framework 2020 (Box 1.1). Trade tensions between the United States and China 
are continuing, and the broadening economic weakness in advanced economies adds substantial uncertainty to export prospects. Stability in the labour market, and in certain cases inflows of income from overseas workers, will sustain domestic consumption. Realisation of infrastructure projects that are already in the pipeline should provide more lift to domestic demand. Given this backdrop, Emerging Asia's expected growth over the next five years will be weaker than the 2013-17 pace of $6.7 \%$. Southeast Asia is estimated to grow by $4.9 \%$ during the period, down from the average rate of 5.0\% in 2013-17. China's growth will taper further as structural reform continues. India is also anticipated to grow relatively more modestly in 2020-24 than in 2013-17 while the banking sector regains its footing.

Table 1.1. Real GDP growth in ASEAN, China and India, 2018-24

\begin{tabular}{|c|c|c|c|c|c|c|c|}
\hline \multirow{2}{*}{$\begin{array}{l}\text { Annual percentage change } \\
\text { ASEAN- } 5 \text { countries }\end{array}$} & \multirow[t]{2}{*}{2018} & \multirow[t]{2}{*}{2019} & \multirow[t]{2}{*}{2020} & \multicolumn{2}{|c|}{$\begin{array}{c}\text { Changes from previous forecast } \\
\text { (July 2019) }\end{array}$} & \multirow[t]{2}{*}{ 2020-24 } & \multirow[t]{2}{*}{ 2013-17 } \\
\hline & & & & 2019 & 2020 & & \\
\hline Indonesia & 5.2 & 5.0 & 5.0 & $\downarrow$ & $\downarrow$ & 5.1 & 5.1 \\
\hline Malaysia & 4.7 & 4.4 & 4.4 & - & $\downarrow$ & 4.4 & 5.2 \\
\hline Philippines & 6.2 & 5.6 & 6.0 & $\downarrow$ & $\downarrow$ & 6.2 & 6.6 \\
\hline Thailand & 4.1 & 2.7 & 3.0 & $\downarrow$ & $\downarrow$ & 3.2 & 2.8 \\
\hline Viet Nam & 7.1 & 6.8 & 6.6 & $\uparrow$ & - & 6.5 & 6.2 \\
\hline \multicolumn{8}{|c|}{ Brunei Darussalam and Singapore } \\
\hline Brunei Darussalam & 0.1 & 2.0 & 1.7 & $\uparrow$ & $\downarrow$ & 1.9 & -1.2 \\
\hline Singapore & 3.1 & 0.6 & 1.2 & $\downarrow$ & $\downarrow$ & 2.3 & 3.7 \\
\hline \multicolumn{8}{|l|}{ CLM countries } \\
\hline Cambodia & 7.5 & 7.0 & 6.8 & - & - & 6.7 & 7.1 \\
\hline Lao PDR & 6.3 & 6.5 & 6.6 & $\downarrow$ & $\downarrow$ & 6.8 & 7.4 \\
\hline Myanmar & 6.5 & 6.6 & 6.7 & $\downarrow$ & $\downarrow$ & 6.9 & 7.2 \\
\hline \multicolumn{8}{|l|}{ China and India } \\
\hline China & 6.6 & 6.2 & 5.7 & - & $\downarrow$ & 5.6 & 7.1 \\
\hline India & 6.8 & 5.8 & 6.2 & $\downarrow$ & $\downarrow$ & 6.6 & 7.4 \\
\hline Average of ASEAN-10 & 5.2 & 4.6 & 4.7 & $\downarrow$ & $\downarrow$ & 4.9 & 5.0 \\
\hline Average of Emerging Asia & 6.4 & 5.8 & 5.6 & $\downarrow$ & $\downarrow$ & 5.7 & 6.7 \\
\hline
\end{tabular}

Note: Data are as of 21 November 2019. Data for India and Myanmar relate to fiscal years. The projections for China, India and Indonesia for 2019 and 2020 are based on the OECD Economic Outlook 106 (database).

Source: OECD Development Centre, Medium-term Projection Framework (MPF-2020).

\section{ASEAN-5}

- Indonesia's GDP growth in the medium term is forecast to reach $5.1 \%$, in line with the 2013-17 average. A steady decline in unemployment rate is fuelling consumption prospects, while the expansion of special economic zones bodes well for investment. Improving efficiency in tax administration and infrastructure spending are among the key challenges.

- Medium-term economic growth in Malaysia is estimated to settle at 4.4\%, slightly lower than the 2013-17 average of 5.2\%. Labour market stability should continue to fuel private consumption, although real-wage growth is slowing. The country's push to improve the digital infrastructure and broaden the economy's technology base are positive, although further policy actions are needed to improve the ease of starting a business and strengthen tax mobilisation. 
- GDP growth in the Philippines is projected to come in at $6.2 \%$ in $2020-24$, below the 2013-17 average of 6.6\%. Labour market conditions are working in favour of consumption, but a thorough examination of the declining labour-force participation rate is needed to deepen the market. Infrastructure implementation delays remain a challenge. Improving disaster resilience is also vital.

- In Thailand, medium-term economic growth is estimated to be $3.2 \%$, higher than the average growth rate $2.8 \%$ in 2013-17. An improvement in the country's business climate metrics is encouraging for capital formation, labour market prospects and private consumption. Facilitating an enabling environment for the growing fintech services field is a key challenge in the coming years.

- Viet Nam's economy is forecast to grow by about $6.5 \%$ in the medium term, surpassing the average rate of expansion of $6.2 \%$ in 2013-17. The vibrant investment climate bodes well for the country's privatisation and foreign investment strategies. Recently signed free trade agreements should buttress the export sector amid external headwinds. Keeping rural areas in step with developments in urban centres is a key challenge.

\section{Brunei Darussalam and Singapore}

- At 1.9\%, Brunei Darussalam's medium-term growth is forecast to be stronger than the 2013-17 average of $-1.2 \%$. A steady improvement in business-climate metrics should buttress efforts to increase private-sector activity and bolster the labour market, while the country's big-ticket projects should help to improve economic efficiency. Strengthening the central bank's capacity to administer monetary policy is a crucial challenge as the country deepens its capital markets.

- Singapore's economy is forecast to grow by $2.3 \%$ in $2020-24$, lower than the 2013-17 average of 3.7\%. Trade will likely dominate the growth story in the next few years. The start-up ecosystem is showing considerable promise, though it requires targeted support. Addressing participation barriers in lifelong learning programmes is another challenge.

\section{Cambodia, Lao PDR and Myanmar}

- Cambodia's average GDP growth in 2020-24 is estimated to come in at $6.7 \%$, slower than the 2013-17 rate of 7.1\%. Fixed investment will remain a key growth anchor as infrastructure development continues. Corporate bond issuances in local currency are helpful for capital market development and facilitate the use of the riel, which is essential for monetary policy efficacy. Continued progress in addressing deficiencies in capital flow regulations is vital.

- The economy of Lao PDR is projected to grow by $6.8 \%$ on average in $2020-24$, a milder expansion than the $7.4 \%$ seen in 2013-17. Infrastructure projects and energy exports are expected to provide much of the growth steam. However, limited improvement in the ease of doing business could hold back the development of other sectors. Coming up with a sound framework to deal with environmental hazards is another challenge for broadening the sources of economic growth.

- Myanmar's GDP is forecast to grow by $6.9 \%$ in the medium term, slightly softer than the 2013-17 average of 7.2\%. Fixed investment backed by foreign direct investment (FDI) is set to propel economic activity. Exports should gain from a planned expansion of special economic zone (SEZ) operations. Nonetheless, the business climate could be improved. Stability and sufficiency of power supply is one issue. As for education, including digital literacy, access and quality - though improving - remain a challenge. 


\section{China and India}

- China's GDP growth will continue to slow at $5.6 \%$ in the medium term from its 2013-17 average of 7.1\%. Growth started to slow a few years ago as the economy is rebalancing from investment-led to consumption-led growth. Investment slows on the back of excess capacity in some manufacturing industries, while consumption is not picking up in a lack of structural reforms to reduce precautionary savings. Nevertheless, consumption remains robust against the backdrop of steadily rising incomes. Ageing pressures are increasing, even though the population is still growing, but the working age population has been falling for several years already. Productivity-boosting structural reforms, including dismantling administrative monopolies and further opening up the economy would lift the growth potential.

- GDP growth in India in 2020-24 is forecast to reach about 6.6\%, slower than its 201317 average of $7.4 \%$. While reliance on consumption will continue, the large informal labour share indicates that there is room to strengthen the consumption base. Sustaining efforts to prop up the health of the banking sector is a vital challenge, while bridging the disparity in urban and rural infrastructure is important for spreading investment and economic opportunities while addressing urbanisation.

\section{Other key points of the economic outlook and assessment}

- As exports cave in to trade tensions, real fixed investment growth is pulling back and cautiousness in business sentiment rises. Nonetheless, current account positions remain solid amid trade uncertainties. The region's lacklustre export earnings were offset by a pullback in import payments.

- Volatility in financial flows has been contained, as has the movement in exchangerate and equity prices.

- Against a backdrop of benign inflationary pressures, monetary authorities are easing liquidity conditions to lift consumer and investment sentiment. Enhancing the effectiveness of monetary policy in a changing economic environment is a challenge in this context. The flattening of the Phillips curve, which indicates a weakening linkage between inflation and the labour market, ought to be considered. Overall, the fiscal stance of many Emerging Asian economies is favouring contained expansion in the near term.

- Strengthening local government participation and capacity in disaster resilience initiatives to address the current environmental and climate risks is another challenge facing the region.

\section{Box 1.1. Key assumptions of the medium-term outlook to 2024}

Projections over 2019-24 are produced using the OECD Development Centre's Medium-term Projection Framework (MPF), which includes the following assumptions:

- The output gap (the gap between actual and potential GDP) will converge to zero by 2024.

- Inflation-targeting countries will continue to pursue stability and to adjust monetary policies to support their targets.

- The national medium-term development plans of Emerging Asian countries will largely be implemented, subject to budgetary and other policy considerations.

- Regional economic integration initiatives and projects will advance at the same pace as before.

- Unanticipated economic events and other external factors will not significantly alter the situation beyond the cut-off date.

- The cut-off date of data for the projection is 21 November 2019. For more detailed information on MPF, please see www.oecd.org/dev/asia-pacific/mpf.htm. 


\section{Recent developments and near-term outlook ${ }^{1}$}

\section{ASEAN-5}

Indonesia's economy rose in Q2 2019 at almost the same rate as in the previous quarter (Table 1.2). ${ }^{2}$ This marks the tenth straight quarter that Indonesia has grown by $5 \%$ or higher, though the recent trend is on a decline. The contribution of private consumption stayed solid in the first six months of 2019, as in previous years (Figure 1.2). ${ }^{3}$ Government spending also rose faster during the first half from the same period last year to increase its contribution to growth. On the other hand, fixed investment grew more slowly than in the first six months of 2018, in line with the softer trade prospects. Exports slipped for the second straight quarter as did imports, which contracted even more sharply. Agricultural production improved markedly on the supply side in Q2 2019 from Q1 2019, thanks to good weather, making up for weakness in manufacturing and mining. Growth in the services sector as a whole remained strong, largely supported by subsectors related to real estate, business services, transportation, education and health.

Table 1.2. Quarterly real GDP growth in ASEAN, China and India, 2018-19

Year-on-year, percentage changes

\begin{tabular}{|c|c|c|c|c|c|c|c|}
\hline & $2018 Q 1$ & $2018 Q 2$ & 2018 a3 & 2018 Q4 & 2019 Q1 & 2019 Q2 & 2019 Q3 \\
\hline \multicolumn{8}{|l|}{ ASEAN-5 countries } \\
\hline Indonesia & 5.1 & 5.3 & 5.2 & 5.2 & 5.1 & 5.0 & - \\
\hline Malaysia & 5.3 & 4.5 & 4.4 & 4.7 & 4.5 & 4.9 & - \\
\hline Philippines & 6.5 & 6.2 & 6.0 & 6.3 & 5.6 & 5.5 & - \\
\hline Thailand & 5.0 & 4.7 & 3.2 & 3.6 & 2.8 & 2.3 & - \\
\hline Viet Nam & 7.5 & 6.7 & 6.8 & 7.3 & 6.8 & 6.7 & 7.3 \\
\hline \multicolumn{8}{|c|}{ Brunei Darussalam and Singapore } \\
\hline Brunei Darussalam & 2.8 & -2.6 & -1.1 & 1.0 & -0.5 & 6.7 & - \\
\hline Singapore & 4.6 & 4.2 & 2.6 & 1.3 & 1.1 & 0.1 & - \\
\hline \multicolumn{8}{|l|}{ China and India } \\
\hline China & 6.8 & 6.7 & 6.5 & 6.4 & 6.4 & 6.2 & 6.0 \\
\hline India & 8.0 & 7.0 & 6.6 & 5.8 & 5.0 & - & - \\
\hline
\end{tabular}

Note: Data for India relate to fiscal years.

Source: OECD Development Centre based on data from CEIC and national sources.

Figure 1.2. Contribution to GDP growth in Indonesia, 2017-19

Percentage points
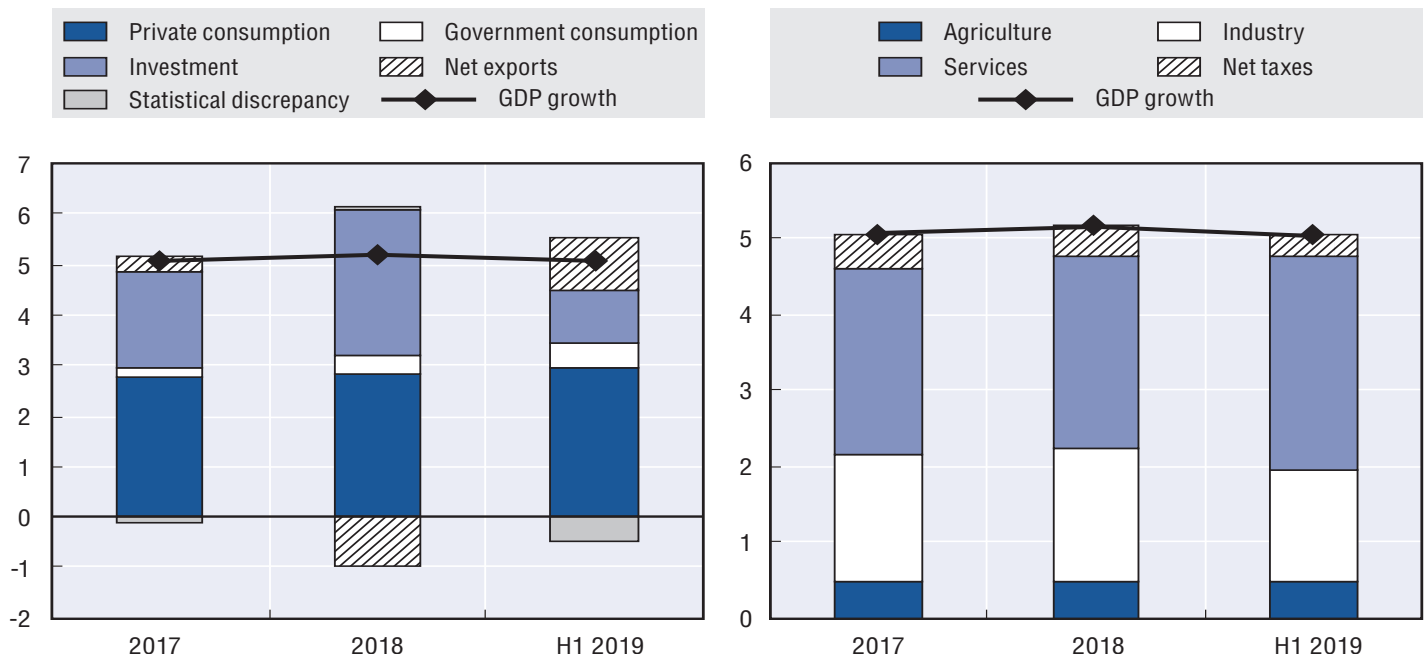

Source: OECD Development Centre based on data from CEIC and national sources. StatLink 年15t https://doi.org/10.1787/888934063195 
Annual growth in Indonesia is expected to be lower in 2019 than in the previous year and will likely hold steady in 2020. Goods exports growth, in nominal value and volume, was still dampened in recent months, as was the growth in visitor arrivals and retail sales. On the upside, the consumer outlook remains optimistic, while demand for loans, mainly for investment and small consumer purchases (i.e. credit-card spending), is gaining traction. Budget spending in 2020 is programmed to expand conservatively, but the government is banking on the quality of outcomes to boost growth momentum.

GDP growth in the medium term is forecast to be in line with the 2013-17 average of $5.1 \%$. Consumption prospects are buoyed by the steady decline in the unemployment rate. The expansion of SEZs bodes well for investment. Key challenges include efficiency in tax administration and infrastructure spending, as well as environmental resilience, highlighted in OECD (2019a). The move to transfer the capital city carries promise for narrowing development gaps among regions, as well as for decongesting Jakarta.

GDP growth in Malaysia rebounded in Q2 2019 from Q1 2019 on the strength of private consumption. Public spending hardly grew during the period, in line with fiscal consolidation. Exports were essentially flat as imports pulled back. Fixed investment in Q2 2019 likewise shrank, continuing the pattern of the previous quarter. Supply-side sectors depict broad-based stability (Figure 1.3). Mining posted its first gain in seven quarters, while agriculture, manufacturing and the large services subsectors registered healthy growth rates.

Figure 1.3. Contribution to GDP growth in Malaysia, 2017-19

Percentage points

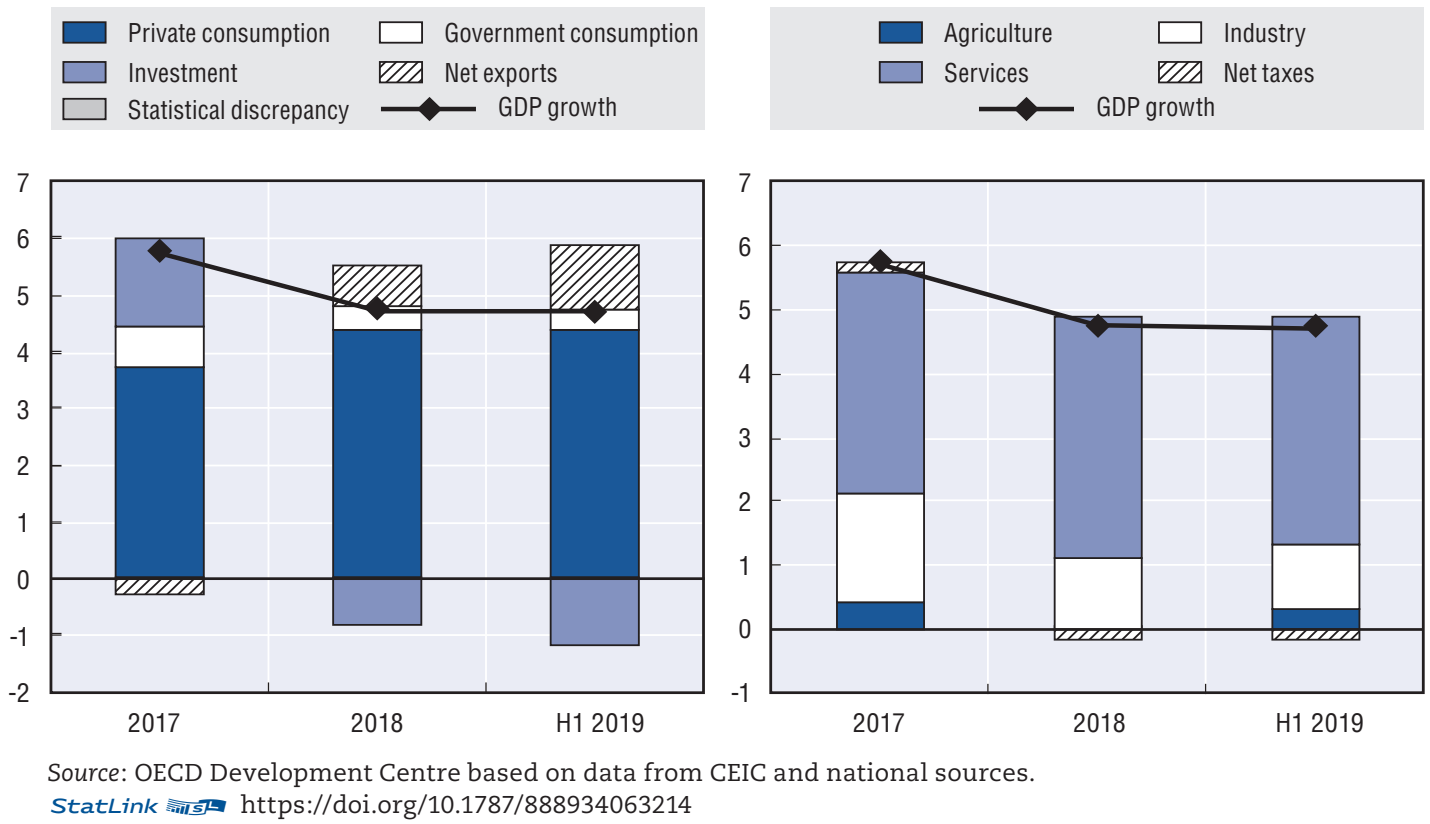

Growth forecast for 2019 is unchanged from July 2019 (OECD, 2019a) though the projected growth in 2020 is revised downwards. Headwinds are mainly coming from the external sector, as suggested by goods exports data. Yet, domestic demand indicators remain solid. The drop in consumer confidence is turning around (Figure 1.4). Growth in tourist arrivals rose, as did growth in non-industrial electricity consumption. A considerable jump in approved capital investment in manufacturing in the first half of 2019, and sustained growth in the industrial production index, further point to a recovery in capital formation. 
Medium-term economic growth is estimated to settle at $4.4 \%$, slightly lower than the 2013-17 average of 5.2\%. Labour market stability should continue to fuel household consumption, although real wage growth is slowing. ${ }^{4}$ Malaysia's push to improve digital infrastructure and broaden the economy's technology base should benefit from the establishment of intellectual property courts. ${ }^{5} \mathrm{~A}$ digital free trade zone, akin to the multimedia super corridor, has been laid out to facilitate the economic transition. Sectors involved in aerospace technology and biotechnology are also getting considerable support. Despite improvements in the ease of starting a business and in enforcing compliance with tax obligations in the past 2-3 years, these policy areas could be pursued further. ${ }^{6}$

Figure 1.4. Consumer confidence indices in Indonesia, Malaysia, the Philippines and Thailand, 2017-19

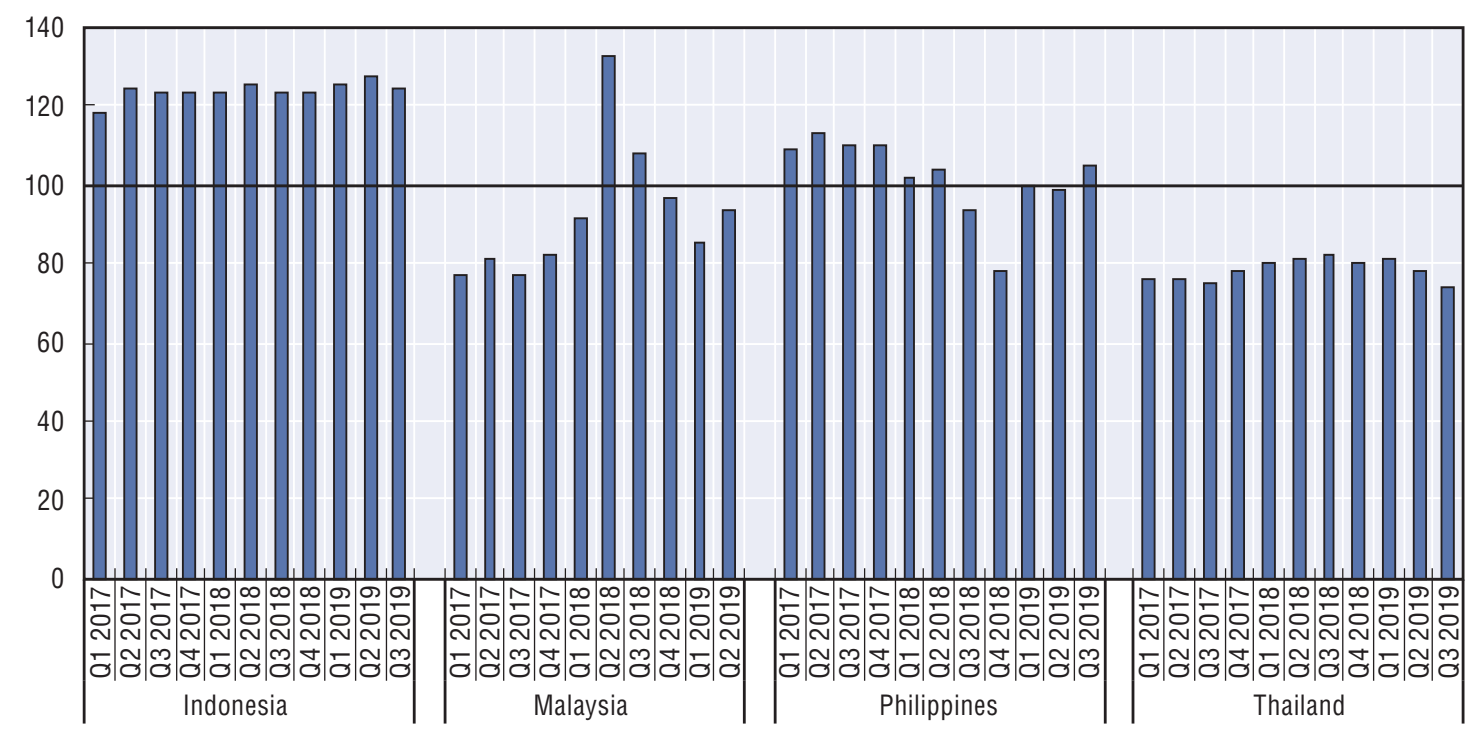

Note: All indices are adjusted to set 100 as the neutral confidence point. The latest data for Indonesia and Thailand are as of August 2019.

Source: OECD Development Centre based on data from CEIC and national sources.

StatLink 解的 https://doi.org/10.1787/888934063233

Aggregate demand is losing steam in the Philippines, dragging economic growth in Q2 2019 down to its lowest point since Q1 2015. Fixed investment shrank for the first time since Q4 2011 on a reduction in durable equipment outlays and a slowdown in construction spending. Private consumption growth skidded from Q1 2019, though aggregate growth in the first half of the year was on par with the same period in 2018. Government consumption and exports recorded slower growth rates relative to Q1 2019, whereas imports flatlined. Production growth is mainly fuelled by the services cluster (Figure 1.5). A jump in mining output provided support. However, manufacturing growth has tapered and agricultural output remained subdued. 
Figure 1.5. Contribution to GDP growth in the Philippines, 2017-19

Percentage points
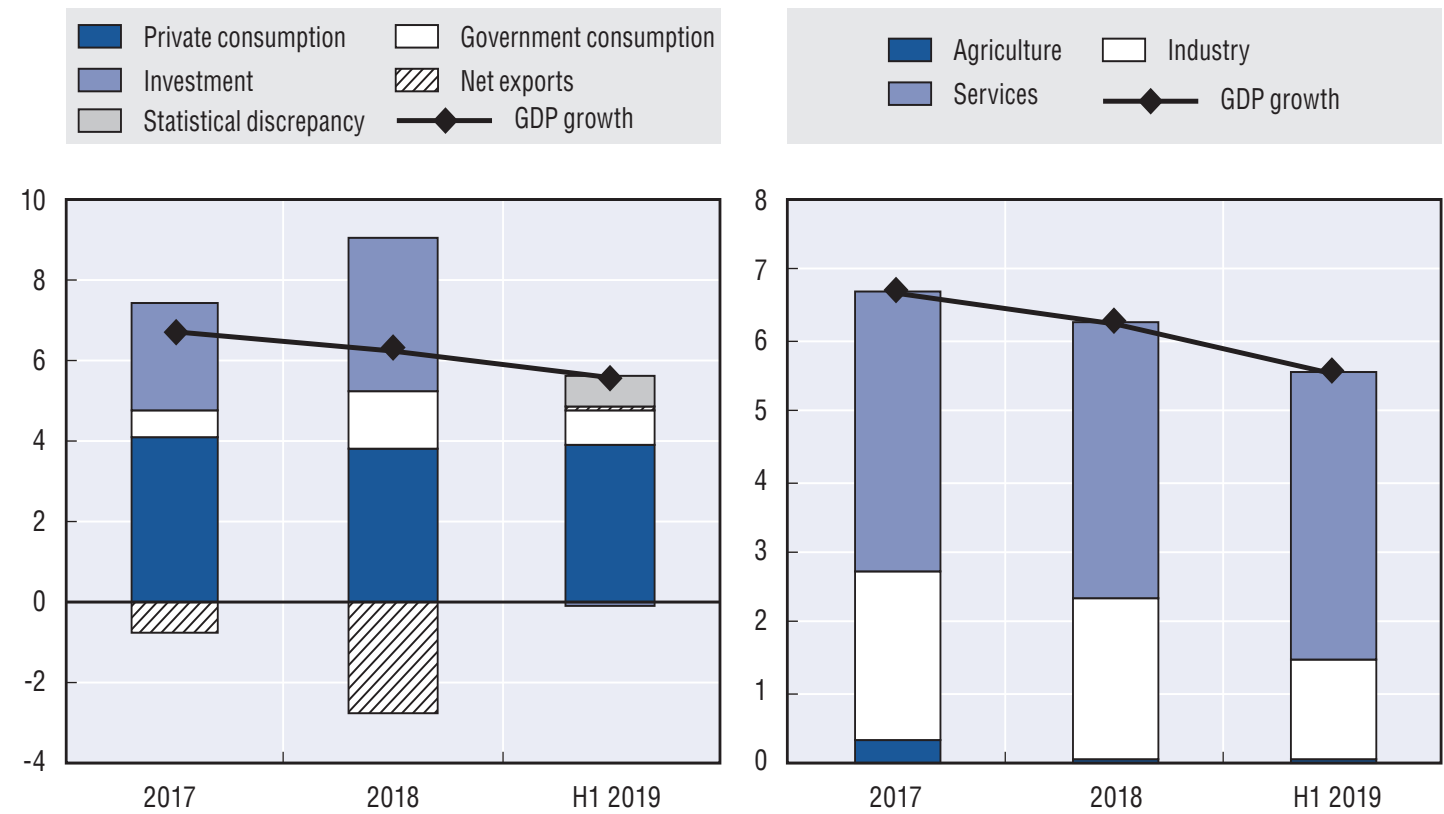

Source: OECD Development Centre based on data from CEIC and national sources.

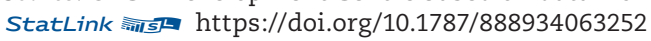

Leading indicators point to slower growth in 2019 and 2020 than initially projected. Nominal growth in goods exports continued to ebb. This is mirrored by a slump in the industrial production index. Stronger tourist arrival momentum and improving consumer sentiment are positives for private spending and the recovery in overseas remittance growth provides additional support to the appetite for spending. Early passage of the 2020 budget could help avert the disbursement bottlenecks experienced in the first half of 2019.

Growth in the medium term is projected to come in at $6.2 \%$, below the $6.6 \%$ average in 2013-17. Consumption is expected to hold up on the stability exhibited by the labour market. A thorough examination of the declining labour force participation rate is key to deepening the market appropriately and absorbing potential upward inflection. While infrastructure spending is expected to continue to provide growth support, implementation delays are a significant challenge. The push to create a Ministry for Disaster Resilience needs to be carefully studied, while ensuring that incentives are appropriate to attract and retain qualified personnel, in line with the experience of similar agencies, would be ideal.

Thailand's economic growth pulled back for the second straight quarter in Q2 2019 as domestic spending moderates further (Figure 1.6). Private consumption still does the heavy lifting, despite its weaker growth. Exports in Q2 2019 plunged by about the same rate as in Q1 2019, while the expansion of fixed investment was tempered, affected by a slower uptick in private-sector fixed capital placements. On the production side, the strong performance of the utilities and mining sectors were offset by a decrease in agricultural and manufacturing output. The main services subsectors (wholesale and retail trade, finance, real estate and accommodation), customarily the most prominent growth drivers, lost momentum as well. 
Figure 1.6. Contribution to GDP growth in Thailand, 2017-19

Percentage points
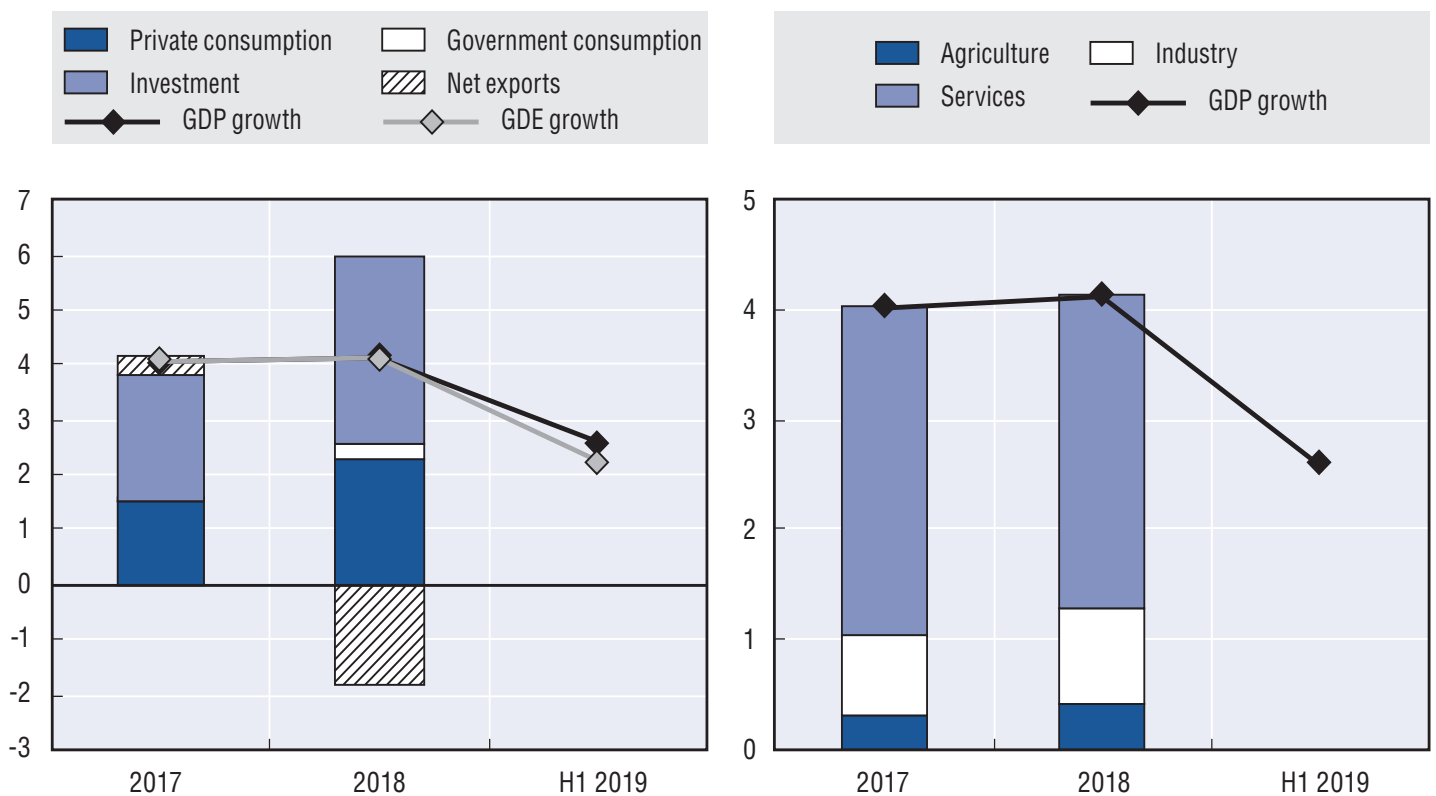

Note: The calculations are based on chain linked volume measure series. The sum of contributions is not necessarily equal to GDP growth. GDE means gross domestic expenditure.

Source: OECD Development Centre based on data from CEIC and national sources.

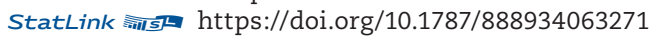

GDP growth in 2019 and 2020 is forecast to fall below our initial estimates. The persistence of export weakness can be associated with a pullback in the industrial and agricultural production indices. While the private consumption index shows stable growth, consumers are becoming more pessimistic. It does not help that tourist arrivals grew at marginal rates in recent months. The mild stimulus programmed for fiscal year 2020 and a policy rate cut in August 2019 should partially arrest the slowdown in activity.

Growth over the medium term is estimated to reach 3.2\%, higher than the average growth rate of $2.8 \%$ in 2013-17. Improvement in the country's business climate metrics - progress in the ease in starting a business, paying taxes and trading across borders (World Bank, 2019a) - is encouraging for capital formation, labour market prospects and private consumption. Facilitating an enabling environment for the growing fintech services sector is a key challenge in the coming years. Relevant measures enacted in 2019 include laws on cybersecurity, personal data and copyright.

Viet Nam's economy remains the most vibrant among the ASEAN-5. The resilience of exports relative to other countries in the region is a considerable factor, supported by buoyant consumer spending, as suggested by increasing growth in retail sales. Providing the growth ammunition on the supply side are the manufacturing and mining industries as well as the services subsectors of wholesale and retail trade, transportation and finance (Figure 1.7). 
Figure 1.7. Contribution to GDP growth in Viet Nam, 2017-19

Percentage points

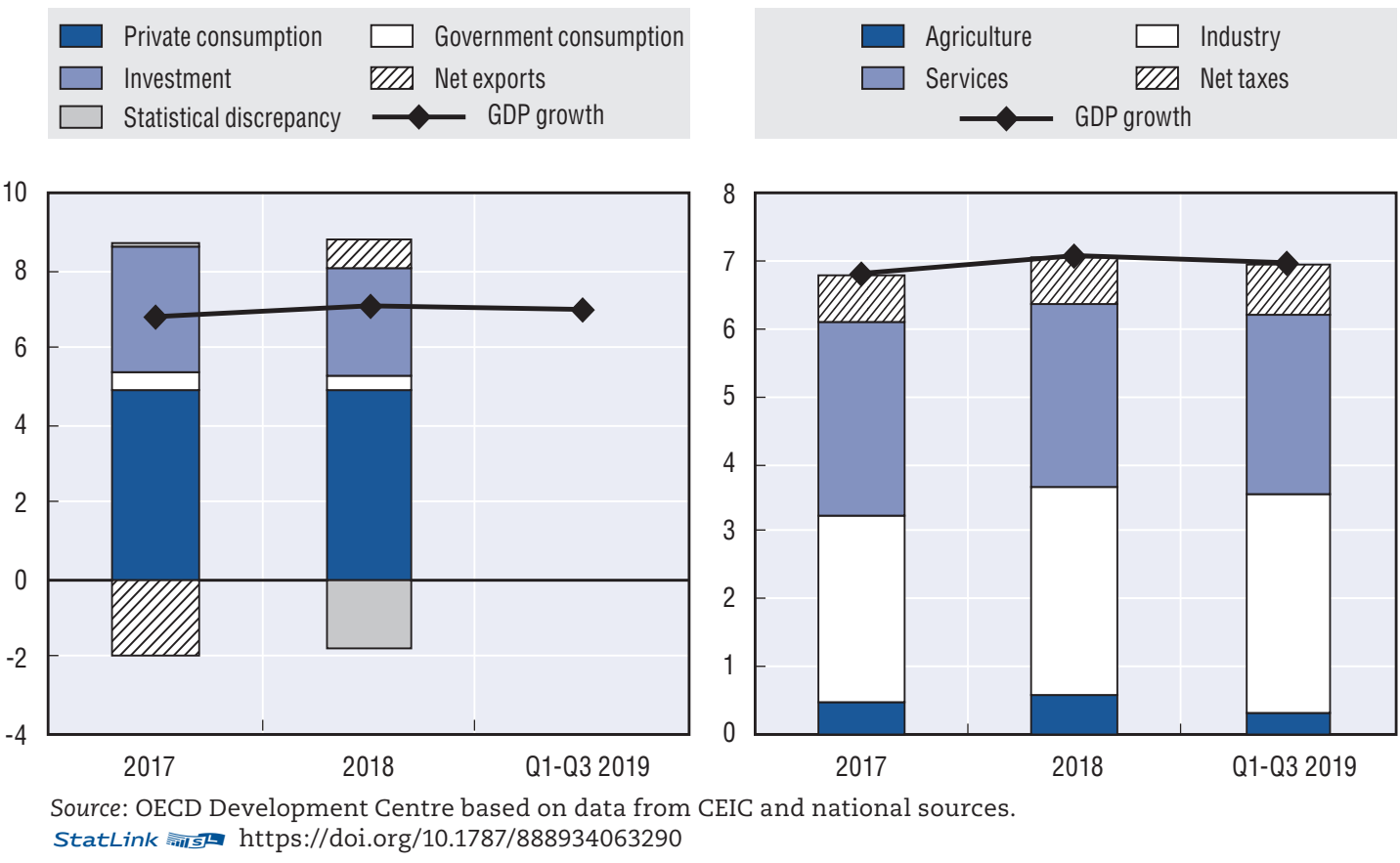

The OECD Development Centre's July 2019 growth forecast is revised upwards for 2019 and maintained for 2020, with leading indicators suggesting sustained momentum. The industrial production index maintained strong growth through October 2019. Growth in retail sales and tourist arrivals remained sturdy. Registered FDI capitalisation and state investment have likewise picked up pace in recent months.

Over the medium term, Viet Nam's economy is forecast to grow by about $6.5 \%$, surpassing the $6.2 \%$ average rate in 2013-17. The vibrant investment climate bodes well for the country's privatisation and foreign investment strategies. Improvements were noted in regulations pertaining to starting a business, paying taxes and enforcing contracts (World Bank, 2019a). Adjustments were made to cybersecurity, intellectual property and antitrust regulations, while a new FDI Attraction Strategy 2020-30, focusing on skills and investment quality, is being formulated. Keeping rural areas in step with the developments in urban centres, particularly in infrastructure, is a key challenge. Broadening the coverage of insurance against natural disasters to mitigate the impact of environmental risks is another (Box 1.2).

\section{Box 1.2. Strengthening the disaster risk insurance market in ASEAN}

The development of disaster risk insurance solutions has been relatively slow in Emerging Asia. According to insurance data collected by Munich Reinsurance Company, the amount of natural disaster losses covered by non-life insurance is relatively small for Emerging Asian countries in comparison to their more-developed neighbours (Figure 1.8). The country with highest insurance coverage of losses in the region between 2012 and 2018 was India where USD 5.4 billion (in constant 2017 US dollars) was insured out of USD 49 billion overall losses. For developing countries in Southeast Asia, the Philippines and Indonesia were relatively well insured while only tiny fractions of natural disaster 


\section{Box 1.2. Strengthening the disaster risk insurance market in ASEAN (cont.)}

losses were insured in Malaysia, Thailand and Viet Nam. There are a variety of causes for the underdevelopment of private disaster risk insurance market in the region. They include a lack of attractive products, limited delivery channels and a lack of technical capacity on the supply side, poor insurance education and limited awareness on exposure to disaster risks on the demand side, as well as a lack of well-established insurance-related legal and regulatory systems at the national and sub-national levels (World Bank, 2012b).

\section{Figure 1.8. Insured losses from natural disasters in Asian countries, 2012-18}

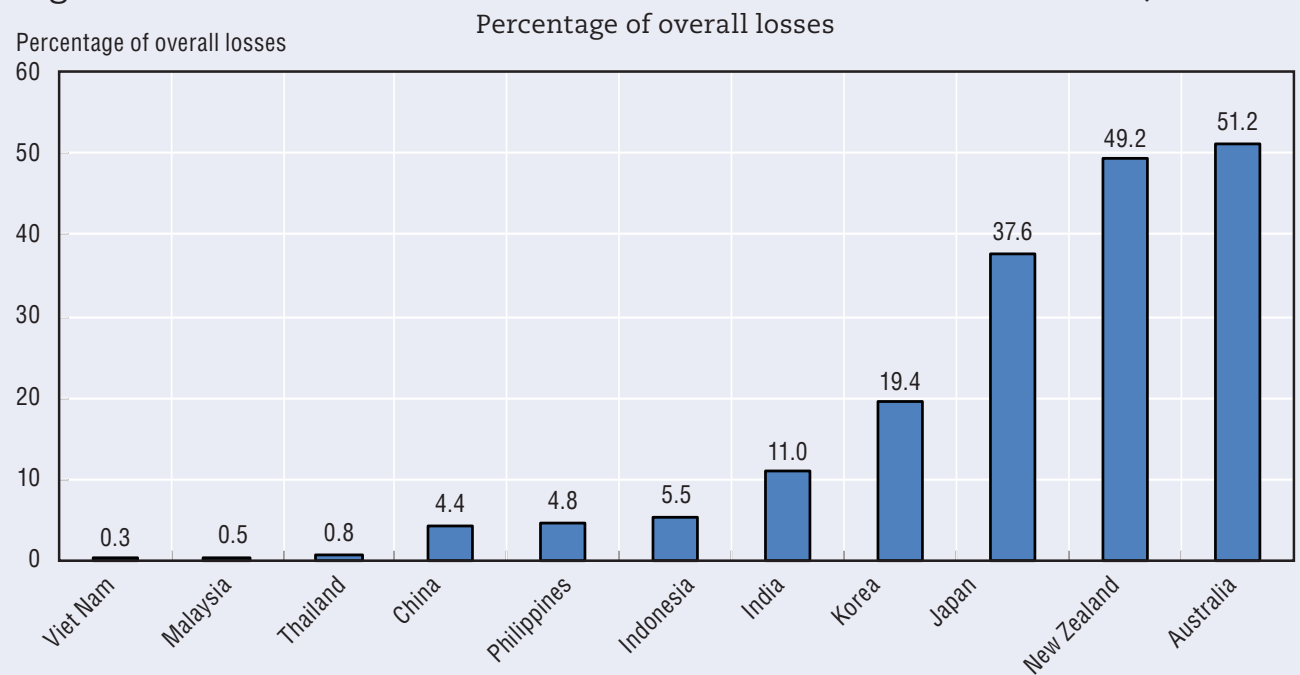

Source: OECD Development Centre calculations using Munich RE (2018), NatCatSERVICE (database), Munich RE Group, Munich, https://natcatservice.munichre.com.

StatLink 形) https://doi.org/10.1787/888934063309

Many countries in the region have taken initiatives to strengthen disaster risk insurance market. In Indonesia, the government is formulating a national strategy on Disaster Risk Financing and Insurance (DRFI) to enhance the existing sectoral regulations on disaster insurance such as law for agricultural insurance and insurance for those working in the fishing industry. In addition, Indonesia will implement the State Assets Insurance Pilot Project managed by the Ministry of Finance and providing DRFI education to key stakeholders. In Malaysia, a disaster insurance scheme is being developed through cooperation between the government and insurance companies which will initially allow 100000 households in flood risk areas across the country to obtain insurance coverage at $1 \%$ of its actual cost with the government subsidizing the remaining amount. In the Philippines, the government, in collaboration with World Bank and the UK Department for International Development, launched a new catastrophe risk insurance program in 2017 to help the country respond better to losses from natural disaster events. This parametric insurance program offers USD 206 million in coverage against losses from major typhoons and earthquakes to national government assets and 25 participating provinces where insurance pay-outs will be made when pre-defined parametric triggers are met. In Viet Nam, the disaster risk insurance market is at its infancy and only $0.3 \%$ of natural disaster losses in the country have been insured. The government of Viet Nam is actively cooperating with international organisations to set up a catastrophe risk model to better assess the likelihood and intensity of natural disasters, increase disaster preparedness and enable faster response. The Ministry of Finance in Viet Nam will also integrate disaster insurance with other insurance programs by the government, and draft guidelines of operation for insurance companies in the country. 


\section{Brunei Darussalam and Singapore}

With investment and exports recovering, the economy of Brunei Darussalam posted a strong growth in Q2 2019 after contracting in Q1 2019. The trade surplus jumped from the previous year even as import growth stayed brisk. Fixed investment rose sharply on the back of private sector outlays. Private consumption held up though government spending slipped. On the supply side, the oil and gas sector (about $57 \%$ of gross value added) also recovered, reversing a trend since Q2 2018. The large services subsectors provided additional lift.

Figure 1.9. Contribution to GDP growth in Brunei Darussalam, 2017-19 Percentage points

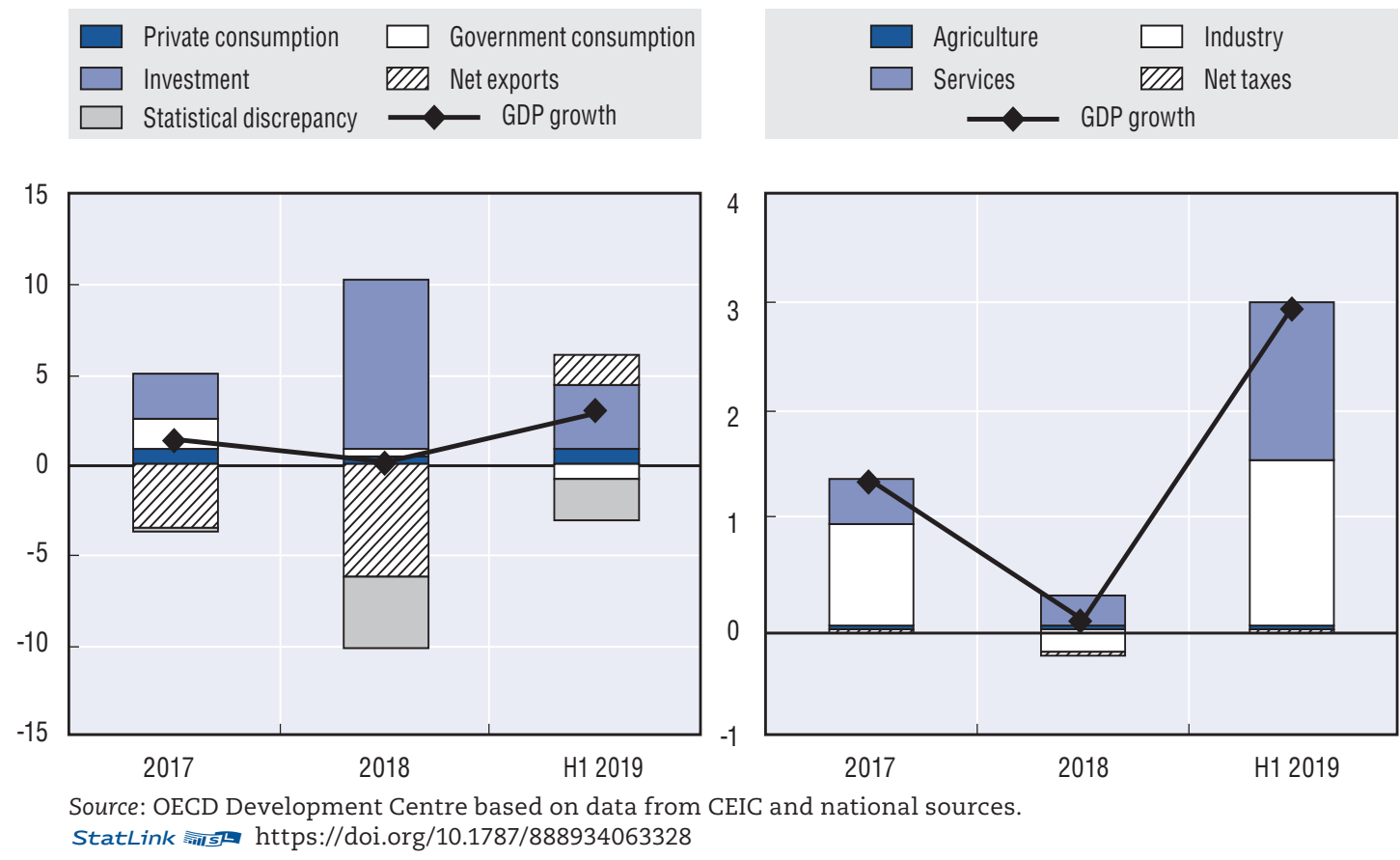

GDP growth in 2019 is expected to stay buoyant though the rate in 2020 will likely fall below the OECD Development Centre's July 2019 forecast. Growth in the nominal export value of crude oil and gas has slid. However, considering the steep drop in global oil and gas prices from the previous year, the volume of energy exports appears to be stern. Infrastructure projects are another prominent growth anchor albeit the large reduction in machinery and transport equipment imports in recent months signals moderation in fixed investment moving forward. Additionally, the low inflation environment and a recovery in household sector loans are encouraging for private spending though public spending will be somewhat constrained as export earnings weaken.

At $1.9 \%$, the forecasted medium-term growth will be faster than the 2013-17 average of $-1.2 \%$. Steady progress in Doing Business indicators (World Bank, 2019a) bodes well for efforts to raise private-sector activity and to lower the unemployment rate (9.3\% in 2017). Mobility and value-adding capacity should benefit from the completion of big ticket projects like the Muara Besar island complex and Temburong bridge. Continued development of the whole Pulau Muara Besar project and the country's telecom infrastructure modernisation plan are likewise good for investment prospects.

Singapore's GDP barely grew in Q2 2019, in line with a trend of decelerating growth in the last four quarters. The net export balance was in surplus, but it decreased 
sharply in Q2 2019 from the previous year following a milder dip in the prior quarter (Figure 1.10). Fixed investment is in the red for the sixth straight quarter, although there was a notable increase in capital inventories. Public fixed investment rose markedly owing to construction works, whereas the much larger private investment component resumed its decline after a lacklustre Q1 2019. Private consumption growth in the first half fared slightly better than a year ago, although growth in Q2 2019 has moderated since Q1 2019. On the supply side, wholesale and retail trade and manufacturing value added deteriorated, while finance services grew faster relative to Q1 2019.

Figure 1.10. Contribution to GDP and total demand growth in Singapore, 2017-19 Percentage points
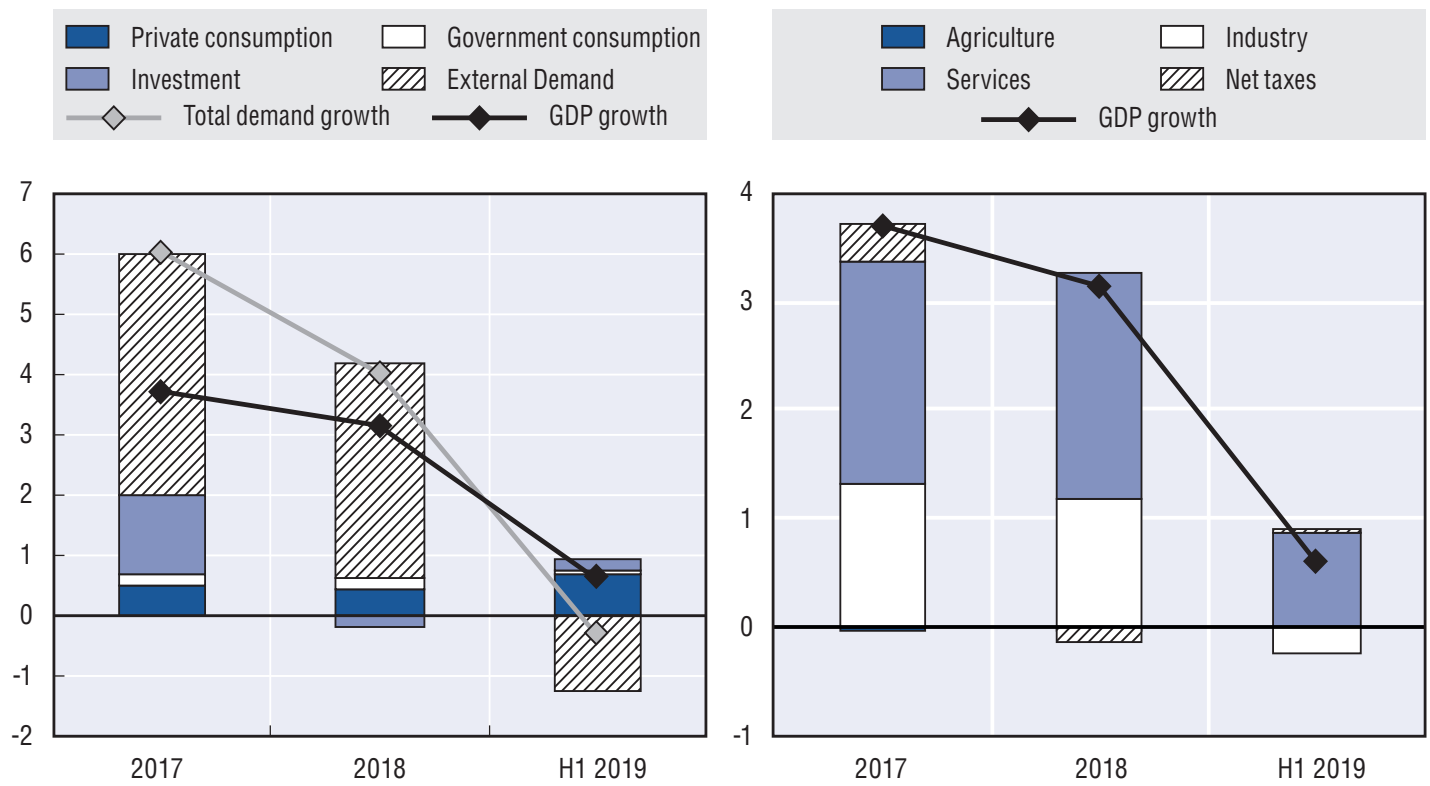

Note: The calculations are based on chain-linked series based on 2015 prices. Demand-side contribution to GDP growth data are not available. Supply and demand data for H1 2019 are the weighted average of the quarterly data. Services include ownership of dwellings.

Source: OECD Development Centre based on data from CEIC and national sources.

StatLink 茼

With protracted instability in global trade weighing heavily on domestic activity, Singapore's economy is expected to record weaker growth in 2019 and 2020 than initially forecast. Trends seen via composite leading indicators and the industrial production index, as well as business expectations in manufacturing and services, suggest cautiousness (Figure 1.11). Private demand is likewise feeling the pinch. Real growth in domestic retail sales continued to hover in the red. Residential property prices appear continue to rise moderately although the transaction value in 2019 is well below the previous year, stalling the decline in the vacancy rate. Materialisation of planned stimulus measures will be crucial in keeping the economy from contracting in the near term.

The economy is forecast to record growth of 2.3\% in 2020-24, weaker than the 2013-17 average of $3.7 \%$. With trade accounting for more than $320 \%$ of GDP, trade will likely dominate the growth story in the next few years. The start-up ecosystem is showing considerable promise, though it requires targeted support. Addressing participation barriers in lifelong learning programmes - some of which were documented by Zher, Sung and Ying (2019) - is also needed to generate productivity gains from ageing and marginalised segments of the population. 
Figure 1.11. Business expectations and leading indicator indices in Singapore, 2017-19
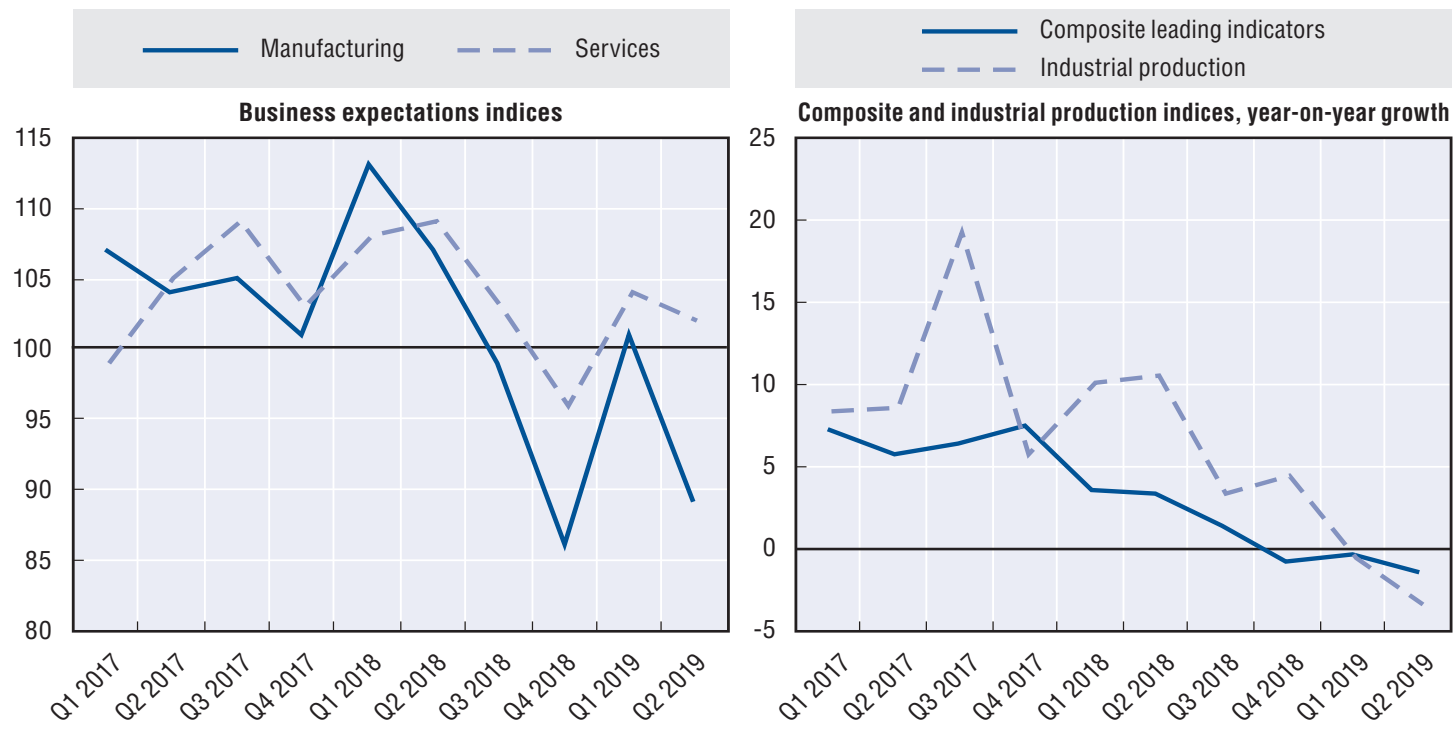

Note: The neutral point for the expectations indices is 100.

Source: OECD Development Centre based on data from CEIC and national sources.

StatLink तils https://doi.org/10.1787/888934063366

\section{Cambodia, Lao PDR and Myanmar}

Cambodia's economy is holding up despite some drags on growth. Approved fixed asset investment more than quadrupled in Q1 2019 from the same period a year earlier. Nominal goods exports rebounded strongly in March and April 2019, although there is a need to sort out the overhanging risk of losing trade privileges in key markets. A substantial increase in outstanding private-sector bank claims as of May 2019, and doubledigit growth in tourism in the first six months of 2019, demonstrate upbeat private-sector spending, and this has been a reliable growth anchor in the past (Figure 1.12). Against this backdrop, the July 2019 growth projections for 2019 and 2020 are maintained.

Figure 1.12. Contribution to GDP growth in Cambodia, 2016-18 Percentage points
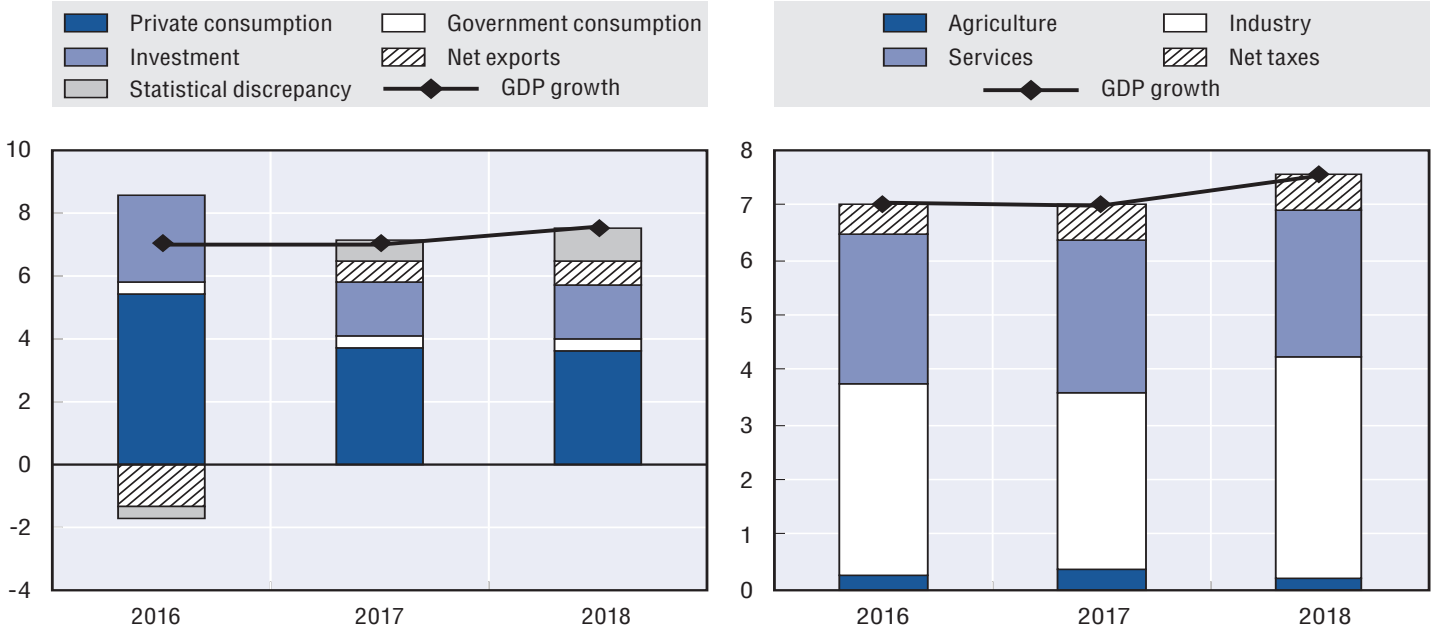

Source: OECD Development Centre based on data from CEIC and national sources.

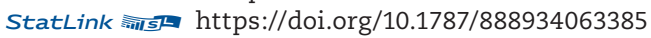


In the medium term, GDP growth of $6.7 \%$ will be weaker than the 2013-17 average of $7.1 \%$. Fixed investment, which grew 11.3\% on average between 2002 and 2017, will remain a key anchor of growth in the next few years. With funding mainly coming from China, infrastructure projects continue to take flight, including new SEZs, residential and commercial complexes, transportation and power. Key guiding frameworks in this respect are the Industrial Development Policy 2015-25, the Logistics Master Plan and the Standard Operating Procedures for Externally Financed Projects in Cambodia. In addition to export gains through SEZs, the job windfall from these projects is a boon for labour-market stability, considering the country's young population and, ultimately, private consumption. Corporate bond issuances in local currency are a positive for deepening the capital market and for facilitating the use of the riel, which is essential for monetary policy efficacy.

Strains on Lao PDR's economy appear to have broadened in the last few months. Nominal export earnings, including from offshore electricity sales, rose relatively modestly in Q1 2019. Domestic demand is likewise hobbled by a sharp year-on-year decline in FDI in Q1 and Q2 2019, weaker outstanding bank lending growth as of June 2019 and food inflation induced by environmental calamities. With the government's commitment to fiscal consolidation, public pump priming is unlikely to be extensive. On the supply side, a severe drought in the first half of 2019, along with serious floods in mid-2018 and in September 2019, made this an immensely difficult year for the agriculture sector. The services sector should partially absorb the slack, with various infrastructure and real estate projects springing up in key areas, as in the previous year (Figure 1.13). In view of these developments, growth in 2019 and 2020 is forecast to be lower than predicted in the July 2019 assessment.

Figure 1.13. Contribution to GDP growth in Lao PDR, 2016-18 Percentage points

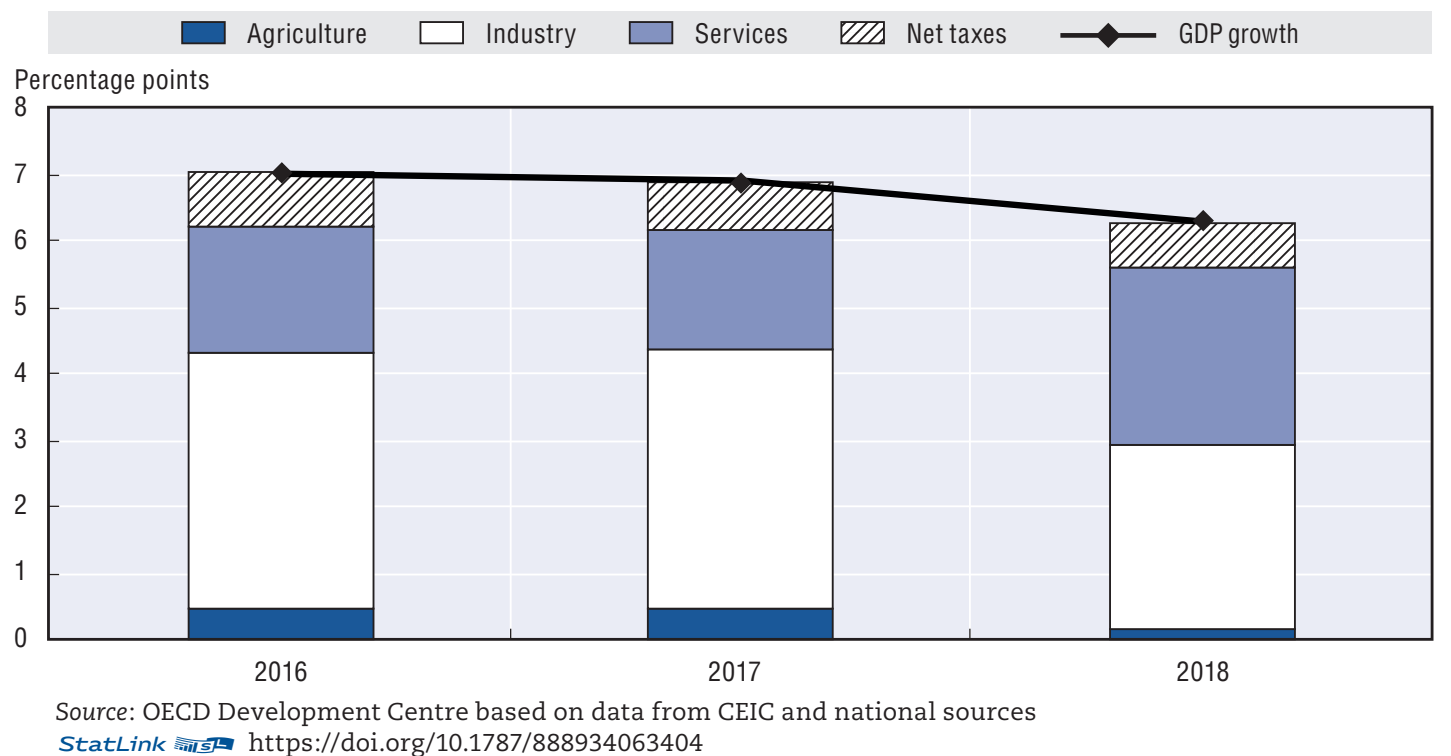

The economy is projected to rise by $6.8 \%$ on average in $2020-24$, a milder expansion than the $7.4 \%$ seen in 2013-17. Infrastructure projects and energy exports are expected to provide much of the growth steam. The country is well placed to gain from the Belt and Road initiative. Projects are also lined up in the Initial Rolling Priority Pipeline of Potential ASEAN Infrastructure Projects, as guided by the Master Plan on ASEAN Connectivity 2025. Separately, energy sector prospects are reinforced by the expansion of the ASEAN grid connectivity project with Malaysia and Thailand, as well as by deals with other countries, 
like the potential inclusion of some ASEAN countries including Lao PDR in the planned global electricity grid. However, progress in promoting the ease of doing business is too limited relative to other countries (World Bank, 2019a). This has led to a steady downtrend of Lao PDR's rank from 2016 to 2018 that is not in line with private-sector development. In particular, the digital industry is lagging (World Bank, 2018). Private sector involvement is vital in this area given the limited public fiscal space. Dealing with environmental hazards such as flood and drought is another crucial challenge for broadening the sources of economic growth.

Myanmar's economic performance in the fiscal year ending September 2019 was affected by weaker offshore sales, as in other Emerging Asian economies. Export growth from October 2018 to April 2019 slowed from the previous year, while a steep rise in inflation since January 2019 and a moderating growth in banks' outstanding claims on the private sector also suggest increased private spending friction. The strong rebound in tourist arrivals in the first seven months of the fiscal year and the faster growth in foreign investment of permitted enterprises should compensate for the drag. On the supply side, manufacturing was buoyed by robust growth in manufactured exports despite moderation in aggregate external sales. Agriculture was likewise having a favourable year (FAO, 2019). However, the momentum of services, traditionally the main value-adding sector (Figure 1.14), is expected to ease based on domestic demand indicators. Against this backdrop, the economic expansion forecast for fiscal years 2019 and 2020 is revised downwards from July 2019.

Figure 1.14. Contribution to GDP growth in Myanmar, 2016-18

Percentage points
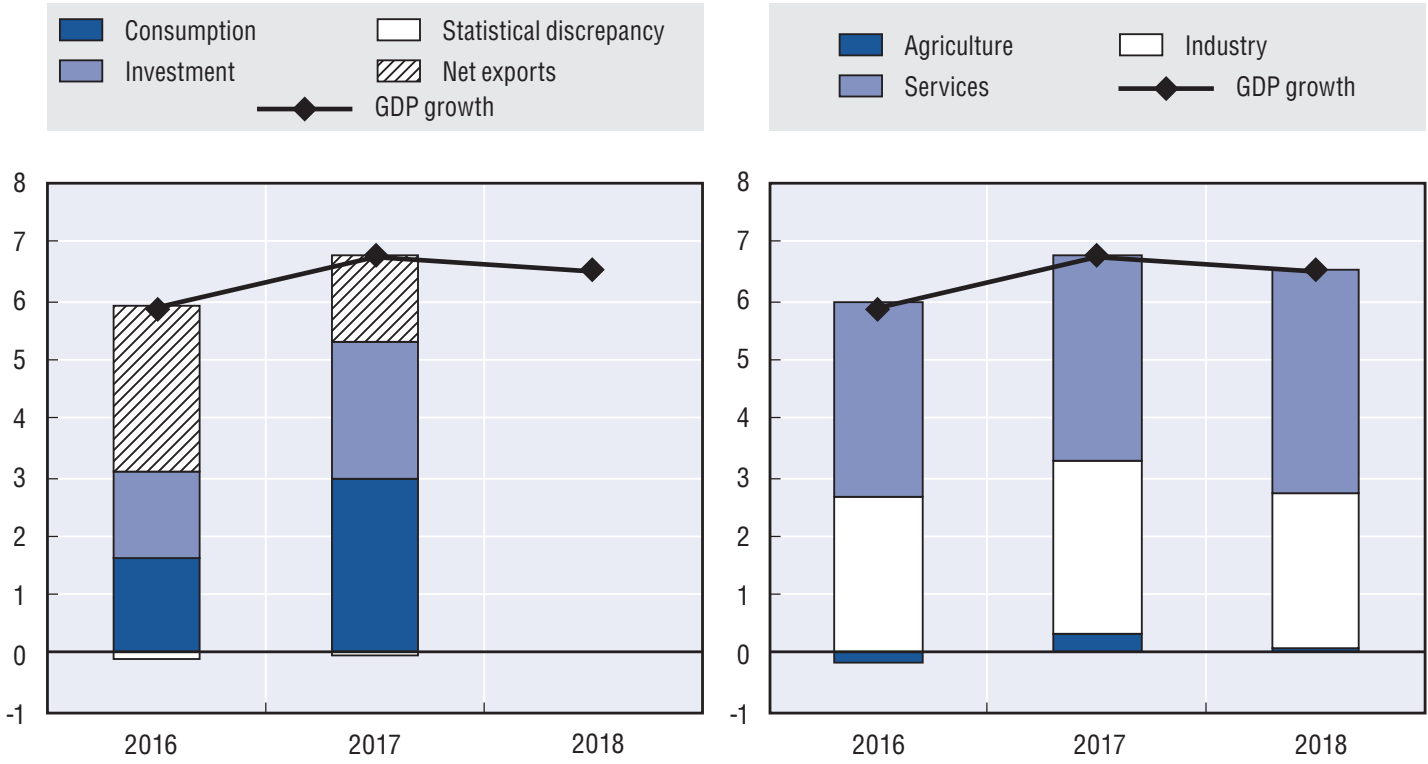

Note: 2018 data relate to the interim period from April to September. 2016 and 2017 data relate to the fiscal year ending March the following year.

Source: OECD Development Centre based on data from CEIC and national sources.

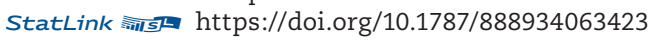

Myanmar's GDP is forecast to expand by $6.9 \%$ in the medium term, a slightly softer rate than the 2013-17 average of 7.2\%. Fixed investment is set to propel economic activity on the back of FDI-funded projects. The FDI channel is also being utilised to develop retail and wholesale trade and the insurance sector. Exports, which have been a growing engine of domestic activity since the economy opened up less than a decade ago, should 
gain from the planned expansion of SEZ operations. Nonetheless, the business climate can still be enhanced. In 2018, the country was ranked in the bottom $10 \%$ globally in terms of the ease of doing business (World Bank, 2019a). Another issue is the stability and sufficiency of power supply. As for education, including digital literacy, access and quality - though improving - remain a challenge that requires a focused approach and the involvement of subnational governments.

\section{China and India}

As expected, China's growth moderated in Q3 2019, its slowest pace since the quarterly series was first published in 1992. Contribution to growth of domestic consumption slid marginally despite the fiscal and monetary cushion rolled out by the government (Figure 1.15). Investment's GDP growth contribution year-to-date rose from the previous quarter, although the rate was substantially lower than in the previous year. Weak private investment weighs on overall investment growth. Access to financing has been increasingly difficult for private and small firms, in particular since the reining in of the shadow banking sector, the major supplier of credit for such firms (Box 1.3). The trade balance improved, yet balance of payments data show that both exports and imports registered weaker readings. Industrial activities like manufacturing and construction felt much of the slowdown in demand. Services growth held steady, while agricultural output grew faster than in the previous quarter despite the swine flu outbreak.

\section{Figure 1.15. Contribution to GDP growth in China, 2017-19}

Percentage points
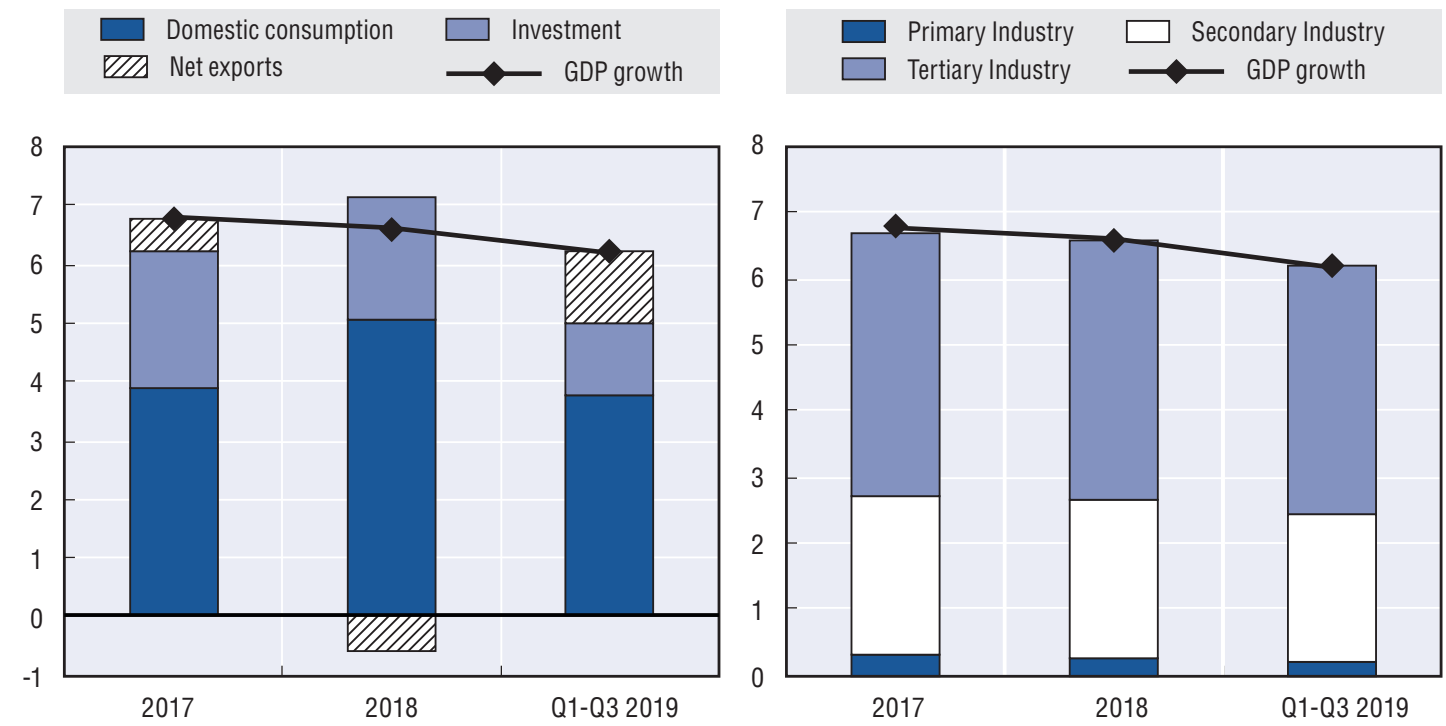

Source: OECD Development Centre based on data from CEIC and national sources.

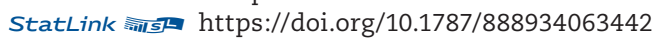

\section{Box 1.3. Shadow banking in China}

Shadow banking in China is being reined in (Figure 1.16), with slowing and then shrinking lending in the past couple of years as stability has become the major focus of financial policy OECD (2019b). Shadow banking was brought into life by unmet demands for loans by riskier borrowers and unmet supply of investment products with high returns. Risk aversion and regulations held back the banking sector from lending to riskier borrowers. At the same time, households had few alternatives to bank deposits, whose returns did not 


\section{Box 1.3. Shadow banking in China (cont.)}

increase much after liberalisation of deposit rates. The larger banks, which boast the largest deposit bases, found myriad ways to channel the funds through intermediaries to riskier borrowers. Inter-company lending arranged by banks, the so-called entrusted lending, implied profits without risk for banks. Wealth management schemes offering higher returns than deposits to return-hungry investors by banks started to proliferate. As such schemes are off balance sheet, they were outside of regulatory oversight and as they avoid capital provisioning, their surge implied heightening financial risks. In addition, wealth management products carried perceived implicit guarantees, with some carrying explicit guarantees on the principal, and involved maturity mismatch. Financial institutions (particularly the smaller ones that had a small deposit base) raised funds through the inter-bank market by issuing certificates of deposit that were considered bonds, and sold wealth management products to each other, thereby enhancing systemic risk.

Figure 1.16. China's shadow banking continues to shrink Seasonally adjusted, 3-month moving average annualised growth rate, percentage

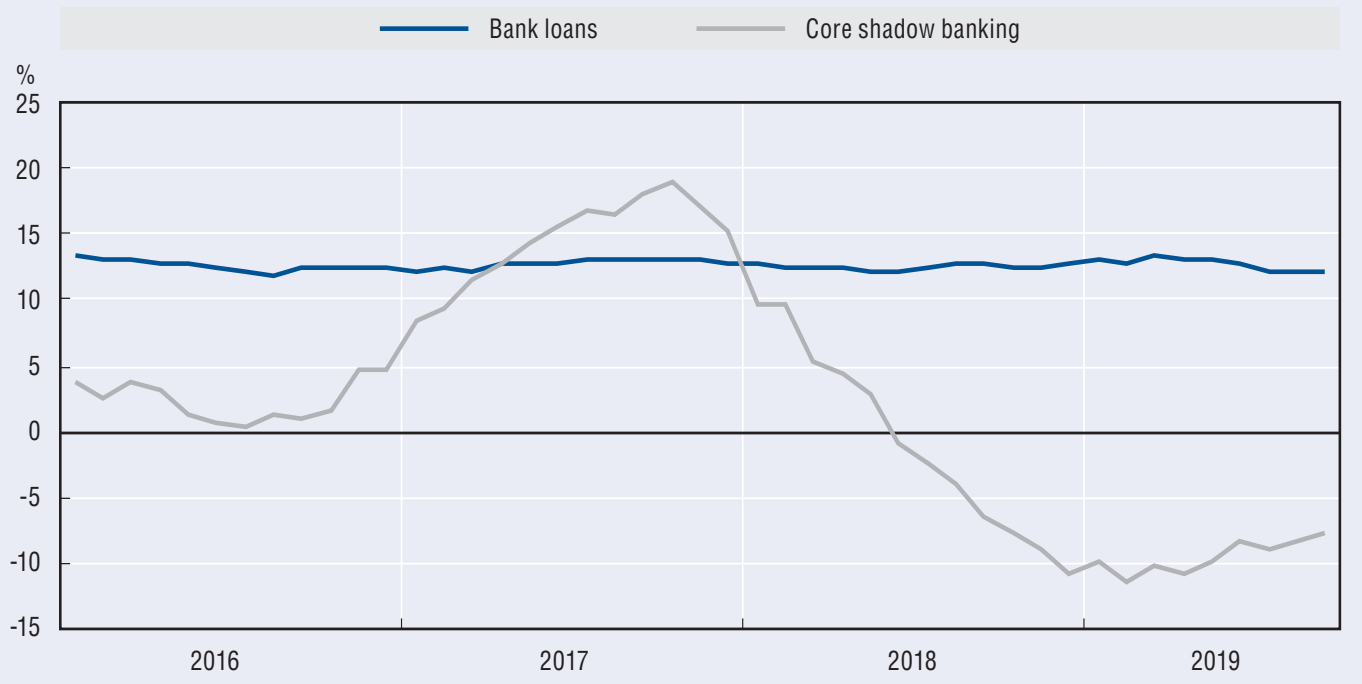

Note: Core shadow banking includes trust loans, entrusted loans and bankers' acceptances. Growth rates are in year-on-year terms.

Source: OECD Development Centre calculations, based on CEIC.

StatLink intst https://doi.org/10.1787/888934063461

Amid heightening systemic risk, regulators brought assets behind wealth management products into macro-prudential assessment in 2017 and subjected certificates of deposits to the inter-bank liability ceiling of $33 \%$ from 2018 . These measures have curbed the size of the shadow lending, which hit private and smaller firms the hardest, as such firms formed the largest part of shadow banking clientele.

Growth in 2020 is expected to come in slower than the rate projected in July 2019 while the initial forecast for 2019 is maintained. The decline in nominal exports growth is showing signs of mending. However, manufacturing and non-manufacturing purchasing managers' indices (PMI) have been losing momentum since March 2019 (Figure 1.17). Growth in utilised FDI and total fixed asset investment is similarly softening, as is private consumption, based on automobile, real estate and retail sales data. ${ }^{8}$ The optimism conveyed by consumers is indicative of the market's response to broad-based government support. 
Figure 1.17. Purchasing managers' and confidence indices in China, 2017-19
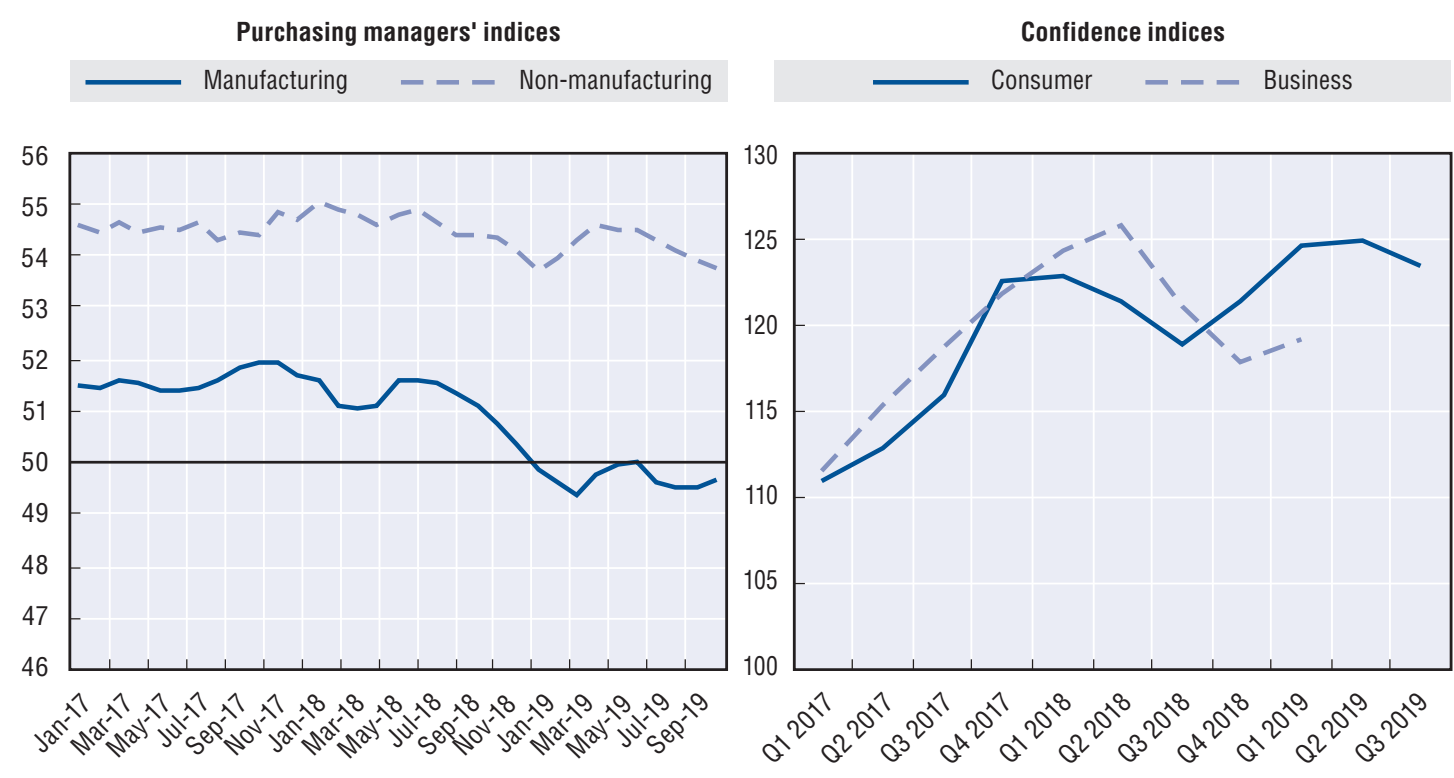

Note: The PMI indices are presented in 3-month moving averages. The neutral point for confidence indices is 100. The latest consumer confidence data is as of August 2019.

Source: OECD Development Centre based on data from CEIC and national sources.

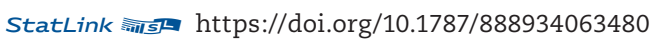

In 2020-24, GDP growth will continue to slow in China. Growth started to slow a few years ago as the economy is rebalancing from investment-led to consumption-led growth. Investment slows on the back of excess capacity in some manufacturing industries, while consumption is not picking up in a lack of structural reforms to reduce precautionary savings. Nevertheless, consumption remains robust against the backdrop of steadily rising incomes. Ageing pressures are increasing, even though the population is still growing, but the working age population has been falling for several years already. Productivityboosting structural reforms, including dismantling administrative monopolies and further opening up the economy would lift the growth potential.

In India, buoyant government spending could not prevent growth from slowing sharply in Q1 2019 of fiscal year 2019-20 (ending March 2020). Private consumption growth has softened markedly, taking away substantial economic growth fuel in the process (Figure 1.18). The same can be said of exports, although the trade deficit narrowed from the previous year, with import growth scaling back at a sharper rate. Fixed investment posted a marginal increase in growth from the previous quarter, but far below the doubledigit rates registered last year. Supply-side data show that growth in agriculture, utilities industry, and wholesale and retail trade gained pace from the previous quarter. However, expansion in the manufacturing and construction industries, as well as finance, real estate and professional services, was more reserved than in the previous four quarters. 
Figure 1.18. Contribution to GDP growth in India, 2017-19

Percentage points

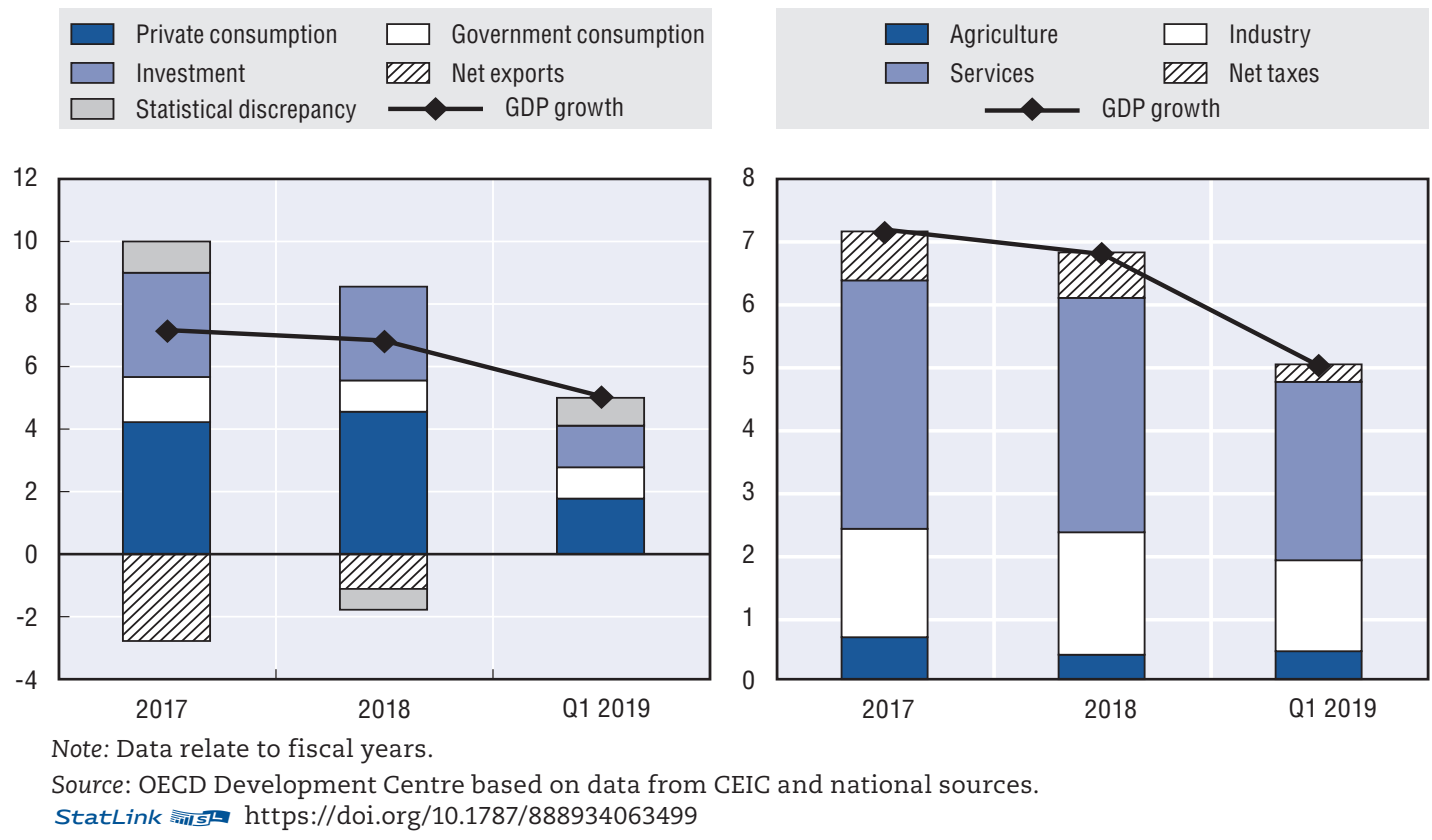

In 2019 and 2020, GDP growth is forecast to settle below the rates recorded in July 2019. Business pessimism persists as exports skid (Figure 1.19). The manufacturing PMI is heading south, as is the infrastructure index. Private spending indicators as of August 2019 are not encouraging. The consumer outlook has dimmed, with passenger car sales heading deep into the red, and tourist arrivals have barely increased. One bright spot is a sharp increase in FDI in June 2019, and the services PMI is also looking up. A stimulus package is being worked out to provide an additional boost.

Figure 1.19. Purchasing managers' and confidence indices in India, 2017-19

Purchasing managers' indices

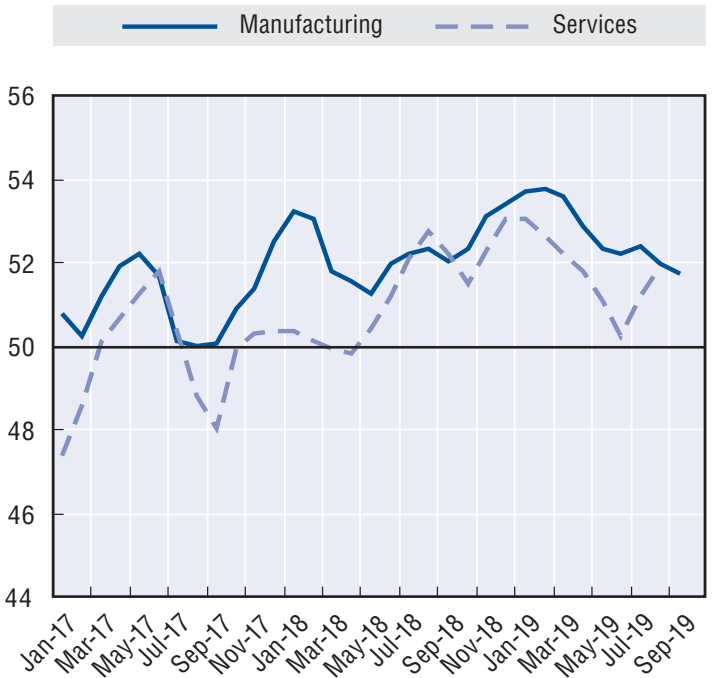

Confidence indices

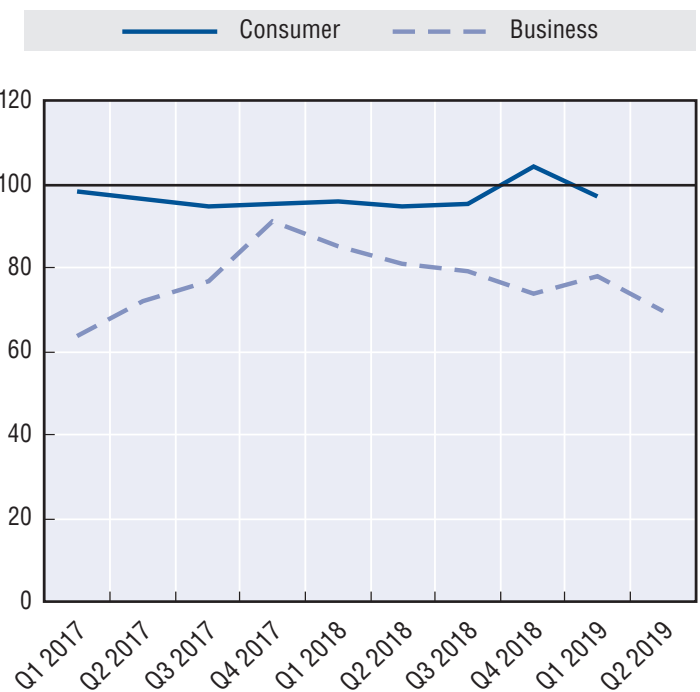

Note: The PMI indices are 3-month moving averages. The neutral point for confidence indices is 100. Quarters relate to fiscal year.

Source: OECD Development Centre based on data from Nikkei Asian Review, CEIC and national sources.

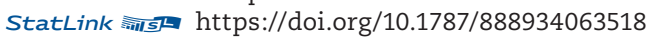


Growth in 2020-24, forecast to be about 6.6\%, will be slower than the 2013-17 average of $7.4 \%$. Reliance on consumption (over $55 \%$ of GDP) will persist during the period. Yet the large, relatively young informal labour share indicates room to strengthen the consumption base. ${ }^{9}$ Timely and detailed data would be valuable for crafting responsive interventions. The investment climate seems to have responded positively to the recapitalisation of public banks. ${ }^{10} \mathrm{~A}$ new bankruptcy law and portfolio allocation regulations could solidify the foundations, though fully restoring the health of public banks requires more work and political capital. ${ }^{11}$ Separately, bridging the disparity in urban and rural infrastructure is important for spreading investment and economic opportunities while addressing urbanisation.

\section{Risks persist for Emerging Asia's exports amid global trade instability}

Trade tensions between the United States and China are continuing, and the broadening economic weakness in advanced economies, compounded by the Brexit process, adds substantial uncertainty to export prospects. There are indications that some countries in the region may benefit from trade diversion and deflection as a result of the US-China trade tensions, but this appears to be outweighed by the global dampening pressures felt across Emerging Asian economies (Figure 1.20). As the trade dispute has unfurled, the US market has proven to be more stable for ASEAN and India than the China market. This could be due to trade redirection, as observed by the OECD (2019).

Policy signals are still quite mixed and risks remain high, even for countries where export growth is stabilising. The announcement in October that the United States and China were finalising a Phase 1 deal was seen as encouraging (Box 1.4). Nevertheless, it is worth noting that the timeline of the trade tensions has seen a succession of new tariff measures and reprieves (Table 1.3).

Figure 1.20. Growth in goods exports of Emerging Asia, 2017-19 3-month moving average, year-on-year, percentage
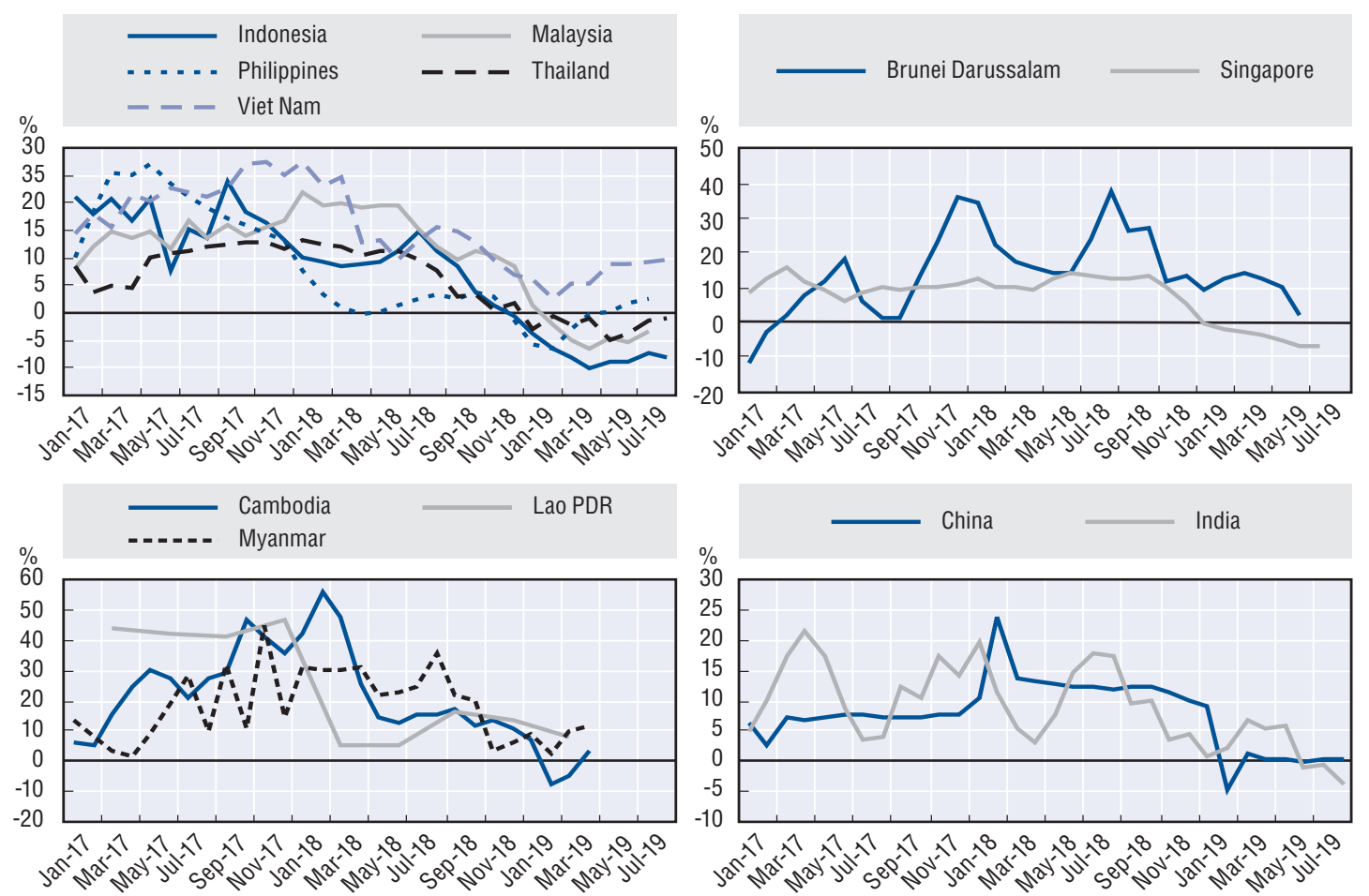

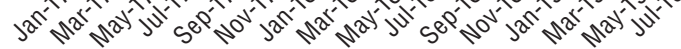

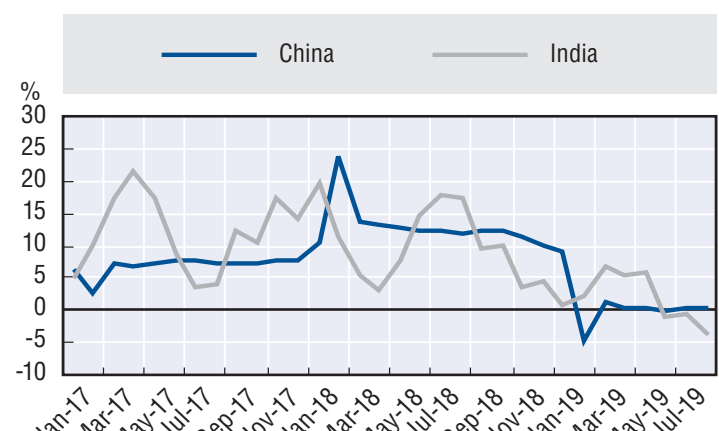

Note: The frequency of Lao PDR's data is quarterly. Growth rates are based on levels in US dollar. Source: OECD Development Centre calculations based on data from CEIC and national sources. StatLink 게대 https://doi.org/10.1787/888934063537 


\section{Box 1.4. Recent developments in the US-China trade tensions}

In mid-October, China and the United States concluded their $13^{\text {th }}$ round of trade talks on an encouraging note when the United States declared that Phase 1 of a trade deal was being finalised (The White House, 2019). Under the supposed deal, the United States will increase agricultural exports to China and, in exchange, will refrain from implementing a scheduled $5 \%$ increase in tariffs on certain imports from China (on List 4 under Section 301 of the US trade law). Should this arrangement go through smoothly, it will calm tensions that have been rising despite previous tariff reprieves (e.g. before the G20 summit in Osaka in June 2019, and during the G20 summit in Buenos Aires in December 2018).

Table 1.3 presents a chronology of measures taken since the US-China trade tensions began in 2018. As the table shows, tariff hikes have been followed by gestures of accommodation on both sides, such as tariff exclusions at certain points in the timeline. Nonetheless, global trade uncertainties have broadened under a cloud of mixed signals as the two sides engaged in a persistent back-and-forth of tariff measures and brought competing complaints before the World Trade Organization (WTO). ${ }^{12}$ Indeed, the US trade policy uncertainty index has been on an uptrend since the cycle started (Baker, Bloom and Davis, 2019). Moreover, the trade tensions are spilling over to investment, both directly, for example through the use of the entity list and investment licenses, and indirectly as a consequence of increasing risk on capital placement. ${ }^{13}$ As such, the importance of a breakthrough deal cannot be overstated.

Meanwhile, import sourcing has shifted on both sides over the course of the dispute. China shifted its soybean imports, though there are indications of a reversal in recent months (Gale, Valdes and Ash 2019). US imports from India and ASEAN of certain goods under Section 301 lists have risen, while imports of the same goods from China have declined (OECD, 2019a). However, the extent to which these shifts can be associated with trade diversion, trade deflection (re-routing), or both, and how long these patterns will prevail, remain unclear. To compensate for the rising cost of its trade with the United States, China has also lowered tariffs on imports from other countries (Bown, Jung and Zhang, 2019).

Table 1.3. Tariff measures and reprieves, United States and China, 2018-19

\begin{tabular}{|c|c|c|c|}
\hline Date & Tariff measures & Date & Reprieves \\
\hline Feb-18 & $\begin{array}{l}\text { Washers (USD } 1.9 \text { billion), } 20 \%-50 \% \\
\text { solar products (USD } 5.2 \text { billion), } 30 \%\end{array}$ & 0ct-18 & $\begin{array}{l}\text { China raises US soybean orders after a substantial cutback } \\
\text { months earlier }\end{array}$ \\
\hline Mar-18 & $\begin{array}{l}\text { Aluminium products (USD } 16.6 \text { billion), } 10 \% \text {; } \\
\text { steel (USD } 23.4 \text { billion), } 25 \%\end{array}$ & Dec-18 & $\begin{array}{l}\text { US postpones tariff hike under List 3; China suspends } \\
\text { additional automobile and auto parts tariff }\end{array}$ \\
\hline Jul-18 & $\begin{array}{l}\text { List } 1 \text { (USD } 34 \text { billion), } 25 \% \Leftrightarrow \text { China, } \\
\text { full retaliation }\end{array}$ & Mar-19 & $\begin{array}{l}\text { US again postpones List } 3 \text { tariff hike; China resuspends } \\
\text { additional automobile and auto parts tariff }\end{array}$ \\
\hline Aug-18 & $\begin{array}{l}\text { List } 2 \text { (USD } 16 \text { billion), } 25 \% \Leftrightarrow \text { China, } \\
\text { full retaliation }\end{array}$ & May-19 & $\begin{array}{l}\text { China sets a trial to exclude imports from tariffs under } \\
\text { Lists } 1 \text { and } 2\end{array}$ \\
\hline $\begin{array}{l}\text { Sep-18; } \\
\text { Jun-19 }\end{array}$ & $\begin{array}{l}\text { List } 3 \text { (USD } 200 \text { billion), } 10 \%-25 \% \Leftrightarrow \text { China } \\
\text { (USD } 60 \text { billion), } 5 \%-25 \%\end{array}$ & Jun-19 & US postpones tariff hike under List 3 for another 15 days \\
\hline \multirow[t]{3}{*}{$\begin{array}{l}\text { Sep-19; } \\
\text { Dec-19 }\end{array}$} & $\begin{array}{l}\text { List } 4 \text { (USD } 300 \text { billion), additional } 5 \%-10 \% \Leftrightarrow \text { China } \\
\text { (USD } 75 \text { billion), } 5 \%-25 \% \text {; China re-imposes additional } \\
\text { tariff on imports of automobile } \\
\text { and auto parts }\end{array}$ & Sep-19 & $\begin{array}{l}\text { Selected US goods on Lists } 1 \text { and } 2 \text { are excluded from } \\
\text { tariffs; selected US agricultural products are excluded } \\
\text { from additional tariffs }\end{array}$ \\
\hline & & Oct-19 & $\begin{array}{l}\text { US announces Phase } 1 \text { deal with China and delays tariff } \\
\text { hike scheduled for October }\end{array}$ \\
\hline & & $\begin{array}{l}\text { Cont. } \\
\text { process }\end{array}$ & $\begin{array}{l}\text { US grants hundreds of exclusion requests pertaining } \\
\text { to Lists 1,2 and 3; exclusion from China's new tariffs is } \\
\text { possible for goods on Lists 1,2 and 3, subject to approval }\end{array}$ \\
\hline
\end{tabular}

Note: This table does not claim to show a complete list of measures and related developments. The dates of tariff measures are the effectivity dates. The percentage rates are the tariffs; the dollar values are the estimated amount of imports affected by the measures. Lists 1-4 are under Section 301 of the US trade act. The table's first two entries are under Sections 201 and 232, respectively. For List 3, the tariff was set 10\% in September 2018, then hiked to 25\% (initially set to be effective in January 2019, but postponed to March 2019 and then to June 2019). As a counter-measure to List 3, China set a tariff of 5-10\% in September 2018, then hiked it to $10-25 \%$ in June 2019. Information is as of 14 October 2019.

Source: OECD Development Centre based on national sources. 
China's prominent role in the global and regional value chain makes its export performance a crucial barometer of how the exports of other Emerging Asian countries perform. As things now stand, the contraction in China's exports may have eased but there are no indications of a strong rebound. China's offshore sales are drawing strength from demand in Africa and ASEAN, particularly the CMLV economies (Cambodia, Lao PDR, Myanmar and Viet Nam), as shipments ease to other partners, such as the European Union, Latin America, the United States and even Japan and Korea. The robustness of export growth to CMLV and Africa could be partially driven by China's FDI-financed corporate representations, which have broadened over the years, although data for performing a thorough validation are limited. This growth could also be an indication of trade rerouting. Incidentally, US imports from the CMLV economies have been quite robust in 2019, outpacing imports from the other ASEAN economies (Figure 1.21).

Figure 1.21. Growth in goods imports of China and the United States by partner, 2017-19

3-month moving average, year-on-year, percentage
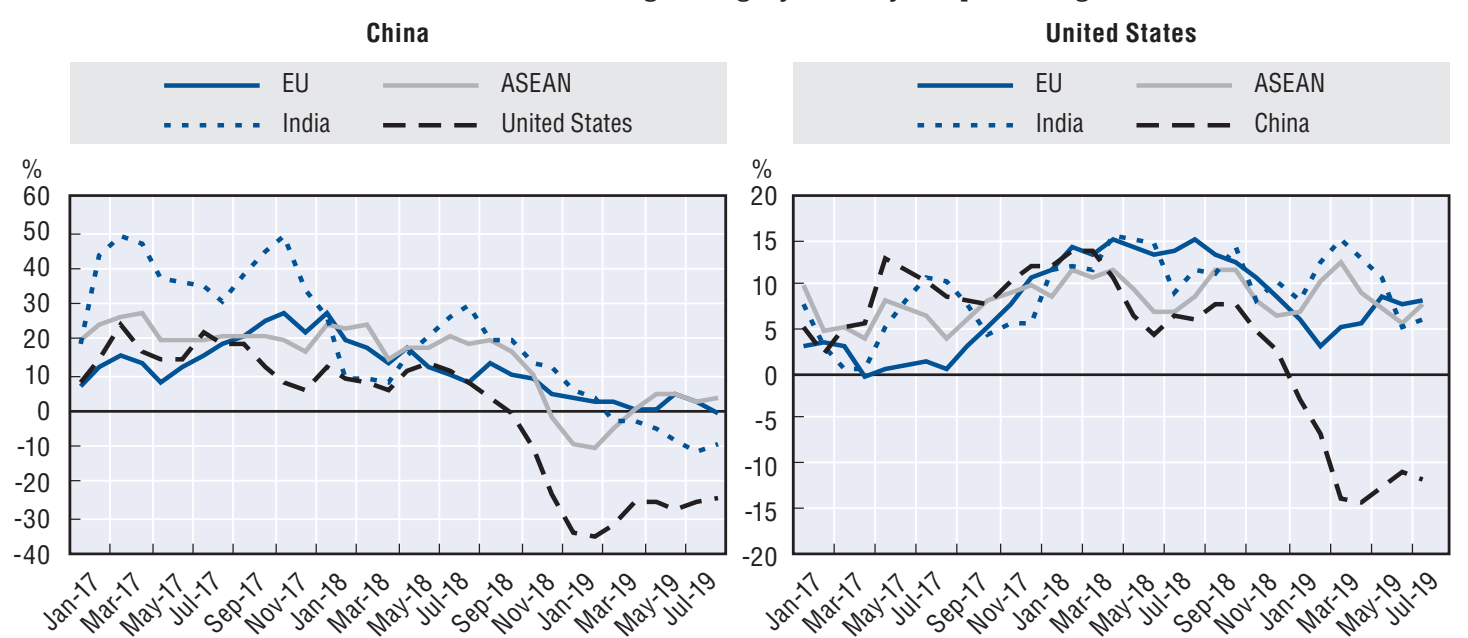

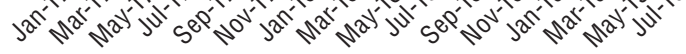
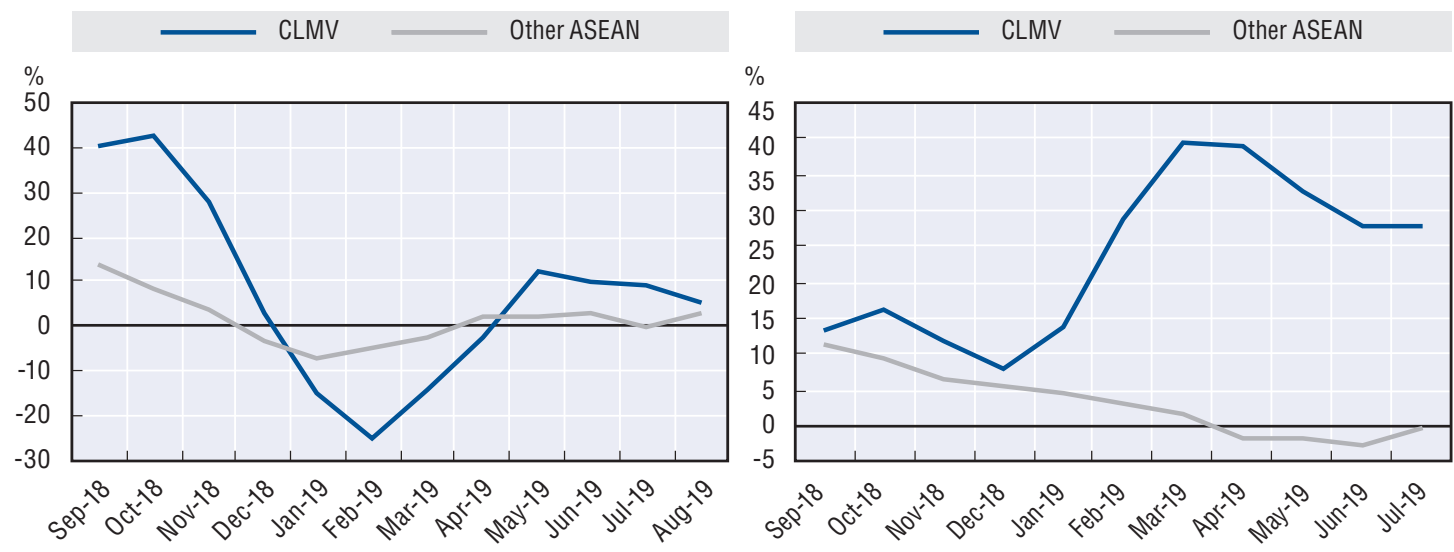

Note: EU grouping is based on the definitions of the national source and may not necessarily be the same in China and the United States. The CMLV countries are Cambodia, Lao PDR, Myanmar and Viet Nam.

Source: OECD Development Centre calculations based on data from CEIC and national sources.

StatLink 需红 https://doi.org/10.1787/888934063556

As the data show, the United States remains a viable market for ASEAN. However, fractures have been appearing in the regional value chain. The softening of China's demand for imports, due to the combined effects of the trade war and structural transformation, has hobbled trading activity in the region overall. Intra-ASEAN goods 
trade has weakened markedly in 2019, and data through April 2019 indicate that this trend is worsening. Orders from other key markets are losing traction as well. Demand for ASEAN's goods has softened in other major East Asian economies, namely Hong Kong, China; Japan and Korea, as well as in the European Union.

Notable variations emerge within ASEAN. The decline in exports appears to be mending in CLMV economies, which are navigating the rough environment comparatively better at this juncture. As mentioned above, the United States has been a buoyant market for the CLMV economies. China, despite the overall weakness in import demand, has also been relatively supportive, as shown in the chart above. Furthermore, advance import data from Indonesia and Thailand indicate that orders are increasing from Cambodia and Myanmar, while Japan's imports from Myanmar and Viet Nam have also been growing at a sturdy pace. Exports from the Philippines are likewise showing signs of revival. Growth in sales to Korea has been a key anchor in recent months.

Although India is less integrated in the global value chain than ASEAN (World Bank et al., 2017), it is also feeling the pinch of the global trade pressures. India's exports have lost steam, including to the United States and China. Imports of Indian goods have also moderated in ASEAN and large East Asian economies like Japan and Korea, as well as in the European Union and United Arab Emirates, India's other two major export partners. India, which was affected by a series of US trade policies over the past two years, including a tariff on steel and aluminium in 2018, followed through on its threat to raise tariffs on certain US goods in June 2019 (Bown, 2019).

\section{Export weakness is accompanied by falling investment as manufacturing struggles}

As exports cave in to trade tensions, real growth in fixed investment is pulling back in a number of Emerging Asian economies, leaving private consumption to do the heavy lifting to support economic activity (Figure 1.22). With the exception of Indonesia, there appears to be a growing reluctance to expand investment in equipment and machinery in the current climate. In Malaysia, outlay on machinery and equipment continued to decline in Q2 2019 for the third quarter running. Capital spent on these production inputs also decreased in Singapore, which at the same time saw a steady pullback in residential building investment. Likewise in Thailand, machinery and equipment spending growth has softened in step with a contraction in private dwelling investment. Durable equipment investment also posted a steep drop in the Philippines in Q2 2019 following several quarters of sustained growth.

Business confidence is thus gradually weakening in some countries, and it is particularly weak in Malaysia and Thailand. In Indonesia, the business tendency index recovered marginally in Q2 2019 amid cautious optimism. In contrast, business confidence remains robust in the Philippines, although it ebbed slightly as the outlook for mining and manufacturing firms dimmed in Q3 2019 from the previous quarter.

Production data show that offshore market-dependent manufacturing sectors are feeling external pressures quite strongly (Figure 1.23). Weakening growth is observable across the large ASEAN economies, especially in Thailand and Singapore. The Purchasing Managers' Index (PMI) in manufacturing has likewise been largely downbeat in these economies. As of September 2019, readings point to a sustained contractionary cycle in Indonesia, Malaysia and Singapore, at least in the last three months. In the Philippines, the index suggests expansion, though it is moderating. Thailand's index is hinting signs of gradual recovery following inflection in September 2019 after five successive months of easing.

In contrast, services sectors, which tend to have a bigger domestic driver component, are projecting a relatively insulated growth path. Nonetheless, the insulation is somewhat diminished in Singapore and Thailand, where key services segments have broader ties with businesses involved in trade. In Indonesia, Malaysia and the Philippines, subsectoral support remains broad based, including the large wholesale and retail trade segment 
as well as transportation and finance. In Singapore, the moderation in services growth is underpinned by wholesale and retail trade and business services. In Thailand, in comparison, the slowdown in growth of value added in transport and storage as well as financial services is weighing on the sector's output.

Figure 1.22. Private consumption, exports and fixed investment real growth Year-on-year percentage change

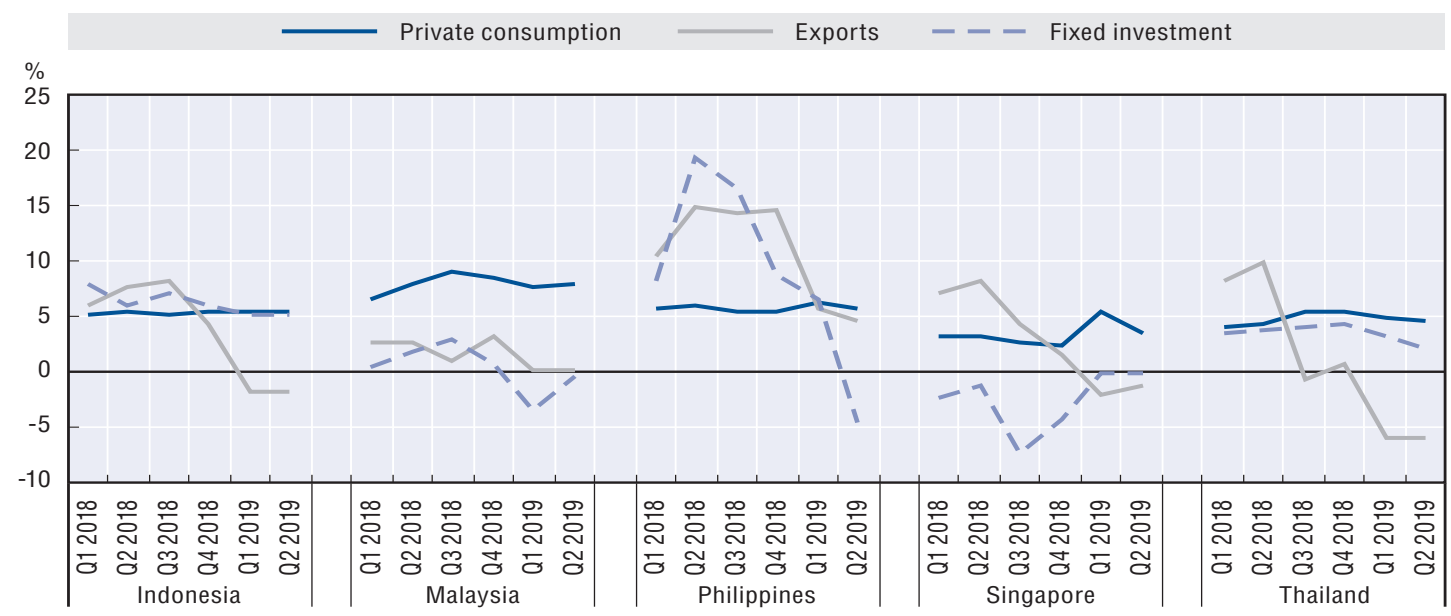

Source: OECD Development Centre based on data from CEIC and national sources.

StatLink 需它L https://doi.org/10.1787/888934063575

Figure 1.23. Manufacturing and services real growth

Year-on-year percentage change

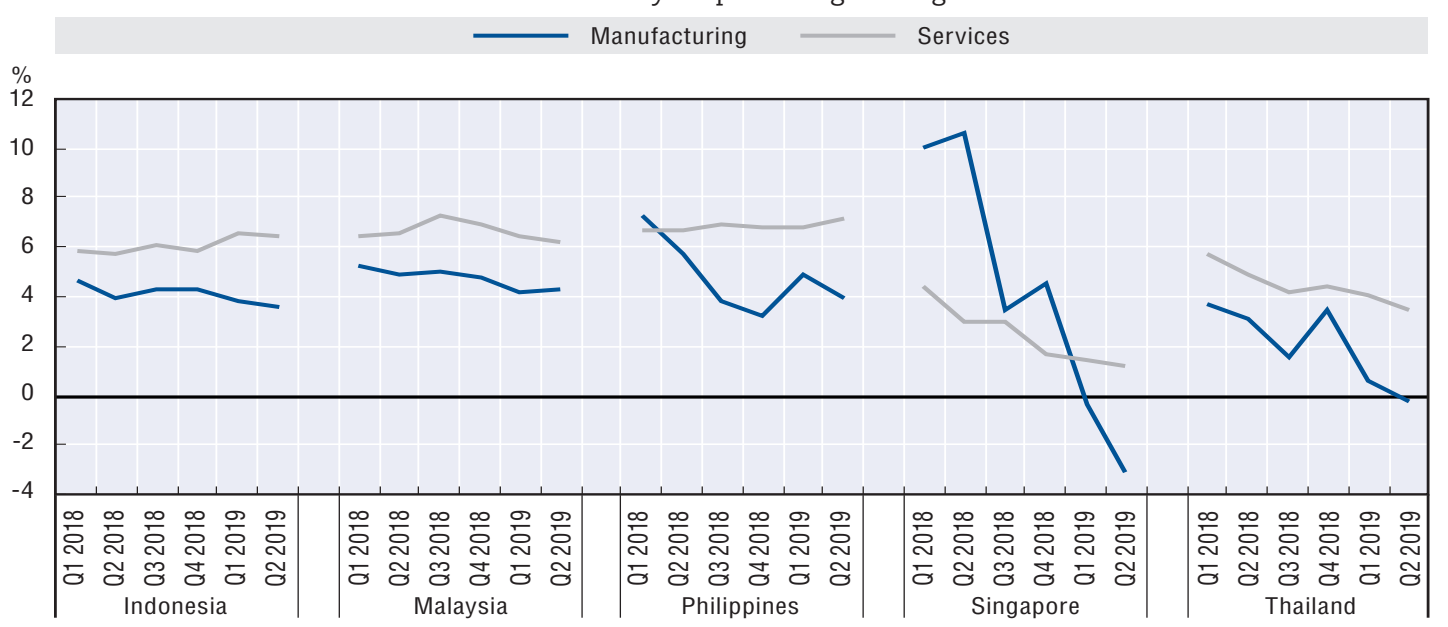

Note: For Singapore, services include ownership of dwellings.

Source: OECD Development Centre based on data from CEIC and national sources.

StatLink 尚isम https://doi.org/10.1787/888934063594

\section{Current account balances are under stress but remain largely stable}

The net trade balances of Emerging Asian economies have been fairly stable, with tariff-induced stresses affecting both exports and imports (Figure 1.24). Interestingly, despite being at the centre of the trade tensions, China saw its trade balance swing upwards, with imports weakening more than exports, as mentioned previously. In contrast, India, Indonesia and Thailand saw their exports pull back slightly more than imports in 2019. Given the way the trade dynamics are playing out, the current-account balances of Emerging Asian economies have generally been steady. Minimal deviations from current trends are expected in 2020, as well as in the medium term (Figure 1.25). 
Foreign direct investment inflows in the region have also generally remained resilient (Figure 1.26). Despite the external pressures, foreign net placements in Cambodia, India, Indonesia, Malaysia, Singapore and Viet Nam have even improved in 2019 from 2018 on an annualised basis.

Figure 1.24. Current account balance and net exports of Emerging Asia, 2017-19 USD billion, annualised
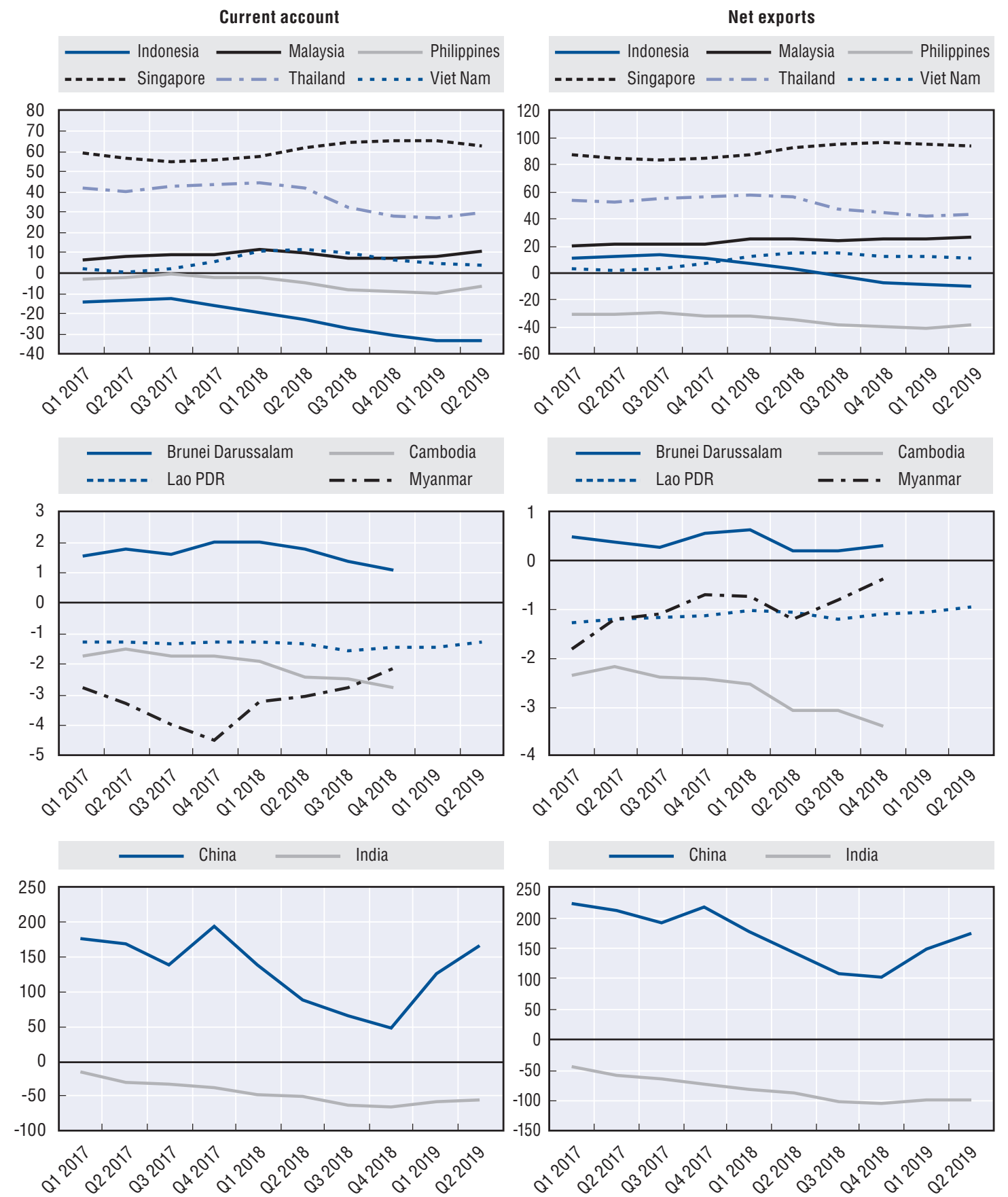

Note: Annualised data refer to the 4-quarter moving sum. Data are based on balance of payments. Dates are all in calendar years.

Source: OECD Development Centre calculations based on data from CEIC and national sources.

StatLink 角Ist https://doi.org/10.1787/888934063613 
Figure 1.25. Current account balance, 2019-24

Percentage of GDP

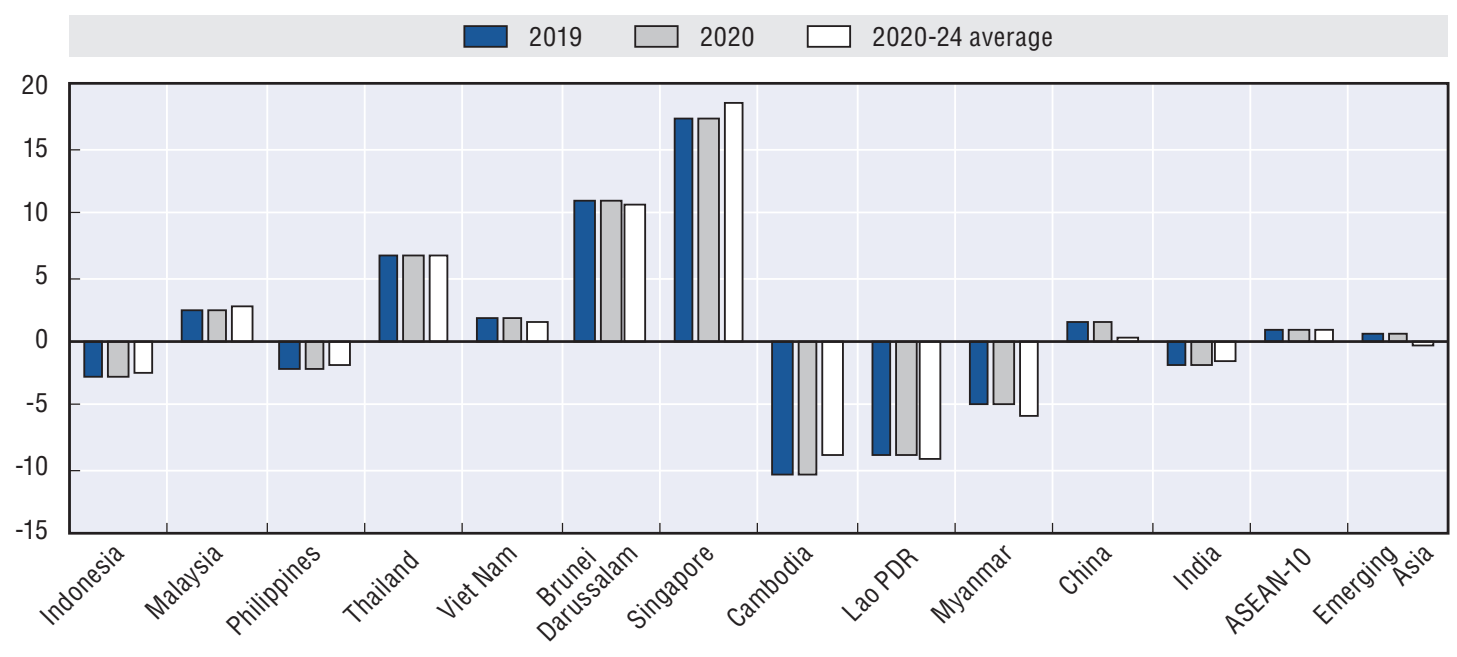

Note: Data are as of 21 November 2019. Data for India and Myanmar relate to fiscal years. The projections for China, India and Indonesia for 2019 and 2020 are based on the OECD Economic Outlook 106 (database).

Source: OECD Development Centre, Medium-term Projection Framework (MPF-2020).

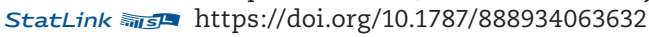

Figure 1.26. Foreign direct investment in Emerging Asia, 2017-19 USD billion, annualised

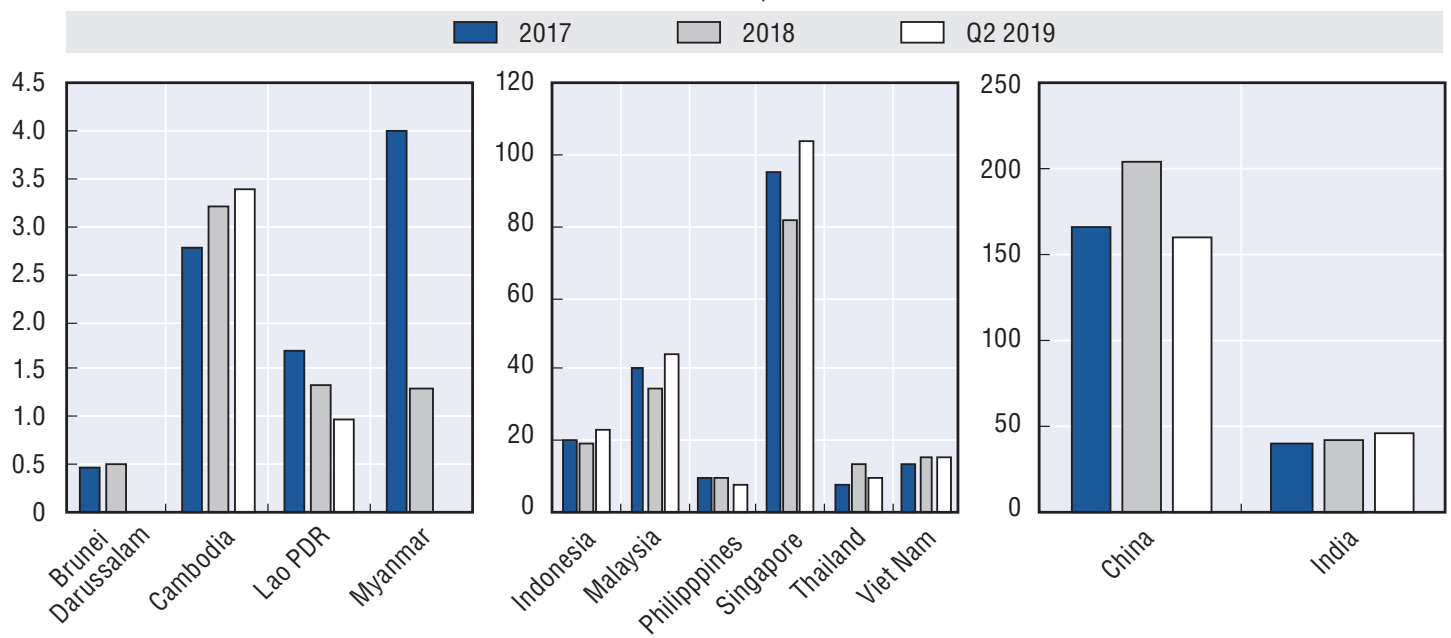

Note: All data are in calendar years. Quarterly data are annualised (i.e. 4-quarter sum as of the period indicated). The latest data for Brunei Darussalam and Myanmar are as of Q4 2018. FDI inflows data refer to foreign investment minus foreign withdrawals (Balance of Payments, liability side).

Source:OECD Development Centre based on data from CEIC and national sources.

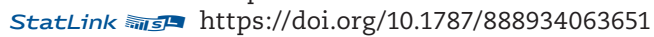

\section{Headline inflation remains subdued but food prices are rising in some countries}

The retreat in global oil prices, along with subsidy measures and stability in agricultural production, have kept headline inflation at bay in most Emerging Asian economies (Figure 1.27). Benign core inflation anchors this trend and suggests a limited demand-side price push as thus far in. Food prices, which carry a large weight in CPI (Box 1.5), are an exception in some countries. Although generally subdued, food inflation has been on a sharp climb in China and Myanmar and is rising gradually in India, Indonesia, Lao PDR and Thailand. 
Figure 1.27. Headline, core and food inflation in Emerging Asia, 2017-19 Percentage

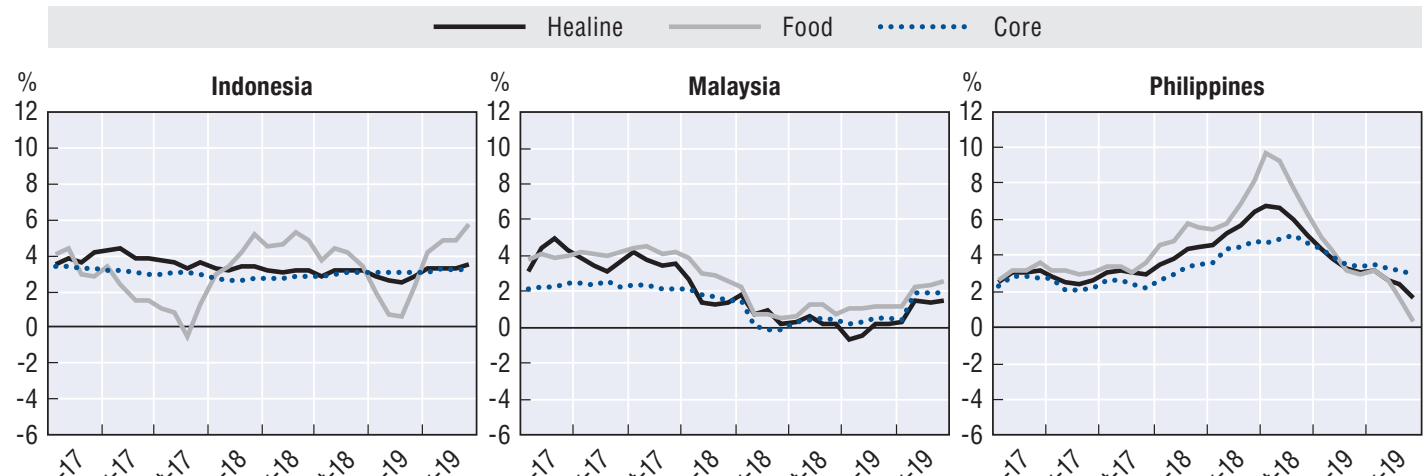

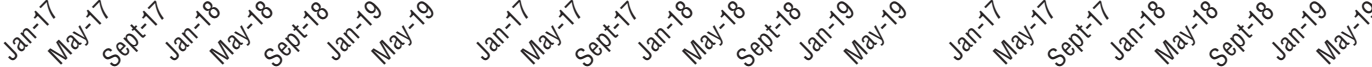
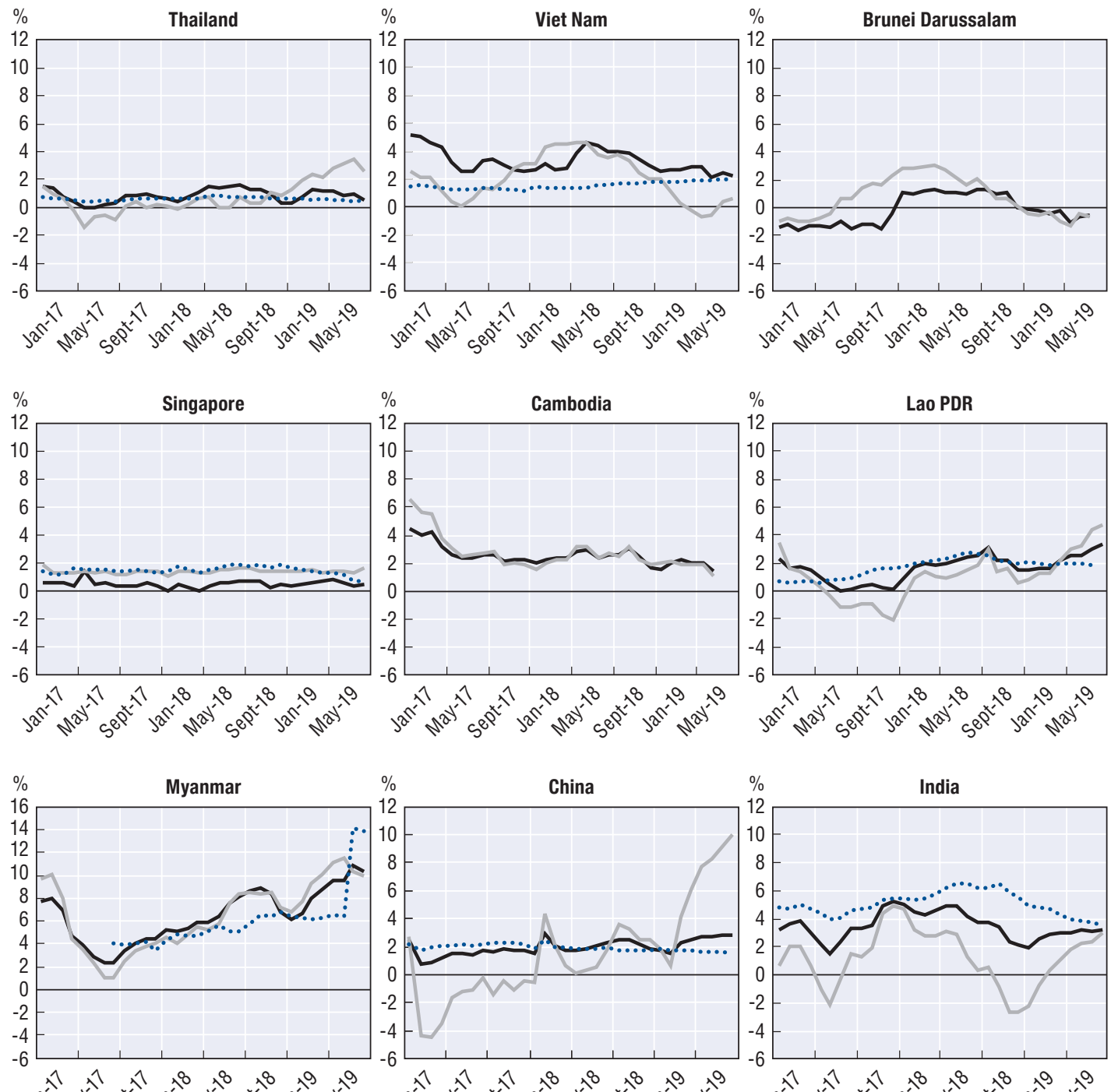

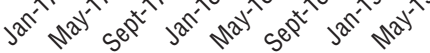

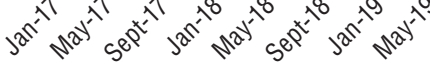

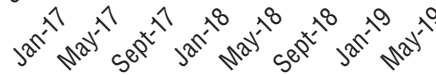

Source: OECD Development Centre based on data from CEIC and national sources.

StatLink (inाIS https://doi.org/10.1787/888934063670 
In China, soaring prices of pork and some fresh produce drove food inflation to about 10\% in August 2019 from less than 1\% in February 2019. Pressures could persist in coming months as the government contains the swine flu epidemic. Higher import tariffs could also result in price spillovers to other food items. On the upside, the price growth of other commodity baskets is holding steady or subsiding to depress consumer price index (CPI) inflation. In Myanmar, the price of rice is climbing fast despite a pick-up in the harvest, stabilisation of the exchange rate in recent months and a fall in global quotations. ${ }^{14}$ This suggests an uptick in processing and distribution cost. A spike in the price of nonalcoholic beverages also steepened through June 2019 before retreating marginally in July 2019; whereas housing, water and energy cost jumped in the same month. Other drivers of headline inflation include health services and household-related items.

Rice prices also surged in Lao PDR due to a drought this year following severe flooding in late 2018, bolstering food inflation, while weaker currency has fuelled a hike in the prices of other non-food and beverage items. Food inflation is gradually rising in Indonesia and Thailand, though the rates are still far from concerning. Notably, while the trend in Thailand is underpinned by structural factors, the trend in Indonesia appears to be influenced more by cyclical factors. The same can be discerned in India, where food prices have risen subtly between March and August 2019, after successive declines in the previous months. Growth in the price indices of other key CPI components has largely slowed.

Elsewhere in the region, inflation is largely muted. In Brunei Darussalam, headline inflation has been negative in recent months. The price indices of major CPI components other than restaurant and hotel services have remained stable or have fallen. In Cambodia, a reduction in transportation and communication costs is depressing the CPI, though this is counterbalanced by a spike in alcoholic beverages and tobacco prices. In Malaysia, the headline rate inched upwards in June-August 2019, mainly because a goods and service tax was scrapped around that time last year before a replacement sales and service tax was imposed in September 2018. In the Philippines, headline inflation is treading down owing to the resolution of shortage in key staples and as base effects of tax measures last year dissipate. In Singapore, a continued decline in the cost of housing, communication and basic consumer goods has pinned headline CPI growth to about 0.5\% in August 2019. Downward headline inflation trend is also observable in Viet Nam as food inflation stays soft. A spurt in education cost (partly owing to gradual privatisation) is also seemingly wearing off albeit health care inflation, which was following a similar path in the first half of 2019, has rebounded markedly in recent months.

\section{Box 1.5. Consumer price index composition in Emerging Asia}

The inflation environment in Emerging Asia, has generally been muted in the last few months, with a few exceptions. The composition of the consumer price index (CPI) is important for understanding how macroeconomic factors influence headline inflation. Food currently carries most weight in the CPIs of India and most ASEAN economies, particularly Cambodia, Lao PDR and Myanmar. An exception is Singapore, where housing and utilities outweigh food in the CPI basket, reflecting differences of economic development and structure. Another exception is Brunei Darussalam, where transportation slightly outweighs food (Figure 1.28).

Stable food and fuel prices in many countries have helped limit headline inflation. But in countries where food inflation is surging, for instance Myanmar and Lao PDR this year and the Philippines last year, headline inflation is also increasing in an almost co-ordinated fashion. As food comprises the largest component of the consumption bundle in typical 


\section{Box 1.5. Consumer price index composition in Emerging Asia (cont.)}

households, trends in food prices tend to influence inflation expectations. This is also true of fuel prices, although fuel is influenced by global markets and gives rise to secondround effects as it feeds into various baskets of CPI.

\section{Figure 1.28. Consumer price index weights}

Percentage

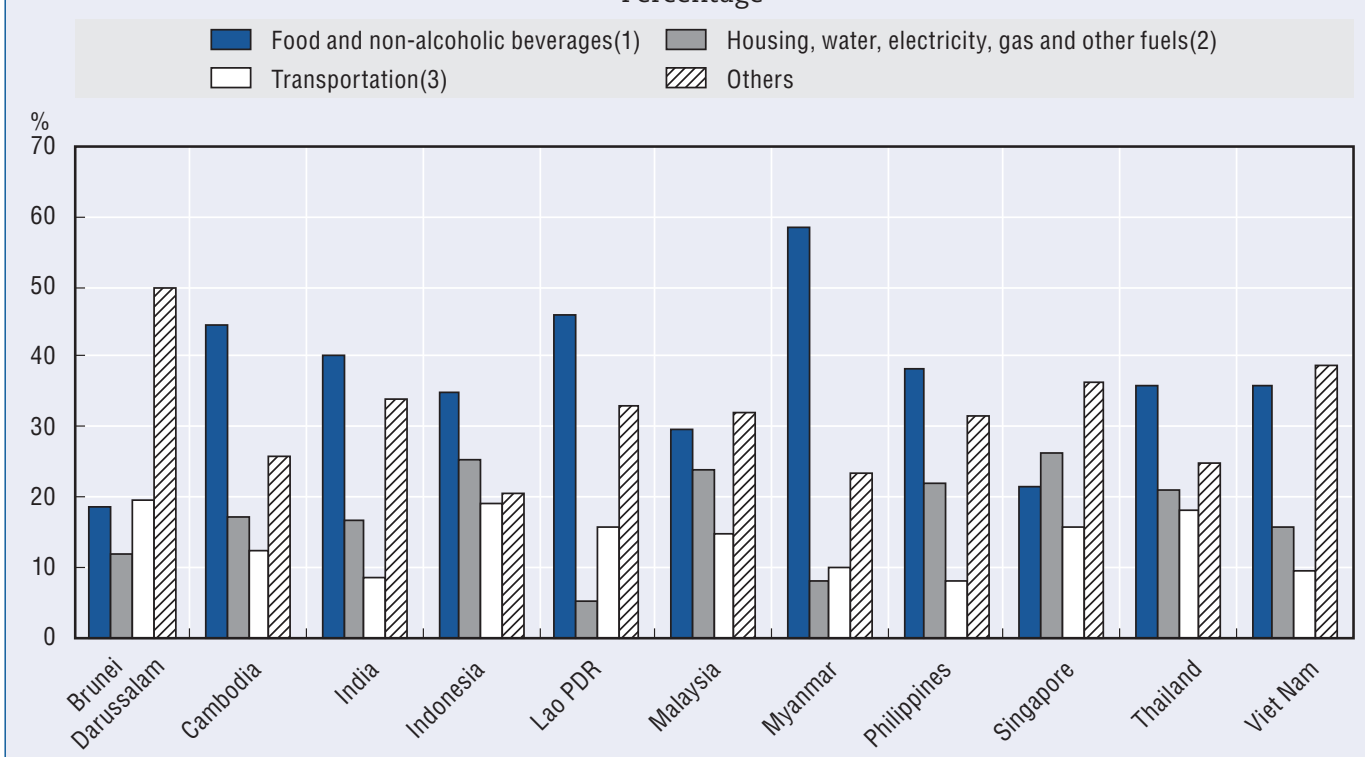

Note: Definitions of the components and the level of breakdown published, may not be necessarily the same across countries. China does not publish the weights of the CPI. (1) For Indonesia, data includes food, processed food, beverages and tobacco. For Viet Nam, data refer to foods and foodstuffs. (2) For Thailand, data refer to shelter and utilities. For Viet Nam, data refer to housing and construction materials. (3) For India and Lao PDR, data include communication. For Indonesia, data include communication and finance. For Thailand, data refer to public transportation, vehicles and vehicle operation.

Source: OECD Development Centre based on data from CEIC and national sources.

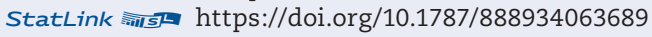

CPI composition aside, it is worth noting that a number of Emerging Asian economies have implemented price management mechanisms, although the extent differs across countries and over time. These mechanisms, or changes to them, can sway the movement of headline inflation. For instance, fuel subsidies are in place in countries like Brunei Darussalam, China, India, Indonesia and Malaysia, as in many other countries globally (IMF, 2019). In other countries, for example Indonesia, Philippines, Thailand and Viet Nam, price supports benefit the farm sector. Similarly, Singapore's social housing programme, which ultimately focuses on ownership, can be seen as a mechanism for mitigating sharp changes in housing costs. Electricity and mass transport cost controls are utlised as well. In the Philippines, for instance, tariffs on electricity are partly regulated but not subsidised, while in Indonesia it is both regulated and subsidised. Meanwhile, public transport fares are partially regulated in countries including the Philippines, Singapore and Thailand.

In summary, the ability of the consumer price index to capture ground-level inflation pressures generally depends both on the weight distribution of CPI across commodity baskets and on price distortions. In countries where foreign currency is used in domestic transactions, such as Cambodia, Lao PDR and Myanmar, exchange rate movement becomes a potent driver of CPI as well. 


\section{Central banks take strong steps to prop up growth and investment sentiment}

Slowing economic growth coupled by easing inflation has provided impetus for loose monetary policy in Emerging Asia. Recent measures have included sizeable cuts in policy rates and in banks' reserve requirement ratios (RRR) (Figure 1.29). In China, efforts to align tools with market dynamics led to a shift in the benchmark interest rate. The likelihood that monetary authorities will ease liquidity conditions further in the coming quarters cannot be discounted. For instance, the Philippines plans to lower the RRR to a single-digit level in the coming years, entailing an additional reduction of over 500 basis points from the current level.

Figure 1.29. Monetary policy actions in selected Emerging Asian economies in 2019

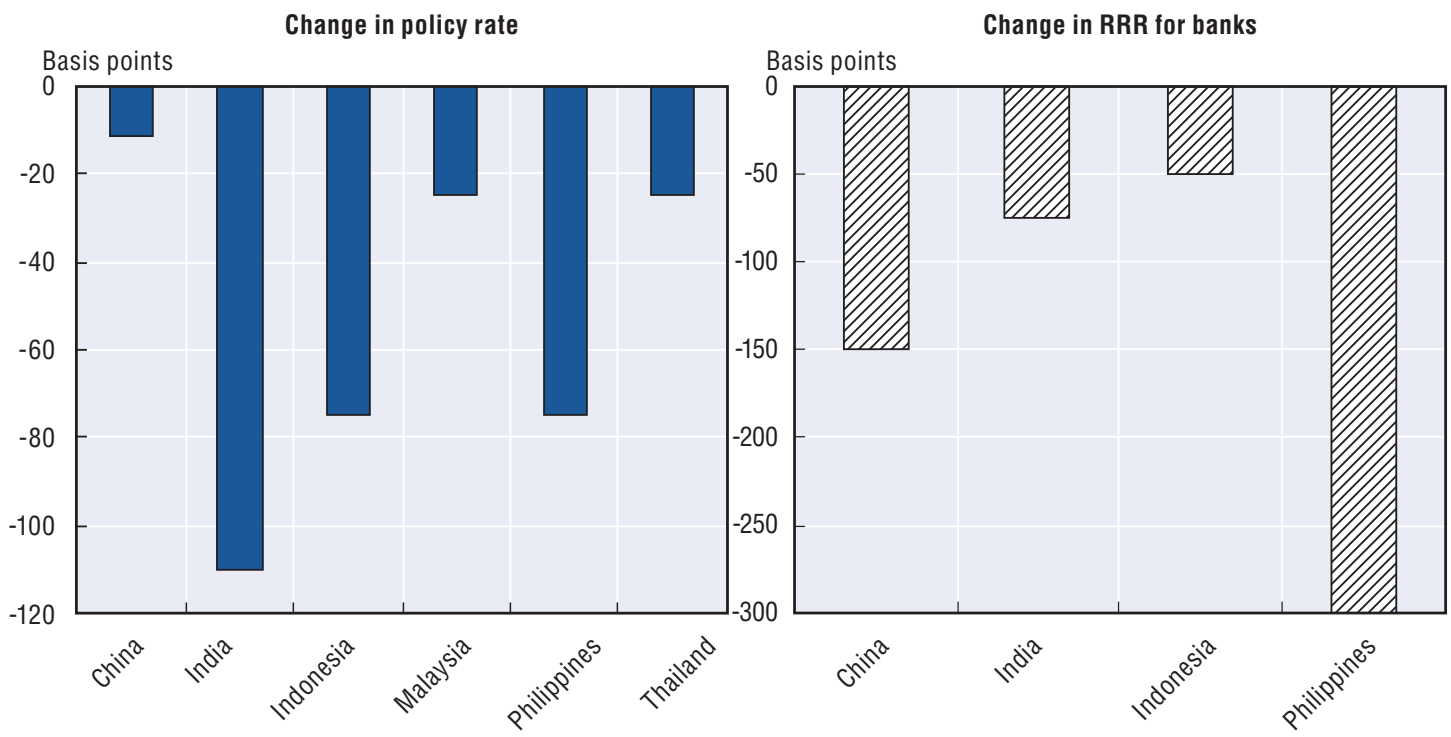

Note: China set the 1-year and 5-year loan prime rate (LPR) as new benchmarks for pricing new loans, in lieu of the 1-year benchmark lending rate, and linked them to the movement of the medium-term lending facility. Data for India relate to the average change in bank rate, repo and reverse repo rate and marginal standing facility rate. The RRR variables used are: RRR for large depository institutions (China), statutory liquidity ratio (India), RRR for banks' local currency deposits (Indonesia) and RRR for commercial banks' local currency deposits (Philippines).

Source: OECD Development Centre based on data from national sources.

StatLink aㅔsम https://doi.org/10.1787/888934063708

Correspondingly, bond yields in the region have fallen on both the short and long ends. Yet despite the decline in domestic debt yields, yield differentials against US bonds are moving upwards somewhat (Figure 1.30). The same trend can be observed against the yields of European benchmark bonds. In the United States, yields on government debt remain positive despite a drop in recent months. Interestingly, however, the yield curve has inverted, signalling a build-up in real sector distress even as inflation stays muted. In Europe, a number of sovereign bond yields are treading deeper into the negative zone as major economies look for complementary mechanisms to boost activity. This scenario could signal sustained margin-seeking foreign capital inflow into the region in the near term, although the flows have not been disruptive thus far. "Hot money" net liability inflows (i.e. portfolio and other investment) are showing no signs of sharp disruptive changes in either direction as yet, even in countries with data until Q2 2019 (Figure 1.31). This provides some elbow room for monetary authorities to tweak their monetary tools. Cross-country trends are fairly stable. Indonesia and, to a certain extent, Lao PDR are seeing a steady uptick in inflows, though the increases are arguably mild. 
Figure 1.30. Benchmark bond yield and term differentials

Percentage points

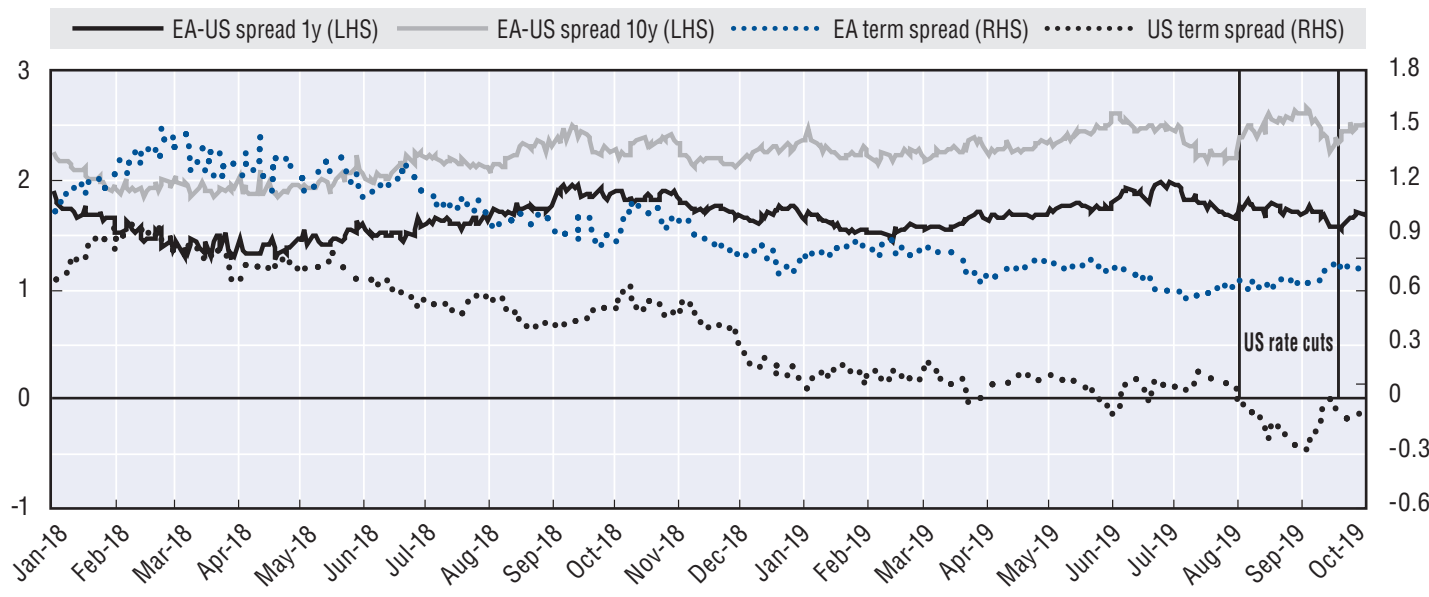

Note: EA means Emerging Asia. Emerging Asia is the simple average of government bond yields of China, India, Indonesia, Philippines, Singapore, Thailand and Viet Nam. Term spread equals 10-year yield minus 1-year yield. LHS means left hand scale. RHS means right hand scale.

Source: OECD Development Centre calculations based on data from Fusion Media Ltd (2019), www.investing.com.

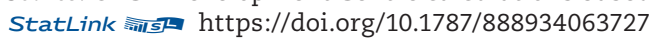

Figure 1.31. Portfolio and other investment liability inflows in Emerging Asia 2017-19 USD billion, annualised
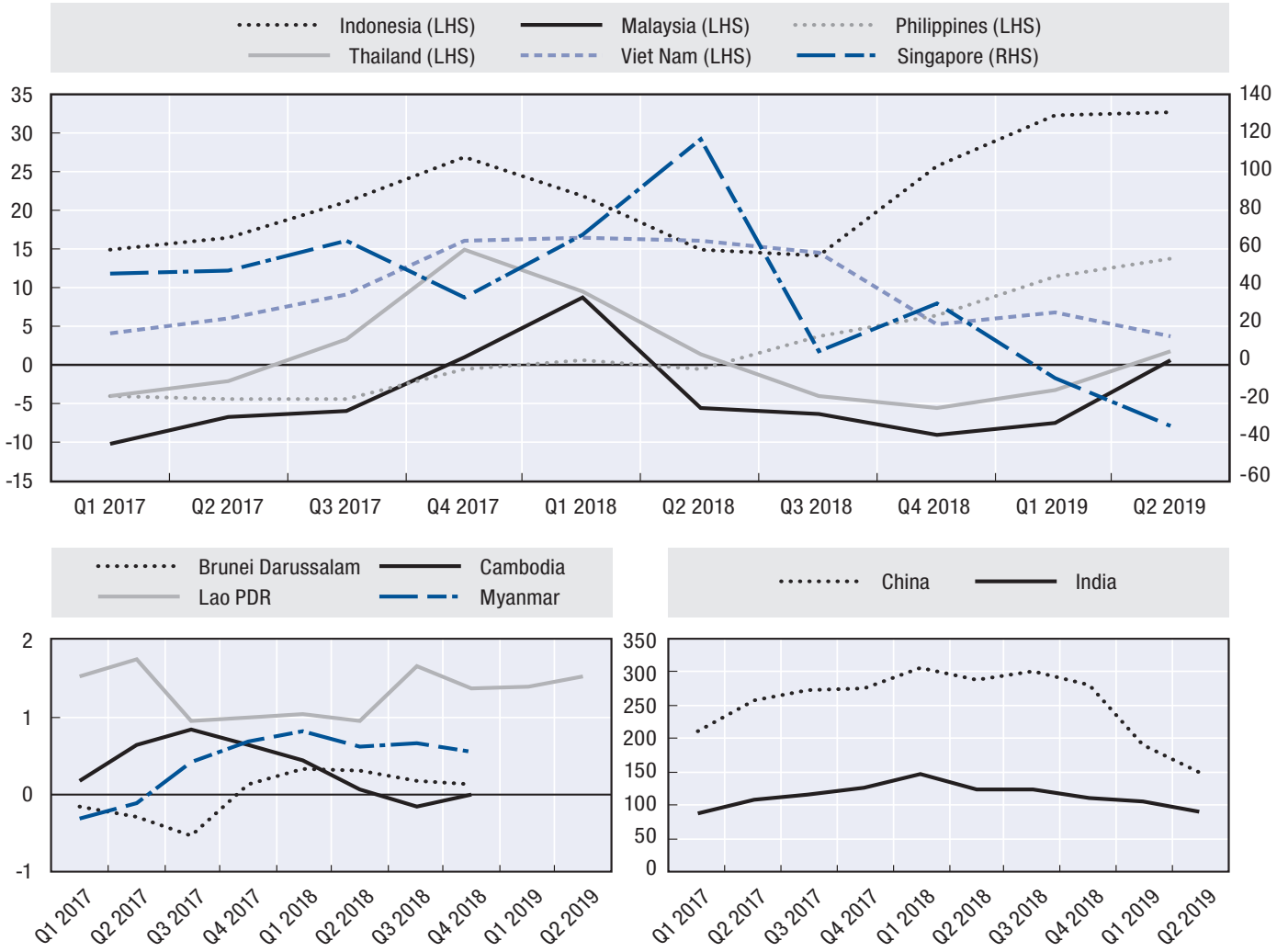

Note: Data are annualised (i.e. 4-quarter sum ending the indicated quarter). Malaysia's data only cover portfolio investment since the BOP report does not publish the breakdown of other investments between assets and liabilities.

Source: OECD Development Centre based on data from CEIC and national sources.

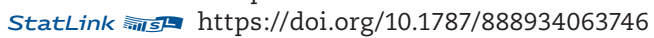


Exchange rate movement in 2019 has similarly been less volatile than in the previous year. The nominal effective exchange rate (NEER) of the Thai baht continued to appreciate through August 2019 on the strength of FDI inflows and Thailand's current account position (Figure 1.32). The strength of the baht is notable, particularly against the backdrop of the resurgence of the US dollar against its major trading partners, though it is seen as a drag on exports and tourism. In contrast, the upward trend of the Chinese yuan renminbi, Indian rupee, Indonesian rupiah and Philippine peso has reversed in recent months as trade uncertainty rises. Meanwhile, the Malaysian ringgit and the Singaporean dollar have remained relatively stable.

Bilateral exchange rates against the US dollar largely mirror the NEER for the aforementioned countries. Additionally, the Myanmar kyat, which has seemingly recovered from a rough 2018, has been on an uptrend against the US dollar since midMay, while the Vietnamese dong has largely moved sideways following a steep drop in June 2018. In contrast, the Brunei dollar and Cambodian riel have been subtly treading downwards in the last few months, while the Laotian kip has been on a sustained but gradual depreciation since May 2018.

Figure 1.32. Nominal effective exchange rate in selected Emerging Asian economies, 2019

1 January $2019=100$
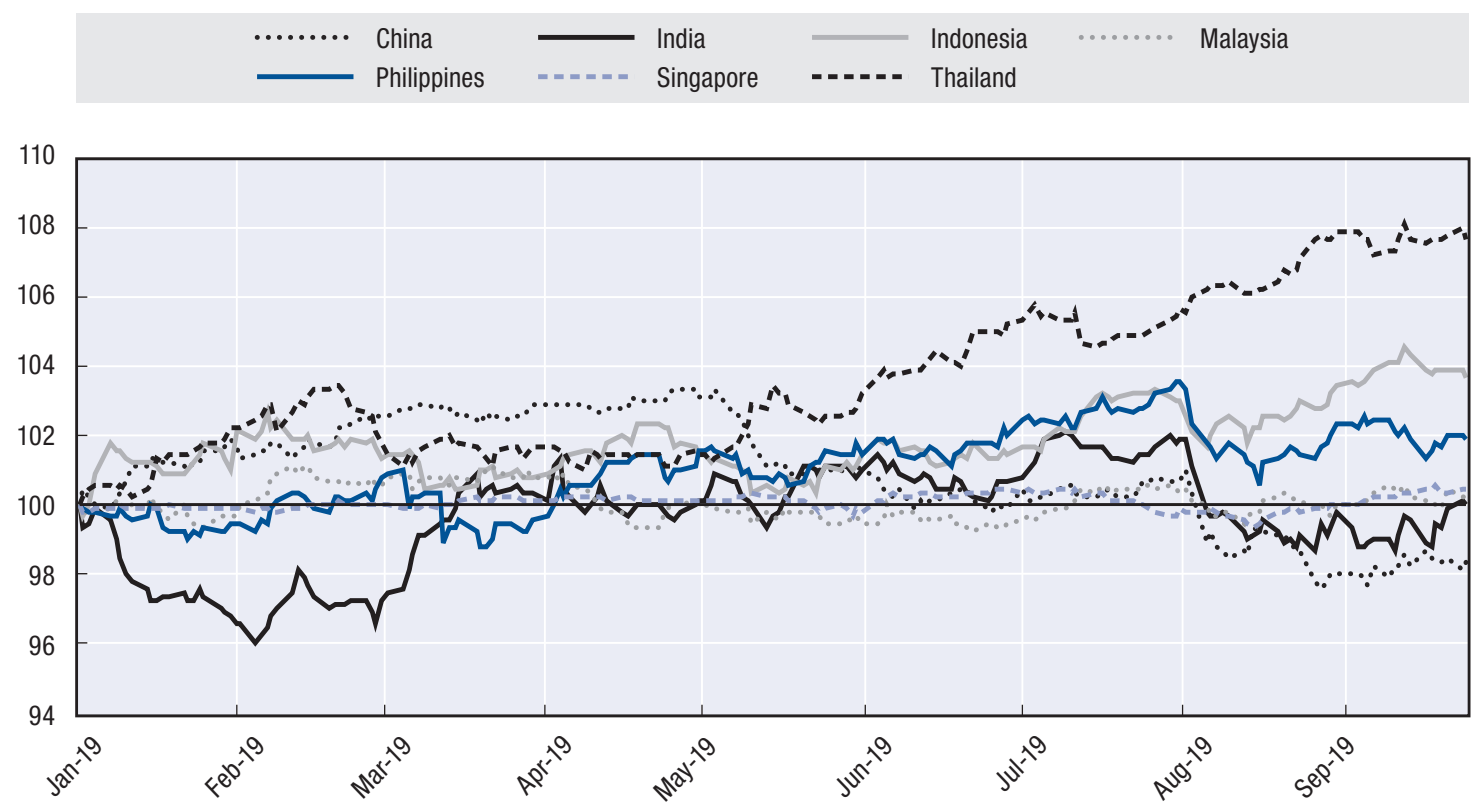

Source: OECD Development Centre based on data from BIS (2019), BIS effective exchange rate indices (database). StatLink 刑ISL https://doi.org/10.1787/888934063765

Equity prices have felt rising pressure on corporate earnings recently. The bellwether indices have pulled back marginally since end-June 2019 in all markets except Cambodia, Myanmar and Viet Nam (Figure 1.33). Nevertheless, the ratio of prevailing prices to the net income of companies has generally risen since the start of 2019. Of note is the price-to-earnings (P/E) ratio of India's equity markets, particularly in the automotive, consumer goods, banking and realty subsectors on the Bombay Stock Exchange. As of July 2019, India was estimated to have the most expensive major market globally for equity investors based on P/E ratio (Keimling, 2019). 
Figure 1.33. Returns on benchmark equity indices in Emerging Asia, 2018-19

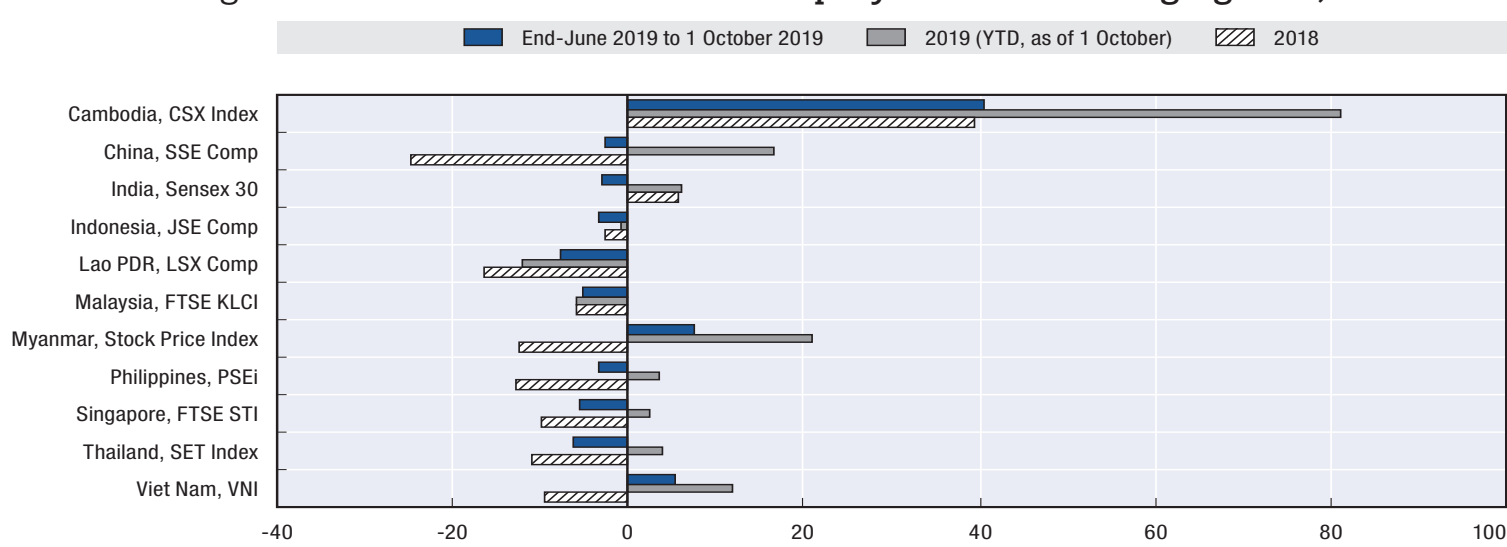

Note: YTD means year-to-date.

Source: OECD Development Centre calculations based on data from Fusion Media Ltd (2019), www.investing.com, and national sources.

StatLink (ailst https://doi.org/10.1787/888934063784

Housing markets in India, Indonesia, Malaysia, Singapore and Thailand are losing steam (Figure 1.34). Domestic dynamics differ across countries, based on available data. In China, the growth in sales of units (commercialised residential buildings) is on a decline. It is a trend that can be traced back to early 2016. It also closely tracks the dip in unit completion rates, which is reflective of the effort to curb the available stock. Since mid2018, however, growth in units under construction has risen anew, decoupling from sales growth somewhat, in a trend presumably instigated by stimulus measures. In Singapore, a reversion in the price growth trend is in line with weakening economic prospects. The vacancy rate as of June 2019 had remained unchanged since 2018, though it was lower than in 2016 and 2017, and no notable change in supply was expected. In Thailand, weak price growth coupled by a drop in completion rates in Bangkok and surrounding areas (prior to the trend reversion in June 2019) similarly indicates that ample available units can be drawn down, which puts a lid on prices.

Figure 1.34. Growth in house price indices of selected Emerging Asian economies, 2018-19

Year-on-year percentage change

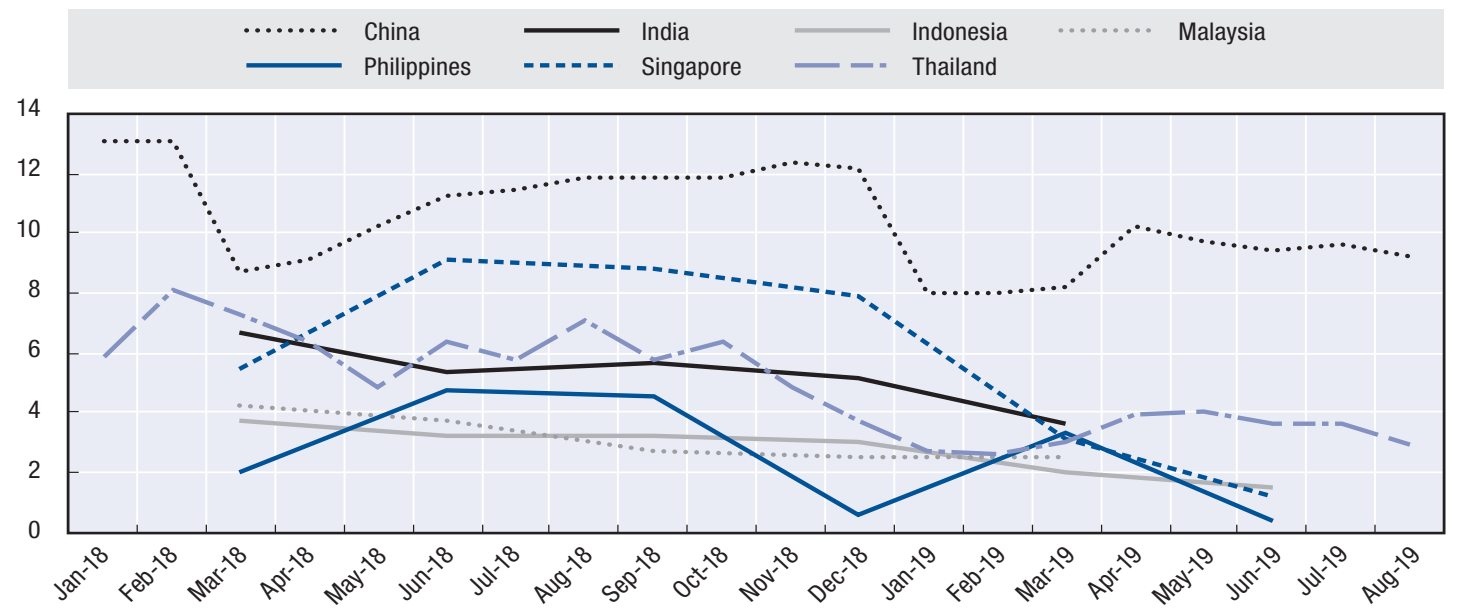

Note: The base indices are not necessarily comparable across countries. Data frequency for China and Thailand is monthly, while it is quarterly for the other countries.

Source: OECD Development Centre based on data from CEIC and national sources.

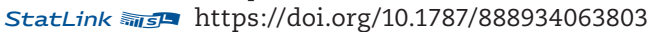




\section{Enhancing the effectiveness of monetary policy in Emerging Asia}

Monetary easing has become the trend in OECD economies, in particular in the euro area and the United States. Emerging Asian economies have followed suit to boost growth in their own economies. However, a key challenge is to make monetary policy effective amid changing economic conditions. One of the changes is the weakening of the relationship between inflation and the output gap or unemployment. In this context, the Phillips curve - the inverse relationship between unemployment and inflation - is attracting increasing attention. The idea of the Phillips curve is that when unused labour market capacity, or labour market slack, is reduced, prices are expected to rise through wage adjustments and consumer demand. Indeed, the shape of the curve in advanced economies has posed policy questions, as inflation has generally stayed weak despite the recovery of the labour market, supported by monetary interventions. Recently the Phillips curve has been flattening in advanced economies such as the euro area and the United States, as well as in Emerging Asia, though the extent differs. Possible explanations for the flattening of Phillips curves include domestic wage rigidities, structural changes, technological shifts, global competitive pressures and changing expectations of inflationary pressures (Ciccarelli and Osbat, 2017; Moretti, Onorante and Zakipour-Saber, 2019).

\section{The flattening of the Phillips curve in Southeast Asia}

In Southeast Asia, inflation has declined in general from previous decades, in line with the global picture (Figure 1.35). Similar to advanced economies, the gradual flattening of the Phillips curve in ASEAN-5 countries like Thailand and Singapore can also be observed (Box 1.6). ${ }^{15}$ Nonetheless, the economic environment in these two countries is different. For instance, Thailand follows an inflation targeting framework while Singapore targets the nominal effective exchange rate, though it takes headline and core inflation into account in policy making (Meng, 2016). The consumer price indices are also nuanced, with Singapore putting more weight on housing and utilities while Thailand puts a greater premium on food. Finally, labour market characteristics differ, with Thailand having a larger informal sector.

Figure 1.35. Headline inflation in Indonesia, Malaysia, Philippines, Singapore and Thailand

Percentage
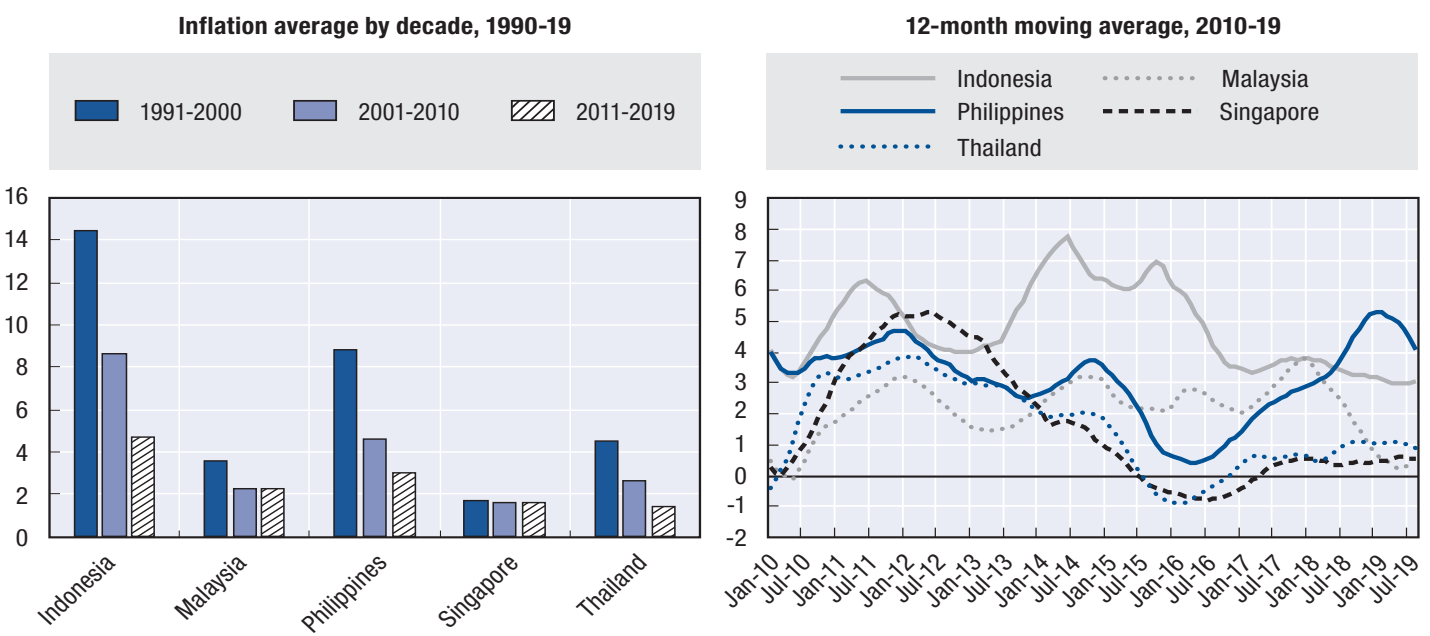

Note: The averages by decade are based on monthly data. Latest data are as of August 2019.

Source: OECD Development Centre based on data from CEIC and national sources.

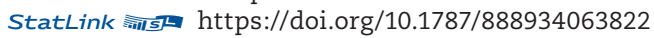




\section{Box 1.6. The Phillips curve: Thailand and Singapore}

First described by A.W. Phillips in 1958, the inverse relationship between unemployment and inflation, also known as the Phillips curve, has since been studied in detail. The reasoning is that when unemployment is low, with many unfilled jobs and few workers to fill them, employers will raise wages to fill positions, and vice versa when unemployment is high. This relationship is highly important since it reflects the trade-off between economic activity and price stability, two important objectives of monetary policy in many central banks. The Phillips curve has evolved since 1958 and is now based on the output gap (i.e. the difference between actual GDP growth and potential growth) and takes into account other factors such as inflation expectations and imported inflation.

In recent years, however, the Phillips curve appears to have flattened, meaning that the relationship between inflation and the unemployment gap seems to have weakened. Among the reasons cited for this trend is globalisation: since large companies in dominant positions can draw from labour forces across the world, employers might respond to tight labour markets by outsourcing production abroad rather than raising wages $(\mathrm{Ng}$, Wessel and Sheiner, 2018). Another possibility is a decrease in the bargaining power of trade unions, or of workers in general, leading to low wage growth irrespective of the state of the economy (Ng, Wessel and Sheiner, 2018). Finally, it could be that inflation expectations are so well anchored that it has become hard to make actual inflation move from the central bank's target (Yellen, 2017).

Figure 1.36. The Phillips curve for Thailand and Singapore

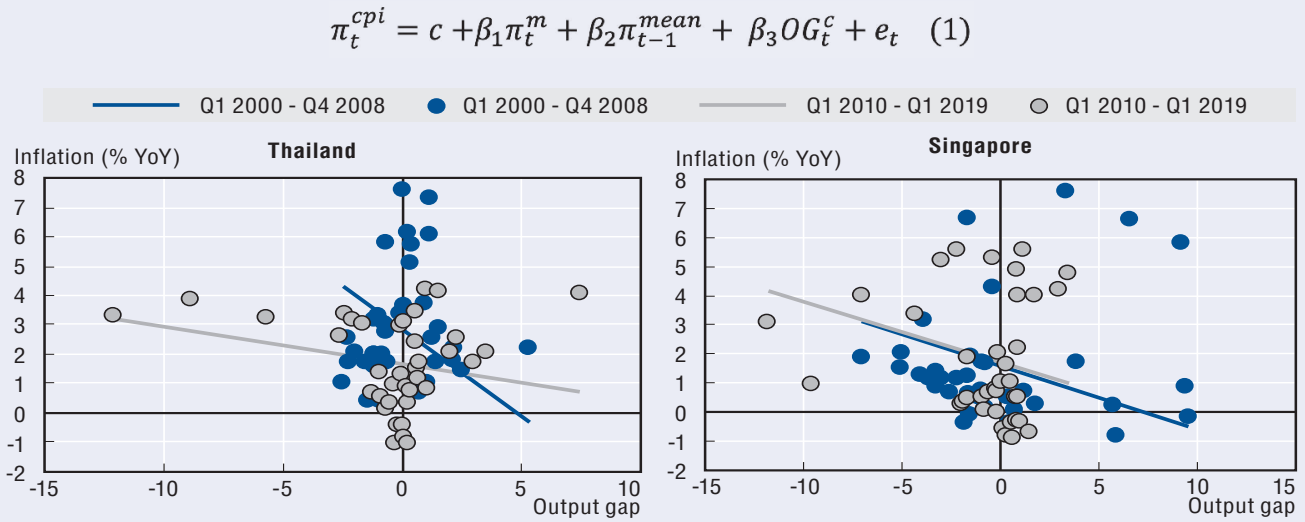

Note: The relative price of imports is measured as the import price deflator divided by the GDP deflator. In equation (1) $\pi_{t}^{c p i}$, stands for the CPI inflation rate; $\pi_{t}^{m}$ stands for the inflation of the relative price of imports; $\pi_{t-1}^{\text {mean }}$ stands for the average inflation rate of the 4 previous quarters at $\mathrm{t}-1$; and $\boldsymbol{O} G_{t}^{c}$ stands for the output gap. The output gap is measured as the difference between the real GDP growth rate and its trend component. The sample was split in two, from Q1 2000 to Q4 2008, and from Q1 2010 to Q1 2019; the estimation thus does not include the global financial crisis (GFC).

Source: OECD Development Centre based on data from CEIC and national sources.

StatLink ints https://doi.org/10.1787/888934063841

Figure 1.36 displays the Phillips curve for Thailand and Singapore under its augmented form, including the output gap, the relative price of imports and past inflation. In Thailand, the Phillips curve relationship appears to exist over both periods, but the curve appears to have flattened after the GFC. Indeed, over the initial period, inflation increased on average by 60 basis points (bps), while the output gap narrowed by 100 bps. In the following period, from 2010 to 2019, there was on average an increase of only 12 bps in inflation for a 100 bps decrease in the output gap. In Singapore, the Phillips curve has flattened earlier than in Thailand. The slope of the curve still decreased in the last 2 decades although the change has been marginal. Between 2000 and 2008, the rate of inflation in Singapore was found to increase on average by 22 bps when there is a 100 bps decrease in the output gap. This number is roughly similar for 


\section{Box 1.6. The Phillips curve: Thailand and Singapore (cont.)}

the post-crisis period, where the effect is estimated to be a 21 bps increase. The effect of change in the unemployment gap on inflation has thus remained stable in Singapore, even after controlling for external factors.

The coefficients associated with imported inflation - the inflation of the relative price of imports - were also significant for the period in both Thailand and Singapore. For Thailand, in line with the results of Manopimoke (2018), the effect of global factors on inflation has risen over time, and this will be reflected by this result as well. For Singapore, this will be partly due to monetary policy framework based on managing the exchange rate to control inflation.

Economists argue that the flattening of the Phillips curve in Southeast Asia is associated more with the increasing role of global factors (Dany-Knedlik and Garcia, 2018), including the "global output gap" (Manopimoke, 2015), than with the domestic factors seen in the euro area and the United States. The importance of inflation expectations is also increasing in determining price trends. Inflation expectations, even over the short term, are argued to be well anchored in Singapore and have become a strong predictor of near-term outcomes (Meng, 2016). In Thailand, the anchoring of inflation expectations is robust over the longer period, while expected and actual inflation in the short term tend to be affected by factors outside the purview of monetary policy (Direkudomsak, 2016). Interestingly, inflation in Thailand has treaded below the target band for most of the last five years under the framework instituted in 2015; this calls for closer inspection of the target-setting mechanism (Figure 1.37). Compared to the previous framework, which targeted core inflation, the change in the central bank's ability to adhere to its band is quite stark. The same can be said if recent performance is pitted against the targeting exercise in Indonesia and the Philippines (Figure 1.38). This may indicate a weakening of forward-looking dynamics in Thailand (Dany-Knedlik and Garcia, 2018), which could potentially lead to a de-anchoring of expectations.

Figure 1.37. Target inflation band and actual inflation in Thailand Percentage

Framework before 2015 targeting quarterly core inflation Targetband Core inflation 3-month moving average

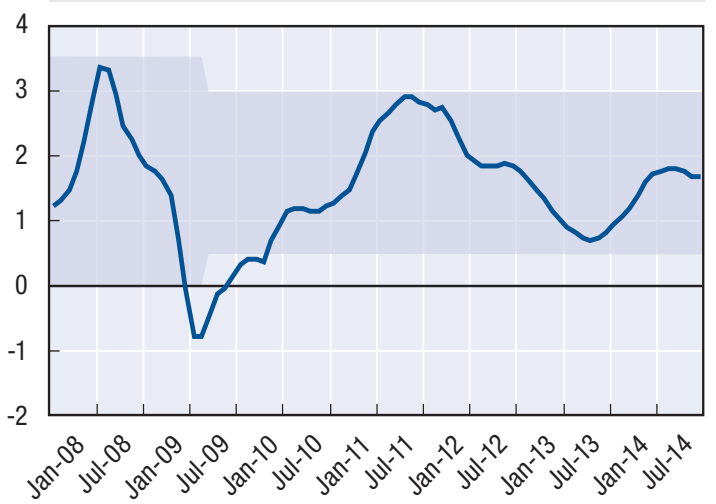

Framework since 2015 targeting annual headline inflation Target band Headline 12-month moving average

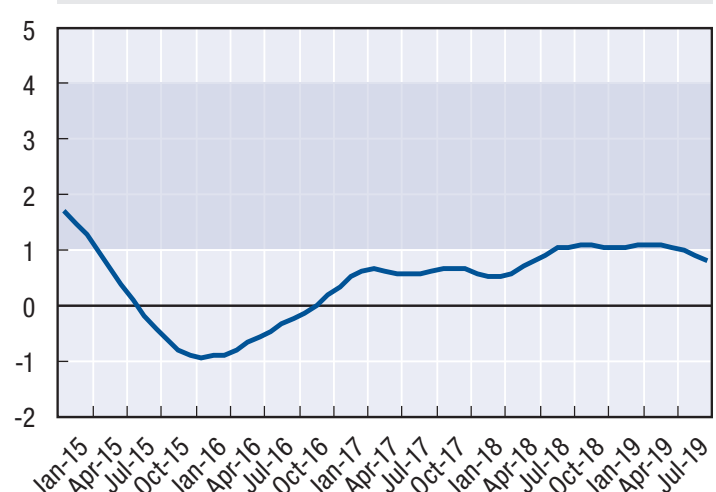

Source: OECD Development Centre based on data from CEIC and national sources.

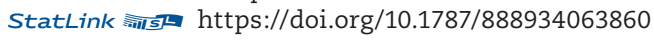


Figure 1.38. Target inflation band and actual inflation in Indonesia and the Philippines

Percentage

Indonesia

Target band

Headline 12-month moving average

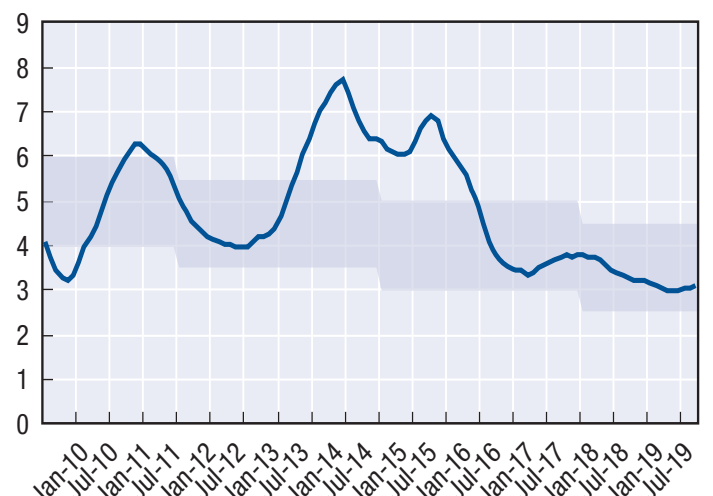

Philippines

Note: Indonesia and the Philippines target annual headline inflation rate.

Source: OECD Development Centre based on data from CEIC and national sources.

StatLink 啇Is https://doi.org/10.1787/888934063879

\section{Governments favour gradual and contained fiscal expansion}

As trade tensions deepen, the fiscal stance of many Emerging Asian economies is favouring contained expansion in the near-term overall. The potential impact of the trade tensions on public revenue in the near term is hard to pin down given the lack of clear direction in the ongoing negotiations.

Among Emerging Asian economies, Myanmar and Singapore look to boost spending in the near-term. The other countries in the region, though not committing to widen their budgetary gaps relative to output, move to improve their infrastructure stock as a way to grease their economies. Timely execution of spending plans remains a challenge in most cases in this respect, as does the ability of the authorities to ensure the quality of spending.

Indonesia's state budget deficit is on track to settle below 2\% of GDP in 2019 for the second year running, though the level could be a bit higher than the initial target of about $1.8 \%$, based on data as of June 2019. ${ }^{16}$ The increase in revenue intake is more subdued than in the same period in 2018 on deteriorating trade activity, while government expenditures are rising faster. In 2020, the deficit-to-GDP ratio is programmed to narrow further, but the government is looking to improve the quality of spending to push economic growth to $5.3 \%$.

In Malaysia, stronger revenue performance and a moderate increase in spending saw the country's annualised deficit ratio move onto a downward trajectory. Data through June 2019 indicate that the shortfall by the end of the year will likely fall below the target of $3.4 \%$ of GDP. However, with trade tensions putting pressure on revenues from external and domestic activities alike, the likelihood of meeting the 3\% threshold in 2020 is decreasing.

The annualised deficit ratio is similarly receding in the Philippines, standing well below the 3.2\% benchmark at the close of the first half. Expenditure has declined minimally year-to-date as of July 2019 owing to a delay in passage of the budget. This is matched by a modest increase in revenues despite the high base the previous year when 
the initial package of the tax reform law took effect. The target deficit ratio in 2020 is also set at $3.2 \%$, with infrastructure getting the biggest boost.

Thailand's annualised budget deficit ratio is following the same trend. Both revenue and expenditure have risen at a tempered pace as of July 2019. In fiscal year 2020 (ending September 2020), the programmed nominal budget gap is marginally larger than in fiscal year 2019 on the back of higher income-generating investment allocation, although the deficit ratio will likely remain unchanged.

Similarly, government efforts to rein in spending in Viet Nam, coupled with robust growth in revenues, drove down the annualised overall budget deficit ratio between 2018 and June 2019 by about one percentage point. Fiscal consolidation is set to continue, while the planned privatisation of public enterprises stands to provide a one-off boost on revenues should it gain traction.

In fiscal year 2018 (ending March 2019), Brunei Darussalam's deficit ratio fell to a single-digit level for the first time in four years on more disciplined spending. Nonetheless, the downward reversion in oil prices midway through 2019, the flare-up of trade tensions and the weakening global economy do not augur well for its revenue prospects moving forward.

Singapore has room to accommodate trade-induced friction in revenues, as well as a modest increase in spending in the coming months, and still meet its deficit ratio target of $0.7 \%$. Data as of the first quarter of fiscal year 2019 (ending March 2020) show that it recorded a small increase in operating revenues, while both operating and development expenditures declined.

Cambodia is heading for another year of budgetary surplus, contrary to our prior expectations. Spending in the first seven months of 2019 hardly increased, while the collection of tax and non-tax revenues rose briskly. The anticipation of slower growth in 2020, however, could reinvigorate public disbursements.

Fiscal consolidation is expected reduce Lao PDR's fiscal deficit ratio further in 2019 following a drop of roughly one percentage point in 2018 (World Bank, 2019b; IMF 2019). Moreover, to reduce its reliance on offshore debt markets, the government is considering issuing local-currency bonds to finance its deficits in the coming years.

Myanmar's budget deficit ratio is expected to come in under 5\% in fiscal year 2019 (ending September 2019). Expenditure was treading below target in the first half of the fiscal year (World Bank, 2019c). Nonetheless, it could rise markedly next year. The government has programmed a deficit ratio of about 5.9\% in fiscal year 2019-20.

China's budgetary deficit ratio, which has trekked upwards this year, is expected to widen further in 2020. Growth in expenditures has outpaced the growth in revenues, based on data as of June 2019. Tax collection has been meek following the tax cuts implemented this year. In line with its "proactive" fiscal policy, the government has pledged further decreases in business taxes, value-added tax and employers' social security contributions, among other measures.

India's final budget for fiscal year 2019-20 (ending March 2020) underlines the government's commitment to fiscal consolidation following the general elections. Fiscal data in the first quarter (ending June 2019) are in line with this objective, with spending increasing less than the same pace as revenues. The medium-term programme also supports moderation in the deficit ratio in the next fiscal year. Nonetheless, policy 
sentiment could change in the coming months given the sharpness of the decline in economic growth in Q1 2019.

Overall, this backdrop suggests that the general government fiscal balances of Emerging Asian economies will remain in good stead (Table A.3 in the Statistical Annex).

\section{Challenges to the Outlook}

Growth momentum in Emerging Asia is expected to slow slightly, though the overall growth will still be robust in the medium term. Countries in the region need to pay careful attention to several challenges. Coping with the ongoing trade tensions coupled by the weakening of the real sectors in advanced economies mentioned previously is one important challenge. Enhancing the effect of monetary policy on economic activity is another. The uncertainties surrounding Brexit and its aftermath as well as the volatile geopolitical situation in the oil producing countries, influencing oil prices are also a cause of concern. For this edition, the focus will be on the challenge of reinforcing the countries' disaster risk management at the local level, considering the susceptibility of the region to natural calamities and the rising socio-economic impact.

\section{Managing natural disaster risks: the importance of local initiatives}

Natural disasters can lead to heavy loss of life and community displacement. They slow economic growth and development by destroying infrastructure and other forms of physical capital, and by interrupting normal economic activity. Natural disasters, which disproportionately affect lower-income citizens, also threaten to reverse progress in poverty reduction. This section will consider the challenges facing Emerging Asia at a time when natural disasters are increasing in force and frequency due to climate change. It will look in particular at the importance of disaster risk management at the local level.

Emerging Asia is relatively exposed to the risk of natural disasters. The region experienced $25.9 \%$ of global disaster events between 2010 and 2017 and suffered $10.6 \%$ of the deaths and $22.7 \%$ of the damage they caused (CRED, 2019). Floods, storms and earthquakes are particularly serious threats in the region. Since 1950, it has experienced more than a thousand floods, nearly as many storms, more than 300 earthquakes and more than 700 other deadly disasters. And the pace is increasing: around $64 \%$ of these floods struck between 2000 and 2018, as did 51\% of the storms, 54\% of the quakes and $50 \%$ of the other disasters (Figure 1.39). The fact that the region sits on several tectonic plates contributes to the occurrence of earthquakes, volcanic eruptions and tsunamis. In addition, cyclonic storms, or typhoons, have increased in frequency and intensity due to climate change. 
Figure 1.39. Recorded occurrences of natural disasters in Emerging Asia, 19502018

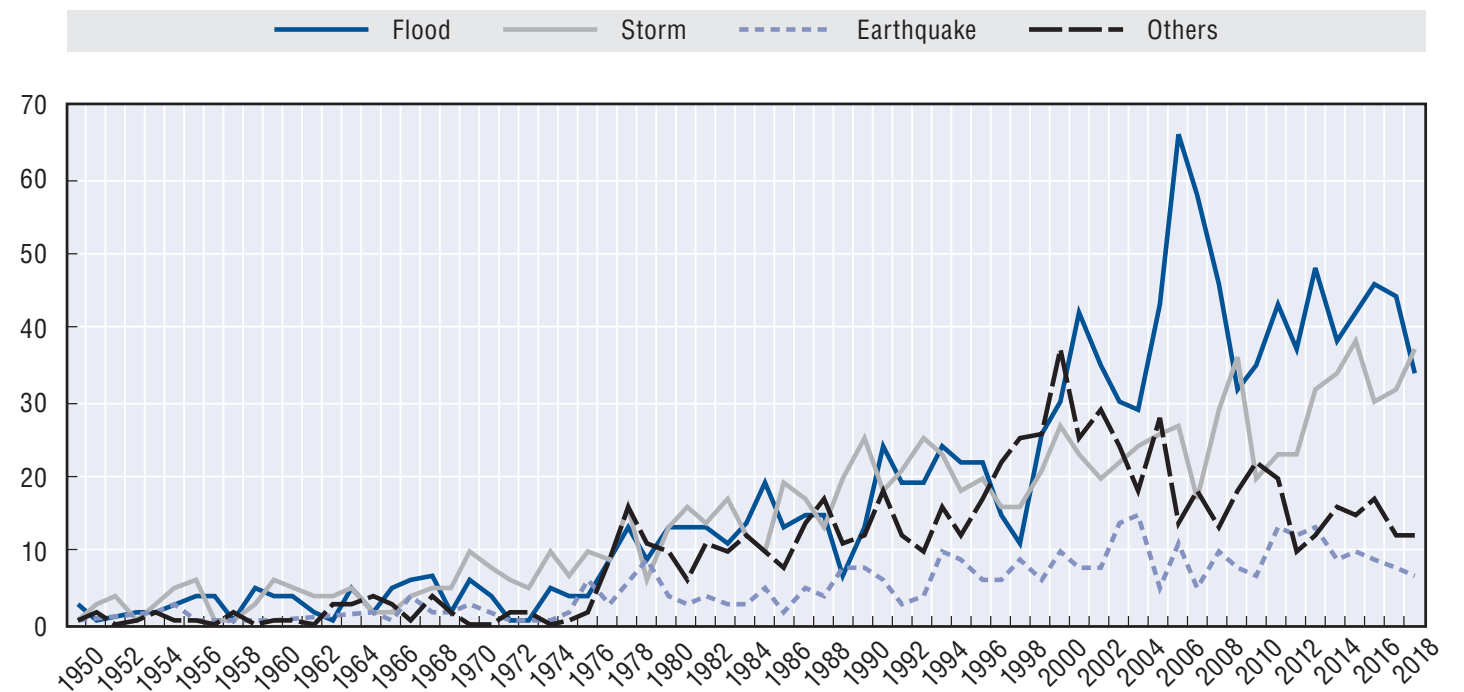

Note: Other disasters include drought, epidemics, volcanic activity, landslides, extreme temperatures, insect infestation, and wildfire. Events are categorised as disasters if they meet at least one of four criteria: 10 or more persons killed; 100 or more persons affected, injured or left homeless; an appeal for international assistance; or an official declaration of a state of emergency.

Source: CRED (2019), Emergency Events Database (database), Centre for Research on the Epidemiology of Disasters, Brussels.

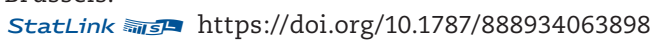

The scope of the problem can be appreciated by considering the many natural disasters that struck the region's countries during the summer of 2019. Cambodia, India, Lao PDR, Malaysia, Myanmar and Viet Nam experienced deadly floods; typhoons pounded China and Viet Nam; earthquakes struck Indonesia and the Philippines; and Thailand suffered a severe drought. Collectively, these disasters killed hundreds of people, displaced hundreds of thousands of families, destroyed homes and buildings, wiped out crops, damaged roads and forced schools to close, at a huge cost to the local economies. With the rate of natural disasters increasing in Emerging Asia, local initiatives are needed to help mitigate risks. Such initiatives could be in the form of flood risk-integrated water resources management, construction of disaster resilient multipurpose evacuation and community centres, mangrove afforestation to protect shorelines from storms and floods, and hydroponics projects that could generate incomes during normal times and maintain food security when disaster occurs.

Tsunamis are of particular concern in the region and could become more damaging in the future due to increased urbanisation along coastlines. Tsunami early warning systems are therefore of increasing importance in at-risk areas, although their deployment and maintenance are costly (Box 1.7). Protecting coral reefs is another way for local authorities to take action to reduce natural disaster risks. Coral reefs are present along the shores of several Emerging Asia countries, notably Indonesia, Malaysia and the Philippines (Box 1.8). Local indigenous knowledge could also play significant role in disaster risk management (DRM). Recent experience after major earthquakes and tropical cyclones in Asia demonstrates the role of local communities and indigenous groups as custodians of local knowledge and experience relevant to effective disaster risk management (ADB, 2019). Indeed, due to their long history in their home location, indigenous groups possess better information about severe yet low frequency events and catastrophes that are invisible to modern modelling techniques and short-time periods observations. 
Example of this local knowledge-based DRM is the traditional building techniques, such as the disaster resilient vernacular housing in Nepal. This housing technology, which incorporates local materials, labour and knowledge is a result of continuous trial and error and experiences of past disaster events. For instance, houses are constructed with raised platforms for flood resilience, or are constructed with earthquake resilient features such as symmetrical construction, high ductility and proper binding of housing units (Gautam et al, 2016).

\section{Box 1.7. The case for installing tsunami detection buoys}

Tsunamis have struck in Emerging Asia with an average frequency of 1.64 per year over the last 50 years. They have mostly occurred in Indonesia and the Philippines, but their effects can spread over several countries. Of the tsunamis recorded in Southeast Asia over the last 50 years, $65 \%$ caused no economic damage, while $7.3 \%$ caused damage in excess of USD 25 million (Figure 1.40). The most damaging, such as the 2004 tsunami resulting from the Sumatra-Andaman earthquake, caused 227899 fatalities and approximately USD 10 billion in damage.

Figure 1.40. Occurrence of tsunamis in Emerging Asia in the last 50 years Damage in current USD

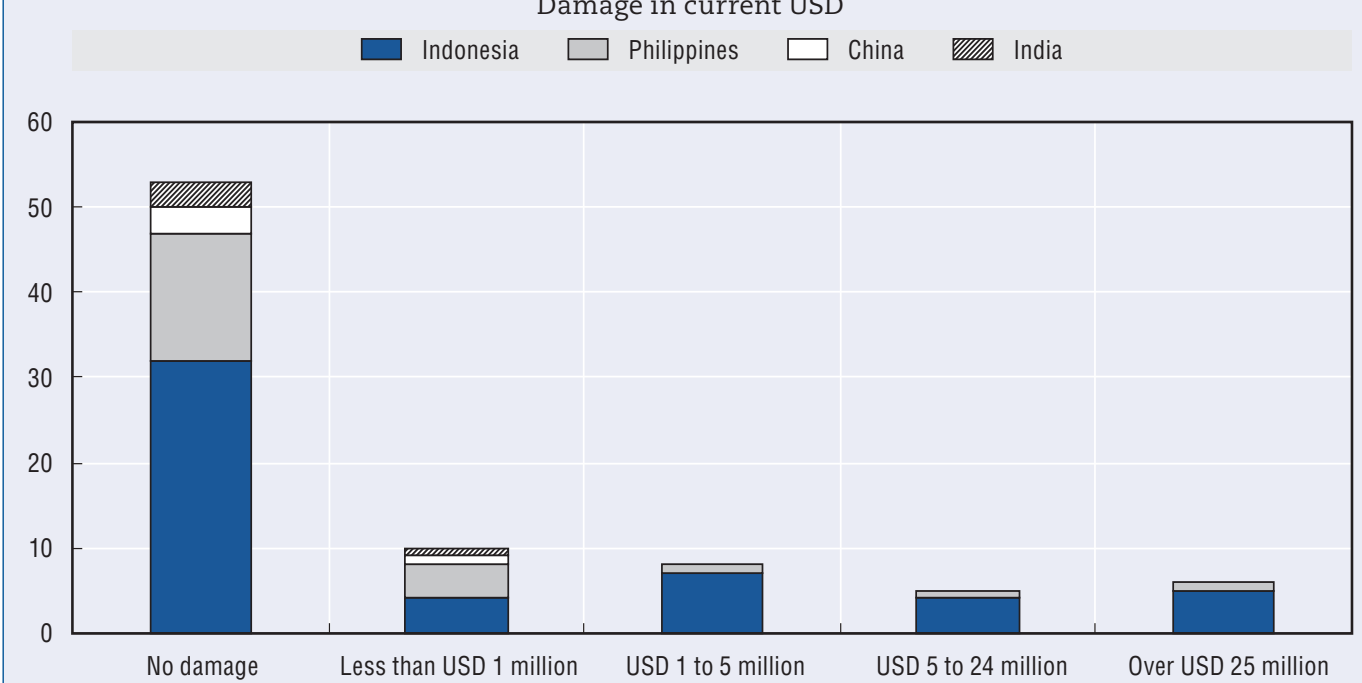

Source: National Oceanic and Atmospheric Administration (NOAA). StatLink नांड़ https://doi.org/10.1787/888934063917

A tsunami early warning system is composed of a network of seismographic centres, tide gauges, tsunami detection buoys, modelling capacity and a warning centre. The yearly cost of a comprehensive early warning system with five detection buoys is estimated at USD 795 million per year for a designed life of 15 years, including 20 tide gauges and communication links (Jin and Lin, 2011). Calculations show that the benefits of such systems greatly exceed the costs in terms of avoidable losses.

Currently, 11 detection buoys are operating in Southeast and South Asia, of which 6 belong to India, 2 to Thailand, 2 to Australia and 1 to the United States. Indonesia formerly had a network of 22 buoys, but due to vandalism and a lack of subsequent maintenance, none of them is currently functional (Lassa, 2018). Vandalism of buoys is usually associated with fishing activities, as moored devices attract fishing stock around them. Usual causes for damage are ship impacts, fishing nets entangling with mooring lines, ships using the buoys as anchors or theft of the electronics payload (WMO and IOC, 2011). 


\section{Box 1.7. The case for installing tsunami detection buoys (cont.)}

These events have a substantial impact on the cost of early warning systems for tsunamis. It is estimated that the cost of vandalism to the Indian Ocean Tsunami Warnings System between 2006 and 2010 exceeded USD 3.4 million (WMO and IOC, 2011). Nevertheless, investing in capacity and sustaining adequate funding is essential to provide economically viable, life-saving early warnings.

\section{Box 1.8. The economic benefits of coral reefs in reducing natural disaster risks}

Coral reefs can be used to provide early warnings. This is relevant for countries with lowlying tropical coasts fronted by coral reefs, which are widespread in Southeast Asia. Such countries are threatened by rising sea levels and wave-induced flooding. For instance, Indonesia's capital city, Jakarta, faces grave flood risks in the coming years since $40 \%$ of its surface area lies below sea level, with the city sinking further every year.

It is hard to predict flooding due to highly heterogeneous conditions along these coasts. However, new tools using reef data as well as water level and wave data have recently allowed experts to create early warning systems for floods and to map out locations vulnerable to rising sea levels (Pearson et al., 2017). A system called BEWARE estimates how different wave, water level and reef combinations can lead to flooding. The system can be used to make short- and long-term predictions of flooding, allowing for contingency planning by the authorities. At the same time, coral reefs can provide significant coastal protection to people and property. The reefs tend to act as natural, low-crested, submerged breakwaters, as they reduce the energy and size of waves. Economic analysis indicates that Southeast Asian countries reap significant benefits from having coral reefs on their shorelines.

Currently, the countries that benefit most from reef protection are Indonesia, the Philippines and Malaysia, while other Southeast Asian countries also benefit from the coral reefs along their shores (Table 1.4). Economic benefits for top-ranking countries exceed USD 500 million per year. Furthermore, if these reefs were to disappear, it is estimated that annual expected damages from flooding would double and that costs from frequent storms would triple (Beck et al., 2018).

Table 1.4. Economic benefits of coral reefs

\begin{tabular}{ccc}
\hline Global rank & Country & Annual averted damage in USD millions \\
\hline 1 & Indonesia & 639 \\
2 & Philippines & 590 \\
3 & Malaysia & 452 \\
11 & Viet Nam & 42 \\
12 & Myanmar & 33 \\
13 & Thailand & 32 \\
\hline
\end{tabular}

Source: Beck et al. (2018).

These protective features of coral reefs, and the benefits they create for tourism and fishing, make it essential for authorities to take them into account when formulating coastal development plans. Policies that promote sustainable coastal development also seem to be economically viable in the long run, although the benefits of coral reefs are hard to quantify. 


\section{Assessing the economic impact of natural disasters: Local data change the picture}

The magnitude of the economic shock and recovery associated with natural disasters depends on a wide range of factors. This heterogeneity in outcomes makes it hard to obtain a "one-size-fits-all" theory (Brata, de Groot and Zant, 2018). Existing literature tends to focus on local GDP growth to measure the impact of a natural disaster, and results indicate that economies recover quickly (Chhibber and Laajaj, 2008; Klomp and Valckx, 2014). However, gross regional domestic product (GRDP) measures might not necessarily reflect the real damages of natural disasters. Figure 1.41 is based on a principal component analysis approach, which captures movements in economic data related to naturaldisaster damage, for instance, energy consumption, healthcare provision, extended credit and agricultural output, factors that are not well reflected by GRDP. Indeed, GRDP data do not reflect the impact of natural disasters over time. The average growth rate after the disaster is higher than the average growth rate of these factors over the three years following the impact. For instance in the cases of the disasters of Dujiangyan, Lushan and Wenchuan in China and that of the state of Jammu and Kashmir in India, GRDP rose in the three years following the disaster, but the data of various other areas of the economy were still displaying negative growth on average.

Figure 1.41. Three-year average growth rates of selected variables after a natural disaster, based on principal component analysis (PCA) approach

Percentage change

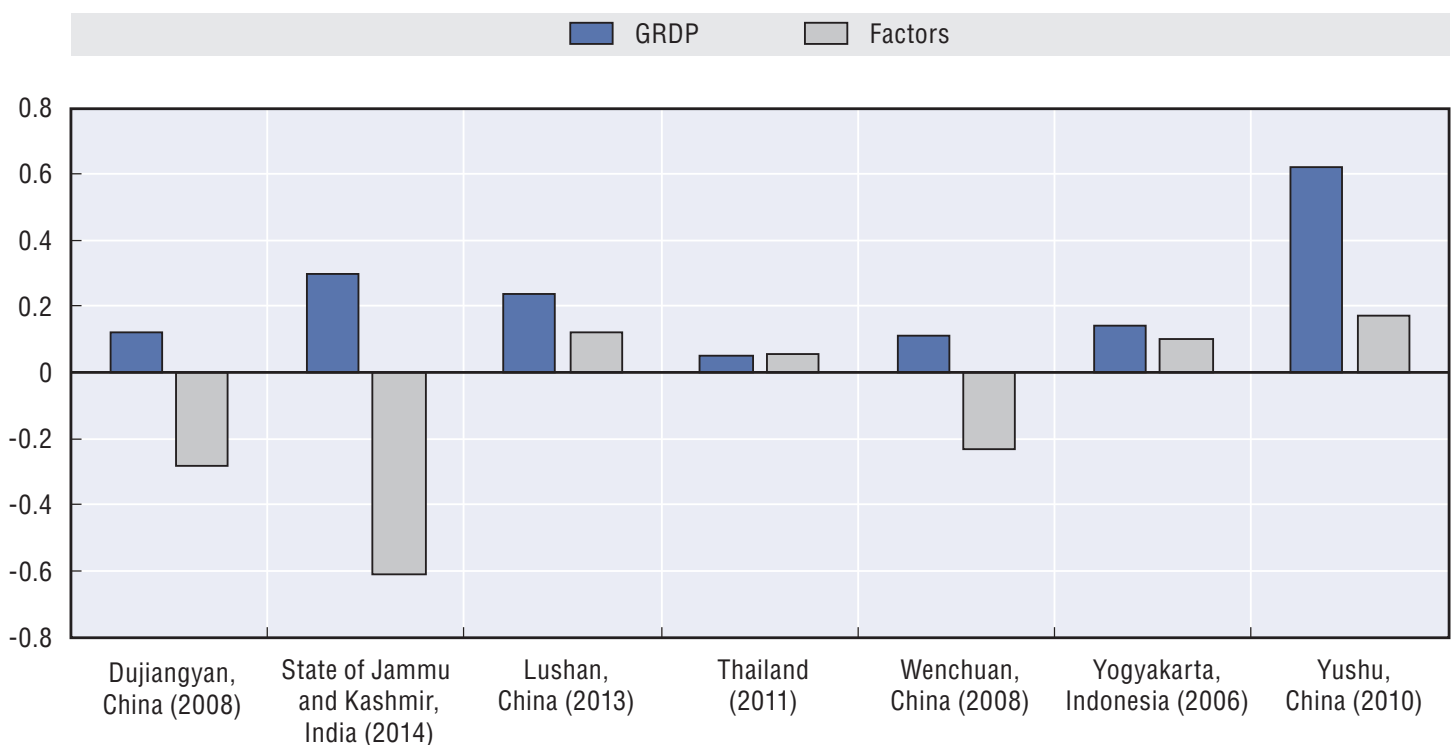

Note: Factors were obtained by extracting the first two principal components from regional time series data and averaging their growth. Between 14 and 38 variables were used per case and the data cover many areas of the economy, including public finance, labour and demographics, agriculture, manufacturing/industry, utilities, construction, logistics and communication, tourism, financial services, public services, consumer goods, entrepreneurship, trade.

Source: OECD Development Centre's calculation based on CEIC.

StatLink 需实 https://doi.org/10.1787/888934063936

\section{New approaches to disaster risk management are needed, including at the local level}

A more comprehensive approach to disaster management, where principles of disaster risk reduction (DRR) and climate change adaptation (CCA) are integrated with overall development, is recognised in major international agreements, such as the Sustainable 
Development Goals (SDGs), the Sendai Framework on Disaster Risk Reduction, the Paris Agreement on Climate Change and the New Urban Agenda.

Where cities are concerned, the broad concept of urban resiliency is advocated. This calls for a proactive and long-term stance on addressing disasters before they occur. Resiliency is underpinned by a scientific, systems-based perspective on urban development. The city is recognised as a dynamic, complex system with interdependent subsystems comprising legal, policy, institutional, economic, socio-cultural, environmental and physical infrastructures. Fundamental to achieving resiliency is understanding the interdependencies, risks and implications of long-term trends such as demographics and climate change.

\section{Institutional reforms can improve disaster risk management, both nationally and locally}

Current disaster prevention and management systems are similar in many Emerging Asian countries, although changes in legal frameworks, organisation and planning are ongoing (Box 1.9). Typically, interministerial co-ordination mechanisms are created in the office of the president or prime minister. These bodies formulate disaster management policies and guiding operations, although the basic responsibilities remain with line ministries, departments or government agencies. In China, for example, the National Committee for Disaster Reduction is headed by a vice-premier of the State Council. The body is composed of 33 ministries and departments, including relevant military agencies and social groups, and operates as an interagency co-ordination body for disaster reduction.

At the regional level, ASEAN plays a key role. Its members adopted the ASEAN Agreement on Disaster Management and Emergency Response (AADMER), a binding agreement that provides a regional framework for co-operation, co-ordination, technical assistance and resource mobilisation. All ASEAN member states have designated national focal points linked to AADMER and to the ASEAN Coordinating Centre for Humanitarian Assistance on Disaster (AHA Centre). Its focus is to send assistance as part of emergency response.

\section{Box 1.9. Recent reforms to disaster risk management frameworks at the national level}

The countries of Emerging Asia have been reforming their natural disaster risk management plans and initiatives, often after catastrophic national disasters. Regional and global frameworks have steered many countries to upgrade their disaster management frameworks to prioritise disaster prevention, risk reduction, cross-sectoral approaches and improving preparedness and response through international co-operation. In line with the convergence of DRR, CCA and urban resiliency, efforts continue to harmonise Nationally Appropriate Plans of Adaptation with natural disaster management strategic plans. The first are usually part of environment and climate change-related ministries, while the second are usually handled by defence and interior or local government ministries.

Indonesia, for example, is seeking to strengthen its decade-old national Disaster Management Law 2007/24 to address gaps in key issues around definitions, status and level of disasters, increased budgets and community participation. Its goal is to shift from a narrow focus on disaster response to comprehensive disaster risk reduction and linkages with climate change adaptation.

The Great Thailand Flood in 2011 was the impetus for the Thai government to adopt a more comprehensive national flood prevention and mitigation strategy and to enact improved budgetary measures to deal with future floods, including both structural and non- 


\section{Box 1.9. Recent reforms to disaster risk management frameworks at the national level (cont.)}

structural measures. Thailand's National Disaster Prevention and Mitigation Committee adopted the National Disaster Risk Management Plan (2015) to consolidate lessons learned from past disasters and to address gaps in the previous national strategy, the National Disaster Prevention and Mitigation Plan (2010-14). The goal was to promote more effective co-ordination and a shared vision among the more than 40 entities involved in disaster management. Together they would set concrete targets; improve harmonisation of data-sharing mechanisms, particularly for risk assessment; ensure greater clarity and consistency on roles, responsibilities and operational protocols; and raise public awareness and participation. The Ministry of Interior was chosen as a lead agency for this strategy. The idea was to increase the accountability and responsibility of subnational entities (provincial, municipal and district) in establishing institutions, plans and budgets for disaster management at the local level (Ministry of Interior, Thailand, 2011).

In the Philippines, the National Disaster Risk Reduction and Management (DRRM) Act of 2010 is undergoing a scheduled review that began in 2015. The act establishes a relatively advanced and multilevel disaster risk management system. A notable feature is its specific mandates on local-level disaster budgeting. A total of $30 \%$ of the National DRRM is allocated to a Quick Response Fund for stand-by relief and recovery funding; the remaining $70 \%$ is reserved for broader pre- and post- disaster measures such as risk reduction, preparedness and recovery activities. Additionally, the DRRM Act mandates local governments to establish Local DRRM Funds by setting aside at least $5 \%$ of their estimated revenue from regular sources (with allocations echoing the National DRRM of $30 \%$ for emergency response and $70 \%$ for pre-disaster activities). The Local DRRM Fund can also be used for the payment of premiums on disaster insurance.

Singapore's comprehensive approach to disaster risk reduction and long-term resiliency is contained in its Climate Action Plan. The Centre for Climate Research Singapore was established in 2015 to conduct cutting-edge research on future risks related to climate change in Singapore and Southeast Asia. Singapore adopted a whole-systems perspective on adapting to the changing climate. Its planned measures blend soft and hard interventions covering coastal protection; water resources and drainage; biodiversity and greenery; public health and food resilience; and buildings, networks and infrastructure.

Cambodia introduced a major shift in its national waste management institutional framework by adopting the Disaster Management Law (2015), which requires subsidiary legislation for the subnational committees it mandates. Such committees were provided for under previous regulations, but were only partially operational. The new law formally established the National Committee for Disaster Management as the lead national entity for disaster management. The framework is similar to Thailand's: it mandates the creation of subnational disaster management institutional arrangements and the continuing devolution of responsibilities from the national to the provincial to the district and village levels.

China has introduced a nationwide "sponge city" initiative to promote a new strategy for urban flood management. This initiative was inspired by developments in the United States, the United Kingdom, Australia and Singapore. It counters conventional flood management philosophy, which focuses on built infrastructure and engineering solutions. The initiative aims to transform China's urban infrastructure to incorporate natural processes as a key component of urban run-off control strategy. The initiative will promote significant investments so that cities will be constructed as "sponges" to soak up $70 \%$ of rainwater. Permeable materials and green spaces that absorb and filter rainfall will replace concrete surfaces, while drainage systems will separate waste water from rain water, which will then be stored and reused for street cleaning, plant watering and even firefighting (Yu and Jia, 2015). 
The integration of disaster risk reduction and climate change adaptation with urban development ultimately needs to be driven at subnational levels. But Emerging Asian cities are in the very early stages of integrating resiliency, DRR and CCA concepts into urban planning, with the support of national agencies as well as international organisations such as the Asian Development Bank, the World Bank and the Rockefeller Foundation through its 100 Resilient Cities initiative. While national policy frameworks acknowledge the need for risk reduction strategies and the importance of CCA, overlapping mandates from line ministries may continue to frustrate local governments, while a lack of details on subsidiary policy, funding and legal instruments is a significant barrier to implementation by actors on the ground in cities.

New approaches to disaster risk management can be adopted at the local level, however. For example, the Thai city of Nonthaburi mapped and identified at-risk areas along the Chao Phraya River and recognised the implications and elevated risks brought about by climate change. Although the city formulated long-term, engineering-based flood prevention plans (e.g. constructed riverside embankments, improved pumping systems and expanded drainage), implementation costs were prohibitive, and smaller upgrades to road and drainage infrastructure were made instead. During flooding in 2011, the city's high vigilance in monitoring rainfall and other hydrological information enabled the local government to predict the peak water level and its effects. As a result, Nonthaburi had ample time to prepare. It took action involving the establishment of a command centre for co-ordinating the flood response, the reassignment of local government officials to tasks related to the emergency, the recruitment and training of 1000 to 2500 volunteers to build sandbag walls around critical facilities and the accessing of reserve funds. As a result, the effects of the flooding in the municipality were minimised.

A similar example of resiliency-focused disaster risk management at the local level was the establishment in the Philippines in 1995 of the Albay Public Safety and Emergency Management Office (APSEMO), the country's first permanent disaster management office. Its goal was to integrate disaster risk reduction into the local government's development plans and programmes. The stability of dedicated staff and funding in a permanent office resulted in greater cost-effectiveness and has allowed for sustained engagement with and co-ordination among diverse stakeholders. This has enabled the local government units in Albay province to develop hazard maps, area- and hazard-specific plans, communitybased early warning systems and well-tested rescue and evacuation protocols (UNISDR, 2010). APSEMO demonstrated that a permanent and institutionalised disaster management office at the local or provincial level can reduce the challenges posed by political pressures and short election cycles. Albay province's advanced practices in mainstreaming DRR and CCA into long-term development have won national and global recognition. Under the Philippines' two national laws on DRR and CCA, the mandate to institutionalise a Disaster Risk Management Office at the subnational level was based on the "Albay Model".

Limited institutional capacities can impose constraints on the disaster risk management strategies of local governments. Cities often lack personnel and a well-resourced department or division dedicated to disaster management. The tendency of governments to transfer personnel is another factor. Since disasters may occur years or decades apart, the valuable know-how and experience of city personnel who responded to past disasters is seldom properly documented and transmitted to their successors. Electoral cycles reinforce a budgeting bias, not only towards more pressing priorities, such as basic infrastructure and interventions during and after disasters, but also away from pre-disaster measures, such as forecasting, risk assessment and mitigation (Hapeman, 2012). Local governments must be able to quickly access and spend emergency funds on rescue and relief operations, but many cities are severely incapacitated at this stage. Community involvement in all stages of disaster planning can help overcome some of these challenges (Box 1.10). 


\section{Box 1.10. Community involvement in disaster risk management}

Civil society and community-based groups can make important contributions to disaster risk management strategies. These groups should be involved in preparing for disasters, for example contributing to and verifying data on local conditions, assets and challenges. The effectiveness of flood warnings can be complemented and even improved by involving local communities in activities such as the creation of flood hazard maps, scientific monitoring and contingency planning. These activities help to increase understanding of the impacts of natural hazards. Public consultation also bolsters the credibility of risk assessment, builds trust, raises public awareness and helps to identify partners and volunteers for implementing plans.

By making use of local knowledge, community-led co-ordinating mechanisms are often cost-effective as well. During and after a disaster, national and international stakeholders often rush in to the affected areas without sufficient co-ordination and understanding of local needs and circumstances. The channelling of assistance by external actors also tends to be uneven due to the influence of organisational biases and geopolitical interests. Community-led co-ordinators can bridge the gaps among external stakeholders and may help to ensure a more equitable distribution of resources. Some critics of community engagement worry about the risk of deferring responsibilities from within the government to external stakeholders. Participatory activities for disaster management must therefore be undertaken to ensure that roles and responsibilities are clearly and fairly balanced among all parties, and that sufficient attention is given to the communities at highest risk.

Local-level natural disaster risk management is particularly critical in cities. With their concentration of people, wealth and construction, urban areas face unique challenges in managing disaster risks. This calls for appropriate policy responses. New approaches to institutional arrangements, financing and the collection and use of data are priorities in this regard. Policy makers should also consider how cities are indirectly affected when natural disasters in rural areas contribute to rural-urban migration (Box 1.11). Natural disasters also result in displacement of people in the affected areas during pre-emptive clearing operations and post disaster relocations. It is estimated that around 13 million people have been displaced by environmental calamities in 2018 alone, of which China and the Philippines accounted for 7.6 million (IDMC and NRC, 2019). Such magnitude of movement of people, which coul ultimately lead to forced migration, thus, necessitates strategic planning. In doing so, UNHCR (2018), which mapped the current international mechanisms to address displacement owing to climate change, highlighted the importance of constant needs assessment and engagements with affected communities to make the existing guidelines more responsive to the ground-level conditions.

\section{Box 1.11. The effect of natural disasters on internal migration}

Migrants often move voluntarily to cities in search of better job opportunities, but a significant fraction of rural-urban migrants are forced out of rural areas due to disasters that damage livelihoods and impose high recovery costs. Millions of people are internally displaced in Emerging Asia each year as a result of natural disasters (Figure 1.42). From 2013-18 in China, an average of 4.8 million people per year were displaced due to disasters. In the Philippines, the figure was lower, at 4.5 million, but this represented the region's highest share of displaced population, 


\section{Box 1.11. The effect of natural disasters on internal migration (cont.)}

at $4.5 \%$. Internal displacement due to disasters was highest in the Philippines in 2013, when the country was hit by Typhoon Haiyan and 7 million people left home. Internal displacement due to natural disasters in East Asia and Pacific is relatively high compared with other parts of the world (IDMC, 2018).

Figure 1.42. Annual new internal displacement associated with disasters, 2013-18 average

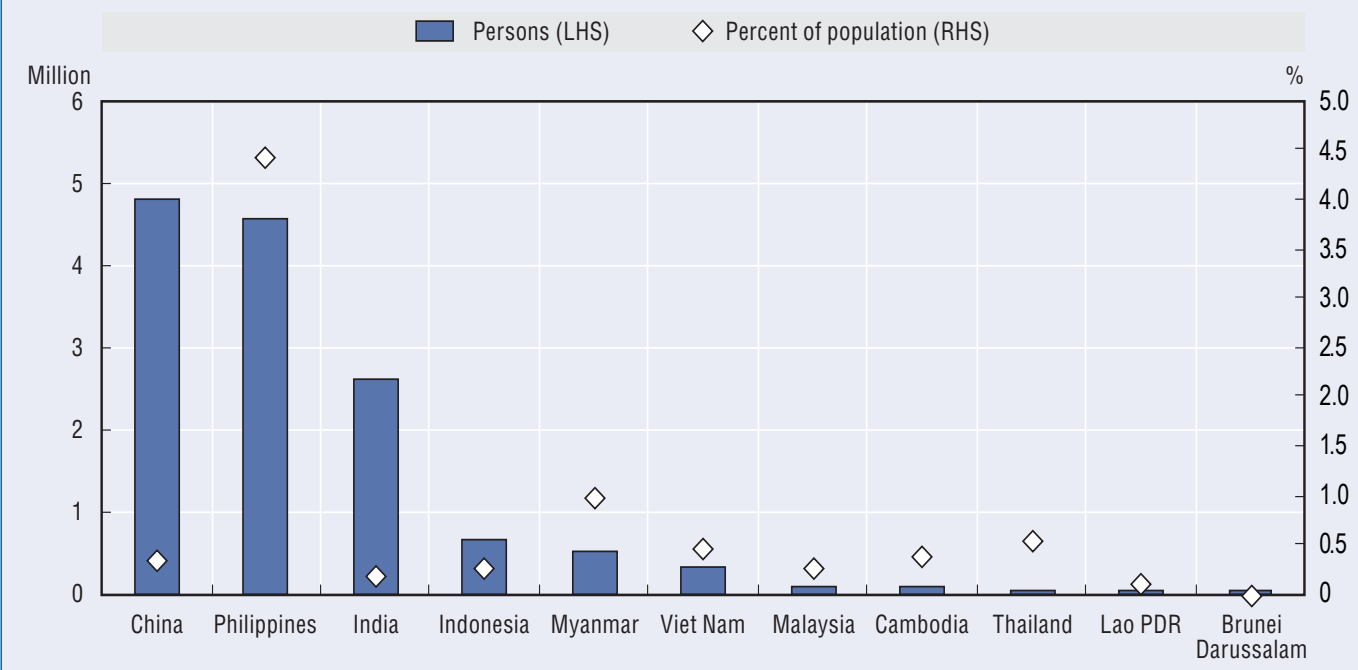

Source: World Bank (2019d), World Development Indicators (database).

StatLink ints' https://doi.org/10.1787/888934063955

Working-age members of families affected by disasters face pressure to look for jobs in nearby cities and megacities. In Viet Nam, for example, around 17000 people, or one in 100 residents, left Kiên Giang province during and after the drought of 2016. Rural to urban displacement carries its own risks, however, and migrants may face unequal access to social services, utilities, land and housing. These impede poor families' access to benefits such as free health care and primary education. Unregistered and temporary migrants may be unable to access any services at all. Large-scale government initiatives may be needed to reduce the vulnerability of people living in areas with high exposure to hazards. At the same time, local governments of big cities may have to do more to strengthen social protections and support for unregistered migrants and to reform administrative systems to close the gap between registered citizens and unregistered migrants.

\section{Smart approaches to early warning systems strengthen disaster risk management}

Technology is central to the innovative approaches to disaster risk management that are needed in the region to monitor, assess and respond to threats. Smart disaster management allows the use of real-time data handling through the extensive deployment of devices such as remote meteorological sensors and cameras to monitor environmental parameters. As costs fall, the use of these tools spreads. However, analytical capabilities are also needed (Graham, 2017). Smart approaches allow governments, businesses and citizens to collect, store, share, combine and analyse vast amounts of disaster-related data more cheaply and easily, and thus to better understand the risks and characteristics of hazards (Table 1.5). 
Table 1.5. Conventional vs. smart approaches to disaster risk management

\begin{tabular}{|c|c|c|}
\hline Aspect & Conventional approaches & Smart approaches \\
\hline $\begin{array}{l}\text { Data availability } \\
\text { and use }\end{array}$ & $\begin{array}{l}\text { Manual formats } \\
\text { Data usefulness is limited by timeliness and accuracy } \\
\text { constraints }\end{array}$ & $\begin{array}{l}\text { Digital formats } \\
\text { Live or nearly live and widely shared data } \\
\text { Effective and targeted early warning }\end{array}$ \\
\hline Infrastructure & $\begin{array}{l}\text { Employed as a substitute for ecological and social systems } \\
\text { Defensive and not reflecting projected threats due to climate } \\
\text { change } \\
\text { Single-use design }\end{array}$ & $\begin{array}{l}\text { Employed as a complement to ecological and social systems } \\
\text { Adaptive, taking into consideration the effects of climate change } \\
\text { Multi-purpose design }\end{array}$ \\
\hline Institutions & $\begin{array}{l}\text { Silos prevent data sharing } \\
\text { Policies and actions are fragmented across sectors and } \\
\text { organisations }\end{array}$ & $\begin{array}{l}\text { Data is developed and used collaboratively } \\
\text { Integrated and co-ordinated policies across sectors and } \\
\text { organisations }\end{array}$ \\
\hline Incentives & Short-term orientation & Long-term orientation \\
\hline
\end{tabular}

Source: OECD Development Centre.

Early warning systems in particular will benefit from the application of smart approaches. A disaster early warning system is an integrated system of hazard monitoring, forecasting and prediction; disaster risk assessment; communication; and systems and processes for preparedness activities. These enable individuals, communities, governments, businesses and others to take timely action to reduce disaster risks before hazardous events occur. An effective early warning system should include four interrelated key elements: disaster risk knowledge based on the systematic collection of data and disaster risk assessments; detection, monitoring, analysis and forecasting of hazards and possible consequences; dissemination and communication of authoritative, timely, accurate and actionable warnings of the likelihood and impact of disasters by an official source; and preparedness at all levels to respond to the warnings (UNISDR, 2017).

Early warning systems are widely recognised as a major component of disaster risk reduction and have been highlighted in two major international initiatives for disaster risk management: the Hyogo Framework for Action 2005-15 and the Sendai Framework for Disaster Risk Reduction 2015-30 (Box 1.12). Hallegatte (2012) estimated that, on an annual basis in Europe, hydro-meteorological information and early warning systems helped save hundreds of lives, avoided asset losses of up to EUR 2.7 billion and produced up to EUR 34 billion of additional benefits through the optimisation of economic production in weather-sensitive sectors such as agriculture and energy.

\section{Box 1.12. Early warning steps in the Hyogo Framework for Action 2005-15}

The "Hyogo Framework for Action 2005-15: Building the Resilience of Nations and Communities to Disasters" was the first attempt to explain and describe the work required from different sectors and actors to reduce disaster losses. It was adopted in January 2005 with a goal of substantially reducing disaster losses by 2015, and was signed by 168 governments at the World Conference on Disaster Reduction held in Kobe, Hyogo, Japan. The Hyogo Framework for Action proposes five key activities related to early warning systems:

- Develop early warning systems that are people centred, in particular systems with warnings that are timely and understandable to those at risk, and that take into account the demographic, gender, cultural and livelihood characteristics of the target populations, including guidance on how to act on warnings. These systems should support effective operations by disaster managers and other decision makers. 
Box 1.12. Early warning steps in the Hyogo Framework for Action 2005-15 (cont.)

- Establish, periodically review and maintain information systems as part of early warning systems to ensure that rapid and co-ordinated action is taken in cases of alert or emergency.

- Establish institutional capacities to ensure that early warning systems are well integrated into governmental policy and decision making, as well as emergency management systems at the national and local levels, and that they are subject to regular testing and performance assessments.

- Implement the outcome of the Second International Conference on Early Warning held in Bonn, Germany, in 2003. This includes strengthening co-ordination and co-operation among all relevant sectors and actors in the early warning chain to achieve fully effective early warning systems.

- Implement the outcome of the Mauritius Strategy for the further implementation of the Barbados Programme of Action for the sustainable development of small island developing states. The key is establishing and strengthening effective early warning systems as well as other mitigation and response measures.

Source: UNISDR (2007), Hyogo Framework for Action 2005-2015: Building the Resilience of Nations and Communities to Disasters, https://www.unisdr.org/we/inform/publications/1037.

The quality, timeliness and lead times of disaster early warnings have improved in recent decades thanks to scientific and technological advances, and especially to the rapid development of information and communication technology. However, there is still a large technological gap between early warning systems used by developing countries and those in developed countries. Upgrading the early warning systems of all developing countries to match developed country standards could generate USD 300 million to USD 2.0 billion through disaster loss reduction. It could also save tens of thousands of lives globally every year (Hallegatte, 2012).

\section{Mobile phones are helping governments alert people to disaster risks}

Mobile phones have been gaining importance in disaster risk mitigation. For an early warning to be effective, it needs to be communicated quickly, and mobile phones enable instant large-scale warnings. In the Philippines, for instance, the Free Mobile Disaster Alert Act of 2014 mandated all telecom operators to send free mobile alerts from authorised government agencies in times of disaster. The mobile alert includes information on how to prepare for a hazard event and on evacuation centres, relief sites and pick-up points. It also provides the contact information of relevant authorities and sends updates from the state weather bureau. The system was used in 2016 when Typhoon Nina made landfall, with the phone operator Globe sending out 11 different text messages warning its customers of potential dangers (Globe, 2016).

Another example is Indonesia's AtmaGo, an app that provides early warnings and allows sharing of real-time information on disaster risk reduction. A recent study estimated that this app could reduce property damage in Jakarta by USD 106 million per year, on the assumption that effective action can reduce damage by $50 \%$ and that $10 \%$ of the population uses the app (CIPG, 2018). This result, which is also based on survey results showing that $30 \%$ of the app users react to warnings (CIPG, 2018), supports the view that the usage of mobile phones has improved disaster risk mitigation. Toya and Skidmore (2018) found that a one-standard-deviation increase in cell phone usage reduced fatalities 
relative to the number of people affected by $47 \%$ on average. This number rises to $69 \%$ for geologic events such as earthquakes and tsunamis, for which in the past there was usually no early warning.

Mobile phones have been found to be most effective in mitigating natural disaster risk in developed countries, where infrastructure and emergency assistance to allow for a response are more readily available.

\section{The role of schools in education for disaster preparedness}

The success of early warnings in preventing fatalities and damage from natural disasters depends on the ability of people to react appropriately. It is therefore essential that people be provided with training on how to react in the event of an emergency. Disaster education is also needed (Box 1.13). Incorporating disaster risk reduction strategies into school curricula is the strongest method for passing on natural disasterrelated reflexes to the largest share of the population (OECD, 2011). This is because what is learned during childhood becomes incorporated into collective knowledge and is carried into future decision making. The inclusion of DRR in formal school curricula is a key element of the Hyogo Framework for Action, where it stands as a core indicator of successful implementation. Furthermore, natural disaster awareness education can build public support for risk reduction through complementary strategies such as land use planning, construction standards, catastrophe insurance and institutional emergency response (OECD, 2011). In Emerging Asia, most countries have incorporated disaster risk reduction into school programmes at all levels, although progress can still be made on the practicality of the knowledge provided.

Disaster preparedness can be included in curricula via existing courses at all grade levels or through stand-alone courses. In Cambodia, for instance, disaster preparedness is included in the subject geography and earth studies, where pupils learn about the different types of natural hazards and how to mitigate them (UNESCO and UNICEF, 2012). The teaching about disaster risks also includes informal approaches such as special assemblies, drills, projects, competitions, festivals and exhibitions (OECD, 2011). Since teachers tend to be overburdened, programmes that are successful include support materials for both curricula and teachers, and formally incorporate these materials into national curricular guidelines (OECD, 2011). At a national level, streamlined material with standardised language, including advice on readiness and risk reduction strategies, helps to disseminate a clear and coherent message. In India, under the National School Safety Project, teachers are provided with a standardised training module for the distribution of disaster preparedness kits, an effective strategy for creating a culture of safety (NDMA, 2019).

\section{Box 1.13. Education to prepare for natural disasters}

Upgrading early warning technology to improve accuracy and assessment speed is not enough. Governments must also provide training and education so that people can understand warnings when disasters hit and take appropriate action to reduce the risk of personal injury and loss of life. This would also minimise damage to assets and property. While technology to detect natural disaster risks has improved in Emerging Asia, the main bottlenecks in disaster reduction are often linked to a lack of rapid and reliable dissemination of warnings to all people at risk and to gaps in building the capacity of communities to act appropriately (UNESCAP, 2015).

Japan's experience in disaster education can offer developing countries in the region valuable lessons. Situated in a seismically active area prone to natural disasters such as earthquakes, tsunamis and typhoons, Japan has a long history of disaster education. Such 


\section{Box 1.13. Education to prepare for natural disasters (cont.)}

education takes two forms: publicly funded and voluntarily organised (Kitagawa, 2016). Public disaster education is carried out by the Japanese government and its agencies at the national, prefecture and municipal levels, as well as by 24 government organisations and 56 public corporations. The framework is the Basic Disaster Management Plan. It offers detailed guidance at different government levels so that region-specific disaster risks and local needs can be taken into consideration. Disaster education is also incorporated into school curricula under the School Health and Safety Act. All school staff must receive relevant training. Local neighbourhoods have traditionally called on volunteers to organise disaster education. Most of the wards in cities and towns have a volunteer disaster prevention organisation called Jishu-bosai-soshiki led by retired firefighters and community leaders. These volunteer organisations collaborate with municipal governments to arrange awareness-raising events as well as disaster drills for their communities.

\section{Notes}

1. The data cut-off date is 1 October 2019 unless stated otherwise.

2. Growth rates are on a year-on-year basis unless stated otherwise.

3. Private consumption includes non-profit institution consumption and is used interchangeably with the term "household consumption" in certain cases.

4. The data on wage per worker only cover the manufacturing sector.

5. It is estimated that the value added of Malaysia's digital economy grew $9 \%$ annually from 2010 to 2016, which is faster than the overall economic growth during the period (Lim, 2019).

6. The reference data are based on World Bank (2019a).

7. In April 2019, five international insurance firms were given licences to offer a wholly foreignowned life insurance option (U Thaung Tun, 2019).

8. Notwithstanding the aggregate trend, sectoral data show that investment in mining has surged while investment in services has been increasing robustly.

9. According to ILO (2018), "more than $51 \%$ of the total employed in India, as per 2011-12 data, were self-employed, and $62 \%$ of wage earners are employed as casual workers". WEF (2019) puts the share of informal employment at $80 \%$.The median age of the population in India is less than 28 years in 2016 .

10. Public banks hold more than two-thirds of the deposits of the system.

11. The central bank mandates banks with more than 20 branches to allocate $40 \%$ of their credit to priority sectors. These include agriculture; micro, small and medium enterprises; export; credit; education; housing; social infrastructure; renewable energy; and others, as defined in the Master Direction (Reserve Bank of India, 2016 and 2018).

12. Between April 2018 and September 2019, China lodged at least four dispute consultations at the WTO against the new US tariffs. In July 2018, the United States lodged a dispute consultation at the WTO against China on additional duties (WTO, 2019).

13. In December 2018, the United States published proposed controls on exports of emerging technologies to China. In May 2019, Huawei was placed on the entity list. In June 2019, the United States added five organisations from China to the entity list. In August 2019, the United States extended the temporary general licence of Huawei and its affiliates by 90 days, deferring the ban in the process, though it added a number of these affiliates to the entities list. And in October 2019, the United States added 28 organisations from China to the entity list.

14. Production data is sourced from FAO (2019).

15. Monetary Authority of Singapore (2018), Direkudomsak (2016) and Dany-Knedlik and Garcia (2018) have similar findings from different approaches.

16. In this section, ratios are with respect to GDP unless otherwise stated. Budget balances include spending on interest payments. Annualised ratio refers to the ratio of the 4-quarter moving sum of the numerator and the denominator. 


\section{References}

ADB (2019), Asian Development Outlook 2019: Strengthening Disaster Resilience, Asian Development Bank, Manila, http://dx.doi.org/10.22617/FLS190070-3.

Baker, S.R., N. Bloom and S.J. Davis (2019), "Measuring Economic Policy Uncertainty", Trade Policy Uncertainty Data, Economic Policy Uncertainty, www.policyuncertainty.com.

Beck, M.W., I.J. Losada, P. Menéndez, B.G. Reguero, P. Díaz-Simal and F. Fernández (2018), “The global flood protection savings provided by coral reefs", Nature Communications, Vol. 9/1, p. 2186, https:// www.nature.com/articles/s41467-018-04568-z.

BIS (2019), Effective exchange rate indices (database), Basel, https://www.bis.org/statistics/eer.htm.

Bown, C. (2019), “Trump's Mini-Trade War with India”, PIIE Trade and Investment Policy Watch, Peterson Institute for International Economics, Washington, DC, https://www.piie.com/blogs/trade-andinvestment-policy-watch/trumps-mini-trade-war-india.

Bown, C., E. Jung and E. Zhang (2019), "Trump Has Gotten China to Lower Its Tariffs. Just Toward Everyone Else", PIIE Trade and Investment Watch, Peterson Institute for International Economics, Washington, DC, https://www.piie.com/blogs/trade-and-investment-policy-watch/trump-hasgotten-china-lower-its-tariffs-just-toward.

Brata, A.G., H.L. de Groot and W. Zant (2018), “The Impact of the 2006 Yogyakarta Earthquake on Local Economic Growth", Economics of Disasters and Climate Change, Vol. 2/2, pp. 203-224, https://doi. org/10.1007/s41885-018-0026-5.

Chhibber, A. and R. Laajaj (2008), "Disasters, climate change and economic development in subSaharan Africa: Lessons and directions”, Journal of African Economies, Vol. 17, pp. 7-49, https://doi. org/10.1093/jae/ejn020.

Ciccarelli, M. and C. Osbat (eds.) (2017), "Low inflation in the euro area: Causes and consequences", Occasional Paper Series, No. 181, European Central Bank, Frankfurt, https://www.ecb.europa.eu/pub/ pdf/scpwps/ecbop181.en.pdf.

CIPG (2018), Can Mobile Phones Improve Disaster Preparedness? A Survey-Based Analysis on the Impact of AtmaGo, Centre for Innovation Policy and Governance, Jakarta, https://www.academia. edu/37730929/Can_Mobile_Phones_Improve_Disaster_Preparedness_A_Survey-Based_Analysis on the Impact_of_AtmaGo.

CRED (2019), Emergency Events Database (database), Centre for Research on the Epidemiology of Disasters, Brussels, https://www.emdat.be/.

Dany-Knedlik, G. and J.A. Garcia (2018), "Monetary policy and inflation dynamics in ASEAN economies", IMF Working Paper, WP/18/147, International Monetary Fund, Washington, DC, https:// www.imf.org/ /media/Files/Publications/WP/2018/wp18147.ashx.

Direkudomsak, W. (2016), "Inflation dynamics and inflation expectations in Thailand", BIS Working Paper, No. 89y, Bank for International Settlements, Basel, https://www.bis.org/publ/bppdf/ bispap89y.pdf.

FAO (2019), "GIEWS country brief Myanmar", Global Information and Early Warning System on Food and Agriculture, Food and Agriculture Organization of the United Nations, Rome, https://reliefweb.int/ sites/reliefweb.int/files/resources/MMR_12.pdf.

Fusion Media Ltd (2019), Government Bond Yields and Stock Market Indices (database), accessed 1 October 2019, www.investing.com.

Gale, F., C. Valdes and M. Ash (2019), "Interdependence of China, United States, and Brazil in Soybean Trade", A Report from the Economic Research Service, United States Department of Agriculture, https:// www.ers.usda.gov/webdocs/publications/93390/ocs-19f-01.pdf?v=3881.

Gautam, D., J. Prajapati, K. Valencia Paterno, K. Kumar Bhetwal and P. Neupane (2016), “Disaster resilient vernacular housing technology in Nepal", Geoenvironmental Disasters, Vol. 3, Article no. 1, SpringerOpen, https://doi.org/10.1186/s40677-016-0036-y.

Globe (2016), "11 SMS alerts sent out to customers prior to Typhoon Nina's landfall", Globe Telecom, Taguig, Philippines, https://www.globe.com.ph/about-us/newsroom/corporate/globe-11-smsalerts-sent.html (accessed 30 January 2019).

Graham, K. (2017), "Using IoT in flood management can save lives", Digital Journal, Toronto, http:// www.digitaljournal.com/tech-and-science/technology/using-the-iot-in-flood-management-cansave-lives/article/503139.

Hallegatte, S. (2012), "A cost effective solution to reduce disaster losses in developing countries: hydrometeorological services, early warning, and evacuation", Policy Research working paper, World Bank, Washington, DC, https://openknowledge.worldbank.org/bitstream/handle/10986/9359/WPS6058. pdf? sequence $=1$ \&isAllowed $=y$. 
Hapeman, K. (2012), "The effects of politics on disasters: Lessons learned from Bangladesh", casespecific briefing paper, University of Denver, https://www.du.edu/korbel/crric/media/documents/ katie_hapeman1.pdf.

IDMC (2018), Global Report on Internal Displacement (GRID) 2018, Internal Displacement Monitoring Centre, Norweigian Refugee Council, Geneva, http://www.internal-displacement.org/globalreport/grid2018/downloads/2018-GRID.pdf.

IDMC and NRC (2019), "More than 13 million people internally displaced across Asia in 2018”, Internal Displacement Monitoring Centre and Norweigian Refugee Council, Geneva, https://reliefweb.int/ sites/reliefweb.int/files/resources/2019-grid-pressrelease-asia-en.pdf.

ILO (2018), "ILO: Strong wage policies are key to promote inclusive growth in India", India Wage Report, International Labour Organization, Geneva, https://www.ilo.org/newdelhi/info/public/pr/ WCMS 638937/lang--en/index.htm.

IMF (2019), “Lao People's Democratic Republic: 2019 Article IV Consultation”, IMF Country Report No. 19/267, International Monetary Fund, Washington, DC, https:/www.imf.org/ /media/Files/ Publications/CR/2019/1LAOEA2019002.ashx.

Jin D. and L. Lin (2011), "Managing tsunamis through early warning systems: A multidisciplinary approach", Ocean \& Coastal Management, Vol. 54, pp. 189-199, Elsevier, Amsterdam, https://doi. org/10.1016/j.ocecoaman.2010.10.025.

Keimling, N. (2019), Stock Market Valuation, July 2019, StarCapital, Oberursel, Germany.

Kitagawa, K. (2016), “Preparing for the worst: Disaster education in Japan,” East Asia Forum, http:// www.eastasiaforum.org/2016/07/01/preparing-for-the-worst-disaster-education-in-japan/.

Klomp, J. and K. Valckx (2014), "Natural disasters and economic growth: A meta-analysis", Global Environmental Change, Vol. 26, pp. 183-195, Elsevier, Amsterdam, https://doi.org/10.1016/j. gloenvcha.2014.02.006.

Lassa, J.A. (2018), “Reviewing Indonesia's tsunami early warning strategy: Reflections from Sulawesi island," The Conversation, https://theconversation.com/reviewing-indonesias-tsunamiearly-warning-strategy-reflections-from-sulawesi-island-104257 (accessed 30 January 2019).

Lim, G.E. (2019), "Unlocking the potential of digital economy", Keynote Address, World Bank, Washington, DC, https://www.treasury.gov.my/index.php/en/gallery-activities/speech/item/5105speech-unlocking-the-potential-of-the-digital-economy.html.

Manopimoke, P. (2018), "Thai inflation dynamics in a globalized economy", Journal of the Asia Pacific Economy, Vol. 23/3, pp. 465-495, https://doi.org/10.1080/13547860.2018.1446673.

Manopimoke, P. (2015), “Globalization and International Inflation Dynamics: The Role of the Global Output Gap", PIER Discussion Paper No. 8, Puey Ungphakorn Institute for Economic Research, Bangkok, https://www.pier.or.th/wp-content/uploads/2015/11/pier dp 008.pdf.

Meng, C.K. (2016), "The inflation process and expectations in Singapore", Inflation Mechanisms, Expectations and Monetary Policy, Vol. 89, pp. 335-343, Bank for International Settlements, Basel, https://www.bis.org/publ/bppdf/bispap89w.pdf.

Ministry of Interior, Thailand (2011), "Thailand national progress report on the implementation of the Hyogo Framework for Action (2009-2011)".

Monetary Authority of Singapore (2018), "Monetary policy \& the economy", Economics Explorer Series, No. 3, Singapore, https://www.mas.gov.sg/-/media/MAS/Monetary-Policy-and-Economics/Education-andResearch/Education/Explorer/Economics-Explorer-3--Monetary-Policy-and-the-Economy.pdf.

Moretti, L., L. Onorante and S. Zakipour-Saber (2019), "Phillips curves in the euro area", Research Technical Papers, Vol. 2019/8, Central Bank of Ireland, Dublin, https://centralbank.ie/docs/defaultsource/publications/research-technical-papers/08rt19-phillips-curve-in-the-euro-area-(morettionorante-and-zakipour-saber).pdf?sfvrsn=4.

NDMA (2019), School Safety Project, National Disaster Management Authority, Government of India, https:// ndma.gov.in/en/ongoing-programmes/school-safety-project.html (accessed 30 January 2019).

Ng, M., D. Wessel and L. Sheiner (2018), “The Hutchins Center explains: The Phillips curve”, Brookings Institution, Washington, DC, https://www.brookings.edu/blog/up-front/2018/08/21/the-hutchinscenter-explains-the-phillips-curve/.

OECD (2019a), Economic Outlook for Southeast Asia, China and India 2019 - Update: Responding to Environmental Hazards in Cities, OECD Publishing, Paris, https://doi.org/10.1787/859159ab-en.

OECD (2019b), OECD Economic Surveys: China 2019, OECD Publishing, Paris, https://doi.org/10.1787/ eco surveys-chn-2019-en.

OECD (2011), Fostering Innovation for Green Growth, OECD Green Growth Studies, OECD Publishing, Paris, http://dx.doi.org/10.1787/22229523. 
Pearson, S.G., C.D. Storlazzi, A.R. van Dongeren, M.F.S. Tissier and A.J.H.M. Reniers. (2017), "A Bayesian-based system to assess wave-driven flooding hazards on coral reef-lined coasts", Journal of Geophysical Research: Oceans, Vol. 122/12, pp. 10099-10117, https://doi.org/10.1002/2017JC013204.

Reserve Bank of India (2018), "Priority sector lending: Targets and classification, Frequently Asked Questions, Mumbai, https://m.rbi.org.in/Scripts/FAQView.aspx?Id=87.

Reserve Bank of India (2016), "Master direction - Priority sector lending: Targets and classification" (updated as of 4 December 2018), Mumbai, https://rbidocs.rbi.org.in/rdocs/notification/PDFs/33M D08B3F0CC0F8C4CE6B844B87F7F990FB6.PDF.

The White House (2019), "Remarks by President Trump and Vice Premier Liu He of the People's Republic of China in a Meeting", Transcript, Washington DC, https://www.whitehouse.gov/briefingsstatements/remarks-president-trump-vice-premier-liu-peoples-republic-china-meeting/.

Toya, H. and M. Skidmore (2018), "Cellular telephones and natural disaster vulnerability", Sustainability, Vol. 10/9, p. 2970, https://doi.org/10.3390/su10092970.

U Thaung Tun (2019), "Investment opportunities in Myanmar for Thai investors", keynote speech, Myanmar Insight Seminar in Bangkok, Ministry of Investment and Foreign Economic Relations, Nay Pyi Taw, Myanmar, https://mifer.gov.mm/keynote-speech-delivered-by-h-e-u-thaung-tunminister-of-investment-and-foreign-economic-relations-government-of-the-republic-of-theunion-of-myanmar-on-the-occasion-of-the-myanmar-insight/.

UNESCAP (2015), "Strengthening regional multi-hazard early warning systems: Note by the secretariat", Committee on Disaster Risk Reduction, United Nations Economic and Social Commission for Asia and the Pacific, Bangkok, https://www.unescap.org/sites/default/files/preods/E_CDR4_2.pdf.

UNESCO and UNICEF (2012), Disaster Risk Reduction in School Curricula: Case Studies from Thirty Countries, United Nations Children's Fund, Geneva, and United Nations Educational, Scientific and Cultural Organization, Paris, https://unesdoc.unesco.org/ark:/48223/pf0000217036.

UNHCR (2018), "Mapping of existing international and regional guidance and tools on averting, minimizing, addressing and facilitating durable solutions to displacement related to the adverse impacts of climate change", WIM Task Force on Displacement, Activity II.4, Geneva, https://unfccc. int/sites/default/files/resource/WIM\%20TFD\%20II.4\%200utput.pdf.

UNISDR (2017), “Terminology: Early warning system”, United Nations International Strategy for Disaster Reduction, Geneva, https://www.unisdr.org/we/inform/terminology.

UNISDR (2010), "Early warning practices can save many lives: Good practices and lessons learned", United Nations International Strategy for Disaster Reduction, Geneva, https://www.unisdr.org/ files/15254_EWSBBLLfinalweb.pdf.

UNISDR (2007), "Hyogo Framework for Action 2005-2015: Building the Resilience of Nations and Communities to Disasters", United Nations Secretariat of the International Strategy for Disaster Reduction, Geneva, https://www.unisdr.org/we/inform/publications/1037.

WEF (2019), “The three biggest challenges for India's future”, World Economic Forum Annual Meeting, World Economic Forum, Geneva, https://www.weforum.org/agenda/2019/01/India-biggest-futurethree-challenges-consumption/.

WMO and IOC (2011), Ocean Data Buoy Vandalism: Incidence, Impact and Responses", DBCP Technical Document, No. 41, World Meteorological Organization, International Oceanographic Commission http://library.wmo.int/pmb_ged/dbcp-td_41.pdf.

World Bank (2019a), Doing Business 2019: Training for Reform, World Bank, Washington, DC, https:// www.worldbank.org/content/dam/doingBusiness/media/Annual-Reports/English/DB2019report web-version.pdf.

World Bank (2019b), "Maintaining economic stability", Lao PDR Economic Monitor, World Bank Group, Washington, DC, http://documents.worldbank.org/curated/en/604471565799670466/pdf/Lao-PDREconomic-Monitor-Maintaining-Economic-Stability.pdf.

World Bank (2019c), "Building Reform Momentum", Myanmar Economic Monitor, World Bank Group, Washington, DC, http://documents.worldbank.org/curated/en/326771560523871008/pdf/BuildingReform-Momentum.pdf.

World Bank (2019d), World Development Indicators (database).

World Bank (2018), Digital Connectivity in Lao PDR: Lagging Behind Peers - A Short Assessment with Policy Recommendations to Catch Up, World Bank, Washington, DC, http://documents.worldbank. org/curated/en/336311549033138864/Digital-Connectivity-in-Lao-PDR-Lagging-Behind-Peers-AShort-Assessment-with-Policy-Recommendations-to-Catch-Up. 
World Bank, IDE-JETRO, OECD, UIBE and WTO (2017), Global Value Chain Development Report 2017 : Measuring and Analyzing the Impact of GVCs on Economic Development, Washington, DC, https:// openknowledge.worldbank.org/handle/10986/29593.

WTO (2019), “Disputes by member”, World Trade Organization, Geneva, https://www.wto.org/english/ tratop_e/dispu_e/dispu_by_country_e.htm.

Yellen, J. (2017), "Inflation, uncertainty and monetary policy", speech at the "Prospects for Growth: Reassessing the Fundamentals" 59th Annual Meeting of the National Association for Business Economics, Cleveland, Ohio, https://www.federalreserve.gov/newsevents/speech/ yellen20170926a.htm.

Yu, S.L. and H. Jia (2015), “China's ambitious sponge city Initiative: A monumental effort for green/ gray infrastructure integration", EWRI Currents, https://issuu.com/asce-ewri/docs/currents fall_2015 final.

Zher, S.Y., J. Sung and C. Ying (2019), "Lifelong learning and ageing: Evidence from Singapore", Civil Service College, Singapore, https://www.csc.gov.sg/articles/lifelong-learning-and-ageingevidence-from-singapore. 


\section{Chapter 2}

\section{Upgrading education for the digital era}

Digitalisation and new technologies are developing rapidly, affecting businesses and the labour market. The digital era presents a huge opportunity while at the same time also brings significant risks. Business in the digital era will demand labour with a new set of skills. Education systems will therefore need to adapt to meet this new demand. Emerging Asian countries need to adopt an allencompassing approach to support teaching at all levels, including providing sufficient ICT infrastructure to schools, improving ICT skills of teachers, adapting curricula to include ICT and addressing the gender digital divide. Enhancing the role of TVET and lifelong learning is another priority area in providing education for the digital era. 


\section{Introduction}

The digital era is bringing important new developments for businesses and the workforce. New technologies, such as robotics, artificial intelligence and advances in information and computer technology (ICT), are changing the way societies interact, produce and create. These advances present a huge opportunity to improve human welfare and well-being through increased productivity and the personalisation of services to fit people's needs. Moreover, as success in the digital era will require a new set of skills, education systems and lifelong training programmes need to adapt in order to give people the means to thrive in this new context and prepare them for the future.

This chapter begins with an overview of how the digital era is changing the workplace, creating demand for new digital skills. It then examines how education systems can adapt to provide people with the tools necessary to succeed in these changed circumstances, with examples from OECD countries and Emerging Asia. The chapter next focuses specifically on the education challenges facing Emerging Asian countries as demand for digital skills outpaces the supply of qualified workers. Finally the chapter explores how societies can make digital education more inclusive by upgrading two alternative pathways: Technical and Vocational Education and Training (TVET) and lifelong learning.

\section{Boosting digital readiness in Emerging Asia $^{1}$}

Digitalisation reshapes the way people work and the type of work they do. According to the OECD Skills Outlook (OECD, 2019a), technologies can (i) lead to automation of some jobs, pushing the workers affected to acquire skills that still have demand; (ii) change the way non-automated jobs are done, necessitating upskilling and reskilling of employees; and (iii) create new types of jobs that would call for practically new skillsets. The impact of technology will vary across occupations and over time. It will largely depend on the technical and economic feasibility of replacing functions with technology alternatives. The overall effect of digitalisation on employment is still hard to gauge, as new occupations will be created while others will be destroyed. However, evidence on the distributional effects suggests that highly skilled workers benefit from digitalisation while lower skilled workers are vulnerable. The main reason is that highly skilled workers tend to perform tasks that are complementary with technology, while lower skilled workers perform substitutable ones.

To be internationally competitive in the digital era, countries need a skilled labour force. In general, the lack of skilled labour is a key challenge in the region. Figure 2.1 shows that Cambodia, Indonesia and Thailand all currently experience a shortage of skilled labour to varying degrees. Cambodia currently faces the largest shortage of skilled workers and Malaysia the smallest, reflecting the two countries' development levels. Looking at the long-term trends, skills mismatch is likely to decrease in 2021 in both skilled and unskilled labour. However, simulation shows that a shortage of skilled labour will remain high in some countries, including Cambodia, Indonesia and Thailand. Indeed, policies to address the lack of skilled labour are strongly needed in the region, in general. Figure 2.1 defines skilled labour broadly and outlines a trend, though a sector-level approach is needed to get a picture of what is happening within the skilled categorisation for each country and to see what type and level of skills will be needed. 
Figure 2.1. Current and future skills demand and supply in three Emerging Asian countries - simulation

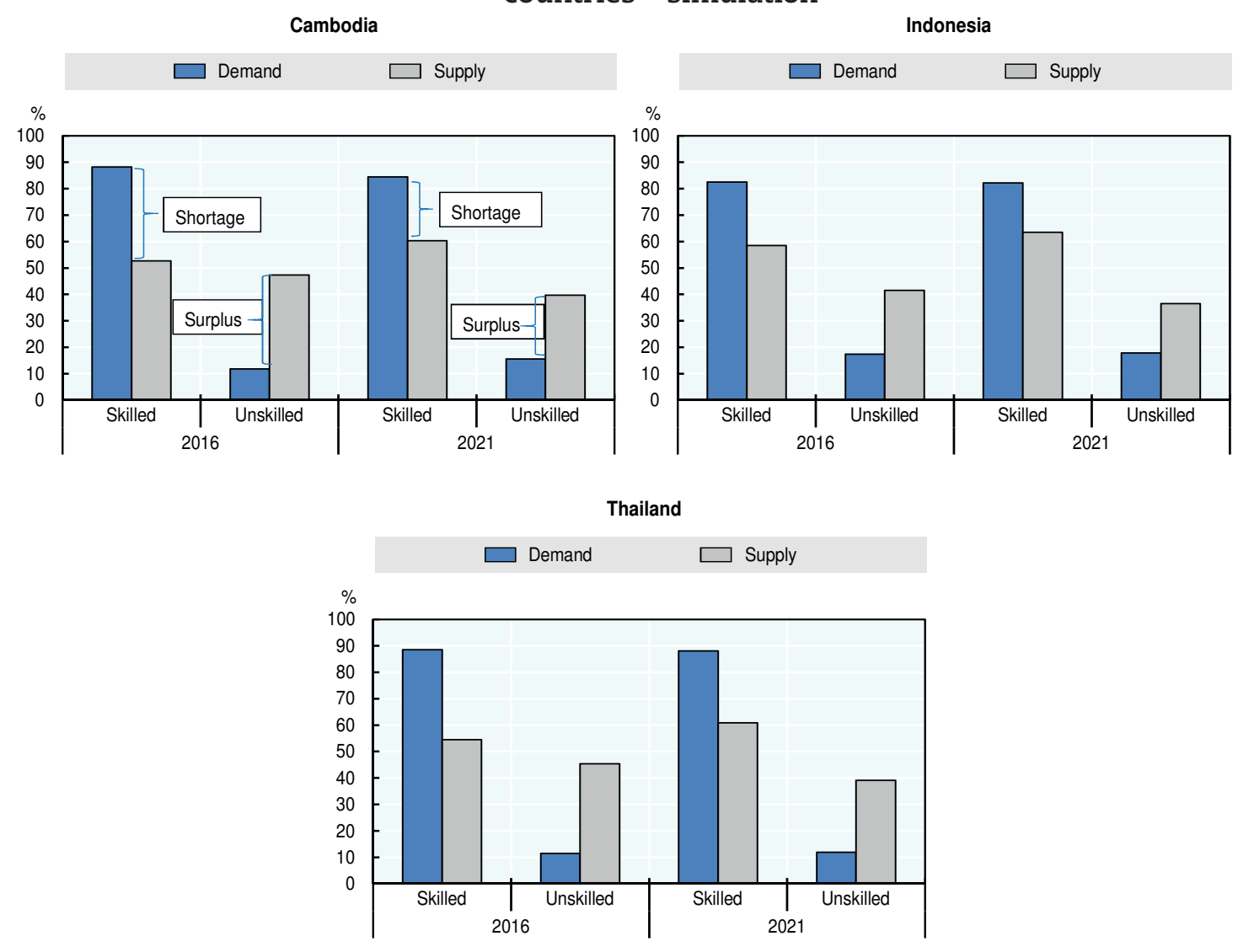

Note: Skilled refers to all occupations above ISCO-08 level 1 and levels of education above ISCED 1997 level 1, while unskilled refers to all occupations of ISCO-08 level 1 and levels of education ISCED 1997 level 1. Forward-looking data points are based on linear projections. Skill levels on the demand side were obtained by mapping ISCO-08 occupational categories from the Labour Force Surveys into ISCO-08 skill levels according to ILO (2012), merging levels 2, 3 and 4 as "skilled". Demand for skills refers to the occupational structure of employment. Skills levels on the supply side were obtained from the educational attainment variable in the Labour Force Surveys and mapped to ISCO-08 skill levels based on ILO (2012). The supply-side structure of skills was then compared with the demand-side data to determine mismatches.

Source: OECD Development Centre calculations based on ILO and national sources data.

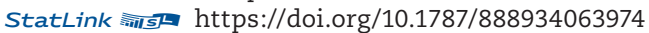

\section{Rising demand for specialised ICT skills in Emerging Asia}

Demand for ICT skills is growing worldwide, and professionals with these skills are earning higher wage premiums. The OECD Skills Outlook 2019 identified occupations with high demand for digital skills such as software and applications developers and analysts, database and network professionals, and ICT operations and user support technicians (OECD, 2019a). What sets workers in these professions apart from their counterparts is their proficiency in literacy, numeracy and problem-solving skills in technology-rich environments, according to the study, which used the Survey of Adult Skills (PIAAC) in its analysis.

Different forms of ICT skills will be needed in the digital era as digitalisation changes the tasks associated with different occupations. New industries requiring advanced and specialised ICT skills are already arising: all Emerging Asian countries have workers employed in the new ICT services sector (Figure 2.2). However, not all countries stand equal when it comes to reaping the benefits of this growing sector. It represents a large share of 
employment in Singapore, is strong in the Philippines and greater numbers are participating in Brunei Darussalam, Indonesia, and Cambodia to a lesser extent. However, according to the latest available data, the sector has stagnated in Thailand and Viet Nam in recent years. Based on a broader definition due to data constraints, thereby including more than just the purely ICT-related sectors, the sector has grown steadily in China over the last years.

Figure 2.2. Employment in the ICT sector in Emerging Asia

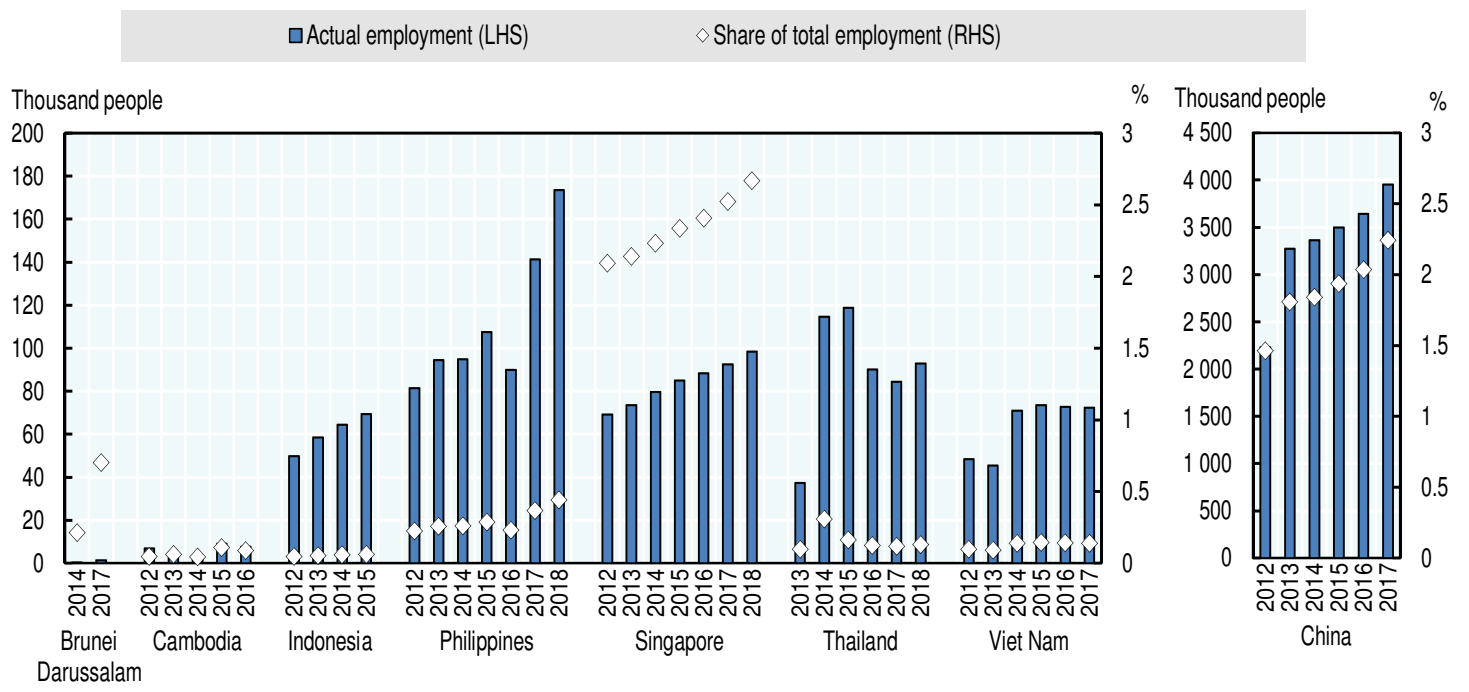

Note: Employment for Southeast Asian countries refers to ISIC rev. 4 Section J., division 62 (Computer programming, consultancy and related activities) and division 63 (Information service activities), and data come from ILO. For Cambodia, there is no division 62 data available for 2012, 2013 and 2014 and no division 63 data available for 2016. Employment for China refers to Information Transmission, Computer Service and Software sectors classified by the National Bureau of Statistics in China which is also the source of data.

Source: OECD Development Centre calculations based on ILO and CEIC data.

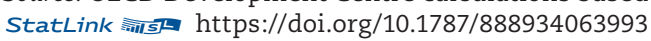

\section{Enhancing the curriculum and updating teachers' skills}

In light of digitalisation's job-market implications, developed and developing economies are taking advantage of ICT to retool the delivery of education and strengthen the resilience of the workforce. The 2015 Qingdao Declaration on harnessing the Internet to meet educational challenges proposes utilising ICT to meet Sustainable Development Goal 4 on education and to narrow opportunity gaps across social and income groups (UNESCO, 2015). Retooling education for the digital era involves two key facets: the curriculum and the quality of teachers, particularly in pre-tertiary levels.

The curriculum plays a pivotal role in programmes to incorporate ICT into education. Essentially a plan for learning, the curriculum determines learning outcomes and how to achieve those outcomes (Zarmati, 2019). It identifies core versus optional subjects and typically underlines to what extent and how tools should be used in a classroom setting. Against this backdrop, the curriculum should reflect students' needs and competencies even as it creates paths for specialisation for certain students, for example those with strength in ICT. Facilitating a seamless transition for students from one level to another and from school to the job market is another key consideration in curriculum design.

Countries have adopted different approaches for updating the curriculum in order to keep abreast of changing demands. Economies like Finland, Norway and Hong Kong, China, take an ongoing approach (i.e. periodical curriculum updating), while Ireland and the Netherlands renew their curricula on an ad hoc basis (Voogt et al., 2017). The choice is 
influenced by procedural, socio-economic and political factors. However the curriculum renewal is approached, engaging various stakeholders is deemed necessary. In their 2017 study, Voogt et al. found that integration of ICT into the curriculum and alignment with pedagogies were key to fostering positive outcomes. The study catalogued empirical exercises in different countries that show a mixed effect of ICT on students' proficiency in reading, writing, mathematics and other subjects, depending on how the use of ICT tools is approached. A number of Emerging Asian economies have recently transitioned or are in the process of updating their curricula.

Factors affecting curriculum-based outcomes include the availability, sufficiency and quality of materials and academic facilities and, importantly, the quality of teachers, as underscored by SDG 4. This is validated by empirical studies (OECD, 2018), and national authorities share the sentiment (UNESCO, 2018a). Broadly, the quality of teachers entails their understanding of the curriculum, their grasp of students' ICT needs and their ability to deliver instructions effectively using the available tools.

Two main underlying dimensions are the quality of higher education for aspiring teachers and the quality and regularity of professional training programmes that help teachers adapt to developments. Selection of aspiring teachers can be strengthened through competitive examinations before they enter teacher training or begin a teaching career, although this can be a problem in countries where there are teacher shortages (OECD, 2018). Regarding professional training programmes, UNESCO's ICT Competency Framework for Teachers provides guidelines for pre- and in-service training and incorporates ways to utilise open education resources (UNESCO, 2019a; n.d.). Indeed, bolstering online training can help address ground-level concerns in Emerging Asian economies, such as difficulty in accessing training locations and in harmonising schedules. The OECD's Innovative Learning Environment project proposes collaboration among teachers in order to foster an enabling environment among students and educators for understanding the nature and use of ICT tools (OECD, 2017; 2015a).

These dimensions are discussed in detail below, taking into account the countryspecific conditions in the region. Issues related to financing will be tackled in the Update edition of the 2020 Outlook.

\section{The gender digital divide in Emerging Asia}

Despite efforts by the region's policy makers to improve ICT access within the education system and to maximise its utilisation for learning activities, women in Emerging Asia continue to face special challenges due to their limited access to ICT.

Women around the world have less access to ICT and make less use of digital technologies than men do (ITU, 2017a), and this issue is of special concern for Emerging Asia. In the Asia-Pacific region, the estimated gender gap in Internet use was 17\% in 2017 - i.e. the proportion of women using the Internet was $17 \%$ lower than the proportion of men. By comparison, the Internet-use gender gap in Europe stood at $7.9 \%$ in the same year.

Improving ICT access for women and increasing their digital skills would boost their participation in the modern economy, yet a gender employment gap persists among ICT specialists. This is partly due to the low proportion of female students in ICT-related training and studies (ILO, 2019). Globally, in higher education, women represent only 35\% of students in the science, technology, engineering and mathematics (STEM) fields, and a tiny $3 \%$ of students of ICT (UNESCO, 2017). The same trend is observed in the TVET sector, where women participate in ICT-related fields of study less frequently then men do (ILO, 
2019). In the Philippines, even though women are better represented in higher education, their most common field of study is business administration, while information technology is the most common field among men (NSCB, 2014). And an ILO report that examined ICT skills shortages in India, Indonesia and Thailand found that women were less represented than men in the ICT sector despite its promise of future employment opportunities.

Against this backdrop, strategies to increase the participation of girls and young women in the field of ICT are needed in Emerging Asia. Some such programmes already exist. For example, India's WeTech Afterschool programme, which targets girls in middle school and high school, proposes technology-based activities for three months to allow them to discover different ICT careers and gain some of the technical skills needed to launch a start-up. Another example is Thailand's Agritech Using ICT training programme, which aims to improve the digital skills of female students and to help them develop smart farming in rural areas (Box 2.1). Indeed, strengthening efforts to improve ICT skills in the agriculture sector is crucial in particular for women, smallholders and youth in rural areas. This can be done by introducing training, education and agricultural extension services aimed at improving the ICT skills of farmers and farm workers

\section{Box 2.1. Teaching digital skills to rural women in Thailand}

Thailand introduced its Agritech Using ICT capacity-building programme in 2017 to impart digital skills to female students in rural areas. The initiative, held under Thailand's Girls In ICT Day programme, was launched by the country's Ministry of Digital Economy and Society in collaboration with the Food and Agriculture Organization (FAO), the International Telecommunication Union (ITU) and the private sector. In 2017, more than 200 female students participated in workshops conducted by the Research Centre of Communication and Development Knowledge Management at Sukhothai Thammathirat Open University (ITU, 2018).

The programme was continued in 2018, with UNESCO, the National Electronics and Computer Technology Centre and other private stakeholders joining as partners. The training focused on ICT skills and other knowledge necessary to apply the Smart Farm Model. The 2018 agenda offered training on the use of unmanned aerial vehicles, or drones, and other digital solutions to drive innovation in agriculture (FAO, 2018). Girls and young women were also taught entrepreneurship skills through courses on agritech start-ups and on smart farmer advance online marketing.

In 2019, the programme proposed training on Blockchain in agriculture, and also touched briefly on the water sector and smart agriculture (ITU, 2019a).

\section{Country-specific challenges in Emerging Asia}

While digitalisation brings common challenges in the region, each country's government also needs to focus on specific challenges. Some need to address the lack of infrastructure and increase access to ICT. In countries where infrastructure is relatively better, teaching capacity needs attention. A skills mismatch is another major issue in some countries in Emerging Asia. Country-specific challenges are discussed below. 
Table 2.1. Country-specific challenges for digital education in Emerging Asia

\begin{tabular}{ll}
\hline \multicolumn{1}{c}{ Countries } & \multicolumn{1}{c}{ Digital education challenges } \\
\hline ASEAN-5 & \\
\hline Indonesia & Ensuring access to technology at schools across the country \\
Malaysia & Bridging the gap between ICT graduates and industry demands \\
Philippines & Providing schools with more ICT infrastructure and trained teachers \\
Thailand & Improving teachers' readiness for digital education \\
Viet Nam & Strengthening vocational education to meet demand for digital skills \\
\hline Brunei Darussalam and Singapore & \\
\hline Brunei Darussalam & Fostering teachers' capacity for ICT use in classrooms \\
Singapore & Strengthening teachers' belief in ICT use in the classroom \\
\hline CLM & \\
\hline Cambodia & Improving ICT infrastructure and power supplies for better access \\
Lao PDR & Increasing access to ICT tools for both teachers and students \\
Myanmar & Providing quality ICT to all schools \\
\hline China and India & \\
\hline China & Bridging the digital talent gap between demand and supply \\
India & Raising digital literacy through broader access to digital devices \\
\hline
\end{tabular}

\section{Indonesia: Ensuring access to technology at schools across the country}

The path to digital readiness in Indonesia is hampered by a lack access to ICT infrastructure in schools (OECD/ADB, 2015). A majority of Indonesian teachers surveyed about ICT use in the classroom indicated that limited access to facilities was the main factor holding them back (Son, Thomas and Indra, 2011). Heavy public investment in education has brought improvements, but there is still progress to be made. In 2017 , only $61.4 \%$ of public secondary schools had access to computers for educational purposes and $39.7 \%$ had access to the Internet in 2018 (Table 2.2). This indicates that while computer access remains low, the schools that do have computers also provide access to the Internet. ${ }^{2}$

\section{Table 2.2. Key figures on ICT and education sectors in Indonesia}

\begin{tabular}{|c|c|c|}
\hline \multicolumn{3}{|c|}{ Access to digital technologies, 2018 or latest year available } \\
\hline a. & Percentage of individuals using the Internet & $39.8 \%$ \\
\hline b. & Percentage of females using the Internet & $37.4 \%$ \\
\hline c. & Percentage of males using the Internet & $42.2 \%$ \\
\hline d. & Percentage of individuals using a computer & $19.0 \% *$ \\
\hline e. & Mobile-cellular telephone subscriptions per 100 inhabitants & 119.8 \\
\hline f. & Proportion of public secondary schools with access to Internet for pedagogical purposes & $39.7 \%$ \\
\hline g. & Proportion of public secondary schools with access to computers for pedagogical purposes & $61.4 \%{ }^{*}$ \\
\hline \multicolumn{3}{|c|}{ TVET and lifelong learning, 2018 or latest year available } \\
\hline h. & Share of all students in secondary education enrolled in vocational programmes & $19.7 \%$ \\
\hline i. & Share of female students in secondary education enrolled in vocational programmes & $17.2 \%$ \\
\hline j. & Share of male students in secondary education enrolled in vocational programmes & $22.1 \%$ \\
\hline k. & Existence of lifelong learning opportunities & Yes \\
\hline
\end{tabular}

Note: (*) 2017 data.

Source: a, b, c, d and e: ITU (2019b); f, g, h, i and j: UNESCO (2019b); k: UIL (2017).

The uneven distribution of ICT infrastructure across Indonesia's schools provides insight into equality of chances and the country's digital divide. According to PISA 2012, there are large differences among schools of different socio-economic backgrounds in terms of access to computers with an Internet connection. In schools where students' mean socio-economic status is above the country's average, the share of computers connected to the Internet is $73.9 \%$, while the share is only $47.3 \%$ in schools where the students' mean socio-economic status is low (OECD, 2015b). This gap is much wider than in the other ASEAN-5 countries, where the average difference is $7.1 \%$ (Figure 2.3). 
Figure 2.3. Socio-economic gap in digital access in schools, 2012

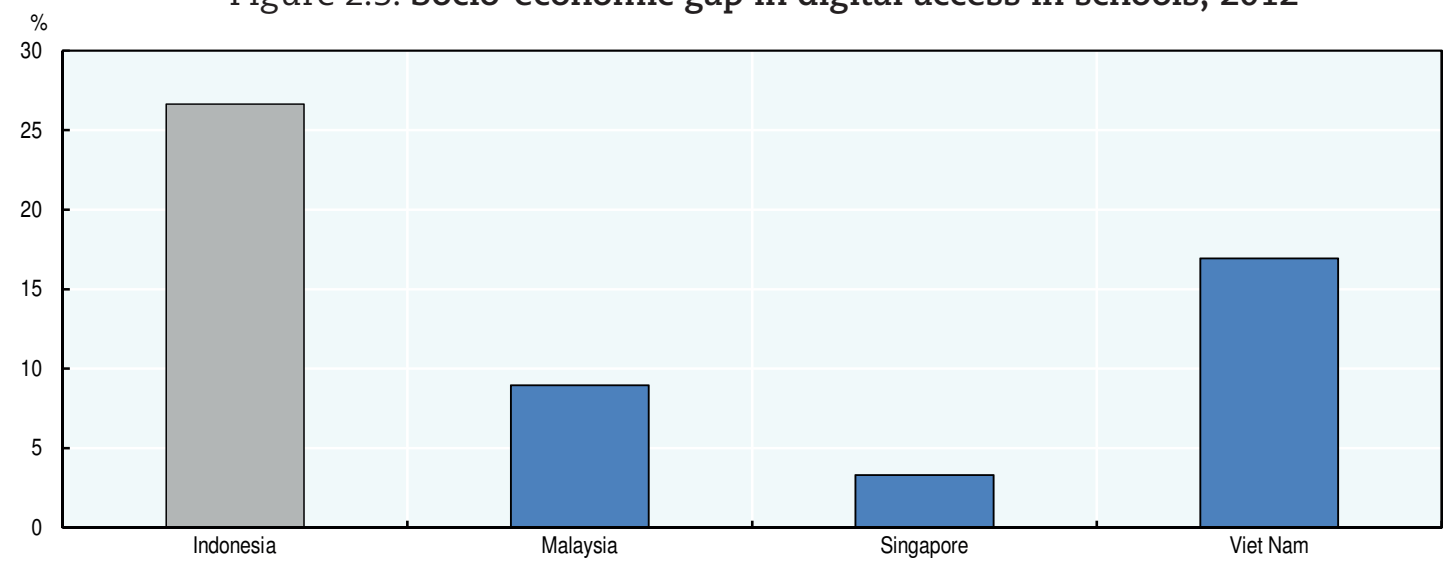

Note: The socio-economic gap in digital access in schools is defined as the difference in internet connection access between schools with students of high socio-economic background and schools with students of low socioeconomic background. The high and low socio-economic background schools are defined based on their students being part of the top quarter or bottom quarter of the PISA index of economic, social and cultural status (ESCS). Source: OECD (2015b), Students, Computers and Learning: Making the Connection.

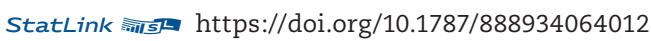

Nonetheless, Indonesia has made progress in connecting schools to the Internet through the Centre for ICT for Education, or Pustekkom, which is part of the Ministry of Education and Culture, and especially the Jardiknas and SchoolNet programmes (Butcher and Bodrogini, 2016). According to Pustekkom (2019), 103779 Indonesian schools had an Internet connection in 2019, and growth in connections amounted to $16.4 \%$ on average over the last three years. Indonesia should continue its investment policy in the future, paying close attention to reducing the gap in access and maintaining stable funding for Jardiknas and SchoolNet. In the past, budget cuts and the yearly nature of budget allocations have hindered the rollout of Internet connections at schools (Butcher and Bodrogini, 2016). Beyond access, the manner and extent to which ICT tools are employed are just as important for achieving good outcomes (Box 2.2).

Indonesia's government has included ICT as a subject in the curriculum since 2004, first as a stand-alone subject and, since the introduction of a new curriculum in 2013, as an element to be integrated into all subjects (Mahdum, Hadriana and Safriyanti, 2019). This ICT-based curriculum, which has been implemented in some pilot schools, uses computer-based learning, blended e-learning, web-based learning, ICT-based assessment, digital libraries and school database applications (Widyastono, 2015).

Nonetheless, uneven classroom use of ICT by teachers remains a challenge. For instance, in a survey of public high school teachers in rural districts, more than half $(54.17 \%)$ indicated that they rarely or never used ICT in their classrooms (Mahdum, Hadriana and Safriyanti, 2019). Efforts have been made to tackle this issue. Under the Universal Service Obligation, the government provides training programmes for teachers in remote areas. However, due to the infrastructure issue, the target number of teachers trained has not yet been reached (MOCI, 2016).

As the new curriculum requires ICT integration in all subjects, teachers need adequate ICT competency in their field. However, a recent study found that Indonesian secondary mathematics teachers had insufficient knowledge of both ICT and the use of ICT in teaching their subjects. For instance, while mathematical software has emerged and is widely used in schools around the world, teachers' knowledge of mathematical software (e.g. Dynamic Geometry Software, Computer Algebra System) was found to be lower than their knowledge of general software, such as word processing and spreadsheets (Mailizar and Fan, 2019). It is therefore important to improve teachers' knowledge of subject-related technology. 


\section{Box 2.2. ICT use in schools: How much is too much?}

Data from PISA 2015 showed that extensive use of ICT is associated with lower student performance. These findings hold true in science, mathematics and reading (Figure 2.4) with the exception of Australia, where students in the top quartile of ICT usage at school performed better than those at the bottom quartile. One plausible explanation is that extensive technology use is crowding out more efficient educational practices.

Figure 2.4. PISA 2015 performance and ICT use at school
- Bottom quartile
$\triangle$ Second quartile
Third quartile
- Top quartile

Students' mean scores in science by quartile of the index of ICT use at school

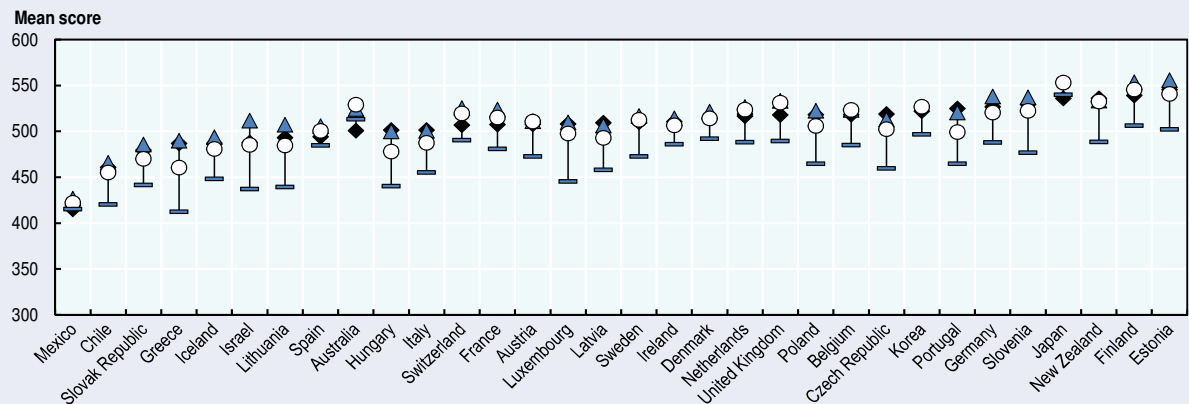

Students' mean scores in mathematics by quartile of the index of ICT use at school
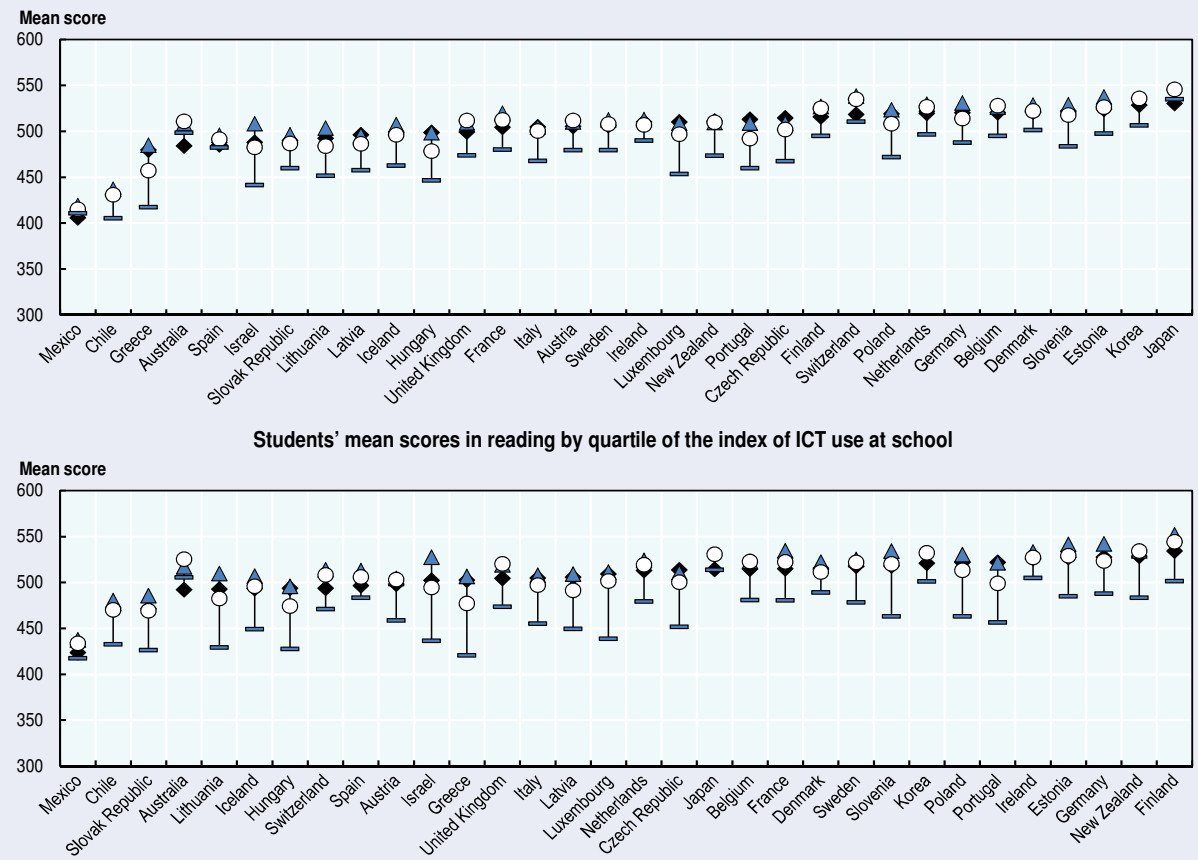

Note: The figure displays students' mean scores in science, mathematics and reading by quartile of the index of ICT use at school. The index of ICT use at school measures how frequently students make a variety of digital device uses at school: playing simulations; posting one's work on the school website; practicing and drilling (such as for foreign languages or mathematics); downloading, uploading or browsing material from the school's website or intranet; chatting online at school; using email at school; doing homework on a school computer; using school computers for group work and communication with other students; browsing the Internet for schoolwork. The frequency of uses goes from never or hardly ever (value of 1) to every day (value of 5). Countries are ranked by the mean score of students in the bottom quartile of the index of ICT use at school.

Source: OECD calculations based on OECD (2015c), PISA database 2015, http://www.oecd.org/pisa/ data/2015database/.

StatLink (inist https://doi.org/10.1787/888934064031 


\section{Box 2.2. ICT use in schools: How much is too much? (cont.)}

The value of ICT in the classroom largely depends on how it is used. To be effective, ICT should be included in formal curricula as a learning tool that complements teaching, and not as an end in itself.

Teachers in Australia perform better than their counterparts in other OECD economies in terms of problem solving in a technology-rich environment. Classroom use of ICT also resulted in better student performance. Australia's use of an all-encompassing approach to pass on digital skills allows students to diversify their use of ICT, from creating artwork to critically analysing a particular topic). The development of ICT capabilities is similarly viewed as a learning continuum rather than a subject-specific endeavour. At the institutional level, the Australian Curriculum Assessment and Reporting Authority (ACARA), formed in 2008, designs the framework for allowing students to use ICT tools to communicate information and ideas, solve problems and collaborate in various ways (ACARA, n.d.).

Several key competencies are highlighted in the ACARA framework. A key pillar is the ability to apply social and ethical protocols when using ICT (recognising intellectual property and following digital information security practices). Other competencies are the ability to investigate using ICT tools (organising information searches and locating, generating, accessing and evaluating the information); creating with ICT (generating ideas, plans and processes); and operating ICT (understanding ICT systems and software) (ACARA, n.d.).

Another example is the Canadian province of Manitoba, where digital competencies are included in all areas of the curriculum, and students are asked to think critically and creatively about their ICT use and to use digital tools safely and ethically (Manitoba Education and Training, n.d.). In Emerging Asia, India has incorporated ICT into its formal school curriculum based on a set of guiding principles (MHRD, n.d.). The ICT curriculum is generic, drawing on a wide range of technological applications and focusing on educational purposes. It emphasises ICT literacy, defined as the knowledge and ability to wield tools and devices. It considers the sharing of learning and critical evaluation of the learning as integral to the strategy. The curriculum promotes safe and secure use of ICT. Finally, it promotes the full utilisation of infrastructure and resources, integrated with the school's programme.

\section{Malaysia: Bridging the gap between ICT graduates and industry demands}

A key challenge to Malaysia's objective of developing the ICT services sector is a lack of industry-ready ICT graduates. Development of the sector was emphasised in the mid-term review of Malaysia's $11^{\text {th }}$ development plan as part of the plan's $6^{\text {th }}$ pillar, "strengthening economic growth". While demand for graduates has been steadily rising in core ICT areas such as computer science, information technology and software engineering, supply has not kept pace. Indeed, a recent report found that $66 \%$ of digital companies in Malaysia face talent shortages (MDEC, 2018).

The Malaysia Digital Economy Corporation (MDEC) projects that the country will face a shortage of 1200 fresh ICT graduates by 2020 (MDEC, 2018). It expects an oversupply of graduates in fields such as business administration and an undersupply of ICT graduates. A forward-looking education policy is needed if Malaysia is to close its shortage of skilled ICT workers by 2021 (as projected in Figure 2.4, above). While the contribution of the ICT services sector to GDP has been growing steadily, Malaysia has seen a steady decline in the share of ICT services sector workers to total employment. 
Malaysia also faces a skills mismatch between ICT graduates and industry. New ICT graduates rarely have the skills needed to transition directly from school to business: only $10 \%$ of new entrants to the ICT workforce are directly employable, while the remaining $90 \%$ require training before they can start work (PIKOM, 2014). At the same time, most unfilled ICT jobs are in positions requiring experience. In this regard, the low supply of new ICT graduates can be attributed in part to the perception of poor career prospects (Tan and Tang, 2016).

An underlying reason for the skills mismatch is the slow pace at which tertiary education programmes develop compared to industry requirements. For instance, Malaysian universities only started offering data science courses from 2015 onwards (Tan and Tang, 2016). As a response to the mismatch, all universities are required to appoint an Industry Advisory Panel to provide feedback on the curriculum and learning activities. Furthermore, government agencies such as the MDEC and the Talent Corporation Malaysia Berhad help to bridge the gap between graduates and industry by offering internship and apprenticeship schemes. The use of internships could be standardised in graduate programmes to smooth the transition from university to industry and ensure that future graduates have a foothold in the private sector upon graduation.

Another issue relating to human capital development is the lack of a clear classification of the ICT skills that fall under different degrees. This causes firms to hire workers who fail to meet their expectations, as there are significant differences between courses in computer science and computer use (PIKOM, 2015). The Malaysian Qualifications Agency has set standards for curricula covering various areas in ICT, but awareness among firms could be raised in this area. Naming degrees in a way that reflects the distinct disciplines in ICT would help to create a more transparent market for ICT graduates.

At lower educational levels, Malaysia has implemented various policies to build ICT competency among students. One of these is the Smart School Initiative (Box 2.3).

\section{Box 2.3. Malaysia's Smart School Initiative}

Malaysia's government promotes ICT at schools through its Malaysian Smart School Initiative (MSSI), an all-encompassing approach to digitalisation at schools. It aims to provide ICT for all as a teaching and learning tool, integrated in other subjects or on a stand-alone basis, and to use ICT to increase the productivity, efficiency and effectiveness of the management system (Lee and Soon, 2016). A pilot study involving 88 schools was launched in 1997, and the initiative was rolled out across the country in 2005 under the "making all schools smart" programme. The overarching aim of the MSSI is to "help students cope and leverage on the information age" (MOE Malaysia, n.d.a).

The MSSI aims to cover all aspects of the digitalisation of the school system. It involves the provision of ICT infrastructure (both hardware and Internet connection), teacher training, curriculum enhancement and support through the release of courseware and other resources for teaching (Lee and Soon, 2016). The MSSI is a dynamic and ongoing programme that was rolled out in four waves. After the pilot study, Wave 2 focused on the consolidation of smart school principles, Wave 3 saw the expansion of the programme to all schools in Malaysia and Wave 4 involved the consolidation and stabilisation of progress (Lee and Soon, 2016). 


\section{Box 2.3. Malaysia's Smart School Initiative (cont.)}

Another key characteristic of the MSSI is outreach. It was designed as a multiple stakeholder process including parents, the community and the private sector. The Ministry of Education (MOE) formed partnerships with leading industry and community players to accelerate the use of ICT at schools. Partners included parent-teacher associations, companies, teachers' unions, alumni and educational associations (Lee and Soon, 2016). Digital industry leaders were asked by the MOE to train teachers to use ICT in schools, to develop digital curriculum materials and to develop information management systems for schools. Partnering with the private sector allowed the MOE to overcome human capital shortages in ICT and to keep up with technological developments. Co-ordination with teacher associations helped to smooth the process of adoption of ICT by teachers.

To ensure the correct rollout of the expansionary phase of the MSSI, and based on experiences from the pilot phase, a monitoring tool called the Smart School Qualification Standards (SSQS) was set up. The SSQS is a set of indicators to monitor, evaluate and categorise schools in the usage and impact of technologies. Its key objectives are to increase the use of ICT in schools; to measure ICT integration in administration, teaching and learning; and to provide a basis for policy planning and programme improvement (Lee and Soon, 2016). The final outcome is a star rating assigned to each school based on an established criterion.

Another initiative is the Malaysia Education Blueprint 2013-25, which aims to provide students with 21st century "higher order thinking skills" and to embed ICT in the curriculum. It includes a Virtual Learning Environment to provide teachers and students with broad access to learning materials. Adequate provision of infrastructure allowed the implementation of this initiative. Indeed, as of $2018,90 \%$ of Malaysia's public secondary schools are equipped with computers and $95.2 \%$ have access to Internet (Table 2.3). As of 2016, the Education Ministry had added more than 13000 learning sites (MOE Malaysia, 2017).

Table 2.3. Key figures on ICT and education sectors in Malaysia

\begin{tabular}{llc}
\hline Access to digital technologies, 2018 or latest year available & \\
\hline a. $\quad$ Percentage of individuals using the Internet & $81.2 \%$ \\
b. $\quad$ Percentage of females using the Internet & $78.7 \%$ \\
c. $\quad$ Percentage of males using the Internet & $83.5 \%$ \\
d. $\quad$ Percentage of individuals using a computer & $69.8 \%$ \\
e. $\quad$ Mobile-cellular telephone subscriptions per 100 inhabitants & 134.5 \\
f. $\quad$ Proportion of public secondary schools with access to Internet for pedagogical purposes & $95.2 \%$ \\
g. $\quad$ Proportion of public secondary schools with access to computers for pedagogical purposes & $90 \%$ \\
\hline TVET and lifelong learning, 2018 or latest year available & $11 \%$ \\
\hline h. $\quad$ Share of all students in secondary education enrolled in vocational programmes & $9.6 \%$ \\
i. $\quad$ Share of female students in secondary education enrolled in vocational programmes & $12.4 \%$ \\
j. $\quad$ Share of male students in secondary education enrolled in vocational programmes & Yes \\
\hline k. $\quad$ Existence of lifelong learning opportunities & \\
\hline
\end{tabular}

Note: (*) 2017 data.

Source:a, b, c, d and e: ITU (2019b); f, g, h, i and j: UNESCO (2019b); k: UIL (2017). 
Despite these initiatives, ICT use in the classroom remains uneven in Malaysia due to some challenges: lack of training for teachers on how to integrate ICT into pedagogy, minimal involvement of school leadership in implementing ICT policies and infrastructure issues (Gryzelius, 2015). A study of Malaysian primary and secondary school teachers found a low level of pre-integration activities, such as producing and delivering presentation slides or preparing lesson plans (Umar and Hassan, 2015). The study also found a low level of actual integration activities, such as teaching computer skills and using ICT in teaching and learning. In an effort to improve teachers' capacity, an Online Digital Literacy Course was implemented in two phases, in 2015 and in 2016 (MOE Malaysia, 2017).

\section{Philippines: Providing schools with more ICT infrastructure and trained teachers}

Active government support in the Philippines has increased ICT representation in school curricula and raised social awareness of digital education, yet the country still faces major challenges including poor school infrastructure for ICT education and a lack of qualified teachers to provide training. Programmes implemented to date include the Philippine Digital Strategy 2011-16, which calls for integration of ICT in the curriculum across all levels of the education system (CICT, 2011); the Department of Education (DepEd) Computerisation Programme, which advocates the deployment of computer packages to public schools (DepEd, 2010); and the DepEd Internet Connectivity Project, which aims to provide Internet access to public secondary schools (DepEd, 2009). As of 2016, the proportion of public secondary schools with access to computers and Internet for pedagogical purposes has reached $86.1 \%$ and $53.9 \%$ respectively (Table 2.4 ).

Table 2.4. Key figures on ICT and education sectors in the Philippines

\begin{tabular}{|c|c|c|}
\hline \multicolumn{3}{|c|}{ Access to digital technologies, 2017 or latest year available } \\
\hline a. & Percentage of individuals using the Internet & $60.1 \%$ \\
\hline b. & Mobile-cellular telephone subscriptions per 100 inhabitants & 110.1 \\
\hline c. & Proportion of public secondary schools with access to Internet for pedagogical purposes & $53.9 \%$ ** \\
\hline d. & Proportion of public secondary schools with access to computers for pedagogical purposes & $86.1 \%$ ** \\
\hline \multicolumn{3}{|c|}{ TVET and lifelong learning, 2017 or latest year available } \\
\hline e. & Share of all students in secondary education enrolled in vocational programmes & $6.3 \%$ \\
\hline f. & Share of female students in secondary education enrolled in vocational programmes & $5.6 \%$ \\
\hline g. & Share of male students in secondary education enrolled in vocational programmes & $7.0 \%$ \\
\hline h. & Existence of lifelong learning opportunities & Yes \\
\hline
\end{tabular}

Note: $\left({ }^{* *}\right) 2016$ data.

Source: a and b: ITU (2019b); c, d, e, f and g: UNESCO (2019b); h: UIL (2017).

In 2012, according to data on the Philippines from the United Nations Educational, Scientific and Cultural Organisation (UNESCO), about $8 \%$ of primary schools and $87 \%$ of secondary schools had computer laboratories, while about $7 \%$ of primary schools and $40 \%$ of secondary schools had access to the Internet (Figure 2.5). Philippine schools generally had weaker ICT infrastructure than other Emerging Asian countries with available data (China, Malaysia, Singapore and Thailand), especially for primary schools. In the Philippines, one computer is shared on average by 412 primary students, compared to 24 students in China, 15 in Thailand and 17 in Malaysia, while one computer is shared by 49 secondary students in the Philippines, compared to 13 in China, 14 in Thailand and 9 in Malaysia (UIS, 2014). 
Figure 2.5. ICT in education in the Philippines, 2012

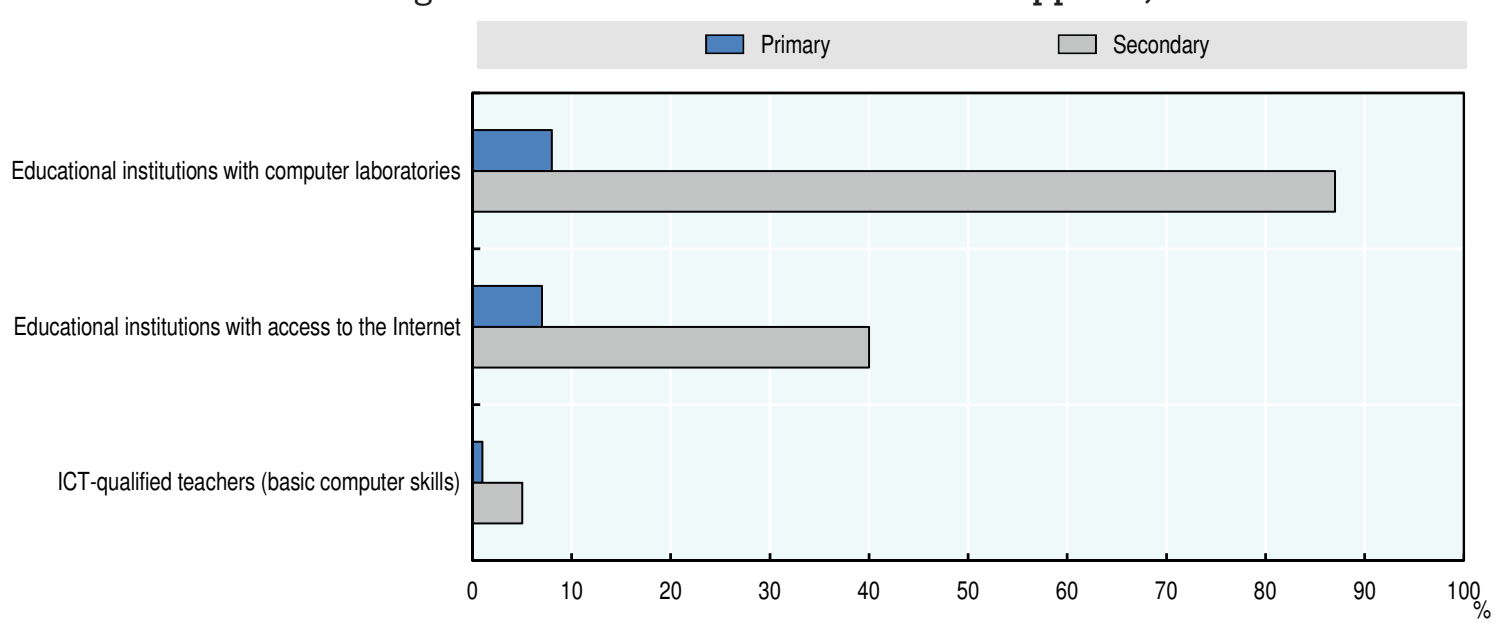

Source: UNESCO (2019b), UIS Statistics (database), http://data.uis.unesco.org/.

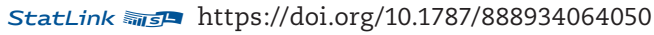

In addition, few teachers in the Philippines have sufficient training in computer skills to be able to provide basic digital education. As shown in Figure 2.5 , only $1 \%$ of teachers in primary schools and $5 \%$ in secondary schools have basic computer skills. At this level, the lowest one in the region, each teacher with basic skills would need to train more than 500 students on average, and this could have significant negative impact on the learning experience. The lack of qualified teachers with computer skills could lower the efficiency of digital education in Philippine schools, as the spread of digital literacy is directly linked to the number of computer literate teachers (Bahian and Sari, 2017).

The implementation of the Philippines' K-12 system beginning 2012 (discussed in the Country Notes, Chapter 3) has arguably broadened the ICT component of the basic education curriculum. Emphasis is placed on ICT as a tool of instruction, and ICT training is offered as non-mandatory courses after the primary level. Exploratory courses are offered to students in grades 7 to 8 under the technology and livelihood subject, while specialised courses are offered in grades 9 to 12 under an optional technical-vocationallivelihood track. Options are aligned with courses offered in the country's separate TVET programme and span subjects from hardware diagnostics to programming (DepEd, 2016). Digital literacy has also been incorporated into the alternative learning system (DepEd, n.d.). The Education Ministry facilitates the use of ICT in teaching and learning through seminars and training sessions (Arayata, 2017; Dar, 2017).

Assessment of ICT use in the curriculum in recent years is difficult in the Philippines given the absence of publicly available national indicators, both on the quality of instruction and on teachers' perceptions. Nonetheless, empirical evidence based on smallsample studies provides a picture of the challenges faced by teachers. Studies by Alba and Trani (2018) and Caluza et al. (2017), which examined teachers' ICT use and competency using primary survey data, suggest that teachers require more training to apply basic ICT skills proficiently in the classroom. Concerns include limited time available for accessing ICT equipment and tools, lack of an Internet connection, a shortage of computer units and other equipment, and lack of technical assistance for operating, maintaining and troubleshooting ICT tools (Caluza et al., 2017). These findings are supported by an earlier study that analysed teachers' ICT competency under UNESCO's ICT Competency Standards for Teachers (Marcial and de la Rama, 2015). The study found that teachers scored well in pedagogy, curriculum and assessment, and professional learning, but that 
use of ICT tools was still at a basic level and that the ability to use new processes in teaching and learning was limited in practice.

More attention should be devoted to primary schools and to schools in the provinces, which lag substantially behind the National Capital Region in terms of ICT infrastructure (Bonifacio, 2013). It is also necessary to explore alternative sources of funding for further ICT integration in schools, such as overseas development aid and private-sector contributions, as government resources may not be enough.

\section{Thailand: Improving teachers' readiness for digital education}

Delivery of basic education in Thailand is guided by the 2008 Basic Education Core Curriculum (Grades 1-12) and the 2003 Early Childhood Curriculum (OEC, 2017). For vocational courses, in which $10.3 \%$ of all students in secondary education are enrolled (Table 2.5), the 2013 Curriculum for the Certificate of Vocational Education (revised in 2014) and the 2014 Curriculum for Diploma of Vocational Education serve as blueprints. Under the basic education curriculum, eight core subjects are common across all levels (primary to upper secondary), including one on occupations and technology. This core area includes strands that focus on developing a good understanding of ICT and the processes behind it, as well as the practical applications and ethical dimensions of ICT use (MOE Thailand, 2018). Grade-level indicators, which are prescribed by law, suggest the intent of introducing students to ICT in a rigorous manner. The indicators cover ICT principles, information search, programming and problem solving, data analysis, product development and ethical assessment, among others.

Table 2.5. Key figures on ICT and education sectors in Thailand

\begin{tabular}{|c|c|c|}
\hline \multicolumn{3}{|c|}{ Access to digital technologies, 2018 or latest year available } \\
\hline a. & Percentage of individuals using the Internet & $56.8 \%$ \\
\hline b. & Percentage of females using the Internet & $55.9 \%$ \\
\hline C. & Percentage of males using the Internet & $57.8 \%$ \\
\hline d. & Percentage of individuals using a computer & $30.7 \%$ * \\
\hline e. & Mobile-cellular telephone subscriptions per 100 inhabitants & 180.2 \\
\hline \multicolumn{3}{|c|}{ TVET and lifelong learning, 2018 or latest year available } \\
\hline f. & Share of all students in secondary education enrolled in vocational programmes & $10.3 \%$ * \\
\hline g. & Share of female students in secondary education enrolled in vocational programmes & $8.3 \%$ * \\
\hline h. & Share of male students in secondary education enrolled in vocational programmes & $12.1 \%$ * \\
\hline i. & Existence of lifelong learning opportunities & Yes \\
\hline
\end{tabular}

Note: $\left(^{*}\right) 2017$ data.

Source: a, b, c, d and e: ITU (2019b); f, g and h: UNESCO (2019b); i: UIL (2017).

Despite the addition of detailed grade-level indicators, and interval indicators for Grades 10-12, a report found that the curriculum was not clear on its theoretical underpinnings, student performance standards, effective pedagogical methods and strategies to meet the needs of different learners (OECD/UNESCO, 2016). A review of the curriculum was initiated in 2011, and a National Scheme of Education (2017-2036) was launched to support the reform agenda. The reforms pursued since 2014 focus on six key areas: appropriateness of class hours; management and decentralisation; staffing and teachers' workload; standards to evaluate students; workforce skills upgrade; and the use of ICT in teaching and learning and in knowledge management (OEC, 2017). Separate initiatives have also been developed, including one to introduce coding courses to primary students (MOE Thailand, 2019).

Thailand's teachers are well-acquainted with ICT tools, given the country's long-standing commitment to incorporate ICT in education and teacher training. Separate surveys in 2008 and 2011 showed that more than $80 \%$ of basic education teachers had their own computers, while in 2010, the ratio between trained and non-trained teachers on ICT stood at 5.5 to 1 
(Makaramani, 2013). Moreover, results in 2011 indicated that almost 70\% of teachers used application programmes to produce teaching materials, more than $84 \%$ used ICT to enhance traditional learning activities and more than $81 \%$ used ICT to create and manage innovative teaching. However, like other developing economies, Thailand faces challenges that complicate the teaching of ICT. In addition to infrastructure and material constraints, such as the quality and accessibility of digital materials for both students and teachers, gaps have been noted in the ability of teachers to deliver ICT modules effectively.

Thai teachers sometimes lack the knowledge and confidence to transmit ICT skills to students, while monitoring of ICT policies is not entirely effective and a coherent framework for investment in ICT is missing (OECD/UNESCO, 2016). Thailand has set out plans to use ICT as a tool to enhance teaching and learning, particularly at the basic education level and coverage of ICT infrastructure is broadening through government and private-sector initiatives, although efforts can be made regarding the maintenance of ICT tools at school (TDRI, 2019). Thai teachers also show mixed attitudes towards the usefulness of ICT as a teaching and learning tool, according to survey data, and this lack of motivation could harm the promotion of ICT usage at schools (OECD/UNESCO, 2016).

The IEA International Computer and Information Literacy Study (ICILS) in 2013 found that Thai teachers systemically display lower confidence levels in performing basic ICT tasks than their counterparts from other countries. This result is noteworthy given that research strongly indicates that the successfulness of ICT use in teaching crucially depends on the teacher's confidence and attitude in using digital technologies (Conrads et al., 2017; Enochsson and Rizza, 2009).

Moreover, 59\% of teachers in Thailand tend to feel unconfident in preparing lessons that involve ICT. Thai teachers reported lower than average confidence levels in performing tasks such as installing software, using a word processing programme, producing presentations, etc. (Fraillon et al., 2014). Ultimately, the student performance can be constrained if the ability of the teachers to deliver ICT-related lessons is wanting (Box 2.4).

\section{Box 2.4. Perspective on teachers' digital skills from OECD economies}

The OECD Skills Outlook argued that teachers' skills, motivation and attitude are essential to reaping the benefits from ICT use in classrooms. Teachers not only need basic digital skills allowing them to use a computer, but also more complex digital skills that allow them to tailor the use of technology for their own teaching. Student performance in general is highly correlated with the quality of teachers, and this is also true for ICT skills. It is estimated that students' test scores in computational problem solving and mathematics could increase by $50 \%$ in some countries were they to increase their teachers' problem-solving skills in a technological environment to the level of the OECD's front runner in this field, Australia.

Evidently, even among OECD economies, there is a large disparity in the ability of the teachers to use ICT tools (OECD, 2016a). Australia has the highest teacher proficiency in ICT, with only $5 \%$ rated as low performers and $63.5 \%$ as high performers. In Israel, in contrast, $29 \%$ of teachers are lower performers and $30 \%$ are top performers. In most OECD countries, more than $30 \%$ of teachers declare a need for further training to perform their duties, and one in five specifically mentions the need to develop their ICT skills for teaching. Training in ICT skills for teaching is one of the most needed types of professional development reported by teachers in the OECD Teaching and Learning International Survey (TALIS) (OECD, 2019b). 
The key to improving teachers' confidence is training. Thailand has already made significant efforts towards preparing teaching staff for the digital era. Future teachers are required to master ICT to fulfil their training (OECD/UNESCO, 2016), and research has shown that Thai teachers display higher than average participation rates in ICT related-professional development activities (Fraillon et al., 2014). Such activities include "training-the-trainer" schemes, where a few teachers transmit the relevant knowledge to their colleagues, school-organised training sessions and external training sessions organised by Education Service Areas. Through digital tools, effective professional learning communities can be built to share best practises across the country. Teachers in Thailand often miss the link between theory and practice (TDRI, 2019), in particular in rural areas. It follows that Thai training schemes should put more emphasis on meaningful uses of technology in the classroom. Teacher confidence could be increased by making ICT skills transmission more intuitive through more hands-on work during teacher training.

A good practice example is Chile, where the government has promoted the use of ICT in schools since the 1990s. Chile now boasts a teaching force with high confidence in the pedagogical use of ICT relative to the other OECD countries (OECD, 2019b). Chile's programme involves initial in-person training before gradually moving on to use of ICT tools at a distance so that teachers can experience the potential of ICT in learning processes. Another example is Israel, where teachers earn credits that lead to wage improvements upon successful completion of the ICT training programme, a strong motivational factor (OECD, 2019b).

Exploring ways to train teachers merits greater attention. A survey-based study found a need for innovation in teacher training to improve their understanding of ICT applications and practical skills (Akarawang, Kidrakran and Nuangchalerm, 2015). Issues raised in the study include: insufficient attention to teachers' needs in teacher-training curricula; distant training locations and limited training time; greater focus on description than on practical aspects; and poor post-training support. The study proposed exploring blended methods that combine traditional training and computer-based instruction, as well as web-based training, which can give teachers practical experience and help overcome scheduling and distance constraints. More than two-thirds of the survey participants expressed support for the blended method.

Thailand has taken many initiatives to bridge gaps in teacher training over the years. For example, the Lead Teacher Programme of the Institute for the Promotion of Teaching Science and Technology commenced in 1999 (OECD/UNESCO, 2016). Private-sector companies have been involved in this endeavour (e.g. the Microsoft Partners in Learning programme and Intel's Teach Thailand programme), as have schools and universities that organise ICT training for teachers. A related undertaking is Teacher Training on ICT Devices and Teaching Methods for Migrant and Thai Teachers, now being conducted for the third time. In this initiative, teachers are taught to use tablets with a learning app that contains e-learning materials in the Thai, Burmese and Karen languages (UNESCO, 2018b). They are also trained in the use of Trueplookpanya satellite TV, the Internet and teaching techniques by experts from the Ministry of Education and its private partners, and they are expected to come up with ICT-integrated lesson plans as a result.

\section{Viet Nam: Strengthening vocational education to meet demand for digital skills}

Viet Nam has shown outstanding performance in general education, with PISA scores equivalent or higher than the OECD average (OECD, 2016b). Yet at a time when demand for digital skills is growing in the country, ICT education is insufficient. According to UNESCO 
data, very few tertiary education students are graduating from ICT programmes: $1.34 \%$ in 2015 and $2.06 \%$ in 2016 (UNESCO, 2019b). Meantime, the local job market is seeking talent in big data, cloud computing, software and user testing, software engineering management and mobile development (LinkedIn, 2017). In order to bridge the gap between supply and demand, and as general education is insufficient to achieve this goal at the moment in the country, Viet Nam needs to strengthen its Technical and Vocational Education and Training (TVET) in the field of ICT. In addition, the existence of lifelong learning programmes in the country, as indicated in Table 2.6, could be an alternative to tackle the supply-demand gap.

Table 2.6. Key figures on ICT and education sectors in Viet Nam

\begin{tabular}{lll}
\hline Access to digital technologies, 2018 or latest year available & $70.3 \%$ \\
\hline a. $\quad$ Percentage of individuals using the Internet & 147.2 \\
\hline b. Mobile-cellular telephone subscriptions per 100 inhabitants & \\
\hline TVET and lifelong learning, 2018 or latest year available & Yes \\
\hline c. $\quad$ Existence of lifelong learning opportunities & \\
\hline
\end{tabular}

Source: a and b: ITU (2019b); c: UIL (2017).

Viet Nam's most recent national development plan recognises the importance of vocational education and training in fields such as software development, computerisation and automation (GOV, 2016). However, to make TVET for digital skills more effective, a number of problems need to be addressed. Despite rapid improvements in general qualification in recent years, vocational teachers remain weak in computer skills, which limits their ability to provide quality ICT training (Figure 2.6). A 2017 survey by National Institute for Vocational Education and Training (NIVET) indicates that the overwhelming majority of vocational teachers $(88.4 \%)$ do not possess certificates of national occupational skills (NOS), which assess skills for occupations including IT and computer programming. Partly as a result, most training curricula are developed by teaching staff with outdated knowledge and disconnection from industry, and do not correspond to the requirements of the workplace (ADB, 2014). This is especially critical for digital skills training, as digital technologies update at a significantly faster pace than other occupational knowledge.

\section{Figure 2.6. Vocational teachers with satisfactory computer skills in Viet Nam, 2017}

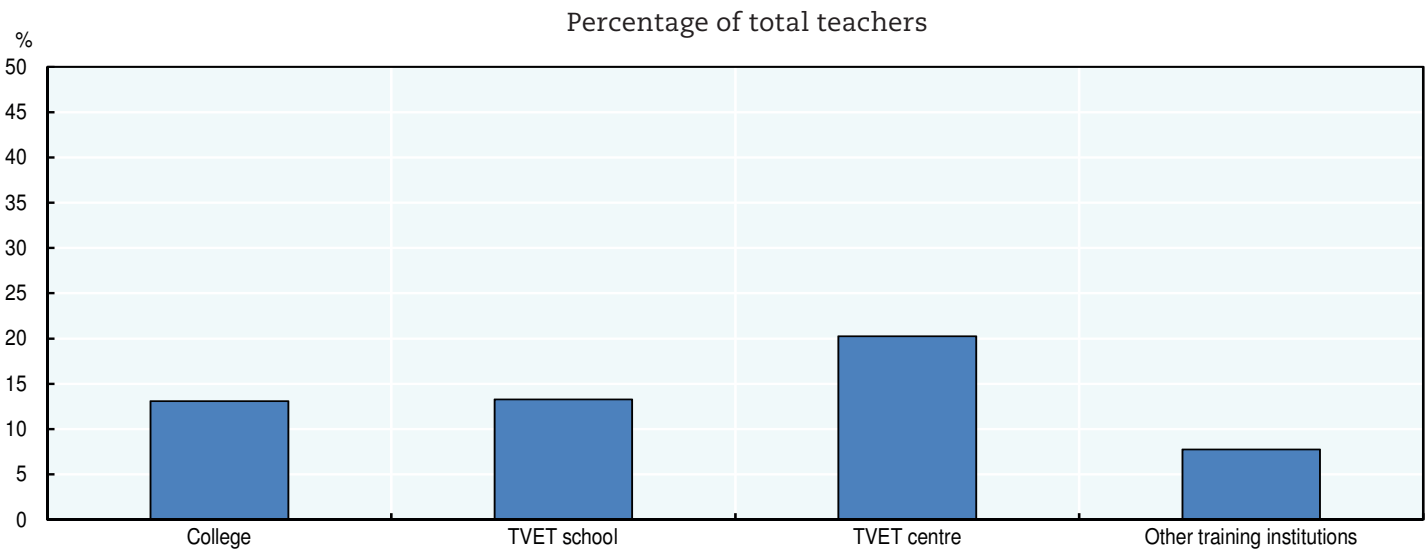

Note: The data refer to teachers in under-enterprise TVET institutes which are institutes that operate under enterprises, companies or business corporations to provide training.

Source: OECD Development Centre calculation based on NIVET (2018).

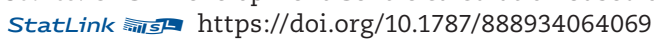

To strengthen TVET for digital skills training, vocational teachers need improved ICT capabilities. Policy makers should place more emphasis on TVET centres, which 
tend to have a lower share of teachers with satisfactory computer skills. While the NOS certification system could be useful in assessing the digital skills of teachers, low participation remains an issue; the government should raise awareness of the benefits of obtaining NOS certificates to encourage higher exam attendance. Finally, the government should invite participation of all stakeholders in fostering digital skills and enhance collaboration among government agencies, TVET institutions and the private sector to ensure that training curricula are consistent with labour market requirements.

In a separate development, Viet Nam's Ministry of Education unveiled a new general curriculum in December 2018 after years of planning and consultation. Among the changes, this curriculum incorporates compulsory ICT courses at all three levels of basic education: primary, lower secondary and upper secondary (MOET, 2018a). More than 20 subject programme guidelines were issued, including one in computer science and another in technology (MOET, 2018b). The new curriculum is to be implemented on a staggered basis over 2020-25. The overarching idea is to modernise the basic education system, integrate the levels more seamlessly and open more learning options for students. The curriculum also seeks to ensure the quality of outcomes vis-à-vis job market demands through more flexible teaching methods. ICT is set to play a crucial role in teaching and learning within this framework, in line with the socio-economic and development plan 2011-15 (World Bank, 2015).

A significant challenge is ensuring that disruptions during the shift are not substantial, especially in terms of the availability of resources and teachers in all schools across the country. For instance, considering the expansion of the ICT course in the new core curriculum, it may be difficult to meet demand for highly qualified computer-science teachers.

At the same time, 55\% of Viet Nam's teachers report a high need for professional development in ICT skills for teaching (OECD, 2019b). This is despite the fact that $80 \%$ say they feel well prepared for the use of ICT for teaching (Figure 2.7). The high demand for further training on how to use ICT in class is an encouraging signal moving forward.

Figure 2.7. Teachers' attitudes towards the use of ICT for teaching

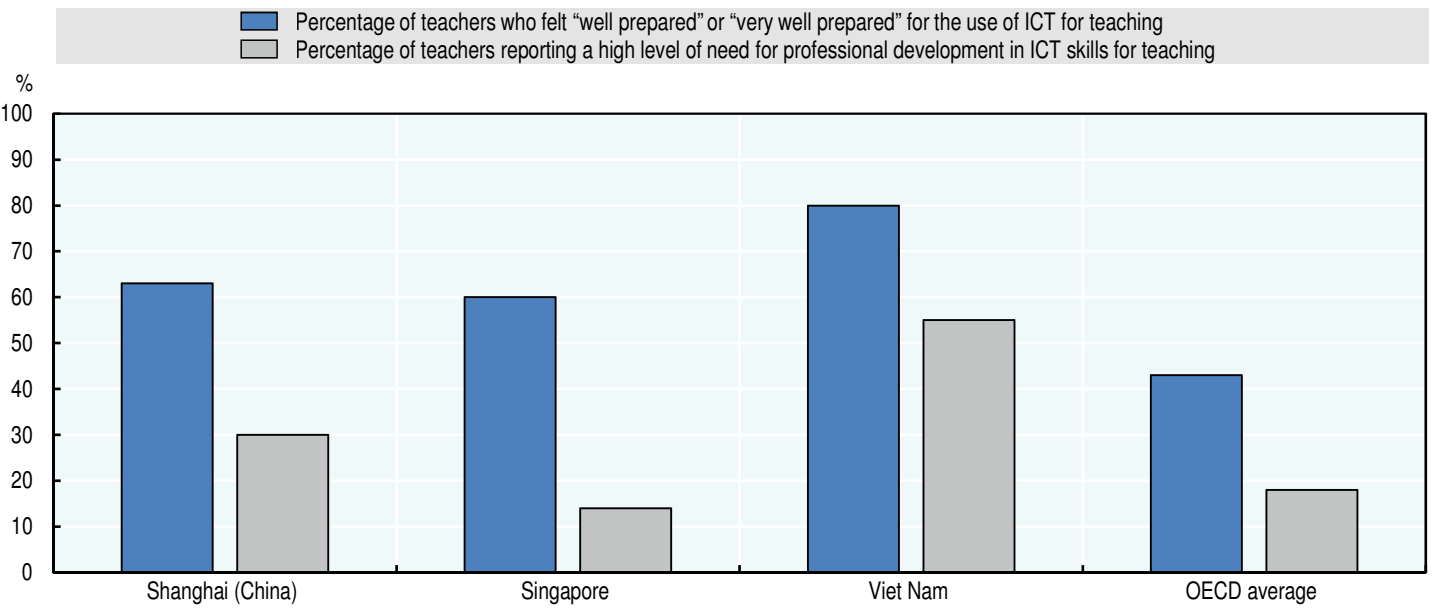

Source: OECD (2019b), TALIS 2018 Results (Volume I): Teachers and School Leaders as Lifelong Learners, TALIS, https://doi. org/10.1787/1d0bc92a-en.

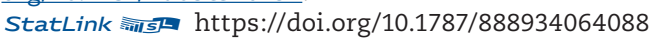

The Enhancing Teacher Education Programme, which aims to train and re-train teachers and academic administrators and is jointly supported by the government and the World Bank, will be crucial in this respect. Indeed, despite progress in developing a 
teacher training plan and preparing for the first teacher-training module, a number of shortcomings remain (World Bank, 2019).

Specifically, the government is urged to work more on: technical risks; the implementation capacity and resources of the Ministry of Education, its programme management unit and the lead teacher-training universities; and the operability of implementation arrangements.

Meeting the objectives of the new curriculum will depend on the success of the Master Plan on Information Technology Application (IT) in Education, which is currently being developed (MOET, 2019). Key elements include identifying potential synergy areas between the business and education sectors, especially at the primary and secondary levels, and broadening linkages between basic and higher education institutions in the ICT sphere. A promising example is the collaboration between the Ministry of Education and the Royal Melbourne Institute of Technology University Vietnam, which trains teachers on digital strategies in classrooms (RMIT, 2016a; 2016b).

\section{Brunei Darussalam: Fostering teachers' capacity for ICT use in classrooms}

Brunei Darussalam has made significant efforts to integrate ICT into classrooms, with $100 \%$ of primary and secondary schools connected to both the Internet and fixed broadband (Table 2.7). This represents the highest level in the region, along with Singapore (UIS, 2014).

Table 2.7. Key figures on ICT and education sectors in Brunei Darussalam

\begin{tabular}{|c|c|c|}
\hline \multicolumn{3}{|c|}{ Access to digital technologies, 2018 or latest year available } \\
\hline a. & Percentage of individuals using the Internet & $94.6 \%$ \\
\hline b. & Percentage of females using the Internet & $94.6 \%$ \\
\hline c. & Percentage of males using the Internet & $94.6 \%$ \\
\hline d. & Percentage of individuals using a computer & $58.0 \% * *$ \\
\hline e. & Mobile-cellular telephone subscriptions per 100 inhabitants & 131.9 \\
\hline f. & Proportion of primary schools with Internet and fixed broadband & $100 \%$ *** \\
\hline g. & Proportion of secondary schools with Internet and fixed broadband & $100 \% * * *$ \\
\hline \multicolumn{3}{|c|}{ TVET and lifelong learning, 2018 or latest year available } \\
\hline h. & Share of all students in secondary education enrolled in vocational programmes & $11.9 \%$ \\
\hline i. & Share of female students in secondary education enrolled in vocational programmes & $11.5 \%$ \\
\hline j. & Share of male students in secondary education enrolled in vocational programmes & $12.3 \%$ \\
\hline k. & Existence of lifelong learning opportunities & Yes \\
\hline
\end{tabular}

Note: $\left({ }^{* *}\right) 2016$ data, $\left({ }^{* * *}\right) 2012$ data.

Source: a, b, c, d and e: ITU (2019b); f and g: UIS (2014), h, i, and j: UNESCO (2019b); k: UIL (2017).

The government has also sought to strengthen ICT in the curriculum within the framework of the National Education System for the 21st Century, which offers preschoolers an introduction to ICT and proposes ICT as a general subject from grades 1 to 8 and as an optional subject from grades 9 to 11 in general secondary education (MOE Brunei Darussalam, 2013).

To complement this effort, the country aims to transform traditional teaching and learning activities into interactive classrooms with technologies via an initiative called e-Hijrah, Brunei's Darussalam's blueprint for ICT in education. The programme has allowed some schools to be equipped with iPads for teaching and learning purposes. This has increased student motivation and improved students' performance in group activities (Finti, Shahrill and Salleh, 2016).

The government also provides training for teachers as part of e-Hijrah, and many now use ICT tools in the classroom. However, there is room for improvement in the ability of teachers to translate this training into effective teaching. 
For instance, with ICT-based learning activities prepared by teachers, primary school students did not demonstrate conceptual understanding when they were asked to apply their knowledge in a new context (Ali, Salleh and Shahrill, 2015). Another study found that the willingness of secondary school teachers to use ICT tools such as liquid crystal display (LCD) projectors was hampered by the inconvenience of setting up the equipment (Ismail, Shahrill and Mundia, 2015).

These studies confirm that more can be done to maximise the benefit of Brunei Darussalam's advanced ICT infrastructure at schools by improving teachers' technical and pedagogical capacity in the use of digital technologies.

\section{Singapore: Strengthening teachers' belief in ICT use in the classroom}

Singapore has been integrating ICT into its education system since 1997 through five-year masterplans developed by the Ministry of Education. The first masterplan put emphasis on building a foundation by conducting ICT training for teachers, providing ICT infrastructure for all schools and facilitating educational software and resources. Since then, there has been continuous scaling up and strengthening of the use of ICT at schools.

The current level of ICT infrastructure in Singapore's classrooms attests to this programme's success: $100 \%$ of public primary and secondary schools have access to computers and Internet for pedagogical purposes (Table 2.8). In addition, primary schools have a learner-to-computer ratio of 4:1 (UIS, 2014). This represents the lowest (best) ratio among neighbouring countries in the Southeast Asia region.

Table 2.8. Key figures on ICT and education sectors in Singapore

\begin{tabular}{llc}
\hline Access to digital technologies, 2018 or latest year available & \\
\hline a. & Percentage of individuals using the Internet & $88.2 \%$ \\
b. $\quad$ Percentage of females using the Internet & $87.6 \%$ \\
c. $\quad$ Percentage of males using the Internet & $88.8 \%$ \\
d. $\quad$ Percentage of individuals using a computer & $73.5 \%^{*}$ \\
e. $\quad$ Mobile-cellular telephone subscriptions per 100 inhabitants & 145.7 \\
f. $\quad$ Proportion of public secondary schools with access to Internet for pedagogical purposes & $100^{*}$ \\
g. Proportion of public secondary schools with access to computers for pedagogical purposes & $100^{*}$ \\
\hline TVET and lifelong learning, 2018 or latest year available & Yes \\
\hline h. $\quad$ Existence of lifelong learning opportunities & \\
\hline
\end{tabular}

Note: $\left(^{*}\right) 2017$ data.

Source: a, b, c, d and e: ITU (2019b); f and g: UNESCO (2019b); h: UIL (2017).

The government is also seeking to shift the teaching paradigm to allow students to learn independently and collaboratively. Conventional teaching methods, where the teacher is the centre of the class, are being replaced by a student-centric system. The government's desired outcome is that this new approach will allow students to develop self-directed and collaborative learning through the use of digital tools (Choi, 2015).

Singapore also aims to improve students' personal development with a more holistic curriculum and value-driven approach. The objective is to equip them with the 21st century skills that will be needed in the digital age, such as collaboration and critical and inventive thinking (MOE Singapore, n.d.b.). This is in line with a recent study indicating that the critical skills most difficult to find by enterprises include strategic thinking, problem solving, technical knowledge and soft skills such as creativity and innovation (ILO, 2016).

At the same time, teachers are being challenged to improve their teaching methods in order to make the most of ICT use. The current masterplan, which has been implemented since 2015, emphasises the quality of overall ICT integration in the education system. 
However, according to the 2018 OECD Teaching and Learning International Survey (TALIS), the percentage of Singapore's teachers who frequently or always let students use ICT for project or class work stands at 43\%, below the OECD average of 53\% (OECD, 2019b). Fostering teachers' and school leaders' belief in the value-added impact of ICT use is essential in order for best practices of ICT integration - which are applied in five pioneer schools under the initiative of FutureSchools@Singapore - to be diffused to all schools in Singapore.

\section{Cambodia: Improving ICT infrastructure and power supplies for better access}

Cambodian students have positive attitudes towards the use of digital technology. A study comparing Cambodian and Japanese students found that, given a choice between technological tools and non-technological tools, such as paper, Cambodian students preferred technology in every instance, while Japanese students took a more varied approach to the use of both tools (Elwood and MacLean, 2009). Yet Cambodia's schools face ICT challenges including a lack of computers, poor Internet access, a shortage of teachers qualified in ICT and, perhaps most importantly, unreliable electricity supplies.

The government has taken steps to address these challenges, but there is room for improvement. Regarding Internet access, the government signed a Memorandum of Understanding with a telecommunications operator in 2009 to increase the number of schools with an Internet connection (MOEYS, 2014). However, the connection covered only 500 of the country's 4000 schools (UN-OHRLLS, 2018). The agreement was renewed in 2015 to expand Internet coverage to all public schools.

Better teaching capacity in ICT would boost the potential shown by Cambodian students' positive attitudes towards digital technology, as indicated by Elwood and MacLean (2009). The government has introduced policy actions to improve the quality and efficiency of the education service, one of which concerns ICT training for all trainers and secondary teachers. However, a shortage of trained teachers persists, especially in ICT, the sciences and foreign languages. In this regard, the authorities plan to focus on strategies to improve teachers' capacity through training in specific subjects, including ICT (MOEYS, 2016).

Another government initiative aims to strengthen teachers' capacity by providing digital materials through open educational resources. The Ministry of Education, Youth and Sport created a website offering a wide range of materials, including interactive multimedia, posters and digital lesson plans, covering different subjects at different educational levels (MOEYS, n.d.). The website also offers manuals, tutorials and templates, as well as information to help teachers create their own digital teaching resources.

Such efforts should be accompanied by improved access to computers, the Internet and electricity. As of 2012, the proportion of combined public primary and secondary schools with access to Internet was 7\% (Table 2.9). In the same year, a reliable power source for ICT use was available in only $7 \%$ of Cambodia's public primary schools and $24 \%$ of its public secondary schools (UNESCO, 2012). Power shortages occur frequently due to the high cost of electricity and unstable supplies. This creates restrictions on computer use outside class hours, with exceptions for administrative tasks performed by teachers. As a result, electricity represents the major challenge for integrating ICT use in Cambodia's education system. 
Table 2.9. Key figures on ICT and education sectors in Cambodia

\begin{tabular}{lc}
\hline Access to digital technologies, 2018 or latest year available & \\
\hline a. $\quad$ Percentage of individuals using the Internet & $40.0 \%$ \\
b. $\quad$ Percentage of females using the Internet & $40.0 \%$ \\
c. $\quad$ Percentage of males using the Internet & $40.0 \%$ \\
d. $\quad$ Percentage of individuals using a computer & $27.4 \%^{*}$ \\
e. $\quad$ Mobile-cellular telephone subscriptions per 100 inhabitants & 119.5 \\
f. $\quad$ Percentage of public primary and secondary schools with access to Internet & $7 \%^{* * *}$ \\
\hline TVET and lifelong learning, 2018 or latest year available & Yes \\
\hline g. $\quad$ Existence of lifelong learning opportunities & \\
\hline Note: $\left(^{*}\right) 2017$ data, $\left({ }^{* * *}\right) 2012$ data. & \\
Source: a, b, c, d and e: ITU (2019b); UIS (2014); g: UIL (2017). &
\end{tabular}

\section{Lao PDR: Increasing access to ICT tools for both teachers and students}

Lao PDR faces ICT infrastructure challenges similar to those of Cambodia. The Internet is costly and its speed is unsatisfactory. In addition, ICT equipment is taxed at $30 \%$, creating an affordability barrier for users (MPT, 2017). The high cost to users is also due to the fact that Lao PDR relies for Internet access on resellers in Thailand and Viet Nam. This because, as a land-locked country, it does not have direct access to submarine fibre optical cables (Souphavady, 2018).

Lack of ICT infrastructure has affected digital development in Lao PDR. As of 2017, Lao PDR's ICT Development Index was ranked lowest among Emerging Asian countries (ITU, 2017 b). As of 2015 , only $24.5 \%$ of urban households owned a computer (Jeon and Song, 2018). In addition, recent data from ITU revealed that the percentage of individuals who use the Internet was $25.5 \%$ in 2017 (Table 2.10). Computer labs exist in some schools, but not all, and due to a lack of qualified teachers, the school administration uses the labs more frequently than the students do.

Table 2.10. Key figures on ICT and education sectors in Lao PDR

\begin{tabular}{lr}
\hline \multicolumn{2}{l}{ Access to digital technologies, 2018 or latest year available } \\
\hline a. $\quad$ Percentage of individuals using the Internet & $25.5 \%{ }^{*}$ \\
b. $\quad$ Mobile-cellular telephone subscriptions per 100 inhabitants & 51.9 \\
\hline TVET and lifelong learning, 2018 or latest year available & $1.0 \%^{*}$ \\
\hline c. $\quad$ Share of all students in secondary education enrolled in vocational programmes & $1.0 \%^{*}$ \\
d. $\quad$ Share of female students in secondary education enrolled in vocational programmes & $1.1 \%^{*}$ \\
e. $\quad$ Share of male students in secondary education enrolled in vocational programmes & Yes \\
f. $\quad$ Existence of lifelong learning opportunities &
\end{tabular}

Note: $\left(^{*}\right) 2017$ data.

Source: a and b: ITU (2019b); c, d, and e: UNESCO (2019b); f: UIL (2017).

Lao PDR also faces teacher shortages in the natural sciences, physical and arts education, basic vocational skills and ICT (MOES, 2015). A study found that a high number of teachers lack sufficient ICT knowledge and skills, and urged the government to increase teachers' ICT proficiency (Thephavongsa and Liu, 2015). In terms of the curriculum, Lao PDR's Education Sector Development Plan 2016-20 states that a review of lower secondary curricula will specifically address the inclusion of appropriate content for ICT.

One initiative aimed at improving teachers' digital literacy is the Lao LEARN project, conducted by a non-governmental organisation in partnership with the government. Through this programme, teachers were trained to deliver core subjects via tablet-enabled e-training 
and face-to-face training (Aide et Action, 2017). The project also aimed to build an online platform to allow publishers, authors and developers to create digital educational content.

Despite low computer ownership and limited Internet access, mobile phones are highly popular in Lao PDR. They are owned by $94.7 \%$ of urban households and $68.7 \%$ of households in rural areas (Jeon and Song, 2018). Students use mobile devices to communicate with lecturers and to access learning content and social media. Yet the development of both e-learning and m-learning is hindered by insufficient resources and training (Murphy, Jones and Farley, 2016). In order to maximise the benefits of mobile phone ownership, the government's ICT education policy should view mobile phones as a digital gateway in the education sector.

\section{Myanmar: Providing quality ICT to all schools}

Myanmar, which is undergoing rapid changes in its transition to an open economy, needs to make a major effort to catch up with its neighbours in terms of development while at the same time preparing for the digital era. Myanmar is advancing quickly in mobile Internet deployment, with more than $90 \%$ of the country now covered by $4 \mathrm{G}$ Internet (Opensignal, 2018). Electrification, at 34\% nationwide in late 2016, is expanding rapidly as well to meet the target of $100 \%$ coverage by 2030 (GIZ, 2017). To make the most of these investments, human capital must be developed accordingly.

The first step is to provide access to ICT at schools. However, data from UNESCO show that only $27.4 \%$ of primary schools and $59.3 \%$ of lower secondary schools have access to electricity, making it hard to bring in any form of ICT into classrooms (UNESCO, 2019b). In addition, only $0.9 \%$ of primary schools have computers, and just $0.8 \%$ of primary schools have access to the Internet. In public secondary schools, digitalisation has been underway for a few years, with $71.2 \%$ of public secondary schools equipped with computers in 2016. Yet access to Internet remains limited, with only $0.3 \%$ of public secondary schools having access in 2017 (Table 2.11). At lower secondary level, 55.6\% of public lower secondary schools were equipped with computers in 2016 and none of these computers were connected to the Internet (Figure 2.8). These data indicate that Myanmar must invest heavily to meet the needs of its students, and it might want to do so in a targeted way, given resource constraints and the large gap to be filled.

Table 2.11. Key figures on ICT and education sectors in Myanmar

\begin{tabular}{|c|c|c|}
\hline \multicolumn{3}{|c|}{ Access to digital technologies, 2018 or latest year available } \\
\hline a. & Percentage of individuals using the Internet & $30.7 \%$ * \\
\hline b. & Mobile-cellular telephone subscriptions per 100 inhabitants & 113.8 \\
\hline C. & Proportion of public secondary schools with access to Internet for pedagogical purposes & $0.3 \%$ * \\
\hline d. & Proportion of public secondary schools with access to computers for pedagogical purposes & $71.2 \%$ ** \\
\hline \multicolumn{3}{|c|}{ TVET and lifelong learning, 2018 or latest year available } \\
\hline e. & Share of all students in secondary education enrolled in vocational programmes & $0.2 \%{ }^{*}$ \\
\hline f. & Share of female students in secondary education enrolled in vocational programmes & $0.1 \%{ }^{*}$ \\
\hline g. & Share of male students in secondary education enrolled in vocational programmes & $0.2 \%{ }^{*}$ \\
\hline h. & Existence of lifelong learning opportunities & Yes \\
\hline
\end{tabular}

Note: $\left(^{*}\right) 2017$ data, $\left({ }^{* *}\right) 2016$ data.

Source: a and b: ITU (2019b); c, d, e, f and g: UNESCO (2019b); h: UIL (2017). 
Figure 2.8. Access to basic services at public lower secondary schools

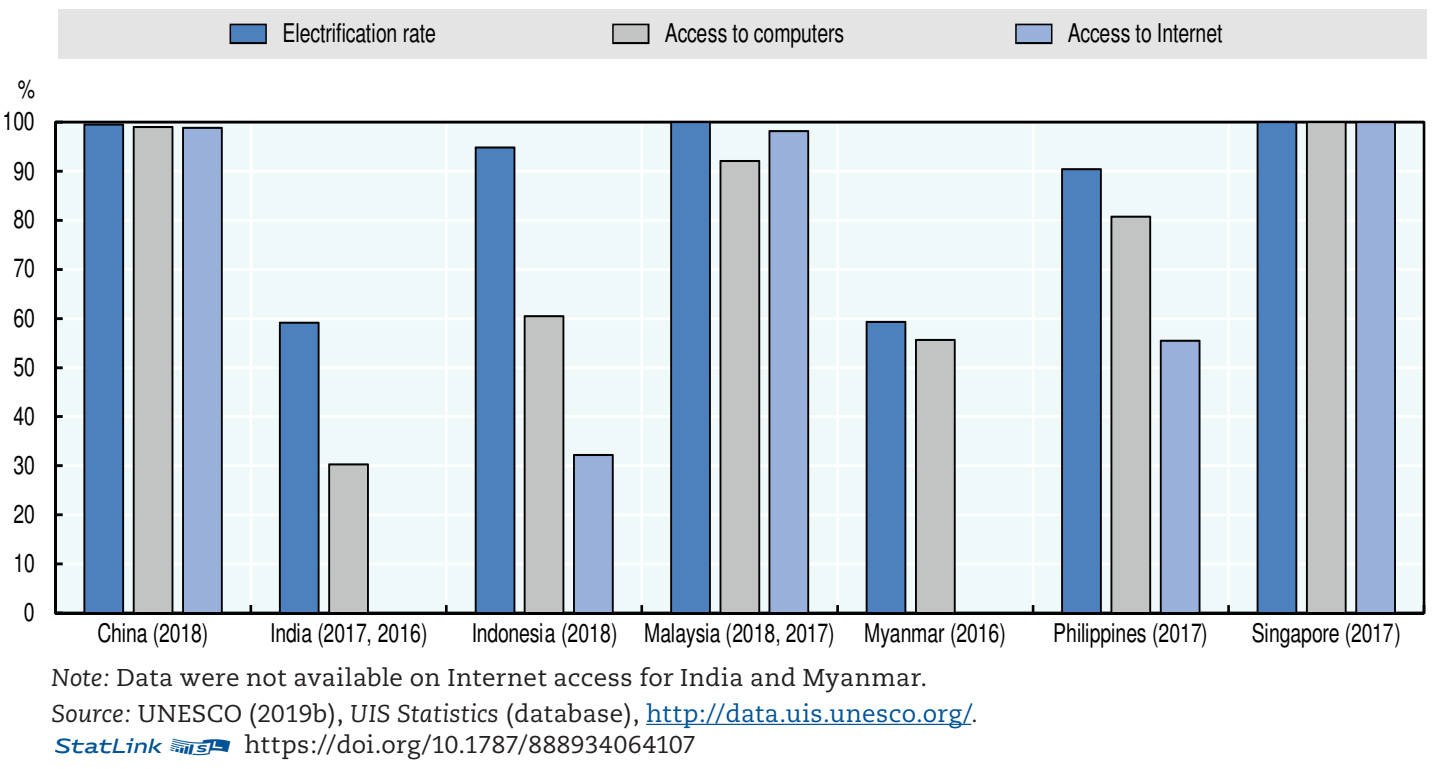

Options exist to reduce the costs of computerisation, for instance through the use of multi-seat computers or networked PCs. The simultaneous use of a single central processing unit and server for multiple individual keyboards and monitors is a way to ease the effects of computer shortages (OECD, 2016b). Furthermore, focusing on first providing teachers with computers might lead to higher value-for-money under a tight budget. Research has shown that ICT investments dedicated to teachers tend to yield higher student performance gains than increases in the number of computers per student (OECD, 2019a).

Internet access at schools needs to be expanded in Myanmar, as most schools across all levels of teaching do not have a connection. Using the country's 4G network to achieve this goal will probably not be enough, as the current downloading speed achieved by the network is slightly below $30 \mathrm{Mbps}$ (Opensignal, 2018). Research recommends a connection of at least $500 \mathrm{Kbps}$ per student for browsing the web, meaning that a connection to Myanmar's 4G network could support a maximum of 60 students working simultaneously (Fox et al., 2012). Broadband Internet therefore needs to be developed in the country and the quality of the Internet connection should be monitored on an Mbps per student basis (OECD, 2016b).

In addition, a recent study found that Myanmar had not yet integrated ICT into the school curriculum and that the limited ICT equipment available, such as computers and video projectors, often sat idle due to the inability of teachers to use the Internet (Blevins et al., 2018). Limited computer literacy among teachers is thus a major challenge.

Various public-private partnership initiatives have sought to address this challenge. For instance, under the Connect to Learn initiative in 2018, nearly 300 teachers in Myanmar were trained to use ICT in day-to-day classroom teaching (Ericsson, 2018). The programme enabled the teachers to put together teaching materials based on information found on the Internet and to create a virtual community for sharing their experiences and knowledge. Still, more efforts are needed to improve teachers' digital literacy and to integrate ICT use into the curriculum in Myanmar's education system. 


\section{China: Bridging the digital talent gap between demand and supply}

The digital economy, an important engine of growth in China, has seen substantial development in the last decade. The size of the digital economy, including digital industries and digitalised traditional industries, exceeds CNY 31 trillion (Chinese yuan renminbi) and accounts for more than $34.8 \%$ of GDP (CAICT, 2019). In response to this trend, the government placed development of the cyber economy in a prominent position in its $13^{\text {th }}$ Five-Year Plan (2016-20) and vowed to deepen the integration of information technology in economic and social development through China's Internet+ initiative (CCCPC, 2016). However, in order to achieve this objective and ensure healthy development of the digital economy, China needs to address the widening gap between demand for digital skills and supply.

The number of available digital jobs in China has been growing at double-digit rates, with annual demand projected to reach 12.46 million positions in 2020, almost double the level of 2017 (Huawei and CCW, 2018). Labour market demand surpasses the supply of digital talent in terms of both quality and quantity. The shortage is due to several factors. First, while university graduates in ICT-related fields make up the majority of science graduates in China each year, their number - around 1 million annually - is far below the digital skills gap of around 10 million in the country. Second, not all of these ICT graduates have reached the digital qualification required by industry due to a skills mismatch between school instruction and actual work requirements (Chen and Ma, 2017). Third, due to the growing importance of digitalised traditional industries, which in 2018 accounted for 178 million of a total of 191 million digital jobs (CAICT, 2019), most positions involving digital skills will require cross-sector experience, such as agriculture for digital farming, retail trade for e-commerce and transportation for the ride-sharing business. The supply of such hybrid skills is scarcer than the supply of pure digital skills in China at the moment. Fourth, a large portion of future demand will centre around advanced digital areas, including cloud computing, big data, the Internet of Things and artificial intelligence. These require more advanced training than basic college-level ICT education, which tends to focus on programming skills.

To address these challenges, the government needs to focus on both digital education at schools and digital training through the vocational education system, as the number of college graduates is not likely to increase drastically in future amid slowing population growth. Improving the digital literacy of the general public, especially people in rural communities, is essential for China to achieve greater development in cyber economy as envisioned in the $13^{\text {th }}$ Five-Year Plan. Based on Internet penetration as an indicator of digital literacy, the number of Internet users in China has increased significantly, from $10.5 \%$ of the total population in 2006 to $54.3 \%$ in 2017, as shown in Table 2.12 (World Bank, 2019b; ITU, 2019b). However, Internet penetration in China's rural areas still trails far behind urban areas, with only around $34 \%$ of the rural population using the Internet (Figure 2.9). By June 2017, there were 201 million rural Internet users, accounting for $26.7 \%$ of total Internet users, and most rural users understand only simple Internet applications such as messaging (CNNIC, 2017). Policies on rural digital development in China tend to focus on building infrastructure. However, a recent survey indicates that non-use of the Internet in China is attributed by only $9.3 \%$ of non-users to "no Internet access devices" and by just $6.2 \%$ "no local access to the Internet", while more than half of non-users cite a lack of computer/Internet knowledge (CNNIC, 2017). In order to raise digital literacy in rural areas, emphasis should thus be placed on education and training programmes in addition to digital infrastructure. 
Table 2.12. Key figures on ICT and education sectors in China

\begin{tabular}{|c|c|c|}
\hline \multicolumn{3}{|c|}{ Access to digital technologies, 2018 or latest year available } \\
\hline a. & Percentage of individuals using the Internet & $54.3 \%$ * \\
\hline b. & Mobile-cellular telephone subscriptions per 100 inhabitants & 114.9 \\
\hline c. & Proportion of public secondary schools with access to Internet for pedagogical purposes & $98.5 \%$ \\
\hline d. & Proportion of public secondary schools with access to computers for pedagogical purposes & $98.3 \%$ \\
\hline \multicolumn{3}{|c|}{ TVET and lifelong learning, 2018 or latest year available } \\
\hline e. & Share of all students in secondary education enrolled in vocational programmes & $18.9 \%$ \\
\hline f. & Share of female students in secondary education enrolled in vocational programmes & $17.2 \%$ \\
\hline g. & Share of male students in secondary education enrolled in vocational programmes & $20.4 \%$ \\
\hline h. & Existence of lifelong learning opportunities & Yes \\
\hline
\end{tabular}

Note: $\left(^{*}\right) 2017$ data.

Source: a and b: ITU (2019b); c, d, e, f and g: UNESCO (2019b); h: National source.

Looking ahead, efforts are needed to ensure that advanced training in ICT is available in classrooms. A road map announced in 2017 outlines China's goal to be the centre of artificial intelligence (AI) by 2030. Given the current extensive development of AI technology, the education sector is key when countries develop national AI strategies (UNESCO, 2019c). Indeed, China plans to establish AI-related courses in primary and secondary schools and gradually to promote programming education (Yu and Chen, 2018).

At present, AI is being taught at many colleges and universities in China, but the discipline has not received much attention in basic education. Development of textbooks, training of teachers and the provision of relevant software and hardware facilities have been slow (Yu and Chen, 2018). It is important to note that the use of AI in education is not intended to replace teachers but rather to make teaching more efficient and fulfilling for teachers (CISTF, 2018). In this respect, teachers' ICT skills are key, since they will have to interpret and implement the new courses.

China has undertaken various initiatives to improve teachers' ICT skills. In 2004, the country developed a national educational technology standard under which teachers are to have necessary ICT knowledge and skills, as well as the ability to apply them. The standard was adopted as a set of compulsory criteria for teacher certification. Teachers are encouraged to facilitate the use of ICT by students in enquiry-based classroom learning activities. They must also receive training and pass assessments based on the standard (UNESCO, 2008).

Despite these efforts, there is room for improvement. Several studies have found that teachers' knowledge of ICT and network technology is still limited in China. One study found that teachers and students in Northwest China were not well prepared for using the Internet for teaching and learning English as a foreign language (EFL) (Zhang, 2013). In another study, which surveyed secondary preservice teachers, participants reported an overall low level of ability to use technology and noted concerns about the technology training they had received (Zhou, Zhang and Li, 2011). 
Figure 2.9. Internet users in China's rural and urban areas, 2014-17 Percentage of regional population

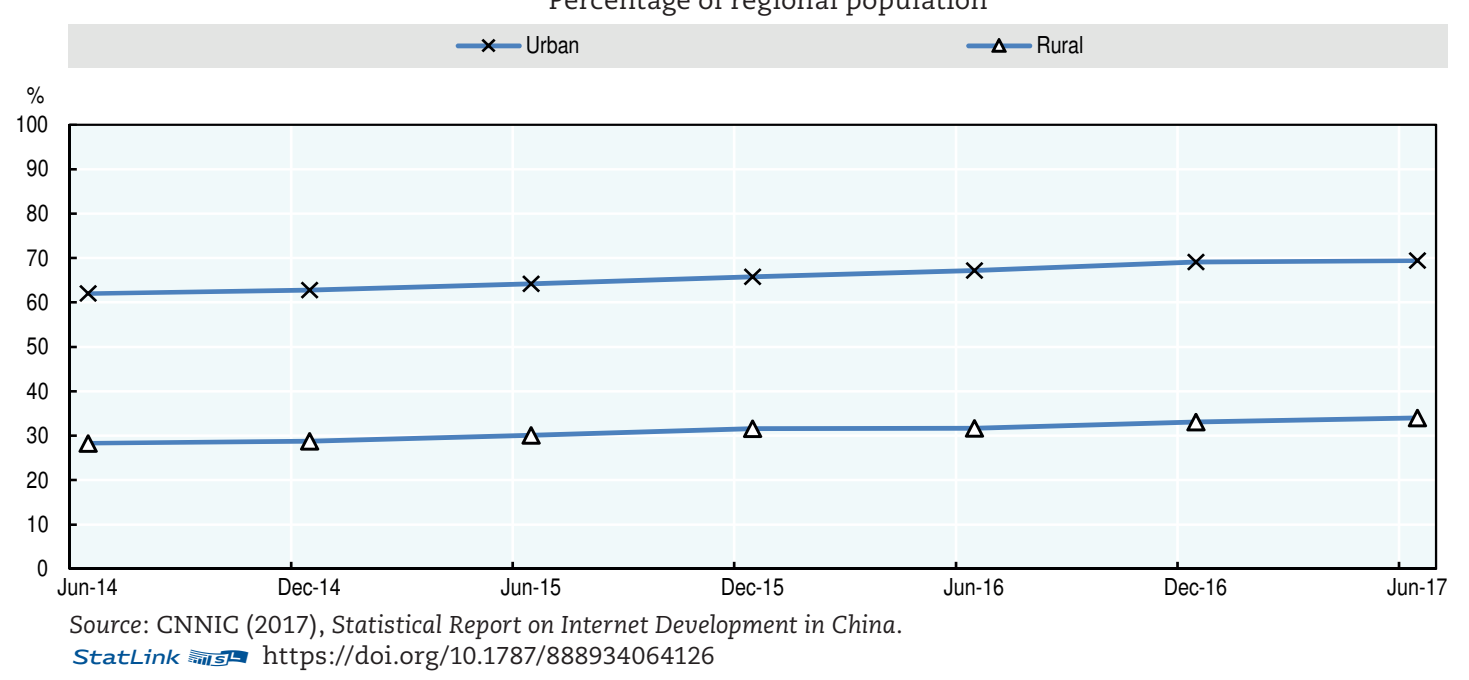

\section{India: Raising digital literacy through broader access to digital devices}

As a major sourcing destination for IT services across the globe, India has demonstrated strong affinity with digital technologies and policy makers have made preparations for the digital era. In 2015, the government launched a nationwide flagship programme called Digital India. It aims to transform the country into a "digitally empowered society and knowledge economy" where digital infrastructure is guaranteed to every citizen as a core utility and government services are digitalised and seamlessly integrated across departments and jurisdictions to improve quality and ensure smooth and timely delivery (MEIT, 2019). However, despite the importance of ICT in the Indian economy and society, data show that India still lags behind its Emerging Asian peers in terms of use of the Internet, computers, social network platforms and smartphones (Figure 2.10). For the majority of Indians to benefit from the country's digital transformation, it is necessary to address the issues of digital literacy and universal access to ICT.

Figure 2.10. ICT usage indicators in selected Emerging Asian countries, 2017

Percentage of adult population (age 15+)

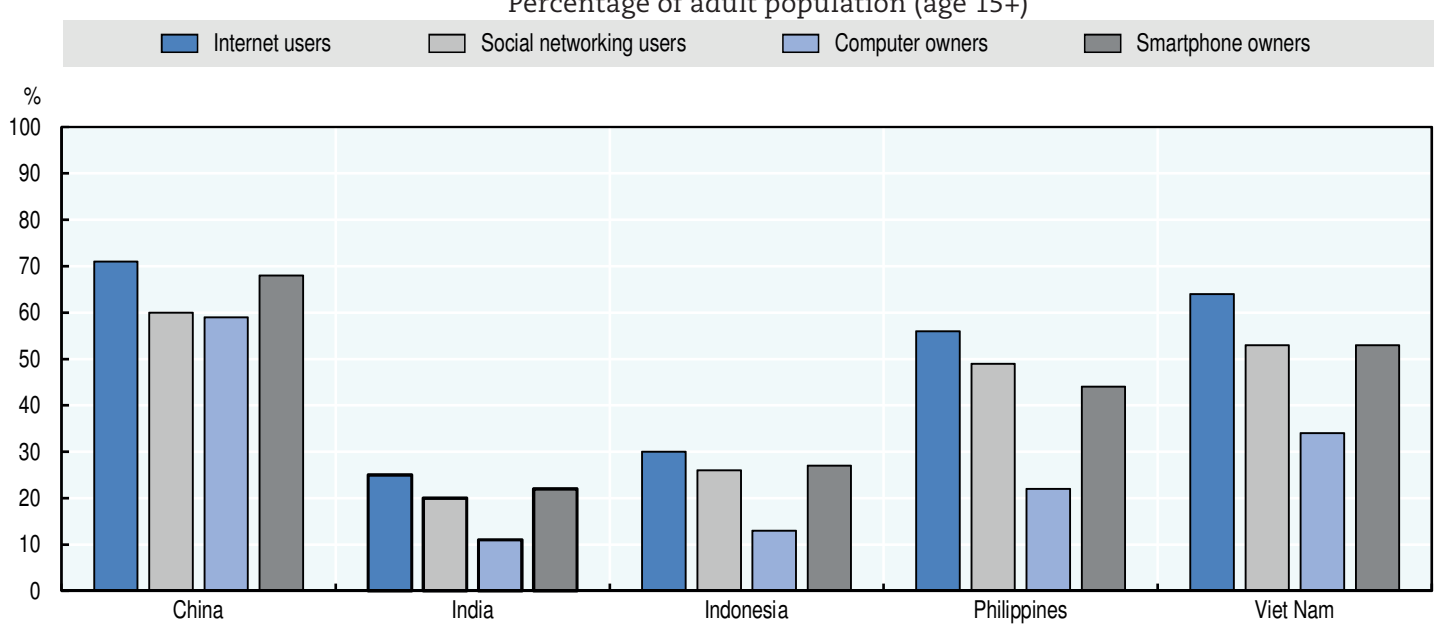

Note: Percentages are based on total survey sample. Computer owner data refer to 2014. Data from China on Internet users, social networking users and smartphone owners are available only for 2016.

Source: Pew (2017), Spring 2017 Global Attitudes Survey; Pew (2014), Spring 2014 Global Attitudes Survey.

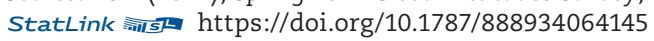


Lack of digital equipment is the biggest challenge for raising digital literacy in India. The National Digital Literacy Mission (NDLM), which was launched in 2014 and aims to train one person per household in selected blocks across India, found that almost half of the graduates from its programme were unable to apply what they learned on a regular basis due to lack of access to digital devices (CSD, 2017).

One approach could be for local governments, the private sector, non-governmental organisations (NGOs) and international organisations to collaborate in providing cheap or even free digital devices to designated regions or populations. However, since offering subsidised or free digital devices might not be financially feasible for all local governments, policy makers could consider creating a cheaper alternative for allowing regular practice of digital skills.

Another important challenge is enhancing both the curriculum and teachers' ICT skills. In 2004, the government launched the ICT@Schools programme, which aimed to provide opportunities for students to build their ICT skills and helped provide schools with ICT infrastructure. New components were added in 2010 and 2012, including incorporating ICT in the teaching-learning process. However, the proportion of public secondary schools with access to computers for pedagogical purposes was only $38.6 \%$ in 2016 (Table 2.13). Another government initiative is an annual national award for teachers who use ICT for innovation in education. The award is given to teachers who effectively and innovatively integrate technology-supported learning into the school curriculum and their teaching, and in so doing promote enquiry-based, co-operative and collaborative learning among students.

Table 2.13. Key figures on ICT and education sectors in India

\begin{tabular}{lcc}
\hline Access to digital technologies, 2018 or latest year available & \\
\hline a. $\quad$ Percentage of individuals using the Internet & $34.5 \%^{*}$ \\
b. $\quad$ Mobile-cellular telephone subscriptions per 100 inhabitants & 86.9 \\
\hline c. $\quad$ Proportion of public secondary schools with access to computers for pedagogical purposes & $38.6 \%^{* *}$ \\
\hline TVET and lifelong learning, 2018 or latest year available & $1.3 \%$ \\
\hline d. $\quad$ Share of all students in secondary education enrolled in vocational programmes & $0.5 \%^{* *}$ \\
e. $\quad$ Share of female students in secondary education enrolled in vocational programmes & $2.1 \%^{* *}$ \\
f. $\quad$ Share of male students in secondary education enrolled in vocational programmes & Yes \\
\hline g. $\quad$ Existence of lifelong learning opportunities &
\end{tabular}

Note: $\left({ }^{*}\right) 2017$ data, $\left({ }^{* *}\right) 2016$ data.

Source: a and b: ITU (2019b); c, d, e and f: UNESCO (2019b); g: National source.

More recently, knowledge-sharing platforms have been introduced that allow interactive teacher training. One of the most comprehensive is the Human Resource Development Ministry's DIKSHA (Digital Infrastructure for Knowledge Sharing) platform. This platform integrates ICT into all aspects of education, including teacher professional development, student assessment tools, data collection and analysis, and communication among teachers, students and parents. However, its implementation varies widely, depending largely on the capacity of states to implement the platform and to communicate and share best practices with each other (Bajpai, Biberman and Sharma, 2019).

\section{Vocational and lifelong learning as paths to digital inclusion}

TVET and lifelong learning have an important role to play in providing education for the digital era. As alternative paths of education, they have the potential to provide digital skills while at the same time taking inclusion into account. However, challenges need to be addressed, including enhancing the image and attractiveness of TVET, encouraging private-sector involvement, improving monitoring of lifelong learning programmes and broadening publicity campaigns to boost participation. This section begins by examining the current status of TVET in Emerging Asia and within the OECD. 


\section{Rethinking vocational education in the digital era}

TVET focuses on preparing students for work, with education and training programmes that are designed for, and typically lead to, a particular job or type of job. The programmes normally involve practical training as well as relevant theory (OECD, 2010). TVET usually begins at upper secondary level (ISCED 3), and typically continues at the post-secondary level. However, TVET starts as early as lower secondary level (ISCED 2) in some OECD countries, including Australia, and some Emerging Asian countries, such as China, India, Malaysia and Viet Nam, for example in India in classes 9 and 10.

In most Emerging Asian countries, secondary-level enrolment is generally much lower in vocational schools than in general education (Figure 2.11). In some countries, almost $100 \%$ of secondary school students are enrolled in general education institutions. In contrast, in some OECD countries, such as Finland, the United Kingdom and Belgium, students participate almost equally in general and vocational secondary education, with more than $45 \%$ of students enrolled in vocational education in 2016.

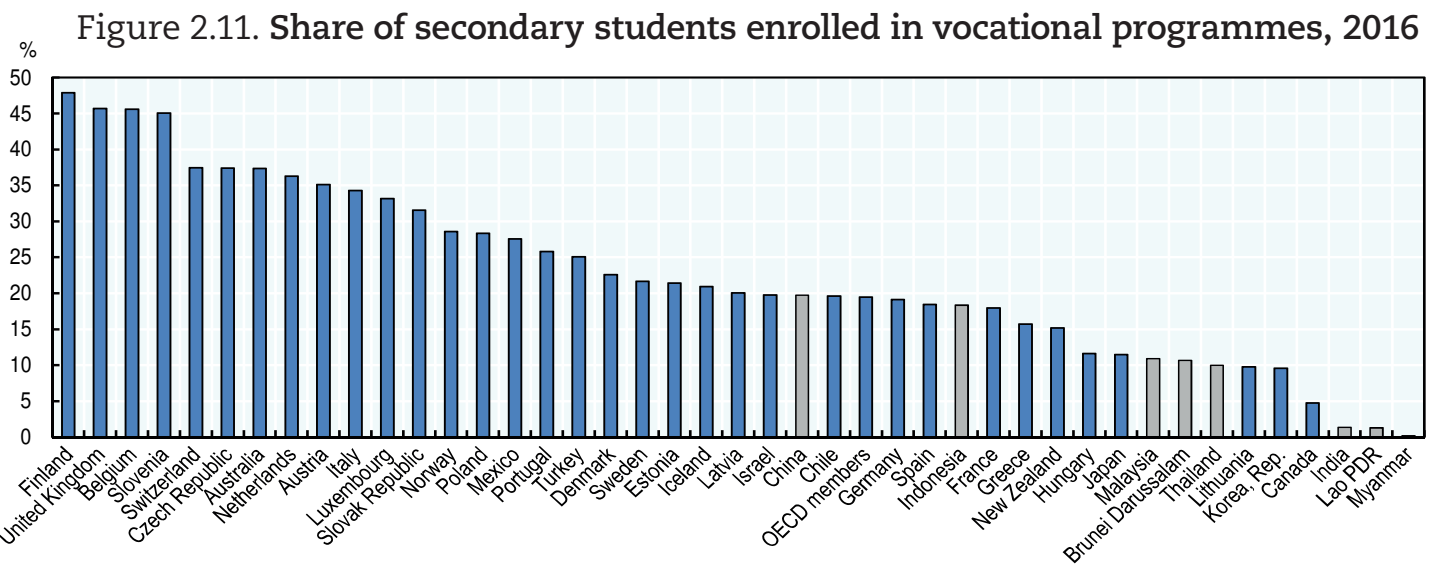

Source: UNESCO (2019b), UIS Statistics (database), http://data.uis.unesco.org/.

StatLink 解年 https://doi.org/10.1787/888934064164

Digitalisation involves science, technology and engineering as well as ICT skills, and vocational education is playing a role in this area. In some countries, ICT training already makes up a significant part of TVET programmes. In Indonesia, for instance, around $56 \%$ of vocational secondary schools are focusing on ICT, and around $46 \%$ on technology and engineering, according to Ministry of Education and Culture data. In other countries, vocational education involves some form of e-learning. In Australia, for example, a 2013 study showed that $91 \%$ of TVET teachers/trainers communicate with learners via email and that $85 \%$ use interactive onsite learning resources involving websites, CDs or computers (FLAG, 2013). In the region, countries like Indonesia, Malaysia, the Philippines and Singapore have taken several initiatives on ICT use in vocational institutions (Table 2.14).

Table 2.14. Examples of initiatives on ICT use in TVET

\begin{tabular}{ll}
\hline \multicolumn{1}{c}{ Country } & \multicolumn{1}{c}{ Initiatives } \\
\hline Indonesia & - Digital Simulation (mainly for all fields of studies in vocational secondary school) \\
& - Course Development Plans for e-commerce and Industry 4.0 in vocational higher institution level \\
Malaysia & - Internet of Things Expertise in Agriculture \\
& - Diploma in Database Management System and Application \\
& - Industrial Centre of Excellence for Integrated Welding Program \\
Philippines & National Technical Education Skills Development Plan 2018-22 \\
Singapore & - SkillsFuture movement \\
\hline
\end{tabular}

Source: OECD Development Centre's compilation based on national sources. 
Nonetheless, attracting students to vocational schools remains a major challenge, largely due to an image problem. Vocational education is often overshadowed by the increasing emphasis on general education and preparing students for university studies. TVET is also often seen by students and the general public as having a low status (OECD, 2010).

This is the case in Emerging Asia. In many countries in the region, vocational education is viewed as second-class, with a lower status than general education, no prestige and as a choice for students who are less qualified academically. Parents of students with higher academic performance prefer to send their children on a general education path. In Malaysia, for instance, the perception of TVET as a less prestigious choice of study than the general academic stream leads to low enrolment in vocational training programmes and hinders collaboration between TVET and industry (UNESCO-UNEVOC, 2019a). A similar problem is observed in Cambodia where negative perceptions of TVET have contributed to a drop of $50 \%$ in the total number of people enrolled in TVET programmes (see the Country Note on Cambodia in Chapter 3).

TVET has a relatively better image in some OECD countries, with vocational school seen as more of a choice than a last resort. A 2011 survey found that 71\% of Europeans think that vocational education has a positive image in their country (Eurobarometer, 2011). TVET is perceived as offering high-quality programmes to prepare people for the world of work by developing the skills required to get a job. In the survey, $82 \%$ of respondents say that vocational education and training deliver skills that are needed by employers, $75 \%$ that vocational education offers high-quality learning, $55 \%$ that TVET leads to jobs that are well paid and $72 \%$ that TVET offers good career opportunities. A more recent survey shows similar results (Cedefop, 2017). TVET has a particularly positive image in countries where the share of students enrolled in vocational education is relatively high. The survey shows that $84 \%$ of people in Finland, $77 \%$ in Czech Republic and $75 \%$ in the United Kingdom and in Italy think that vocational education has a positive image.

\section{Enhancing the image of TVET in Emerging Asia}

Most countries in Emerging Asia have recognised that enhancing the image and attractiveness of TVET is crucial. Some have taken initiatives to improve TVET. Indonesia, for example, is reforming its TVET system to address the lack of linkage between training and the demands of the labour market, and to encourage creativity and collaboration (See the Country Note on Indonesia in Chapter 3). In the Philippines, the Ladderised Education Act of 2014 aims to create a more open and integrated education system by allowing easier transitions between TVET and higher education. In Thailand, the Office of the Vocational Education Commission is implementing projects to increase enrolment in TVET, enhance the quality of TVET programmes and increase the efficiency of TVET administration.

However, improving TVET's image remains a big challenge in the region. One possible way to address this is to promote pathways for TVET students onto a university track. TVET programmes should be designed to prepare students not only for the job market but also for continuing to a higher level of education. A balance is needed between occupationspecific, practical skills and broader education, including core academic competencies and theoretical knowledge. To achieve this, efforts are needed by all stakeholders. Governments should formulate policy that supports the acceptance of TVET students by universities. At the same time, universities need to embrace TVET not only by accepting TVET students, but also by contributing to the development of TVET programmes.

Education systems are more permeable in some OECD countries, including Australia, Austria, Finland, France and Germany, where graduates from TVET secondary education can go on to tertiary general education. In Austria, the TVET system offers different paths at various levels to avoid dead ends and to link vocational education to general tertiary education through the professional baccalaureate. In Finland, a flexible education system allows both general education and TVET students to continue their studies at the university 
or at polytechnics (Figure 2.12). The country reformed the TVET curriculum to include the national core curriculum required for access to university as well as strong on-the-job training and lifelong learning components. It aims to ensure that TVET graduates are ready to enter the job market and at the same time prepared to adapt to changing skills requirements.

Figure 2.12. The education system in Finland

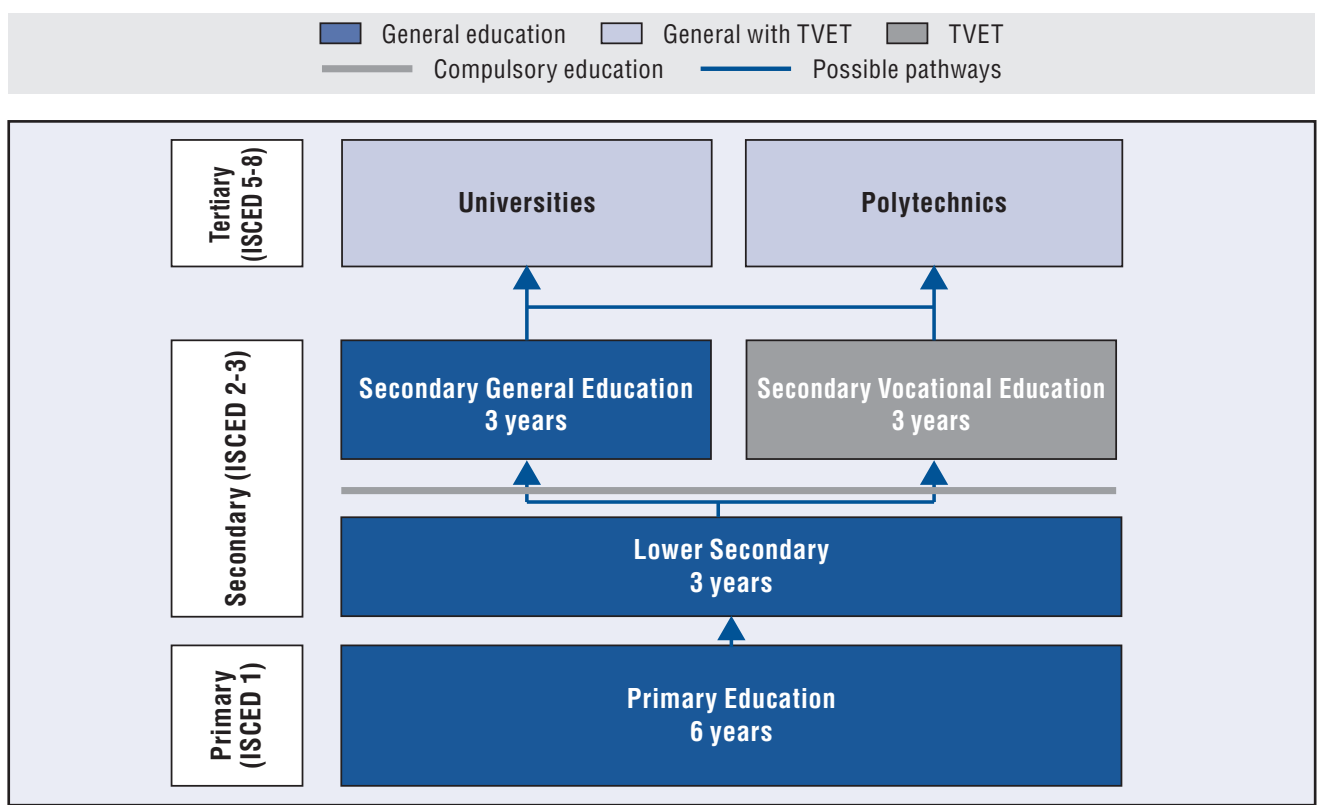

Source: UNESCO-UNEVOC (2013a), World TVET Database Finland.

Some countries of Emerging Asia already allow TVET students to move on to general education, although usually not directly after graduating from secondary level but rather after completing a post-secondary non-tertiary level. For example, graduates from the post-secondary non-tertiary level (ISCED 4) in Myanmar (engineering courses) and Viet Nam can go on to general education at the tertiary level (ISCED 5-8), or to high-level engineering courses (ISCED 6) in the case of Myanmar.

The framework in the Philippines gives graduates from secondary TVET programmes the option of continuing directly to university or of obtaining a national certificate first. Students with national certificates (NC) I and II can go directly into university-level Bachelor's programmes, although the transferability of qualifications and study between TVET and tertiary education remains limited (Macha et al., 2018). Students can also choose to continue to post-secondary non-tertiary TVET and obtain NC III-IV or a diploma (NC V) before going on to tertiary education to pursue a degree (Figure 2.13). 
Figure 2.13. The education system in the Philippines

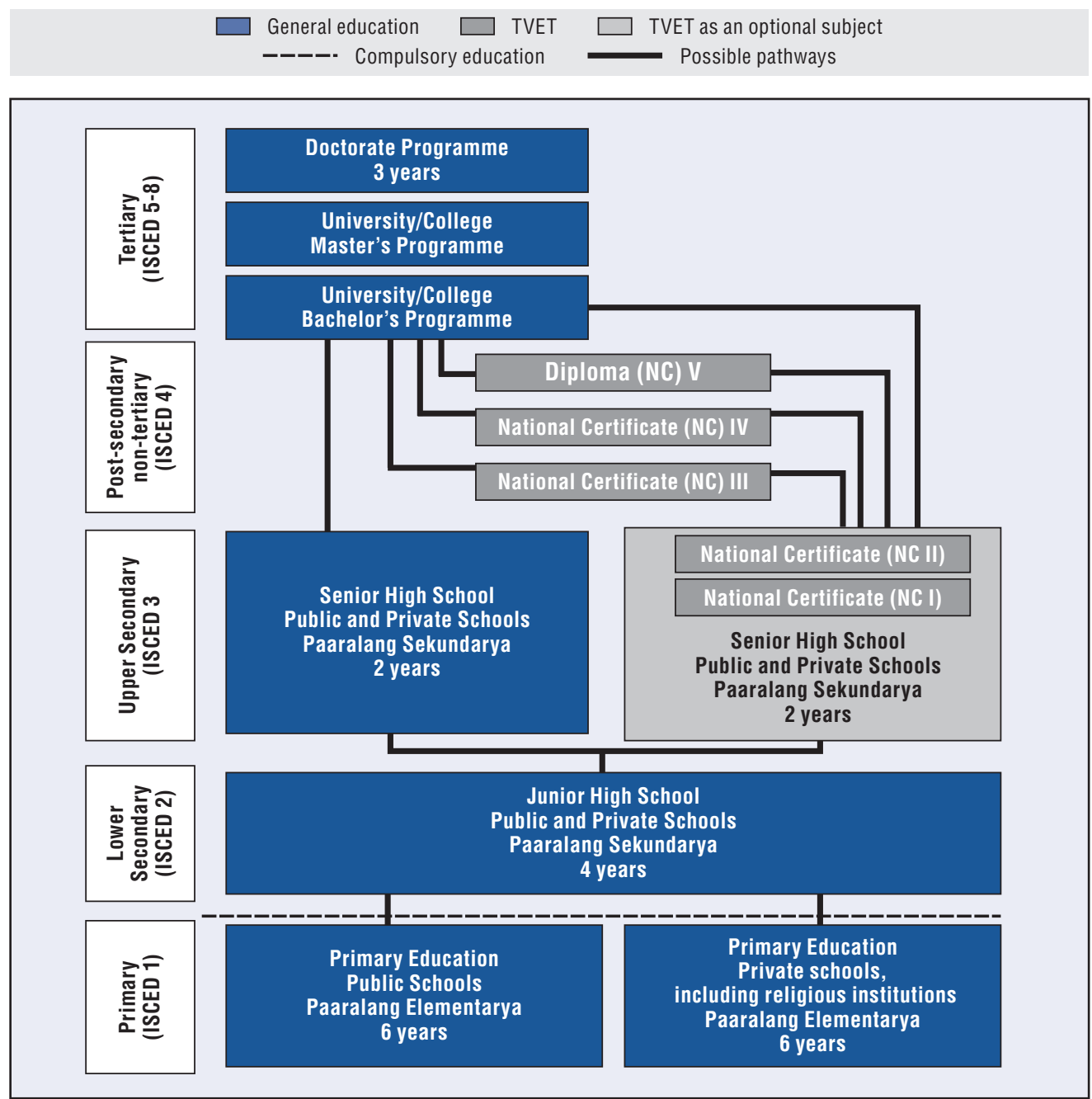

Source: UNESCO-UNEVOC (2019b), TVET Country Profile Philippines.

In other Emerging Asian countries, including India, Indonesia and Malaysia, vocational education is offered at the tertiary level in Bachelor-equivalent programmes (called Bachelor of Applied Science in Indonesia). In Malaysia, TVET programmes are offered at technical universities (Bachelor-equivalent programmes, diplomas and advanced diplomas), and pathways exist for students to move into general tertiary education at the Master's and doctoral level. Students graduating in India from TVET secondary schools are able to continue to a Bachelor of Vocational Education programme.

For TVET to be attractive, it should provide flexible programmes rather than focusing only on occupation-specific skills. Offering students the option of combining studies from different TVET programmes, for example robotic technology with mechanical and software engineering, is one possible approach. In addition to reforming the structure and design of TVET to allow higher permeability and diversity of programmes, the image of TVET among students and their parents can be enhanced through publicity campaigns, promotion and information dissemination (Box 2.5). 


\section{Box 2.5. Making TVET more attractive}

Enhancing the image of TVET among students and their parents is crucial, and campaigns can take various forms. Denmark, for instance, uses television and other media to target companies, students and parents, and its national database for citizens includes an education guide detailing the country's qualifications system and outlining the requirements for particular jobs or courses. In Greece, websites were created to provide information on TVET and employment (Cedefop, 2014). TVET schools across Finland promote their services to parents by arranging regular visits and parents' evenings. In Emerging Asia, Malaysia's $11^{\text {th }}$ Development Plan 2016-20 includes strategies for increasing the attractiveness of TVET, such as targeted media campaigns that showcase success stories to inform students and parents about the career and entrepreneurship opportunities that TVET can offer.

Enhancing the role of employers is also crucial. Systems that give students practical experience in the workplace can help to enhance the attractiveness of TVET. For example, the dual training system used in Germany, Austria and Switzerland allows students to work in a company on apprenticeships in addition to their classroom studies. Upon completion of the programme, qualified students receive a standardised and widely acknowledged certificate from competent issuers. Another example is England's National Apprenticeship Week, which is organised annually to promote apprenticeship as part of efforts to inform the public about the wider opportunities of TVET.

Changes in the labour market are also needed to enhance the attractiveness of TVET. These changes include the financial recognition of qualifications, the opening up of opportunities across occupations and the development of progression routes (UNESCOUNEVOC, 2013b).

However, improving the image of TVET in the region will take time, while the rapid pace of digitalisation is affecting the labour market and the skills it requires. Relying on TVET alone is therefore not enough to provide adequate education for the digital era. Instead, the digital skills provided by vocational schools on the one hand, and general education, including universities, on the other, should complement each other. Both systems can teach the basics, with vocational education providing practical digital skills and general education providing more advanced theoretical skills.

\section{Maximising the private sector's role in TVET}

The role of the private sector is crucial in helping TVET to adapt to an evolving labour market in the digital era. The private sector can provide a clearer view of the changes occurring amid rapid digitalisation as well as information on the skills needed by industry. To ensure that TVET prepares its students to be ready for work, companies and other key stakeholders must be encouraged to co-operate and become more engaged in TVET planning and processes, including curriculum design, training and mentoring. The role of the private sector could be enhanced in many countries in the region. In Viet Nam, for instance, employers appear to be weakly engaged in the TVET system. While some vocational schools have partnerships with local companies, systematic and close collaboration with companies is not widespread, and the influence of employers in national policy making is limited (Kis, 2017). 
The private sector plays a more significant role in some OECD countries. In Germany, for example, stakeholders including the government, employers and trade unions take part in decision making, with influence on the form and content of TVET. In Germany's dual system of vocational education, students spend part of their time in school and the rest as employees in companies, with an apprenticeship contract. The combination of workplace experience and school-based training allows a smooth transition of students to the labour market. Work-based learning has many benefits, both as a learning environment and as a means of fostering partnership with employers. It should be integrated into all vocational programmes while also being systematic, quality-assured, assessed and credit-bearing (Kis, 2017).

\section{The rising importance of lifelong learning in the digital era}

Lifelong learning is a key facet of the human capital development agenda in Emerging Asia. Lifelong learning can help the working population adapt to changing labour market conditions. It can help people with limited education to improve their social condition. It is also associated with initiatives that encourage older people to stay economically active. In other words, lifelong learning involves efforts to skill, upskill and reskill people across the social spectrum through formal and informal mechanisms.

Deepening digitalisation underpins the growing importance of lifelong learning in the region. To have a solid policy base moving forward, Emerging Asian economies can work on systematic monitoring of participation in lifelong learning programmes and the progress of target groups. To enhance participation, lifelong learning campaigns must be actively publicised, programmes should be co-ordinated and the expectations of participants addressed. Key to advancing this framework of learning will be the ability of governments to maximise available digital solutions, encourage private-sector participation in content design and distribution, and foster coalitions among learning institutions to generate synergy gains.

Lifelong learning has deep historical roots. It has been closely examined as a policy area on a global scale (UIL, 2017; Field, 2001; Kallen and Bengtsson, 1973) and is integrated into the development frameworks of many countries. It is also espoused by multilateral initiatives such as the 2030 Agenda for Sustainable Development and the Belém Framework for Action. Collaborators in lifelong learning initiatives can include traditional educational institutions (from basic to tertiary), portals for open online courses, open high schools and universities, community-based learning groups, and technical and vocational schools. The promotion of lifelong learning through various channels has in turn led to the idea of "learning communities" or "learning cities" in a number of countries, including in Emerging Asia (Osborne and Borkowska, 2017). The idea essentially aims to make lifelong learning opportunities available in various forms and accessible by everyone, typically spearheaded by the city or community leadership.

Southeast Asian economies have penned national strategies to pursue lifelong learning objectives by various means, and these policies are backstopped by communiqués and initiatives of ASEAN as a group. ${ }^{3}$ There is widespread support for community learning centres in Southeast Asia, with the aim of reaching the underserved areas (UIL, 2017). Distance learning and virtual learning have been facilitated through open high schools and open universities as well as massive open online courses (MOOCs). TVET has also been integrated with lifelong learning in certain cases. The trends are somewhat similar in India, where an array of interventions have been rolled out. Adult education centres have been established in villages (UIL, 2016a). Distance learning is integrated in technical education following a blended learning model (AICTE, 2017), while MOOCs increase the 
reach of instruction (Chauhan, 2017). Likewise, China has employed various methods to promote adult education and lifelong learning, such as state-led training programmes, community schools and learning organisations, and the integration of learning at workplaces (Huang and Shi, 2008). The use of MOOCs in China to foster learning is also gaining traction (Wang Yidan, 2015).

To improve equity in access to learning, various sectors have been targeted by the initiatives in Asia. They include the illiterate, migrants, low-skilled people, drop-outs, rural households, women and seniors, as well as prisoners, road workers and army camps (UIL, 2017; Govinda, 2017). While this section focuses heavily on skills needed to boost labour market productivity, it is also worth noting that lifelong learning extends to other areas like personal financial management. In the context of digitalisation, approaches to financial literacy have to move outside the core principles of finance. The need to have a thorough understanding of the underlying technology in financial services delivery is growing in importance (Box 2.6). As regards promoting technological literacy per se across levels of education, Estonia's ProgeTiger programme inititated in 2012 provides some valuable lessons (Box 2.7).

\section{Box 2.6. Financial literacy strategies and digitalisation}

Digitalisation has transformed the way financial services are delivered, and this has implications for the promotion of financial literacy. The aim of financial literary is to minimise the build-up of credit risks. While digital financial mechanisms have improved the convenience of transactions and broadened access to financial options, they have also created new risks: digital data privacy, digital fund security, digital system stability, etc.

In Emerging Asia, Singapore is the early mover in developing a national financial literacy strategy. In 2003, MoneySense was rolled out as the country's national financial education programme under the auspices of a council co-chaired by the Monetary Authority of Singapore and the Ministry of Manpower (MoneySense, 2019). It conveys information through its online platform, social media and television as well as through forums and workshops run by its Institute for Financial Literacy. Awareness campaigns extend to alternative digital finance platforms (MAS, 2018). MoneySense also works with partner institutions, including academia, to meet the needs of various socio-demographic clusters. In addition to MoneySense, Singapore utilises its education system to boost financial literacy, with private sector involvement in many cases (Messy and Monticone, 2016; Hartung, 2019).

Other Emerging Asian economies are following suit. Strategies have mainly revolved around a national financial literacy plan, pursued along the lines of financial inclusion and consumer protection (Messy and Monticone, 2016). They are largely under the guidance of the central bank and the securities commission, although the approach tends to involve multiple stakeholders, including academia, the private sector (particularly financial institutions), nongovernmental organisations and other government agencies. 


\section{Box 2.7. The Estonian digital education framework}

Estonia is in the process of digitalising all aspects of society. The Baltic state of 1.3 million inhabitants began this process in 1997, with e-governance, and has since brought health, public safety, taxation, voting and residency matters online (e-Estonia, n.d.). Its innovative programme aims to digitalise other aspects of society, such corporate reporting, transactions and industry. Regarding education, the country aims to digitalise all study materials by 2020 and make them available through an online "e-schoolbag", and to "implement modern digital technology efficiently and effectively in learning and teaching" (e-Estonia, n.d.).

In PISA 2015, Estonia was Europe's best performer in the sciences and second in mathematics, showing its strength and quick progress in education (OECD, 2019c). Among other initiatives, the government recently introduced the Estonian Education Information System (EHIS), a comprehensive database on education-related data from students, teachers, educational institutions, study materials and curricula. The innovative aspect of this database is its comprehensive nature: while other countries collect such data, Estonia has compounded all types of data in one framework (OECD, 2019c). The database is integrated in the accountability and monitoring framework for education, which helps the government to monitor performance.

Furthermore, in 2012 the country launched the ProgeTiger programme, which aims to enhance learners' technological literacy and digital competence, as part of Estonia's Lifelong Learning Strategy. The programme is managed by a dedicated agency for the digitalisation of education, the Information Technology Foundation for Education (HITSA), which aims to ensure that "sufficient age-appropriate digital competence necessary for further studies and to succeed in society is acquired at all levels of education, by integrating the use of digital solutions into the entire process of teaching and learning" (HITSA, 2015).

ProgeTiger is regarded as a best practise by the European Commission, which chose it as one of the best programmes in the European Union for the development of digital skills (HITSA, 2018). ProgeTiger focuses on three fields: engineering sciences; design and technology; and ICT. It has developed and adapted learning materials, trained teachers, reinforced knowledge sharing among teachers, supported procurement of technological equipment and communicated on the benefits of ICT. The programme requires teachers to integrate technology in different subjects while allowing them to choose the type of technology they use (OECD, 2019c). Teachers have access to face-to-face and online training, and benefit from the support of local networks related to the programme. An estimated $85 \%$ of Estonian schools, $44 \%$ of kindergartens and more than 4100 teachers have benefited from the programme (HITSA, 2018).

\section{Financing adult education and ICT human resource development}

Globally, there have been improvements in key pillars of adult education and lifelong learning, namely more precise targeting of policy, governance, consultation and financing (UIL, 2016b). In terms of financing, schemes can vary, taking the form of publicprivate partnerships or government grants and subsidies. In Singapore, for instance, the government is highly involved in funding for lifelong learning programmes via incentives and subsidies under the SkillsFuture initiative, targeted at recipients of different ages.

One example is the SkillsFuture Credit incentive, which provides an opening credit of SGD 500 (Singapore dollars) to Singaporeans aged 25 years and above to pay for a wide range of approved courses related to work skills, including the SkillsFuture series such as advanced manufacturing, cybersecurity, data analytics and digital media (SkillsFuture, 2019a). This credit, which comes with future top-ups at periodic intervals, lapses only 
upon a change of citizenship or death, thus allowing beneficiaries to accumulate credit and use it at any time.

The Singaporean government also offers a SkillsFuture Mid-Career Enhanced Subsidy that allows mid-career Singaporeans, in particular those who are aged 40 years and older, to upskill, re-skill and stay responsive to the changing workplace (SkillsFuture, 2019b). These additional subsidies - for courses that are already subsidised - are intended to help address the opportunity costs that mid-career Singaporeans may face when embarking on training, due to higher competing demands in the form of job and family commitments, compared to the younger individuals targeted under SkillsFuture Credit.

Luxembourg and Korea also offer interesting funding examples. In Luxembourg, private-sector companies can benefit from government financial assistance for their training plans under co-funding legislation, with the support amounting to $15 \%$ of the company's total annual training investment (INFPC, n.d.). In Korea, the government has established special funds that mobilise profits from ICT industries to help build the ICT sector. For example, Korea's 5G spectrum auction in 2018 raised around USD 3 billion, which will be a source for the funds. This financing method has allowed the country to nurture ICT human resources and develop the ecosystem of the ICT industry (Box 2.8).

\section{Box 2.8. Korea's ICT human resource development policy}

Korea jump-started investment in ICT human resource development (HRD) in 1996 with the creation of an Informatisation Promotion Fund, built on the principle that profits from ICT industries should be reinvested in the ICT sector. The fund was also used for $R \& D$, infrastructure roll-out and standardisation, and allowed the government to carry out high-cost projects with national impact.

Financing for this fund, and for a Broadcasting Communications Development Fund, came through contributions of government, telecommunications operators and broadcasting business entities. The use of these funds was governed by the Information and Communications Technology Industry Promotion Act and the Framework Act on Broadcasting Communication Development.

Two accounts were created under the Informatisation Promotion Fund: a general account and an R\&D account. These accounts had separate sources of funding and served different purposes (Table 2.15).

Table 2.15. Purposes and sources of the Informatisation Promotion Fund

\begin{tabular}{lll}
\hline & \multicolumn{1}{c}{ Purposes } & \multicolumn{1}{c}{ Sources } \\
\hline General account & - Build a broadband network and promote its utilisation & - Government contribution \\
& - Facilitate informatisation in the public, regional and industrial areas & - Profits from operation of the fund \\
& - Build a foundation for growth of the ICT industry & • Borrowings and other revenue \\
R\&D account & - Develop ICT technologies & - Government contribution or loans \\
& - Nurture skilled ICT resources & - Mandatory contribution from \\
& - Develop and set ICT standards & telecommunication operators \\
& - Build a foundation for ICT research & - Profits from operation of the fund \\
& & - Borrowings and other revenue \\
\hline
\end{tabular}

Source: Ko, Sangwon (2010).

After the completion of large-scale informatisation projects, such as the information superhighway and a first-stage E-Government project, the general account of Informatisation Promotion Fund had achieved its purpose. This account was abolished 


\section{Box 2.8. Korea's ICT human resource development policy (cont.)}

in 2005 and the name of the fund was changed back to its original title, ICT Promotion Fund, which has been focused on investing in R\&D for ICT.

The long-term and continuous investment of the Korean government in ICT HRD was made possible largely through the Informatisation Promotion Fund. Thanks to the fund, the Korean government was financially stable and flexible enough to invest in nationwide information technology projects for the future, to respond swiftly to the changing skills requirements of the market, and to reflect shifts in the technological environment when implementing ICT HRD policies (Ko and Kang, 2014).

\section{Monitoring and publicity can boost participation}

Substantial gaps remain in areas such as improving monitoring and increasing participation via publicity. In a UNESCO study, more than half of 25 Asian countries indicated that overall participation in adult learning had increased between 2009 and 2015 , in line with the world average, but $40 \%$ of the countries did not know the extent of progress (UIL, 2016b). Among the 12 Emerging Asian economies, five noted improvements during the period, while the other seven had no information on changes (UIL, 2016c). ${ }^{4}$

Data at the population subgroup level are even more telling. Six of the Emerging Asian economies indicated an increase in adult learning participation between 2009 and 2015 among residents of rural areas and workers in low-skilled jobs, while one indicated a deterioration. The other five countries either had no information or failed to answer (Figure 2.14). Worryingly, the number of countries noting improved participation for other target groups is lower, and the number that did not provide any information is higher. This is particularly evident regarding migrants and adults seeking recognition for prior learning.

Figure 2.14. Change in adult learning participation rates in Emerging Asia since 2009

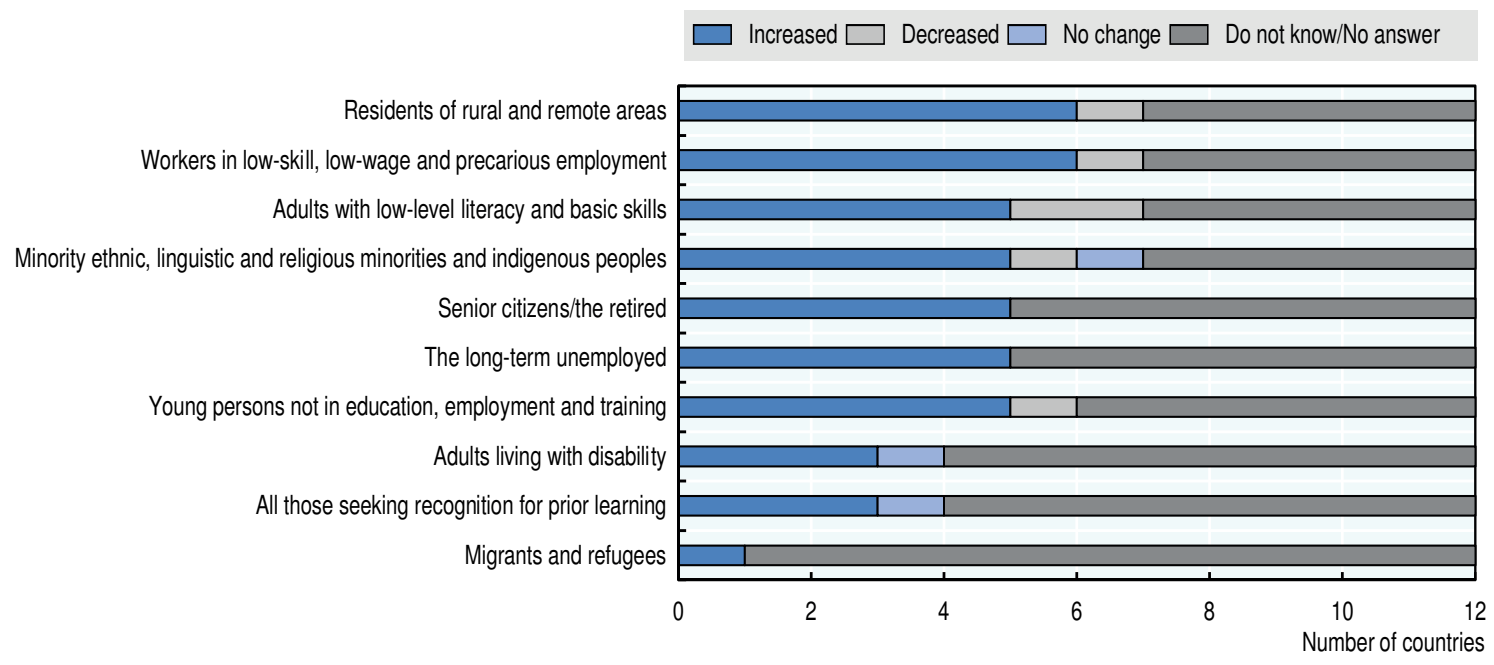

Note: GRALE 3 survey results were published in 2016 benchmarking on the GRALE 1 survey results published in 2009. Source: OECD Development Centre calculations based on UIL (2016c), GRALE 3 (database).

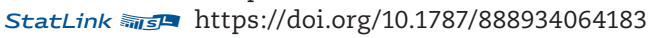

The dearth of information on participation in adult learning, as shown in the figure above, suggests that systematic data collection is lacking in the region. Indeed, only seven 
Emerging Asian countries monitor adult learning certificates, and just six monitor labour market outcomes (Figure 2.15). The number that monitor completion rates and social outcomes is even lower.

Figure 2.15. Countries collecting information by type of outcome in Emerging Asia

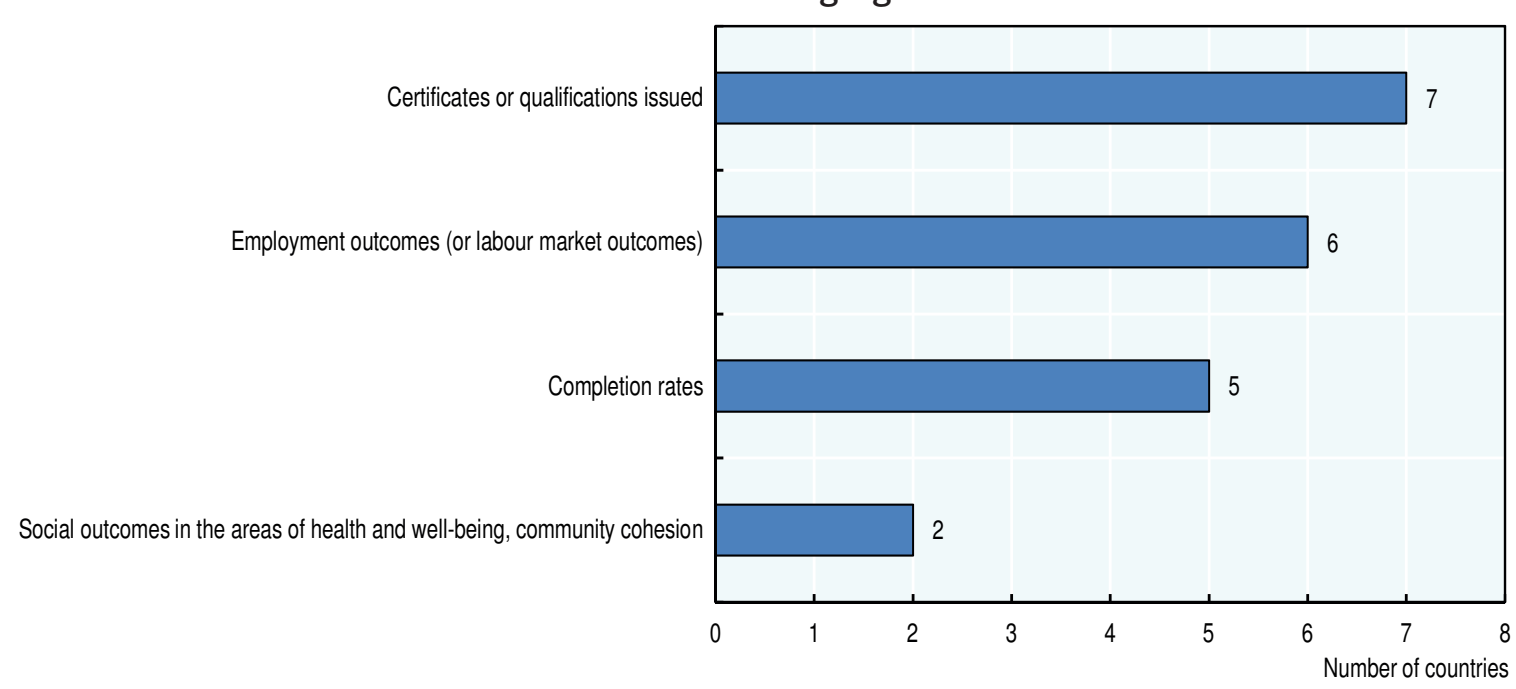

Note: GRALE 3 survey results were published in 2016 benchmarking on the GRALE 1 survey results published in 2009. Source: OECD Development Centre calculations based on UIL (2016c), GRALE 3 (database).

StatLink (intsl https://doi.org/10.1787/888934064202

Against this backdrop, there is a need to strengthen data collection and monitoring on adult learning, at least on the extent of participation. The addition to the monitoring framework of other dimensions of outcomes and implementation is encouraged. It cannot be overstated that formulating effective ways forward demands an extensive information base of good quality. The labour force survey is one instrument that can be exploited to gather data on this policy area with regularity.

To enhance participation, adult learning campaigns can be publicised through mass, social and other media. In many countries in the region, programme delivery is still fragmented. To address these issues, countries need a clear national plan on how to get various stakeholders involved (e.g. private-sector firms, government agencies, academia and the informal sector) and on how to connect the different learning channels, including community learning centres. Japan, Korea and the United Kingdom have established agencies that specifically deal with lifelong learning, and this has made their programmes more cohesive. Anchoring the expectations of potential participants is also crucial for the credibility of adult learning programmes. Participation can be constrained by perceptions that the programmes offer limited value (due to opportunity cost, the quality of teachers and the value of accreditation), as well as by cultural sensitivities and lack of awareness.

\section{Digital advances open the door to massive online education}

Digitalisation can facilitate lifelong learning frameworks in the region through MOOCs, open educational resources and online open university courses. It is encouraging that the use of such open and distance learning is increasing in Asia. These platforms not only widen the scope of training, but also make access to learning materials more flexible. Initiatives to make the most of mobile phone and mobile Internet penetration to promote learning opportunities through applications also carry substantial promise 
(Farley and Song, 2015). However, capitalising on these developments requires an enabling environment.

First, acquiring basic digital literacy has to be incentivised through lower Internet costs and better Internet service. Emerging Asian economies have arguably advanced in this area, as suggested by the sharp growth in e-commerce, e-payments and other digital solutions. However, the level of understanding is still uneven across and within countries. Moreover, raising digital know-how should go beyond the working age or midstream population to reach older people and young children (Park, 2019). With this in mind, an effective national programme for promoting digital learning tools requires a thorough understanding of the learning preferences of people of different age groups and with different socio-economic backgrounds.

Second, deeper private-sector engagement can help scale up the use of MOOCs. Private firms can be a valuable source of insight concerning course content in relation to the evolution of skills needed in the labour market. They can also be a source of capital to expand programme coverage and can make learning platforms more sustainable by taking maintenance and the updating of materials into account. Increased capital outlay may be needed in many countries to reach digitally marginalised sectors. Programmes are currently spearheaded by governments and academia in a number of Asian countries (Kim, 2015).

Third, the integrity of the MOOC modules must be reaffirmed regularly. This can be done via a system that validates their quality following a standardised set of parameters. Multilateral forums have jumpstarted discussions to co-develop MOOC content and cooperate in information flow between countries (ASEM, 2017). They have also moved to institutionalise acceptable quality-assurance frameworks and standards to facilitate a credit transfer mechanism within the region (dela Peña Bandalaria, 2018). Bahrain, Korea and Malta are countries that have a specific quality-assurance system for adult learning modules (UIL, 2016b).

Finally, collaboration among institutions can yield significant synergy gains. Strengthening inter-scholastic ties within each country can help to broaden the network, while incorporating community learning centres into the network can bolster awareness, especially in rural areas. China provides a model on alliances among universities in exploring MOOCs as channels of learning (Wang Ying, 2015). The University Alliance Joint Platform and the Online Course Sharing Alliance are examples of such coalitions. China also opened the door for enterprises to participate in building the platform support systems that allow course accreditation, credit transfer among universities, online learning and offline examination. Collaborations between private instruction, private institutions and international MOOC platforms are likewise being harnessed in Japan and Korea (Yamada, 2015; Lee, 2015). Some international MOOCs (Coursera, EdX, Khan Academy, Udacity and Udemy) have been in the business long enough to impart critical knowledge in massive online education for people with different profiles.

\section{Conclusion}

Digitalisation and new technologies are developing rapidly, affecting businesses and the labour market. The changes brought by digitalisation present a huge opportunity while at the same time carrying significant risks. Business in the digital era will demand labour with a new set of skills. Education systems will need to adapt in order to meet this new demand. Emerging Asian countries need to address certain challenges to ensure that their education systems are ready to provide the right ICT skills to all citizens. Priorities include providing sufficient ICT infrastructure to schools, training teachers to 
boost their digital skills for use in the classroom and adapting curricula to include ICT to support teaching at all levels, in an all-encompassing fashion rather than for its own sake. Enhancing the role of TVET and lifelong learning is another priority area in providing education for the digital era.

\section{Notes}

1. Examples and case studies from the OECD economies were largely drawn from the OECD Skills Outlook (OECD, 2019a).

2. The quality of the connection is not included in this statistic, however, and it should therefore be taken with caution.

3. The coverage and cohesiveness of national policies on lifelong learning tend to vary among ASEAN economies. Some examples of regional initiatives that promote lifelong learning are the Hanoi Advocacy Brief on Promoting Lifelong Learning for All, Southeast Asian Ministers of Education Organization (SEAMEO) Southeast Asian Education Agenda 7 Priority Action Areas (2015-35) and the ASEAN Socio-Cultural Community Blueprint 2025 (UIL, 2017).

4. The data are based on the results of the GRALE 3 survey published by UIL in 2016.

\section{References}

ACARA (n.d.), Information and Communication Technology (ICT) Capability, Australian Curriculum, Australian Curriculum, Assessment and Reporting Authority, https://www.australiancurriculum.edu.au/f-10curriculum/general-capabilities/information-and-communication-technology-ict-capability/.

ADB (2014), Technical and Vocational Education and Training in the Socialist Republic of Viet Nam: An Assessment, Asian Development Bank, Manila, https://www.adb.org/publications/technicaland-vocational-education-and-training-socialist-republic-viet-nam-assessment.

AICTE (2017), Distance Education, All India Council for Technical Education, New Delhi, https://www.aicte-india.org/education/distance-education.

Aide et Action (2017), "Lao LEARN: Harnessing Innovative ICT for Improved Literacy, Teaching and Learning (Past Project)", Aide et Action, Phnom Penh, http://seac.aide-et-action.org/project/laolearn-harnessing-innovative-ict-for-improved-literacy-teaching-and-learning/.

Akarawang, C., P. Kidrakran and P. Nuangchalerm (2015), "Enhancing ICT Competency for Teachers in the Thailand Basic Education System", International Education Studies, Vol. 8/6, Canadian Centre of Science and Education, http://dx.doi.org/10.5539/ies.v8n6p1.

Alba, A.B. and L.C. Trani (2018), "Extent of Utilization of Information and Communication Technology (ICT) by Selected Secondary School Teachers of City Schools Division of Malolos: Basis for the Development of Strategic Action Plan", International Journal of Education and Research, Vol. 6/1, https://www.ijern.com/journal/2018/January-2018/16.pdf.

Ali, H.A.H., S.M. Salleh and M. Shahrill (2015), “Technology Integration in the Context of Brunei Primary Schools", The Turkish Online Journal of Educational Technology, Special Issue 2, pp. 558-568, https://www.researchgate.net/publication/278156559_Technology_Integration_in_the_Context of Brunei_Primary_Schools.

Arayata, M.C. (2017), "Deped to boost ICT in schools starting 2018", Philippine News Agency, Manila, https://www.pna.gov.ph/articles/1018975.

ASEM (2017), ASEM MOOC Stakeholders' Forum: Executive Summary, ASEM Education, Asia-Europe Meeting, Brussels, https://www.asem-education.org/documents/initiatives-priority-themes/ lifelong-learning-including-tvet/asem-mooc-network.

Bahian, E.V. and A.M. Sari (2017), "On the spread of computer literacy among education students", International Journal of eBusiness and eGovernment Studies, Vol. 9/1.

Bajpai N., J. Biberman and A. Sharma (2019), "Information and communications technology in the education sector in India", ICT India Working Paper, No. 3, Center for Sustainable Development, Columbia University, New York, https://academiccommons.columbia.edu/doi/10.7916/d89anm-mc81.

Blevins, B.K. et al. (2018), "An Experimental Approach to ICT for Climate Change Awareness in Myanmar", Asian Journal of Education and Social Studies, Vol. 2/4, pp. 1-13, https://www. researchgate.net/publication/327842038_An_Experimental_Approach_to_ICT_for_Climate Change_Awareness_in_Myanmar/link/5ba903a9299bf13e6049056e/download. 
Bonifacio, A.L. (2013), Developing Information Communication Technology (ICT) Curriculum Standards for K-12 Schools in the Philippines, Sixth Conference of MIT's Learning International Networks Consortium (LINC), http://linc.mit.edu/linc2013/proceedings/Session7/Session7Bonifacio.pdf.

Butcher, N. and P. Bodrogini (2016), "Building and sustaining national ICT education agencies: Lessons from Indonesia (Pustekkom)", World Bank Education, Technology \& Innovation: SABERICT Technical Paper Series, No. 10, Washington, DC, https://openknowledge.worldbank.org/ handle/10986/26087.

CAICT (2019), China Digital Economy Development and Employment White Paper, China Academy of Information and Communications Technology, http://www.caict.ac.cn/kxyj/qwfb/bps/201904/ P020190417344468720243.pdf.

Caluza, L.J. et al. (2017), "An Assessment of ICT Competencies of Public School Teachers: Basis for Community Extension Program", IOSR Journal Of Humanities and Social Science, Vol. 22/3, https://doi.org/10.9790/0837-2203040113.

CCCPC (2016), 13th Five-Year Plan for Economic and Social Development of the People's Republic of China (2016-2020), Central Committee of the Communist Party of China, http://en.ndrc.gov.cn/ newsrelease/201612/P020161207645765233498.pdf.

Cedefop (2017), "Cedefop European public opinion survey on vocational education and training", European Centre for the Development of Vocational Training (Cedefop) research paper, No. 62, Luxembourg Publications Office, http://dx.doi.org/10.2801/264585.

Cedefop (2014), Attractiveness of Initial Vocational Education and Training: Identifying What Matters, Research Paper No. 39, European Centre for the Development of Educational Training, Luxembourg. https://www.cedefop.europa.eu/files/5539 en.pdf.

Chauhan, J. (2017), "An Overview of MOOC in India", International Journal of Computer Trends and Technology, Vol. 49/ 2, https://www.ijcttjournal.org/2017/Volume49/number-2/IJCTT-V49P117.pdf.

Chen, Y. and Y. Ma (2017), China Digital Economy Talent Report, Tsinghua SEM CIDG and LinkedIn, https://economicgraph.linkedin.com/research/china-digital-economy-talent-report.

Choi, D. (2015), “Teachers' perceptions of engaging students in self-directed learning and collaborative learning in Singapore classrooms", American Educational Research Association (AERA) Annual Meeting, Chicago, https://repository.nie.edu.sg/bitstream/10497/17205/1/AERA2015-ChoyD a.pdf.

CICT (2011), The Philippine Digital Strategy 2011-2016, Commission on Information and Communication Technology, https://dict.gov.ph/wp-content/uploads/2014/06/philippine-digitalstrategy-2011-2015.pdf.

CISTF (2018), China AI Development Report 2018, China Institute for Science and Technology Policy, Tsinghua University, Beijing, http://www.sppm.tsinghua.edu.cn/eWebEditor/UploadFile/China AI development report_2018.pdf.

CNNIC (2017), Statistical Report on Internet Development in China, China Internet Network Information Centre, https://cnnic.com.cn/IDR/ReportDownloads/201807/P020180711387563090220.pdf.

Conrads, J. et al. (2017), Digital Education Policies in Europe and Beyond: Key Design Principles for More Effective Policies, Publications Office of the European Union, Luxembourg, http://publications.jrc. ec.europa.eu/repository/bitstream/JRC109311/jrc109311_digedupol_2017-12_final.pdf.

CSD (2017), Digital Literacy Training to Non-IT Literate Citizens: Impact Assessment of the NDLM, Council for Social Development, http://www.csdindia.org/pdfs/Project-reports/Digital-LiteracyReport-2017.pdf.

Dar, C. (2017), "DepEd intensifies use of ICT in school and office management", Philippine Information Agency, Manila, https://pia.gov.ph/news/articles/1002520.

Dela Peña Bandalaria, M. (2018), "Open and distance e-learning in Asia: Country initiatives and institutional co-operation for the transformation of higher education in the region", Journal of Learning for Development, Vol. 5/2, https://j14d.org/index.php/ejl4d/article/view/301/328.

DepEd (2016), Sample ICT Curriculum Map, Philippines Department of Education, Manila, https://www.deped.gov.ph/wp-content/uploads/2019/01/ICT-Sample-Curriculum-Map.pdf.

DepEd (2010), "DO 78: Guidelines on the implementation of the DepEd Computerization Program (DCP)", Philippines Department of Education, https://www.deped.gov.ph/2010/06/10/do-78-s2010-guidelines-on-the-implementation-of-the-deped-computerization-program-dcp/.

DepEd (2009), "DO 50: Launching the DepEd Internet Connectivity Project and directing all public high schools to subscribe to Internet connectivity services", Philippines Department of Education, https://www.deped.gov.ph/2009/05/15/do-50-s-2009-launching-the-deped-Internet-connectivityproject-and-directing-all-public-high-schools-to-subscribe-to-Internet-connectivity-services/.

DepEd (n.d.), $\mathrm{K}$ to 12 Basic Education Curriculum, Philippines Department of Education, Manila, https://www.deped.gov.ph/k-to-12/about/k-to-12-basic-education-curriculum/. 
e-Estonia (n.d.), "We have built a digital society and so can you", https://e-estonia.com/.

Elwood, J., and G. MacLean (2009), "ICT usage and student perceptions in Cambodia and Japan", International Journal of Emerging Technologies \& Society, Vol. 7/2, pp. 66-82, http://unpan1.un.org/ intradoc/groups/public/documents/apcity/unpan037132.pdf.

Enochsson, A. and C. Rizza (2009), "ICT in initial teacher training: Research review", OECD Education Working Papers, No. 38, OECD Publishing, Paris, https://doi.org/10.1787/220502872611.

Ericsson (2018), "ICT in Education: Perspectives from Myanmar", Ericsson blog, https://www. ericsson.com/en/blog/2018/6/ict-in-education--perspectives-from-myanmar.

Escueta, M. et al. (2017), "Education technology: An evidence-based review", http://www.nber.org/ papers/w23744.

Eurobarometer (2011), Attitudes Towards Vocational Education and Training, Special Eurobarometer 369, http://ec.europa.eu/commfrontoffice/publicopinion/archives/ebs/ebs 369 en.pdf.

European Union (2018), EU Gender Action Plan II: Annual Implementation Report 2017, https://ec.europa. eu/europeaid/sites/devco/files/eu gap 2017.pdf.

FAO (2018), "Training on 'Agritech Using ICTs'”, Food and Agriculture Organization, Rome, http://www.fao.org/3/CA0872EN/ca0872en.pdf.

Farley H. and H. Song (2015), "Mobile Learning in Southeast Asia: Opportunities and Challenges", Handbook of Mobile Teaching and Learning, Zhang Y. (ed), Springer, Berlin, Heidelberg, https://doi. org/10.1007/978-3-642-54146-9_2.

Field, J. (2001), "Lifelong education", International Journal of Lifelong Education, Vol. 20/1-2, pp. 3-15, https://doi.org/10.1080/09638280010008291.

Finti, H.N.F.M.M., M. Shahrill and S.M. Salleh (2016), "Integrating Virtual Manipulative with the Use of iPad in the Teaching and Learning of Fractions", Knowledge Management \& E-Learning, Vol.8/4, pp. 581-601, https://www.researchgate.net/publication/311652506 Integrating_Virtual Manipulative with the Use of iPad in the Teaching and Learning of Fractions.

FLAG (2013), 2013 E-learning Benchmarking Survey, Flexible Learning Advisory Group, Melbourne, Australia, https://www.voced.edu.au/content/ngv\%3A58359.

Fox, C., et al. (2012), The Broadband Imperative: Recommendations to Address K-12 Education Infrastructure Needs, State Educational Technology Directors Association (SETDA), Washington, DC, http:// www.setda.org/wp-content/uploads/2013/09/SETDA BroadbandImperative May20Final.pdf.

Fraillon et al. (2014), Preparing for Life in a Digital Age: The IEA International Computer and Information Literacy Study International Report, Australian Council for Educational Research, Melbourne, https://www.iea.nl/fileadmin/user_upload/Publications/Electronic_versions/ICILS 2013 International_Report.pdf.

GIZ (2017), Promoting Rural Electrification Through Mini-Grids, Deutsche Gesellschaft für Internationale Zusammenarbeit (GIZ) GmbH, Bonn, Germany, https:/www.giz.de/en/downloads/giz2017-enFactsheet_PRE_Project.pdf.

GOV (2016), The Five-Year Socio-Economic Development Plan 2016-2020, Government of Viet Nam, http://pubdocs.worldbank.org/en/839361477533488479/Vietnam-SEDP-2016-2020.pdf.

Govinda, R. (2017), CONFINTEA VI Mid-Term Review: The status of adult learning and education in Asia and the Pacific, Regional Report, UNESCO Institute for Lifelong Learning, Hamburg, https://unesdoc. unesco.org/ark:/48223/pf0000259722.

Gryzelius, J. (2015), "ICT in Classroom Learning: Exploring the Discrepancies between Ideal Conditions and Current Malaysian Policy", Policy Ideas, No. 18, Institute for Democracy and Economic Affairs, Kuala Lumpur, http://ideas.org.my/wp-content/uploads/2017/03/PI-no-18ICT-in-Classroom-Education.pdf.

Hartung, R. (2019), "Financial Literacy For All", Challenge, Singapore Public Service, Singapore, https://www.psd.gov.sg/challenge/ideas/deep-dive/financial-literacy-for-all.

HITSA (2018), "Technology education has reached majority of Estonian schools by support of the ProgeTiger program", Information and Technology Foundation for Education (HITSA), Tallinn, Estonia, https://www.hitsa.ee/about-us/news/technology-education-has-reached-majority-ofestonian-schools-by-support-of-the-progetiger-program.

HITSA (2015), ProgeTiger Programme 2015-2017, Information and Technology Foundation for Education (HITSA), Tallinn, Estonia, https://www.hitsa.ee/it-education/educational-programmes/progetiger.

Huang, J. and W. Shi (2008), "Policies and practices of lifelong learning in China", International Journal of Lifelong Education, Vol. 27/5, https://doi.org/10.1080/02601370802051603.

Huawei and CCW (2018), China ICT Talent Ecosystem Whitepaper, Huawei Technologies Company and CCW Research, http://support.huawei.com/edownload/enterprise/DSDPDownload!download. action? contentType =M000003\&partNo=e001\&contentId=Node1000012581. 
ILO (2019), "Skills shortages and labour migration in the field of information and communication technology in India, Indonesia and Thailand", 'The Future of Work in ICT' Project, International Labour Office, Geneva, https://www.ilo.org/wcmsp5/groups/public/---ed dialogue/---sector/ documents/publication/wcms 710031.pdf.

ILO (2016), "ASEAN in transformation: Perspectives of enterprises and students on future work", International Labour Office, Geneva, https:/www.ilo.org/wcmsp5/groups/public/---ed_dialogue/--act_emp/documents/publication/wcms 579556.pdf.

ILO (2012), International Standard Classification of Occupations: Structure, Group Definitions and Correspondence Tables, International Labour Office, Geneva, https://www.ilo.org/wcmsp5/ groups/public/---dgreports/---dcomm/---publ/documents/publication/wcms_172572.pdf.

INFPC (n.d.), "Co-funding of training", Institut national pour le développement de la formation professionnelle continue (National Institute for the Development of Continuing Vocational Training), Howald, Luxembourg, http://www.infpc.lu/Cofinancement/Article/accueil-cofinancement/en.

Ismail, S.F.Z.H., M. Shahrill and L. Mundia (2015), "Factors Contributing to Effective Mathematics Teaching in Secondary Schools in Brunei Darussalam", Procedia - Social and Behavioral Sciences, Vol. 186, pp. 474-481, https://www.researchgate.net/publication/277684997_Factors Contributing to Effective_Mathematics_Teaching_in_Secondary_Schools_in_Brunei Darussalam.

ITU (2019a), "Final agenda: Training in 'Agritech Using ICTs", International Telecommunication Union, Geneva, https://www.itu.int/itu-d/apis/images/uploads/files/yc46ifv91557307330925.pdf.

ITU (2019b), Country ICT Data (database), the International Telecommunication Union, Geneva, https://www.itu.int/en/ITU-D/Statistics/Pages/stat/default.aspx.

ITU (2018), "Spotlight on digital inclusion for girls and women in rural Thailand", ITU News, International Telecommunication Union, Geneva, https://news.itu.int/spotlight-digital-inclusiongirls-women-rural-thailand/.

ITU (2017a), ICT Facts and Figures 2017, International Telecommunication Union, Geneva, https:// www.itu.int/en/ITU-D/Statistics/Documents/facts/ICTFactsFigures2017.pdf.

ITU (2017b), ICT Development Index 2017, International Telecommunication Union, Geneva, https:// www.itu.int/net4/ITU-D/idi/2017/\#idi2017comparison-tab.

Jeon, Y. and K. Song (2018), "Short-term ICT training program for non-computer science major teachers in developing countries for improving ICT teaching efficacy, International Journal of Advanced Smart Convergence, Vol.7/2, Daejeon, Korea, pp. 73-85, http://dx.doi.org/10.7236/ IJASC. 2018.7.2.73.

Kallen, D. and J. Bengtsson (1973), Recurrent Education: A Strategy for Lifelong Learning, OECD Centre for Educational Research and Innovation (France), OECD Publications Centre, Washington, DC, https://files.eric.ed.gov/fulltext/ED083365.pdf.

Kim, B. (2015), "What do we know about MOOCs?", MOOCs and Educational Challenges around Asia and Europe, KNOU Press, Seoul, http://asemlllhub.org/fileadmin/www.asem.au.dk/publications/ MOOCs and Educational Challenges around Asia and Europe FINAL.pdf.

Kis, V. (2017), "A skills beyond school commentary on Viet Nam", OECD Reviews of Vocational Education and Training, OECD Publishing, Paris, https://doi.org/10.1787/20777736.

Ko, S. (2010), "ICT Industry", 60 Years History of Korean Economy: Industry, Korea Development Institute, Seoul, Korea (in Korean)

Ko, S. and H. Kang (2014), ICT Human Resource Development Policy, Korea Information Society Development Institute, KDI School of Public Policy and Management, Seoul, https://www. kdevelopedia.org/resource/view/04201405130131816.do\#.XaNfPSVoSb8.

Lee, M. and S.T. Soon (2016), "Building and sustaining national ICT/education agencies: Lessons from Malaysia”, World Bank Education, Technology \& Innovation: SABER-ICT Technical Paper Series, No. 4, Washington, DC, http://documents.worldbank.org/curated/en/396631488313507885/ pdf/113112-NWP-Agencies-Malaysia-MSSI-SABER-ICTno04.pdf.

Lee, T. (2015), "A case study of MOOC at KNOU: KNOU MOOC for knowledge sharing", MOOCs and Educational Challenges around Asia and Europe, KNOU Press, Seoul, http://asemlllhub.org/ fileadmin/www.asem.au.dk/publications/MOOCs and Educational Challenges around Asia and Europe FINAL.pdfhttp://asemlllhub.org/fileadmin/www.asem.au.dk/publications/ MOOCs and Educational Challenges around Asia and Europe FINAL.pdf.

LinkedIn (2017), The Digital Workforce of the Future, LinkedIn Business Solutions, https://business.linkedin. $\mathrm{com} / \mathrm{content} / \mathrm{dam} / \mathrm{me} / \mathrm{business/en-us/talent-} \mathrm{solutions/cx/2017/PDFs/digital} \mathrm{workforce} \mathrm{future.pdf.}$

Macha, W. et al. (2018), "Education in the Philippines", WENR Education System Profiles, https://wenr.wes.org/2018/03/education-in-the-philippines. 
Mahdum, M., H. Hadriana and M. Safriyanti (2019), "Exploring teacher perceptions and motivations to ICT use in learning activities in Indonesia", Journal of Information Technology Education: Research, Vol. 18, pp. 293-317, Santa Rosa, California, https://doi.org/10.28945/4366.

Mailizar, M. and L. Fan (2019), “Indonesian Teachers' Knowledge of ICT and the Use of ICT in Secondary Mathematics Teaching", EURASIA Journal of Mathematics, Science and Technology Education, Vol. 16/1, London, https://doi.org/10.29333/ejmste/110352.

Makaramani, R. (2013), ICT in Education Country Report, UNESCO Resource Training and Distribution Centre Regional Seminar in Penang, Malaysia, United Nations Educational, Scientific and Cultural Organization, https://www.academia.edu/4778226/ICT in Education Country Report_Thailand.

Manitoba Education and Training (n.d.), "What is LwICT?", Literacy with ICT Across the Curriculum, Winnipeg, Canada, https://www.edu.gov.mb.ca/k12/tech/lict/what/index.html.

Marcial, D.E. and P.A. de la Rama (2015), "ICT Competency Level of Teacher Education Professionals in the Central Visayas Region, Philippines", Asia Pacific Journal of Multidisciplinary Research, Vol. 3/5, pp. 28-38, http://www.apjmr.com/wp-content/uploads/2015/12/APJMR-2015-3.5.1.04.pdf.

MAS (2018), "MoneySENSE organises second run of 'World Investor Week in Singapore' to equip investing public with financial knowledge", Media Release, Monetary Authority of Singapore, Singapore, https://www.mas.gov.sg/news/media-releases/2018/world-investor-week-in-singapore.

MDEC (2018), MDEC Digital Talent Report 2017, Malaysia Digital Economy Corporation (MDEC), Cyberjaya, Malaysia, https://mdec.my/assets/pdf/DTR 2017.pdf.

MEIT (2019), “About Digital India”, Ministry of Electronics \& Information Technology, Government of India, https://digitalindia.gov.in/content/about-programme.

Messy, F. and C. Monticone (2016), "Financial Education Policies in Asia and the Pacific", OECD Working Papers on Finance, Insurance and Private Pensions, No. 40, OECD Publishing, Paris, https://doi.org/10.1787/5jm5b32v5vvc-en.

MHRD (n.d.), "The Curricula for ICT in education", Ministry of Human Resources Development Government of India, https://ictcurriculum.gov.in/mod/page/view.php?id=311 (accessed 4 July 2019).

MOCI (2016), “Teachers Must Be Internet-Literate” (in Indonesian), Ministry of Communication and Informatics, https://kominfo.go.id/content/detail/7674/guru-harus-melek-internet/0/sorotan_media.

MOE Brunei Darussalam (2013), The National Education System for the 21 $1^{\text {st }}$ Century, SPN21, Ministry of Education Brunei Darussalam, http://www.moe.gov.bn/spn21dl/SPN21\%20ENG\%20(2013)\%20 COMPLETE.pdf.

MOE Malaysia (2017), “Malaysia Education Blueprint 2013-2025”, Malaysian Ministry of Education, Putrajaya, Malaysia, https://www.moe.gov.my/images/kpm/KPM/UKK/2017/08 Ogo/MEB\%20 2016\%20Annual\%20Report.pdf.

MOE Malaysia (n.d.a), The Malaysian Smart Schools: Developing 21st Century Skills" Department of Education Technology, Ministry of Education of Malaysia, http://www.jaet.jp/katudou/seminar ict/Malaysia.pdf.

MOE Singapore (n.d.b), “21 ${ }^{\text {st }}$ Century competencies”, Ministry of Education, Singapore, https:// www.moe.gov.sg/education/education-system/21st-century-competencies.

MOES (2015), Education and Sports Sector Development Plan (2016-2020), Lao PDR Ministry of Education and Sports, Vientiane, https://planipolis.iiep.unesco.org/sites/planipolis/files/ressources/lao_pdr_ esdp 2016-2020 eng 1.pdf.

MOE Thailand (2019), "Primary schools to start teaching coding: deputy education minister", Ministry of Education Thailand, Bangkok, http://www.en.moe.go.th/enMoe2017/index.php/ news/432-primary-schools-to-start-teaching-coding-deputy-education-minister.

MOE Thailand (2008), “The Basic Education Core Curriculum: B.E. 2551 (A.D. 2008)", Ministry of Education Thailand, Bangkok, http://www.act.ac.th/document/1741.pdf.

MOET (2019), “Triên khai kiên trúc tổng thể ứng dụng CNTT trong ngành Giáo dục” (Deploying the overall architecture of IT application in Education), Viet Nam Ministry of Education and Training, Hanoi, https://moet.gov.vn/giaoducquocdan/tang-cuong-ung-dung-cntt/Pages/Default. aspx?ItemID $=6097$.

MOET (2018a), "Họp báo công bố chương trình giáo dục phổ thông mới” (Press conference to announce new school education programme), Tin hoạt động của Bộ, Viet Nam Ministry of Education and Training, Hanoi, https://moet.gov.vn/tintuc/Pages/tin-hoat-dong-cua-bo.aspx?ItemID=5756.

MOET (2018b), "Bộ GD\&ĐT công bố chương trình giáo dục phổ thông mới" (Ministry of Education and Training announces a new general education programme), Tin hoat động của Bộ, Viet Nam Ministry of Education and Training, Hanoi, https://moet.gov.vn/tintuc/Pages/tin-hoat-dong-cuabo.aspx?ItemID $=5755$. 
MOEYS (2016), Mid-Term Review Report in 2016 of the Education Strategic Plan 2014-2018 and Projection to 2020, Cambodia's Ministry of Education, Youth and Sport, retrieved from https://cambodiancorner.files.wordpress.com/2018/05/mid-term-review-report-in-2016-ofthe-education-strategic-plan-2014-2018-and-project-to-2020.pdf.

MOEYS (2014), EMIS Master Plan 2014-2018, Cambodia's Ministry of Education, Youth and Sport, https://www.moeys.gov.kh/images/moeys/policies-and-strategies/578-en.pdf.

MOEYS (n.d.), Open Educational Resource, Ministry of Education, Youth and Sport, http://www.krou. moeys.gov.kh/en/.

MoneySense (2019), MoneySense - About Us, accessed on 17 September 2019, https://www. moneysense.gov.sg/about-us.

MPT (2017), ICT \& e-Government in Laos, Lao PDR Ministry of Post and Telecommunications, https:// www.itu.int/en/ITU-D/Regional-Presence/AsiaPacific/Documents/Events/2017/Sep-SCEG2017/ SESSION-1 Lao Ms Kesone Soulivong.pdf.

Murphy, A., H. Jones and H. Farley (2016). "Mobile learning in the Asia-Pacific region: Exploring challenges hindering the sustainable design of mobile learning initiatives", in Barker, S. et al. (eds.), Show Me The Learning, Proceedings ASCILITE 2016 Adelaide, pp. 461-469, http://2016conference.ascilite.org/wp-content/uploads/ascilite2016 murphy full.pdf.

NIVET (2018), Viet Nam Vocational Education and Training Report 2016, National Institute for Vocational Education and Training, Hanoi, Viet Nam, https://www.bibb.de/dokumente/pdf/2018 0529 vocational training_report_vietnam_2016.pdf.

NSCB (2014), Fact sheet on women and men in the Philippines, National Statistical Coordination Board, Makati, Philippines, http://nap.psa.gov.ph/pressreleases/2014/PSA_NSCB_2014Factsheet.pdf.

OEC (2017), Education in Thailand, Office of the Education Council, Thailand Ministry of Education, Bangkok, https://www.bic.moe.go.th/images/stories/pdf/EDUCATION_IN_THAILAND_2017.pdf.

OECD (2019a), OECD Skills Outlook 2019: Thriving in a Digital World, OECD Publishing, Paris, https://doi.org/10.1787/df80bc12-en.

OECD (2019b), TALIS 2018 Results (Volume I): Teachers and School Leaders as Lifelong Learners, OECD Teaching and Learning International Survey (TALIS), OECD Publishing, Paris, https://doi. org/10.1787/1d0bc92a-en.

OECD (2019c), OECD Skills Strategy 2019: Skills to Shape a Better Future, OECD Publishing, Paris, https://doi.org/10.1787/9789264313835-en.

OECD (2018), Effective Teacher Policies: Insights from PISA, PISA, OECD Publishing, Paris, http://dx.doi. org/10.1787/9789264301603-en.

OECD (2017), The OECD Handbook for Innovative Learning Environments, Centre for Educational Research and Innovation, OECD Publishing, Paris, https://doi.org/10.1787/9789264277274-en.

OECD (2016a), "Skills matter: Further results from the survey of adult skills", OECD Skills Studies, OECD Publishing, Paris, https://dx.doi.org/10.1787/9789264258051-en.

OECD (2016b), PISA 2015 Results (Volume I): Excellence and Equity in Education, PISA, OECD Publishing, Paris, http://dx.doi.org/10.1787/9789264266490-en.

OECD (2015a), Schooling Redesigned: Towards Innovative Learning Systems, Centre for Educational Research and Innovation, OECD Publishing, Paris. http://dx.doi.org/10.1787/9789264245914-en.

OECD (2015b), Students, Computers and Learning: Making the Connection, PISA, OECD Publishing, Paris, http://dx.doi.org/10.1787/9789264239555-en.

OECD (2015c), PISA database 2015, OECD, Paris, http://www.oecd.org/pisa/data/2015database/.

OECD (2010), Learning for Jobs, OECD Reviews of Vocational Education and Training, OECD Publishing, Paris, https://dx.doi.org/10.1787/9789264087460-en.

OECD/ADB (2015), Education in Indonesia: Rising to the Challenge, Reviews of National Policies for Education, OECD Publishing, Paris, https://doi.org/10.1787/9789264230750-en.

OECD/UNESCO (2016), Education in Thailand: An OECD-UNESCO Perspective, Reviews of National Policies for Education, OECD Publishing, Paris, https://doi.org/10.1787/9789264259119-en.

Opensignal (2018), Mobile Networks Update: Myanmar (website), October 2018, https://www. opensignal.com/reports/2018/10/myanmar/mobile-networks-update.

Osborne and Borkowska (2017), "A European lens upon adult and lifelong learning in Asia", Asia Pacific Education Review, Vol. 18/2, pp. 269-280, https://doi.org/10.1007/s12564-017-9479-4.

Park, C.Y. (2019), "Lifelong learning and education policies to capture digital gains", The Future of Work and Education for the Digital Age, T20-Japan 2019, https://t20japan.org/wp-content/ uploads/2019/03/t20-japan-tf7-5-lifelong-learning-education-policies-digital-gains.pdf. 
Pew (2017), Spring 2017 Global Attitudes Survey, Pew Research Center, Washington, DC, https://www. pewresearch.org/global/2018/06/19/global-technology-use-appendix-d-detailed-tables/.

Pew (2014), Spring 2014 Global Attitudes Survey, Pew Research Center, Washington, DC, https://www.pewresearch.org/global/wp-content/uploads/sites/2/2015/03/TechnologyReport-15.png?w=309.

PIKOM (2015), ICT Job Market Outlook in Malaysia 2015, National ICT Association of Malaysia (PIKOM), Petaling Jaya, Malaysia, http://www.pikom.org.my/2015/ICT Job Market Outlook/090715ictjobmarket2015_Final.pdf.

PIKOM (2014), ICT Job Market Outlook in Malaysia 2014, National ICT Association of Malaysia (PIKOM), Petaling Jaya, Malaysia, http://www.pikom.org.my/2014/ICT Job Market Outlook 2014/140714 ICTJOBMARKET14 softcopy.pdf.

Pustekkom (2019), Performance Report in 2018, Centre of Education and Cultural Information and Communication Technology (Pustekkom), South Tangerang, Indonesia, http://pustekkom. kemdikbud.go.id/wp-content/uploads/2019/01/Buku-Pustekkom-LAKIP TAHUNAN-2018 Digital Email-2-1.pdf.

Richardson, J.W., J. Nash and K. Flora (2014), "Unsystematic technology adoption in Cambodia: Students' perceptions of computer and Internet use", International Journal of Education and Development Using Information and Communication Technology (online journal) Vol. 10/2, pp. 63-76, https://files.eric.ed.gov/fulltext/EJ1071301.pdf.

RMIT (2016a), "Local educators gain digital learning and teaching strategies", RMIT Vietnam News, Royal Melbourne Institute of Technology University Vietnam, https://www.rmit.edu.vn/news/ local-educators-gain-digital-learning-and-teaching-strategies.

RMIT (2016b), "RMIT Vietnam launches centre to build country's educational capacity", RMIT Vietnam News, Royal Melbourne Institute of Technology University Vietnam, https://www.rmit. edu.vn/news/rmit-vietnam-launches-centre-build-countrys-educational-capacity.

SkillsFuture (2019a), Lifelong Learning Begins With Me, SkillsFuture Credit, Singapore, https://www. skillsfuture.sg/-/media/A9B1DF3D25BE4AE5ACADB02CF07F4E03.ashx.

SkillsFuture (2019b), "SkillsFuture Mid-Career Enhanced Subsidy", SkillsFuture, Singapore, https://www.skillsfuture.sg/enhancedsubsidy.

SkillsFuture (n.d.), "About SkillsFuture", SkillsFuture, Singapore, https://www.skillsfuture.sg/ AboutSkillsFuture\#section2.

Son J.B., R. Thomas and C. Indra (2011), “Computer literacy and competency: A survey of Indonesian teachers of English as a foreign language", Computer-Assisted Language Learning Electronic Journal (CALL-EJ), Vol. 12/1, pp. 26-42, http://callej.org/journal/12-1/Son_2011.pdf.

Souphavady, L. (2018), "A qualitative investigation of factors underlying slow development of e-government in Lao People's Democratic Republic, Public Policy and Administration Research, Vol. 8/5, https://pdfs.semanticscholar.org/9138/42d43020fc45de388a73efc7ba36abb0370b.pdf.

SSG (2019), Transform, Upskill and Grow: Annual Report 2018/2019, SkillsFuture, Singapore, https://www.ssg-wsg.gov.sg/content/dam/ssg-wsg/ssgwsg/about/annual-reports/SF\%20 Annual\%20Report\%20FY18.pdf.

SSG (2017), Reimagining Our Future Workforce: Annual Report 2016/2017, SkillsFuture, Singapore, https://www.ssg-wsg.gov.sg/content/dam/ssg-wsg/ssgwsg/about/annual-reports/SSG_ AR_2017_Spread\%20Full.pdf.

Tan, K.S. and J.T.H. Tang (2016), “New skills at work: Managing skills challenges in ASEAN-5”, Research Collection School of Economics, Singapore, http://ink.library.smu.edu.sg/soe_research/1891.

TDRI (2019), Interview with education expert from the Thailand Development Research Institute in Bangkok on 22 July 2019.

Thephavongsa, S. and Q. Liu (2015), Exploring the ICT Proficiency Level Among Primary and Secondary School Teachers in Lao PDR, http://ceur-ws.org/Vol-2105/10000405.pdf.

UIL (2017), "Lifelong learning in transformation: Promising practices in Southeast Asia", ed. R. Yorozu, UIL Publications Series on Lifelong Learning Policies and Strategies: No. 4, UNESCO Institute for Lifelong Learning, Hamburg, https://unesdoc.unesco.org/ark:/48223/pf0000253603.

UIL (2016a), "Saakshar Bharat Mission, India", UNESCO Institute for Lifelong Learning, Hamburg, https://uil.unesco.org/case-study/effective-practices-database-litbase-0/saakshar-bharat-mission-india.

UIL (2016b), Third Global Report on Adult Learning and Education: The Impact of Adult Learning and Education on Health and Well-Being, Employment and the Labour Market, and Social, Civic and Community Life, UNESCO Institute for Lifelong Learning, Hamburg, https://unesdoc.unesco.org/ark:/48223/pf0000245913. 
UIL (2016c), Third Global Report on Adult Learning and Education (GRALE 3) (database), UNESCO Institute for Lifelong Learning, Hamburg, http://uil.unesco.org/adult-education/global-report/ third-global-report-adult-learning-and-education-grale-3.

UIS (2014), "Information and Communication Technology (ICT) in education in Asia: A comparative analysis of ICT integration and e-readiness in schools across Asia", Information Paper No. 22, UNESCO Institute for Statistics, Montreal, http://uis.unesco.org/sites/default/files/documents/informationcommunication-technologies-education-asia-ict-integration-e-readiness-schools-2014-en 0.pdf.

Umar, I.N. and A.S.A. Hassan (2015), "Malaysian Teachers' Levels of ICT Integration and Its Perceived Impact on Teaching and Learning", Procedia-Social and Behavioral Sciences, Vol. 197, pp. 2015-2021, Elsevier, Amsterdam, https://doi.org/10.1016/j.sbspro.2015.07.586.

UNESCO (2019a), Guidelines on the Development of Open Educational Resources Policies, UNESCO, Paris, https://unesdoc.unesco.org/ark:/48223/pf0000371129.

UNESCO (2019b), UIS Statistics (database), the United Nations Educational, Scientific and Cultural Organization, Paris, http://data.uis.unesco.org/.

UNESCO (2019c), "Artificial intelligence in education: Challenges and opportunities for sustainable development", Working Papers on Education Policy, No. 7, UNESCO Education Sector, Paris, https://backend.educ.ar/refactor resource/getBook/1097.

UNESCO (2018a), Positioning ICT In Education to Achieve the Education 2030 Agenda in Asia and the Pacific, UNESCO Bangkok Office, Asia and Pacific Regional Bureau for Education, Bangkok, https://www.ictedupolicy.org/system/files/261661e.pdf.

UNESCO (2018b), "Champions of out-of-school children: ICT training for teachers of stateless and nonThai students”, UNESCO Bangkok, Asia and Pacific Regional Bureau for Education, Bangkok, https:// bangkok.unesco.org/content/champions-out-school-children-ict-training-teachers-stateless-andnon-thai-students.

UNESCO (2017), Cracking the Code: Girls' and Women's Education in Science, Technology, Engineering and Mathematics (STEM), UNESCO, Paris, https://unesdoc.unesco.org/ark:/48223/pf0000253479/ PDF/253479eng.pdf.multi.

UNESCO (2015), Qingdao Declaration, 2015: Seize Digital Opportunities, Lead Education Transformation, UNESCO, Paris, https://unesdoc.unesco.org/ark:/48223/pf0000233352.

UNESCO (2012), “ICT Infrastructure I: ISCED 1, 2 and 3”, UIS Statistics (database), the United Nations Educational, Scientific and Cultural Organization, Paris, http://data.uis.unesco.org/.

UNESCO (2008), "ICT in teacher education: Case studies from the Asia-Pacific region", UNESCO Office Bangkok and Regional Bureau for Education in Asia and the Pacific, http://www. unesco.org/new/en/communication-and-information/resources/publications-andcommunication-materials/publications/full-list/ict-in-teacher-education-case-studiesfrom-the-asia-pacific-region/.

UNESCO (n.d.), "ICT competency framework for teachers harnessing open educational resources", UNESCO, Paris, https://en.unesco.org/themes/ict-eduction/competency-framework-teachers-oer.

UN-OHRLLS (2018), "Leveraging Investments in Broadband for National Development: The Case of Cambodia", United Nations - Office of the High Representative for the Least Developed Countries, Landlocked Developing Countries and Small Island Developing States, New York, http://unohrlls.org/custom-content/uploads/2019/02/Cambodia-Broadband-Case-StudyUNOHRLLS-2018.pdf.

UNESCO-UNEVOC (2019a), “TVET Country Profile Malaysia”, UNESCO-UNEVOC World TVET Database, June 2019, https://unevoc.unesco.org/wtdb/worldtvetdatabase_mys_en.pdf.

UNESCO-UNEVOC (2019b), "TVET Country Profile Philippines”, UNESCO-UNEVOC World TVET Database, June 2019, https://unevoc.unesco.org/wtdb/worldtvetdatabase phl en.pdf.

UNESCO-UNEVOC (2013a), World TVET Database Finland, November 2013, https://unevoc.unesco. org/wtdb/worldtvetdatabase_fin_en.pdf.

UNESCO-UNEVOC (2013b), Revisiting Global Trends in TVET: Reflections on Theory and Practice, UNESCOUNEVOC International Centre for Technical and Vocational Education and Training, Bonn, https:// unevoc.unesco.org/fileadmin/up/2013_epub_revisiting_global_trends_in_tvet_book.pdf.

Voogt, J., et al. (2017), "Education 2030-Curriculum analysis: Literature review on managing time lag and technology in education", $6^{\text {th }}$ Informal Working Group Meeting, OECD Directorate for Education and Skills, OECD Publishing, Paris, https://www.oecd.org/education/2030-project/ contact/Curriculum_analysis_Literature_review_on_managing_time_lag_and_technology in_education.pdf.

Wang, Yidan (2015), "MOOCs in China are growing”, Education for Global Development, World Bank, Washington, DC, https://blogs.worldbank.org/education/moocs-china-are-growing. 
Wang, Ying (2015), "A case study: The development of MOOCs in China", MOOCs and Educational Challenges Around Asia and Europe, KNOU Press, Seoul, http://asemlllhub.org/fileadmin/www.asem. au.dk/publications/MOOCs_and_Educational_Challenges_around_Asia_and_Europe_FINAL.pdf.

Widyastono, H. (2015), "Information and Communication Technology Utilization (ICT) in the Development of Learning and Management of Pilot Schools for Implementation of Curriculum 2013", Kwangsan: Jurnal Teknologi Pendidikan, Vol. 3/2, https://jurnalkwangsan.kemdikbud.go.id/ index.php/jurnalkwangsan/article/view/26/25.

World Bank (2019a), "Vietnam Enhancing Teacher Education Program (P150060)", Implementation Status and Results Report, World Bank, http://documents.worldbank.org/curated/en/792491566332393439/ pdf/Disclosable-Version-of-the-ISR-Vietnam-Enhancing-Teacher-Education-Program-P150060Sequence-No-06.pdf.

World Bank (2019b), World Development Indicators (database), World Bank, Washington, DC, https://databank.worldbank.org/source/world-development-indicators.

World Bank (2015), Vietnam-Renovation of General Education Project, World Bank, Washington, DC, http://documents.worldbank.org/curated/en/464051468188677368/Vietnam-Renovation-ofGeneral-Education-Project.

Yamada, T. (2015), "MOOC phenomena in Japan: JMOOC and OUJ-MOOC", MOOCs and Educational Challenges Around Asia and Europe, KNOU Press, Seoul, http://asemlllhub.org/fileadmin/www.asem. au.dk/publications/MOOCs_and_Educational_Challenges_around_Asia_and_Europe_FINAL.pdf.

Yu, Y.F. and Y. Chen (2018), "Design and Development of High School Artificial Intelligence Textbook Based on Computational Thinking", Open Access Library Journal, Vol. 5/e4898, https:// doi.org/10.4236/oalib.1104898.

Zarmati, L. (2019), "Future of education and skills 2030: Curriculum analysis", The Future of Education and Skills 2030, OECD Directorate for Education and Skills, OECD Publishing, Paris, https://www.oecd. org/education/2030-project/about/documents/Learning\%20progression\%20in\%20history\%20-\%20 Zarmati.pdf.

Zhang, C. (2013), "A study of Internet use in EFL teaching and learning in Northwest China", Asian Social Science, Vol. 9/2, pp. 48-52, Canadian Centre of Science and Education, XX.

Zhou, G., Z. Zhang and Y. Li (2011), "Are secondary preservice teachers well prepared to teach with technology? A case study from China”, Australasian Journal of Educational Technology, Vol. 27/6, pp. 943-960, https://doi.org/10.14742/ajet.922. 


\section{Chapter 3}

\section{Structural policy country notes}

Domestic structural reforms are needed to maintain robust growth. This chapter discusses the key policy areas for reform in each of the ASEAN member countries, China and India. The structural policy country notes include topics on education, SME development, social safety net, digital trade, start-up eco-system, agriculture, infrastructure, investment and urban transportation. Examples from the OECD and other countries in the region are also included where relevant. 



\section{ASEAN-5}




\section{Indonesia}

\section{A. Medium-term economic outlook (forecast, 2020-24 average) \\ GDP growth (percentage change): \\ Current account balance (\% of GDP): \\ Fiscal balance (\% of GDP) (central government): $\quad-1.7$ \\ 5.1 \\ $-2.5$}

\section{B. Basic data (in 2018)}

Total population:

Population of DKI Jakarta:

Nominal GDP (US dollar):

GDP per capita at PPP:

Exchange rate in the first half

of 2019 (period average):

264.2 million *

10.5 million *

1022.5 billion **

13229.5 (current

International Dollar) **

14195.2 (IDR/USD)

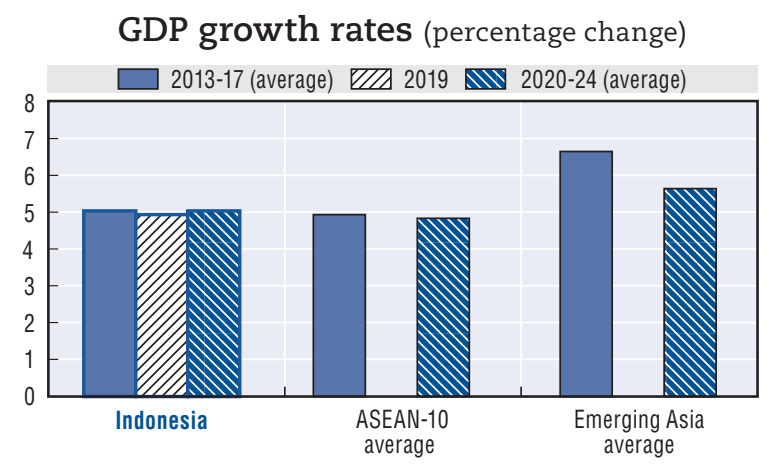

Source: OECD Development Centre.

GDP per capita, 2018

(PPP, current international dollar)

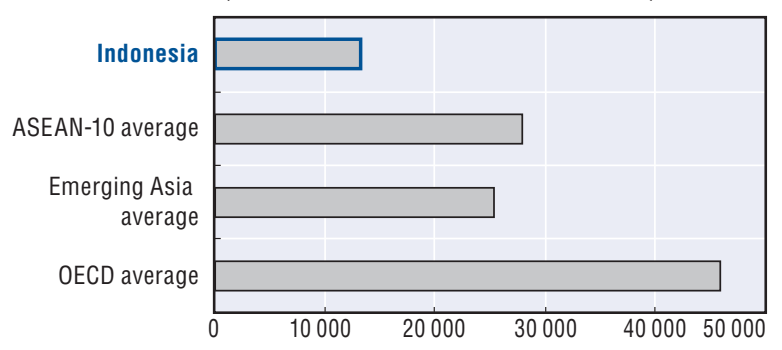

Source: IMF.

Composition of imports, 2018

(percentage of total imports)

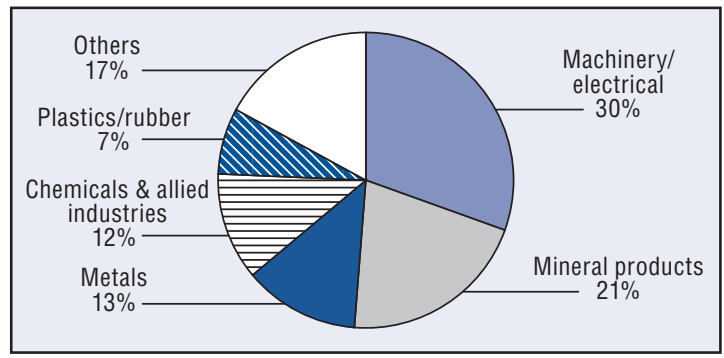

Source: Trademap.

Source: Trademap.

Structural policy challenges discussed in previous editions of the Outlook

\begin{tabular}{|c|c|c|}
\hline \multirow{3}{*}{2014} & Education & Widening access to education, in particular for low-income households \\
\hline & Disaster management & Strengthening natural-disaster management and protection infrastructure \\
\hline & Social security reform & Accelerating reform of the pension system to improve transparency and quality \\
\hline \multirow{3}{*}{2015} & Social security reform & $\begin{array}{l}\text { Improving access to and the quality of health services and expanding the coverage of the newly implemented } \\
\text { health insurance scheme }\end{array}$ \\
\hline & Education & Further improving the education system, including through greater accessibility \\
\hline & Inequality & Adequately addressing rising inequality \\
\hline \multirow{3}{*}{2016} & Infrastructure & Improving infrastructure for maritime connectivity \\
\hline & Social security & Reforming the national social security system \\
\hline & Food security & Improving food security \\
\hline \multirow{3}{*}{2017} & Tourism & Strengthening investment in tourism \\
\hline & Infrastructure & Improving connectivity and infrastructure development \\
\hline & Energy access & Reducing gaps in energy access between urban and rural areas \\
\hline 2018 & Green finance & Fostering green finance \\
\hline 2019 & Financial inclusion & Leveraging financial technology to bring banking services closer to the people \\
\hline
\end{tabular}




\section{POLICY FOCUS}

Reforming technical and vocational education and training

TVET has a key role to play in creating a skilled workforce. In light of this, TVET is an important part of Indonesia's "Industry 4.0" strategy. Indeed, the low percentage of skilled labour in Indonesia makes it indispensable for the government to improve the country's human capital. According to 2018 statistics, $40.7 \%$ of the workforce had completed lower or primary school education, $18.1 \%$ had finished lower secondary school, and $18 \%$ and $11 \%$ respectively were general and vocational secondary graduates. The numbers fell still further for university graduates $(9.4 \%)$, and vocational tertiary graduates $(2.8 \%)$. Taking into account the country's opportunity for a so-called demographic dividend - the large proportion of the population that is now at or entering working age - the government is eager to foster more skilled and competitive human resources by increasing the number of vocational secondary school, notably in the sector of maritime, tourism, agriculture and creative industry.

However, vocational graduates still often find it difficult to integrate into labour market. Indeed, Indonesia's TVET sector faces an important mismatch between the vocational graduates' skills, and the demands and needs of industry. According to an OECD report from 2015, vocational secondary school graduates did not meet employers' expectations, and their skills were often perceived to be low or very low in quality (OECD, 2015).

Another major challenge that vocational institutions face is a certain negativity towards and even stigmatisation of their courses, in that many Indonesians still see taking a vocational track in tertiary education as a second-rate option compared to the academic track (Allen, 2016). This negativity also exists among some employers, many of which still perceive graduates from vocational programmes less favourably than those graduating from academic programmes (Kadir, Nirwansyah and Bachrul, 2016). In effect, most graduates of vocational secondary schools go directly into the labour market, with less than $15 \%$ of them choosing to go on to higher institutions (OECD, 2015).

\section{Box 3.1.1. Indonesia's education system}

The education system in Indonesia is divided into four levels: pre-school, basic education, middle education, and higher education. Three different ministries administer the education system. The Ministry of Education and Culture manages the first, second, and third levels of education. Meanwhile, the Ministry of Research, Technology and Higher Education deals with higher education*, and the Ministry of Religious Affairs manages Islamic education institutions operating at all of these levels. 


\section{Box 3.1.1. Indonesia's education system (cont.)}

Figure 3.1.1. Levels of education in Indonesia

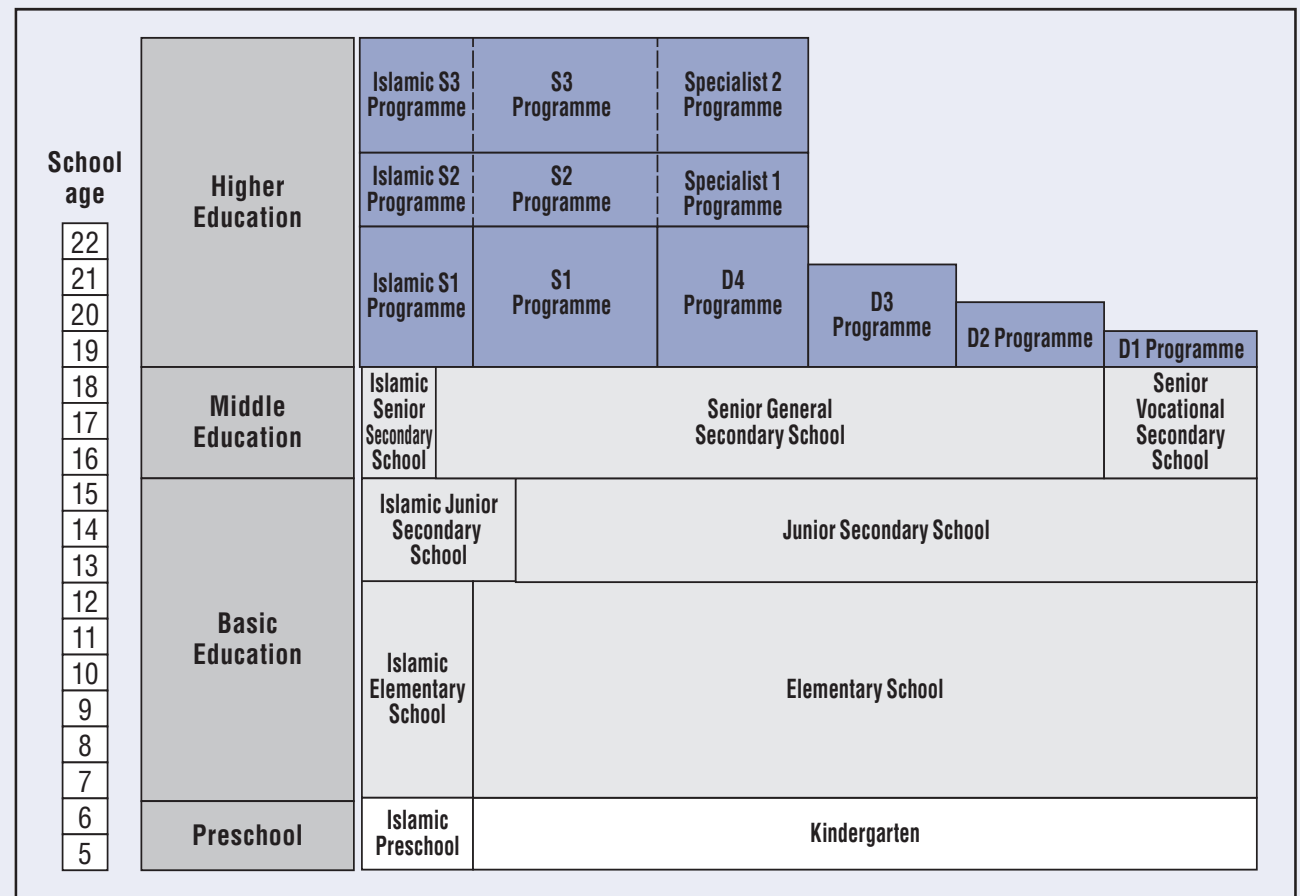

Source: UNESCO-IBE (2006), World Data on Education: Indonesia.

As of 2016, and as part of its Smart Indonesia Programme, or Program Indonesia Pintar, the government changed the compulsory age of school attendance from nine years to 12 , which consist of six years of elementary school, three years of junior secondary school, and three years of senior secondary school. At senior secondary school, the course of study divides into general and vocational tracks. Both tracks allow students to continue to higher education with two options. The first option is an academic programme with three levels: S1 (bachelor's degree), S2 (master's degree), and S3 (doctoral programme). The second option is a vocational programme which features four sub-levels (D1-4), and two broader levels - Specialist 1 (equivalent to a master's degree), and Specialist 2 (equivalent to a doctoral degree). Alongside Indonesia's formal system, there is also a non-formal system of vocational education. This takes the form of Public Vocational Training Centres, or Balai Latihan Kerja (BLK), which are managed by the Ministry of Manpower.

Note: As of August 2019. Within Indonesia's new cabinet, starting from 23 October 2019, the Ministry of Research, Technology and Higher Education becomes the Ministry of Research and Technology, while the management of higher education falls under the Ministry of Education and Culture.

\section{Revitalising vocational institutions to make sure they foster more relevant skills}

In order to tackle the mismatch between the skills that employers want and the educational outcomes that the TVET system currently produces, the government embarked in 2016 - by way of presidential instruction INPRES No.9/2016 - on a process of revitalising the country's vocational institutions. This process includes an overhaul of curricula to improve the quality of graduates' skills and to increase their employability. 
The policy seeks to shift TVET away from a supply-driven approach towards a demanddriven ethos that focuses more on producing graduates with the skills that industry actually wants.

In several provinces, some of Indonesia's vocational secondary schools (Sekolah Menengah Kejuruan [SMKs]) have already carried out the revitalisation programme. In West Java and the Riau islands, for example, they have taken a number of different approaches. One of these has been to establish a so-called "teaching factory", which applies industrial working culture at school. They have also synchronised their curricula with industry, with partner industries now deciding up to $60 \%$ of their content. Some other approaches also include facilitating the certification of graduates' actual skills (Box 3.1.2), improving teachers' practical skills by immersing them in industrial internships, and upgrading learning equipment and facilities. At the level of higher education, meanwhile, the process of revitalisation has focused on a range of measures, including an effort to improve the certification of skills. There has also been a push to make sure that lecturers have a balanced background, with the aim of ensuring a 50:50 ratio between academic and industrial influences, as well as initiatives to retool or retrain vocational teachers. Finally, another measure has been to implement the so-called 3-2-1 dual system, which offers students three semesters in class, two semesters in industry, and one semester working on a final assignment.

\section{Box 3.1.2. Harmonising certification system and improving non-formal institutions}

Building up the kinds of skills certification that can send a reliable signal to employers continues to pose a challenge in Indonesia. Against the backdrop of opportunity that the ASEAN Economic Community offers to Indonesia, as well as broader opportunities in the global economy, skills certification is much more of an urgent thing for TVET graduates to be able to present to employers than the vocational school diploma (Ijazah). Yet despite this glaring need, certification systems for certain skills are still under development (Ministry of Education and Culture, 2019d). Moreover, a rather large set of actors remains in charge of TVET in Indonesia, with the manpower and industry ministries both playing supervisory roles in the professional certification system, and with operational management falling either to vocational institutions or to independent bodies. Indeed, a total of 1479 professional certification agencies are registered with the National Professional Certification Agency (BNSP). As of 2018, these agencies consist of 791 vocational secondary schools who own a licence to test and issue a competency certificate for their students.

Indonesia's non-formal vocational institutions (BLK) also face challenges as they seek to improve. One of these challenges - as is the case in other areas of TVET in Indonesia - is finding effective and reliable ways to certify skills. Indeed, it is the BLKs themselves that manage the final assessment for participants in the training courses they offer, and they rarely refer to the national certification system or seek verification from registered independent assessors. Aside from certification, most BLKs were established in the 1980s, meaning that facilities tend now to be outdated. As with other parts of Indonesia's TVET system, therefore, efforts are under way to revitalise them. Recently, for example, Indonesia's central and local governments worked on a pilot project to restructure the curricula of BLKs, matching up their courses with the needs and expectations of the industries that operate in their region of the country. However, many BLKs in some regions are still offering basic skills that do not relate well to what industry actually needs. 
In a bid to adapt to rapid technological change and to strengthen digital literacy, the revitalisation of Indonesia's SMKs also includes the implementation of an approach to learning that is more solidly based on ICT. Moreover, thinking-related skills such as critical thinking, creativity, innovation, problem solving, and decision making, are also being strengthened by building an entrepreneurial culture within the school environment. In addition to entrepreneurship, the government has been taking into consideration Indonesia's regional uniqueness by encouraging students to work on the development of a locally-based industry. In turn, this approach aims to improve the competitiveness of the local comparative advantage, and to bolster sustainable prosperity at the regional level. One example of this approach can be found by examining evidence from several of the SMKs in the province of Papua, where the regional government has established local-based curricula.

\section{The fundamental necessity of improving public-private partnerships in TVET}

In addition to revitalising its vocational institutions from within, Indonesia's government has also been emphasising the need to improve public-private partnerships (PPPs) in the TVET sector (SEA-VET, n.d.). According to the Indonesian government, 2700 vocational secondary schools had been revitalised by 2019, out of a total of 14064 (Ministry of Education and Culture, 2019b; 2019c). This result may be due not just to a lack of budget, but also to a lack willingness from private-sector actors to co-operate. In $2019,3.4 \%$ of the government's overall spending on education is allocated to vocational education. Most of the budget allocation for TVET is being spent on improving facilities and equipment. However, according to some revitalised SMKs, the allocated budget is still insufficient. This might create an obstacle for SMKs as they seek to maximise the quality of their learning facilities. According to the World Bank's survey of Indonesian employees, indeed, the quality of the facilities in Indonesian TVET institutions constitutes a major weakness, since it is often outdated and has not kept up with the latest innovation and technology (Figure 3.1.2). Moreover, outdated technology may accentuate the mismatch between TVET institutions' programmes and the professional environment as it actually is.

$\%$

Figure 3.1.2. Main weaknesses of SMKs as perceived by employees in Indonesia

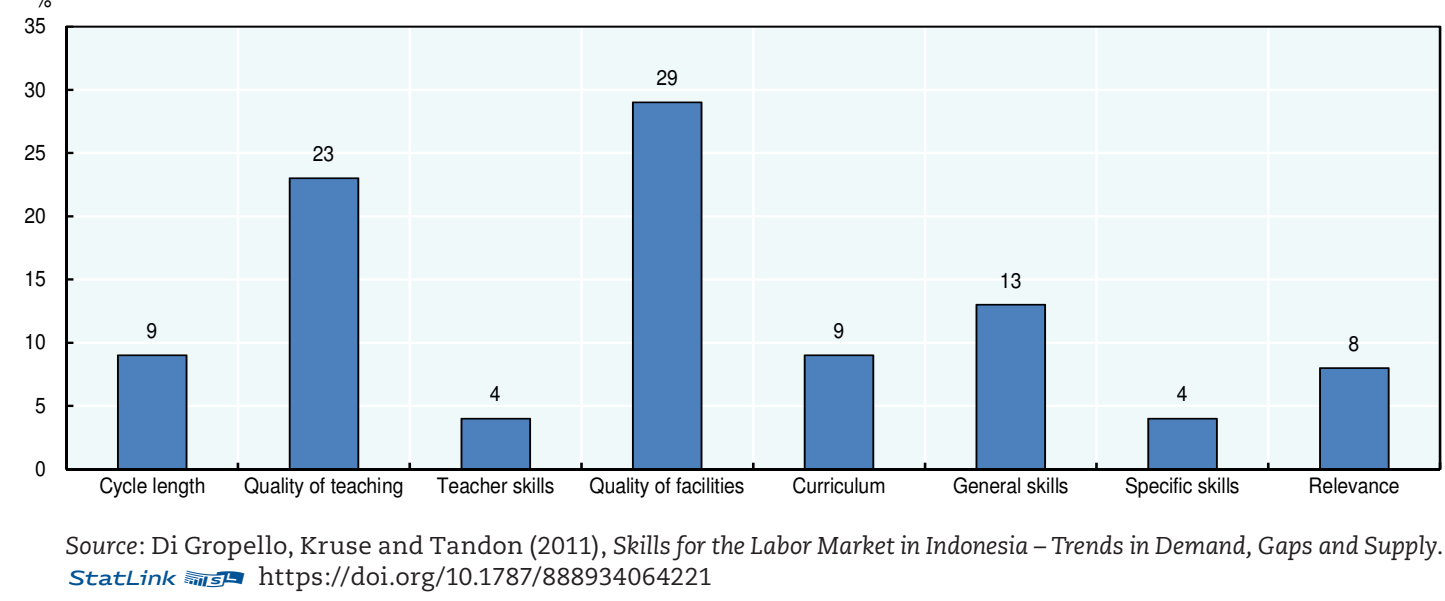

Currently, the education ministry promotes PPPs by encouraging SMKs to initiate partnerships with the private sector. However, Indonesian SMKs face some challenges in seeking out co-operation with the private sector. Most private-sector actors in the country still perceive student involvement in industry as a disruption to their business activities (Bai and Paryono, 2019). A further complication comes from the high proportion of Indonesia's vocational secondary schools - 75\% of 14064 institutions - that are themselves private. These private schools still have not met Indonesia's national standards 
of educational quality (Ministry of Education and Culture, 2019a). This perception of low-quality education at these private schools might then be one of the reasons making private industrial actors reluctant to co-operate with them.

Private-sector engagement is necessary in order to make training programmes more relevant to its needs. Aside from making changes to curricula, for example by including work placements or apprenticeships, PPPs have the potential to provide better learning facilities, and also - since TVET institutions currently rely heavily on the central government, local government, and communities - to tackle the issue of financing. Offering incentives to the private sector is one potential way to accelerate the dynamic of PPPs. Once they are involved in funding TVET, private-sector actors' sense of engagement in improving the quality of Indonesian TVET is likely to grow. PPPs have also the potential to complement the government's efforts to improve the quality of teaching. A key part of future improvements will be to offer training both on industrial know-how and ICT, thus making teaching more relevant, and complementing the government's efforts to increase digital literacy.

\section{Indonesian TVET is struggling with a shortage of qualified vocational teachers}

The number of SMKs has grown rapidly between 2016 and 2018, with approximately 828 new SMKs opening their doors to students. However, the current demand for vocational teachers cannot be satisfied. Recent statistics have shown that the proportion of teachers in SMKs who hold at least a bachelor's degree declined from 95\% in 2018 to 73\% in 2019 (Figure 3.1.3). As a result, there is a shortage of teachers with sufficient educational background. In a bid to produce more vocational teachers, the country's ministry for research, technology and higher education recently held a group discussion with public university chancellors in order to develop a degree programme for vocational education. In addition to academic experience, ensuring industrial experience of TVET teachers is also necessary. Teachers' limited, or even non-existent, professional experiences in the sector in which they specialise could mean that the skills they impart to TVET graduates lack relevance to what industry actually needs (OECD, 2015; Di Gropello, Kruse and Tandon, 2011).

Figure 3.1.3. SMK teachers' level of education in Indonesia

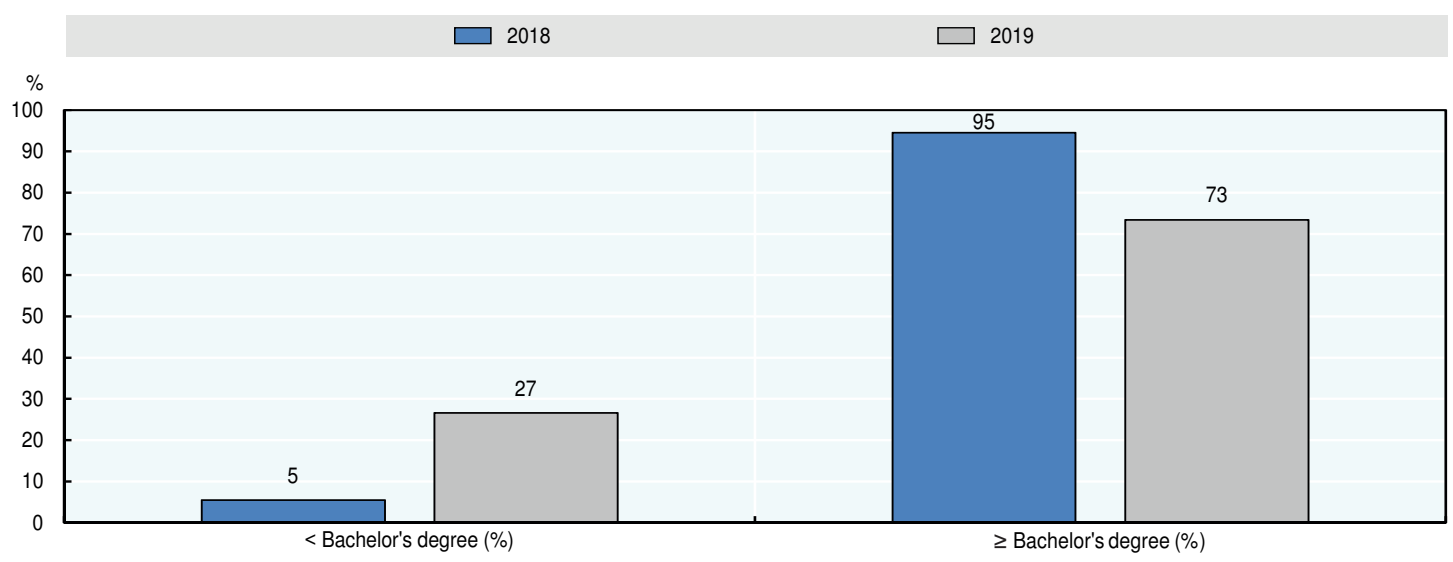

Source: Ministry of Education and Culture (2019c), Statistik Persekolahan SMK 2018/2019; Ministry of Education and Culture (2018), Statistik Persekolahan SMK 2017/2018.

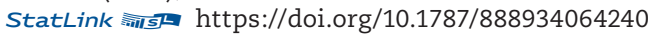

\section{Revitalisation aside, inter-agency co-ordination is crucial}

Since different ministries are responsible for managing the vocational secondary, and tertiary institutions in Indonesia, different levels of achievement in revitalising these institutions have already become apparent. So while the government's efforts to promote 
and revitalise vocational secondary institutions seems to have made consistent progress, improvement at the level of vocational tertiary institutions is still insufficient. As of 2017, only $5.4 \%$ of Indonesia's 4529 tertiary institutions were vocational polytechnics, and some of them are not accredited, so their quality remains unclear (Ministry of Research, Technology and Higher Education, 2017). According to Indonesia's ministry for research, technology, and higher education, only two polytechnics were in a good collaboration with the private sector as of 2019.

The government's focus on producing more vocational teachers and improving the quality of their work might be the reason behind slow improvement in revitalising tertiary institutions. However, efforts are being made to speed up progress. Indeed, the research, technology and higher education ministry has recently submitted a budget proposal for upgrading vocational infrastructures, and this is expected to start making a difference as of 2020. As the vocational higher education system awaits the effects of such initiatives, its revitalisation remains at early stage.

There is scope to strengthen co-ordination between authorities in order to accelerate the revitalisation process and to render it more effective. Ministries, local government, private-sector actors, chambers of commerce, employers' associations, and other stakeholders should sit down together to design a TVET system that can deliver higher quality. Good co-ordination is critical. This would allow for the synchronisation of authorities' different agendas, as well as for an improvement in the communication between them.

Finally, it is necessary for Indonesia's TVET system to allow an internationally recognised form of skills certification to take hold throughout. This will mean harmonising the certification system and distributing professional certification agencies more evenly across Indonesia. In addition, encouraging vocational institutions to seek accreditation in order to send a proper quality signal is also important, since it will make it more attractive for private-sector actors to co-operate with TVET institutions. In so doing, the government also stands to bolster its broader agenda of enhancing public-private partnerships in the Indonesian economy.

\section{References}

Allen, E.R. (2016), "Analysis of Trends and Challenges in the Indonesian Labor Market”, ADB Papers on Indonesia, No. 16, Asian Development Bank, Manila, https://www.adb.org/sites/default/files/ publication/182935/ino-paper-16-2016.pdf.

Bai, B. and Paryono (2019), Vocational Education and Training in ASEAN Member States: Current Status and Future Development, Springer, Singapore.

Di Gropello, E., A. Kruse and P. Tandon (2011), Skills for the Labor Market in Indonesia - Trends in Demand, Gaps and Supply, World Bank, Washington, DC, http://documents.worldbank.org/ curated/en/840381468262793742/pdf/608120PUB0Skil10Box358333B01PUBLIC1.pdf.

Kadir, S., Nirwansyah and B.A. Bachrul (2016), “Technical and Vocational Education and Training in Indonesia: Challenges and Opportunities for the Future", Lee Kuan Yew School of Public Policy Microsoft Case Study Series on Technical and Vocational Education and Training, Lee Kuan Yew School of Public Policy, National University of Singapore, https://lkyspp.nus.edu.sg/docs/default-source/ case-studies/lkysppms case_study_technical_and_vocational_education_and_training_in indonesia.pdf?sfvrsn $=\mathrm{e} 5 \mathrm{c} 5960 \mathrm{~b} 2$.

Ministry of Education and Culture (2019a), "Kemendikbud Selesaikan Revitalisasi terhadap 2.000 SMK", News, Kemendikbud, Jakarta, http://psmk.kemdikbud.go.id/konten/4240/kemendikbudselesaikan-revitalisasi-terhadap-2000-smk.

Ministry of Education and Culture (2019b), "Pemerintah Fokus Pendidikan Kejuruan, Revitalisasi SMK Tunjukkan Dampak Positif", Kemendikbud, Jakarta, https://www.kemdikbud.go.id/main/ blog/2019/04/pemerintah-fokus-pendidikan-kejuruan-revitalisasi-smk-tunjukkan-dampakpositif. 
Ministry of Education and Culture (2019c), Statistik Persekolahan SMK 2018/2019 (The Statistics of Vocational Senior Secondary School (VSSS) Year 2018/2019), PSDPK Kemendikbud, Jakarta, http://publikasi.data.kemdikbud.go.id/uploadDir/isi_B8C0D956-74F4-41D9-8E455AF346DF8098.pdf.

Ministry of Education and Culture (2019d), “Tingkatkan Kualitas SMK, Kemendikbud dan BNSP Sahkan Skema Sertifikasi KKNI Level II dan III", Kemendikbud, Jakarta, https://www.kemdikbud. go.id/main/blog/2019/04/tingkatkan-kualitas-smk-kemendikbud-dan-bnsp-sahkan-skemasertifikasi-kkni-level-ii-dan-iii.

Ministry of Education and Culture (2018), Statistik Persekolahan SMK 2017/2018 (The Statistics of Vocational Senior Secondary School (VSSS) Year 2017/2018), PSDPK Kemendikbud, Jakarta, http://publikasi.data.kemdikbud.go.id/uploadDir/isi_B5497FED-88A5-47CD-949278B703B41D28.pdf.

Ministry of Research, Technology and Higher Education (2017), "Kemenristekdikti Akan Terus Tingkatkan Kualitas dan Jumlah Perguruan Tinggi Vokasi”, Kemenristekdikti, Jakarta, https:// kelembagaan.ristekdikti.go.id/index.php/2017/08/23/kemenristekdikti-akan-perbanyakjumlah-perguruan-tinggi-vokasi/.

OECD (2015), "Initial vocational education and training in Indonesia", in Education in Indonesia: Rising to the Challenge, OECD Publishing, Paris, https://doi.org/10.1787/9789264230750-9-en.

SEA-VET (n.d.), "Indonesia", Country Profiles, https://sea-vet.net/indonesia.

UNESCO-IBE (2006), World Data on Education: Indonesia, UNESCO International Bureau of Education, http://www.ibe.unesco.org/fileadmin/user_upload/archive/Countries/WDE/2006/ASIA_and the PACIFIC/Indonesia/Indonesia.pdf. 


\section{Malaysia}

A. Medium-term economic outlook (forecast, 2020-24 average)

GDP growth (percentage change):

Current account balance (\% of GDP):

Fiscal balance (\% of GDP) (central government): $\quad-2.9$

\section{B. Basic data (in 2018)}

Total population:

Population of Kuala Lumpur: 1.8 million *

Nominal GDP (US dollar): $\quad 354.3$ billion **

GDP per capita at PPP: $\quad 30859.9$ (current

Exchange rate in the first half

of 2019 (period average): $\quad 4.1$ (MYR/USD)

Note: * Population data are mid-year government projections based on 2010 Census.

** IMF estimate.

Sources: OECD Development Centre, national sources, CEIC and IMF.

\section{Composition of exports, 2018}

(percentage of total exports)

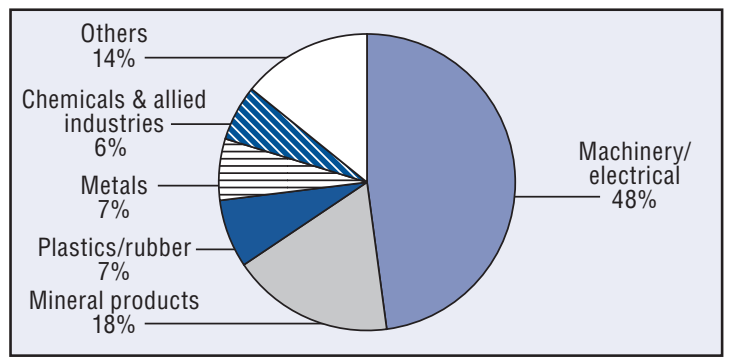

Source: Trademap.
GDP growth rates (percentage change)

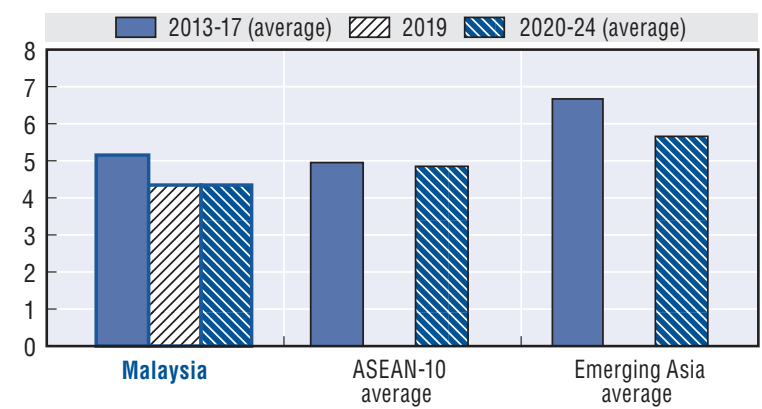

Source: OECD Development Centre.

GDP per capita, 2018

(PPP, current international dollar)

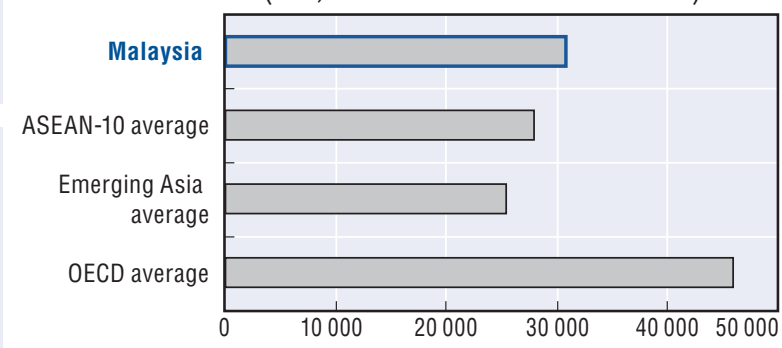

Source: IMF.

Composition of imports, 2018

(percentage of total imports)

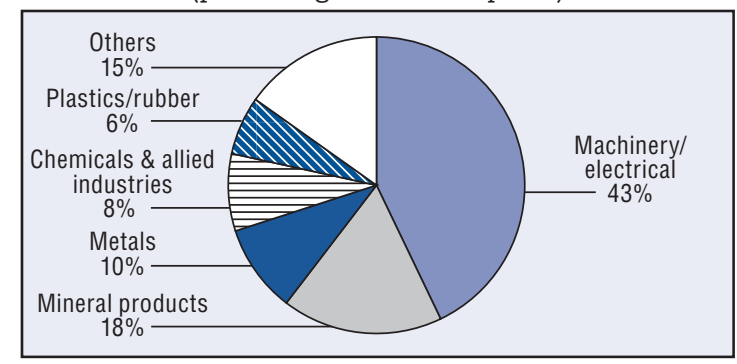

Source: Trademap.

\section{Structural policy challenges discussed in previous editions of the Outlook}

\begin{tabular}{|c|c|c|}
\hline \multirow{3}{*}{2014} & Education & Improving the quality of education \\
\hline & SME development & Improving the productivity of small and medium sized enterprises (SMEs) \\
\hline & Taxation & Widening the tax base and improving tax administration and compliance \\
\hline \multirow{3}{*}{2015} & Productivity & $\begin{array}{l}\text { Improving productivity to support sustainable economic growth and transform Malaysia into a high-income } \\
\text { developed nation }\end{array}$ \\
\hline & ICT & $\begin{array}{l}\text { Further development of Information and Communication Technology (ICT), which is particularly important in } \\
\text { supporting growth }\end{array}$ \\
\hline & Taxation and fiscal system & $\begin{array}{l}\text { Enhancements to fiscal stability, and a reduction in the country's dependence on oil, including through the } \\
\text { introduction of a goods and services tax (GST) }\end{array}$ \\
\hline \multirow{3}{*}{2016} & SMES & Raising the productivity of SMEs \\
\hline & Education & Upgrading education to meet industry needs \\
\hline & Urban green growth & Promoting urban green growth \\
\hline \multirow{2}{*}{2017} & Housing & Keeping housing affordable and ensuring a supply of affordable housing \\
\hline & Social safety net & Enhancing the social safety net to ensure citizens' well-being and participation \\
\hline 2018 & Halal industry & Enhancing trade growth by strengthening the Halal sector \\
\hline 2019 & Taxation & Reintroducing a sales and services tax after the scrapping of the goods and services tax \\
\hline
\end{tabular}




\section{POLICY FOCUS}

Developing the entrepreneurship of SMEs

Malaysia has made significant strides in improving its domestic business climate for small and medium-sized enterprises (SMEs) over the years. The growth in the output of Malaysia's SMEs outpaced the country's overall economic growth in every year from 2004-17 (SME Corporation Malaysia, 2018). Against a backdrop of overall improvement in Malaysia's SME sector, the ratio of enterprises to the population aged 15-64 also jumped in the years 2010-15, which suggests an increased interest among Malaysians in starting up a business (Figure 3.2.1). Another encouraging sign has been the moderate-to-high entrepreneurial intuition and inclination of technical and vocational students in Malaysia (Dahalan et al., 2018; Ibrahim et al., 2015).

A broad set of government initiatives to support SMEs - including programmes to develop human capital and to strengthen entrepreneurship by fostering innovation - have contributed to the overall improvements that Malaysia's SME's have made (Box 3.2.1). There are also initiatives for SMEs to keep pace with digitalisation (e.g. skills upgrade and guidance for effective usage of business technologies); and for technology-oriented start-ups to create new products and services. Consolidating the SME programmes and their administration can yield efficiency gains and promote eveness in quality of programme delivery.

Figure 3.2.1. Proportion of enterprises per 1000 people in Malaysia

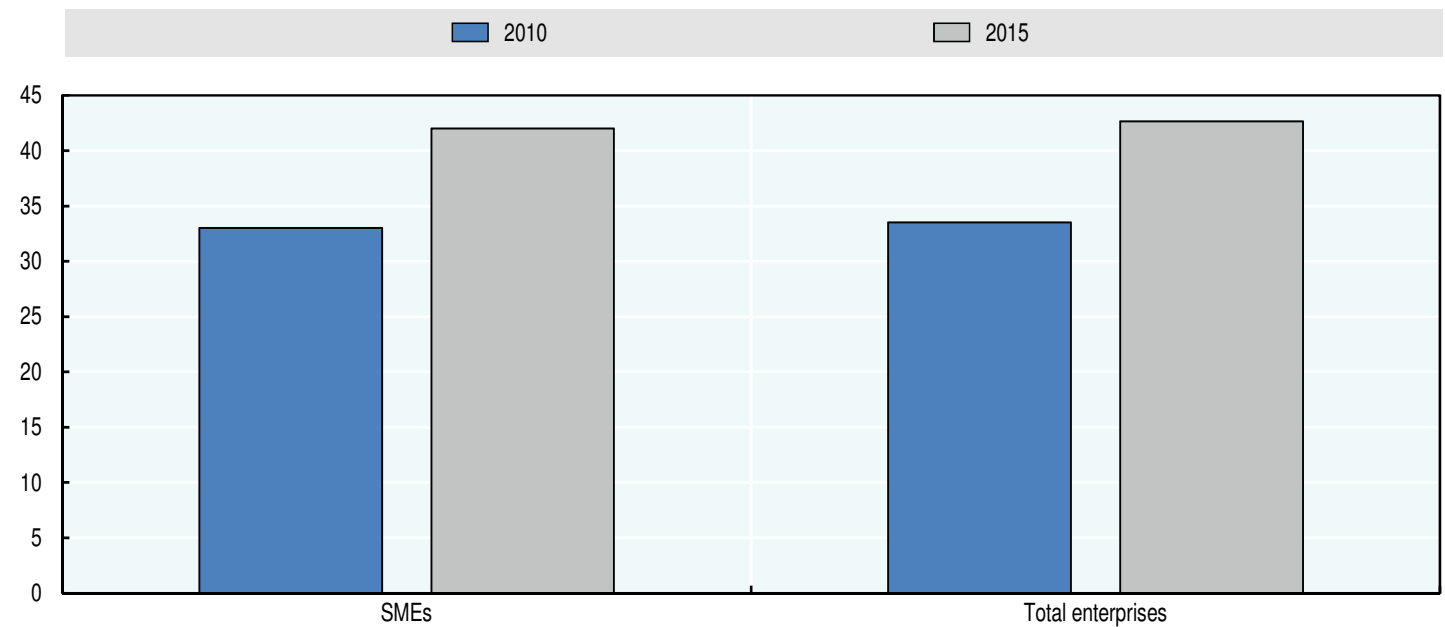

Note: Population coverage is from age 15 to 64 .

Source: OECD Development Centre based on national sources.

StatLink 刑Ist https://doi.org/10.1787/888934064259

\section{Box 3.2.1. Human capital and innovation programmes for SMEs in Malaysia}

Malaysia has launched an array of programmes to help its SMEs both to shore up human capital and to adopt innovations. One such initiative has been to provide training on business skills and leadership development. Examples of this include the TERAS Enhancement and Development training at the Institut Keusahawanan Negara, a business school, as well as programmes to upgrade skills and capacities throughout Malaysia's SMEs. There are initiatives that encourage women and youth in rural areas to take up 
Box 3.2.1. Human capital and innovation programmes for SMEs in Malaysia (cont.) entrepreneurship as well. Specific examples of this include the Rural Business Challenge and Inkubator Keusahawanan Wanita, a business incubator for women entrepreneurs. Among Malaysia's other entrepreneurship initiatives are skill-development courses for school leavers and the unemployed such as the National Dual Training System and targeted efforts to engage academia such as the SME@University Programme (SME Corporation Malaysia, 2018, 2016).

Assisting technology-oriented start-ups constitute another prominent component of Malaysia's policies to support SMEs. For a start, there are incubators and accelerator programmes that operate under the auspices of a number of the country's government ministries. In addition to these, the Malaysian Global Innovation and Creativity Centre was unveiled in 2014. It seeks to develop a business eco-system that encourages local people to compete with their foreign counterparts in coming up with new goods and services. The National eCommerce Strategic Roadmap, and the Digital Free Trade Zone, are among other undertakings of the central government in Malaysia to help SMEs to participate in local and offshore business ventures. The state-level governments - for instance in Sabah and Sarawak - also have a number of programmes on entrepreneurship, targeting various segments of society (SME Corporation Malaysia, 2016).

\section{The restoration of a central institution should facilitate consolidation of programmes}

The restoration of Malaysia's Ministry of Entrepreneur Development (MED) in 2018 after it was disbanded in 2009 has the potential to be a key catalyst in further enhancing the effectiveness of the country's SME programmes. The newly-restored ministry has laid out a new National Entrepreneurship Framework (NEF), which contains 21 strategic objectives under four key policy subheadings (MED, 2018). The NEF's objectives include fostering an innovative ecosystem for SMEs, developing alternative funding sources, creating a database of stakeholders, and boosting the implementation and administration of existing programmes.

Consolidating Malaysia's entrepreneurship programmes and their administration under the central agency while still providing room for inter-agency collaboration has ample advantages. As it is, there are several ministries and line agencies involved in entrepreneurship programmes (SME Corporation Malaysia 2018, 2016, 2015). Moreover, a number of the programmes implemented by different offices overlap in certain areas including those that focus on innovation and the development of human capital. The process of consolidation can be done along the lines of NEF strategy objectives 8, 9 and 11, i.e. rationalising the roles and functions of entrepreneur development agencies, establishing a national entrepreneurship training council and consolidating existing entrepreneurship development funds, respectively.

\section{Effective management of information about programmes makes it easier to monitor their outcomes}

Malaysia's creation of central systems to pool data, and to disseminate information and research about entrepreneurship, bodes well for the country in its efforts both to help SMEs to update their practices in line with the latest industry developments, and to improve the flow of information. In this regard, the launching of Entrepreneur Development One-Stop Centre is a step in the right direction. Establishment of a dedicated research agency for entrepreneurship (NEF strategy objective 17) and development of an integrated database of entrepreneurship and SMEs (NEF strategy objective 7) also carry substantial upsides. 
As the management of information improves, it will be important to strengthen the framework and mechanisms for assessing how well the different measures are working. Doing this will help to make the different programmes more responsive to the needs of entrepreneurs. In this respect, the OECD's six-step assessment framework, which draws on the experiences and policies of some developed economies, may be useful for Malaysia (OECD, 2008).

In addition, there is considerable merit in maintaining if not broadening collaborations with external stakeholders. For instance, making the contents of the forthcoming SME database accessible to various sectors such as academic institutions and private research agencies could enrich the SME policy perspectives.

\section{Entrepreneurship programmes can be leveraged to bring informal enterprises into the formal sector}

Based on the results of the enterprise survey of the World Bank in 2015, Malaysia fared well in incentivising informal enterprises to formalise their operations relative to the averages of East Asia and the Pacific and upper middle-income countries (World Bank, 2015). The share of formal-sector firms that said they were competing with informal-sector counterparts was also lower in Malaysia than the average of the two aforementioned groups. Nonetheless, the results of the same survey showed that the practices in the informal sector are still the top constraint to the business environment in the country and by a wide margin. Unsurprisingly, small and medium-sized firms were more likely to find this to be restrictive than large firms.

The World Bank study argued that generally informal sector enterprises' aversion to becoming part of the tax base was their most tangible concern about formalisation. However, more than the tax burden, formalisation also entails being subjected to labour, health and environmental regulations, among other laws. To this end, a clear strategic framework to formalise informal enterprises, which builds on the SME Masterplan 20122020 , ought to be considered. A dedicated group with functions similar to the Special Task Force to Facilitate Business (PEMUDAH) that caters to concerns related to formalisation of informal businesses including dialogues for policy formulation may be worth exploring.

Concerning the cost of doing a formal business, the government's move to lower the tax rate of SMEs (MIDA, 2018) may help reduce friction in this respect. There also remains scope to boost awareness of the digital platforms launched (e.g. e-ledger, e-registration and e-filing, etc.) as cost saving mechanisms to encourage compliance particularly among informal single proprietors and informal SMEs outside the urban centres.

Beyond cost issues, entrepreneurship programmes can be leveraged further to assist firms to navigate the process of formalisation. Mechanisms to gather information on concrete problems preventing informal firms from joining the mainstream could be established on the side. Co-ordination with relevant private institutions-say, with the banks-could be similarly harnessed to help disseminate information on formalisation gains such as lower cost of financing. Moreover, Chacaltana, Leung and Lee (2018) put forth policy options to facilitate transition using new technologies, which the Malaysian government could adjust to the local conditions. These cover the areas of business registration, tax compliance, information campaign, among others.

Persistently reaching out to informal enterprises has the capacity not just to even out the playing field for formal-sector SMEs - particularly in wholesale retail and trade - but also to bring substantial socio-economic welfare upsides. Data from 2017 show that the number of workers involved in the informal sector declined compared to 2015, yet it remained substantial at around 1.4 million, or 9.4\% of total employment in Malaysia (DOSM, 2018). 


\section{Harnessing entrepreneurship ought to go beyond increasing SMEs' contribution to growth}

The NEF's first strategic objective, which sets out to increase the contribution of SMEs to gross domestic product (GDP) to over $40 \%$ by 2020 , is meaningful in a macroeconomic sense. Beyond increasing the value that SMEs add to the economy, however, it also pays to set target outcomes in terms of firm-level competitiveness. Such metrics can include the distribution of economic activity by sector and firm size, firms' survival rates, their resilience to economic shocks, and their rate of graduation to the next bracket - i.e. from micro to small, small to medium, and medium to large. Moreover, it is important to bear in mind that SMEs turning into large enterprises could result in a mathematical reduction in SMEs' overall contribution to GDP without necessarily signalling a deterioration in conditions in the SME sector. Similarly, when large firms downscale and fall into the SME category, the contribution of the SME sector to GDP could increase without entailing an improvement of the overall situation for SMEs.

It would be beneficial if the forthcoming SME database could put together ample amounts of hard, firm-level data to make it possible to track the distribution of market shares, concentration of market power, and relative competitiveness, in markets both domestic and external. It also pays to have data that allow observers to examine the linkages between firms, the evolution of their individual performances, mergers and acquisitions, and even firm closures or failures. Measuring these aspects will be helpful over the coming years to build a holistic view of SME development and the behaviour of entrepreneurs. It should likewise provide valuable insights on how the government should proceed with its interventions and programmes.

In summary, Malaysia has made significant inroads in promoting the welfare of SMEs in the country. The restoration of the central agency for entrepreneurship could enhance further the effectiveness of the SME programmes. However, there is room to improve the depth of information on firms and the utilisation of available firm-level data to make the policies more responsive. Strengthening collaborations with external stakeholders could help generate fresh policy insights. It is also relevant to keep abreast with the issues concerning informal SMEs. In addition, the policy objectives should go beyond SMEs' contribution to national output.

\section{References}

Chacaltana, J., V. Leung and M. Lee (2018), "New technologies and the transition to formality: The trend towards e-formality", ILO Employment Working Paper, No. 247, International Labour Organization, Geneva, https://www.ilo.org/wcmsp5/groups/public/---ed emp/---emp policy/ documents/publication/wcms 635996.pdf.

Dahalan, D., J.L. D'Silva, I. A. Ismail and N.A. Mohamed (2018), "Entrepreneurial Mindset Among Students of Technical and Vocational Education and Training (TVET) Institutions in Malaysia", The Journal of Social Sciences Research, Vol. 4, Issue. 11, pp. 303-311, https://doi.org/10.32861/ jssr.411.303.311.

DOSM (2018), "Informal Sector Work Force Survey Report, Malaysia 2017", DOSM Press Release, Department of Statistics Malaysia, Kuala Lumpur, https://www.dosm.gov.my/v1/index. php? $r=$ column/pdfPrev\&id=TStvalVDc3krRG5hSHByQjczd21FZz09.

Ibrahim, W.N.A., A.R. Bakar, S. Asimiran, S. Mohamed and N.S. Zakaria (2015), "Impact of Entrepreneurship Education on the Entrepreneurial Intentions of Students in Technical and Vocational Education and Training Institutions (TVET) in Malaysia", International Education Studies, Vol. 8, No. 12, Canadian Center of Science and Education, Beaver Creek, Ontario, https://doi.org/10.5539/ies.v8n12p141.

MED (2018), National Entrepreneurship Framework: Strategic Thrusts \& Objectives, Ministry of Entrepreneur Development, Kuala Lumpur, http:/www.med.gov.my/portal/document/files/ 
Booklet\%20NEF.pdf.

MIDA (2018), Budget 2019, MIDA E-Newsletter, October Issue, Malaysian Investment Development Authority, Kuala Lumpur, https://www.mida.gov.my/home/administrator/system files/modules/ photo/uploads/20181112172229_MIDA\%20E-Newsletter\%200ct\%202018\%20FA.pdf.

OECD (2008), OECD Framework for the Evaluation of SME and Entrepreneurship Policies and Programmes, OECD Publishing, Paris, https://doi.org/10.1787/9789264040090-en.

SME Corporation Malaysia (2018), SME Annual Report 2017/18-A Connected World: Digitalising SMEs, SME Corporation Malaysia, Kuala Lumpur, http://www.smecorp.gov.my/index.php/ en/?option=com_content\&view=article\&layout=edit\&id=3342.

SME Corporation Malaysia (2016), SME Annual Report 2015/16-Breaking Barriers, SME Corporation Malaysia, Kuala Lumpur, http://www.smecorp.gov.my/index.php/en/sme-annual-report-2015-16.

SME Corporation Malaysia (2015), SME Annual Report 2015/16-One Business, One Community, SME Corporation Malaysia, Kuala Lumpur, http://www.smecorp.gov.my/index.php/en/ resources/2015-12-21-11-07-06/sme-annual-report/book/7-annual-report-2014/2-annual-report.

World Bank (2015), Enterprise Surveys What Business Experience: Malaysia 2015 Country Profile, Washington, DC, http://documents.worldbank.org/curated/en/855771482736800396/Enterprisesurveys-Malaysia-country-profile-2015. 


\title{
Philippines
}

A. Medium-term economic outlook (forecast, 2020-24 average)

GDP growth (percentage change): Current account balance (\% of GDP):

Fiscal balance (\% of GDP) (central government):
6.2

$-1.9$

$-2.6$

\section{B. Basic data (in 2018) \\ Total population: \\ Population of \\ Metro Manila (NCR): \\ 105.8 million * \\ Nominal GDP (US dollar): \\ 13.5 million * \\ GDP per capita at PPP: \\ 330.8 billion ** \\ 8935.9 (current \\ International Dollar) ** \\ Exchange rate in the first half \\ of 2019 (period average): \\ 52.2 (PHP/USD)}

\author{
Note: * Population data are mid-year government \\ projections based on 2015 Census. \\ ** IMF estimate. \\ Sources: OECD Development Centre, national sources, \\ CEIC and IMF.
}

\section{Composition of exports, 2018}

(percentage of total exports)

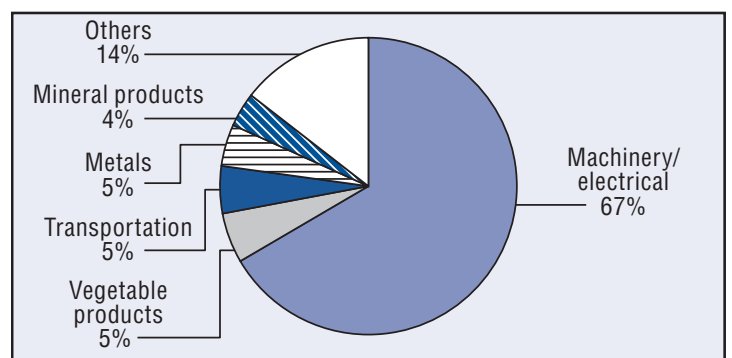

Source: Trademap.

\section{Structural policy challenges discussed in previous editions of the Outlook}

\begin{tabular}{|c|c|c|}
\hline \multirow[b]{2}{*}{2014} & Job creation & Creating more jobs for sustainable poverty reduction \\
\hline & $\begin{array}{l}\text { Disaster-risk management } \\
\text { Develop Mindanao }\end{array}$ & $\begin{array}{l}\text { Building holistic disaster-risk reduction and management capacities to reduce vulnerability to natural hazards } \\
\text { Improving agricultural productivity and transport infrastructure in Mindanao }\end{array}$ \\
\hline \multirow{3}{*}{2015} & Competitiveness & Sustaining economic growth by stepping up the country's global competitiveness through quality employment \\
\hline & Financial system & $\begin{array}{l}\text { Striving to put in place a responsive, development-oriented, and inclusive financial system to serve as a } \\
\text { platform for efficient management and the mobilisation of resources }\end{array}$ \\
\hline & Social development & $\begin{array}{l}\text { Further improving social development to make sure all Filipinos benefit from equal opportunities when it comes } \\
\text { to having a decent job, acquiring assets, and enjoying higher living standards }\end{array}$ \\
\hline \multirow{3}{*}{2016} & Job creation & Encouraging faster job creation \\
\hline & Infrastructure & Strengthening infrastructure and the transport sector \\
\hline & Disaster-risk management & Improving disaster-risk management \\
\hline \multirow{3}{*}{2017} & Infrastructure & Investing in infrastructure improvements \\
\hline & Job creation & Targeting faster growth in the services sector to create new jobs \\
\hline & Foreign direct investment (FDI) & )Eliminating hurdles in a bid to attract more FDI \\
\hline 2018 & Infrastructure & Optimising infrastructure financing \\
\hline 2019 & Digitalisation & Coping with the risk of job automation in the offshoring and outsourcing industry \\
\hline
\end{tabular}




\section{POLICY FOCUS}

Enhancing the outcomes of a new basic education framework

Following the passage of the base legislation in 2013, the Philippines rolled out a new framework of basic education extending from kindergarten through to a twelfth grade (K-12). ${ }^{1}$ This essentially requires children to attend kindergarten before elementary school, and has added two years at the end of the programme at senior-high school. Academic, technicalvocational-livelihood, and sports and arts are the three tracks offered. Aligning the duration of basic education in the Philippines with practices in many other countries, addressing congestion in the curriculum of core courses, and increasing the likelihood that pupils will enjoy immediate employability after high school are the programme's main objectives.

As it is, the share of the workforce that does not have a high-school diploma has declined slightly since 2012, yet it remains high, at around 40\% (Figure 3.3.1). Among nonhigh school graduates, the share of those who are employed may have gradually risen over the same period, in line with the general decline in national unemployment rate, but the underemployment rate stays elevated. Notably, labour informality is also widespread in the Philippines.

\section{Figure 3.3.1. Participation of non-high school graduates in the Philippine labour force, 2012-18}

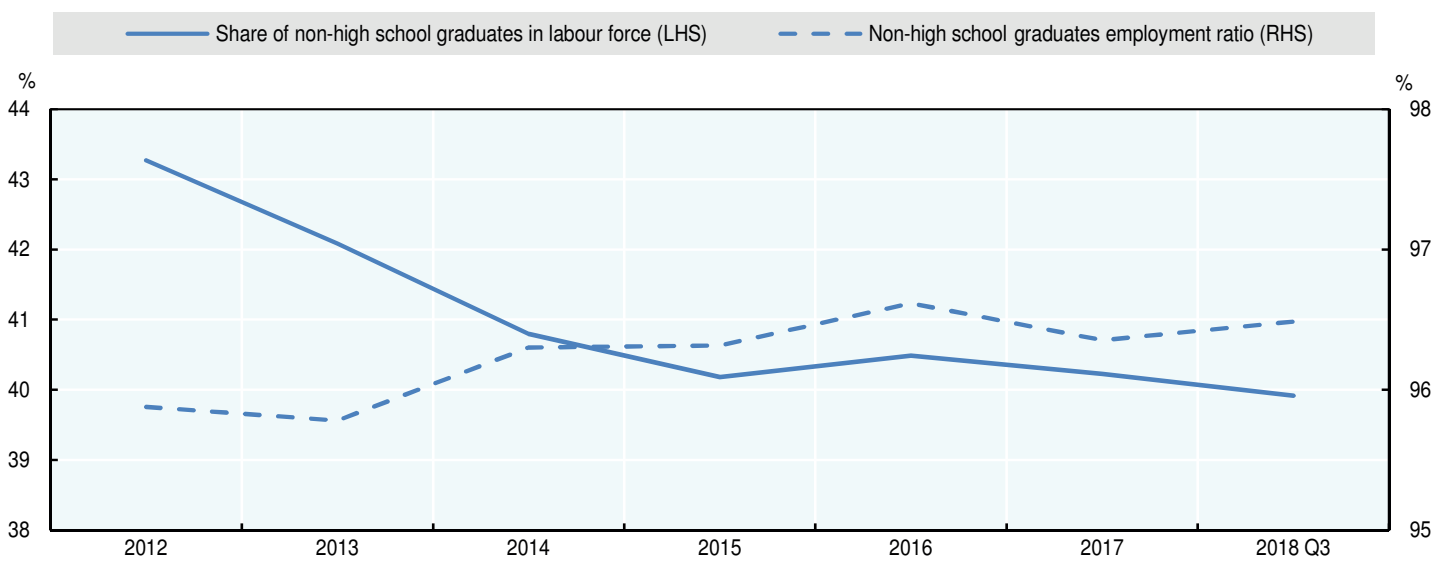

Note: For 2018, data are averages for the year from the fourth quarter of 2017 to the third quarter of 2018 . There is a break in the series between 2016 and 2017, when the first batch of senior-high school students enrolled. In labour force surveys, job seekers with junior-high school qualifications in the old curriculum are considered high school graduates. RHS means right hand scale. LHS means left hand scale.

Source: OECD Development Centre calculations based on national labour force survey data.

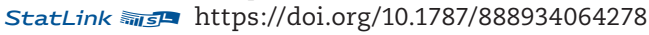

\section{Longstanding issues continue to undermine basic education's credibility}

The aggregate and per-student budget spending of the education department rose substantially in real terms between 2015 and 2017 (Table 3.3.1). ${ }^{2}$ Meanwhile, the spending shortfall declined from 12\% in 2015 to 3\% in 2017 (DepEd, 2018a). Apart from the direct support it provides, the government also involves the private sector in improving the delivery of basic education. One such initiative is the Education Service Contracting Scheme, which offers subsidies as an incentive for students to transfer to private schools, thereby helping to ease congestion at public schools. Private institutions have also been active in construction of classrooms, among other forms of assistance (LaRocque, 2008; PIA, 2016). 
Table 3.3.1. Budget spending of the Department of Education

Year-on-year percentage change in real terms

\begin{tabular}{lrrrc|c}
\hline Year & Total & Personnel & Maintenance and operations & Capital outlays & Budget spending per student enrolled in public schools \\
\hline 2012 & 6.4 & 5.5 & 5.2 & 25.2 & 4.9 \\
2013 & 13.7 & 10.0 & 13.3 & 68.5 & 12.9 \\
2014 & -5.6 & 2.3 & -6.7 & -81.0 & -6.2 \\
2015 & 12.2 & 8.2 & 21.7 & 165.5 & 11.1 \\
2016 & 18.3 & 9.7 & 52.4 & 111.9 & 18.6 \\
2017 & 20.1 & 8.0 & 80.4 & 41.3 & - \\
\hline
\end{tabular}

Note: Nominal data refer to the actual budgetary spending of the education department taken from the Budget of Expenditures and Sources of Financing report of the budget department.

Source: OECD Development Centre calculations based on DBM (various years) and PSA (2018), 2018 Philippine Statistical Yearbook.

However, resource-related issues continue to pose a challenge for state-funded education in the Philippines, even with the increase in the government's education budget and support from the private sector. The student-to-teacher ratio remains persistently high in many schools, and especially when calculated on a subject by subject basis. Meanwhile, the supply of learning materials, classrooms, and other necessities, remains tight (Mocon-Ciriaco, 2018). The gravity of these challenges varies from school to school, typically, determined by population density if it is an urban area and remoteness if it is a rural area. The practice of double shifts had been institutionalised to cope with this limitation (DepEd, 2004 and 2008). ${ }^{3}$

In 2016, the Philippine government rolled out a senior-high school voucher programme linked to the new K-12 approach, aiming to provide financial assistance to low-income families. Yet, the acceptability of the K-12 framework among students, communities, teachers, and administrators, though improving, can still be enhanced. Local government's participation is vital in this respect. And although it varies greatly across local governments, their declining financial share in education as a whole following World Bank (2016) necessitates reassessment.

Aside from budgetary constraints, concerns regarding the management of resources are also a persistent problem in public schools. Institutional barriers, which prevent midtier officials from adopting technology-based initiatives; misalignment in the timing of budget decisions, coupled with a retention of funds in division offices; narrow use of collected information; and the limited extent of decentralisation in the system limits school officials' discretion are some of the concerns noted (Read and Atinc, 2017). ${ }^{4}$

The quality of instruction in public schools is another sticking point. For instance, the World Bank has noted that the grasp that teachers at elementary and high schools have of the subjects they teach often falls short of their own perceptions of their teaching skills (World Bank, 2016). Moreover, teachers are expected to come up with their own professional development plans, which administrators then look at in aggregate in order to organise training. However, many of the teachers have never prepared such plan, presumably due to the weight of their workload.

\section{Improvement in resource management and programme implementation is vital}

Improving the outcomes of the $\mathrm{K}+12$ programme can benefit from more transparent and responsive resource management as well as from increased execution efficiency through simplification of certain procedures and actively engaging various stakeholders.

While increases in funding for basic education from the national budget are a good sign, the basic education system still needs to broaden its sources of financing. Pointing the way in this regard, initiatives such as "adopt a school" and "adopt a student" have already 
provided valuable help to the education system, as have philanthropic contributions. These successes notwithstanding, it is crucial to strengthen the participation of the private sector in order to support the funding needs.

Human resource-management issues cannot be overlooked. For instance, redistributing teachers between schools has been raised to ensure consistent ratios of students to teachers (World Bank, 2016). Relocating teachers, however, necessitates an attractive incentive mechanism since it would often require them to move away from family members and other local ties. Concerning the work load and the leeway for teachers to upskill while continuing at their jobs, the move to reduce the amount of forms that the teachers need to fill in is an encouraging step (DepEd, 2018b). Institutional and financial support also needs to be enhanced to facilitate professional development of teachers.

As regards fund management, there is merit in regular disclosures of fund disbursements to schools from all sub national education line agencies to increase transparency and efficiency in fund utilisation. Furthermore, ground-level experience suggests that procedures for accessing and utilising educational funds require simplification in order to encourage school administrators to tap into all of the sources of funding that are available. One way to ease delays in the procurement of necessary facilities and services for schools would be to ensure close co-operation with the Commission on Audit, while also improving the education department's capacity to plan big-ticket purchases.

Transparent and timely releases of education indicators and other information are just as crucial. Organising a team in the education department's central office that would hasten the flow of information down to individual schools would be beneficial for budgeting, assessment, and administrative purposes. Making some school-level data from the Learner Information System database publicly available would also help to elicit constructive external insights. The government's open government and open data initiatives provide a workable platform to disseminate information extensively, as opposed to distributing it on request.

\section{Involvement of multiple stakeholders in the programme appraisal would be valuable}

The education department's review of the K-12 curriculum in 2018 is a welcome development. It reassures stakeholders of the government's commitment to making sure that the curriculum is responding well to the objectives it was set up to achieve. Getting the higher education institutions and businesses involved in the review or assessment of the review would be valuable. Discussions on the manner at which the execution of new courses could be standardised could benefit from views of external stakeholders. ${ }^{5}$

Meanwhile, the education department could utilise its division and regional offices to conduct research into the execution of courses, and into teachers' needs in terms of professional training. This can complement or even replace the current set-up in which teachers are asked to submit their own professional-development plans. This would also mean involving division and regional supervisors directly in designing in-service training programmes though the channel for feedback and evaluation has to be available to all teachers. This can be augmented by putting in place mechanisms to share information on the execution of courses, teacher-training plans, and implementation of interventions, across divisions and regions.

Efforts to narrow the gap in the quality of instruction in schools across the country need appraisal. The education department produced guidelines in 2016 to promote school-to-school collaboration, which could serve as an instrument to reduce the disparities (DepEd, 2016). However, the implementation of these guidelines has yet to gain significant traction. Even more affluent OECD countries have taken similar initiatives in order to overcome certain limitations in resources, to improve standards, and to share 
learning and teaching experiences (Armstrong, 2015; Atkinson et. al., 2007). Linking resource-constrained schools and specialised science high schools, for instance, can yield substantial synergy gains. Furthermore, this can be a way of broadening the reach of high-performing teachers. Extending this approach by involving institutions of higher education is also worthy of consideration.

Meanwhile, the conditional cash transfer programme has been positively associated with school enrolment of children (World Bank, 2014). The challenge now is to leverage further these programmes in order to raise completion rates and, eventually, to increase school graduates' success in employment. Tracking K-12 graduates is crucial in this respect, but the relevant government agencies have yet to clarify how a mechanism for doing this would work. Incorporating this kind of tracking in the quarterly survey of the labour force is one potentially viable option.

The coverage of the "open high school" initiative can be similarly expanded. First implemented in 1998, this distance-learning initiative was deemed to be a viable alternative form of secondary education to reach out to students at risk of dropping out. Enrolment in this system has risen substantially since 2008 (SEAMEO INNOTECH, 2015) and its reach could be increased further. Establishing a more systematic approach to disseminate information and having a dedicated digital platform could be helpful in this respect. Through the use of online infrastructure, the open high school initiative can also serve as a supplementary learning platform for those in the formal education system.

The memorandum of understanding in 2015 between the education department and the Philippine Chamber of Commerce and Industry to tackle the skills mismatch is an encouraging signal for the future. Another encouraging sign is the commitment of the business sector to help the K-12 programme to progress. Increasing the role of local governments in promoting basic education is a crucial next step.

\section{Notes}

1. This refers to Republic Act 10533, whose legal standing was affirmed by the Supreme Court in November 2018. The programme started in school year 2011-12 and the last phase of transition to the new system was completed in school year 2017-18.

2. Around 1.4 million pupils are estimated to have enrolled in grade 11 in school year $2016-17$, or $93 \%$ of those who finished grade 10, mostly going to public schools (Mateo, 2018).

3. The Department of Education also required additional justification to process the requests for classroom construction if the school has not yet adopted the policy and directed future calculation of classroom adequacy based on the notion of double-shifts.

4. The management of basic education in the Philippines had been gradually decentralised over the years. The legal basis is provided by the 2001 Governance of Basic Education Act.

5. Employers appear cautious to take on K-12 graduates (Jobstreet.com, 2018). The Philippine Chamber of Commerce and Industry has likewise expressed scepticism regarding the adequacy of the 80 -hour job immersion component of the K-12 programme (Aguinaldo, 2018). The hiring prospects of $\mathrm{K}-12$ graduates have to be taken in light of the large pool of job seekers with tertiary education. In 2018, 21\% of unemployed workers had higher-education degrees, with another $15.9 \%$ having studied part of the way towards such a degree.

\section{References}

Aguinaldo, C. (2018), "Business groups take stand to open jobs to K-to-12 graduates", BusinessWorld, 21 April, Manila, https://www.bworldonline.com/business-groups-take-stand-to-open-jobs-tok-to-12-graduates/.

Armstrong, P. (2015), Effective School Partnerships and Collaboration for School Improvement: A Review of the Evidence, United Kingdom Department of Education, Manchester, https://assets.publishing. service.gov.uk/government/uploads/system/uploads/attachment_data/file/467855/DFERR466_-SChool_improvement_effective_school_partnerships.pdf. 
Atkinson, M., I. Springate, F. Johnson and K. Halsey (2007), Inter-school Collaboration: A Literature Review", NFER, Slough, https://www.nfer.ac.uk/media/1616/atp01.pdf.

DBM (various years), Budget of Expenditures and Sources of Financing Fiscal Years 2014-2019, Department of Budget and Management-Philippines, Manila, https://www.dbm.gov.ph/index. $\mathrm{php} / \mathrm{dbm}$-publications/budget-of-expenditures-and-sources-of-financing-besf.

DepEd (2018a), DepEd Reports Increased Budget Utilization, Closes Gap of Underspending in Education, Department of Education, Manila, http://www.deped.gov.ph/2018/07/12/deped-reportsincreased-budget-utilization-closes-gap-of-underspending-in-education/.

DepEd (2018b), Statement on DepEd's Review of Teachers' Workload, Department of Education, Manila, http://www.deped.gov.ph/2018/09/04/statement-on-depeds-review-of-teachers-workload/

DepEd (2016), Guidelines on the School-to-School Partnerships for Fiscal Year 2016, Department of Education, Manila, http://www.deped.gov.ph/2016/06/23/do-44-s-2016-guidelines-on-theschool-to-school-partnerships-for-fiscal-year-2016/.

DepEd (2008), Reiterating the Policy on Double Shifting of Classes and Requiring Strict Compliance Thereto, Department of Education, Manila, http://www.deped.gov.ph/2008/07/07/do-54-s-2008reiterating-the-policy-on-double-shifting-of-classes-and-requiring-strict-compliance-thereto/.

DepEd (2004), Adoption of Double Shift Policy in Public School to Address Classroom Shortage, Department of Education, Manila, http://www.deped.gov.ph/2004/12/13/do-62-s-2004-adoption-of-doubleshift-policy-in-public-school-to-address-classroom-shortage/.

Jobstreet.com (2018), "Fresh graduate hiring shows shifts in demand and preferences", Jobstreet. com, 27 April, Manila, https://www.jobstreet.com.ph/career-resources/fresh-graduate-hiringshows-shifts-demand-preferences\#.XBOqa2j0mUk.

LaRocque, N. (2008), Public-Private Partnerships in Basic Education: An International Review, CfBT Education Trust, Reading, UK, https://olc.worldbank.org/sites/default/files/CfBT LaRocque PPPs\%20in\%20Basic\%20Education\%20An\%20International\%20Review_0.pdf.

Mateo, J. (2018), "Senior high school results exceeded expectations-DepEd shares", The Philippine Star, 11 May, Manila, https://www.philstar.com/headlines/2018/05/11/1814173/senior-highschool-results-exceeded-expectations-deped.

Mocon-Ciriaco, C. (2018), "Classroom, teacher shortages hound schools, but DepEd says they're but 'challenges'”, BusinessMirror, 4 June, Manila, https://businessmirror.com.ph/classroom-teachershortages-hound-schools-but-deped-says-theyre-but-challenges/.

PIA (2016), "DepEd boosts innovative strategies to achieve universal basic education", Philippine Information Agency, 29 September, Manila, https://ppp.gov.ph/in the news/deped-boostsinnovative-strategies-to-achieve-universal-basic-education/.

PSA (2018), 2018 Philippine Statistical Yearbook, Philippine Statistics Authority, Manila, https://psa. gov.ph/products-and-services/publications/philippine-statistical-yearbook.

Read, L. and T.M. Atinc (2017), "Investigations into Using Data to Improve Learning: Philippines Case Study", Global Development and Economy, The Brookings Institution, Massachusetts.

SEAMEO INNOTECH (2015), Evaluation of the Open High School Program in the Philippines, Southeast Asian Ministers of Education Organization-Regional Center for Educational Innovation and Technology, Quezon City, https://www.seameo-innotech.org/wp-content/uploads/2017/07/ OHSP 2015 Dec compressed.pdf.

World Bank (2016), Assessing Basic Education Service Delivery in the Philippines: The Philippines Public Education Expenditure Tracking and Quantitative Service Delivery Study, World Bank, Washington, DC, http://documents.worldbank.org/curated/en/507531468325807323/pdf/AUS6799-REVISEDPH-PETS-QSDS-Final-Report.pdf.

World Bank (2014), Philippines Conditional Cash Transfer Program Impact Evaluation 2012 (Report Number 75533-PH), World Bank, Manila, https://openknowledge.worldbank.org/bitstream/handle/10986 /13244/755330REVISED000Revised0June0402014.pdf? sequence=8\&isAllowed =y. 


\section{Thailand}

A. Medium-term economic outlook (forecast, 2020-24 average)

GDP growth (percentage change):

Current account balance (\% of GDP):

Fiscal balance (\% of GDP) (central government):
3.2

6.6

$-2.8$

\section{B. Basic data (in 2018)}

Total population:

Population of Bangkok: Nominal GDP (US dollar): GDP per capita at PPP:

Exchange rate in the first half of 2019 (period average):

66.4 million * 5.7 million * 487.2 billion ** 19476.5 (current International Dollar) **

31.6 (THB/USD)

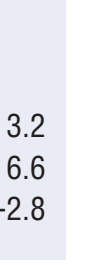
Note: * Population data are year-end government estimates.
** IMF estimate.
Sources: OECD Development Centre, national sources, CEIC and IMF.

\section{Composition of exports, 2018}

(percentage of total exports)

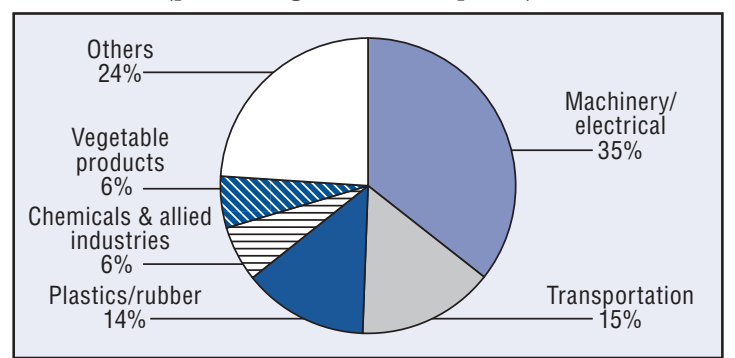

Source: Trademap.

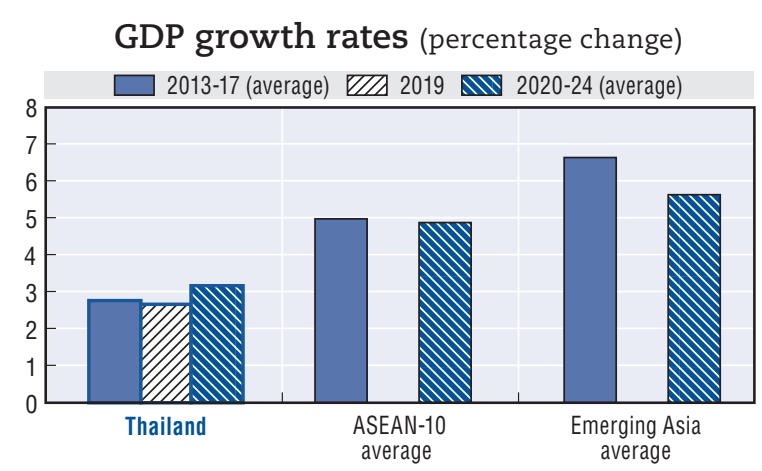

Source: OECD Development Centre.

GDP per capita, 2018

(PPP, current international dollar)

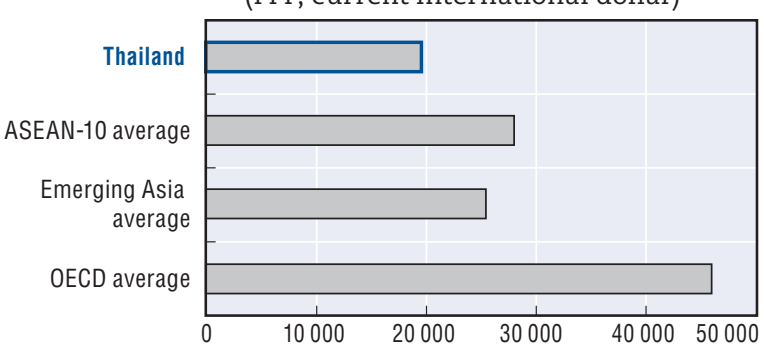

Source: IMF.

\section{Composition of imports, 2018}

(percentage of total imports)

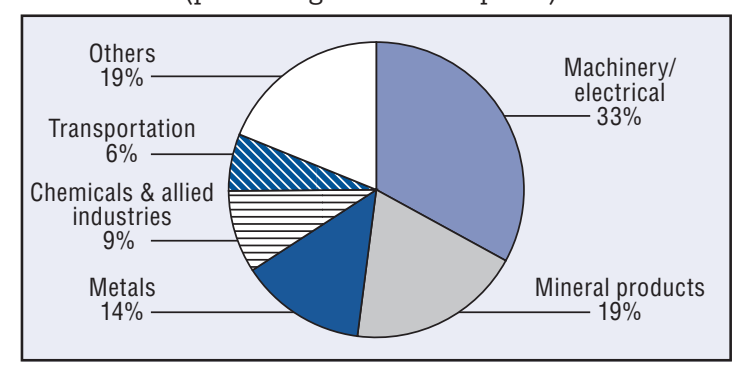

Source: Trademap.

\section{Structural policy challenges discussed in previous editions of the Outlook}

\begin{tabular}{|c|c|c|}
\hline \multirow{3}{*}{2014} & Education & Upgrade human capital by improving the national curriculum and teaching standards \\
\hline & Agriculture & Improve agricultural productivity through modernisation and education \\
\hline & Green growth & Improve institutional co-ordination to achieve green growth \\
\hline \multirow{3}{*}{2015} & Productivity & Accelerate improvements in productivity to ensure sustainable economic growth and enhance competitiveness \\
\hline & Environment & Make further efforts in environmental management in order to support green growth \\
\hline & Governance & $\begin{array}{l}\text { Improve good governance - with particular emphasis on corruption and transparency } \\
\text { - to reduce obstacles to growth }\end{array}$ \\
\hline \multirow{2}{*}{2016} & Macroeconomic performance & Use macroeconomic policies to revive growth \\
\hline & Tourism & Strengthen sustainable tourism \\
\hline \multirow{2}{*}{2017} & Digital economy & Develop the digital economy as a new engine of growth \\
\hline & Human capital & Develop human capital through education to make the most of the country's economic potential \\
\hline 2018 & Digital economy & Strengthening information and communications technology (ICT) skills to develop the digital economy \\
\hline 2019 & Eastern Economic Corridor & Foster human capital development for Eastern Economic Corridor \\
\hline
\end{tabular}




\section{POLICY FOCUS}

Improving the social safety net to help elderly people

Changes in Thailand's demographic trends - including a decline in its overall rates of fertility, births, and deaths - have resulted in an ageing population. Indeed, a recent projection predicted that the proportion of elderly people aged 60 and over will increase from $14.9 \%$ in 2016 to $19.1 \%$ in 2020 , and will go on to rise to $32.1 \%$ in 2040 (NSO, 2017), while the median age of Thai population is 38.1 years as of 2018 (BOI, n.d.). Under its second national plan for the elderly, which runs from 2002-21, the government's overall aim has been to promote and develop older people as valuable assets to society, and to ensure their well-being. The plan has set out a range of strategies to improve the life of the nation's elderly citizens, including a special focus on encouraging people to prepare in advance to make sure they thrive as they grow older. This objective encompasses themes such as income security and education and lifelong learning. It also seeks to promote a social conscience towards the elderly, and respect for them as senior citizens.

Thailand's government believes that developing and improving this social sentiment of understanding and respect towards the elderly can provide a boost to senior citizens' physical and mental health. One example of the initiatives the government has taken in this regard is a volunteering programme for home caregivers (DOP, 2016). It involves people of all ages, in line with the government's aim of strengthening the relationships between different generations. Moreover, the programme targets family and community members who have previously neglected or given insufficient care to the elderly. This programme operates against a backdrop in which smaller family sizes and an increase in migration among younger adults have contributed to a sharp increase in long-term care needs, particularly for very elderly people. This is especially true considering that family - in particular daughters and wives - represents the most important provider of personalcare assistance in Thai society. In addition, despite the programme's efforts to shore up traditions of respect and care for the elderly, the perceived value to society of the elderly has been on the decline among teenagers. According to the 2011 Survey on Social and Cultural Conditions, teenagers view the elderly as old fashioned, difficult to understand, hard to please, and boring (Sasiwongsaroj and Burasit, 2019).

One way to address this challenge could be to encourage elderly's participation in various social activities, helping them to enjoy access to lifelong learning and to prepare for better, more active ageing. A programme called "School for the Elderly", along with other community-based learning centres, provides a platform for elderly people to share and transfer knowledge between themselves. However, learning in these contexts tends to focus mainly on health-related topics, despite there being demand for other subjects such as how to use the Internet and other information and computer technology (ICT) tools. Although the Internet has become the main channel for disseminating the kinds of information that older people are interested in - on topics such as news, events, and welfare benefits the proportion of elderly people in Thailand who get these kinds of information from the Internet and social media remains low, at just 4\% (TGRI and IPSR, 2019). Considering the likelihood that ICT will play an even more central role as time goes by, lifelong learning and education programmes for the elderly may need to adjust to the skills that technology will increasingly demand. Indeed, this presents an opportunity to improve the social integration of the elderly and to help people to extend their working lives.

In terms of income security, Thailand's government has put in place a variety of reforms to help prevent old people falling into poverty. These efforts date back notably to 1993, when Thailand introduced its old-age allowance system (DOP, 2016). Since then, 
elderly people have received a monthly allowance from the government. The government pays this allowance to people over 60 years of age who were not engaged in the formal sector employment, and who do not live in a public residential facility for the elderly. The system used to be a targeted pension scheme, making use of a selection process to identify recipients. Several qualifying conditions were taken into consideration, such as the lack of an income, having no relatives able to provide support, or being abandoned (DOP, 2016). However, this tax-financed and non-contributory programme changed in 2009 into a universal pension scheme, providing income for all old people who are not covered by any other form of social protection, and especially for those who worked in the informal economy. The government also provides other social protection schemes in the form of contributory programmes, both compulsory and voluntary, which aim to ensure income security after the age of retirement.

\section{More and more of Thailand's senior citizens depend on the government's old-age allowance}

According to surveys of elderly people in Thailand, their three main sources of income are family transfers - notably from their children - as well as work and the old-age allowance. Indeed, a survey in 2017 showed that $40.7 \%$ of Thailand's older people reported family transfers as their main source of income. In the same survey, $31 \%$ reported work as their main source of income, with $20 \%$ stating that it was the government's old-age living allowance (Figure 3.4.1). Over time, however, the number of elderly people relying on family transfers and work has gradually fallen, while the number who rely on the government's elderly allowance has been on the rise. Indeed, by 2017 it was already 1.5 times the level of 2009 (TGRI and IPSR, 2019). Over the same period, the size of the monthly old-age allowance has gradually increased. From the initial amount of 200 Baht per month given in 1993, it rose to 500 Baht per month in 2007 and since 2012 it has increased with the recipient's age (DOP, 2016). People aged 60-69 now receive 600 Thai baht (THB), rising to THB 700 for those aged 70-79, THB 800 for people of $80-89$ years, and THB 1000 for people who are 90 years old and over.

Figure 3.4.1. The main sources of income for elderly people in Thailand, 2007 and 2017

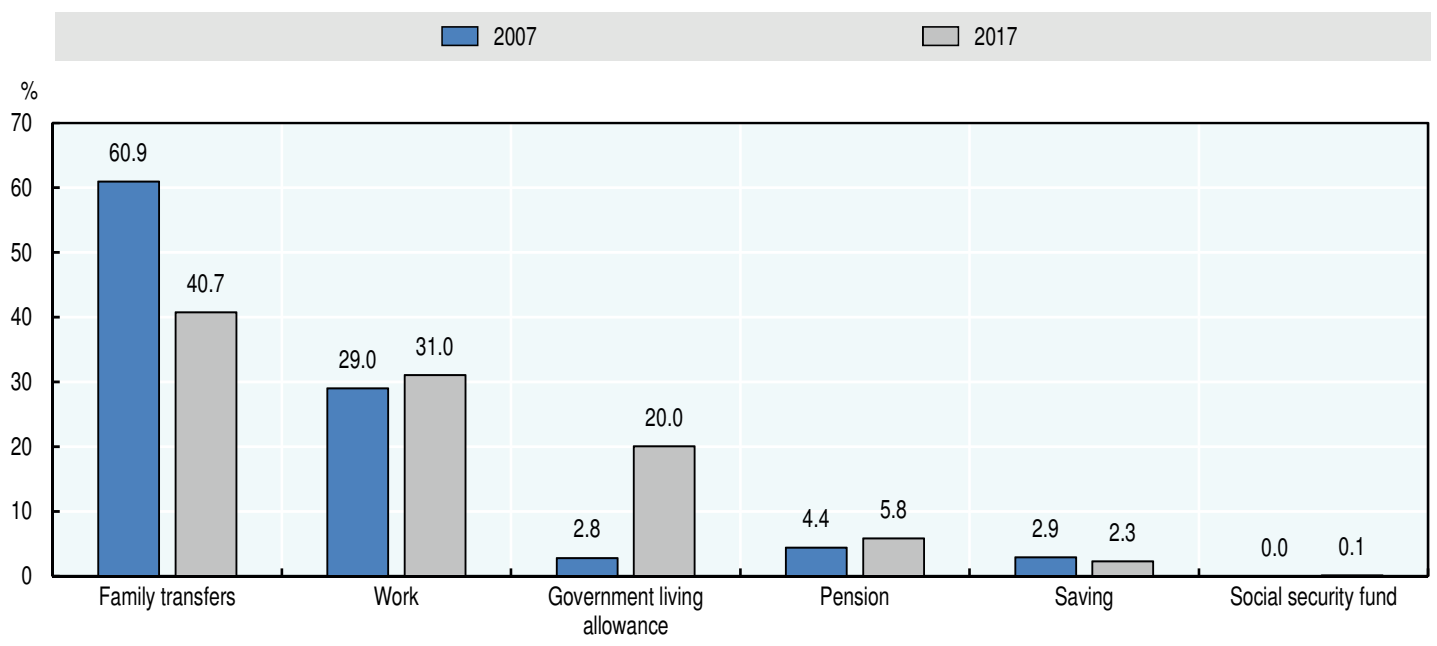

Note: Family transfers include transfers from a spouse, a child, a parent, and a brother, sister, or other relative. Saving includes both interest and assets.

Source: NSO (2018), Report on the 2017 Survey of the Older Persons in Thailand; NSO (2007), Report on the 2007 survey of the older persons in Thailand.

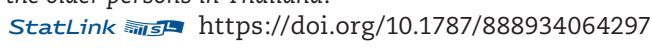


Yet despite the increase in the government's budget for old-age allowances, the monthly amount paid to the elderly remains below the official poverty line. According to the National Economic and Social Development Council, the poverty line in 2013 - which refers to the minimum monthly cost of food and other basic needs - was THB 2572 baht per month (TGRI and IPSR, 2016). By this yardstick, one third of Thailand's elderly people are living below the poverty line (TGRI and IPSR, 2016). Against this backdrop, the inadequate size of public benefits may help to explain why family transfers still represent the main source of income for the majority of Thailand's elderly people. By way of comparison, in OECD countries it is public transfers that account for the biggest share of elderly people's incomes, accounting on average for $58 \%$ (Figure 3.4.2). Considering the pace at which Thailand's population is ageing, the current reliance on family transfers for older people to maintain a decent life could come under strain. Against this backdrop, the government may need to increase its capacity to provide them with income security, especially when it comes to particularly vulnerable elderly people.

Figure 3.4.2. Average sources of income for older people for OECD countries, 2014 or latest available year

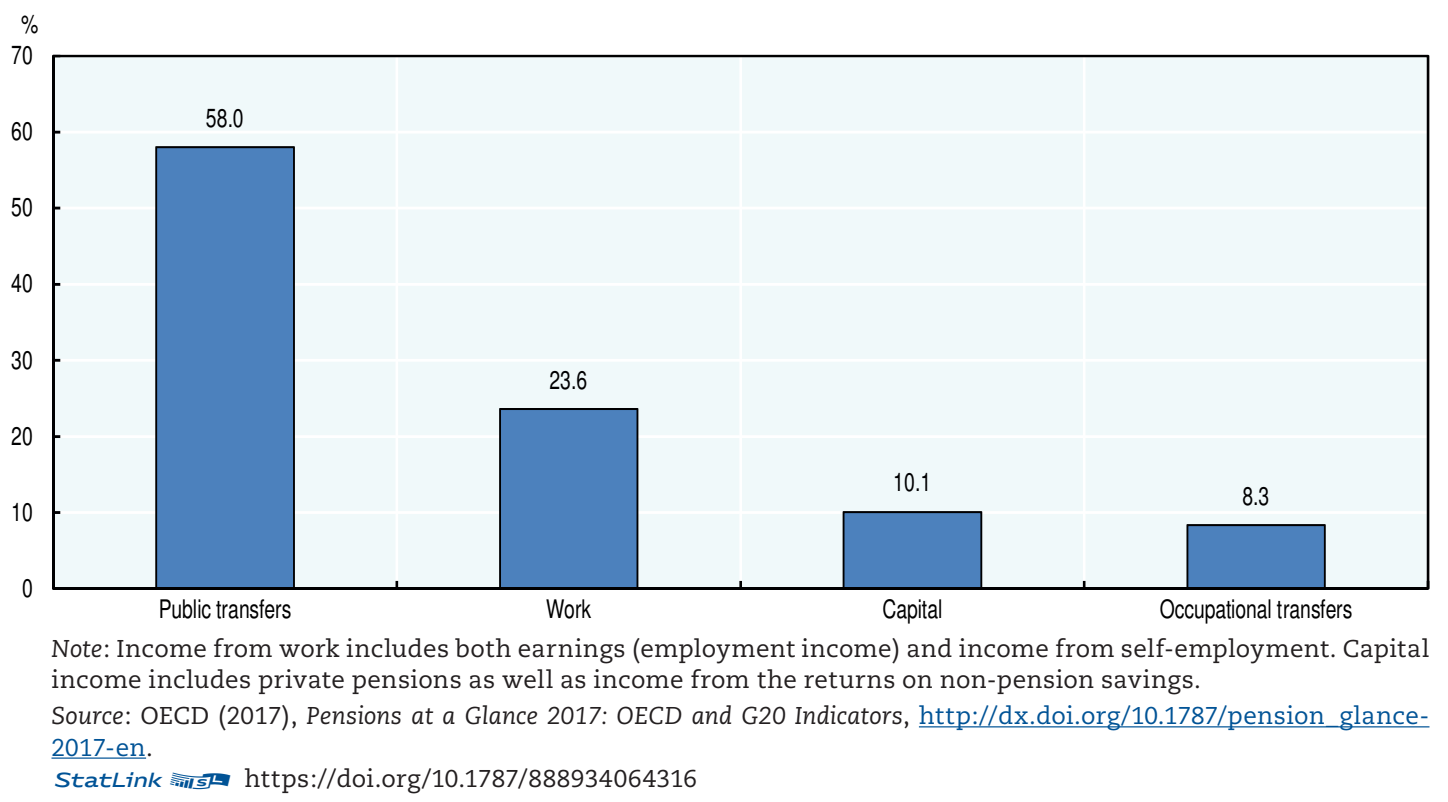

\section{Encouraging people to save helps them to lay the foundations for a better retirement}

The challenge that Thailand's government faces in ensuring an adequate safety net for retirement also extends to the country's other types of public pensions, such as its provision of old-age insurance as part of its social security fund scheme. People who had contributed to this insurance scheme began receiving old-age pensions in 2014. Since then, however, Thailand's social security office has taken stock of the increasing burden of liabilities that it faces due to the rapidly changing population structure, underscoring the need to ensure the ongoing stability and viability of the fund.

Aside from the desirability of increasing the government's budget allocation for the elderly, and from the challenge it faces in managing its social security fund, a low propensity to save for retirement may also increase the financial burden that the government will have to bear. Indeed, only a small minority of older people - around 2.3\% - listed savings as their main source of income in 2017 (Figure 3.4.1). According to 
the rules of the Thai system, formal workers have to be part of the compulsory pension scheme, but they are then free to choose whether or not to participate in the voluntary component that complements it. However, the number of participants in voluntary schemes remains relatively modest. For example, the provident fund - a voluntary pension scheme established mutually by employers and employees in 1987 - covers only 2.8 million employees in 2015 (DOP, 2016).

More can be done to boost saving among formal workers. One successful voluntary scheme to encourage saving for retirement is New Zealand's KiwiSaver (Box 3.4.1). This scheme's features include automatic enrolment, a "default" mechanism, and matching contributions, and these have helped it to reach a significant number of participants since its introduction in 2007. A recent report on KiwiSaver revealed that, as of 2018, 2.8 million individuals were enrolled in the scheme (FMA, 2018). Effective communication and education campaigns during the programme's launch also contributed to its success. The scheme has also proven its ability to reach all income groups equally, meaning that no-one is left out (OECD, 2018a).

\section{Box 3.4.1. KiwiSaver's strategies for boosting people's propensity to save}

As a voluntary scheme, KiwiSaver offers various enrolment methods. One of these is automatic enrolment, under which new employees are automatically enrolled on their employer's chosen scheme - or to a "default scheme" in case the employer's chosen scheme is not available. Once they have enrolled, contributors' savings will be locked in until they reach the age of 65 . Within the default scheme, one of the nine governmentappointed default providers is selected to manage the employee's savings contributions. Different contribution rates are available at $3 \%, 4 \%, 6 \%, 8 \%$ or $10 \%$ of earnings, and members can easily change their contribution rate once every three months. Those who are enrolled to the default scheme make their contributions at a default rate of $3 \%$.

The scheme's default mechanism has simplified the choices that new employees have to make. According to a survey, KiwiSaver members reported that their main reason for joining the scheme was that it offered an easy way to save. By taking contributions from employees' pay at source, it helps to minimise the effort required to contribute to the scheme. Moreover, in 2013, those who contributed at the $3 \%$ default contribution rate represented $58 \%$ of the members whose payment was deducted at source, meanwhile the $4 \%$ default contribution rate set in 2008 was reported to discourage people from joining the scheme (Inland Revenue, 2015). This shows that the default mechanism, in particular the one with appropriate level of default contribution rate plays an important role.

Another factor that has contributed to the success of KiwiSaver's implementation has been the targeted communications campaign it has run. The launch campaign consisted of advertising on television, radio, online, and also in print materials such as a guide for employers and an information pack for employees. There have also been events such as seminars and trade-show presentations for employers and other professionals (OECD, 2014). The campaign has increased the level of awareness among employers, and has helped employees to make the necessary decisions. According to the survey, $81 \%$ of employers who were interviewed reported that the campaign material was straightforward and easy to understand (Inland Revenue, 2015). Among the members who responded to the survey, meanwhile, $80 \%$ reported that they had enough information to help them decide whether or not to join the scheme. 


\section{The conundrum of encouraging more low-income workers to save}

Despite the benefits that the KiwiSaver scheme offers, and the possibility of taking breaks from paying in or of making an early withdrawal for reasons such as buying a first home, moving overseas permanently, encountering significant financial hardship, or suffering serious illness, a lower level of engagement with KiwiSaver could still be observed and it is associated with lower annual income (Inland Revenue, 2015). Affordability represents the main reason that people give for opting out of the scheme. This has underscored the conundrum of how to encourage low-income workers to start saving more. One potential answer to this problem is for the government to offer fixed nominal subsidies as an incentive for low-income earners to participate in retirement saving plans. For instance, Germany's so-called Riester pensions offer basic nominal subsidies of 175 euros per year to individuals who contribute at least $4 \%$ of their income into the scheme (OECD, 2018b). A study of Germany's Riester pensions have shown that the participation rates among low-income households are higher than for other types of private pension plans (Börsch-Supan, Coppola and Reil-Held, 2012).

In Thailand's case, while formal workers have access both to the compulsory and voluntary pension schemes, most informal workers do not have any social protection for their retirement. Informal workers with social security represent only a small minority, of $10.9 \%$ (NESDC, 2018). Indeed, their low level of protection from a social-security safety net puts them at greater risk of economic and health-care insecurity. Given that Thailand's informal workers outnumber those in the formal sector (Buddhari and Rugpenthum, 2019), the government provides retirement savings programme. One such initiative on the part of Thailand's government has been the National Savings Fund, which began operating in 2015, and aims to encourage regular saving among working-age Thais (15-59 years old). This programme specifically targets informal workers who are not covered by any social security or any pension scheme, encouraging them to make monthly contributions, and helping them to make sure that they will enjoy income security in retirement.

After several years in operation, however, the fund's total membership extends to just 580000 people, which is relatively low compared to the total number of self-employed workers in Thailand (NNT, 2018). One way to increase the participation rate, especially among low-income workers, would be to offer saving incentives such as the fixed nominal subsidies mentioned above. Moreover, accompanying this measure with targeted campaigns of communication and education in order to increase people's awareness of the importance of saving for retirement might also increase the participation rate. In addition, the co-existence of multiple schemes for informal workers makes it necessary to provide clear information on each scheme, so that future contributors can make wellinformed decision. An easier procedure for workers to register - including by being more flexible about the documents they must provide - could also help boost participation. In order to improve access - including among the rural poor and commonly stigmatised groups - other helpful measures could include giving people the opportunity to register and claim in different localities, and developing a system of online registration. Mexico, for instance, has launched an application system in which people can open pensions and savings accounts online. Indeed, Mexico has also sought to make it easier to save by building a network of 7000 convenience stores where people can make voluntary savings deposits. These practices have resulted in an average annual increase of $33 \%$ in voluntary savings balances since 2014 (OECD, 2018b). 


\section{References}

BOI (n.d.), "Thailand in Brief" Thailand Board of Investment, Bangkok, https://www.boi.go.th/ index.php?page = demographic.

Börsch-Supan, A., M. Coppola and A. Reil-Held (2012), "Riester pensions in Germany: Design, dynamics, targetting success and crowding-in", NBER Working Paper Series, No. 18014, National Bureau of Economic Research, http://www.nber.org/papers/w18014.

Buddhari, A. and P. Rugpenthum (2019), "A Better Understanding of Thailand's Informal Sector", Focused and Quick (FAQ), Issue 156, Bank of Thailand, Bangkok, https://www.bot.or.th/Thai/ MonetaryPolicy/ArticleAndResearch/FAQ/FAQ 156.pdf.

DOP (2016), Thailand's Implementation of the Madrid International Plan of Action in Ageing (MIPAA) 200216, The Department for Older Persons, The Ministry of Social Development and Human Security, Bangkok, http://www.dop.go.th/download/laws/law th 20161107085250 1.pdf.

FMA (2018), KiwiSaver Annual Report, Financial Markets Authority, Wellington, https://www.fma. govt.nz/assets/Reports/KiwiSaver-Report-2018.pdf.

Inland Revenue (2015), KiwiSaver evaluation: Final summary report, New Zealand Inland Revenue, Wellington, https://www.classic.ird.govt.nz/resources/3/8/38e71a99-51cd-4971-abb7-87ee68497b23/ ks-evaluation-final-summary-report.pdf.

NESDC (2018), Thailand's Social Situation and Outlook in Q4/2018 and Overview in 2018, Office of the National Economic and Social Development Council (NESDC), Bangkok, https://www.nesdb. go.th/nesdb en/download/Social\%20Press Eng.pdf.

NNT (2018), "National Savings Fund launches savings program for civil servants", National News Bureau of Thailand, Bangkok, http://thainews.prd.go.th/th/news/detail/WNSOC6109110010063.

NSO (2018), Report on the 2017 Survey of the Older Persons in Thailand, National Statistical Office, http://www.nso.go.th/sites/2014en/Survey/social/domographic/OlderPersons/2017/Full\%20 Report_080618.pdf.

NSO (2017), Social Indicators 2017, National Statistical Office/Ministry of Digital Economy and Society, Bangkok, http://service.nso.go.th/nso/nsopublish/pubs/e-book/Indicators Social 2560/files/assets/ common/downloads/publication.pdf.

NSO (2007), "Report on the 2007 survey of the older persons in Thailand", National Statistical Office, http://web.nso.go.th/en/survey/age/tables_older_50.pdf.

OECD (2018a), Financial Incentives and Retirement Savings, OECD Publishing, Paris, https://doi. org/10.1787/9789264306929-en.

OECD (2018b), OECD Pensions Outlook 2018, OECD Publishing, Paris, https://doi.org/10.1787/pens outlook-2018-en.

OECD (2017), Pensions at a Glance 2017: OECD and G20 Indicators, OECD Publishing, Paris, http://dx.doi. org/10.1787/pension glance-2017-en.

OECD (2014), OECD Pensions Outlook 2014, OECD Publishing, Paris, http://dx.doi. org/10.1787/9789264222687-en.

Sasiwongsaroj, K. and Y. Burasit, (2019), Managing Thailand's Ageing Population, ISEAS - Yusof Ishak Institute, Singapore, https://www.iseas.edu.sg/images/pdf/ISEAS_Perspective_2019_32.pdf.

TGRI and IPSR (2019), Situation of the Thai Elderly 2017, Foundation of Thai Gerontology Research and Development Institute (TGRI) and Institute for Population and Social Research (IPSR), Bangkok, http://www.dop.go.th/download/knowledge/th1552463947-147 1.pdf.

TGRI and IPSR (2016), Situation of the Thai Elderly 2014, Foundation of Thai Gerontology Research and Development Institute and Institute for Population and Social Research, Bangkok, http://www. dop.go.th/download/knowledge/knowledge th 20161608145327 1.pdf. 


\section{Viet Nam}

\section{A. Medium-term economic outlook (forecast, 2020-24 average) \\ GDP growth (percentage change): \\ Current account balance ( $\%$ of GDP): \\ Fiscal balance (\% of GDP) (central government): \\ 6.5 \\ 1.5 \\ $-4.1$}

\section{B. Basic data (in 2018) \\ Total population: Population of Hanoi: Nominal GDP (US dollar): GDP per capita at PPP: \\ Exchange rate in the first half of 2019 (period average): \\ 94.7 million * 7.5 million * 241.3 billion ** 7510.5 (current International Dollar) ** \\ 22970.2 (VND/USD) \\ Note: * Population data are year-end government estimates. \\ ** IMF estimate. \\ Sources: OECD Development Centre, national sources, CEIC and IMF.}

\section{Composition of exports, 2018}

(percentage of total exports)

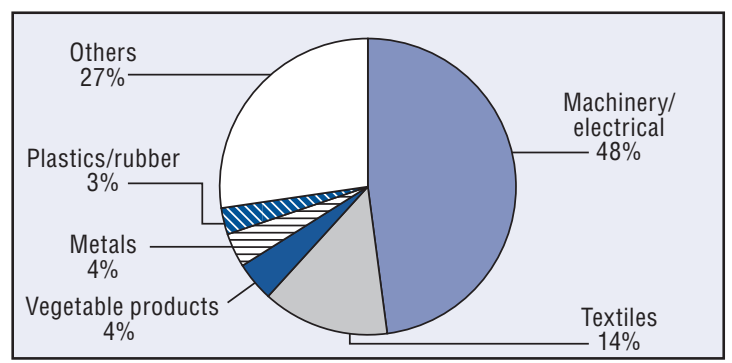

Source: Trademap.
GDP growth rates (percentage change)

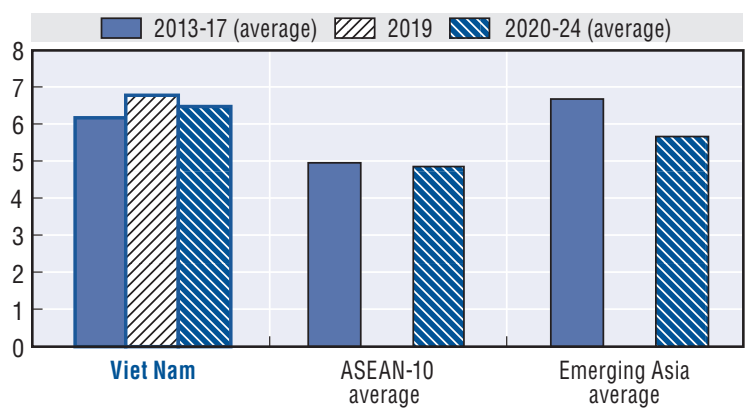

Source: OECD Development Centre.

GDP per capita, 2018

(PPP, current international dollar)

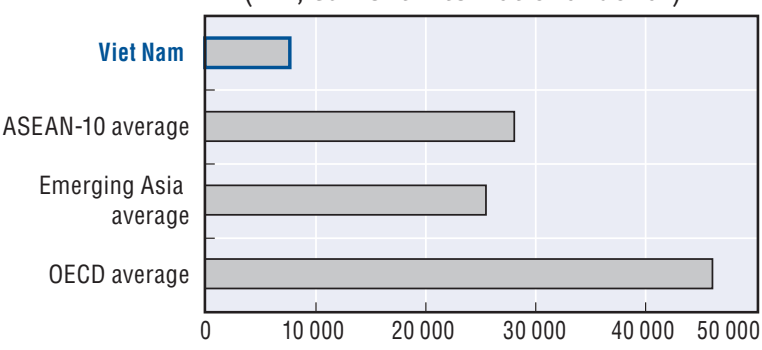

Source: IMF.

\section{Composition of imports, 2018}

(percentage of total imports)

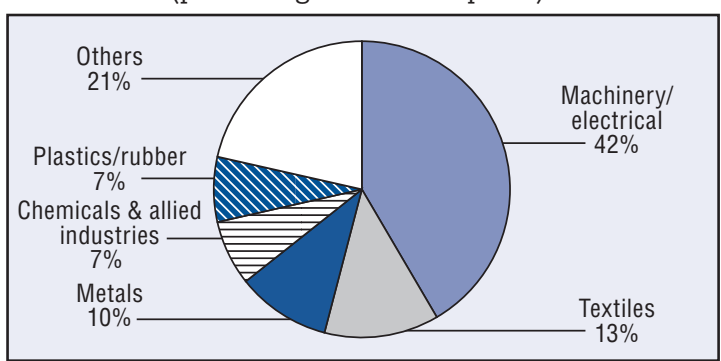

Source: Trademap.

Structural policy challenges discussed in previous editions of the Outlook

\begin{tabular}{|c|c|c|}
\hline \multirow{3}{*}{2014} & Skilled labour & $\begin{array}{l}\text { Increasing access to education, and strengthening Technical and Vocational Education and Training (TVET), } \\
\text { to improve the quality of human capital }\end{array}$ \\
\hline & Private sector development & Making it easier to access to credit, and lowering transport costs to develop the private sector \\
\hline & Financial sector development & Restructuring the financial system to enhance the effectiveness of monetary policy \\
\hline \multirow[t]{2}{*}{2015} & Policy stability & $\begin{array}{l}\text { Maintaining stability in key economic and social-policy areas in order to be able to implement socio- } \\
\text { economic strategies for the country }\end{array}$ \\
\hline & Skilled labour & Fulfilling the as-yet-incomplete implementation of measures to develop high-tech industries and skills training \\
\hline \multirow{3}{*}{2016} & Infrastructure & Improving infrastructure to support growth \\
\hline & State-owned enterprises (SOEs) & Reforming and restructuring SOES \\
\hline & Skilled labour & Promoting both job creation and productivity growth \\
\hline & Skilled labour & Training a skilled workforce to work in high-tech manufacturing \\
\hline 2017 & Infrastructure & $\begin{array}{l}\text { Building hard and soft infrastructure to allow the country to participate as fully as possible in promising } \\
\text { new technologies and industries }\end{array}$ \\
\hline 2018 & State-owned enterprises (SOEs) & Building momentum towards greater privatisation of state-owned enterprises (SOEs) \\
\hline 2019 & Education and training & Improving access to secondary education as a driver for social equality and social mobility \\
\hline
\end{tabular}




\section{POLICY FOCUS}

Developing the digital economy to enhance trade

While Viet Nam's government has paid special attention to the application of digital technology - both for economic development in general, and for trade in particular - the regulations and policies that relate to digital trade have come into force largely over the past 15 years, as laws, decrees, directives, and circulars. Aside from legislative instruments of this kind, Viet Nam has also integrated its efforts to boost digital trade into its national development strategies, plans, and programmes.

\section{Fostering a favourable environment for innovation and the digital eco-system through a wide range of legislation}

As of 2005, a few laws began to craft a regulatory framework for digital trade, addressing commercial questions, electronic transactions, and intellectual property. Then, over the five years that followed, more detailed guidelines for these laws appeared, providing basic regulations covering electronic transactions, ICT applications, and both the development of these activities and the provision of safeguards. From 2011-15, the government issued a range of regulations on e-commerce. These defined businesses' obligations, prohibited certain activities, and set out regulations for e-commerce websites. They also sought to strengthen the management role of state agencies, in areas such as internet provision, online information, and the inspection of e-commerce operations. More recently, the government demonstrated its determination to keep on developing e-commerce by approving an over-arching plan for the development of e-commerce in 2016-20.

In 2016, Viet Nam's policies to foster a more propitious environment for innovation and to improve the digital eco-system expanded from an exclusive focus on e-commerce to integrate fully with Viet Nam's overall vision for harnessing the so-called fourth Industrial revolution. From 2016-19, the government's policies for fostering the kind of creative, innovative environment that can boost digital trade focused on encouraging research and development (R\&D), and promoting eco-systems of entrepreneurship, innovation and creativity, as well as other digital initiatives.

Meanwhile, the government has developed a number of policies to encourage investment capital to flow into $R \& D$, while also establishing agencies to support firms in their innovative endeavours. Thanks, for example, to Decree No. 95/2014/ND-CP, state-owned enterprises now have to invest 3-10\% of their revenue into R\&D. A number of new agencies for startups and innovation have been established, such as the National Foundation for Technology Innovation, the Hoa Lac High-tech Service Centre, the National Innovation Centre, and the National Start-up Centre. In 2017, the government formulated the Directive No. 16/CT-TTg for strengthening progress towards the 4th Industrial Revolution which focuses on the establishment and development of the digital economy and the smart industry. They are considered as key tasks in restructuring the economy as well as shifting the growth model towards improved productivity, quality, efficiency and competitiveness.

Initiatives have also been taken to improve government management capacity. In 2018, for instance, the government set up the e-Government Committee to study and propose policies to create a legal environment that will speed up the digitalisation process and the roll-out of e-government (Hinrich Foundation, CIEM and Alphabeta, 2019). However, despite the efforts, investment in science and technology remains relatively low, accounting for about $0.8 \%$ of the total state budget in 2017.

To further improve digital eco-system, some challenges will still need to be addressed. Raising awareness of digital trade among citizens, businesses, and regulatory authorities 
is crucial. Regulatory authorities should develop direct regulations on digital trade rather than scattering the regulatory framework across various policies, while at the same time enhancing the enforcement of existing regulations that relate to digital trade. The country also needs to find ways to reduce barriers to its companies' digital exports, promote cashless payments, accelerate ICT infrastructure development, and become more effective at training a skilled labour force in e-commerce and ICT. E-commerce enterprises in general, and trading platforms in particular, also need to win more trust from customers. Reducing the cost of logistics is also a must for digital trade in Viet Nam to become more competitive.

\section{Unlocking the significant benefits that digital trade can bring to Viet Nam}

There is broad consensus that digital trade can bring significant benefits to Viet Nam's economy. These include the ways in which digital trade can allow its companies to open up new markets for their products and services. Moreover, digital data can help enterprises to gain a better understanding of their markets and customers. Indeed, digital trade can allow Viet Nam's companies to unlock cost savings, to intensify their co-operation with other enterprises and partners, to participate in global supply chains, and to manage the performance of their supply chains around the world. Examples of this include using blockchain technology to check and monitor the delivery of goods, or making use of online banking services to transfer and receive payments for goods and services from anywhere in the world.

Broadly speaking, the benefits that digital trade can bring to Viet Nam's economy fall into two categories: domestic trade and digital exports. In the first category, it is estimated that digital trade contributes VND 81 trillion a year to Viet Nam's economy, or around USD 3.5 billion in 2017. This equates to $1.7 \%$ of the country's gross domestic product (GDP), a similar percentage to that in other countries in the region, such as Malaysia and the Philippines. However, compared to more developed economies in the Asia-Pacific region, such as Australia's rate of $3 \%$, this figure is still modest.

With regard to the benefits that digital trade can bring to the export economy, it is worthy of note that digital exports already account for $2 \%$ of the total value of Viet Nam's exports. Indeed, the total value of tangible and intangible exports supported by digital technology is estimated to be around VND 97 trillion (USD 4.3 billion). Within this, the value of digitally-enabled products is estimated at around VND 52 trillion, while digitallyenabled services account for around VND 11 trillion and indirect digital services make up VND 34 trillion. Moreover, if there were no barriers to digital trade, it is estimated that Viet Nam's digital exports would rise to USD 28.7 billion by 2030 (Hinrich Foundation, CIEM and Alphabeta, 2019). One case study of how digital trade can help exporters comes from Topica, an educational technology company based in Ha Noi that provides online learning services and promotes its business over the Internet. Topica has grown strongly, and not just in Viet Nam but also in countries like Thailand, Singapore and the Philippines.

In order to promote export-oriented digital business still further, it will be necessary to eliminate barriers affecting the competitiveness of Viet Nam's digital exports (Hinrich Foundation, CIEM and Alphabeta, 2019).

\section{Accelerating the ongoing development of digital payments in Viet Nam}

Viet Nam has been promoting electronic payments since 2008, and the country is experiencing a boom in this area. In addition to payment forms with already longstanding popularity, such as Visa and MasterCard, there are new forms of digital payments. These include mobile point of sale, or mPOS, Internet banking, mobile web payments, and quick response (QR) codes. Moreover, Vietnamese payment intermediaries such as MoMo, 
OnePay and VNPay have emerged, facilitating cashless applications. Indeed, Viet Nam has about 150 financial technology, or fintech companies (Bizhub, 2019). These fintech companies are co-operating with banks to facilitate payments. Moreover, Viet Nam has worked with the World Economic Forum (WEF) on Digital Trade project, focusing on mobile money to develop policies facilitating financial transactions through mobile phone. This diversity has created a dynamic environment for cashless payments.

Still, only $30 \%$ of Viet Nam's adult population had a bank account in 2017, which is much lower than in some other Asian countries (Table 3.5.1). In advanced countries like Japan, Singapore and South Korea, for example, over $90 \%$ of adults have bank accounts. Moreover, the proportion of people receiving wages through the formal financial system is low in Viet Nam. In 2017, only $10 \%$ of wage recipients received their money through an account at a financial institution, compared to at least $49 \%$, in leading Asian economies like Japan, Singapore and South Korea. This lack of formalisation restricts transparency, while also discouraging the development of non-cash transactions. In 2017 , only $4 \%$ of the population over the age of 15 had owned a credit card in the preceding year. Moreover, only $21 \%$ of people had paid bills over the Internet or bought something online in the preceding year. Furthermore, only $23 \%$ of the population over the age of 15 had made or received digital payments over that period. This compared to $95 \%$ in Japan, $92 \%$ in South Korea, 68\% in China, and 35\% in Indonesia. Digital payments are still not popular in Viet Nam compared with other countries.

Table 3.5.1. Digital payments in Viet Nam

\begin{tabular}{|c|c|c|c|c|c|c|}
\hline & $\begin{array}{c}\text { Account } \\
\text { with a financial } \\
\text { institution } \\
(\% \text { age } 15+) 2017\end{array}$ & $\begin{array}{c}\text { Received wages } \\
\text { into a financial- } \\
\text { institution account } \\
(\% \text { age } 15+)\end{array}$ & $\begin{array}{l}\text { Credit-card } \\
\text { ownership } \\
\text { (\% age } 15+\text { ) }\end{array}$ & $\begin{array}{c}\text { Used a debit or } \\
\text { credit card to make } \\
\text { a purchase over the } \\
\text { past year } \\
(\% \text { age } 15+)\end{array}$ & $\begin{array}{l}\text { Used the internet to } \\
\text { pay bills or to buy } \\
\text { something online } \\
\text { over the past year } \\
\text { (\% age } 15+)\end{array}$ & $\begin{array}{c}\text { Made or } \\
\text { received } \\
\text { digital payments } \\
\text { over the past year } \\
\text { (\% age } 15+)\end{array}$ \\
\hline China & 80 & 22 & 21 & 42 & 49 & 68 \\
\hline Indonesia & 48 & 9 & 2 & 12 & 11 & 35 \\
\hline Japan & 98 & 51 & 68 & 69 & 48 & 95 \\
\hline Korea & 95 & 49 & 64 & 84 & 76 & 92 \\
\hline Malaysia & 85 & 28 & 21 & 39 & 39 & 70 \\
\hline Philippines & 32 & 11 & 2 & 5 & 10 & 25 \\
\hline Singapore & 98 & 57 & 49 & 77 & 57 & 90 \\
\hline Thailand & 81 & 18 & 10 & 21 & 19 & 62 \\
\hline Viet Nam & 30 & 10 & 4 & 4 & 21 & 23 \\
\hline
\end{tabular}

Source: World Bank (2017), Global Fintech Database, https://globalfindex.worldbank.org.

Viet Nam authority is strengthening digital payments. It is in this spirit that the country organised, as of 2019, a nationwide cashless day on June 16 to encourage consumers to use cashless payment facilities. Indeed, there are signs of progress. According to the figures from the State Bank of Viet Nam in March 2019, the value of domestic payment transactions via bank cards has risen to more than VND 171 trillion, a jump of nearly 19\% compared to the same period a year earlier. Notably, payments via mobile phones have now reached more than 76 million transactions, or VND 924 trillion, representing an increase of $232 \%$ compared to the same period in 2018. Moreover, 16 banks now offer payments that use $Q R$ codes, and there are now over 30000 QR code payment points (Lee, 2019).

Looking ahead, cashless payments will continue becoming more and more popular in Viet Nam, as demand for and access to technology increase. Electronic wallets and payment intermediaries are gradually becoming familiar to consumers across Viet Nam. Moreover, several ride-sharing services and mobile network providers in Viet Nam have said they want to become payment intermediaries. Furthermore, payments via Internet 
or mobile banking have made such inroads into a market traditionally dominated by over-the-counter payments that they now account for more than a quarter of all banking transactions in Viet Nam.

\section{Box 3.5.1. Ride-sharing apps in Viet Nam}

When BE, the ride-hailing app of Viet Nam's transport start-up BE Group, entered the market in Viet Nam - in which a number of other app-providers were active - it decided to offer a full gamut of services. When the company rolled out its very first offering, in December 2018, it featured two main services: beBike, a motorbike ride-hailing app, and beCar, a ride-hailing for cars. Payment for BE's services is by cash or by Visa or MasterCard. $\mathrm{BE}$ then develops into a platform rather than an application allowing suitable partners to operate. In 2019, BE Group released beFinancial, a mobile financial service platform. Moreover, BE Group also co-operates with the Viet Nam Prosperity Commercial Joint Stock Bank (VPbank). VPBank's financial services are integrated into beFinance technology and fintech ecosystem including payment via cards, delivery services, and e-wallets. BE and VPBank decided to issue co-branded credit cards and debit cards. Furthermore, holders of BE-VPBank co-branded cards are entitled to consumer loans. In addition, BE drivers are able to access VPBank's services, as well obtaining loans with preferential interest rates for purchasing cars and motorbikes. In turn, VPBank uses BE's transport service, provides financial support for $\mathrm{BE}$, and at the same time studies and deploys individual credit packages to support BE's drivers. According to BE's data as of May 2019, the ridesharing app has been downloaded 4 million times with about 30000 drivers and about 200000 trips each day.

Another ride-sharing app, Fastgo chose to associate with Vimo e-wallet to solve payment problems for customers. The Fastgo ride-sharing app has the advantage of using technology from its parent company, so it has favourable conditions for deploying a range of new services, including payment from cards and electronic wallets. Fastgo also works with small and medium-sized enterprises to provide delivery services, thereby creating a flexible electronic payment eco-system.

Source: Vietnam Investment Review (2019), Bizhub (2019), Vietnam Prosperity Joint-Stock Commercial Bank (2019) and Nikkei Asian Review (2019).

\section{Expanding ICT infrastructure across the economy and ensuring network security}

Viet Nam's government has sought to build up digital infrastructure by developing Internet infrastructure systems, and by promoting ICT and the application of technologies that can improve workers' productivity. The first step in this regard was to set the goal of ensuring nationwide connection coverage. The government implemented its first coverage programme in 2005-10, with a total investment of up to 5 trillion Vietnamese dong (VND). As of 2015, it continued this push with a programme of investment of up to USD 7.3 billion to develop broadband Internet infrastructure nationwide ${ }^{1}$. Viet Nam also plans to roll out pilot 5G services in 2019 and deploy 5G commercial mobile service by 2020.

As noted above, Viet Nam offers a significant market for firms that wish to make the most of digital trade. In terms of people's capacity to access ICT, for example, Viet Nam had just over 128 mobile-cellular telephone subscriptions per 100 inhabitants in 2017 (ITU, 2017). On average, therefore, each person has more than one mobile subscription. Moreover, $84 \%$ of mobile phones active in Viet Nam are smartphones that offer Internet access (Nielsen Viet Nam, 2017). Indeed, the habit of accessing the Internet on a mobile phone - a necessary condition for digital commercial development - is becoming more and 
more popular in Viet Nam. The International Telecommunication Union's Information and Communication Technology Development Index (IDI) covers three main areas: the level of access to ICT, the level of ICT application, and the skills that are available for ICT. In 2010, Viet Nam ranked 86th out of 152 countries, featuring among the top 57\% of countries. By 2017, however, the country had dropped to 108th place out of 176 countries, putting it in the top $61 \%$. This notwithstanding, the absolute value of Viet Nam's IDI increased from 3.41 to 4.43 (see Table 3.5.2). Viet Nam is ranked 50th out of 175 countries on the Global Cybersecurity Index (GCI) 2018 (ITU, 2019).

Table 3.5.2. ICT development index for Viet Nam and selected Asian countries

\begin{tabular}{lcccccccccc}
\hline & \multicolumn{2}{c}{$\mathbf{2 0 1 0}$} & \multicolumn{2}{c}{$\mathbf{2 0 1 1}$} & \multicolumn{2}{c}{$\mathbf{2 0 1 5}$} & \multicolumn{2}{c}{$\mathbf{2 0 1 6}$} & \multicolumn{2}{c}{$\mathbf{2 0 1 7}$} \\
\cline { 2 - 12 } & Ranking & IDI & Ranking & IDI & Ranking & IDI & Ranking & IDI & Ranking & IDI \\
\hline China & 79 & 3.58 & 78 & 3.88 & 82 & 5.05 & 81 & 5.19 & 80 & 5.6 \\
Indonesia & 97 & 3.01 & 95 & 3.19 & 115 & 3.63 & 115 & 3.86 & 111 & 4.33 \\
Japan & 8 & 7.57 & 8 & 7.76 & 11 & 8.47 & 10 & 8.37 & 10 & 8.43 \\
Korea & 1 & 8.45 & 1 & 8.56 & 1 & 8.93 & 1 & 8.84 & 2 & 8.85 \\
Malaysia & 57 & 4.63 & 58 & 4.82 & 64 & 5.9 & 61 & 6.22 & 63 & 6.38 \\
Philippines & 94 & 3.04 & 94 & 3.19 & 106 & 3.97 & 107 & 4.28 & 101 & 4.67 \\
Singapore & 10 & 7.47 & 12 & 7.66 & 19 & 8.08 & 20 & 7.95 & 18 & 8.05 \\
Thailand & 89 & 3.29 & 92 & 3.41 & 74 & 5.36 & 82 & 5.18 & 78 & 5.67 \\
Viet Nam & $\mathbf{8 6}$ & $\mathbf{3 . 4 1}$ & $\mathbf{8 1}$ & $\mathbf{3 . 6 8}$ & $\mathbf{1 0 2}$ & $\mathbf{4 . 2 8}$ & $\mathbf{1 0 5}$ & $\mathbf{4 . 2 9}$ & $\mathbf{1 0 8}$ & $\mathbf{4 . 4 3}$ \\
\% ranking of Viet Nam & $57 \%$ & & $49 \%$ & & $61 \%$ & & $60 \%$ & & $61 \%$ & \\
& & & & & & & & & & \\
\hline
\end{tabular}

Source: ITU (2017), Global ICT Development Index 2017, International Telecommunication Union, Geneva, https://www.itu.int/net4/ITU-D/idi/2017/index.html\#idi2017economycard-tab\&VNM.

In addition to the expansion of infrastructure, to make sure that digital trade takes place in a safe environment, Viet Nam has also promulgated laws both on network information security and on cyber security. Under Viet Nam's cyber security law, moreover, all enterprises that provide telecommunications or value-added digital services in the country, and that thereby collect, exploit, analyse, or process personal information or data, must establish a branch or representative office within its jurisdiction.

\section{Improving ICT capacity of Viet Nam's workforce and companies, and among consumers}

In order for a country to develop digital trade, it also needs to have high-quality human resources. Efforts have been implemented by the government to develop human resources. In 2017, the Ministry of Education and Training and the Ministry for Labour, Invalids, and Social Affairs, developed a new education model for science, technology, engineering and mathematics (STEM). Moreover, Viet Nam's ministry for science and technology has also been implementingin partnership with other agencies - an important project to develop digital knowledge.

According to the Vietnam ICT White Book 2018 (Vietnam e-Commerce and Digital Economy Agency, 2018), 922521 employees worked in IT, electronics and telecommunication in 2017. Moreover, currently, around 153 universities, 213 colleges and 237 vocational schools provide ICT education. On average, the country has over 50000 IT, electronics and telecommunications graduates each year. However, challenges remain in the quality of human resources. Despite the large number of IT graduates, companies still have difficulties to recruit suitable employees, reflecting a mismatch between the quality of training and the actual requirements of businesses and markets.

When it comes to Viet Nam's individual businesses, nearly $49 \%$ have their own websites and $32 \%$ of them have established relations with foreign partners over the 
Internet (VECITA, 2016). International business platforms such as Alibaba, Amazon and Lazada are also present in Viet Nam. According to the Ministry of Industry and Trade's department for e-commerce and the digital economy, meanwhile, $84 \%$ of Viet Nam's enterprises chose email as their main means of making transactions in 2017. In addition, the number of enterprises using digital signatures reached $61 \%$ in 2018 , nearly three times higher than in 2012, while the number of enterprises using electronic contract reached 26\% in 2018 (VECOM, 2019). In 2017, the local domain name of ".vn" ranked seventh among the ten biggest registered domain names in Asia, encompassing 422061 different names (VNNIC, 2017). Meanwhile, Viet Nam's largest trading platform, Lazada, features over 50000 merchants and partners and attracts over 100 million visitors every month (VECOM, 2019).

In Viet Nam's consumer market, online shopping platforms such as Lazada, Shopee. vn, Sendo.vn, Hotdeal.vn, Zalora.vn, Tiki.vn and Adayroi.com have been proving popular too. However, businesses still need time to build trust with customers. In 2017, one of the most popular payment methods on online shopping platforms was COD (or cash on delivery), higher than electronic wallets and international payment cards. Viet Nam's online shoppers take a keen interest in shipping and delivery, with $47 \%$ of respondents in 2017 saying this was the case. However, only $41 \%$ of respondents said they were satisfied with this aspect of the service, because of the limited capacity of logistics businesses in the country (Viet Nam e-Commerce and Digital Economy Agency, 2018). Indeed, logistics costs in Viet Nam are among the highest in the world. Viet Nam needs to address these restrictions in order to encourage the development of digital trade.

To conclude, digital trade is increasingly important to Viet Nam as it can bring significant benefits to the country's economy through domestic trade and digital exports. However, some key challenges would need to be addressed. To further improve the digital eco-system and facilitate the development of digital trade, regulatory authorities should develop direct regulations on digital trade rather than scattered ones across various policies and at the same time enhance the enforcement of existing regulations. More efforts are also needed in finding ways to reduce barriers which affect the competitiveness of Viet Nam's companies' digital exports. Moreover, promoting electronic payments, expanding ICT infrastructure and ensuring network security, as well as ensuring more effective training for a skilled labour force in e-commerce and ICT are also crucial. E-commerce enterprises in general, and trading platforms in particular, also need to win more trust from customers.

\section{Note}

1. This programme was revised in 2018, under Decision No. 868 / QD-TTg.

\section{References}

A\&A (2018), Global 3PL Market Size Estimates, Armstrong \& Associates, Inc., https://www.3plogistics. com/3pl-market-info-resources/3pl-market-information/global-3pl-market-size-estimates/.

Bizhub (2019), "Fintech firms need clear policy to develop", http://bizhub.vn/banking/fintechfirms-need-clear-policy-to-develop_308404.html (accessed 20 September 2019).

Hinrich Foundation, CIEM and Alphabeta (2019), The Data Revolution: How Viet Nam Can Capture the Digital Trade Opportunity at Home and Abroad, Hinrich Foundation in partnership with Central Institute for Economic Management and AlphaBeta.

ITU (2019), Global Cybersecurity Index (CGI) 2018, International Telecommunication Union, Geneva, https://www.itu.int/en/ITU-D/Cybersecurity/Pages/global-cybersecurity-index.aspx.

ITU (2017), Global ICT Development Index 2017, International Telecommunication Union, Geneva, https://www.itu.int/net4/ITU-D/idi/2017/index.html - idi2017economycard-tab\&VNM. 
Lee, J. (2019), "Vietnam and Thailand lead drive to make Southeast Asia cashless", Nikkei Asian Review, 18 April, https://asia.nikkei.com/Business/Business-trends/Viet Nam-and-Thailand-lead-driveto-make-Southeast-Asia-cashless.

Ministry of Information and Communication (2019), "Vietnam to lack 400,000 IT workers by 2020", https://english.mic.gov.vn/Pages/TinTuc/138819/VN-to-lack-400-000-IT-workers-by-2020.html (accessed 20 September 2019).

Nielsen Vietnam (2017), Vietnam Smartphone Insights Report 2017, Nielsen Vietnam, https://nielsen. com/wp-content/uploads/sites/3/2019/04/Web_Nielsen_Smartphones20Insights_EN.pdf.

Nikkei Asian Review (2019), "Vietnam's first car-hailing app FastGo heads overseas", https://asia.nikkei.com/Spotlight/Sharing-Economy/Vietnam-s-first-car-hailing-app-FastGoheads-overseas (accessed 20 September 2019).

VECITA (2016), E-commerce Survey, Vietnam e-Commerce and Information Technology Agency, Ha Noi. VECOM (2019), Vietnam E-Business Index Report 2019, Vietnam e-Commerce Association, Ha Noi.

Vietnam e-Commerce and Digital Economy Agency (2018), White Book on Vietnam's E-commerce 2018, Vietnam e-Commerce and Digital Economy Agency, Ha Noi.

Vietnam Investment Review (2019), “BE Group and VPBank tie up to roll out payment and financial services", https://vir.com.vn/be-group-and-vpbank-tie-up-to-roll-out-payment-and-financialservices-68170.html (accessed 20 September 2019).

Vietnam Prosperity Joint-Stock Commercial Bank (2019), "Strategic Partnership between BE GROUP and VPBank for Financial Technology Ecosystem", https://vpbank.com.vn/ bai-viet/press-releases/strategic-partnership-between-be-group-and-vpbank-financialtechnology?target=en (accessed 20 September 2019).

VNNIC (2017), Internet Resources Report 2017, Vietnam Internet Network Information Center, Ha Noi.

World Bank (2017), Global Fintech Database, The World Bank, Washington, DC, https://globalfindex. worldbank.org. 


\section{BRUNEI DARUSSALAM AND SINGAPORE}




\section{Brunei Darussalam}

\section{A. Medium-term economic outlook (forecast, 2020-24 average) \\ GDP growth (percentage change): \\ Current account balance (\% of GDP):}

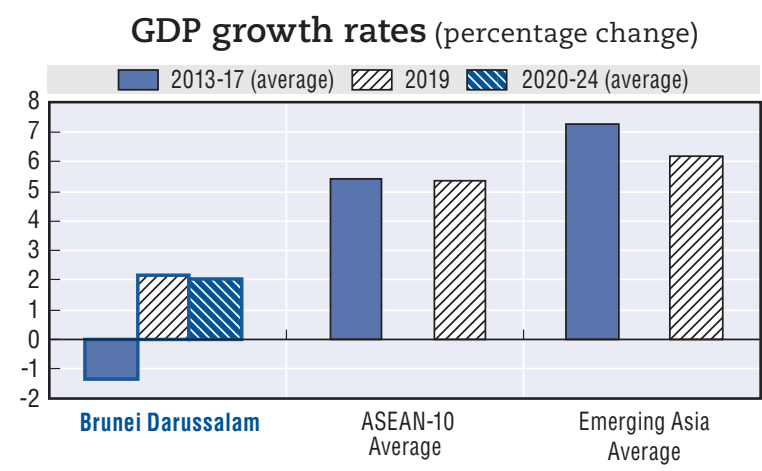

Source: OECD Development Centre.

GDP per capita, 2018

(PPP, current international dollar)

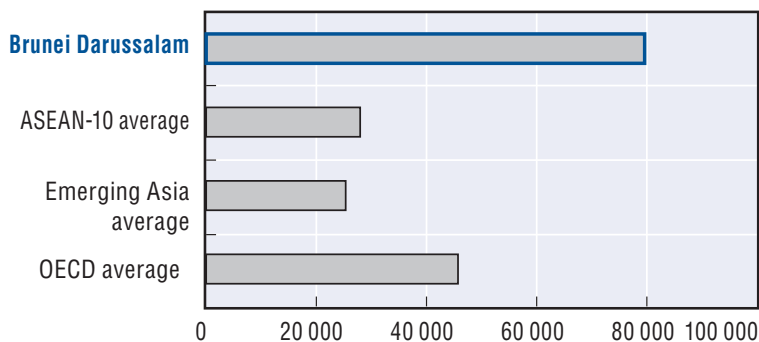

Source: IMF.

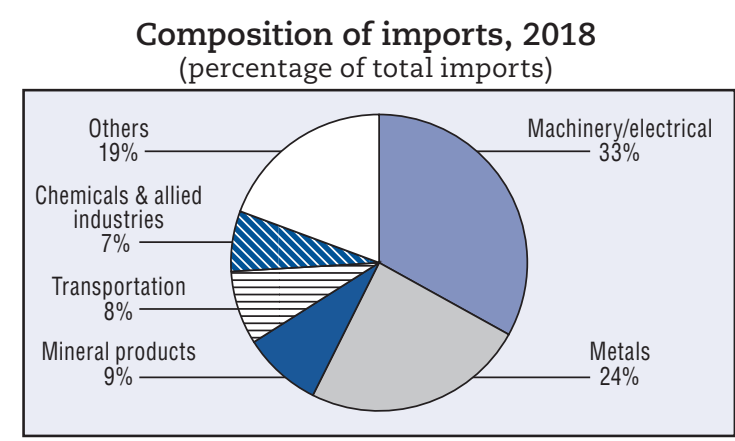

Source: Trademap.
Composition of exports, 2018

(percentage of total exports)

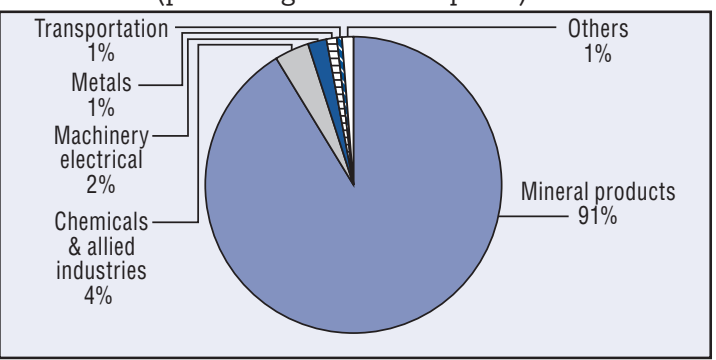

Source: Trademap.
0.4 million *

14.1 billion *

79529.9 (current

1.4 (BND/USD)

Note: * Population data are mid-year government estimates.

Sources: OECD Development Centre, national sources, CEIC and IMF.

Structural policy challenges discussed in previous editions of the Outlook

\begin{tabular}{|c|c|c|}
\hline \multirow{3}{*}{2014} & Human capital development & Improve tertiary education attainment \\
\hline & Private sector development & Improve private sector development to diversify beyond the hydrocarbon economy \\
\hline & Competition & Legislate and implement competition policy \\
\hline \multirow{3}{*}{2016} & FDI & Encourage foreign direct investment inflows \\
\hline & Business sector & Reform the business sector to promote diversification \\
\hline & Public finance & Reform public finance \\
\hline 2017 & $\begin{array}{l}\text { Economic diversification } \\
\text { Competition }\end{array}$ & $\begin{array}{l}\text { Promote economic diversification by inviting foreign investment and supporting the private sector } \\
\text { Improve legislation on business competition }\end{array}$ \\
\hline 2018 & FDI & Attracting foreign direct investment (FDI) to diversify the economy and create more jobs \\
\hline 2019 & SMES & Strengthening local small and medium-sized enterprises \\
\hline
\end{tabular}




\section{POLICY FOCUS}

Developing an economic environment that spurs start-ups

Conscious of the degree to which Brunei Darussalam still depends largely on oil and gas exports, the government is continuing with its push for economic diversification. Given Brunei Darussalam's particular situation - not just its relative dependency on oil and gas but also the characteristics of its population - developing a dynamic eco-system for business start-ups will help the government to achieve the strategic goals that it has set out in its national vision, "Wawasan 2035". Under the auspices of this programme, the country aims to enhance the skills and quality of life of its people, and to build a dynamic and sustainable economy.

\section{Brunei Darussalam possesses a range of competitive advantages for developing start-ups}

For a start, the country already has a highly-educated, English-speaking population, and $19.1 \%$ of the labour force has a tertiary degree (MOFE, 2018). Although this falls short of the average level for OECD countries, Brunei Darussalam still ranks at the same level as successfully innovative economies such as France and Italy (Figure 3.6.1).

Figure 3.6.1. Share of workforce with tertiary education as highest educational

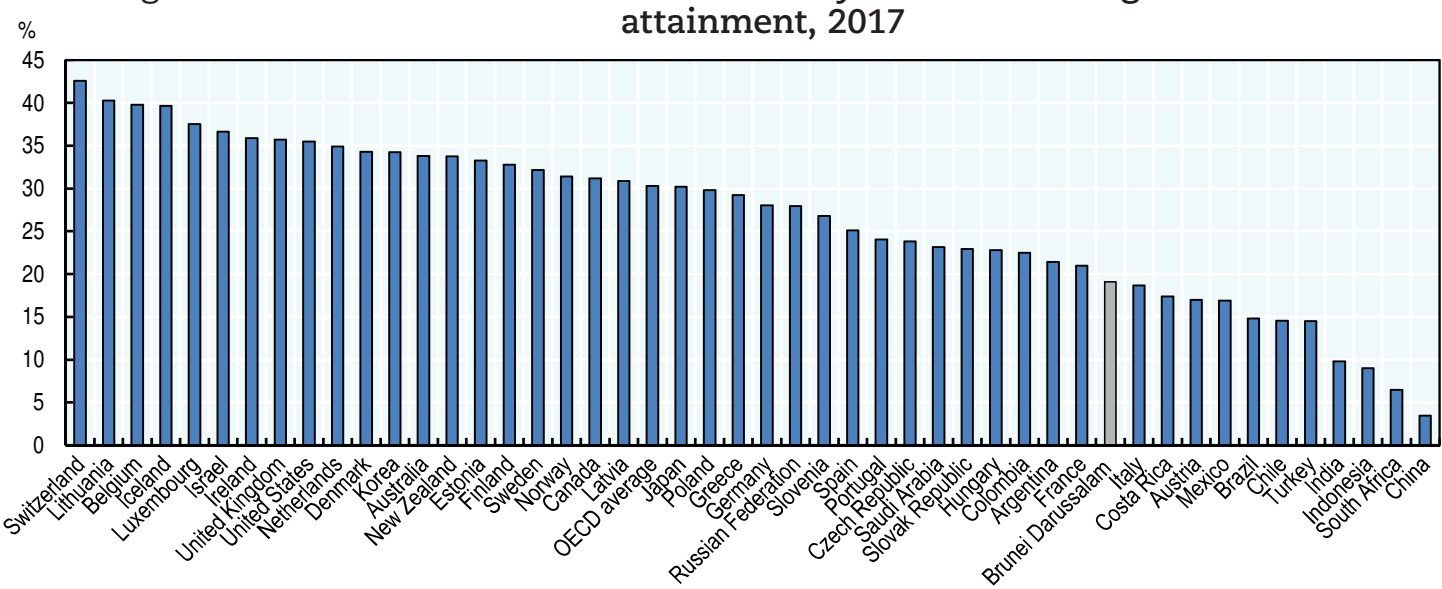

Source: OECD (2018a), “Table A1.1 - Educational attainment of 25-64 year-olds (2017): Percentage of adults with a given level of education as the highest level attained", in The Output of Educational Institutions and the Impact of Learning; MOFE (2018), "Educational attainment and illiteracy".

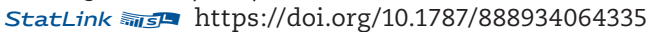

Another advantage Brunei could harness to develop a start-up friendly eco-system is its position within the ASEAN, which gives it access to a market of 642.1 million potential consumers (ASEAN, 2018). In addition, and given that most start-ups operate in the digital and technology sector, such services are easily scalable by their very nature. Therefore, regional integration and digitalisation provide Brunei Darussalam with an opportunity to overcome the constraints of its relatively small domestic market, which has been an important structural economic weakness for the country.

Thanks to revenues from its oil and gas sector, Brunei Darussalam disposes of a sovereign wealth fund that has 40 billion US dollars-worth of capital, and it is the Brunei Investment Agency that manages this fund (SWFI, 2017). This agency already has experience in venture capital investments, and there is scope for it to contribute to innovation programmes such as publicly-backed venture capital funds. Brunei Darussalam's healthy banking sector, and its stable macro-economic climate, also bode well for its capacity to 
finance new business ventures. Indeed, the country currently ranks second in the world for the ease with which business can get credit for projects, according to the World Bank's Doing Business report (World Bank, 2017). Moreover, Brunei Darussalam aims to become a leader in Islamic finance, which relies on equity financing in order to avoid interest payments. This represents an opportunity both for Brunei Darussalam's start-ups, and for the Islamic financial sector in general. In this connection, it is worthy of note that the country's finance ministry already runs a joint-venture Islamic fund with a Japanese group, although to date this has focused mostly not so much on start-ups, but on largerscale investment opportunities in Indonesia (OECD/ERIA, 2018).

\section{Brunei Darussalam already has an embryonic start-up eco-system on which to build}

Brunei Darussalam already has its own start-up eco-system, in which a wide range of small and developing firms provide services in sectors such as e-commerce, smart farming, sports clothes, and digital learning tools. From a broader perspective, out of the 5342 enterprises operating in Brunei Darussalam in 2015, small enterprises were the most common, representing $49.6 \%$ of the total (JPKE, 2016). However, their economic importance is still somewhat limited, as they account for only $19 \%$ of employment, and $10.2 \%$ of gross business revenue (JPKE, 2016).

In 2016, the government launched Darussalam Enterprise, a statutory body with the mission of helping to develop domestic enterprises, and with a particular view to helping small, and medium-sized enterprises (SMEs). This new body provides help to start-ups - both existing and potential ones - through initiatives such as the iCentre, a start-up incubator that offers the administrative guidance, technical support, and necessary physical infrastructure that new firms need in order to thrive. Furthermore, Darussalam Enterprise has set up a one-stop-shop called the Business Support Centre, which provides guidance and support directly to SMEs, as well as an education programme, the Industry Business Academy, which offers free classes to aspiring and existing business owners. Darussalam Enterprise also runs a start-up "boot-camp" programme, which offers a 100-day accelerator course in which entrepreneurs participate in weekly pitches and monitoring sessions, and work towards a final presentation, which they make to a panel of judges and investors.

When it comes to financing, most start-ups in Brunei Darussalam currently rely on bank funding (World Bank, 2016). Outside of the banking sector, however, there are some schemes to support lending to start-ups, such as the Micro Financing Scheme, which provides loans up to 15000 Brunei dollars (BND) to SMEs. These loans do not require collateral, and they offer a low interest rate (OECD/ERIA, 2018). Since its launch in October 2016, this scheme has provided BND 563000 in financing to 56 firms. Meanwhile, although venture capital financing is still rather small in Brunei Darussalam, initiatives are already in place to expand its use. For instance, the Livewire programme is a joint initiative on the part of Brunei Shell Petroleum and the national government. It rewards and supports start-ups by running the country's Business Awards Start-Up Funding Scheme. Winners of the award receive favourable loans, ranging from BND 5000 to BND 50 000, which are repayable over 36 months. Livewire Brunei provided BND 155000 in funding to its laureates in 2018, and plans to scale up to BND 300000 (Shell Livewire, 2018). Another relevant initiative here is Darussalam Enterprise's aforementioned start-up "bootcamp", which provides venture capital funding with the support of a Singaporean consultancy firm. This programme has so far proven successful in that it has provided a helping hand in the development of 70 companies, helping them to raise 750000 Singapore dollars, and creating 250 jobs over three editions of the programme (Chewandi, 2018) 


\section{Local universities have an important role to play in fostering the knowledge that fuels} innovation

Technological and scientific knowledge are crucial assets for an innovative start-up. In a knowledge-based society-and especially in the world of start-ups-knowledge composes the largest share of the value that these companies create. Moreover, holding intellectual property rights significantly improves a company's chances of attracting venture capital funding (Breschi, Lassebie and Menon, 2018). Indeed, there is also evidence that start-ups that hold patents experience substantially higher growth in terms of employment and sales (Farre-Mensa, Hegde and Ljungqvist, 2017). As a result, the government - which is the main provider of research facilities in Brunei Darussalam, both through universities and the Brunei Research Council - has an active role to play in stimulating the production of knowledge. Indeed, universities have a key role to play in ensuring a vigorous flow of knowledge throughout the economy, and have a further mission to accomplish in working together with actors in the local economy to accelerate development.

In order to foster co-operation between universities and entrepreneurs, Brunei Darussalam's government could finance special centres at universities to stimulate academic spin-offs. Such a programme could facilitate transfers from academic research into commercial activity. An endeavour of this kind also has the potential to anchor entrepreneurship in the minds of new graduates as a highly-desirable exit option from their academic studies (OECD, 2010). In addition to building awareness among university students about entrepreneurship, the potential tasks of a special centre like this include helping students and researchers to identify niche markets, coaching them about business planning, facilitating their access to external experts, and providing access to physical office space. Such a programme could take the form of an extension of the iCentre, with a special focus on university graduates. Alternatively, such an initiative could create a new centre, potentially through a partnership with the country's main university. Austria has set up a similar programme of start-up centres called "AplusB", which has won praise for the successes it has already achieved (OECD, 2018b).

Such an initiative could also help to foster awareness among students about intellectual property rights. These rights play an important role in the development of start-ups, yet SMEs tend not to make full use of the protections that intellectual property law can offer them. Indeed, they often fail to do so even in a situation where information on these rights would easily be within their reach, simply because of a lack of knowledge about the topic (OECD, 2011). Therefore, to develop awareness about intellectual property rights amongst university graduates, courses in fields like science, engineering, design, and creative arts should include some education on intellectual property rights, and on their strategic uses and implications (OECD, 2011).

\section{Enhancing equity financing for start-ups, and boosting Islamic finance into the bargain}

Venture capital is a preferable means of financing for start-ups than bank loans, as it is better suited for high-risk projects and long-term returns. The availability of venture capital funding allows companies with high levels of potential to overcome the kinds of obstacles they typically face, such as a shortage of financial resources or a lack of knowledge about business development. In addition to offering financial backing to entrepreneurs, venture capital investors help them to recruit talented managers and to formulate new strategies. They also use their own networks to garner resources for the company (Gompers and Lerner, 2004). For these reasons, firms that have the support of venture capital firms tend to take aim at more radical innovations, to be significantly faster in introducing their products to the market, and to pursue more aggressive market strategies than other start-ups (Hellmann and Puri, 2000, 2002). 
When it comes to providing equity financing for start-ups, governments can play an active role - as is already the case in several OECD economies, where governments are among the main venture capital investors (Breschi, Lassebie and Menon, 2018). In Europe for instance, government agencies represent $22 \%$ of venture capital funding, which makes them the largest providers of funding in the sector (BPIfrance et al., 2016). In the United States, the venture capital business has relied - especially in the past on various government initiatives such as defence contracts, public procurement, and the Small Business Investment Companies Programme to develop. In the latter initiative, the government does not invest directly in small businesses, but it does provide loans to private investors to fund start-ups, matching their private stake with two dollars for every one dollar they invest themselves. In a similar manner, the government of Brunei Darussalam can provide support for private venture capital firms as it seeks to help them to carve out a bigger foothold in a country whose domestic market is not yet mature. As it seeks to do this, Brunei Darussalam can call on a relevant institution that it already has to hand - the Brunei Investment Agency.

Indeed, programmes in which the government and the private sector work in tandem to provide investment can often offer useful solutions. Moreover, the creation of venture funds that draw their financing partly from the government and partly from foreign private investment can help to overcome the failure of a local market to provide such services. Syndicating the investments of many smaller investors, meanwhile, and having the government cover a share of the risk, may indeed attract newcomers to the market. In this way, a government can show the way forward and demonstrate the viability of the venture capital ecosystem for private investors (BPIfrance et al., 2016). Furthermore, by offering the option to private investors to buy out its share in the medium term, the government can make sure it acts solely as a catalyst for private-sector involvement rather than threatening to crowd out the private sector. A practical example of such a programme is the "Yozma" initiative in Israel, which has won plaudits for the significant contribution it has made to the thriving Israeli venture capital industry (OECD, 2010).

Finally, adapting such a policy of support for venture capital to the setting of Brunei Darussalam would be a way to promote another of the country's policy priorities - the further development of Islamic finance. Indeed, venture capital funding can become compatible with Sharia Law if it takes place under a contract where the fund's depositors are shareholders, and are then entitled to a predetermined share of the profits. In this way, developing a market for venture capital in Brunei Darussalam will present opportunities both for start-ups, and for the country's growing Islamic financial sector.

\section{References}

ASEAN (2018), ASEAN Statistical Highlights 2018, ASEAN secretariat, Jakarta, https://www. aseanstats.org/wp-content/uploads/2018/10/ASEAN-Statistical-Highlights-2018.pdf.

BPIfrance et al. (2016), Building Momentum in Venture Capital across Europe, BPIfrance, CDP, ICO, British Business Bank, KfW, https://www.bpifrance.fr/content/download/60338/549921/file/ Building\%20Momentum\%20in\%20Venture\%20Capital\%20across\%20Europe.pdf.

Breschi, S., J. Lassebie and C. Menon (2018), "A portrait of innovative start-ups across countries", OECD Science, Technology and Industry Working Papers, 2018/02, OECD Publishing, Paris, http://dx.doi.org/10.1787/f9ff02f4-en.

Chewandi S. (2018), “Singapore's ‘Golden Equator Consulting’ Kickstarted Startup and Micro Business Bootcamp Programmes by Brunei’s Darussalam Enterprise”, Golden Equator Consulting, Singapore, https://www.goldenequatorconsulting.com/blog/singapores-golden-equator-consultingkickstarted-startup-micro-business-bootcamp-programmes-bruneis-darussalam-enterprise/.

Farre-Mensa, J., D. Hegde and A. Ljungqvist (2017), "What is a Patent Worth? Evidence from the U.S. Patent 'Lottery'", NBER Working Papers, National Bureau of Economic Research, Cambridge, Massachusetts. 
Gompers, P.A. and J. Lerner (2004), The Venture Capital Cycle, MIT Press, Cambridge, Massachusetts. Hellmann, T. and M. Puri (2002), "Venture capital and the professionalization of start-up firms: Empirical evidence", Journal of Finance, 57(1).

Hellmann, T. and M. Puri (2000), "The interaction between product market and financing strategy: The role of venture capital", Review of Financial Studies, 13(4).

JPKE (2016), Economic Census of Enterprises (ECE) 2016, http://www.depd.gov.bn/SitePages/ Statistical\%20Publications.aspx.

MOFE (2018), "Educational attainment and illiteracy", Ministry of Finance and Economics of Brunei Darussalam, http://www.depd.gov.bn/SitePages/Educational\%20attainment\%20and\%20 illiteracy.aspx.

OECD (2018a), "Table A1.1 - Educational attainment of 25-64 year-olds (2017): Percentage of adults with a given level of education as the highest level attained", in The Output of Educational Institutions and the Impact of Learning, OECD Publishing, Paris, https://doi.org/10.1787/eag-2018table14-en.

OECD (2018b), OECD Reviews of Innovation Policy: Austria 2018, OECD Reviews of Innovation Policy, OECD Publishing, Paris, https://doi.org/10.1787/9789264309470-en.

OECD (2011), Intellectual Assets and Innovation: The SME Dimension, OECD Studies on SMEs and Entrepreneurship, OECD Publishing, http://dx.doi.org/10.1787/9789264118263-en.

OECD (2010), SMEs, Entrepreneurship and Innovation, OECD Studies on SMEs and Entrepreneurship, OECD Publishing, Paris, https://doi.org/10.1787/9789264080355-en.

OECD/ERIA (2018), SME Policy Index: ASEAN 2018: Boosting Competitiveness and Inclusive Growth, SME Policy Index, OECD Publishing, Paris/ERIA, Jakarta, https://doi.org/10.1787/9789264305328-en.

Shell Livewire (2018), "Five start-ups receive \$155k from livewire Brunei", Shell Livewire, https://www.livewire.shell/what-is-shell-livewire/news/five-start-ups-receive-155k-dollarfrom-livewire-brunei.html.

SWFI (2017), Sovereign Wealth Fund Rankings, Sovereign Wealth Fund Institute, https://www. swfinstitute.org/sovereign-wealth-fund-rankings/.

World Bank (2017), Doing Business 2018: Reforming to Create Jobs, World Bank Group, Washington, DC, https://openknowledge.worldbank.org/handle/10986/28608.

World Bank (2016), World Development Indicators, https://doi.org/10.1596/978-1-4648-0683-4. 


\section{Singapore}

\section{A. Medium-term economic outlook (forecast, 2020-24 average) \\ GDP growth (percentage change): \\ Current account balance (\% of GDP):}

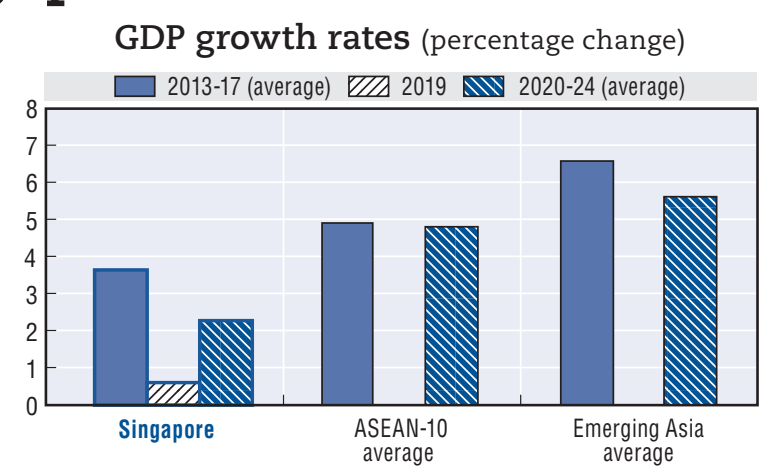

Source: OECD Development Centre.

GDP per capita, 2018

(PPP, current international dollar)

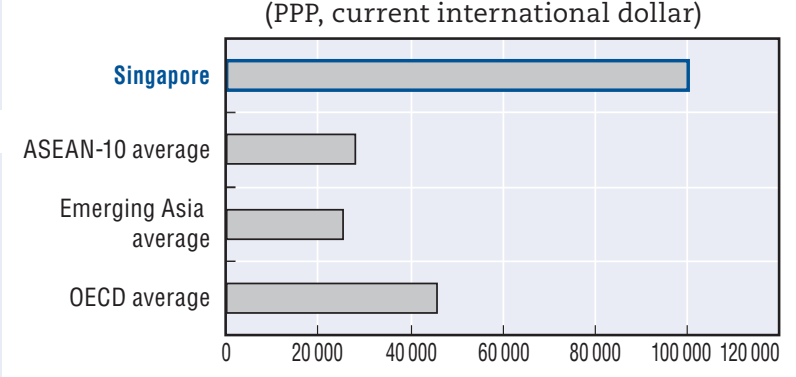

Source: IMF.

\section{Composition of exports, 2018}

(percentage of total exports)

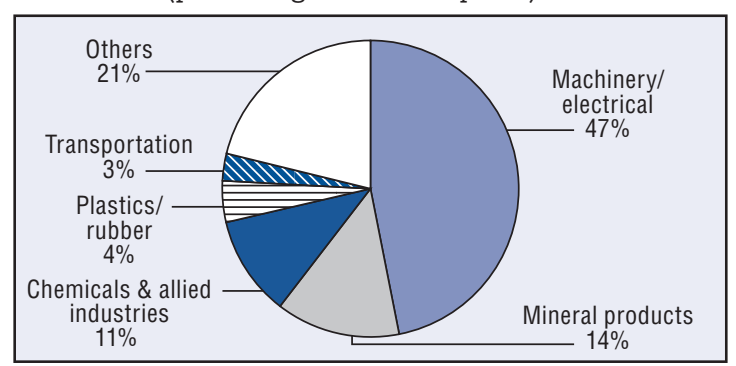

Source: Trademap.

\section{Composition of imports, 2018}

(percentage of total imports)

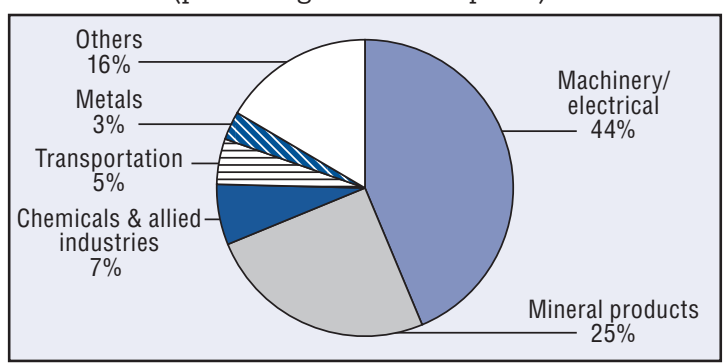

Source: Trademap.

\section{Structural policy challenges discussed in previous editions of the Outlook}

\begin{tabular}{|c|c|c|}
\hline \multirow{3}{*}{2014} & Land use & Optimise land use and allocation by incorporating a green growth strategy \\
\hline & SME development & Raise SME productivity through well co-ordinated assistance programmes \\
\hline & Education & Strengthen life-long learning to increase labour market flexibility \\
\hline \multirow{2}{*}{2016} & Ageing population & Strengthen labour market and social policies for aging population \\
\hline & Infrastructure (land use) & Leverage data to build a smart, energy-efficient city \\
\hline \multirow{2}{*}{2017} & Population ageing & Support the older population in the labour market and strengthen their social safety net \\
\hline & Urban planning & Pursue efficient urban planning and optimise land use \\
\hline 2018 & Land use & Optimising the use of Singapore's limited land \\
\hline 2019 & Education and training & Enhancing strategies for lifelong learning programmes \\
\hline
\end{tabular}




\section{POLICY FOCUS}

Boosting investment and parental involvement in pre-schools

Education plays an important role in Singapore, and the government has invested heavily in ensuring high quality. As such, $16.6 \%$ of government spending was dedicated to education in 2015 compared to an average of 14.9\% for OECD countries (UNESCO, 2018).

Pre-school programmes are important as they yield positive outcomes. This is especially true for disadvantaged children, for whom a high-quality pre-school experience tends to promote social mobility. For instance, evidence from Norway points to a USD 1.32 return on every dollar invested for children of low-income parents (Havnes and Mogstad, 2014). When it comes to academic performance, moreover, findings from the US support the view that quality pre-school education brings significant benefits to those who attend it (Cascio and Scahnzenback, 2013). Furthermore, there is evidence that education in early childhood has a highly positive effect on economic growth, with most benefits occurring in the long run when the children join the labour force (Dickens, Sawhill and Tebbs, 2006). Research has also pointed to sizeable gains in productivity, with education in early childhood contributing as much to rising productivity over the period of 1961-2008 as formal education (Delalibera and Ferreira, 2019). Together, this evidence underlines the fundamental importance of high-quality pre-school education, and the benefits it brings both to the children themselves and to the economic performance of a country. In Singapore, like in other developed countries, there is still room for improvement in the pre-school system.

\section{Increasing spending on early childhood education and care could lower the child-to- teacher ratio}

Compared to other countries with a high gross domestic product (GDP) per capita, Singapore currently invests less in early-childhood education and care (ECEC). It is worthy of note, however, that this is partly due to Singapore's efforts to focus on private-sector provision, while investing through targeted transfers and since 2014 also through public kindergartens in ECEC services for vulnerable layers of society. Currently, the median fullday childcare fee is 856 Singapore dollars (SGD) per month, while the maximum subsidy that a family in the lowest income bracket could obtain is SGD 740. These subsidies render the government provided kindergartens virtually free of charge for the lowest earning parents. (ECDA, 2018).

Singapore's lower levels of public funding for ECEC compared to OECD countries may help to explain the difference in child-to-teacher ratios that is also apparent. In Singapore, the set guideline for pre-schools stipulates that they should not exceed a child-to-teacher ratio of 20 to 1 in year one of kindergarten (K1) and 25 to 1 in year two (K2).

This is higher than the OECD average of 16 to 1 (Figure 3.7.1). Moreover, studies have shown that low child-to-teacher ratios are a key factor in ensuring both the quality of pre-school education and future outcomes for the children who study there (OECD, 2017; Blau and Currie, 2006). It is also worthy of note that while guidelines from Singapore's Early Childhood Development Agency stipulate child-to-teacher ratios of 20:1 and 25:1 for years one and two of kindergarten respectively, many private operators offer much lower child-to-teacher ratios. 
Figure 3.7.1. Child-to-teacher ratios in early childhood education and care in 2017

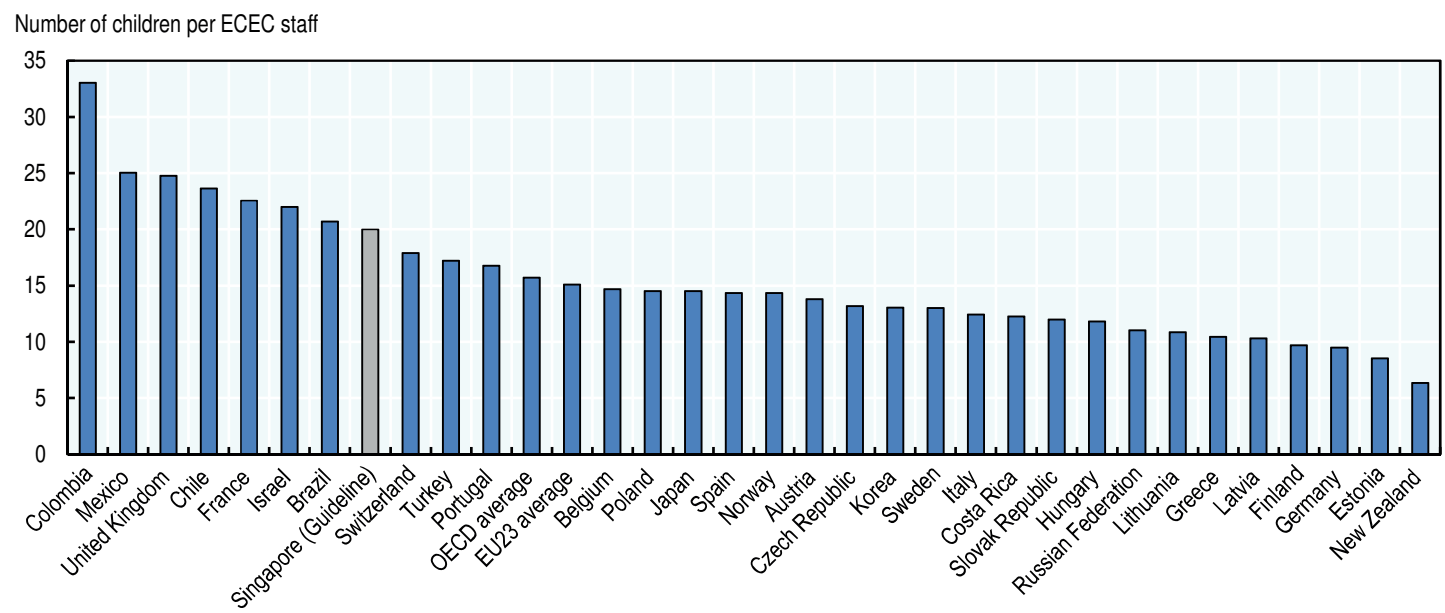

Note: For France, data represent public and government-dependent private institutions only, and data on teachers are not comparable with previous years due to a new methodology introduced. For Japan, data on staff do not cover all ECEC services. Singapore data refer to the government guideline of child-to-teacher ratio at 20:1 for year one of kindergarten instead of actual ratio.

Source: OECD (2019a), "Ratio of children to staff in pre-primary (ISCED 02) education (2017): Public and private institutions, calculation based on full-time equivalents", in Access to education, participation and progress, https://doi.org/10.1787/02fe776d-en.

StatLink Ainst https://doi.org/10.1787/888934064354

Increasing public spending offers one clear way to reduce the child-to-teacher ratio while not affecting accessibility. In 2018, Singapore's spending on early-childhood education and care came to around SGD 1 billion. Yet at $0.19 \%$ of Singapore's GDP, this level falls below the average level of spending for OECD countries, which was estimated at $0.6 \%$ in 2013 (OECD, 2017; MSF, 2018a). With respect to spending per child, however, Singapore performs better by comparison, with current spending at USD 7926 at purchasing power parity (PPP). However, this still comes in below the OECD average of USD 8141 at PPP (MSF, 2018a; OECD, 2019b).

By way of comparison, however, Singapore tends to invest more on average in primary education than the OECD countries, for which average spending per child amounted to USD 8631 at PPP in 2015. Singapore spent USD 9678 at PPP per child in 2017 (MOE, 2018a; OECD, 2018a). Still, this difference is not reflected in the child-to-teacher ratio in primary schools, which was 15 to 1 in 2017, matching the OECD average of 2016 (MOE, 2018b; OECD, 2018b). However, Singapore's excellent scores in the OECD's Programme for International Student Assessment (PISA) rankings attest to a high degree of quality in its education system. Indeed, Singapore outperformed all other ranked countries in 2015 (OECD, 2016). In order to enhance this success further, Singapore can now seek to improve its preschool outcomes to match those it achieves in primary and secondary education.

Under the current spending plan, which the government published in 2017 and runs through to 2023, Singapore will boost ECEC spending to SGD 1.7 billion by 2023. This will represent $0.29 \%$ of GDP according to forecasted data, meaning it will still fall short of OECD levels as a percentage of GDP. Still, the plan involves creating 40000 extra places, and implies per-child spending of USD 9830 at PPP. This is above the 2016 OECD average. However, it still falls below top performers such as Luxembourg (USD 17539 in 2016), Sweden (USD 14 528), and Norway (USD 14 344) (Figure 3.7.2). Nonetheless, high level of public spending alone would not be enough and it should also be accompanied by effective measures to achieve desired outcomes and guarantee its sustainability. It is also worthy of note that occupancy rates are currently low and on the rise. As a result of this, the actual level of spending per child is likely to be lower by 2023. 
Figure 3.7.2. Public spending on ECEC per child, 2016

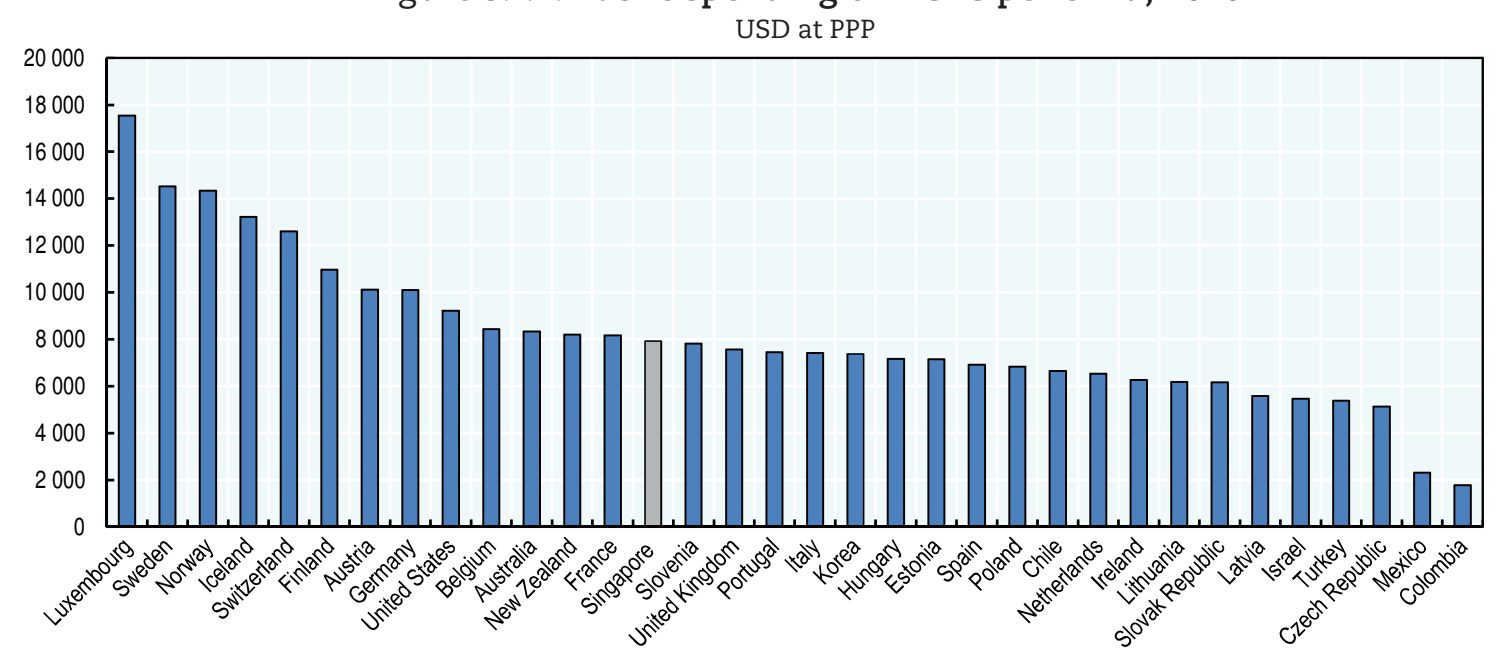

Note: For Chile and Colombia, data refer to 2017 instead of 2016. For Finland, expenditures are underestimated due to the estimation method used. For Japan, data on financing do not cover all ECEC services. For Switzerland, data refer to public sources only.

Source: OECD (2019b), "Financing of early childhood education and care (ISCED 0) and change in expenditure as a percentage of GDP (2012 and 2016): Public and private institutions", in Access to education, participation and progress, https://doi.org/10.1787/eb483bd2-en.

StatLink 前实 https://doi.org/10.1787/888934064373

The increase in ECEC spending marks government's efforts to raise the quality, accessibility and affordability of preschools. These efforts include doubling the number of full-day preschool places from 90000 in 2012 to almost 180000 in 2019, making preschool more affordable - in particular for the majority of low and middle-income families, enhancing means-tested preschools subsidies for families, uplifting early childhood standards in the sector, enhancing its resources, introducing kindergartens run by the Ministry of Education and last but not least, strengthening professional development of early childhood educators. With such efforts that cover teacher, centre and curriculum dimensions, it is expected that the annual government spending on the early childhood sector will increase more than double over the next few years, from around SGD 1 billion in 2018. Nonetheless, an evaluation of outcomes across various dimensions previously mentioned would be necessary to gain insight for further improvement of the quality of ECEC service.

\section{Fostering a high-quality home learning environment}

Parents' involvement in the provision of a good home-learning environment (HLE) is essential for their children's development. Indeed, a wide range of research shows that increased parental involvement correlates both with better academic performance later in life and greater social inclusion. Studies have found a particular link between proficiency in English and mathematics and the frequency of opportunities for learning at home, while the quality of the HLE is also essential for improving overall outcomes for children (OECD, 2012). This is because a child's early experiences build the architecture of the brain, and lay the foundations for their lifelong thinking skills and approach to learning. Parental interaction is, therefore, a key factor in improving educational outcomes (Hadani and Rood, 2018).

By supporting the parents of young children, early-childhood education and care can play an active role in fostering a better home-learning environment. Indeed, in Singapore in 2014, 55\% of parents relied on ECEC centres for acquiring knowledge about parenting (ECDA, 2014). Parents indicated that they found the workshops that these centres offered 
in this regard to be very useful. First of all, ECEC providers can inspire parents to offer their children all kinds of learning situations at home, both informal and explicit. Such a "home curriculum" can involve routine activities such as cooking meals, building, shopping, and fixing things, yet it should also be complemented with cognitive tasks such as shared book reading or engaging in stimulating discussions (OECD, 2012). Activities should be oriented both towards developing literacy skills and towards science, technology, engineering and mathematics (STEM) learning. Indeed, there should be a specific focus on the latter since caregivers and parents are currently more comfortable in supporting their children's literacy development than their progress with STEM subjects (Hadani and Rood, 2018). Finally, support in creating a high quality HLE is especially important for parents from low-income families.

Practical examples of ways to enhance the home-learning environment through ECEC services include providing activities and materials to parents to allow them to build on the work being done in the classroom. Indeed, this also allows parents to follow the academic progress of their child. Reading stories has also been recognised as a key driver for a child's cognitive development. The OECD found that children whose parents often read to them showed markedly higher scores in PISA 2009 than students whose parents read with them infrequently or not at all, regardless of their family's socio-economic background (OECD, 2011). In Singapore, 57\% of parents read story books to their child twice a week or even daily, but $24 \%$ never read to their child or do so only once a month (ECDA, 2014).

Given the importance of parenting for a child's school outcomes, offering parenting courses to the parents of pre-schoolers can be a good way of improving the overall quality of education. Indeed, studies indicate that providing such courses to parents has positive results on children's later school achievements, regardless of family background or income (OECD, 2012). Furthermore, it helps to make parents feel confident in their parenting, and more secure in their interaction with their child. Several initiatives have been put in place by the government in regards to impart essential parenting skills, especially for new parents or those from low-income families who may require more support. For instance, the Moments of Life application, which was launched in 2018, includes a section on parenting resources that parents can easily access on their mobile phones. The "Embracing PArenthood" movement, a community initiative launched in 2017 by the People's Association, also enables community partners to equip parents with young children with information on parenting. In one constituency, this led to the formation of a Parents' Support Group, which meets quarterly to share tips about child development, infant nutrition and other parenting pointers. Other initiative that targets low-income families was also introduced back in 2016. This initiative is called KidSTART programme and it reaches out to families right from the antenatal stage. This programme helps to equip parents with child development skills and provides health and social support to families and their children in their homes, preschools and communities. Despite the fact that such parenting programmes can be offered directly at the ECEC centre, or through home visits, they do, however, require time from parents.

\section{Building a strategic relationship between parents and ECEC services}

As well as enhancing the home learning environment, ECEC policies should aim to create a constructive and supportive relationship between parents and teachers. This is because there is a positive correlation between the frequency of high-quality interactions between parents and staff and the quality of care provided in centres (OECD, 2012). 
Possible policies for ECEC providers to promote better parent-teacher communication could include organising parent-staff meetings, sending newsletters, and setting up home visits. These different channels are beneficial as they provide extra opportunities for dialogue that go beyond the interactions parents get with teachers when they drop their children off or pick them up - which tend to focus on immediate concerns. Staff also benefit by building a better relationship with children and their families, and by obtaining a better understanding how a child's home environment might affect school performance (Halgunseth and Peterson, 2009).

Indeed, the authority has taken some measures to strengthen partnership between parents and preschools. For instance, preschools are encouraged to build close parentcentre relationships. Individual centres retain the flexibility to do so in a way which best caters of the needs of enrolled children and their parents, including those working full-time. The Early Childhood Development Agency (ECDA) also guides preschools in developing supportive and warm environments that welcome family participation through the Good Practices Handbook for Child Care Centres.

Besides regulatory requirements, Singapore has the Singapore Preschool Accreditation Framework (SPARK) that serves as a benchmark for preschools to assess and continually raise the quality of their programmes, including through collaboration with parents. In addition, the Government has introduced initiatives that promote greater involvement of families and the community in preschools' activities. For example, under the Start Small Dream Big (SSDB) initiative, in which the government encourages preschools to create platforms for children to give back to the community, preschools are encouraged to partner parents on their community project.

\section{Finding time to partake in parental engagement activities may be challenging}

Singaporean parents might find it hard to attend parenting courses or meetings organised by ECEC providers, as a large majority of both males and females are active participants in the labour market. Indeed, in 2015, the share of dual-career couples out of all married couples under 35 years old, was $75.9 \%$, falling to $69.1 \%$ for those aged between 35 and 49 (MTI, 2016). This means that a large share of pre-schooler parents do not necessarily have time to attend ECEC support programmes.

Furthermore, part-time work is uncommon in Singapore, with only $10.5 \%$ of the employed labour force falling under such a contract in 2017, compared to $16.5 \%$ on average in the OECD (MSF, 2018b; OECD, 2018c). This prevents arrangements in which one of the spouses focuses more on the upbringing of children by taking a part-time job (MSF, 2018b). In addition, the average number of hours that a Singaporean worked per week came to 45.1 in 2017, underscoring the fact that most parents of pre-schoolers have very busy schedules (Department of Statistics Singapore, 2018).

However, under Singapore's Child Development Co-Savings Act, each parent of a child under seven years old is entitled to six days a year of childcare leave (MOM, 2018). This leave is funded for the first three days by the employer, and for the second three days by the government. It allows parents to take the time to attend ECEC activities, as a couple can take a total of 12 days a year for activities related to their child. In order to support this policy further, however, awareness about the importance of parental involvement could be raised amongst young parents. 


\section{References}

Blau, D. and J. Currie (2006), "Preschool, daycare, and afterschool care: Who's minding the kids?", Handbook of the Economics of Education, Vol. 2, pp. 1163-1278, Amsterdam.

Cascio, E.U. and D.W. Schanzenbach (2013), "The impacts of expanding access to high-quality preschool education", National Bureau of Economic Research Working Paper 19735.

Delalibera B.R. and P.C. Ferreira (2019), "Early childhood education and economic growth", Journal of Economic Dynamics and Control, Vol. 98, pp. 82-104, https://doi.org/10.1016/j.jedc.2018.10.002.

Department of Statistics Singapore (2018), Singapore in Figures 2018, Department of Statistics Singapore, Singapore, https://www.singstat.gov.sg/-/media/files/publications/reference/ sif2018.pdf.

Dickens W. T., I. Sawhill and J. Tebbs (2006), "The Effects of Investing in Early Education on Economic Growth", The Brookings Institution, https://www.brookings.edu/wp-content/uploads/2016/06/ pb153.pdf.

ECDA (2018), Quarterly Report Statistics on Child Care Services, Early Childhood Development Agency, Singapore, https://www.ecda.gov.sg/Documents/Resources/Statistics on child care(STENT).pdf.

ECDA (2014), Early Childhood Parenting Landscape Study, Early Childhood Development Agency, Singapore, https://www.ecda.gov.sg/growatbeanstalk/Documents/Read\%20Publications\%20 and\%20Research/Executive\%20Summary Parenting\%20Study.pdf.

Economist Intelligence Unit (2012), Starting well Benchmarking early education across the world, The Economist, London, http://graphics.eiu.com/upload/eb/lienstartingwell.pdf.

Hadani, H.S. and E. Rood (2018), "The roots of STEM success: changing early learning experiences to build lifelong thinking skills", Center for Childhood Creativity, http://448bn62kp97s140org3xs7hnwpengine.netdna-ssl.com/wp-content/uploads/sites/2/2018/02/CCC The Roots of STEM Early Learning.pdf.

Halgunseth, L.C. and A. Peterson (2009), "Family Engagement, Diverse Families, and Early Childhood Education Programs: An Integrated Review of the Literature", Young Children, Vol. 64, No. 5.

Havnes, T. and M. Mogstad (2014), "Is universal child care levelling the playing field?", Journal of Public Economics, Vol. 127, pp. 100-114.

MOE (2018a), Government Recurrent Expenditure on Education per Student, Singapore Ministry of Education, Singapore.

MOE (2018b), Pupils per Teacher in Primary and Secondary Schools, Singapore Ministry of Education, Singapore.

MOM (2018), Childcare Leave Eligibility and Entitlement, Singapore Ministry of Manpower, Singapore, https://www.mom.gov.sg/employment-practices/leave/childcare-leave/eligibility-andentitlement.

MSF (2018a), FY2019 Expenditure Estimates, Singapore Ministry of Social and Family Development, Singapore, https://www.singaporebudget.gov.sg/docs/default-source/budget 2019/download/ pdf/23-MSF-2019.pdf.

MSF (2018b), Labour Force and the Economy: Part Time Workforce, Ministry of Social and Family Development, Singapore.

MTI (2016), General Household Survey 2015, Singapore Ministry of Trade \& Industry, Singapore, https://www.singstat.gov.sg/-/media/files/publications/ghs/ghs2015/ghs2015.pdf.

OECD (2019a), "Ratio of children to staff in pre-primary (ISCED 02) education (2017): Public and private institutions, calculation based on full-time equivalents", in Access to Education, Participation and Progress, OECD Publishing, Paris, https://doi.org/10.1787/02fe776d-en.

OECD (2019b), "Financing of early childhood education and care (ISCED 0) and change in expenditure as a percentage of GDP (2012 and 2016): Public and private institutions", in Access to Education, Participation and Progress, OECD Publishing, Paris, https://doi.org/10.1787/eb483bd2-en.

OECD (2018a), "Indicator D2 What is the student-teacher ratio and how big are classes?", in Education at a Glance 2018: OECD Indicators, OECD Publishing, Paris, https://doi.org/10.1787/eag-2018-29-en.

OECD (2018b), "Indicator C1 How much is spent per student on educational institutions?", in Education at a Glance 2018: OECD Indicators, OECD Publishing, Paris, https://doi.org/10.1787/ eag-2018-21-en.

OECD (2018c), “Table 24 - Part-time employment as a percentage of employment”, in OECD Labour Force Statistics 2018, OECD Publishing, Paris, https://doi.org/10.1787/oecd lfs-2018-table24-en.

OECD (2017), Starting Strong V: Transitions from Early Childhood Education and Care to Primary Education, OECD Publishing, Paris, http://dx.doi.org/10.1787/9789264276253-en. 
OECD (2016), PISA 2015 Results (Volume I): Excellence and Equity in Education, PISA, OECD Publishing, Paris, https://doi.org/10.1787/9789264266490-en.

OECD (2012), Starting Strong III: A Quality Toolbox for Early Childhood Education and Care, OECD Publishing, http://dx.doi.org/10.1787/9789264123564-en.

OECD (2011), "What Can Parents Do to Help Their Children Succeed in School?", PISA in Focus, No. 10, OECD Publishing, Paris, https://doi.org/10.1787/5k9h362jdgnq-en.

UNESCO (2018), "Education: Expenditure on education as \% of total government expenditure", UNESCO Institute for Statistics, Paris, http://data.uis.unesco.org/Index.aspx?queryid=183. 



\section{CLM}




\section{Cambodia}

\section{A. Medium-term economic outlook (forecast, 2020-24 average) \\ GDP growth (percentage change): \\ Current account balance (\% of GDP):}

GDP growth rates (percentage changes)

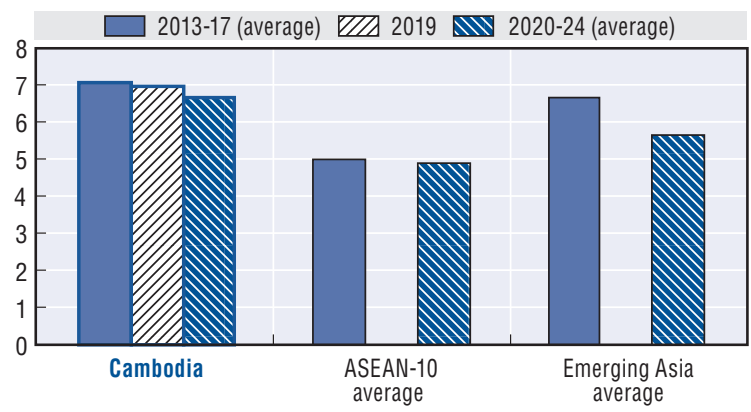

Source: OECD Development Centre.

GDP per capita, 2018

(PPP, current international dollar)

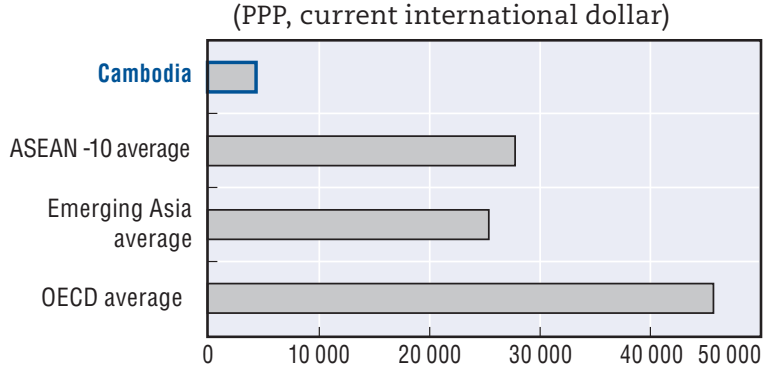

Source: IMF.

Composition of imports, 2018

(percentage share of total imports)

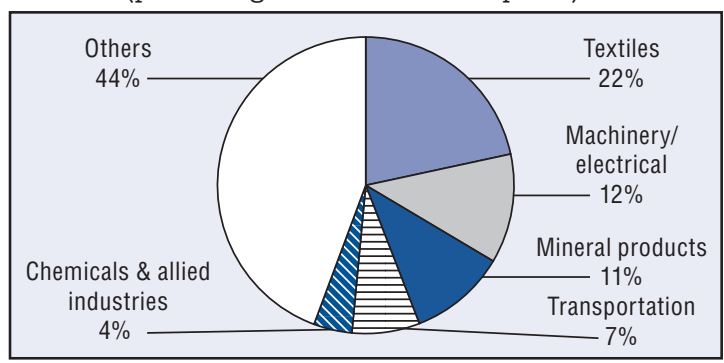

Source: Trademap.
Source: Trademap.

Composition of exports, 2018

(percentage share of total exports)

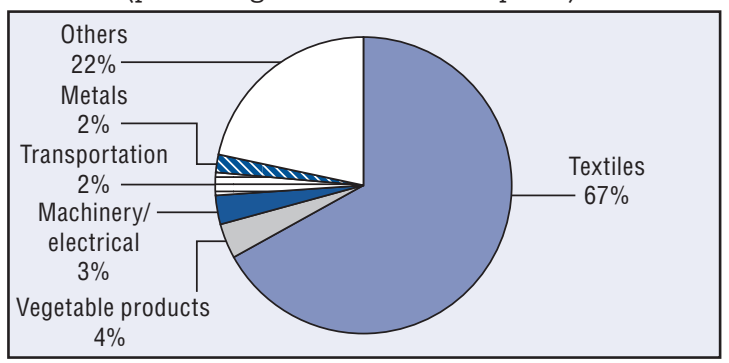

15.8 million (in 2017) *

1.9 million (in 2017)

4334.7 (current

4029.3 (KHR/USD)

\section{Structural policy challenges discussed in previous editions of the Outlook}

\begin{tabular}{lll}
\hline \multicolumn{2}{c}{ Agriculture } & Improving the productivity of agriculture, in particular for rice production \\
2014 & Financial sector & Improving the prudential and supervisory framework for the financial sector \\
& Tourism & Developing tourism-specific infrastructure \\
2016 & Education (TVET) & Improving competitiveness by strengthening TVET \\
& Tourism & Addressing complex challenges in developing tourism \\
2017 & Agriculture & Helping the agricultural sector to move ahead \\
2018 & Education & Strengthening financial education \\
2019 & Tourism & Addressing challenges in developing ecotourism \\
\hline
\end{tabular}




\section{POLICY FOCUS}

Improving training for MSMEs to achieve inclusive growth

Micro, small, and medium-sized enterprises (MSMEs) form the backbone of the Cambodian economy. Based on data from the country's Ministry for Industry and Handicrafts, the overwhelming majority of companies in Cambodia are MSMEs. Furthermore, these businesses account for $70 \%$ of employment in Cambodia, and contribute $58 \%$ of the country's gross domestic product (GDP) (Chhea, 2019). Moreover, MSMEs are more likely to be owned by Cambodians, and are more evenly distributed across the country.

\section{Human resources are one of the main challenges that MSMEs face in Cambodia}

Since the early 2000s, the Cambodian government has introduced policies and measures to facilitate and guide the development of MSMEs. In 2004, for example, it launched its so-called "Rectangular Strategy for Growth, Employment, Equity and Efficiency". The promotion of SMEs and entrepreneurship formed an integral part of one of this strategy's four pillars, whose focus was on development and employment in the private sector. That same year, the government also created a dedicated sub-committee for SMEs, as well as a special development framework for these companies. The goal was to identify barriers and provide solutions to help MSMEs to develop (Baily, 2008). In its National Strategic Development Plan for 2014-18, meanwhile, the Cambodian government set out a range of policies to cut red tape for MSMEs, including by making it easier, quicker, and cheaper to register a business, and by improving their access to credit (RGC, 2014). Furthermore, Cambodia's policy framework for industrial development for 2015-25 called for the expansion and modernisation of MSMEs across the country (RGC, 2015). Even more recently, the government introduced a set of tax incentives for MSMEs that operate in specified priority sectors such as agriculture and information technology (DFDL, 2018).

The government's supportive measures have helped MSMEs to grow, with the number of registered businesses in this category increasing every year. However, recent reports show that there is still plenty of room for improvement in comparison with other countries in ASEAN. For example, data from the World Bank have rated the business environment in Cambodia as being below average for ASEAN, especially in terms of market entry, power infrastructure, and regulatory environment (World Bank, 2018).

Human resources is one of the most pressing issues that Cambodia's MSMEs face as they seek to develop. As is apparent from statistics from the International Labour Organisation, many MSMEs in Cambodia have difficulties in acquiring and retaining skilled workers, due to the limited size of the country's pool of skilled labour (Figure 3.8.1). Moreover, most skilled workers prefer to work in large corporations, which usually offer better benefits than MSMEs in terms of wages, social security, and other forms of welfare (JICA, 2015). Unlike large companies - which tend to have well-established employee training programmes and can afford on-the-job training - MSMEs are more reliant on public education and training systems. Indeed, the skills shortage for mediumsized companies is most common for occupations such as plant and machine operators and assemblers, managers, service and sales workers, and technicians and associate professionals (NEA, 2016). 
Figure 3.8.1. Labour force distribution in Cambodia by education level, 2010-16 Percentage of population age 15+

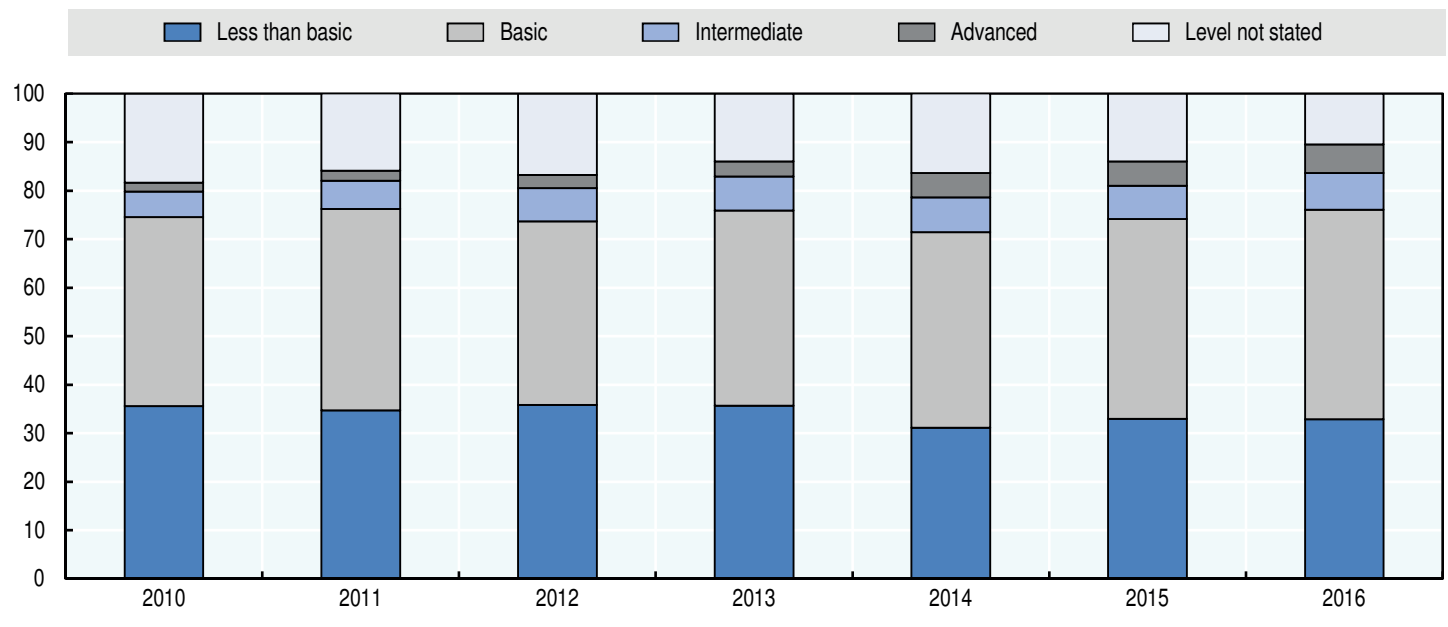

Source: ILO (2019), "Employment by education", ILOSTAT (database), https://ilostat.ilo.org/data/. StatLink 髚 https://doi.org/10.1787/888934064392

The government of Cambodia has implemented several initiatives and projects to develop human capital in the country (Box 3.8.1). In light of this situation, improvements in training and education - such as delivering a high quality technical and vocational education and training (TVET) system - can play a critical role in addressing this challenge.

\section{Box 3.8.1. Recent programmes to develop human capital in Cambodia}

In 2017, Cambodia's government launched the Capacity Building, Research and Development (CBRD) Fund, which draws its financial resources from a 1\% levy on the gross revenues of telecom operators across the country. The goal of the CBRD Fund is to develop human capital in the ICT sector. Thus far, its actions have included providing scholarships to ICT students, building computer laboratories in high schools, deploying research and development infrastructure, and supporting digital entrepreneurship. With specific regard to supporting MSMEs, the CBRD Fund has contributed to the government's "SMEs Go Digital" initiative by providing information, funding, and technical support to business start-ups in digital industries, as well as to MSMEs seeking digital transformation.

In 2019, moreover, the Cambodian government launched the Techo Startup Centre at the Royal University of Phnom Penh in order to teach students the skills they will need to succeed in the digital era, and to foster digital entrepreneurship. This new unit offers four main services to help young entrepreneurs to develop their start-ups. The first of these is a specialised training programme on entrepreneurship, business development, pitching for funding, and marketing strategy. The second of the four main services it offers is one of mentorship. This seeks to help guide the direction of young entrepreneurs' projects, and to provide management advice for start-ups. Thirdly, the centre offers technical assistance to help start-ups to resolve issues they may encounter with regard to emerging technology. The fourth element is a so-called talent accelerator, whose aim is to develop capacity in the latest technology through project-based and research-based learning (Techo Startup Centre, 2019). 
Box 3.8.1. Recent programmes to develop human capital in Cambodia (cont.)

Furthermore, the government is currently planning to set up a skills-development fund (ASEAN, 2019). The aim of this fund is to establish a trusted financing platform outside of normal government budgetary channels to support both pre-employment training and an upgrade of skills in the existing workforce thanks to a cost-sharing initiative with the private sector. The expectation is that this will help to provide workers with timely training for the most in-demand skills. In so doing, it will help respond to the fastchanging demands of an increasingly advanced technological economy, while also raising productivity, competitiveness, and incomes among Cambodia's MSMEs (ADB, 2018).

\section{Improving technical and vocational education in Cambodia to assist the development of MSMEs}

Technical and vocational education and training (TVET) in Cambodia features a formal system that operates in parallel to traditional education. There is also a nonformal system of TVET, in which a wide variety of stakeholders - such as private-sector firms, non-governmental organisations (NGOs), and local-government authorities provide training programmes. These tend to be relatively short in length (UNESCO, 2015). Under the formal TVET system, students who have completed nine years of compulsory general education may then choose - at the upper-secondary level - between three years of TVET or three more years of general education. Upper-secondary TVET programmes offer training in areas including vehicle maintenance, general mechanics, computer technology, and civil engineering. For students who finish twelve years of education, it is possible to enter formal tertiary TVET programmes at technical and professional training institutions, polytechnics, and other vocational training centres or schools. Meanwhile, informal TVET training is mainly provided by provincial and vocational training centres (PTCs \& VTCs), private-sector actors, and NGOs. As already noted, this latter category tends to feature short courses that last just a few months. They aim mainly to address social dislocation and poverty reduction, particularly in rural areas. Yet despite some successes, the TVET system in Cambodia requires improvements to address three main challenges: a low participation rate, poor quality, and insufficient relevance to employers' real needs.

Compounding these challenges, there is a widespread perception in Cambodia that TVET education is a second-tier option for those who have "underperformed" academically. This deep-rooted negative perception of TVET, together with the country's continued emphasis on higher education, has led to a low enrolment rate and a high rate of dropouts (OECD, 2016). Moreover, data from Cambodia's Ministry for Labour and Vocational Training show that the total amount of people enrolled in TVET programmes has dropped by about $50 \%$ over the past six years (MLVT, 2019). Against this backdrop, fostering a positive image of TVET in society, and improving the quality of the programmes on offer, will be key to boosting participation.

The poor quality of TVET is a well-known problem in Cambodia, and it has contributed to the negative perception of this kind of education and to its low levels of participation and general acceptance. According to a survey of employers by Cambodia's National Employment Agency, the preparedness for work among first-time jobseekers graduating from TVET programmes is - in eight out of ten industries covered by the study - lower than those graduating from general education (NEA, 2016). Moreover, employers perceive 
TVET alumni as lacking basic soft skills such as teamwork and self-motivation, and as having a bad attitude to work.

Limited financial resources continue to present a major obstacle as Cambodia seeks to deliver accessible and high-quality TVET products and services to students. To improve quality, the government needs to strengthen collaboration with the private sector - through public-private partnerships (PPPs), for instance. It also needs to establish a comprehensive quality-assurance framework across all aspects of TVET, to improve TVET curricula, to boost the capacity of teachers and non-teaching staff, and to upgrade training methods and infrastructure (OECD, 2016).

\section{References}

ADB (2018), Toward Adopting a Skills Development Fund for Cambodia, Asian Development Bank, Manila, https://www.adb.org/sites/default/files/publication/401746/adb-brief-090-skills-developmentfund-cambodia.pdf.

ASEAN (2019), MSMEs, Key of Cambodia's Future Economic Success, ASEAN Secretariat, Jakarta, https:// asean.org/msmes-key-cambodias-future-economic-success/.

Baily, P. (2008), "Cambodian Small and Medium Sized: Enterprises: Constraints, Policies and Proposals for Their Development", in Lim, H. (ed.), SME in Asia and Globalization, ERIA Research Project Report 2007-5, pp.1-36, http://www.eria.org/Cambodian\%20Small\%20and\%20 Medium\%20sized\%20Enterprises\%20Constraints\%20Policies\%20and\%20Proposals\%20for\%20 their\%20Development.pdf.

Chhea, L. (2019), The Current Situation of SME in Cambodia - MSME Financing, Ministry of Industry and Handicraft, Phnom Penh, https://www.unescap.org/sites/default/files/SME\%20FinancingChhea\%20Layhy\%202019.pdf.

DFDL (2018), Cambodia Tax Update: SME Tax Incentives Announced, DFDL Law Firm, Phnom Penh https://www.dfdl.com/resources/legal-and-tax-updates/cambodia-tax-update-sme-taxincentives-announced/.

ILO (2019), "Employment by education”, ILOSTAT (database), https://ilostat.ilo.org/data/.

JICA (2015), Project for Strategic Strengthening of Small and Medium Enterprise (SME) Support System: Final Report, Japan International Cooperation Agency, Tokyo, http://open_jicareport.jica.go.jp/ pdf/12245049 01.pdf.

MLVT (2019), TVET Statistics Reports 2012-18, Ministry of Labour and Vocational Training, Phnom Penh, http://www.tvetmis.com/public/english/report.php.

MLVT (2017), National Technical Vocational Education and Training Policy 2017-25, Ministry of Labour and Vocational Training, Phnom Penh, http://tvetsdp.ntb.gov.kh/2018/02/05/download/.

NEA (2016), Skills Shortages and Skills Gaps in the Cambodian Labour Market: Evidence from Employer Skills Needs Survey 2015, National Employment Agency, Ministry of Labour and Vocational Training, Phnom Penh, http://www.nea.gov.kh/images/survay/Report_Cambodia_2015.pdf.

OECD (2016), Economic Outlook for Southeast Asia, China and India 2016: Enhancing Regional Ties, OECD Publishing, Paris, http://dx.doi.org/10.1787/saeo-2016-en.

RGC (2015), Cambodia Industrial Development Policy 2015-25, Royal Government of Cambodia, http://www.mih.gov.kh/File/UploadedFiles/12_9_2016_4_29_43.pdf.

RGC (2014), National Strategic Development Plan 2014-18, Royal Government of Cambodia, Phnom Penh, http://www.cdc-crdb.gov.kh/cdc/documents/NSDP 2014-2018.pdf.

Techo Startup Centre (2019), What We Do, Techo Startup Centre, Phnom Penh, http://techostartup. center/what-we-do.

UNESCO (2015), World TVET Database: Cambodia, UNESCO-UNEVOC International Centre for Technical and Vocational Education and Training, Bonn, https://unevoc.unesco.org/wtdb/ worldtvetdatabase_khm_en.pdf.

World Bank (2018), Doing Business (database), World Bank, Washington, DC, http://www. doingbusiness.org/en/data. 


\section{Lao PDR}

A. Medium-term economic outlook (forecast, 2020-24 average)

GDP growth (percentage change):

Current account balance (\% of GDP):
GDP growth rates (percentage changes)

2013-17 (average) DIA 2019 NIN 2020-24 (average)

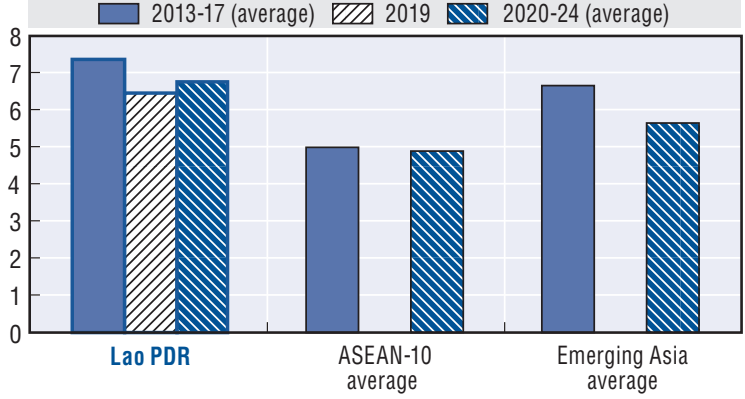

Source: OECD Development Centre.

GDP per capita, 2018

(PPP, current international dollar)

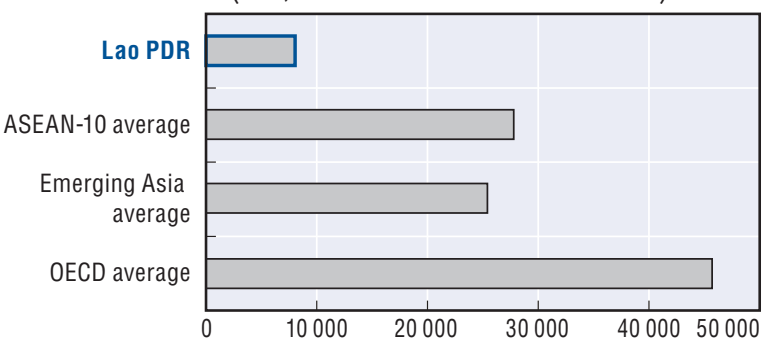

Source: IMF.

\section{Composition of imports, 2018}

(percentage of total imports)

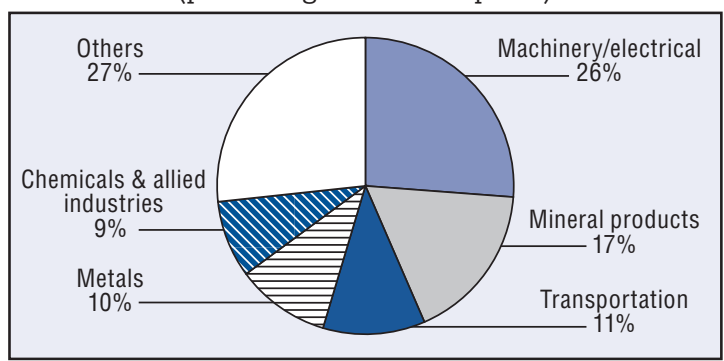

Source: Trademap.

Source: Trademap.

Mineral products

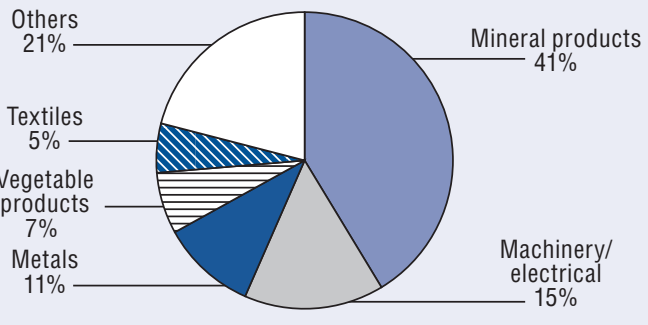

Structural policy challenges discussed in previous editions of the Outlook

\section{Reducing poverty through inclusive growth}

Improving national resource management, in particular in mining, to ensure environmental sustainability Developing transport infrastructure to speed up rural development

Managing the boom in natural resources

Fostering the development of SMEs

Promoting travel and tourism

Promoting small hydropower projects

Strengthening skills to make the most of the country's SEZs

Boosting tourism by fully exploring opportunities in the Association of Southeast Asian Nations (ASEAN)

Improving access to education and reducing disparities

Diversifying Lao PDR's energy portfolio by developing solar power 


\section{POLICY FOCUS}

Promoting export-oriented organic agriculture

Over the past few decades of Lao PDR's economic development, the industrial and services sectors have made increased contributions to growth. Yet growth in the country's agricultural sector has been stagnant in recent years, falling below the government's target. Still, despite expanding at a lower rate than other sectors and not living up to the goals of the government in Vientiane, agriculture still plays an important role in Lao PDR's overall economy, employing over 65\% of the country's labour force (MPI, 2016). Moreover, agricultural products still count among the country's top five exports (OECD, 2018). Given its existing domestic importance and its potential to make a bigger contribution to growth and exports, bolstering the development of Lao PDR's agricultural sector will play an important role in maintaining sustainable and inclusive growth in the country. In its fiveyear socio-economic development plan for 2016-20, the country's government recognised this potential, highlighting the role that an increased deployment of organic agriculture and modern technology can play in developing Lao PDR's agriculture and forestry sectors, and in increasing agricultural production.

\section{The rollout of organic agriculture in Lao PDR is at an early stage but has strong potential}

At its core, organic agriculture avoids using synthetic inputs such as artificial fertilisers, pesticides, or herbicides. Instead, it relies on organic fertilisers such as manure and vegetable-based compost. It also uses organic methods to maximise food production, such as introducing natural predators to remove pests. Organic agricultural products have a reputation for being safer to consume, for boosting human health, and for tasting better too. Evidence from scientific research, field trials, and farm experience, also shows that organic agriculture tends to be more environmentally friendly when it comes to its impact on the use of pesticides, the boost it provides to biodiversity, and the way in which it strengthens the environment's resilience to effects of climate change, such as drought (OECD, 2003).

Non-governmental organisations (NGOs) were the first to introduce the modern concept of organic and sustainable agriculture to Lao PDR in the 1990s. With help from foreign donors, the government's agriculture agency subsequently introduced several initiatives to provide more systematic support for organic agriculture, such as the "Promotion of Organic Farming and Marketing in Lao PDR", which ran from 2004-11. These initiatives have made contributions over the past decades to the proliferation of organic agricultural knowledge, to the marketing efforts of organic food and to the creation and improvement of an accompanying regulatory environment. Lao PDR's government approved its first national organic standards in 2005. Then, in 2008, it created the Lao Certification Body, aiming to promote organic production by offering a domestic system of certification. Since 2008, certified organic agriculture in Lao PDR has been growing steadily.

Although there has been progress, the development of organic agriculture in Lao PDR is still at early stage. As of 2017, around 7668 hectares of farmland were being used specifically for the cultivation of organic agricultural products. That accounted for just $0.32 \%$ of total farmland in Lao PDR (Figure 3.9.1). Although market-driven commercial production of organic products remains modest in Lao PDR, there is vast potential to expand the organic sector. This is because around $80 \%$ of the rural population in Lao PDR still depends on subsistence agriculture (FAO, 2019), and most of these subsistence farmers follow traditional methods of production that make little use of external and 
synthetic inputs such as chemical fertilisers. If the necessary technical and marketing assistance is forthcoming, it is possible to turn subsistence farms organic at a relatively low extra cost.

Figure 3.9.1. Organic farming area in ASEAN, 2017

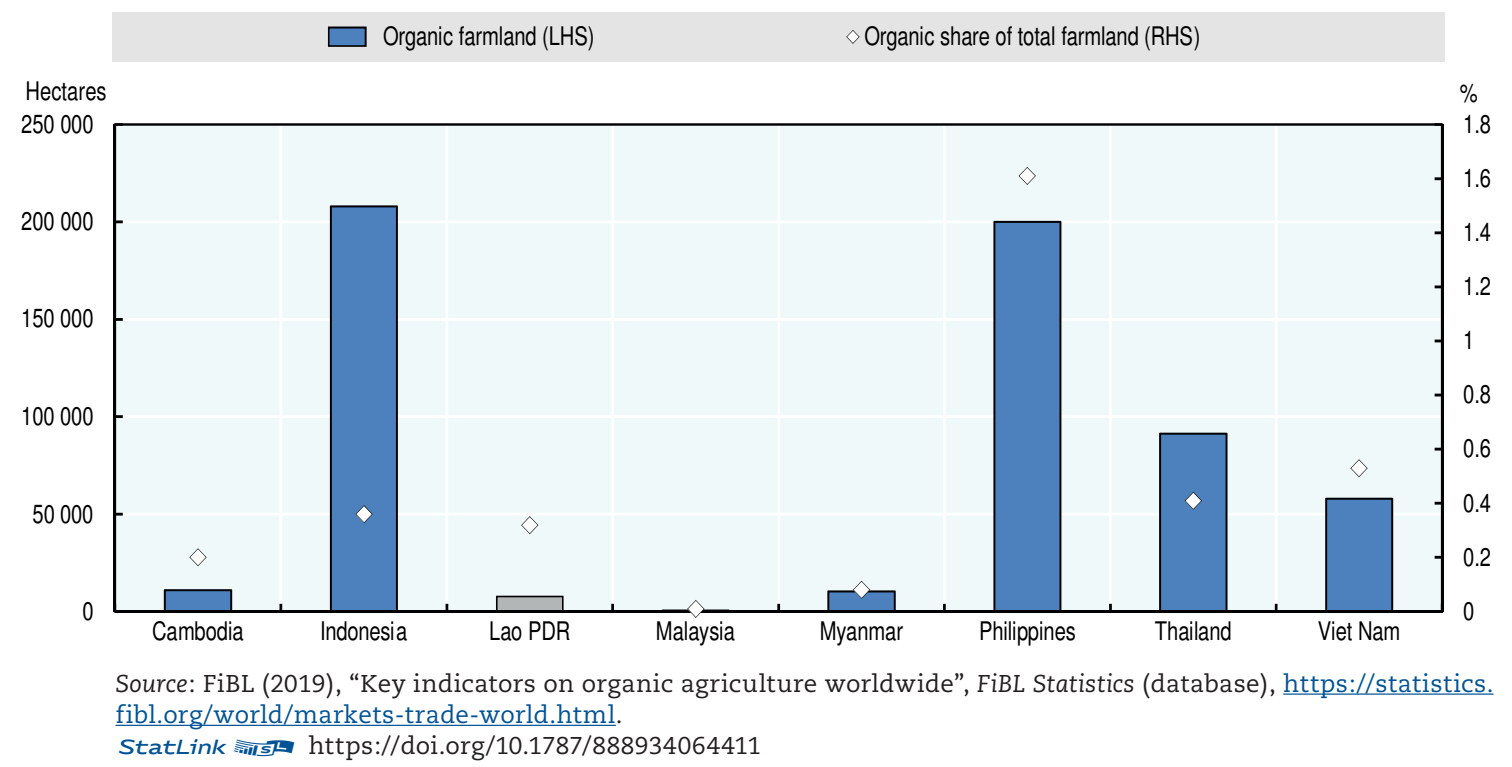

The domestic market for organic products remains limited, but global markets are booming

The development of organic agriculture faces several critical challenges in the domestic market. One of these challenges is that despite the market having grown somewhat, overall domestic demand for organic products remains relatively low in Lao PDR. A survey conducted in 2015 suggested that only $34.3 \%$ of the population bought organic products (Kousonsavath, Vagneron and Xiong, 2018). Another challenge to overcome is that only a limited number of shops dedicate themselves to stocking organic agricultural products, and even then the variety tends to be limited as organic coffee accounts for $71.8 \%$ of total organic production in the country (UNCTAD, 2012). In addition, a key challenge confronting the development of organic food in Lao PDR is that local consumers are less willing to pay a price premium for organic products than are foreign or expatriate customers. Statistics from AgroAsie, an organic shop in Vientiane, show that $95 \%$ of its customers are foreign expatriates, with the majority being Europeans and Americans. Only 5\% of AgroAsie's customers are locals (Sibounnavong et al., 2012).

Nevertheless, the popularity of organic products is on the rise around the world, and the global market for organic agriculture grew more than six-fold from 2000-17, rising to 92 billion euros from a baseline of EUR 15 billion (Willer and Lernoud, 2019). As of 2017, the biggest organic market by region in the world was North America, accounting for $46.7 \%$ of the global market, followed by Europe at $40.6 \%$ and Asia at 10.4\% (Figure 3.9.2). Within Asia, Japan and South Korea are key markets for organic food. Still, growth in China has been especially notable, with the organic market there expanding from merely EUR 0.4 billion in 2007 to EUR 7.6 billion in 2017. Growth in the Indian market has also been significant, from EUR 7.8 million in 2008 to EUR 186 million in 2017 (FiBL, 2019). In light of the exciting potential of markets of organic products in Asia and beyond, the development of organic agriculture in Lao PDR could, in the medium term, benefit from ratcheting up its exports to these more mature regional and international organic markets. As it 
looks ahead to these opportunities, however, Lao PDR will need to address a range of key challenges in order to strengthen the competitiveness of its organic sector.

Figure 3.9.2. Global organic markets by region, 2008-17

Retail sales in million Euros

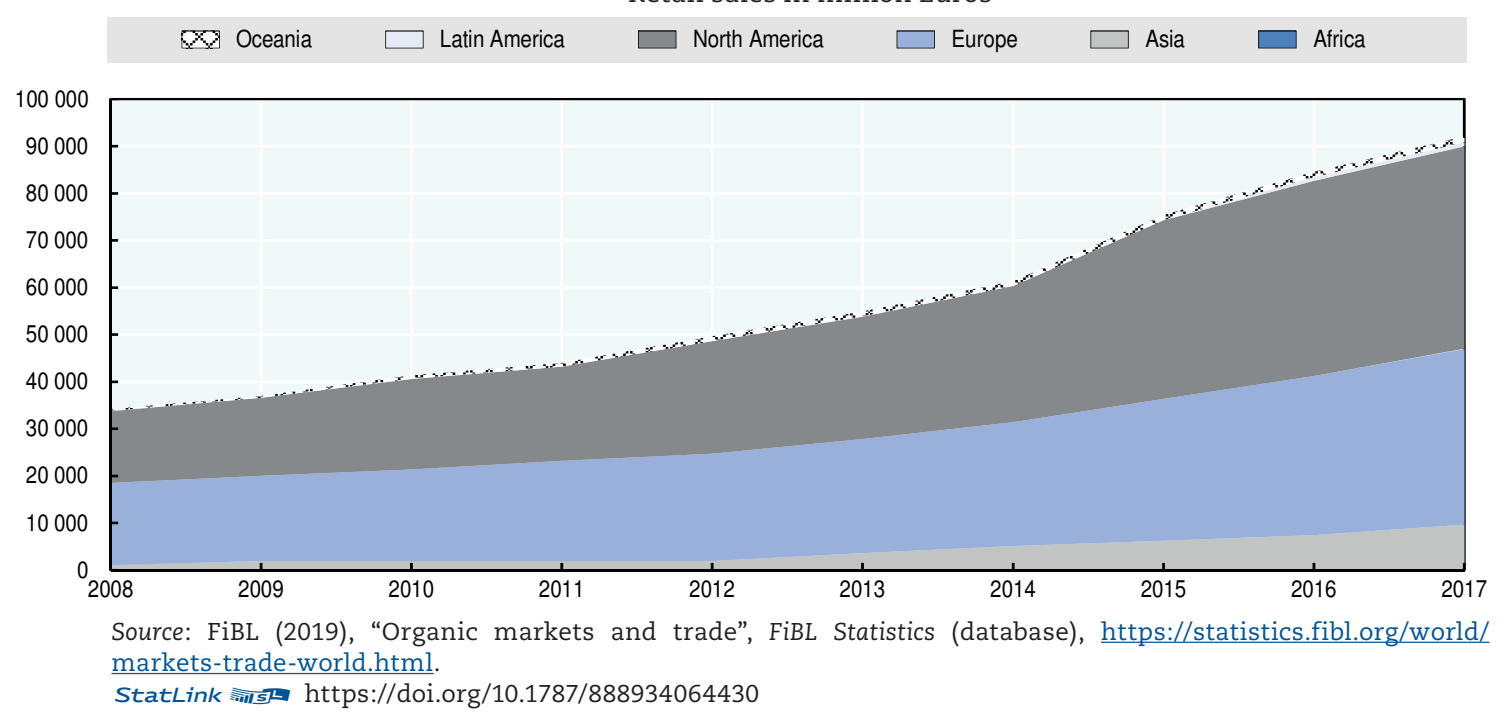

\section{Strengthening the competitiveness of organic exports from Lao PDR}

Improving the quality of its organic products will be the key factor in making sure that Lao PDR succeeds in growing the international appetite for these potential exports. Indeed, while Lao PDR has already gained some experience of exporting certified organic products to Europe and rest of Asia, issues of quality and low added value have tended to hamper its overall performance as an exporter of such goods. Indeed, it will be necessary to improve standards both of quality and safety in order for organic products from Lao PDR to win acceptance and demand from foreign consumers. Developing internationally recognisable local organic brands that enjoy a proven track record of quality would help to build this kind of consumer confidence in the new markets that present opportunities for Lao PDR's budding organic agriculture sector.

As it seeks to boost the organic sector, the government of Lao PDR also needs to strengthen co-ordination among the key stakeholders in organic agriculture and trade. These include not just organic producers, but also other businesses that are active in the supply and export chains, in addition to a range of government agencies and financial institutions (UNCTAD, 2017).

Meanwhile, drafting a framework of national regulation on organic agriculture and organic trade could help to clarify and streamline the process of organic agricultural production, processing, certification, and exportation. In addition, it will also be important to create an effective information distribution platform capable of making vital and timely information accessible to local producers and traders, so that they can learn more about organic trade and what end consumers in export markets are looking for.

In addition to addressing the quality and supply of organic products from Lao PDR, good marketing will also be necessary in order to introduce the country's organic products to potential buyers. In this connection, the rise of e-commerce points to a promising channel to promote organic products across long distances, even as traditional methods such as bilateral agreements between governments retain great relevance when it comes to opening up new markets. 


\section{References}

FAO (2019), "Laos at a glance", FAO in Laos, Food and Agriculture Organization of the United Nations, http://www.fao.org/laos/fao-in-laos/laos-at-a-glance/en/.

FiBL (2019), "Key indicators on organic agriculture worldwide", FiBL Statistics (database), https://statistics.fibl.org/world/markets-trade-world.html.

Kousonsavath, C., I. Vagneron and M. Xiong (2018), Boosting the Demand for Organic Products: The Role of Consumer Trust and Product Availability, Market and Agricultural Linking Chains in Asia, https://www.malica.org/publications/policy-brief.

MPI (2016), $8^{\text {th }}$ Five-Year National Socio-Economic Development Plan (2016-20), Ministry of Planning and Investment in Lao PDR, http://www.la.one.un.org/images/publications/8th NSEDP 2016-2020.pdf.

OECD (2018), Economic Outlook for Southeast Asia, China and India 2019: Towards Smart Urban Transportation, OECD Publishing, Paris, https://doi.org/10.1787/saeo-2019-en.

OECD (2003), Organic Agriculture: Sustainability, Markets and Policies, OECD Publishing, Paris, https://doi.org/10.1787/9789264101517-en.

Sibounnavong, P. et al. (2012), Organic Agriculture in Lao PDR, Faculty of Agriculture, National University of Lao PDR, Vientiane, http://afh-jp.com/pdf/laos.pdf.

UNCTAD (2017), 6th Lao Organic Agriculture Forum (LOAF 6): Expanding Organic Exports Through Sustainability Standards, https://unctad.org/en/pages/MeetingDetails.aspx?meetingid=1662.

UNCTAD (2012), Organic Agriculture in Lao PDR: Overview, United Nations Conference on Trade and Development, https://unctad.org/meetings/en/SessionalDocuments/DITC_TED_OA1212LOAF_ OAinLao.pdf.

Willer, H. and J. Lernoud (2019), The World of Organic Agriculture: Statistics and Emerging Trends 2019, Research Institute of Organic Agriculture (FiBL), Frick, and IFOAM-Organics International, Bonn. 


\section{Myanmar}

\section{A. Medium-term economic outlook (forecast, 2020-24 average) \\ GDP growth (percentage change): \\ Current account balance ( $\%$ of GDP):}

GDP growth rates (percentage changes)

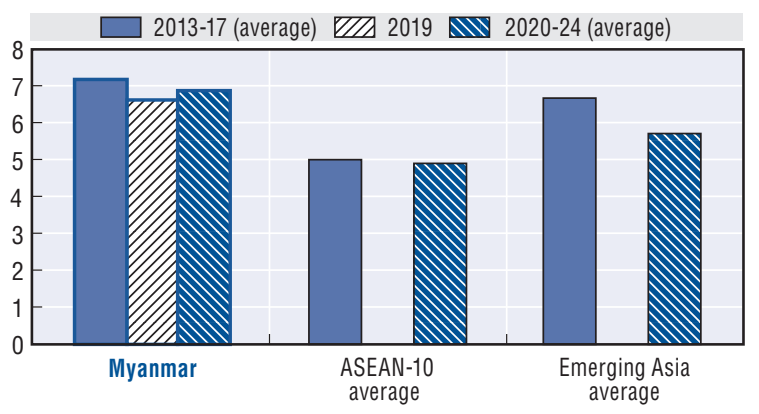

Source: OECD Development Centre.

GDP per capita, 2018

(PPP, current international dollar)

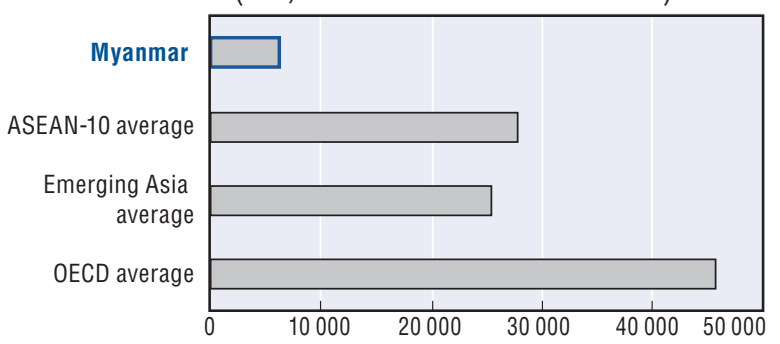

Source: IMF.
53.8 million *

1.3 million *

6216.7 (current International Dollar) **

1526.5 (MMK/USD)
Sources: OECD Development Centre, national sources, CEIC and IMF.

\section{Composition of imports, 2018}

(percentage of total imports)

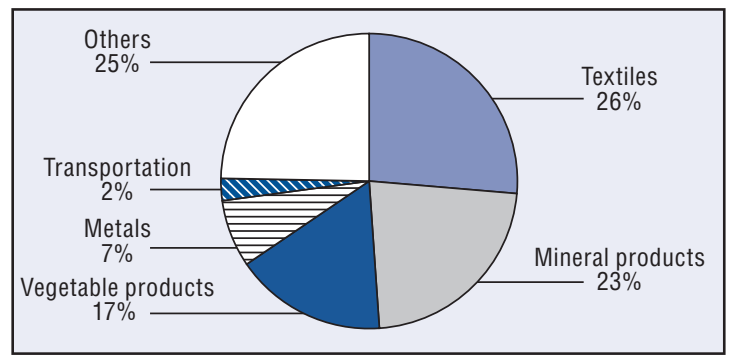

Source: Trademap.

\section{Composition of exports, 2018}

(percentage of total exports)

\section{Structural policy challenges discussed in previous editions of the Outlook}

\begin{tabular}{|c|c|c|}
\hline 2014 & $\begin{array}{l}\text { Business sector } \\
\text { Education } \\
\text { Finance }\end{array}$ & $\begin{array}{l}\text { Creating an environment that enables business } \\
\text { Upgrading education, and anticipating future demands for skilled labour } \\
\text { Creating a stable and efficient financial system }\end{array}$ \\
\hline \multirow[t]{3}{*}{2015} & Statistics & $\begin{array}{l}\text { Developing reliable indicators, quantifiable goals, and measurements of government performance, particularly in } \\
\text { the areas of regulatory reform and public finance }\end{array}$ \\
\hline & Budget & Developing policy-planning and budgeting, including appropriate financial support in agriculture and education \\
\hline & Private sector & $\begin{array}{l}\text { Co-operating with the private sector through public-private partnerships, in the setting up of new businesses, and } \\
\text { by promoting the involvement of civil society. }\end{array}$ \\
\hline \multirow[t]{3}{*}{2016} & Agriculture & Upgrading and modernising agriculture \\
\hline & Education & Developing human capital \\
\hline & Finance & Financing development \\
\hline \multirow[t]{3}{*}{2017} & Finance & Promoting capital markets to bolster the private sector \\
\hline & Infrastructure & Supporting investment in infrastructure \\
\hline & Education & Reforming higher education to deliver better quality \\
\hline 2018 & FDI & Continuing reforms to attract foreign direct investment for development \\
\hline 2019 & Tourism & Fostering the inclusive development of the travel and tourism sector \\
\hline
\end{tabular}




\section{POLICY FOCUS}

Unleashing the potential of the railways

Land transport - and rail-transport infrastructure in particular - have increasingly been in the spotlight in Myanmar in recent times, as the country seeks to accelerate its development and maintain strong economic growth. The rail sector has not, however, been in the news because it is playing an important role in the country's economic development, but because it is in regrettable decline. Between 2010 and 2014, overall passenger travel by rail in Myanmar has declined by $21 \%$, according to a study by the Asian Development Bank (ADB, 2016). Over the same period, passenger numbers on the intercity trains of Myanma Railways (MR) declined by $36 \%$. Indeed, road transport has become a strong competitor to these rail passenger services, despite the relatively low fares on the MR network. Nearly $75 \%$ of passengers' journeys are short, involving distances under 150 kilometres. As a result, it is often convenient to substitute them for rides by bus or in private vehicles. Indeed, these modes of transport are frequently preferred to train rides because MR's inter-city services have a reputation for providing a poor-quality service. This includes trains running at slow speeds, crowded and uncomfortable carriages, and frequent delays due to equipment failures and track restrictions.

Commercial freight traffic on MR's trains has also declined. As of the 2013-14 fiscal year, MR had a market share of just 5\% for freight transport overall, and just $1.5 \%$ for commercial freight traffic in particular. In fact, even though its tariffs compared favourably with highway logistics, MR's lack of necessary operating resources led to a decline in the volume of freight traffic that uses its services. This lack of resources includes deficiencies both of rolling stock and of the kinds of locomotives that can provide traction power for dedicated freight trains on Myanmar's two key freight corridors - Yangon-Mandalay, and Mandalay-Mytkina - which accounted for $87 \%$ of MR's commercial freight traffic in 2013. The other major deficiencies that MR suffers from include an insufficient capacity for modern bulk handling, and an absence of container-transport services. Against this backdrop of meagre resources, both the quality of MR's service, and the volume of traffic on its trains, have been in decline. In turn, this has prevented Myanmar's railway system from maximising its utility, and has resulted in sub-optimal railway efficiency and financial performance.

\section{Shifting the focus of policy goals from laying new track to sector-wide efficiency gains}

As of the fiscal year of 2014, MR's freight revenues covered only $65 \%$ of the total costs of the corresponding service in terms of operations and infrastructure. The overall costcoverage ratio for passenger rail services, moreover, was as low as 37\% (ADB, 2016). The limited extent to which revenue-generating services cover costs stems from the fact that many of the government's investments in the rail sector have been for new tracks. Furthermore, these investments have mainly gone into expanding the tertiary network, which hosts small traffic. While expanding the network makes a contribution to gross fixed capital formation for Myanmar's transport sector, its productivity has been low, as suggested by low cost-coverage ratios and rail track density.

There is room for improvements on efficiency of recent Myanmar's capital investments. Indeed, the upkeep of old and ageing coaches and wagons, the cost of manual maintenance of the tracks, and the poor fuel efficiency of old locomotives, have kept operating costs high. Moreover, the poor condition of Myanmar's railway tracks, and a lack of signaling, train-control, and communications systems, have further obstructed the quest to improve the quality of service that MR can provide, while also contributing to the ongoing decline of traffic volumes. High operating costs coupled with low revenues 
have resulted in an unsustainable operating ratio, nullifying the value created by the gross fixed capital formation that resulted from expansions to the network.

Against this backdrop, Myanmar's investment priorities with regard to its rail network need to pay more attention to improve the operational performance of critical railway assets. Among these critical assets is the Yangon Circular Railway. Myanmar's other critical railway assets include the infrastructure and rolling stock of the six out of 34 of MR's routes. These include the Yangon-Mandalay trunk line. They also include secondary lines between Amarapura and Mytkina, Kemendine and Pyay, Pathein and Kyangin, Pyudwin and Chauk, and Naungpattaya and Mawlamyine.

As far as the railway sector is concerned, the government injected approximately USD 405 million, or around 620 billion Myanmar kyat (MMK), into capital investments in Myanmar Railways from 2009-14. It is recommended that Myanmar maintain an investment trend of around USD 100 million a year, albeit in line with modified priorities that aim for a revival of the system rather than ploughing ahead with extensive growth. Ensuring a meaningful revival of the railway sector will require the government to get the system onto a sound financial footing, making it self-sustaining by improving the efficiency of its operations and achieving an adequate ratio of cost-coverage. Making performance-oriented investments to put the railways on a sound financial footing is critical. The government needs to pave the way for efficient and consistent pricing systems. These would allow the railway system to cover its long-term marginal costs while capturing more revenue as improvements in service allow MR to charge higher prices as it competes with other forms of transport

\section{Scenarios of railway revival point to a much better future, heralding many opportunities}

Efforts to revive MR's freight operations should seek to improve performance by prioritising the expansion of existing services, and by exploring operational efficiencies. Some other measures that can help improve performance include better allowing for the seamless transport of the containers that come off of freight ships, and a proactive marketing strategy that seeks to take MR's services into new markets. In order to deliver such improvements, Myanmar will need to channel capital investments into priorities such as the modernisation of equipment for loading and unloading freight trains, in addition to other facilities that allow the efficient handling of freight. Priority areas for capital investment will also need to include the introduction of container train services and inter-modal facilities such as inland container depots. Furthermore, another key priority for investment will be the repowering or replacement of existing locomotives. In addition, the Mandalay to Mytkina section of railway - which shares a major portion of freight traffic with the trunk line - may also require investments in extra track capacity in order to designate a dedicated freight corridor.

The government has now started work on the Myanma Railways Transformation Plan, signalling that efforts to increase efficiency and asset utilisation on the country's railways are now underway. Moreover, with projections for traffic volumes predicting a moderate increase, Myanmar's transport and communication ministry has set its sights on increasing the cost-coverage ratio. Furthermore, upgrade projects on corridors that form strategic priorities under the new transformation plan are either about to commence or are under consideration for financing. The government of Myanmar is looking to provide financing for the Yangon to Mawlamyine line. In a further sign of progress, the transport and communication ministry has, since 2017, been discontinuing loss-making services on tertiary and quaternary lines.

To conclude, Myanmar's railway sector has been weakening due to the declining numbers of passenger and freight traffic. Poor-quality service and lack of necessary operating resources are among the challenges that will need to be addressed to allow Myanmar's railway system to maximise its utility, as well as to improve its efficiency and financial performance. Potential policy measures include focusing the country's 
rail network investment policy more to improve the operational performance of critical railway assets rather than expanding a tertiary network, which hosts a limited amount of traffic. It is also crucial to ensure efficient and consistent pricing systems, improve railway services, modernise equipment for efficient handling of freight, introduce container train services and inter-modal facilities, and renovate and upgrade existing locomotives.

\section{Reference}

ADB (2016), "Myanmar Transport Sector Policy Note - Summary for Decision Makers", Asian Development Bank, Manila, https://www.adb.org/sites/default/files/publication/184794/mya-transportpolicy-note-es.pdf. 



\section{CHINA AND INDIA}




\section{China}

\section{A. Medium-term economic outlook (forecast, 2020-24 average) \\ GDP growth (percentage change): Current account balance (\% of GDP): \\ Fiscal balance (\% of GDP) (central government):}

\section{B. Basic data (in 2018)}

Total population:

Population of Beijing: Nominal GDP (US dollar): GDP per capita at PPP:

Exchange rate in the first half of 2019 (period average):

\author{
1395.4 million * \\ 21.5 million * \\ 13407.4 billion ** \\ 18109.8 (current \\ International Dollar) **
}

6.8 (RMB/USD)

Note: * Population data are year-end government estimates.

** IMF estimate.

Sources: OECD Development Centre, national sources, CEIC and IMF.

\section{Composition of exports, 2018}

(percentage of total exports)

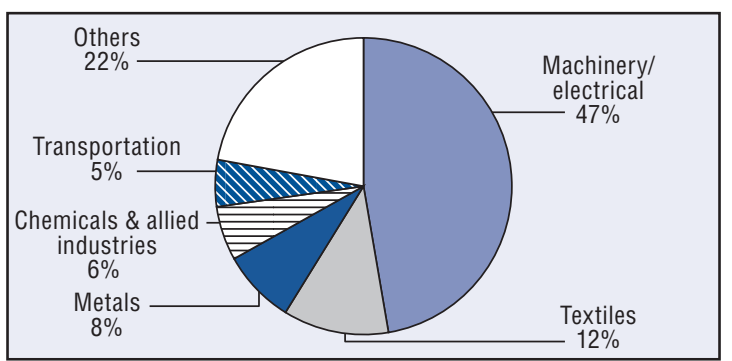

Source: Trademap.
GDP growth rates (percentage changes) 2013-17 (average) ZII 2019 MIV 2020-24 (average)

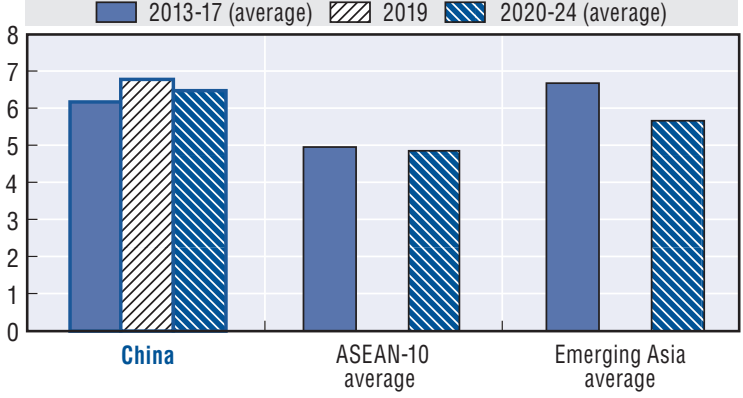

Source: OECD Development Centre.

GDP per capita, 2018

(PPP, current international dollar)

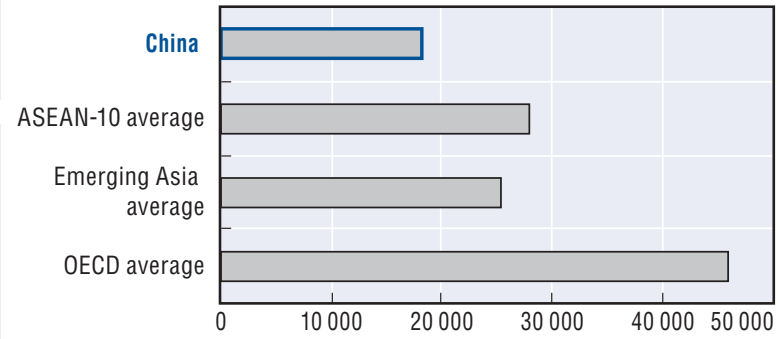

Source: IMF.

\section{Composition of imports, 2018}

(percentage of total imports)

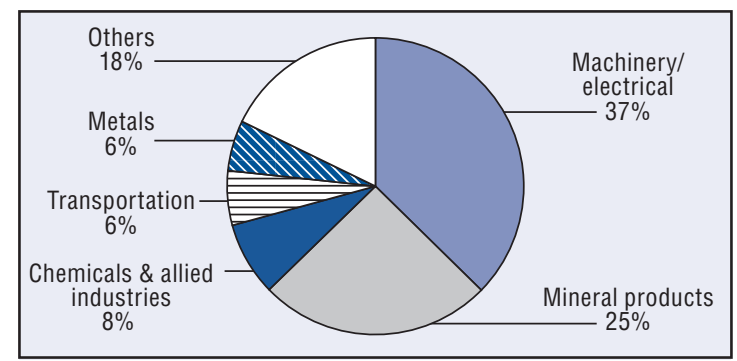

Source: Trademap.

\section{Structural policy challenges discussed in previous editions of the Outlook}

\begin{tabular}{lll}
\hline 2014 & Fiscal policy & $\begin{array}{l}\text { Improving fiscal efficiency through institutional reform } \\
\text { Increasing clean-energy consumption in response to the serious environmental degradation that persists despite the } \\
\text { country's efforts to reduce pollution }\end{array}$ \\
$\begin{array}{ll}\text { Environment } \\
\text { Rural development } \\
\text { Education and skills }\end{array}$ & $\begin{array}{l}\text { Expanding rural and agricultural development to help improve equality between urban and rural areas } \\
\text { Continuing with reforms and improving education in order to exploit the service sector's potential to drive future } \\
\text { growth }\end{array}$ \\
2016 & $\begin{array}{l}\text { Environment } \\
\text { Education and skills } \\
\text { Rural development }\end{array}$ & $\begin{array}{l}\text { Strengthening environmental regulations to improve the quality of growth } \\
\text { Boosting rural development to ensure robust growth in incomes }\end{array}$ \\
2017 & $\begin{array}{l}\text { Capacity utilisation } \\
\text { Environment }\end{array}$ & $\begin{array}{l}\text { Working off excess capacity } \\
\text { Upgrading the quality of the environment }\end{array}$ \\
2018 & $\begin{array}{l}\text { Connectivity and } \\
\text { integration }\end{array}$ & Unlocking synergies with the Belt and Road Initiative \\
Innovation & Making innovation a new driver of growth \\
\hline
\end{tabular}




\section{POLICY FOCUS}

Allocating investment more efficiently

For many years, investment has been the main driver of China's robust growth (OECD, 2019). A demographic dividend in the form of a large number of people entering the workforce also spurred growth, although this effect faded over time (Cai and Lu, 2015; Lu and Cai, 2014). Indeed, the working-age population has been falling since the early 2010s, both in absolute terms and as a share of the total population. China's overall population is still growing as life expectancy has increased steadily in the past decades. Yet this population growth is expected to continue for less than a decade. China's population will then peak and start shrinking. Moreover, the recent relaxation of the longstanding onechild policy is unlikely to stop this. Against this background, China's future growth will hinge - alongside productivity dynamics - upon investment in productive capital.

Rebalancing from investment to consumption is advancing, with investment's contribution to growth shrinking

As China acceded to the World Trade Organisation (WTO) and proceeded to open up its economy, investment was the engine of the double-digit growth that the country experienced in the 2000s (Figure 3.11.1). The expansion of the export sector following WTO accession in 2001 played a crucial role in this rapid investment growth. During this period, massive public investments played a big role in facilitating this economic transformation, and the government occasionally used public investment - primarily in infrastructure - to boost growth when the economy experienced negative shocks. This is what happened in 2009, when a large stimulus package of investment contributed over $8 \%$ to growth that year. Following the global financial crisis, the Chinese economy started to rebalance away from a reliance on investment and towards consumption. This "passive" rebalancing is still taking place, as the contribution of investment continues to decrease while the contribution of consumption remains broadly stable.

Figure 3.11.1. Contribution to growth 2000-18: A key role for investment in China

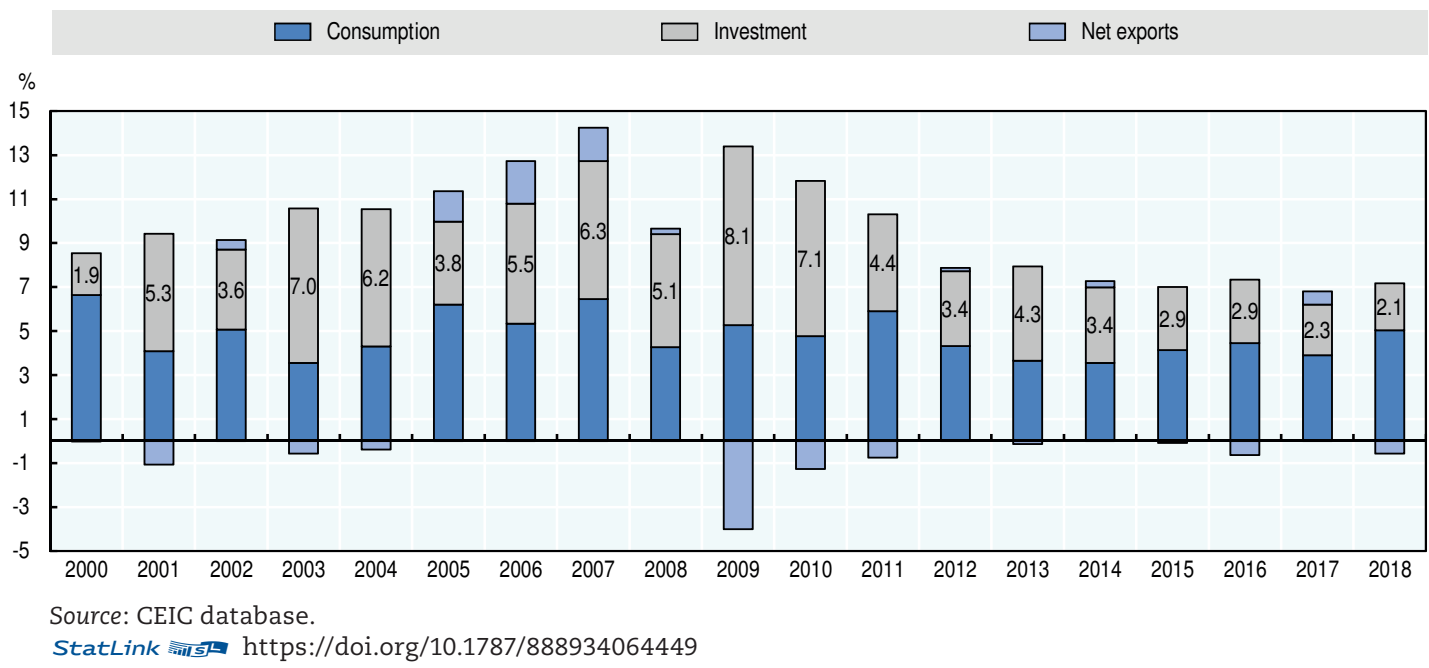

Consistent investment rates of $40-45 \%$ over the past decade or so boosted the capital stock and lifted the economy's potential for growth (Figure 3.11.2). Meanwhile, very high saving rates of $45-50 \%$ supported investment, a process that was intermediated through 
the banking system. In addition to households - the traditional savers - non-financial enterprises were also important contributors to this high rate of saving. Over the past decade, however, the saving rate in China has fallen by around $5 \%$, even as the investment rate has decreased by only about $2 \%$. As the saving rate fell sharper than the investment rate, the current account surplus shrank to below $0.5 \%$ of gross domestic product (GDP) in 2018. This fall in the saving rate was mostly driven by decreasing savings in the nonfinancial corporate sector.

Figure 3.11.2. China's current account balance, saving rate and investment rate, 1997-2018

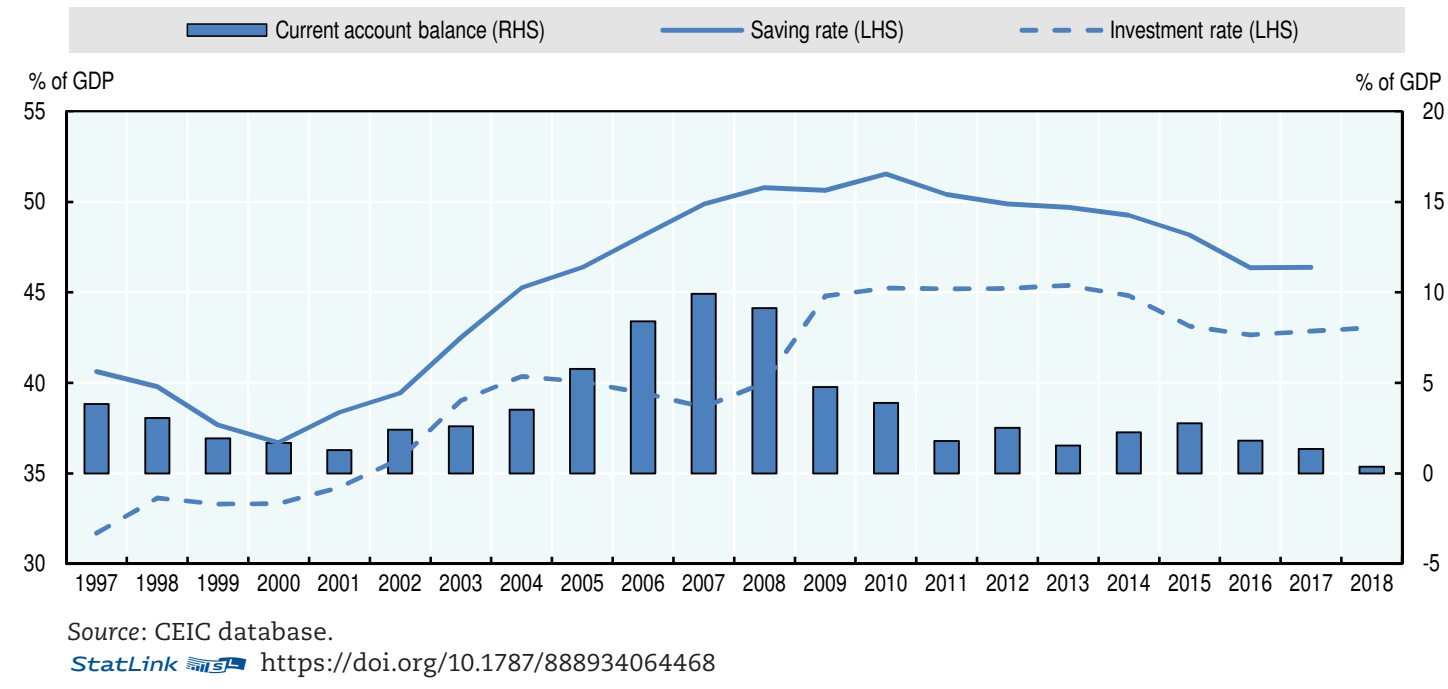

As a result of massive investment in China in recent decades, the country's capital stock has accumulated rapidly. In 2018, it reached 2.6 times the size of China's GDP in real terms. This is a higher level than in the United States, although lower than in Japan or Indonesia (Figure 3.11.3.A). China's relatively low GDP per capita means that the country fares especially well by comparison to other economies when capital stock is measured against GDP per capita (Figure 3.11.3.B).

Figure 3.11.3. China's capital stock relative to selected countries

\section{A. Capital stock to GDP ratio in multiples}

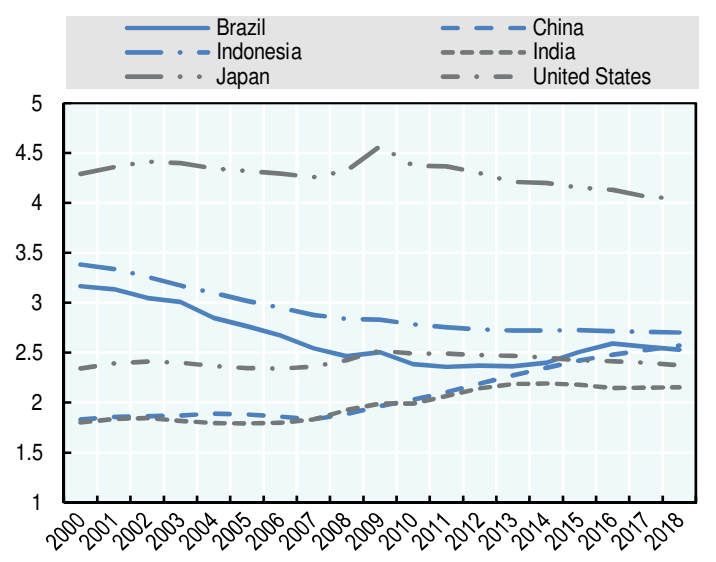

\section{B. Capital stock to GDP per capita, in million multiples}

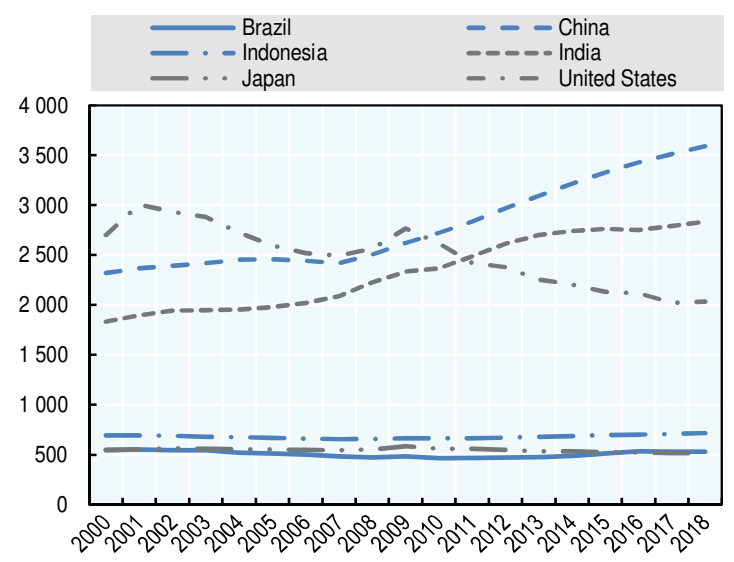

Note: Both capital stock and GDP are in national currencies, in real terms.

Source: OECD Development Centre's calculations based on the OECD Economic Projections database.

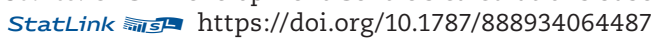


Notwithstanding China's relatively high level of capital stock, the economy still needs investment in several areas. For example, there is a need for infrastructure upgrades in rural areas, and for better connections between suburban areas and cities. Within urban areas, meanwhile, underground structures such as water, gas and other pipes require improvements and electricity wires need to be moved under the ground. China's industrial capital stock also needs to be upgraded to meet environmental and efficiency standards. This is also true for the country's agricultural capital stock, in particular when it comes to irrigation systems. Furthermore - and just as China is in the process of leapfrogging ahead in IT-based industries such as mobile payments, crowdfunding, and shared services - the country's emerging services industries require massive new investments in more sophisticated types of capital (Molnar and Wang, 2015).

Against a backdrop of slowing investment, China needs to place a greater emphasis on the efficiency of investment projects. Indeed, investment efficiency has fallen considerably in recent years, as measured by the incremental capital-output ratio. However, this can partly be attributed to the changing composition of investment. During the period in which China began to accelerate the opening up of its economy following its accession to the WTO, investment was directed mostly into the accumulation of productive capital such as infrastructure or equipment. More recently, however, the share of investment flowing into real estate has increased significantly, approaching three quarters of overall investment in 2019.

Amid falling efficiency and lower returns, and considering the fall in investment in recent years, the investment-led growth model has increasingly proved to be unsustainable. Moreover, the high investment rates that have underpinned growth in recent times have left a challenging legacy. Excessive capacity is plaguing several sectors including construction, steel, cement, aluminium, shipbuilding, flat glass, and electrical and railway equipment. At the same time, corporate debt - which has been accumulated mostly by state-owned enterprises (Molnar and Lu, 2019) - is worryingly high, standing at around $155 \%$ of GDP in early 2019. The old growth model has also had significant negative externalities. For example, carbon dioxide emissions have more than tripled in two decades, and air pollution has caused over a million premature deaths.

\section{Allowing the market to play a greater role in the pricing of capital}

As the Chinese economy embarks on a more balanced and sustainable growth path, it is important to let the market play a greater role in the allocation of resources and in the pricing of the factors of production. In recent decades, a lack of market forces in the pricing and allocation of capital has translated into a low cost of capital and led to widespread misallocation. Coupled with government officials' longstanding focus on a single performance indicator - output growth - this has encouraged more and more investment to go into the expansion of production capacity. In the process, local officials competed to attract investment by offering cheap or free land, cheap credit, tax concessions, and other subsidies. Moreover, industrial policy guaranteed cheap credit and energy to favoured sectors, and gave a competitive edge in global markets to capital- and energy-intensive products.

Allowing the market to play a greater role in the allocation of resources and the pricing of production factors will be indispensable as China makes the transition to ensuring a higher quality of economic growth. It will entail removing implicit guarantees to public entities, and ending bail-outs. Hitherto, and owing to the implicit guarantees the state has provided to public borrowers, private businesses get crowded out of the formal market. This is especially the case for smaller companies. In turn, firms have to resort to retained earnings or informal borrowing to finance their activities. In addition, small 
firms' access to credit would be enhanced if they were subject to more rigorous reporting and disclosure requirements.

Furthermore, monetary policy has repeatedly come to the rescue of corporates and other public entities by lowering interest rates and reducing reserve requirements in order to boost liquidity and support debt servicing. While this provides an opportunity for firms to re-finance their debt at a lower cost, many of them are not able to borrow to finance more investment. Indeed, falling profitability and already-high leverage curtail firms' room to further increase their leverage.

Going forward, and as investment slows, a greater emphasis should be put on the allocation efficiency of investment. Market-based pricing of capital, greater transparency both in the investment process and with procurement contracts, and rigorous feasibility studies before investing in projects - as well evaluation studies once they have been completed - are among the steps that would work to that end.

\section{References}

Cai, F. and Y. Lu (2015), Take-off, Persistence and Sustainability: The Demographic Factor of Chinese Growth, East Asian Bureau of Economic Research, Canberra, http://www.eaber.org/system/tdf/ documents/EABER Working Paper 96 Cai and Lu.pdf? file=1\&type=node\&id=24834\&force $=$.

Lu, Y. and F. Cai (2014), "China's shift from the demographic dividend to the reform dividend”, in R. Garnaut, F. Cai and S. Ligang (eds.), Deepening Reform for China's Long-Term Growth and Development, Australian National University Press, Canberra, http://dx.doi.org/10.22459/DRCLTGD.07.2014.

Molnar, M. and J. Lu (2019), State-owned Enterprises behind China's Corporate Debt, OECD Publishing, Paris, https://doi.org/10.1787/7c66570e-en.

Molnar, M. and W. Wang (2015), A Snapshot of China's Service Sector, OECD Publishing, Paris, https://doi.org/10.1787/5js1j19lhbkl-en.

OECD (2019), OECD Economic Surveys: China 2019, OECD Publishing, Paris, https://doi.org/10.1787/ eco surveys-chn-2019-en. 


\section{India}

A. Medium-term economic outlook (forecast, 2020-24 average)

GDP growth (percentage change): Current account balance (\% of GDP):

Fiscal balance (\% of GDP) (central government):

B. Basic data (in 2018)

Total population:

Population of Delhi: Nominal GDP (US dollar): GDP per capita at PPP:

Exchange rate in the first half of 2019 (period average): $\quad 70.0$ (INR/USD)

Note: * Population data are government estimates. Indian data are based on fiscal year ending in March. Population data in 2016 refer to fiscal year 2016/17 ending in March 2017.

** IMF estimate.

Sources: OECD Development Centre, national sources, CEIC and IMF.

Composition of exports, 2018

(percentage of total exports)

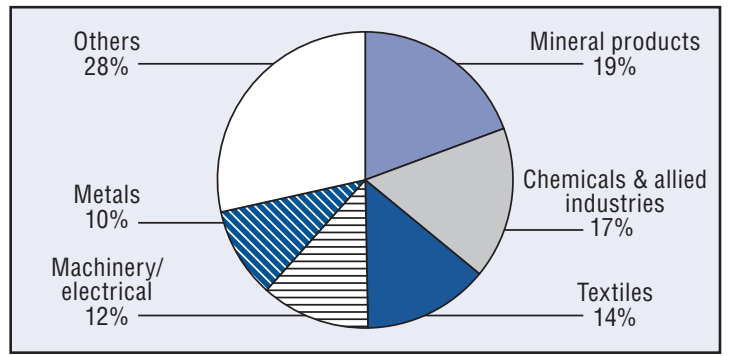

Source: Trademap.
GDP growth rates (percentage change) $\square$ 2013-17 (average) WIA 2019 MIV 2020-24 (average)

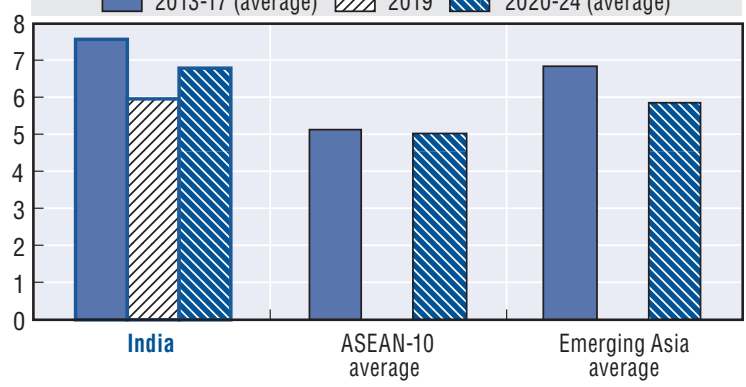

Source: OECD Development Centre.

GDP per capita, 2018

(PPP, current international dollar)

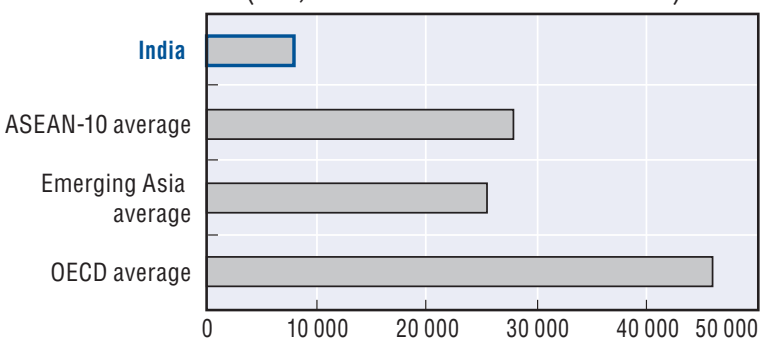

Source: IMF.

(percentage of total imports)

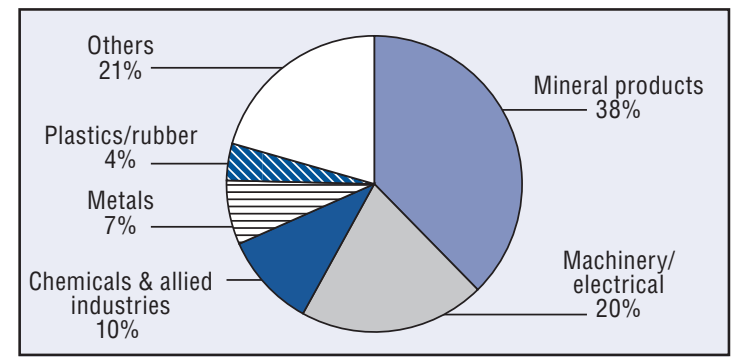

Source: Trademap.

\section{Structural policy challenges discussed in previous editions of the Outlook}

\begin{tabular}{|c|c|c|}
\hline 2014 & Education & Improving teaching and national assessment systems to raise education standards \\
\hline \multirow[t]{4}{*}{2015} & Manufacturing & $\begin{array}{l}\text { Restoring growth to reverse the trend of slower growth (and even negative growth in 2013-14) in manufacturing over the } \\
\text { past few years }\end{array}$ \\
\hline & Education & Widening access to secondary education in order to meet the goal of universal secondary education by 2017 \\
\hline & Health & Strengthening the public health system. Improving access to curative and preventative healthcare facilities \\
\hline & Infrastructure & Accelerating the development of infrastructure, especially in rural areas \\
\hline \multirow[t]{2}{*}{2016} & Financial literacy & Strengthening financial-education initiatives \\
\hline & Education & Enhancing education in terms of both access and quality \\
\hline \multirow[t]{2}{*}{2017} & FDI & Encouraging foreign direct investment (FDI) and promoting the made-in-India brand \\
\hline & Entrepreneurship & Strengthening the set of initiatives known as Startup India \\
\hline 2018 & Innovation & Fostering inclusive innovation to boost growth and development \\
\hline 2019 & FDI & Continuing FDI reforms and develop opportunities for technology transfer \\
\hline
\end{tabular}




\section{POLICY FOCUS}

\section{Strengthening smart land transportation}

India has been looking for smart solutions for urban transport as long-standing issues of congestion, pollution and traffic inefficiency persist despite the interventions over the years. These issues weigh on the overall quality of life, especially of those at the lower end of the income spectrum. They also have ramifications on other socio-economic issues such as urbanisation and business climate.

The focus of this country note is on the metropolitan areas of Bangalore, Delhi, Kolkata, and Mumbai. These are four of the most populated urban agglomerations in India. They are also India's most congested cities, experiencing the slowest-moving traffic in the country (Akbar, et. al., 2018). Indeed, one estimate puts combined congestion cost (in fuel waste, productivity loss, pollution and accident) in these four cities at USD 22 billion per year (Chin, et. al., 2018). As it stands, Bangalore and Delhi are part of the central government's so-called Smart Cities Mission, while Kolkata and Mumbai do not come under the purview of this initiative. In brief, the Smart Cities Mission aims to retrofit 100 cities to enhance citizen experience and promote sustainability through smart solutions.

\section{India is making ever-deeper use of technology to deliver transport services}

Bangalore, Delhi, Kolkata and Mumbai have embarked on a number of transport systems and IT-enabled mechanisms to address the surge in commuter demands over the years (Table 3.12.1). However, while these interventions may have helped ameliorate the conditions, there remain concerns regarding the interconnectedness of the modes of transport; sufficiency and interoperability of mechanisms; and availability of funding to maintain and advance the existing systems.

In 2016, the Bangalore Metropolitan Transport Corporation (BMTC) launched an intelligent transport system - a term whose definition and component technologies vary from one city to another. BMTC's approach to intelligent transport includes systems for vehicle tracking, electronic ticketing, passenger information, and a data and control centre (Mukherjee, Toshniwa and Mulukutla, 2016). The local government has been making strides in introducing a multi-modal mass transport pass, and at least two expressways are under construction (BMRCL, 2019; MRTH, 2018 and Philip, 2019a). A bus rapid transit system is one mechanism that Bangalore does not have relative to other major urban agglomerations in India.

Delhi has the most sophisticated transport network of all of India's urban agglomerations. Indeed, Delhi has the most extensive metro lines augmented by a bus rapid transit system. It also has an inter-operable public transport pass that can be used on buses, the metro system, and trains around the urban area (Kejriwal, 2019) - even before the launching of the national common mobility card in March 2019. Furthermore, the local government is gradually rolling out its intelligent traffic-management system (Shekhar, 2018). This mechanism will employ artificial intelligence solutions to lessen human involvement in traffic management, and will hasten procedures such as the issuance of traffic violation tickets by facilitating the entire process electronically. 
Table 3.12.1. Mechanisms employed to manage the flow of road traffic

\begin{tabular}{|c|c|c|c|c|}
\hline Mechanism & Bangalore & Delhi & Kolkata & Mumbai \\
\hline \multicolumn{5}{|l|}{ Infrastructure } \\
\hline Metro lines & $\checkmark$ & $\checkmark$ & $\checkmark$ & $\checkmark$ \\
\hline Bus rapid transit & $x$ & $\checkmark$ & $\checkmark$ & $\checkmark$ \\
\hline Express lanes & $\checkmark$ & $\checkmark$ & $\checkmark$ & $\checkmark$ \\
\hline Bicycle lanes & $\checkmark$ & $\checkmark$ & $\checkmark$ & $\checkmark$ \\
\hline Train & $\checkmark$ & $\checkmark$ & $\checkmark$ & $\checkmark$ \\
\hline \multicolumn{5}{|l|}{ IT-enabled mechanisms } \\
\hline Road traffic control room & $\checkmark$ & $\checkmark$ & $\checkmark$ & $\checkmark$ \\
\hline Automated parking management & $\checkmark$ & $\checkmark$ & $\checkmark$ & $\checkmark$ \\
\hline Sensors, drones, and other traffic monitoring facilities & $\checkmark$ & $\checkmark$ & $\checkmark$ & $\checkmark$ \\
\hline Electronic toll collection & $\checkmark$ & $\checkmark$ & $\checkmark$ & $\checkmark$ \\
\hline Ride-sharing platforms & $\checkmark$ & $\checkmark$ & $\checkmark$ & $\checkmark$ \\
\hline Public transport tracking & $\checkmark$ & $\checkmark$ & $\checkmark$ & $\checkmark$ \\
\hline
\end{tabular}

Note: $\checkmark=$ existent; $X=$ non-existent. The table does not compare the safety, quality and extent of coverage of the mechanisms across cities. Information is as of 13 September 2019.

Source: OECD Development Centre, based on national sources.

Meanwhile, the city of Kolkata has managed to keep abreast of road transport technology and innovation by adopting a range of approaches, from automated parking to bus tracking and electronic toll collection. The city has also established dedicated lanes for the bus rapid transit system and, in 2017, launched a fare smartcard - doing so ahead of a similar move in Delhi (Sinha, 2019; WBTC, 2018). Although it is not part of the Smart Cities Mission, Kolkata is part of West Bengal's own Green Cities Mission (HLRN, 2018; GWB, 2018). In line with this framework, the first batch of electric buses of West Bengal Transport Corporation (WBTC) were rolled out just a few months after the publication of the relevant implementation plan (WBTC, 2019).

Elsewhere in India, the city of Mumbai has invested heavily in transport technology and infrastructure over the past decade. In 2011, the local government together with the World Bank closed the first phase of a comprehensive urban transport project that began in 2002, which explored the use of technology in the real-time management of public transport, road congestion, accidents, and other aspects of the transport network (IEGWorld Bank, 2016). An intelligent transport management system that utilises machine learning is also currently in the works. The idea is to implement it first in Mumbai before it goes state-wide. Like Kolkata, however, Mumbai is not part of India's central Smart Cities Mission (HLRN, 2018).

Across India, the use of quick response (QR) codes is one of technologies that is becoming ubiquitous. From the rickshaws and buses in Ranchi city to the car and taxi drivers of Delhi, QR codes are now being utilised both to facilitate payment and to protect passengers (Dyade and Bhande, 2017). The QR code is also being considered as a potential feature for driving licenses, thus doing away with many of the documents that a driver has to keep at the ready for possible inspections. Ride-hailing platforms and GPS tracking applications for public transport are the other commonly used innovations. Other transport and vehicle technologies are being developed and facilitated under separate programmes. These include the Electronic Stability Program, Atal Mission for Rejuvenation and Urban Transformation and National Electric Mobility Mission Plan (GrantThorton, 2016). 
On the implementation side, the government understands the need to progress further in co-ordinating the technology systems used in managing transportation as noted by the Planning Commission (2014). Improving the gathering and transmission of traffic data through sensors is one of these. Working towards interoperability and uniformity of systems used around the country is another - a concern that prompted the government to create a national register and state registers of driving licences and registration certificates. Standardising the toll-based payment systems and centralising different transportation data are similarly on the table. On the financing side, securing a steady stream of funds to advance the penetration of technology in transport management as well as integrating the systems is also an issue in India, especially at the local level.

\section{Improvements in public transport capacity, staffing and rule-compliance remain crucial}

Beyond matters of technology, the efficiency in deepening the absorptive capacity of public transportation options, affecting quality, coverage and reliability of service in the process cannot be overlooked. Evidently, these four urban areas have the highest public transport patronage among large cities in the country, particularly Mumbai and Kolkata, where the rate is estimated to hover around 80\% in 2017 (Roychowdhury and Dubey, 2018).

In order to encourage more people to use mass transport, meanwhile, the absorptive capacity and the quality of public transport need to be addressed comprehensively. Of particular concern are delays in the procurement of new buses and train coaches due to institutional and financial frictions. In Delhi, for example, the number of operational buses is estimated to be only between $33 \%$ and $50 \%$ of the required number (PTI, 2018). In Mumbai, the government is in the process of expanding the metro lines to alleviate congestion in suburban rails, which are operating at 3 to 4 times their capacity, i.e. about 5000 passengers competing for coach space intended for 1750 passengers per trip (Saxena, 2019). However, delays and cost overruns hamper the progress of the projects (Bhanushali, et. al., 2018). Delays also hobbled the metro rail initiative in Kolkata (KMRC, 2016). Aside from the poor state of many units that are currently operating, the shortage in buses and metro coaches in many of India's large urban areas leads to overcrowding. In turn, this results in safety hazards and a higher cost of capital depreciation.

In Bangalore, the increase in the capacity of the city's metro thanks to the introduction of new six-car trains has managed to steer a significant number of people away from using private transport, and the number of people using public transport has increased (Philip, 2019b). Still, this improvement has brought with it a fresh challenge in terms of integrating different modes of transportation. This is because auto rickshaws and private vehicles have begun lining up in increasing numbers near the metro stations where they set down and pick up passengers, congesting the roads in the process.

Attracting talent is another concern as India seeks to broaden its use of intelligent transport systems. Indeed, the National Institution for Transforming India has observed that graduates of science, technology, engineering, and mathematics courses largely move away from emergent technologies, and are mostly concentrated in routine IT development, while others prefer to ply their trade overseas (NITI Aayog, 2018). The agency also noted weaknesses in quality at many institutions of higher education.

Persistent blockages in arterial roads such as illegally parked cars, street vendors, and other contraptions, constitute another pressing issue. Moving informal vendors and streetsettlers, however, requires a broad approach that includes a broadly consultative clearing process, as well as relocation and livelihood plans. Financing limitations underpin many difficulties in improving the hardware capacity of public transport, not to mention that the 
gap is substantial. Outside of the traditional funding sources including partnership with private sector, the strategy employed by Bangalore's transport corporation of leveraging its land assets to generate revenue and pare down cost (Roychowdhury and Dubey, 2018) is an interesting example of innovative financing that can be explored in other cities. Vehicle use and ownership charges (discussed in the subsequent section) are also worth a consideration in this respect.

\section{Unifying road management is key, and there is scope for vehicle ownership and use policies}

There seems to be a consensus in India on the important role that unified metropolitan transport authorities (UMTA) and urban transport funds (UTF) can play in addressing the fragmented nature of urban-transport management in India. ${ }^{1}$ Yet despite the publication of operational guidelines (MOUD, 2016a, 2016b) and incentives - such as providing access to funds from the Jawaharlal Nehru National Urban Renewal Mission - the formation of such unifying institutions has stalled. As it is, in the absence of an autonomous and fully-fledged UMTA, governance of urban transport involves a constellation of actors including municipal police, state and city governments, metro rail corporations, transport corporations, municipal corporations, local urban-development authorities, specialpurpose vehicles as with the Smart Cities Mission, and the transport ministry.

Mumbai is one of the Indian cities that does already have a fully-fledged UMTA. This is the Unified Mumbai Metropolitan Transport Authority, which was created by the government of Maharashtra in 2008. Mumbai's UMTA is still not autonomous, although the government is moving in that direction. In Delhi, the consolidation of transport oversight has been limited to the establishment of standards and the approval of transport engineering and infrastructure projects. This consolidation has taken place within the framework of Unified Traffic and Transport Infrastructure (Planning and Engineering) Centre that the Delhi Development Authority created in 2009. Delhi's experience indicates that creating an UMTA-style institution with relatively limited scope can be a viable solution, as long as it has the appropriate authority. In Bangalore, meanwhile, the local authorities first considered creating an UMTA in 2007, but it did not materialise. In 2018, the state government has again pledged to introduce legislation to pave the way towards creating one. As for Kolkata, the authorities have given scant indication as to whether or not the city is inclined to create a UMTA.

Aside from the concerns that can arise over how to manage the consolidation of the diverse aspects of urban transport, another relevant consideration is that vehicle ownership and road-use measures - including those envisioned in the urban development ministry's operations document on UTFs (MOUD, 2016b) - necessitate political backing. As it appears, the appetite to enact measures relating to the supply of vehicles differs between urban areas, and depends on the kind of measure that is being proposed. Although limited in scope, Delhi pushed ahead with its vehicle-scrappage policy in 2018 while a broader policy at the national level is being finalised. Kolkata, for its part, has been a leader in parking policy design and administration as Bangalore, Delhi, and Mumbai catch up. Other common measures that the four cities have embraced are a vehicle-purchase tax, a road-use tax, and a fuel tax (Table 3.12.2). Congestion tax is another tool that is currently being considered at least in Delhi and Mumbai. On the other hand, cordon charges and quota-based right to own a vehicle, akin to Singapore's certificate of entitlement, have yet to take serious policy traction. Beyond having a set of rules in place, enforcing these rules is also challenging. It is equally important that the users of the transport network find the penalties for violations such as illegal parking prohibitive (Roychowdhury and Nasim, 2017). 
Table 3.12.2. Examples of vehicle ownership and road-use charges

\begin{tabular}{lcccc}
\hline \multicolumn{1}{c}{ Policy } & Bangalore & Delhi & Kolkata & Mumbai \\
\hline Vehicle ownership & & & & \\
\hline Licence/Right to own & X & X & X & X \\
Comprehensive parking policy & ${ }^{*}$ & $\checkmark$ & $\checkmark$ & $\checkmark$ \\
Emission policy & $\checkmark$ & $\checkmark$ & $\checkmark$ & $\checkmark$ \\
Purchase tax and road tax & $\checkmark$ & $\checkmark$ & & $\checkmark$ \\
\hline Vehicle usage & & & --- & \\
\hline Congestion fees & --- & $\checkmark$ & $\checkmark$ \\
Road use/toll fees & $\checkmark$ & $\checkmark$ & $X$ & $\checkmark$ \\
Cordon charges & X & $X$ & $\checkmark$ & X \\
Fuel tax & $\checkmark$ & $\checkmark$ & & $\checkmark$ \\
\hline
\end{tabular}

Note: $\checkmark=$ existent; $C=$ under study/consultation; $X=$ non-existent; ${ }^{*}=$ a new policy is under consultation. Vehicle purchase tax, road tax and fuel tax vary by local governments. The Motor Vehicle Act of 1988 has broad provisions on illegal parking as well. The table does not compare the quality of administration and extent of coverage of the mechanisms across cities. Information is as of 13 September 2019.

Source: OECD Development Centre compilation from national sources.

\section{The importance of involving the private sector in transport management}

Beyond the traditional framework of public-private partnerships, the private sector can be a key partner for transport authorities as they seek to find and implement smart solutions to the challenges that they and their users face. One of the ways in which the private sector can make an important contribution is by developing innovative solutions, as was the case with the tracking applications for public transport that use GPS technology. Another way in which it can help is by supporting start-ups that plan to develop innovative solutions. The private sector can also be an important partner in other ways, such as by allowing people whenever it is feasible to work and study remotely, thus reducing traffic.

Telecommuting and online learning are not new concepts in India. According to KPMG India and Google (2017), online education in India has grown rapidly in recent years, even if the courses on offer tend not to be core modules. At state-run institutions of education, the government has the opportunity to expand the offering of online courses. As regards teleworking or telecommuting, information on the prevalence of such practices in India is currently limited, but one survey does show that the demand for such arrangements does appear to be high (Randstad India, 2016). The growth in co-working spaces over recent years also suggests that businesses are open to non-traditional working arrangements. However, in order to support a development that has the potential to ease congestion on the transport network, regulatory changes may be necessary to alleviate concerns about teleworking such as the potential for workers' productivity to fluctuate, or data security.

Next step: Use innovation fully, manage infrastructure better and keep the private sector involved

Making full use of innovations in technology is one of the three main things to bear in mind as India seeks to improve transport in its cities. As outlined above, the use of technology to improve the delivery of transport services and enhance safety is an ongoing initiative in India. A vital component in maximising the impact of these innovations will be making continual improvements in terms of administrative efficiency, as well as ensuring a consistent application of the rules of the road. It will, as touched on above, also be important to pay appropriate heed to the effects that changes will have on the informal economy. Making the most of the solutions that are available will also require substantial political will, and wide-ranging campaigns to improve awareness among 
commuters, especially when it comes to ensuring seamless linkages between modes of transport. Considering the financing constraints faced by less wealthy agglomerations, the government should closely monitor the performance of the systems that are in place, or those that will be launched, documenting key lessons from their implementation in various contexts, and developing plans to make the systems more scalable.

Strengthening the management of road transport infrastructure is the second key point to keep in mind in seeking smarter transport arrangements. It will indeed be worthwhile for the central government to step up its material assistance and political support to urban agglomerations that face difficulties in setting up UMTAs and UTFs. In urban areas where such mechanisms are already in place, meanwhile, pushing for their institutional autonomy, and professionalising their organisation, are some of the challenges to work on. In areas where these mechanisms are still work in progress, the government may choose to begin with an entity that is more modest in scope and less legally cumbersome to put in place. This is a way to jump start the process of bringing together urban roadmanagement functions under a single body. Similarly, local governments might benefit from implementing measures to reduce the number of vehicles on the roads in order to ease congestion. They also stand to benefit from finding alternative sources of financing.

Keeping the private sector involved is the third key point. It is clear that the private sector can play an important role in advancing the overall road-management framework, and not just through conventional public-private partnerships. Thus, it pays for the government to consult and work with private firms as it develops transport-management solutions. As also noted above, the private sector can also play a role in broadening the coverage of remote work and study arrangements whenever this is feasible.

\section{Note}

1. India's national policy on urban transport suggested as early as 2006 that urban agglomerations with more than 1 million inhabitants should create a UMTA in order to consolidate the management of urban roads (MOUD, 2016a). The plan also recommended setting up a UTF that would come up with innovative funding sources and manage the allocation of capital.

\section{References}

Akbar, P.A., V. Couture, G. Duranton and A. Storeygard (2018), "Mobility and Congestion in Urban India”, NBER Working Paper No. 25218, JEL No. R41, National Bureau of Economic Research, Cambridge, MA, https://www.nber.org/papers/w25218.pdf.

Bhanushali, U., A. Prabhu, P. Dagli, S. Chheda and A. Vyas (2018), "Studying Project Management System for Mumbai Metro", International Advanced Research Journal in Science, Engineering and Technology, Vol. 5, Special Issue 3, https://iarjset.com/wp-content/uploads/2018/07/ICACE-18-1.pdf.

BMRCL (2019), "Bengaluru Transit Oriented Development Policy" (Draft, February, 2019), Bangalore Metro Rail Corporation Limited, Bangalore, http://urbantransport.kar.gov.in/Draft\%20 Bengaluru\%20ToD\%20Policy\%20with\%20Annexure.pdf.

Chin, V., M. Jaafar, S. Subudhi, N. Shelomentsev, D. Do and I. Prawiradinata (2018), Unlocking Cities: The impact of ridesharing across India, Boston Consulting Group, Boston, http://image-src.bcg.com/ Images/BCG-Unlocking-Cities-Ridesharing-India_tcm9-185213.pdf.

Dyade, M.A. and Y.V. Bhande (2017), "Use of QR code: A step towards development in India", International Research Journal of Engineering and Technology (IRJET), Vol. 4, Issue 9, pp.1165-1168, https://www.irjet.net/archives/V4/i9/IRJET-V4I9221.pdf.

GrantThorton (2016), Smart Transportation-transforming Indian cities, New Delhi, https://www. grantthornton.in/globalassets/1.-member-firms/india/assets/pdfs/smart-transportationreport.pdf.

GWB (2018), Green City Administrative Approval 2017-18, Urban Development and Municipal Affairs Department, Government of West Bengal, Kolkata, https://www.wburbandev.gov.in/Home/ adm appv green 201718. 
HLRN (2018), India's Smart Cities Mission: Smart for Whom? Cities for Whom? Update 2018, Housing and Land Rights Network, New Delhi, https://www.hlrn.org.in/documents/Smart Cities Report 2018.pdf.

IEG-World Bank (2016), Project Performance Assessment Report: Mumbai Urban Transport Project, Independent Evaluation Group, World Bank, Washington, DC, https://ieg.worldbankgroup.org/ sites/default/files/Data/reports/ppar_india_0716.pdf.

Kejriwal, K.A. (2019), "Budget Speech 2019-2020”, Directorate of Training and Technical Education, Delhi Government, http://tte.delhigovt.nic.in/wps/wcm/connect/84861b0044d0f23e9990db829 11e8eeb/Budget_Speech_English_2019-20.pdf?MOD=AJPERES\&lmod=-359219120.

KMRC (2016), Annual Report 2014-2015, Kolkata Metro Rail Corporation Limited, Kolkata, http://kmrc. in/admin/uploads/1415.pdf.

KPMG India and Google (2017), “Online Education in India: 2021", https://assets.kpmg/content/ dam/kpmg/in/pdf/2017/05/Online-Education-in-India-2021.pdf.

MOUD (2016a), Operations Document for Unified Metropolitan Transport Authority (UMTA), Ministry of Urban Development, Government of India, New Delhi, http://www.sutpindia.com/skin/pdf/ Operations Document_for_UMTA.pdf.

MOUD (2016b), Operations Document for Urban Transport Fund (UTF), Ministry of Urban Development, Government of India, New Delhi, http://www.sutpindia.com/skin/pdf/Operations Document for UTF.pdf.

MRTH (2018), "Year-end Review: Ministry of Road Transport and Highways 2018: the Highway Construction Year", Press Release, Ministry of Road Transport \& Highways and Press Information Bureau, Delhi, https://pib.gov.in/newsite/PrintRelease.aspx?relid=186932.

Mukherjee, A., R. Toshniwa and P. Mulukutla (2016), "Enhancing Bengaluru's public transport network: approaches and challenges", Journal of Sustainable Urbanization, Planning and Progress, Vol.2, pp. 37-50. http://doi.org/10.18063/JSUPP.2017.01.005.

NITI Aayog (2018), National Strategy for Artificial Intelligence, National Institution for Transforming India, Delhi, http://niti.gov.in/writereaddata/files/document_publication/NationalStrategyfor-AI-Discussion-Paper.pdf.

Planning Commission (2014), India Transport Report: Moving India to 2032, National Transport Development Policy Committee-Government of India, New Delhi, http://planningcommission. nic.in/reports/genrep/NTDPC_Vol_01.pdf.

Philip, C.M. (2019a), "With new ticketing machines, BMTC all set to go cashless", The Times of India, Gurugram, https://timesofindia.indiatimes.com/city/bengaluru/with-new-ticketing-machinesbmtc-all-set-to-go-cashless/articleshowprint/67768445.cms.

Philip, C.M. (2019b), "Namma Metro surges ahead, clocks four-crore jump in annual ridership", The Times of India, Gurugram, https://timesofindia.indiatimes.com/city/bengaluru/namma-metrosurges-ahead-clocks-four-crore-jump-in-annual-ridership/articleshow/67631785.cms.

PTI (2018), "Delhi Cabinet likely to approve proposal for procurement of 1,000 buses tomorrow", Financial Express, 10 May, Uttar Pradesh, https://www.financialexpress.com/india-news/delhicabinet-likely-to-approve-proposal-for-procurement-of-1000-buses-tomorrow/1162983/.

Randstad India (2016), 1 in 2 Indian Employees Prefer Telecommuting: Randstad Survey, Randstad India, Chennai, https://www.randstad.in/about-us/press-releases/press-releases/1-in-2-indian-employeesprefer-telecommuting-randstad-survey/.

Roychowdhury, A. and G. Dubey (2018), The Urban Commute: And how it contributes to pollution and energy consumption, Centre for Science and Environment, New Delhi, https://www.cseindia.org/ the-urban-commute-8950.

Roychowdhury, A. and U. Nasim (2017), Parking Policy for Clean Air and Liveable Cities: A Guidance Framework, Centre for Science and Environment, Delhi, http://admin.indiaenvironmentportal. org.in/files/file/parking-report-dec27.pdf.

Saxena, S. (2019), “Mumbai Metro: Transforming transport in a megacity”, Asian Development Blog, Asian Development Bank, Manila, https://blogs.adb.org/blog/mumbai-metro-transformingtransport-megacity.

Shekhar, R. (2018), "Delhi: Smart traffic system hits road to reality", The Times of India, Gurugram, https://timesofindia.indiatimes.com/city/delhi/smart-traffic-system-hits-road-to-reality/ articleshow/67212110.cms. 
Sinha, S. (2019), "BRT Governance and Challenges-A Case of Indian Cities", Background Paper, VREF Research Synthesis Project, Governance of Metropolitan Transport, Gothenburg, http:// www.vref.se/download/18.45182a5f16a84e95fac6750b/1560236439026/BRT\%20Governance\%20 and $\% 20$ Challenges $\% 20 \%$ E2\% $80 \% 93 \% 20$ A 20 case $\% 20$ of $\% 20$ Indian $\% 20$ Cities.pdf.

WBTC (2019), “Inauguration of 20 Electric Buses by Hon'ble Chief Minister on 20th February, 2019 from Nabanna”, Press Release, West Bengal Transport Corporation, Kolkata, https://wbtc.co.in/ wbtc-inaugurates-20-electric-buses/.

WBTC (2018), "Launching of Intelligent Transport System in WBTC", West Bengal Transport Corporation, Kolkata, https://wbtc.co.in/smart-transport-system/. 


\section{Annex A. Statistical annex}

Table A.1. Real GDP growth in ASEAN, China and India, 2018-24

Annual percentage change

\begin{tabular}{|c|c|c|c|c|c|c|c|}
\hline \multirow[b]{2}{*}{ ASEAN-5 countries } & \multirow[t]{2}{*}{2018} & \multirow[t]{2}{*}{2019} & \multirow[t]{2}{*}{2020} & \multicolumn{2}{|c|}{$\begin{array}{l}\text { Changes from previous forecast } \\
\text { (July 2019) }\end{array}$} & \multirow[t]{2}{*}{$2020-24$} & \multirow[t]{2}{*}{ 2013-17 } \\
\hline & & & & 2019 & 2020 & & \\
\hline Indonesia & 5.2 & 5.0 & 5.0 & $\downarrow$ & $\downarrow$ & 5.1 & 5.1 \\
\hline Malaysia & 4.7 & 4.4 & 4.4 & - & $\downarrow$ & 4.4 & 5.2 \\
\hline Philippines & 6.2 & 5.6 & 6.0 & $\downarrow$ & $\downarrow$ & 6.2 & 6.6 \\
\hline Thailand & 4.1 & 2.7 & 3.0 & $\downarrow$ & $\downarrow$ & 3.2 & 2.8 \\
\hline Viet Nam & 7.1 & 6.8 & 6.6 & $\uparrow$ & - & 6.5 & 6.2 \\
\hline \multicolumn{8}{|c|}{ Brunei Darussalam and Singapore } \\
\hline Brunei Darussalam & 0.1 & 2.0 & 1.7 & $\uparrow$ & $\downarrow$ & 1.9 & -1.2 \\
\hline Singapore & 3.1 & 0.6 & 1.2 & $\downarrow$ & $\downarrow$ & 2.3 & 3.7 \\
\hline \multicolumn{8}{|l|}{ CLM countries } \\
\hline Cambodia & 7.5 & 7.0 & 6.8 & - & - & 6.7 & 7.1 \\
\hline Lao PDR & 6.3 & 6.5 & 6.6 & $\downarrow$ & $\downarrow$ & 6.8 & 7.4 \\
\hline Myanmar & 6.5 & 6.6 & 6.7 & $\downarrow$ & $\downarrow$ & 6.9 & 7.2 \\
\hline \multicolumn{8}{|l|}{ China and India } \\
\hline $\begin{array}{l}\text { China } \\
\text {. }\end{array}$ & 6.6 & 6.2 & 5.7 & - & $\downarrow$ & 5.6 & 7.1 \\
\hline India & 6.8 & 5.8 & 6.2 & $\downarrow$ & $\downarrow$ & 6.6 & 7.4 \\
\hline ASEAN-10 average & 5.2 & 4.6 & 4.7 & $\downarrow$ & $\downarrow$ & 4.9 & 5.0 \\
\hline Emerging Asia average & 6.4 & 5.8 & 5.6 & $\downarrow$ & $\downarrow$ & 5.7 & 6.7 \\
\hline
\end{tabular}

Note: Data are as of 21 November 2019. Data for India and Myanmar relate to fiscal years. The projections for China, India and Indonesia for 2019 and 2020 are based on the OECD Economic Outlook 106 (database).

Source: OECD Development Centre, Medium-term Projection Framework (MPF-2020).

Table A.2. Current account balances of ASEAN, China and India, 2019-24

Percentage of GDP

\begin{tabular}{lccc}
\hline & $\mathbf{2 0 1 9}$ & $\mathbf{2 0 2 0}$ & 2020-24 average \\
\hline ASEAN-5 countries & & & -2.5 \\
\hline Indonesia & -2.8 & -2.8 & 2.8 \\
Malaysia & 2.3 & 2.3 & -1.9 \\
Philippines & -1.9 & -2.1 & 6.6 \\
Thailand & 6.8 & 6.8 & 1.5 \\
Viet Nam & 2.1 & 1.9 & 10.5 \\
\hline Brunei Darussalam and Singapore & & & 18.5 \\
\hline Brunei Darussalam & 11.0 & 11.0 & \\
Singapore & 17.7 & 17.5 & -9.0 \\
\hline CLM countries & & & -9.1 \\
\hline Cambodia & -11.2 & -10.5 & -5.9 \\
Lao PDR & -9.0 & -8.8 & \\
Myanmar & -4.0 & -5.0 & -1.6 \\
\hline China and India & & & 0.9 \\
\hline China & 1.4 & 1.4 & -0.2 \\
\hline India & -1.7 & -1.8 & 0.8 \\
ASEAN-10 average & 1.0 & 0.5 & \\
Emerging Asia average & 0.6 & & \\
\hline
\end{tabular}

Note: Data are as of 21 November 2019. Data for India and Myanmar relate to fiscal years. The projections for China, India and Indonesia for 2019 and 2020 are based on the OECD Economic Outlook 106 (database).

Source: OECD Development Centre, Medium-term Projection Framework (MPF-2020). 
Table A.3. General government fiscal balances of ASEAN, China and India, 2019-24

Percentage of GDP

\begin{tabular}{lccc}
\hline & $\mathbf{2 0 1 9}$ & $\mathbf{2 0 2 0}$ & $\mathbf{2 0 2 0 - 2 4}$ \\
\hline ASEAN-5 countries & & & -1.7 \\
\hline Indonesia & -1.9 & -1.7 & -2.9 \\
Malaysia & -3.5 & -3.3 & -2.6 \\
Philippines & -2.7 & -3.2 & -2.8 \\
Thailand & -3.0 & -3.1 & -4.1 \\
Viet Nam & -4.0 & -4.0 & -4.1 \\
\hline China and India & & & -5.9 \\
\hline China & -3.3 & -3.6 & -2.4 \\
India & -6.2 & -6.3 & -4.3 \\
Average of ASEAN-5 & -2.6 & -2.6 & -4.1 \\
Average of Emerging Asia & -3.9 & & \\
\hline
\end{tabular}

Note: Data are as of 21 November 2019. Data for India and Myanmar relate to fiscal years. The projections for China, India and Indonesia for 2019 and 2020 are based on the OECD Economic Outlook 106 (database). General government balances data are not necessarily comparable to the budget balances published by the national governments. Emerging Asia is comprised of ASEAN-5, China and India.

Source: OECD Development Centre, Medium-term Projection Framework (MPF-2020). 


\section{Economic Outlook for Southeast Asia, China and India 2020}

\section{RETHINKING EDUCATION FOR THE DIGITAL ERA}

The Economic Outlook for Southeast Asia, China and India is a bi-annual publication on regional economic growth, development and regional integration in Emerging Asia. It focuses on the economic conditions of Association of Southeast Asian Nations (ASEAN) member countries: Brunei Darussalam, Cambodia, Indonesia, Lao PDR, Malaysia, Myanmar, the Philippines, Singapore, Thailand and Viet Nam. It also addresses relevant economic issues in China and India to fully reflect economic developments in the region.

The Outlook comprises three main parts, each highlighting a particular dimension of recent economic developments in the region. The first part presents the regional economic monitor, depicting the economic outlook and macroeconomic challenges in the region. The second part consists of a special thematic chapter addressing a major issue facing the region. The 2020 edition of the Outlook looks at human capital development, with a special focus on education for the digital era. The digital era is bringing important new developments for businesses and the workforce. As success in the digital era will require a new set of skills, education systems will need to adapt. Emerging Asian countries need to address certain challenges including improving ICT infrastructure, enhancing capacity of teachers, adapting curricula, as well as enhancing the role of TVET and lifelong learning. The third part of the report includes structural country notes offering specific recommendations for each country.

Consult this publication on line at $h$ ttps://doi.org/10.1787/1ba6cde0-en

This work is published on the OECD iLibrary, which gathers all OECD books, periodicals and statistical databases. Visit www.oecd-ilibrary.org for more information.

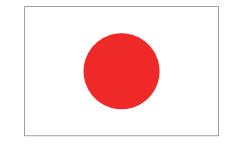

JAPANGOV

THE GOVERNMENT OF JAPAN
The Government of the Republic of Korea

\section{OECDpublishing} www.oecd.org/publishing

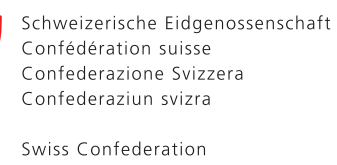

Schweizerische Eidgenossenschaft Confédération suisse Confederazione Svizzera Confederaziun svizra

Swiss Confederation

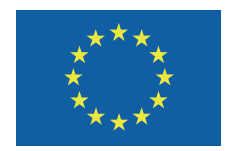

Co-funded by the European Union
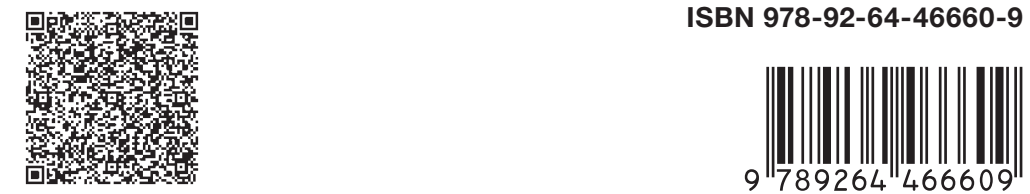